(12) H(t) If:

H. Q1.

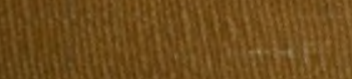

Whing Whangen (1) H. H. (1) (1)t

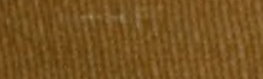

(t) S6: 6ux (5) Hen (5) (⿻) 6hy 

Digitized by the Internet Archive in 2010 with funding from University of Toronto

http://www.archive.org/details/memoirs15harv 



ftemoirs of the ftluscum of Comparatibe Zoologe

AT HARVARD COLLEGE.

VOL. XV.

\section{REPORT S}

ON THE

\section{RESULTS OF DREDGING,}

UNDER THE DIRECTION OF

L. F. POURTALES,

DURING THE YEARS $1868-1870$,

AND OF

ALEXANDER AGASSIZ,

IN THE GULF OF MEXICO (1877-78), AND IN THE CARIBBEAN SEA (1878-79), IN THE

U. S. COAST SURVEY STEAMER "BLAKE,"

Lieft.-Com. C. D. Sigsbee, U.S. N., axd Commander J. R. Barteett, U.S. N., Commanding.

XXXI.

Report on the Annelids. By E. EHLERs.

(Published by permission of Benjamix Peirce, Carlile P. Pattersox, and J. E. Hilgard, Superintendents U. S. Coast Survey.)

WITH SIXTY PLATES.

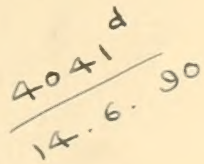

CAMBRIDGE:

Fjinter for the ftluseum.

OCTOBER, 1887. 


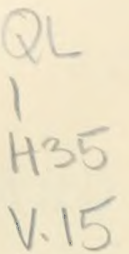

Fnibersitu 狂ess:

Johy Wilgox and Son, Cambridge. 


\section{N H A L T.}

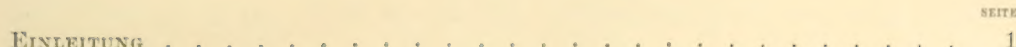

Verzerchniss der Anneliden aus dem Flontda Gebiete. . . . . . . . . 5

Zusamenstelluvg der Würmer aUf einzelnen Fundorte. . . . . . . . 9

Famiten der Florida-Anneliden . . . . . . . . . . . . . . . . . 12

Verticale Verbeitung der Florida-Anneliden . . . . . . . . . . . 15

AMPhinomidae . . . . . . . . . . . . . . . . . . . . . . . . 18

Chloeia euglochis. Taf. 1, Fig. 1, 2; Taf. 2, Fig. 1, 8; Taf. 8, Fig. 1-4. . . . 18

Notopygos erinita. Taf. 1, Fig. S; Taf. S, Fig. 5-7. . . . . . . . . . . 24

Amphinome Pallasit. Taf. 1, Fig. 4. . . . . . . . . . . . . . . . . 26

Hermodice carunculata . . . . . . . . . . . . . . . . . 27

Eurythoe complanata . . . . . . . . . . . . . . . . . . . . . . 29

Euphrosyne triloba, Taf. 4 . . . . . . . . . . . . . . . . . . . . . . . . . . . . . . . .

Palmytidae . . . . . . . . . . . . . . . . . . . . . . 34

Palmyra sp.? . . . . . . . . . . . . . . . . . . . . . . . . 34

ApHrodttidae . . . . . . . . . . . . . . . . . . . . . . . 35

Hermionea . . . . . . . . . . . . . . . . . . . . . . . . . 36

APHRODIte . . . . . . . . . . . . . . . . . . . . 39

Aphrodite acuminata. Taf. 5 . . . . . . . . . . . . . . . . 39

Aphrodite obtecta. Taf. 6, Fig. 1-8. . . . . . . . . . . . . . . . . 42

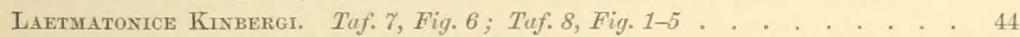

Pontogenia . . . . . . . . . . . . . . . . . . 46

Pontogenia sericoma. Taf. 7 , Fig. $1-5$. . . . . . . . . . . . . . . . 46

Polynorna . . . . . . . . . . . . . . . . . . 48

Polynoe polytricha. Taf. 10, Fig. 9, 10; Taf. 11, Fig. i. . . . . . . . . . 49

Polynoe granulata. Taf. 11, Fig. 2-7. . . . . . . . . . . . . . . 50

Polynoe taeniata. Taf. 10 , Fig. $1-8$. . . . . . . . . . . . . . 51

Polynoe lactea. Taf. 9, Fig. 1-7. . . . . . . . . . . . . . . . . . 52

АсоетеА . . . . . . . . . . . . . . . . . . 53

ЕUARche . . . . . . . . . . . . . . . . . . . 53

Euarche tubifex. Taf. 12, Fig. 1-7; Taf. 18, Fig. 1. . . . . . . . . . . 54

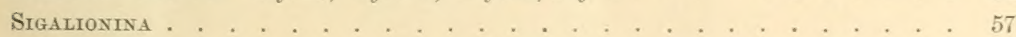

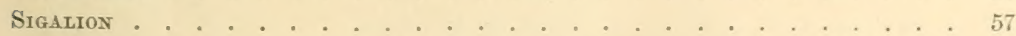

Sigalion Pourtalesil. Taf. 15, Fig. 1-4; Taf. 16, Fig. 1-10 . . . . . . . . 57

Sthenelats . . . . . . . . . . . . . . . . 60 
Sruesbuas simplex. Tro: 13, Fig. 2, \&; Taf. 14, Fig. 1-6. . . . . . . . . 60

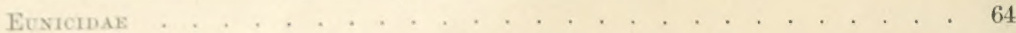

Rнименоввдситал . . . . . . . . . . . . . . . . . . . 70

Rimpromionium Agassizn. Taf. 17, Fig. 1-5; Taf. 18, Fig. 1-9 . . . . . . 70

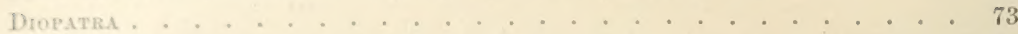

Dropatra Eschrichtil . . . . . . . . . . . . . . . . . . . . . . 73

Diopatra Pourtalesit, Taf. 19, Fig. 6-10; Taf. 20, Fig. 1-6. . . . . . . . 74

Diopatra (Pakadiopatka) fragosa. Taf: 20, Fig. 7-14; Taf. 21, Fig. 1-4. . . 75

Diopatra (Paradiopatra) glutinatrix. Taf. 18, Fig. 10-15; Taf. 19, Fig. 1-5 . 76

Oxuphis . . . . . . . . . . . . . . . . . . 78

Oxuphis (Paronuphis) graclis. Taf. 21, Fig. 5-18. . . . . . . . . . 78

EvNice . . . . . . . . . . . . . . . . . . . . . 82

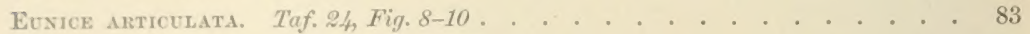

Euniee axtillexsis. Taf. 24 Fig. $5-7$. . . . . . . . . . . . . . . 84

Eunice bixomisata . . . . . . . . . . . . . . . . . . . . . . 85

Eunice violaceo-maculata. Ta . 24, Fig. 11, 12 ; Taf. 25, Fig. 1-7 . . . . . 86

Eunice rubra, Taf. 26, Fig. 1-11. . . . . . . . . . . . . . . . . . 87

Eunice floridana. Tuf. 22, Fig. $1-7$. . . . . . . . . . . . . . . 88

Eunice tibiana. Taf. 27 , Fig. $1-18$. . . . . . . . . . . . . . 90

Eunice fucata. Taf. 25, Fig. $8-20$. . . . . . . . . . . . . . . 91

Eunice conglomerans. Taf. 2S, Fig. 1-9; Taf. 24, Fig. 1-4 . . . . . . . . 93

Marphysa Bellit. Taf. 28, Fig. 1-8. . . . . . . . . . . . . . . 95

Mrrphysa Parisht . . . . . . . . . . . . . . . . . . . . . . 9 97

Marphysa sanguinea . . . . . . . . . . . . . . . . . . . . . . . . 9 97

Nicidion Brevis. Taf. 28, Fig. 9-14; Taf. 29, Fig. 1 \& . . . . . . . . . . 98

Paramarphysa . . . . . . . . . . . . . . . . . . . . . . . . . 99

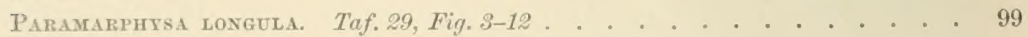

Lysidice notata. Taf. 30, Fig. 1-9 . . . . . . . . . . . . . . 100

LuMbriconereis . . . . . . . . . . . . . . . . . . . . . 102

Lumbriconereis floridana, Taf. 80 , Fig. 10-15 . . . . . . . . . . . 103

Lumbriconereis bidens, Taf. 31, Fig. 7-17 . . . . . . . . . . . . . . 103

Lumbriconerets robusta. Taf. 31, Fig. 1-6. . . . . . . . . . . . . . 104

Ninoe Kinbergi, Taf. 82, Fig. 1-9 . . . . . . . . . . . . . . . . . 105

Irsarete Brasiliensis, Taf. 83 , Fig. 1-8. . . . . . . . . . . . . 107

OeNONE DIPHYLlidia. Taf. S/4, Fig. 1-7. . . . . . . . . . . . . . . . 109

ARACODA . . . . . . . . . . . . . . . . . . . 111

Aracoda mulimentata. Ta S4, Fig. 8,9; Taf. 85, Fig. 1-4 . . . . . . 112

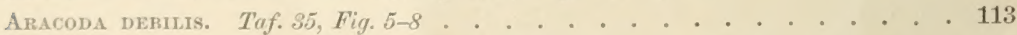

LYCORIDAE . . . . . . . . . . . . . . . . . . . . . . 114

Nereis articulata. Taf. S6, Fig. 1-4. . . . . . . . . . . . . . . 114

Nereis (Ceratonereis) versipedata. Taf. 66, Fig.5-10. . . . . . . . . . 116

Nereis (Ceratonereis) mirabiuis, Taf. 37, Fig. 1-6. . . . . . . . . . . 117

GLtceridae . . . . . . . . . . . . . . . . . . . 121 


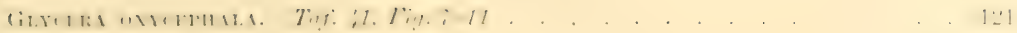

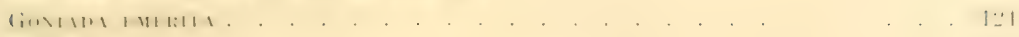

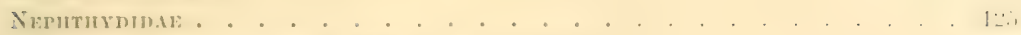

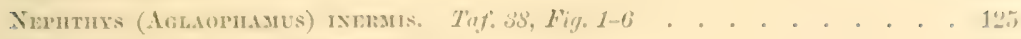

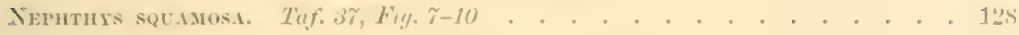

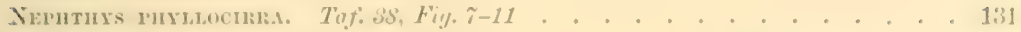

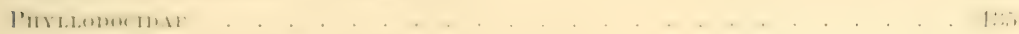

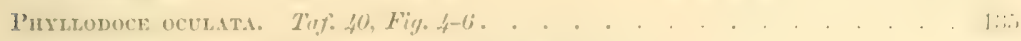

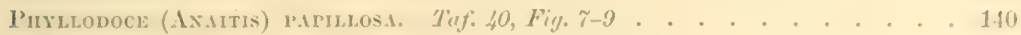

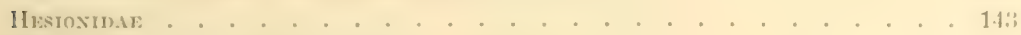

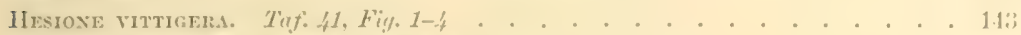

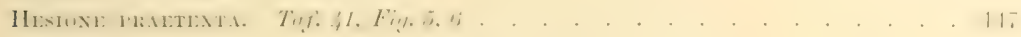

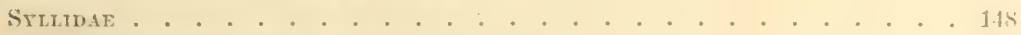

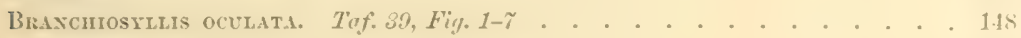

'Tripaxostlis . . . . . . . . . . . . . . . . . . . . 151

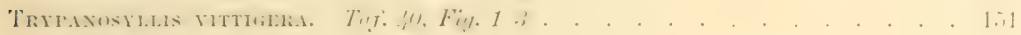

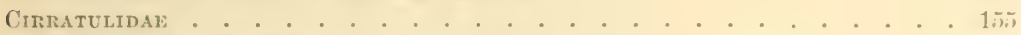

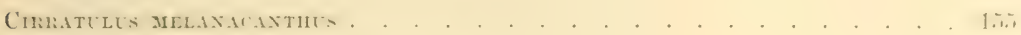

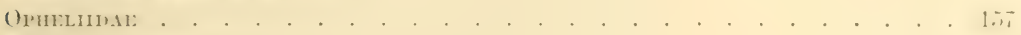

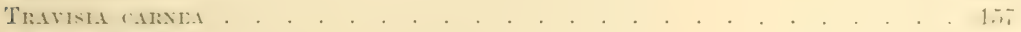

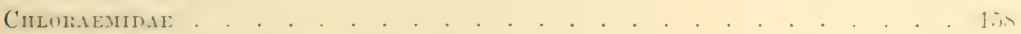

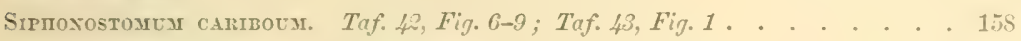

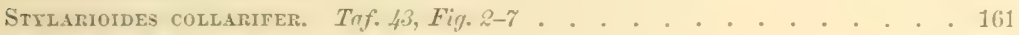

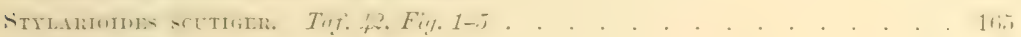

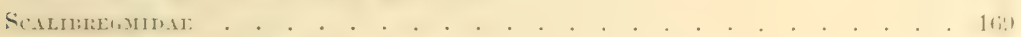

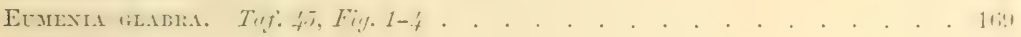

'T'ELETHUSAE . . . . . . . . . . . . . . . . . . . . . 178

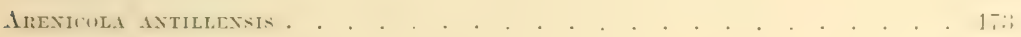

Capitellidae . . . . . . . . . . . . . . . . . . . . . . . . 1it

Dastbraxchus luxulates. Taf. 45, Fig. 5-9. . . . . . . . . . . . . 174

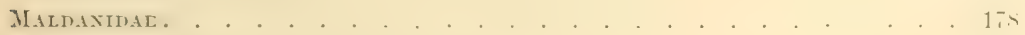

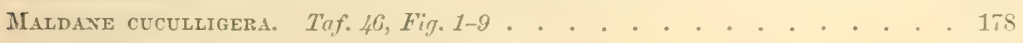

Clymexe cirrata. Taf. 46, Fig. 10-13 . . . . . . . . . . . . . 18z

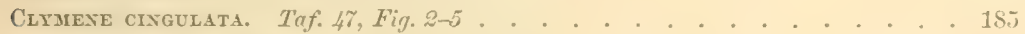

Rнodrse sima. Taf: 47, Fig. $6-10$. . . . . . . . . . . . . . . . . 189

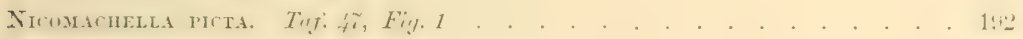

Amphimesinal. . . . . . . . . . . . . . . . . . . . . . 1111

Pectivaria (petta) pellucida. Taf. 4́, Fig. 1-9. . . . . . . . . . . . 194

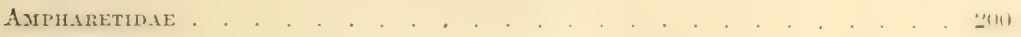

Auchexoplax . . . . . . . . . . . . . . . . . . . . . . 20S

Auchexoplax crinita. Taf. 4 H Fig. 10-16 . . . . . . . . . . . . . 209

Melinna parumdentata. Taf. 50, Fig. 1-9. . . . . . . . . . . . . 214

AMAge tumida. Taf. 48, Fig. 10-19. . . . . . . . . . . . . . . 220 


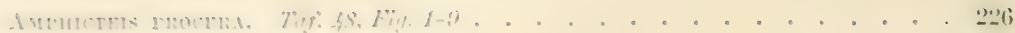

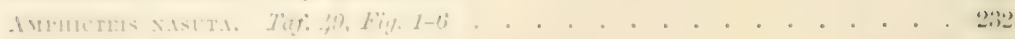

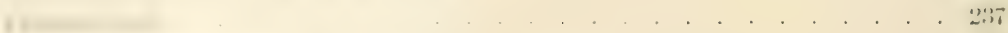

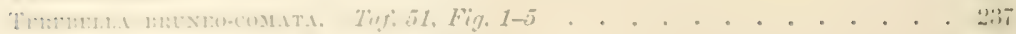

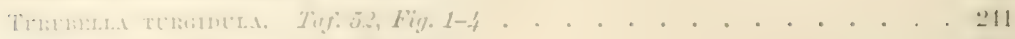

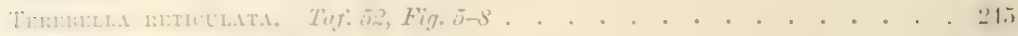

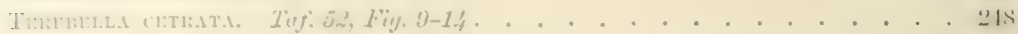

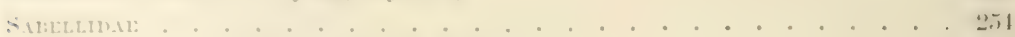

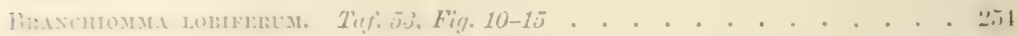

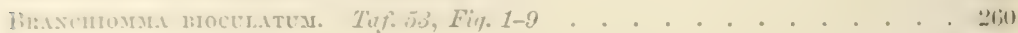

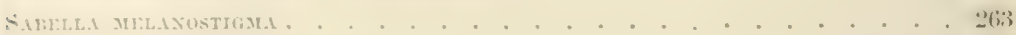

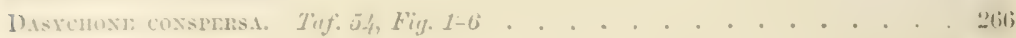

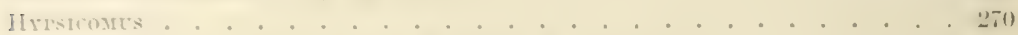

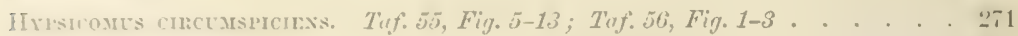

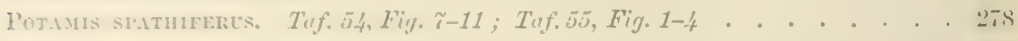

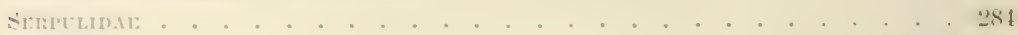

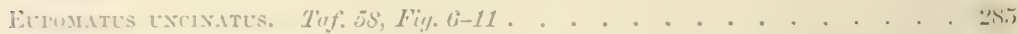

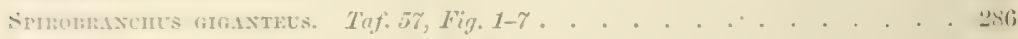

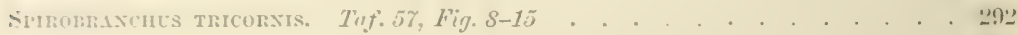

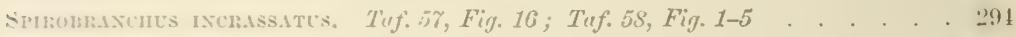

lostatostrgies stmihates . . . . . . . . . . . . . . . . . . . 296

l'r.enstegls ixcomites. Tuf. G0, Fig. 1-9. . . . . . . . . . . . . . 300

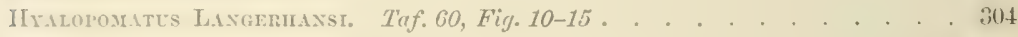

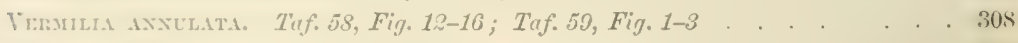

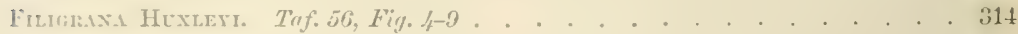

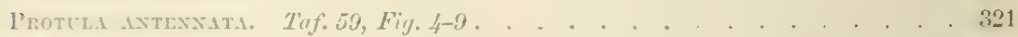

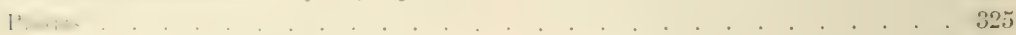

l'mots smatex. Tiff. 5G, Fig. 10-14. . . . . . . . . . . . . . . . 325

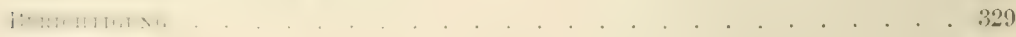

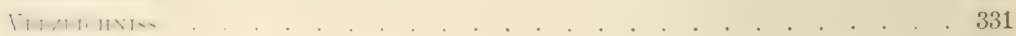

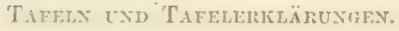




\title{
FLORIDA-A NNELTDEN.
}

\author{
BH.LIBBEITET YON \\ E. EHLERS, \\ Profissor un der Unirersität au Gütlingen.
}

Die Borstenwürmer, deren Darstellung die folgenden Blätter gewidmet sind, gehören im Wesentlichen der Ausbeute an, welche im Floridargebiet theils auf Expeditionen in den Jahren 1868-1870 unter der Leitung von Graf Pourtalès, theils auf der "Blake" Expedition unter der $\Lambda$ ufsicht von A. Agassiz gemacht wurde; nur wenige Wiirmer, die nicht hier gesammelt wurden oder einem anderen Faunengebiete angehören, habe ich aus besonderen Grïnden mitbehandelt. Diese gehören zum Theil einer AmnelidenSammlung an, welche aus dem Besitz des Museum of Comparative Zoölogry in Cambridge (Mass.), mir seit langerer Zeit anvertraut ist. Für die Ueberlassung dieses Materiales sowie fiir die Drucklegung der daran gemachten Untersuchungen bin ich Herm A. Agrassiz zu Danke verpffichtet.

Bei der Durchsicht und eingehenden Prifung des mir überwiesenen umfangreichen Materiales stellte sich bald heraus, dass in doppelter Hinsicht eine Beschränkung in Rücksicht auf das zur Darstellung zu bringende geboten sei. Denn zunächst war es unabweislich, in der Regel nur solche Würmer zu bearbeiten, deren Erhaltungstand ein derartiger war, dass eine Identificirung der vorliegenden Thiere mit bereits beschriebenen Arten mit einiger Sicherheit gemacht orler eine kinntlich machende Beschreibung daron gegeben werden konnte. Damit musste eine nicht geringe Anzahl von zu unvollständig erhaltenen Thieren völlig bei Seite geschoben werden; und ich habe auch meistens keine Veranlassung gehabt, solche zweifelhaft bleibende Formen in der Aufzählung zu erwälınen, da damit für das Gesammtbild der Fauna eine nennenswerthe Erweiterung nicht erreicht sein würde. Aus dem gleichen Grunde habe ich auch Wurmröhren, die oft in grosser Menge 
von cimzehen limatorfen ronlagen, nicht weiter berieksichtigt, wenn deren Futaner nicht mit aller sicherheit fistzustellen wax; dem wem in einzelnen Piillen II urmröhren anch ein so hestimmtes Geprïge besitzen, dass sie mit when w) wrower Sicherheit wie Conchylien zu bezeichnen sind, so finden sich mnterereits - und wohl viel häufiger - Wurmröhren, welche von ganz indillientem IIabitus simb oder bei gewisser Gestaltung, wiewohl von ganz varehientenen 'Thieren crbaut, so iibereinstimmend, dass eine sichere Bestimmung nur dimn moglich ist, wemn der Wurm als Insasse der Röhre angetroffen wirl.

Anlererseits war eine Beschränkung darin geboten, dass ein Eingehen anf anatomische orler histologische Verhïltnisse in der Regel ansser Acht gelassen werden musste; dem theils waren die nach dieser Richtung hin am meisten interessirenden Würmer in zu wenigen Exemplaren vertreten, als dias eine anatomische Untersuchung mit Aussicht auf Erfolg hätte angrestellt werden kïmen, theils erwies sich der Erhaltungzustand der Thiere als ein solcher, dass dadurch die Anstellung derartiger Untersuchungen von romherein als unfruchtbar erscheinen musste.

Diunit trat die descriptiv-taxonomische Behandlung in den Vordergrund; md mit der Feststellung der gefundenen Arten musste ein Material geliefert werden, welches für systematische wie für zoogeographische Ziele brauchbar sein sollte.

Die Feststellumg der Arten ${ }^{1}$ hatte mit den Schwierigkeiten zu kämpfen, welche zur Zeit noch in grosser Ausclehmung der Bestimmung von polycluneten Amneliclen entrgegentreten; dass nämlich wohl mannigfaltige Arten beschrieben, ein kleiner Theil derselben auch abgebildet ist, dass aber in schr vielen Fïllen Beschreibung und Abbildung für eine sichere Wiedererkennung nicht ausreicht. Für einzelne der von Grube in den Annulata Derstediann beschriebenen Arten aus dem westindischen Meere konnte ich die Originalexemplare vergleichen; dafür habe ich Herrn Staatsrath Jap. Steenstrup zu danken, welcher die im Kopenhagener Zoologischen Universitäts IIuseum aufhewahrten Exemplare mir auf meine Bitte zur Ansicht iibersen-

1 SpAtrerer 7usatz. - Das Manuscript dieser Arbeit war im December 1885 vollständig abgeschlosen; leiler verzögerte sich die Fertirstelluxg der Tafeln durch den Lithographen weit mehr als erwartet werilen komnte, und damit die Drucklegnng des Ganzen. Daher ist die inzwischen veröflentlichte Bearbeitung der auf der Challenger-Expeelition gesammelten Anneliden durch William C. II'Intosh (Iiepurt on the Scientific Results of the Vnyage of II. M. S. Challenger. Zoolog. Vol. XII.) in dieser Bearbeitum iler Florida-Anneliden noch nicht berüeksichtigt. Sollte, was ich zur Zeit nicht beurtbeilen kann, eine besondere Feststellung der Synonymik dardurch nöthig werden, so werde ich das nachzuholen versuchen. 
dete. In anderen Fitlen komme ich eine volle sichespeit iiber rlic Irontitii der Art nicht erhalten. Jeh hate in solehen billen die Art moch eimmal

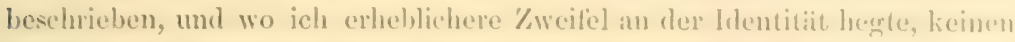
Anstand genommen, die von mir beschriebene form mer einem nenen Nalmen aufufuibren. Nur ansnahmsweise habe ich die Beschroibung soleher Anneliden mitgegeben, welehe dem durehforschten Ciebiede nicht angehiiren; dam geschah es, um die Abweichumgen kilurer heransmbeben, mit welchen eine von mir als umbeschrieben angesehene drt von ciner anderen friiher besehriebenen zu unterseheiden war.

Bei den Beschreibungen selbst bin ich in umeleicher Weise verfilnen; eine kurze Beschreibung schien mix bei solehen Arten auseichend zu sein, von denen nah verwanlte formen in grösserer Kahl durch srute lieschreibungen bereits hinlïgrlich bekannt gemacht waren; ausfïhrichere Darstellungen aber habe ich da gegeben, wo unsere Kenntnisse von dem ganzen Formenkreise, welchen die zu schilkernde Art angrehörte, noch wenigg auscrebreitet sind und noch festzustellen bleibt, welehe Kennzeichen fiir eine Characterisirung der Arten besondere Beriieksichtigung verdienen müchten.

Unter allen Verhältnissen habe ich es für geboten gehalten, dic Beschreibungen dureh Abbildungen zu ergänzen; an einem Fehler missen dieselben leiden; dieser ist durch das Material bedingt. Ich habe die Wriumer, die in Weingeist conservirt waren, auch in den Fällen abbilden lassen, wo es mir um die Darstellung eines Gesammtbildes zu thm war, dabei aber vermieden, irgendwie zu idealisiren oder den Effect durzustellen, welchen der lebende Wurm etwa hervorgebracht haben möchte. Das ist besonders auch da zu betonen, wo ich in einzelnen Fällen farbige Bilder habe anfertigen laswen; diese sind getreu nach dem dermaligen Erhaltungzustande der Thiere gemacht. In einzelnen Fällen habe ich damit ein Bild fixirt, welches an den Objecten selbst jetzt nach dem längeren Terweilen in Weingeist nicht mehr vorhanden ist. Sollen meine Darstellungen mit den lebenden Thieren confrontirt werden, so wird solches zu beriicksichtigen sein; in den meisten Fïllen wird die ron mir gegebene Darstellung ausreichen, dir die systematische Bearbeitung dieser Thiere doch wohl immer an Exemplaren gemacht werlen wirl, welche in Weingeist conservirt sind, wem auch die Kunst der Conservirung unseren Sammlungen ein stets besser die ursprünglichen Formen zeigendes Material zuführen wird.

Bei den Abbildungen habe ich einen gewissen Werth auch auf die Darstellung der von den Würmern erbauten Röhren gelegt, welche beim Sam- 
mehn der. Thiere mit Recht mehr Berïcksichtigung gefunden haben, als dits bis jetzt in vielen fillen geschehen war.

Die grissere Mehrzahl der von mir erwïhnten oder beschriebenen Wimmer halhe ich als bisher unbeschriebene Arten behandeln zu müssen groglaubt; in solchen läillen kounte die Berechtigung dazu angezweifelt werten, wo offenbar ïhnliche Arten nur ungenügend beschrieben waren, oter wo die unterscheidenden Merkmale geringfüigig erscheinen; ich habe d:mu so viel als mir müghlich, auf diese Verhältnisse hingewiesen; es aber füir greboten gehalten, eine wohl zu characterisirende Art als solche hinzustellen ohne auf eine wohl kaum zu entwirrende Synonymie Rüicksicht z.11 nehmen; geringfiigig erscheinende Unterschiede aber durch die Aufstellung einer neuen Art vorliiufigr besonders hervorzuheben, sobald die nïichst stehenile, vielleicht identische Art einem anderen Faunengebiete als dem untersuchten angehörte, da nur dadurch ein weiterer Anlass gegeben werden kimn, nachzuforschen, wie weit mit den Unterschieden der geographischen Verbreitung Formeigenthimlichkeiten ihr besonderes Gepräge erhalten, nächst verwandte Formen als geographisch viearïrende Arten erscheinen. Nach dieser Richtung werden unsere Kenntnisse von den Borstenwiimern noch eine grosse Erweiterung erfahren, allerdings nicht anders, als dass mit sorgfältigen Beschreibungen der Thiere sich herausstellt, was in den einzelnen Arten nur den geringeren Werth einer individuelten Abweichung oder den grösseren in der Bildung einer Varietät oder eines Varietätenkreises besitzt.

Ueber die nïchsten Grenzen meiner Aufgabe, die gesammelten Würmer zu bestimmen und zu beschreiben, bin ich in einzelnen Fällen allerdings hinausgegangen, indem ich Auffassungen mitgetheilt habe, die mir bei der Betrachtung einer Familie, welche meist in etwas grösserer Anzahl von Tertretern vorlag, entgegengetreten waren. Sie waren entweder geboten, um meinen Standpunkt in der Beschreibung der Würmer anderen Schriftstellern auf demsclben Gebiete gegenüber zu kennzeichnen und zu rechtfertigen, oder um auf Verhältnisse hinzureisen, welche für die Feststellung der systematischen Auffassungen von Interesse sein können.

Was ich dagegen in der Reihenfolge, mit welcher ich die Familien aufgezïhlt gregreben habe, bitte ich nicht als einen Ausdruck meiner Auffassung der Verwandtschaftsverhältnisse der Annelidenfamilien zu einander ansehen zu wollen; ich habe mich dem angeschlossen, was zur Zeit mehr orler minder in L'ebung ist; bin aber überzengt, dass für zahlreiche Familien 
die verwandschattlichen Bezichungen zu einander durchats nicht klat vorliegren, und sich vieltach wohl noch anders als zur \%eit darstellen werden, wemn die Kenntniss des anatomischen batues so wie der Jugendformen ausgelehnter geworden ist.

Die folgende Tabelle giebt in systematischer Reihenfolge ein Verzeichniss der von mir behandelten Anmeliden aus dem Floridagebiete sowie aus dem Antillenmeere; himzngesetzt habe ich die Fundorte, die Neerestiele derselben und so weit es rerzeichnet war die Zeit des Fanges. Ich erachte das leatere fïr nicht unbedentend, da ich nach Beobachtungen, die allerdings noch wenig ausgedehnt sind, die Erfalrung gemacht habe, dass fitir gewisse Ammeliden die Standorte mit den Jahreszeiten sich änclern.

\begin{tabular}{|c|c|c|c|}
\hline & zat. & Fundort. & Falen. \\
\hline $\begin{array}{l}\text { Palmyridae. } \\
\text { Palmyra (Psectra Gr.) sp.? } \\
\text { Aphroditidae. } \\
\text { Aphrodite acumiuata, n. sp. } \\
\text { Aphrodite obtecta, n. sp. } \\
\text { Laetmatonice Kinbergi (Baird). }\end{array}$ & $\begin{array}{l}11 \text { i. } 1869 \\
\text { April, } 1858 \\
1859 \\
186: 3 \\
\text { April, } 1865 \\
1868 \\
16 \text { i. } 1869 \\
\text { iv. } 1869 \\
\text {. . . . } \\
21 \text { iii. } 1869 \\
13 \text { iii. } 1865 \\
21 \text { iii. } 1869 \\
7 \text { i. } 1868 \\
. . .\end{array}$ & $\begin{array}{l}\text { Tortugas, Florida, Cape Florida. } \\
\text { Tortugas, Florida. } \\
\text { W. of Tortugas. } \\
\text { Tortugas, Florida, Bahia IIonda. } \\
\text { Cape Florida. } \\
\text { Hayti. } \\
\text { Florida Reef. } \\
\text { Hayti, Sea near Caymites. } \\
\text { Tortugas. } \\
\text { W. of Tortugas. } \\
\text { Off French Reef. } \\
\text { Lat. } 24.43 \text { N. Long. } 83.25 \mathrm{Wr} \text {. } \\
\text { Lat.22.9.15 N.; Long. } 82.21 \mathrm{~W} \text {. } \\
\text { Tortugas; in channel between } \\
\text { East Key and Middle Key. } \\
\text { Off Carysfort lieef. } \\
\text { Tortugas, Cape Florida. } \\
\text { Silver liey Bank, Tortugas. } \\
\text { S. of East Key. } \\
\text { Off Carysfort Reef. } \\
\frac{1}{1} \text { m. S. of Sand Key. } \\
\text { Key West. }\end{array}$ & $\begin{array}{r}30-35 \\
15 \\
37 \\
177 \\
5-7 \\
35 \\
\\
\\
13 \\
35 \\
10 \\
1-2\end{array}$ \\
\hline
\end{tabular}




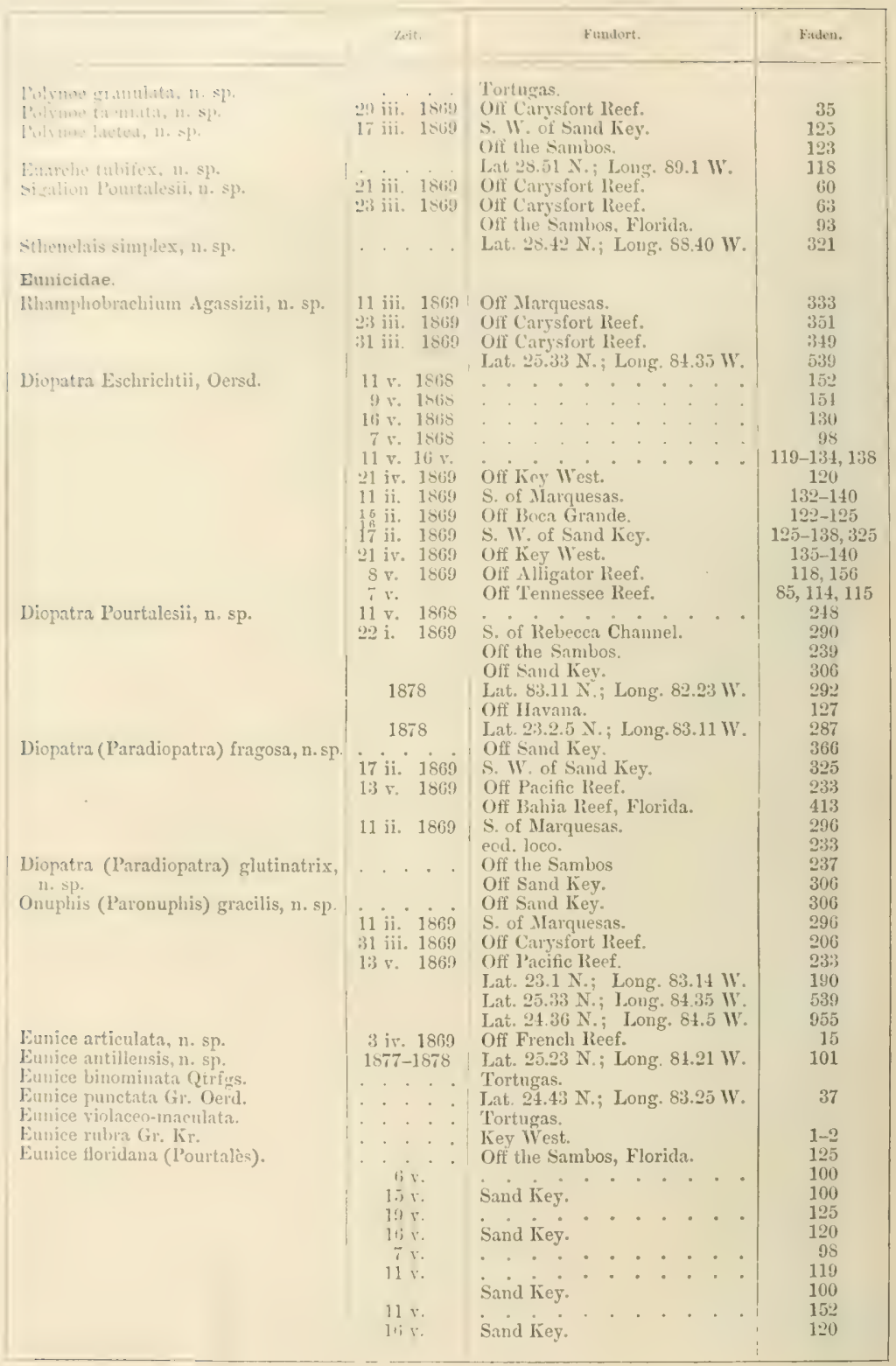




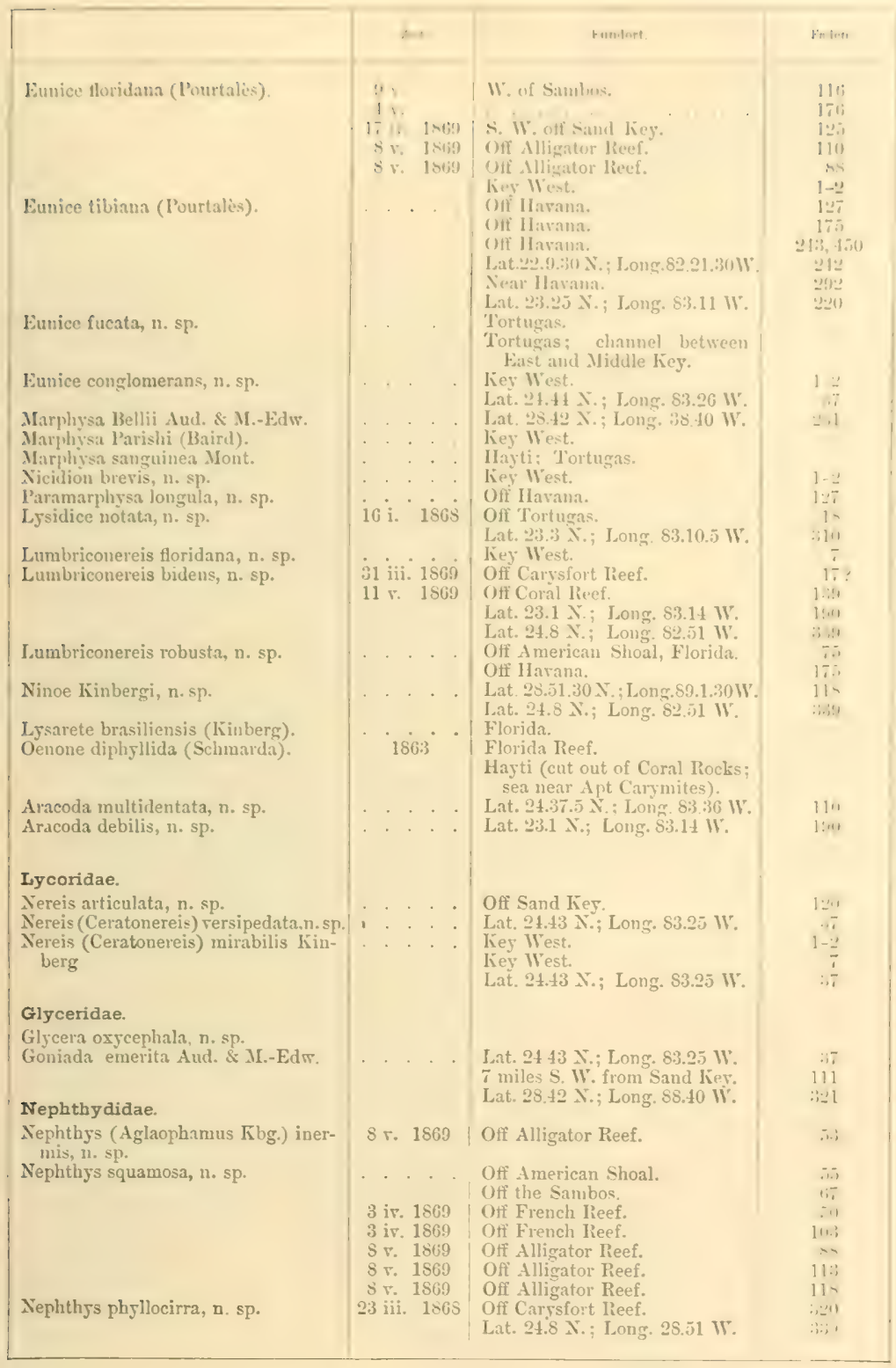




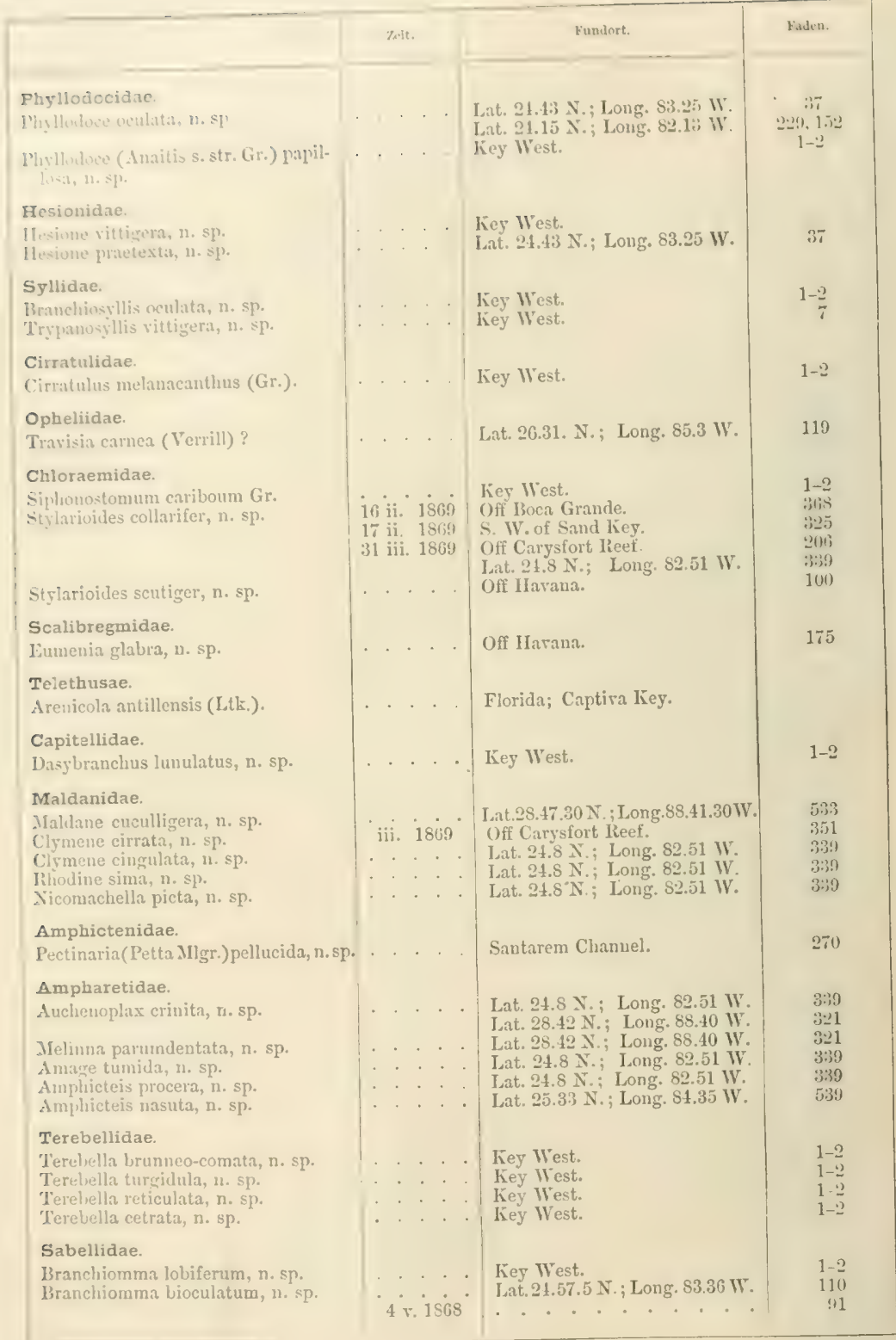




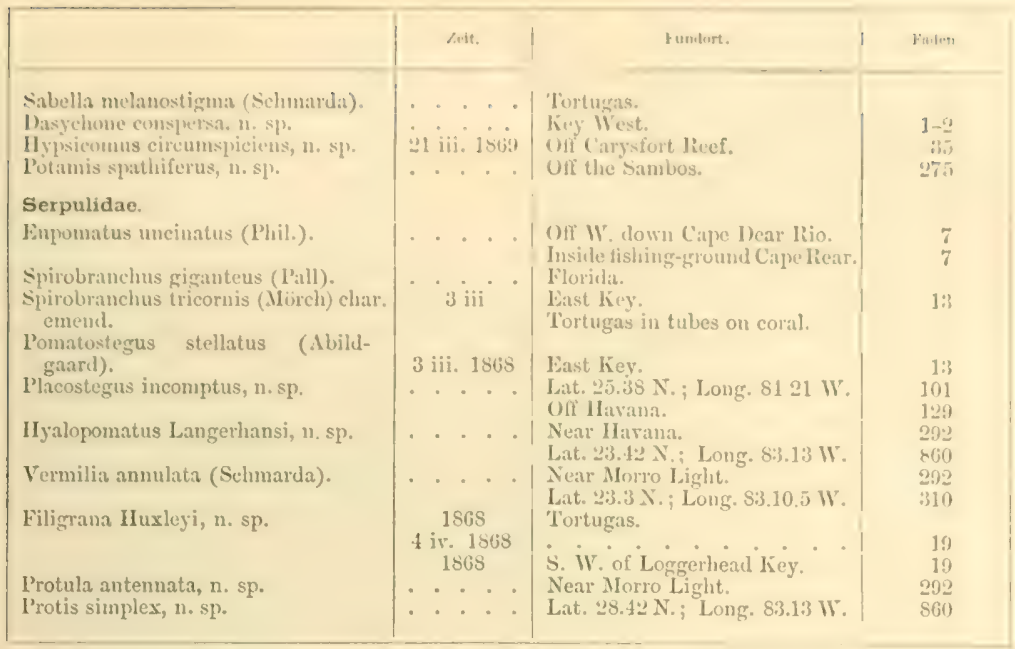

Eine Vertheilung der Wiimer auf die einzelnen Fundorte ist in der folgenden Zusammenstellung gegeben; die daneben gesetzten Zahlen zeigen die Meerestiefe in Faden an.

Florida: Chloeia euglochis, n. sp.

Notopygos crinita (Gr.).

Lysarete brasiliensis (Kbg.).

Arenicola antillensis ( $\mathrm{Ltk}$.).

Spirobranchus giganteus (Pall.).

Cap. Florida: Chloeia englochis, n. sp.

Hermodice carunculata (Pall.).

Lurythoe complanata (Pall).

Florida reef: Hermodice carunculata (Pall.). Oenone diphyllitlia (Schm.).

Off Bahia reef, Florida: Diopatra (Paradiopatra) fragosa, 413.

Off Pacific reef: Aphrodite acuminata, n. sp., 60. Diopatra (Paradiopatra) fragosa, n.sp., 233.

Onuphis (Taronuphis) gracilis, n. sp., 233.

Off Carysfort reef: Euphrosyne triloba, n. sp., 35.

Aphrodite acuminata, n. sp., 17.

Polynoe taeniata, n. sp., 35.

Sigalion Pourtalesii, n. sp., 60, 63.

Rhamphobrachium Agassizii, n. sp., 349, 351.

Onuphis (Paronuphis) gracilis, n. sp., 206. Lumbriconereis bidens, $\mathrm{n}$. sp., 17?
Off Carysfort recf: Nephthys phyllocirra, n. sp., $3 \geq 0$.

Stylarioides collarifer, n. sp., 206.

Clymene cirrata, n. sp., 35) 1.

Hypisicomus circumspiciens, n. sp., 35.

Off French reef : Hermodice carunculata (I'all.), 1 5.

Polynoe polytricha (Schm.), 34.

Eunice articulata, n. sp., 15.

Sephthys squamosa, n. sp., 50, 103.

Off Alligrator reef: Aphrodite acuminata, n. sp., 88.

Diopatra Eschrichtii (Oerd.), 118, 156.

Eunice floridana (Pourt.), 86, 110.

Nephthys inermis, n. sp., 53.

Neplitlys squamosa, n. sp., 88, 113, 118

Off'Tennessee reef: Lactmatonice Kinbergi (Bul.), 174.

Diopatra Eschrichtii (Oerd.), 114, 115.

Bahia, Florida: Amphinome Pallasii (Qtfgr).

Oft American Shoal : Lumbriconereis robusta, 11. sp., 75.

Nephtiuys squamosa, n. sp., 55 . 


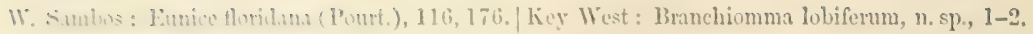

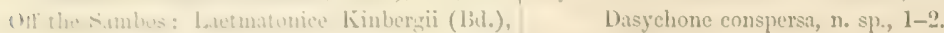

$$
1=1,5 \text {. }
$$

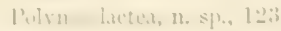

sicalim b'urtalesii, n. sp., :13.

1). putar l'ourtalesii, u. sp., 2339.

Dioputm (l'andiopntra) glutinatrix, n. sp), -..1.

Eunice thriclana (Potut.), 125.

dephthys styuamosa, n. sp), 6 .7.

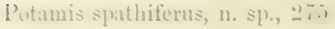

Sam? liey : Emice florilan (Pourt.), 98, 100, 119, $1 \pm 2(1,1 \pm 5,152$.

(UIt Saml Key: 1)iopatra Pourtalesii, 11. sp., 306.

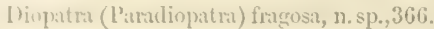

1)iupatra (laradiopatra) glutinatrix, n. sp., 306 .

Onuphis (Paromuplis) sracilis, n. sp., 306.

Nereis articulata, n. sp., $1 \geq 0$.

7 miles S. Wr. from Sand Key : Goniada emerita (Auil. \& M.-Eilw.), 111.

1t miles south of Sand liey: Euphrosyne triloba, n. sp., 10.

S. WF. of Sand Key : Laetmatonice Kinhergi (Bd.), $1: 5.5$

Polynou lactea, n. sp., 125.

Diopatra Eschrichtii (Oerd.), 125, 138.

Diopatra (Paradiopatra) fragosa, n.sp., 325.

Eunice florilama (Pourt.), 125.

Stylarioides collarifer, n. sp., 325.

Key West: Palmyra (Psectra Gr.), sp. ? 1-2.

Eunice rubra ((ir., Kr.), 1-2.

Eunice floridaua (Pourt.), 1-2.

Eunice conglomerans, n. sp., 1-2.

Marphysa R'arishi (Baird).

Xicilion brevis, 11. sp), 1-2.

Lnmbriconereis floridana, n. sp., 7 .

Jereis (Ceratonereis) miralbilis (Kbg.), $1-2,7$.

Phyllorloce (Annihis, s. str. Gr.) papillosa, n. sp., 1-".

Hesione vittigera, $\mathrm{n}$. sp.

Branchiosfllis oculata, $\mathrm{n}, \mathrm{sp}, \mathrm{1}-2$.

'Irypanosyllis vittigera, $11 . \mathrm{sp} ., 7$.

Cirratulus melanacanthus (Gr.), 1-2.

Siphonostomum cariboum (Gr.), 1-2.

Dasybranchus linulatus, 11. sp., 1-2.

Terebella brunneo-comatn, n. sp., 1-2.

Terebella turcridula, y. sp., 1-2.

Tereluella reticulata, n. sp., 1-2.

Terebella cetrata, n. sp., 1-2.
Utl' liey Wost: Lactmatonice Kinbergi (Bel.), 125. Diopatra Eschrichtii (Oerd.), 120, 135, 140.

Near Morro Light: Vermilia ammulata (Schm.), 292.

Protula antemmata, n. sp., 292.

Ofl Boea (irande : Aphrodite obtecta, n. sp., 122. Diopatra Eschrichtii (Uerd.), 122, 125.

Stylarioictes collarifer, n. sp., 368.

Off Marquesas: Rhamphobrachium Agassizii, n. sp., 333.

Sunth off Marques.s: Diopatra Eschrichtii (Oerd.), 132, 140 .

Diopatra (Paradiopatra) fragosa, n. sp., 296.

Onuphis (I'aronuplis) gracilis, I1. sp., 296.

South of Rebeca Channel: Diopatra Pourtalesii, n. sp., 290.

East Key : Spirobranchus tricornis (Mörch), char. emd., 13.

Pomatostegus stellatus ( $\mathrm{b}$ bdgd.), 13.

South of Eist Key : Euphrosyne triloba, n. sp., 13.

S. W. of Loggerhead Key: Filigrana Huxleyi, 11. sp., 19.

T'ortugas: Chloeia euglochis, n. sp.

Notopygos crinita (Gr.).

Amphinome Pallasii (Qtrfgs:).

Hermodice carunculata (Pall.).

Polynoe granulata, n. sp.

Eunice binominata (Qtrfgs.).

Eunice violaceo-maculata, n. sp.

Eunice fucata, n. sp.

Marphysa sanguinea (Mont.).

Sabella melanostigma (Schm.).

Spirobranchus tricornis (Mörch), char. emenil.

Filigrana Huxleyi, n. sp.

Tortugas, in channel between East Key and Nidlle Key: Eurythoe complanata (Pall.), 57.

Eunice fucata, n. sp.

Of Tortugas : Lysidice notata, n. sp., 18.

West of Tortugas: Notopygos crinita (Gr.), 30.

Hermodice carunculata (l'all.), 30-35.

Sautarem Channel: Pectinaria (Petta) pellucila, n. sp., 270.

Silver Key Bank: Eurythoe complanata (Pall.).

Ofi Coral reef : Lumbriconereis biclens, n. sp., 139.

Captiva Key: Arenicola antillensis (Ltk.).

Off W. down Cape Dear Rio: Eupomatus uncinatus (Phil.), 7. 


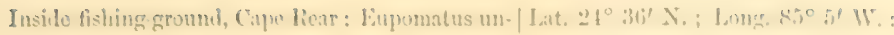
cinatus (Phil.), 7.

Ilayti: Hermodice carmenulita (I'all.).

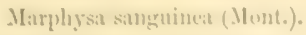

QEnone diphyllitlit (Schum.).

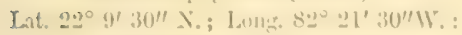

Finnice tibiana (1'unt.), 212.

Lat. $\left.22^{\circ} 99^{\prime} 15^{\prime \prime}\right)^{\prime}$; ; Leng $82^{\circ} 1^{\prime} 11$; :

Hermolice carunculata (P:all.), 177.

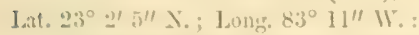

Diopatrat l'ourtalesii, n. sp., $28 \%$.

Lat. $23^{\circ} 3^{\prime} \mathrm{X}$.; Long. $83^{\circ} 10^{\prime} 5^{\prime \prime} \mathrm{II}^{\prime}$ :

L.rsillice notata, n. sp., 310.

Vermili: annulata (Sclmo.), 310.

Lat. $23^{\circ} 1^{\prime} \mathrm{x}_{\text {. }}$ : Long. $83^{\circ} 14^{\prime} \mathrm{W}$. :

Onuphis (Paronuphis) gracilis, n. sp., 190.

Lumbriconereis bislens, n. sp., 190.

Aracoda debilis, n. sp.. 190.

Lat. $23^{\circ} 11^{\prime} \mathrm{x}$.; Long. $82^{\circ} 23^{\prime \prime} \mathrm{W}$. :

Diopatra Pourtalesii, 11. sp., 292.

Lat. $23^{\circ} 25^{\prime} \mathrm{X}$.; Long. $83^{\circ} 11^{\prime} \mathrm{W}$. :

Eunice tibiana (Pourt.), 220.

Lat. $23^{\circ} 42^{\prime} \mathrm{N}$.; Long. $83^{\circ} 13^{\prime} \mathrm{W}$. :

Hyalopomatus Langerhansi, n. sp., 860.

Lat. $24^{\circ} 8^{\prime} \mathrm{N}$.; Long. $82^{\circ} 51^{\prime} \mathrm{W}$.:

Lumbriconereis biltens, n. sp., 339.

Ninoe Kinbergi, n. sp., 339.

Neplithys plyyllocirm, n. sp., 339.

Stylarioides collarifer, n. sp., 339 .

Clymene cingulata, n. sp., 339.

Nicomachella picta, n. sp., 339.

lihodine sima, n. sp., 339.

Auchenoplax criniti, 11. sp., 339.

Amage tumida, n. sp., 339.

Amphicteis procera, 11. sp., 339.

Lat. $21^{\circ} 15^{\prime} \mathrm{N}$.; Long. $82^{\circ} 13^{\prime} \mathrm{W}$. :

Phyllodloce oculata, n. sp., 152, 229.

Lat. $24^{\circ} 17_{2}^{\prime \prime} \mathrm{N}$.; Long. $82^{\circ} 9^{\prime} \mathrm{W}$. :

Laetwatonice Kinbergi (Bil.), 137.

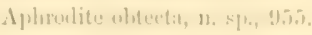

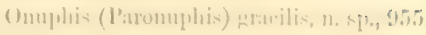

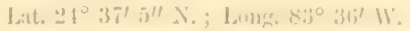

Aracoda multidentatit, ne, sp., 110 .

Branchiommat hisenlatum, 11. :5., 110.

Lat. $24^{\circ} 43^{\prime} \mathrm{X}$. ; Lome. $\left.83^{\circ} \pm .5\right)^{\prime} \mathrm{W}$.

Hermodice earmentatit (I'all.), :37.

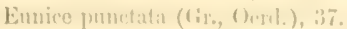

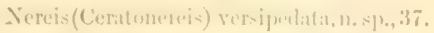

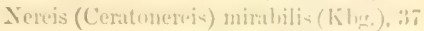

Guniada emerita (Aul. \& .l.-15lw.), 37.

Phyllorloce oculit:a, n. sp., :37.

IIesione prictexti, n. sp., 37 .

Lat. $24^{\circ}+\mathrm{H}^{\prime} \mathrm{N}$; ; Lon: $83^{\circ} 26 \mathrm{i}^{\prime} \mathrm{II}^{\circ}$.

Eunice conclomerans, n1, sp., 37 .

Lat. $25^{\circ} 23^{\prime} \mathrm{X}$, ; Long. $84^{\circ} 2 \mathrm{I}^{\prime} \mathrm{W}$.

Eunice autillensis, 11. sp., 131.

Lat. $25^{\circ} 38^{\prime} \mathrm{X}$.; Longr. $8 t^{\circ} \geq 21^{\prime} \mathrm{W}$.

I'lacostegus incomptus, 31. .5\%, 101.

Lat. $25^{\circ} 33^{\prime} \mathrm{N}$.; Long. $84^{\circ} 35^{\prime} \mathrm{W}$. :

lihamphobrachinm $A$ massizii, n. sp., 539.

Onuphis (I'aromplis) fracilis, 11. sp., 539.

Amplicteis masnta, n. sp., 539.

Lat. $26^{\circ} 31^{\prime}$ N.; Long. $85^{\circ} 3^{\prime \prime}$ II. :

Travisia carnea (Verrill) ? 119.

Lat. $28^{\circ}+2^{\circ} \mathrm{X}$.; Long. $88^{\circ} 40^{\prime} 11$.

Sthenclais simplex, n. sp., 321.

Marphysa Bellii (Aucl. \& M.-Eilw.), 321.

Goniada emerita (Aut. \& M.-Flw.), 321.

Auchenoplax crinita, n. sp., 321.

Melima parımdentata, 3. sp., 331.

Lat. $28^{\circ}+2 \prime$ I.; Long. $83^{\circ} 13^{\prime} \mathrm{W}$. :

Protis simplex, n. sp., 860 .

Lat. $28^{\circ} 4 i^{\prime} 30^{\prime \prime}$ N. : Long. $88^{\circ} 41^{\prime} \mathrm{W}^{\prime}$. :

Maldane cueulligera, n. sp., .533.

Lat. $28^{\circ} 51^{\prime}$ న.; ; Long. $89^{\circ} 1^{\prime} \mathrm{WI}^{\prime}$ :

Euarche tubifex, n. sp., 118.

Ninoe Kinbergi, n. sp., 118.

Diese Zusammenstellung kamn nicht den Anspruch erheben, die Ammelidenfauna des durchforschten Gebietes auch nur amnähernd erschöpfend darzustellen. Es ist unzweifelhaft nur ein kleiner Bruchtheil dieser Wurmfauna darin enthalten. Von dem Versuche, eine grössere Vollständigkeit dadurch zu erzielen, dass ich die aus dem gleichen oder benachbarten marinen Bezirke beschriebenen Ameliden mit aufzählte habe ich Alsstand genommen, da viele der hier dann aufzuführenden Arten nur als Aamen 
liguriren wiirden, welche mit Sicherheit fuir ein bestimmtes Thier nie zu rerwenden sein wiirden.

I'rotz lieser Liickenhaltigkeit liisst das V'erzeichniss einige 'Ziige erkennen, welche fiir das untersuchte fiunistische Gebiet characteristisch sind und bei genanerer birkemntniss desselben auch wohl bleiben werden. Das tritt in dem ungluichen Umfange hervor, mit welcher die verschiedenen Familien der Amneliden an diesem Verzeichniss theilnehmen. Es enthält dasselbe folgende Familien mit nachstehend verzeichneter Zahl der Gattungen und Arten.

\begin{tabular}{|c|c|c|c|c|}
\hline Fanilie. & & & & Gattungen. \\
\hline Amplhinomicla & & & • & 5 \\
\hline lalmyriclae. & - & - & . & 1 \\
\hline Aplıroditidae & . & & . & 7 \\
\hline Emnicidae. & - & . & . & . 13 \\
\hline Iycoridae & 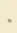 & & . & 1 \\
\hline Glycerilias. & & & . & 2 \\
\hline Sephthylidae & - & & . & 1 \\
\hline Phyllodocilae & - & & . & \\
\hline Hesionidae. & 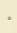 & & . & 1 \\
\hline Syllidae. . & & & . & \\
\hline Cirratulidae & ${ }^{*}$ & " & . & 1 \\
\hline
\end{tabular}

\begin{tabular}{|c|c|c|c|c|c|}
\hline Arten. & Familie. & & & Gattungen. & Arter \\
\hline 5 & Opheliidize . & . & - & . 1 & 1 \\
\hline 1 & Chlornemidre & . & . & 2 & 3 \\
\hline 11 & Sealibrermidae & . & . & 1 & 1 \\
\hline 30 & Telethusae. & . & . & 1 & 1 \\
\hline 3 & Capitellidue. & . & . & 1 & 1 \\
\hline 2 & Maluanidae . & . & . & 4 & 5 \\
\hline 3 & Amplictevidae & . & . & 1 & 1 \\
\hline 2 & Ampharetidae & , & . & 4 & 5 \\
\hline 2 & Terrebellidae & . & . & 1 & 4 \\
\hline 2 & Sabellidae . & . & . & 5 & 6 \\
\hline 1 & Serpulidine. & . & - & . & 10 \\
\hline
\end{tabular}

In dieser Zusammenstellung fehlen Vertreter der Familien der Sphaerodoridae, Nerillidae, Spionidae, Chaetopteridae, Ariciidae, Ammocharidae und Hermellidae; allein das wird, ebenso wie die geringe 'Zahl der Lycoridae, Phyllodocidae, Syllidae und wohl auch 'l'erebellidae, nicht eine Liickenhaltigheit der Fauma sondem der gemachten Sammlung auslriicken. Die Thätigkeit eines Sammlers, der seine Aufmerksamkeit besonders auch den kleineren oder den sehr leicht zerstörbaren Anneliden zuwendete, wïrde den grössten Theil dieser Liicken vermuthlich in kiirzester Zeit ausfüllen, die geringen Zahlen mancher Familien erheblich steigern. Ich lege deshalb auf die negative Seite der Zusammenstellung gar kein Gewicht.

Damn tragen aber diejenigen Familien, welche zahlreich vertreten sind, gewiss zur Characterisirung der Fauna bei, da es kaum wahrscheinlich ist, dass ilıre relativ grosse Anzahl das zufällige Resultat der Sammlung sein sollte. Ich stelle hier voran die Familie des Amphinomidae. Sie ist es, welche in der Vertretung, die sie hier findet, die Fauna als eine tropische characterisirt; fallt damit zusammen. dias die grïseren Amphinomiden als Bewohner der Corallenriffe, an denen sie weiden, bezeichnet werden, so ist damit eine 
Besonderheit des durchforschten marinen fiebietes zum Anwruck gobracht. - Von den ibrigen familien, welche zahlreicher vertreten sind, ist bis jetzt nieht bekamnt, dass sie in gleicher. Weise wie die Amphinomiden in hervorragender 11 eise Bewohner der tropisehen oder subtropischen Neere sind. Unter ihmen fiillt damn dureh die grosse Kahl ihrer Vertreter die Fanilie der Euniciden auf. So weit ich-fimnistische '/nsammenstellungen von Anneliden, deren wir allerdings nur wenige besitzen, kenne, ist mir in liener derselben die Fimilie der Euniciden mit einem gleich hohen Lrocentsat\% entgegengetreten. Dass diese Borstenwiimer hier vorziigliche Existenzbedingungen finden, daher als sehr characteristische Glieder der Amuclidenfauma fïr dieses Meeresgebiet zu bezeichnen sind, greht aber auch aus der grossen Anzahl von Individuen hervor, mit denen eimzelne Emiciden-Arten wie Diopatra Eschrichtii (Oerd.) und firagosa, n. sp., Eunice Horiduna, n. sp., und conglomerais, n. sp., in der Sammlung vorhanden sind.-Ich glaube, dass man diese Familie wohl als eine fïr die Fanna characteristische bezeichnen darf; für die anderen Familien aber, welche danach zalilreichere Vertreter besitzen, ist die Entscheidung in dieser Hinsicht noch zu trefien, denn die Zahlen, mit denen sie auftreten, sind nicht so hoch, dass sic dimit in besonderer Weise ausgezeichnet sind.

Die Beziehungen dieser floridaner Ammelidenfauna zu anderen faunistischen Bezirken sind zur 'Leit nur in geringem Grade zu erkennen; und es beruht das im Wesentlichen wohl nur auf unserer liickenhaften Kenntniss der nicht europäischen Anneliden. Aus der Fauna der brasilischen Küste gehen in die Horidaner Fauna hinuiber: Lysarete brasiliensis (Kbgr), Nercis mirabilis und Cirratulus matranacanthus (Gr.). - Von Bewohnern der nordamerikanischen Küste und wahrscheinlich allgemein der arctisch-borealen Zone treten im Florida-Gebiet auf Ladmatonice Kinbergi (Baird), Diopatia Eschrichlii (Oerd.) und Trarisia carnea (Verr.?); dass diese drei Arten nur als Bewohner des tiefen Wassers gefunden sind, entspricht den Erfilnrumgen, welche sonst ïber suidwïrts vorgeschobene Verbreitung nordischer Würmer gremacht sind. -

Die Angabe Levinsen's (Systematisk-geografisk-Oversigt over de nordiske

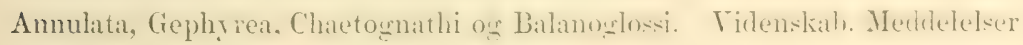
fia d. naturh. Foren. i Kjфbenlavn, 1883, pg. 287) dass die westindische Wurmfauna eine grosse Aehnlichkeit mit derjenigen des Mittelmeeres habe, und dass manche der westindischen Borstenwürmer mediterrunen so ähnlich seien, dass man versucht sei sie für identisch zu halten, will ich nicht 
abreisen; von wirklich identischen Arten habe ich jedoch nur drei gefunden: Mturylusse senguincu (Mont.), Goniude emerite (Aud. \& M.-Edw.) und Eupomutus uncinetus (Phil.); die letztere scheint im Nittelmeer nicht ihre hauptsiichliche Verbreitung zu haben, da sie nicht hïufig dort gefunden wird. - Merrphysu Bellii (Aud. \& M.-Edw.) von der Canalkiiste Frankreichs kommt im Floridagebiete vor, liegt mir aber nur in einem Exemplar aus 231 Faden 'liefe vor.- Eine Gattung, welche wahrscheinlich den europäischen Kïsten fehlt, und als amerikanische Form in der Florida-Fauna auftritt, ist die Emiciden-Gattung Ninoe.

Eine Gemeinsimkeit der westafrikanischen Fauna mit der floridaner ist nur durch den Fund ron Notopygos crimite (Gr.) angedeutet. Dass die Fatuna Madeiras mit der letztgenannten zusammenhängt, hat Langerhans (Die Wurmfiuma Madeiras, Zeitschrift f. wiss. Zoologie, Bd. 33, pg. 289) mit dem Nachweis des Torkommens der Amphinome carunculata (Pall.) und Nereis foridune (Ehl.) bei Madeira dargethan.

Dass eine Verwandtschaft getreunter Litoralfuunen gezeigt werden kann, sobald man dieselbe nicht durch identische, sondern durch nah verwandte Arten belegen will, ist selbstverstïndlich, zur Zeit aber für das uns hier interessirende Gebiet im Allgemeinen von keinem Belang. Nur auf ein Vorkommen müchte ich hinweisen: das ist die Gattung Spirobranchus, deren sicher zu trennende Arten gigunters und tricornis Mörch, mit einer dritten Art, incrassatus, zusammengezogen hatte; die beiden ersten gehören aber zur westindischen, die dritte Art zur pacificischen Küstenfiuna, und in dieser Hinsicht bieten diese nah verwandten Arten uns einen Hinweis darauf, dass diese Faunengebiete einst einen unmittelbaren Zusammenhang besessen haben mögen.

Ich gebe zum Schluss eine Zusammenstellung der gefundenen Arten nach der verticalen Verbreitung, indem ich mit Rücksicht auf die Tiefe der Fundorte die Wuirmer in zwei Reihen ordne. Um je 200 Faden vorschreitend stelle ich in der ersten Reihe die Maximaltiefen zusammen, bis zu welchen die Würmer gefunden sind, in der zweiten Reihe diejenigen Tiefen, mit welchen die Würmer zuerst gefunden wurden. Eine vor dem Namen des Wurmes stehende Zahl bezeichnet im Besonderen die Tiefe, in welcher derselbe zuerst gefunden, ein hinter ihm stehende Zahl giebt an, bis in welche Tiefe hinab das Thier nachgewiesen ist. 


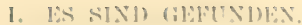

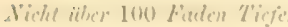

chlovia engluehis, n. sp.

Notopyros crinita (tir.).

Amplineme Pallasii (c)trligse).

liurythoe complamata (l'all.).

Euphrosyne triloha, n. sp.

Palmysa (Psectra), (ir. sp).

Aphrodite acuminata, 12, sp.

l'ontogenia sericuma, n, sp.

Polynoe polytrichat (sctm.m.).

l'olynoe taeniata, n. sp.

Sigalion Pourtalesii, no sp.

Eusice articulata, n. sp.

Eunico binominata (Qtrfoss.).

Eunico punctatia (Cir. Oeri.).

Eumico violaceo-maculatia, n. sp.

Lunico rubra, n, sp.

Eunice fuenta, n, sp.

Limice conglomerans, n. sp.

Marphysa P'arishi (Baird).

Marpliysas sanguinea (Mont.)

Nicilion brevis, 11. sp.

Lysarete brasiliensis (Kbg.).

Oenone diphyllidia (Schm.)

Lumbriconereis thoridana, $\mathrm{n}$. sp.

Nereis (Ceratonereis) versipedata, n. sp.

Nereis (Ceratonercis) mirabilis (Kibg.).

Nephthys (Aglaophemus) inermis, n. sp.

Plyyllodoce (.Inaitis. s. str. Gr.) papillosa, n. sp.

Hesione vittigera, n. Sp.

Hesione praetexta, n. sp.

Branchiosyllis oculata, $\mathrm{nl}$. sp.

Trypanosyllis rittigera, n. sp.

Cirratulus melanacanthus (Gr.).

Siphonostomum eariboum (Gr.).

Arenicolis antillensis (Ltk.).

Dasybranchus lunulatus, n. sp.

Terebella brunneo-comata, n. sp.

Terebella turgidula, n. sp.

Terebella reticulatia, n. sp.

Terebella cetrata, n, sp.

Branchiomma lobiferum, n. sp.

Sibella melanostigma (Schnr.).

Dasychone conspersa, n. sp.

Hypsicomus circumspiciens, n. sp.

Eupomatus uncinatus (Phil.).

Spirobranchus giganteus (Pall.).

Spirobranchus tricornis (Mörch).

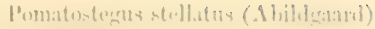

Filingmat Huxleyi, 11. sp.

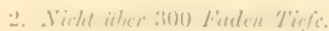

4). Hermorliee carmenenlatil (l'all.).

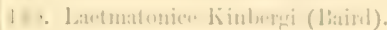

1:3. 1'olynom lactua, n. +1".

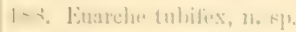

]11. Eunies :ntillumis, n, sp.

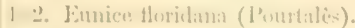

: il. Marphysa lichlii (Aul. of . M.-Eilw.)

I:-. l'amanarphysia longula, n. sp.

T. Lumbriconerris rolusta, 11, sp.

il1. Ameola valticlentatis, n. sp.

1."1. Aracoda dehilis, n. sp.

1.39. Dereis articulata, n. sp.

$\therefore$ : . Nephlathys squamosil, n. sj).

:i.. Mlyllodoce oculata, n. sp).

11". 'Travisia carnea (Verr.)

lin. Stylariviles ecutiger, n. sp.

175. Eumenia glabri, 11. s1.

270. I'ectinaria (['ettit) pellueida, n. s]).

:1. Branchiomma bioculatum, n. sp.

275. Potamis spathiferus, 13. sp.

[11. Placostegus incomptus, n. sp.

2'.'.). Protula antennata, n. sp.

\section{Vicht über 500 Faden T'iefe.}

: $: 1$. Sthenclais simplex, $11, \mathrm{sp}$.

95. Divjatra Eschrichtii (Uerl.).

127. Diopatra Pourtalesii, n. sp.

233. Diopatrat (Parudiojatra) fragosa, n. sp.

237. Diopatra (Paraliojatra) glutinatrix, n. sp.

12:- Eunice tibiama (Pourtale's).

1-. Lysidice notata, n. sp.

17. Lumbriconcreis bidens, n. sp.

11: Ninoe Kinbergi, n. sp.

32'!. Nephthys phyllocirra, n, s\}.

8:. Goniada emerita (Aul. \& MI.-Edw.).

20: . Stylarioicles collarifer, 1 i. $\mathrm{sp}$.

:3.. Clymene cirrata, u. sp.

:3:!. Clywene cingulata, n. sp.

:3:39. Rhodine sima, n. sp.

3i:3. Nicomachella picta, n. sp.

:31. Auchenoplax crinita, n. sp.

:21. Melinna parumdentata, n. sp.

:2:4. Amage tumicla, $\mathrm{n}, \mathrm{sp}$.

:394. Amphicteis procera, n. sp?

:2.2. Termilia annulata (Schnnarta). 
4. Sicht ïter 700 Firten Tiefe.

333. Rhamphobnelhum A.sissizii, no sp.

(3). Maldune cuculligera, ne spe.

(2). Amphicteis misut:ı, 11. sp.

5. Nitht über 900 Finlen Tieje.

202. Hyalopomatus Laugerhansi, n. sp.

s60. Protis simplex, n. sp.

6. Nicht ïber 1,000 Fulen Tieje.

1:2. Aphrodite obtecta, n. sp., (5).5.

190. Onuphis (I'aronuphis) gracilis, n. sp., 955.

\section{ES SIND GEFUNDEN.}

1. Nur über 100 Fuden Tieje.

122. Apliredite ubtecta, 11. sp., 955.

120. Lactmatonice Kinbergi (Baird), 17 t.

123. Polynoe lactea, n. sp., 125.

118. Enarehe tubifex, n, sp.

127. Diopatra Pourtalesii, n. sp., 306.

233. Diopatra (Paraliopatra) fiagosa, n. sp. 413.

190. Onuphis (Paromuphis) gracilis, n, sp. 955.

101. Eunice antillensis, n. sp.

12.2. Eunice tibiana ('ourtalis), 450.

231. Marphysa Bellii (Aud. \& M.-Edw.).

123. Paramarphysa longula, n. sp.

118. Ninoe Kinbergi, n. sp.

110. Aracoda multidentata, n. sp.

190. Aracoda debilis, n. sp.
120. Nereis articulita, 21. sp.

119. I'ravisia camea (Verrill)?

206. Stylarioides collaufer, n. sp. 368.

100. Stylarioides seutiger, n. sp.

175. Eumenia glabra, n. sp.

270. Peetinaria (Petta) pellucida, n. sp.

275. Potamis spathiferus, n. sp.

101. Plizcostegus incomptus, 3. sp., 129.

292. Hyalopomatus Langerhansi, n. sp., 860 .

292. P'rutula antenuata, n. sp.

2. Nur über 300 Faden Tiefe.

321. Sthenelais simplex, n. sp.

333. Rhamphobrachium Agassizii, 539.

320. Neplithys phyllocirra, n. sp.

351. Clymene cirrata, n. sp.

351. Clymene cingulata, n. sp.

339. Rhorline sima, n. sp.

339. Nicomachella picta, n. sp.

321. Auchenoplax crinita, n. sp.

321. Melinna parumdentata, n. sp.

339. Amage tumida, n. sp.

339. Amplicteis procera, n. sp.

Nur über 500 Faden.

533. Maldane cuculligera, n. sp.

539. Amplicteis nasuta, n. sp.

4. Nur über 700 Faden.

860. Protis simplex, n. sp.

Diese 'Musammenstellungen zeigen zunïchst, in welcher' Weise die Annelidenfuma ron der Litoralzone gegen die Tiefe des Meeres hin an Artenzahl abnimmt; ihre Anfung- und Endglieder haben in gleicher Weise einen bestimmten Ausdruck, insofern als die Reihe I, 1, unzweifelhaft die Repräsentanten der Litoralfauna enthält, während die Reihen I, 4, 5, 6 und II, 2, 3, 4, Würmer aufführen, welehe als Bewohner der Tiefsee characteristisch sein dürften, allerdings insofern in ungleicher Weise, als die einen von ihnen auch im flacheren Wasser, die anderen dagegen nur in grösseren Tiefen gefunden sind.

Tiefseebewohner der ersten Categorie sind danach Aphrodite obtecta n. sp., welche auf 122 Faden und 955 Faden Tiefe, so wie Omphis gracilis n. sp., welche auf 190 Faden und 955 Faden Tiefe gefunden sind. Die der Aphrodite obtectu nahe stehende Aphrodite alla (Kbg.) ist bei Rio Janeiro auf 20-30 Faden Tiefe gefunden; Verwandte der Omuphis gracilis sind weit 


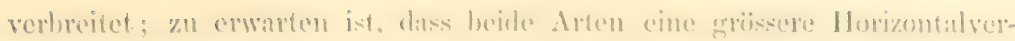
bevitumer hesitzens.

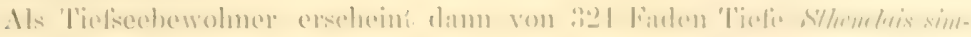

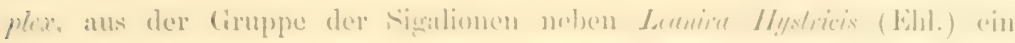

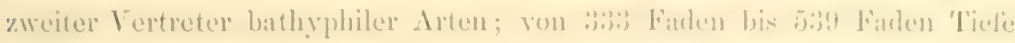

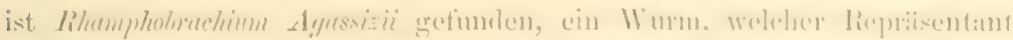

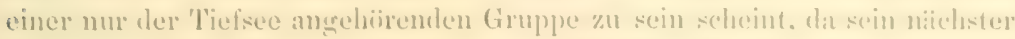

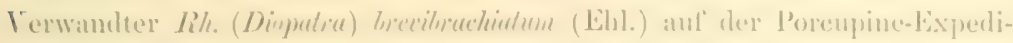

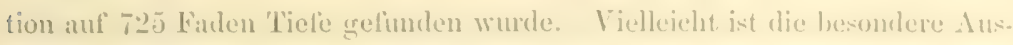
riistung der ersten Ruder dieses Wurmes mit langen, am linkle hakenfirmior gekrimmten Borsten, wie sie sonst in der Fumilie der Euniciden, oder bei den zum Theil bathyphilen Diopatra und Onuphis-Arten nicht vorkonmen. eine hiir das Leben in der 'Tiefsee ausgezeichete Bildung.

Es erscheinen ferner als Bewohner der Tiefsee dieses (iehietes die simmtlichen gefundenen Vertretex der Maldaniden, Amphickeniden und Ampliaretiden. Die Arten, welche ich davon zu verzeichnen habe, schliessen sich anderen Arten der arctisch-borealen Fanma an, und da diese nicht ansschliesslich Tiefseebewohmer sind, ist es sehr wahreheinlich, dass die Glieder dieser Familien, welehe im Florida-Gebiete gefunden sind, nur dureh die localen Verhiiltnisse Bewohner der Tiefsee geworden sind, und nicht allgenein als Tiefseethiere hezeichnet werten kiinnen.

Es sind schliesslich zwei Serpuliden, welche aus gröisseren 'Tiefen stammen : Hytopomatus Langerhansi, n. sp., ron 292 und 860 Faden, und Protis sinplex ron 860 Faden Tiefe. Sie liefern den Beweis, der iibrigens durch Armaner IAansen (Norske Nordhars-Expedition 1S76-1875, Zoologi Ammelida, pg. 48) schon erbracht war, dass Serpulirten in der Tiefsee ihre Existenzbedingumgen finden. Unsicher bleibt es digegen, ob diese Arten als ausschliessliche Bewrohner der Tiefsee anfgefasst werden kïnnen; eine IIyalopomatus-Art ( $H$. Claparedii, v. Mar) gehört dem aretischen Kireise, eine andere (H. Marenzelleri, Lghs.) ist dagegen vou Laugerhans (Zeitsch. f. wiss. Zoolog. Bd. 40, p. 27S), in der Fama von Madeira nachgerriesen; die Prolis simplex; n. sp., steht der Piotula arclica (Arm. Hans.) so nahe, dass ich die letztere zur Gattung Protis ziehen möchte; insofern num als diese $P$ \% arotica in der arctisch-borealen Zoue auch aus bedentender Tiefe (1163 Farleu) grehoben ist, tritt die Vermuthung auf, diese Wïrmer müchten cler Tiefsee angehören; doch sind dariber weitere Erfihrungen alozurarten, da die Synonymie der Pr. arctica noch nicht vüllig klar gestellt ist. 


\title{
AMPHINOMIDAE.
}

Die Familie der Amphinomiden fasse ich hier, wie friher schon, in der Weise, dass ich die Gattung Eupluosyne in Uebereinstimmung mit Quatrefages ${ }^{1}$ und Kinberg' ${ }^{2}$ in sie mit aufnehme. Dagegen möchte ich mich eines Urtheiles iiber die Verwandtschaftsbeziehungen dieser Familie zu den übrigen Familien der Chaetopoden zur Zeit noch enthalten; der Auffassung, welcher in ungleicher Wreise Claparède ${ }^{3}$ und Quatrefages ${ }^{4}$ durch die Einreihung der Familie zwischen andere Familien der "Rapacia" Ausdruck gegeben haben, vermagr ich mich nicht anzuschliessen; zu prïfen ist wohl noch näher die von Levinsen ${ }^{5}$ vorgeschlargene Verbindung der Amphinomeen unit den Telethusen und Scalibregmiden, in welcher die ersten als Amphinomiformia v'era, die beiden letzteren als $A$. aronicolina zusammengestellt werden.

Die ron Kinberg ${ }^{6}$ gegebene Vertheilung der Gattungen dieser Familie in einzelne Gruppen ist offenbar eine gute Grundlage fuir den weiteren systematischen Ausbau.

\section{CHLOELA.}

\section{Chloeia euglochis v. sp.}

\author{
(Taf. 1, Fig. 1 und 2, Tuf. 2, Fig. 1-S, Taf. 3, Fig. 1-4.)
}

Adulta robusta, utrimque attenuata, subtus pallida, supra in segmentis singulis brunneoviolacen ad crueis instar signata, setarum. fasciculis laete rubro vittatis ornata, segmentis 36-39.

Carumeula utrimque in lobo mediano elevato et in basalibus plicata ad segnentum 5 um patens. Tentaculorum impar caruncula brevius merliis sub illo approximatis externisque remotis longins; oculi utrinque 2 coaliti. Segmenta priora 3 ebranchiata cirris 2 dorsualibus, ventrali 1 , reliqua

1 Quratrefagss, Histoire der Annelés., T. I. pag. 3ะ3.

2 Kinberg, Om Amphinomernas systematik. Oefversigt af $\mathrm{k}$. Vetenskaps-Akademiens Förhandlingar, 1807, pay. $83,91$.

${ }^{3}$ Claparède, Les Annélides cuétopodes du Golfe de Naples, pag. 459.

4 Quatrefages, a. a. 0 .

5 G. M. I. Iexinsen, Systematisk geografisk Orersigt over de noriliske Annulata. Videnskabel. Meddel, fra den naturh. Foren. in Kjфbenhavn.

${ }^{6}$ Kinberg, a, a. O. 


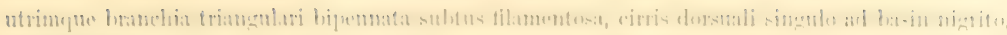

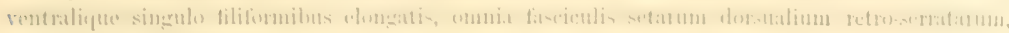

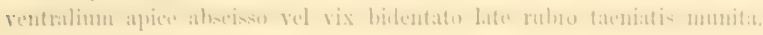

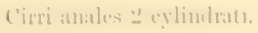

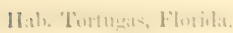

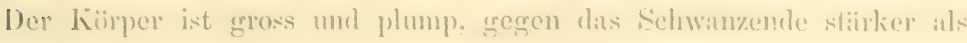

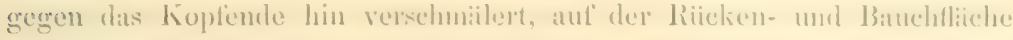
wenigr gewölht, besonders anflallend durelı eine rothe binde der langen Bor-

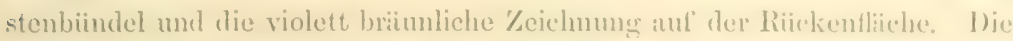

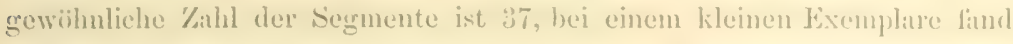
ich 36, bei einem grossen 39; ein Exemplar von $117 m$. Linge war in der Mitte des Körpers 2tmm. breit, am Kopfende bum., am Niterende s̈mm. breit.

Der Kopftheil triigt vor der Carunkel 5 Fïhler; die 2 mittleren entspringen ummittelbar an und vor dem umparen, die beiden iiusseren dureh einen Zwischenram davon getrennt etwas ventralwaints geriielst. Der unpare ist der liingste, meistentheils litizer als die Carunkel und mindestens um ein Drittel liinger als die ïusseren Fiihler. Die ausgedehnte Carmbel ist ein seitlich zusammengedrïcktes. Blatt, mit gefültelten Seitenfliichen, und einem schmalen grleichfills grefiiltelten Basalstreifen; sie steht aul den beiden ersten Segmenten, lïuft mach hinten spitz aus und reicht mit der freien Spitze bis an das Jte Segment. An vorderen Theile der Carmkelbasis steht jederseit ein fast verschmolzenes Augenparar.

Die vor der Mundibfinung gelegenen Polster sini etwa dreimal so lang als breit, sie nehmen das erste Segment und einen melir oder weniger grossen Theil des 2 ten ein. Den hinteren Unfing der Mundüflinung bildet das 3te Segment (Taf. 2, Fig. 1, 2).

Die folgenden Kürpersegmente zeigen ziemlich gleiche Grïssenverhältnisse, indem sie etwa 6 mal breiter als lang sind; die Segmentfurchen sind auf der Rücken- und Bauchfliche scharf, schneiden aber an den Seiten des Körpers nicht tief ein. Die Bauchfiiche aller Segmente ist einfurbig, mehr oder weniger röthlich grau; auf der Rïckenfliche steht, wenn dic Zeichnung scharf begrenzt ist, ein violetter Fleck rou der Form eines Krenzes, dessen quer über das Segment laufender Schenkel breiter als der längslaufende ist, und dessen Enden sich oft noch so verbreitern, dass sie an dic hintere, bisweilen auch an die vordere Segmentgrenze stossen; eine gleich grefäbte, undeutlich begrenzte Binde läuft auf den Seitentheilen der. Segmente vor den 
Basen der Borstenbiintel. In manchen frillen sind diese 'Zeichnungen an don liantern verwatsehen, sodiss sich damn die bram-violette färbung weit iiber tie Riitckentliche aushreitet.

An den flanken der segmente treten 2 grosse Borstenbiindel aus, die durch keinen grossen Abstand von einander getremnt sind; diese Bündel sind an den mittleren sugmenten am grössten, die ventralen linger als die dorsilen; bei dem 'Thiere, dessen Dimensionen oben angegeben sind, wurden die ventralen Biindel 12mm. ling; die Bindel sind seidenglänzend weiss und vor ihrer spitze kirsch- oder orangeroth gebiindert, die Spitze selbst bisweilen schwefelgelb. An dieser Firbung nehmen nicht alle, sondern meist nur die grïsseren Borsten und zwar beider Bïndel Theil. Die Borsten eines Bündels treten anf einer kreistömigen Linie ans; in beiden Biindeln sind alle Borsten reich an kohlensaurem Kalk, dem sie ihre weisse fiübung verdanken; nach Entfernung des Kalkes durch eine Säure sind die Borsten sehr durchsichtir. wihrend der J'arbstoff sich erhält. Die Borsten des dorsalen Bündels, meistens kiirzer und weniger zahlreich als die des ventralen, sind vor ihrer Spitze mit riickwïrts gerichteten Sägezïlmen besetzt und fast bis in die spitze hohl ('Taf. 2, Fig. 4). Die ventralen Borsten zeigen vor der Spitze einen deutlichen Absatz: es sind Borsten, die der Aulage nach zweizinkig sind, in denen aber nur die grare Endzinke völlig ausgebildet ist. während die andere so reduciert ist. dass sie nur den erwïhnten Absatz bildet; der Hohlraum erstreckt sich in die Hauptzinke hinein, giebt aber anch gegen die rudimentäre Zinke einen Auslïufer (Fig. 5).

An den 3 ersten Segmenten, denen die Kieme fehlt, stehen 3 Cirren, wihhend alle folgenden nur 2 besitzen: diese drei Cirren sind zwei dorsale, von denen der obere, weleher der diimnere und kürzere ist, medianwärts rom Borstenbindel, der untere hinter diesem Bündel steht; der dritte Cirrus ist ein unter dem ventralen Bïndel stehender Bauchcirrus. - Von diesen Cirren fehlt vom vierten Segmente ab der obere der dorsalen, und es tragen rliese Segrmente eine Kieme und einen dorsalen und ventralen Cirrus. Der dorsale Cirrus behïlt seine Stellung hinter dem Borstenbündel, ist lïnger als dieses und durch ein langes dunkelfarbiges Wurzelglied ausgezeichnet, von welchem das schlanke fadenförmige Endglied ausgeht. Der farblose einfach fadenförmige Bauchcirrus unter dem ventralen Bündel ist etwas kürzer als dieses; er besteht ans einem fast kugeligen Basalgliede, auf welchem der lange einfache Endfarlen sitzt. Die Kieme steht medianwärts vom dorsalen Borstenbündel jederseits hart am hinteren Rande des Segments 
und ist nach hinten ererichtet, so dass sie iiher die Linge des niichst folerenden ferments sich erstreckt; von oben gresehen hat sie dats Anschen eines

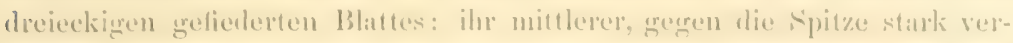
jüngter Hamptstamm tright jederseits eine lieihe alternierend grestellep Seiteniste, die je mehr sie von der Kiemenbasis entlent entspringen um so kiirzer werlen; an den gröissten kiemen zilhle ieh lo soleher deste:

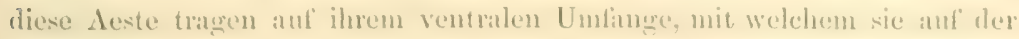

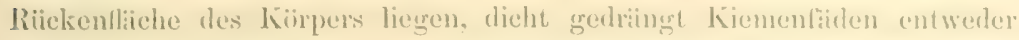
ummittelbar in zweizeiliger Anordnung oder so, dass die budfiden erst wieder von kleineren secumbären $/$ weigen getragen werden. Wibrend demmach die Kieme von oben gresehen grlatt erseheint, zeigt ihre Unterflitehe ein dichtes buschighes Aussehen ('Tiaf. 3, l̈ig. 1, 2).

Am Aftersegment stehen 2 dicke cylindrische Afterciren.

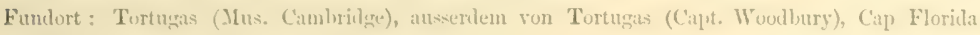
(Capt. Würdemam) und Flurilit (L. Agassiz).

In der Sammlung finden sieh 3 Exemplare einer Chloeia, welche ich eine 'Zeitlang als eine unbeschriebene Art unter' dem Namen Ch. marlesh hier glaubte auftiihren zu miissen, bis es mir wahrscheinlicher wurde, dass es sich um Jugendformen der Chl. ouglochis handele. Eine Entscheidung kann ich dariber nicht treften, da mir eine Reihe von Uebergangsformen von dieser Chl. modesta zu der Chl. eugloctis fehlt; ich gebe deshalb im Anschluss an die Beschreibung der letzteren eine solche der ersteren, auch mit liiicksicht daranf, dass es ein Interesse hat, eimen Theil derjenigen Bildungen, dureh welche beide Formen sich von einander unterscheiden, als Jugendzustainde kennen zu lemen.

Der kurze nach rorn und hinten wenig verjüngte Körper hatte bei einem Thiere von 12mm. Lïnge 22 Segmente, bei $16 \mathrm{~mm}$. Liinge 25 Segmente, und war etwa tmal so lang als ohne die Borsten breit. Rüicken-wie Bauchfliche waren in grosser Austehnung gleichmässig gelblich grau, auf der Mittellinie der Rïckentlïche lïuft ein wenig hervortretendes, an den Rïndern verwaschenes etwas dumkleres Band; bei einem Exemplare stand dameben anf den letzten Segmenten jederseits eir brannvioletter Lingsstreif; die Rïickencirren eines anderen Thieres waren ähnlich gefirht; die Borstenbünclel ganz farblos.

Der Koptappen triigt schwarze Augenflecke vor mud zur Seite des umparen Fühlers. Die Fülıler sind schlank fadenfürmig; der umpare, von 
einem kngeligen Wrumelgherte entspringende ist linger als die Carunkel mul als dic piarigen. von denen die mittleren am Ursprunge sich berihren, wihreml die itusseren weit von ihmen getrennt, am Vorderrande der Mundpolster stehen. Durch urrössere Lingre unterscheirlen sich die Fiihler von denen der erwachsenen Chlocin cuglochis. Die Carmkel reicht bis auf dive halbe Linge des vierten Segmentes; ihr hoher Nittellappen und die schmalen Basallitppen sind ganz ähnlich gefiltelt wie bei der erwachsenen Chlociu entrichis. Die Muntpolster sind bei den mir vorliegrenden Thicren in Tordertheile stark verschmälert und zusammen dadurch ausgesprochen herzfïmig; solche Form mag aber je nach der Forminderung, welche durch Bewegungen des Mumleinganges veranlasst werden, herbeigefiihrt sein. Die hintere Begrenzung der Nundöfhumg liegt auf der Grenze des 3ten Segmentes; ein ron der Fläche des 4 ten Segmentes ausgehender längsgefurchter Fortsatz tritt hier heran (Taf. 2, Fig. 6, 7).

Die drei ersten Segmente tragen jederseits je 2 lange fadenförmige Rïckencirren und einen grleichfalls schlank fadenförmigen Bauchcirrus; vom 4ten Segmente ab ist jederseits nur je ein Riickencirrus vorhanden. Die Cirren sind lïnger als die Borstenbiindel, die dorsalen etwas mehr als die ventralen; die Rückenciren waren hïufig violett gefirbt, nicht aber ihr Grundtheil vor dem Endabschnitt durch dumkle Pigmentiermog ausgezeichnet. Verglichen mit denjenigen der erwachsenen Chlocia cuglochis sind diese Cirren, wie die Fiihler, durch bedentendere Liinge ausgezeichnet.

Die Borstenbiindel, in Stellungr und Grössenverhïiltniss mit denen der oben beschriebenen Chl. cuglochis iibereinstimmend, unterscheiden sich von diesen durch die Farblosigkeit, und zwar fehlt ihnen ebensowohl der wohl auf reichlichere Kalkeinlagerung zuriickzufïhrende weisse Atlasglanz, wie die schwefelgelbe Spitzenfärbung und rothe Bünderung. Letztere fehlte allerdings auch einem nicht ganz vollwüchsigen Thiere der Chl. engloctis, so dass diese Schmuckfarbe wohl erst bei voller Reife sich einstellt. Die Borsten des dorsalen Biindels sind vor der graden Endspitze sägezähnig, wie die der erwachsenen Chl. explochis, die des ventralen sind ausgesprochen zweizinkig (Taf. 2, Figr. S), und ich habe an den gleichen Borsten der erwachsenen Chl. cuglockis nie eine so starke Entwicklung der kleinen Nebenzinke gesehen.

Die in der Gesammtform dreieckigen zweifiedrigen Kiemen stehen vom tten Segmente, ganz wie bei der erwachsenen Chl. englochis, von der Austrittstelle des dorsalen Borstenbiindels medianwïrts verschoben unmittelbar vor der hinteren Segmentgrenze und sind so lang, dass sie ïber die Länge 


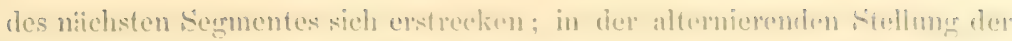

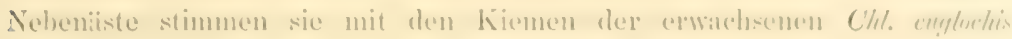

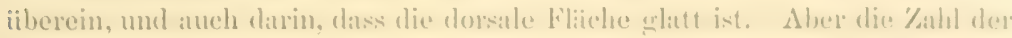

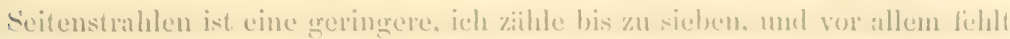
den Nehenstrahlen der diehte Besatz mit kleinen Kienentialen. In dem kleineren meiner lixemplate lehlen den primären Vebenstrahlen alle weiteren

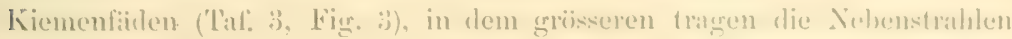

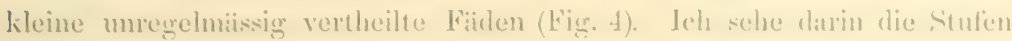
einer Sintwicklung, welche nit zumehmenden Alter zu der Form der dichtbuschigen Kieme fïhrt. Das Aftersegment ist gestaltet, mol mit zwei Afterciren ausgreriistet wie bei (ler erwachsenen C'hl. rugluchis:

'Trift meine IIuthmassung zu, dass die hier beschriebenen 'Thiere die Jugendstände der Chl. cryluchis sind, so wiirde mit fortschreitendem Wachsthum eine Aenderung in den Grössenverhïltnissen der Carunkel, Fiilıler und Cirren, und eine reiche Entwicklung sekmdïrer Kiemenfäden eintreten; die zweizinkigen Borsten des ventrilen Bïndels dureh solche mit ohsolet gewordener Nebenzinke ersetzt werden, und schliesslich die Finbung und /eichnumg sorohl in der Riickenhaut wie in den kalkhaltig werdenden Borsten sich einstellen.

Es könnte auffallend erscheinen, dass eine so grrosse durch die Fïrbung so ausgezeichnete Annelide eines doch mehrfach faunistisch durchforschten Gebietes umbeschrieben geblicben sein sollte; und doch rermag ich dieselbe mit keiner der aus dem westindischen Meere bekamnt gemachten Chloeia-Arten zu identifizieren. Chloria virilis (Schm.) von Jamaica hat nach der Beschreibung, welche Schmarda ${ }^{1}$ davon gregeben hat, in Weingeist eine riolette Rïckenflïche mit dunkler Lïngsbinde und fast schwarzen Querbinden auf den Segmentgrenzen; solche Zeichnung könnte als eine Variierung dessen, was ich bei der Chl. cuglochis gefunden und heschrieben habe, aufigelasst werden; aber es wird der aufallenden rothen Bänderung der Borstenbiindel weder in Wort noch Bild Erwïhnung gethan, und doch sind die von Schmarda untersuchten Thiere, welehe 30 Segmente besassen, wohl vollwiichsigg geresen. Sehr wesentlich ist Schmarda's Angube, dass die zwei ersten und zwei letzten Kiemen rler Chlociu ziritis nicht doppelt gefierlert seien; damit steht leider die Abbildung in Widerspruch. Die abgebildeten ventralen Borsten der Chlocia vibitis sind so stark zweizinkig, wie ich es ron erwachsenen Thieren der Chlocia euglochis nicht gresehen habe. Doppelte Riickencirren,

$$
1 \text { Tene wirbellose Thiere, I-II, pas. 141, Taf. XXXT, Fig. 295-305. }
$$


wie sie der Chloche ergluehis an den drei ersten Segmenten zukommen, sind werler beschrieben noch abgrebildet.

Kinherrar hat von st. Thomas (West-Indien?) eine Chlociu candida bekannt gemalnt. welche nach dem llabitusbilkle als eine junge $C h$. euglochis gedentet werten kömnte; dagegen spricht aber, von anderen Merkmalen, auch ron den vier weit getrennten Augen abgesehen, der Umstand, dass diese Art iiberall nur einzelne Riickencirren und die erste Kieme schon am zweiten Segmente trïigt.

Unter den beschriebenen Chloeia-Arten, welche aus anderen als dem westintischen Meere stammen, finde ich keine, welche die der Chlocia englochis zukommenten Kenmeichen besisse; doch sind allerdings einige der hier zu berieksichtigenden Beschreibungen völlig unzulïnglich.

\section{NOTOPYGOS, Ginue.}

\section{Notopygos crinita, Gr.}

$$
\text { Taf. 1, Fig. 8; Taf. 3, Fig. 5, 6, 7. }
$$

Grube, Beschreibung nener oiler wenig bekamnter Amneliden. Archiv für Naturgeschichte. Jhrg. 21. Bd. I, 1855. pag. 93.

Grube, Amnulata Semperiana 1878, a. a. 0. p. 7.

Drei Exemplare liegen vor, auf welche ich diese Bezeichnung glaube in Anwendung bringen zu dïfen, indem ich dabei auf die zweite verbesserte Beschreibung Bezug nehme, welche Grube ${ }^{2}$ von dieser von ihm aufgestellten Art gegeben hat, und damit zugleich den bezeichnenden ailteren Gattungsnamen statt des offeubar symonymen Lirione (Kinb.) beibehalte.

Dann aber habe ich einige Eigenthiimlichkeiten hervorzuheben, in welchen die bislang gregebenen Beschreibungen nicht ganz auf die mir vorliegenden 'Thiere passen.

Grube griebt 28 Segmente an, Kinberg ${ }^{3}$ von jüngeren Thieren 19: das grösste mir vorliegende Thier von $43 \mathrm{~mm}$. Länge hat 29 Segmente, eins von $30 \mathrm{~mm}$. Liinge 26, eins von 8, 5mm. 21 Segmente; die von Kinberg gesehenen 'Thiere waren nur $6 \mathrm{~mm}$. lang.

1 Fregatten Eugeniens Resa. Zö̈log. Annulata tal. XI. f. 2, und Animalia annulata nova. Öfvers. af. k. Vet. Akarl. Förh. 1857. Jan. 14, pag. 11.

2 Grube, Annulata Semperiana, a. a. O. p. 7.

3 Kinberg, Övers. af. k. Vet. Akud. Förh. 1857, pag. 11. 


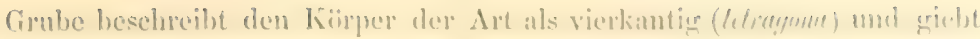

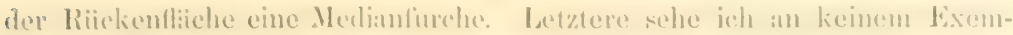
plane, die Kinten des kiirpers, welehe ich an den Orieginal-kixesuplaten der

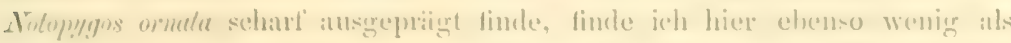

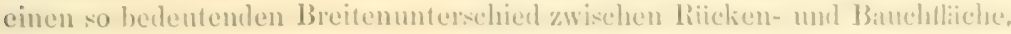
wie er von (irube angegreben wirl. Solche Dilleren\% kamn aber in mgleichem Evhaltumgsznstande berröndet sein. - Ich vermisce fenner an den mir vordiegrenden 'Lhieren, olne daranf besonderen Wherth zu leuren. die violette von Grube hervorgeholene Zeichumg an der IV urzel des dorsalen Borstenbiindels.

Die Alteriflinung liegt auf dem hinteren Theile der Liiickenfliche des '2 Iten Segmentes (T'af. 3, Fig. 6), was zu Grube's Angabe stimnt. Von der Koplbildung hebe ich hervor, dass die vier im 'Trapez gestellten Augen atul einer scheibenförmigen Platte stehen; von ihr erhebt sich ummittelbar vor der Carumkel der mpanre Fühler, während die mittleren und iusseren Fïhler vor dieser Platte entspringen; die mittleren in der Mittellinie sich beriihrend, die äusseren weiter abwïrts verschoben an Aussenrande der Mundpolster. Die Anheftumg und Ausdehnumg der Carunkel stimunt mit Grube's Angraben dariiber überein; ich zihle an dem mittleren anfrechtstehenden Blatte jederseits, sowie an jedem Rande des basalen Blattes 17 vom Rande her eindringrende Einfaltungen (Taf. 3, Fig. 5); Grube zählt fast 30 solcher Falten: das erscheint auf den ersten Blick als ein bedentender Linterschied; vergleicht man aber Grube's ${ }^{1}$ Beschreibung und Abbildung der Volopygos muculute, so ergriebt sich, dass er die Einfultungren in ganzen Umfange der Carunkel zïhlt, mithin nach meiner Ziihlung $3 \pm$ Falten wiirde angegeben haben; der damn bestehende Unterschied in den Zahlen diesel. Falten ist unwichtig."

Was Grube rom "torus praelucealis" aussagrt, in dessen Hiilften ich dic Mundpolster der Euniciden zu schen meine, passt auf die gleichen Organe meiner Exemplare.

Die 4 Bucealsegmente Grube's nehme ich an, füge aber ergiinzend hinzu, dass die 2 vorderen die Mundöffnung nicht erreichen, das äte den seitlichen Umfing des Mundeinganges begrenzt, das 4 te mit einem von vier scharfen Lingsfurchen gerieften Polster die hintere Begrenzung desselben bildet.

Sehr wesentlich ist, dass diese vier ersten Segmente kiemenlos sind, damit

1 Grube, Annulata Semperiana, a. a. O. p. 7. Taf. I, Fig. 3.

2 Kinberg's Ahlililung ron der Carnukel ist nicht ganz zutreffend, insofern man won cinem gufiltelten Busalblatte nichts sieht : ich mag nicht annehmen, dass dieser Theil der Carunkel jüngeren Thieren gan\% fehle. 


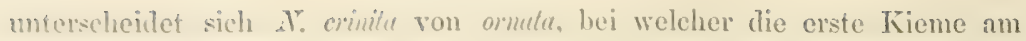
ften serguente steht.

Cirube's Beschreibung der Borsten und Cirren ist fï die mir vorliegenden Thicre. gimz verwendber' ; nur wiirde ich einen Grössenunterschied des dorsalen und ventralen Borstenbindels nicht so betonen, wie es Grube gethan hat. Kimberg hat in die Gattungediagnose von Notopygos aufgenommen, dass der lïngere Zinken am inneren Untange leicht gesïgt sei und giebt anch eine das zeigente Abbildung; eine eigentliche Zïhnelung habe ich nicht gesehen, wohl aber hier, wie an den Borsten anderer $\Delta$ mplinomeen, die Beobachtung gemacht, dass sowohl am Schaft wie an den Zinken der Borsten eine ïussere Schicht sich wie in kleinen Gürtehn von einander sondert und abhebt: solch ein Kustand, dessen kntstehung ich nicht kenne, kaun wohl das Bild einer sehwatien Zïhnelung erzeugen.

Ich hebe zum Schluss hervor, dass Grube den Kiemenbiischel als einen dreitheiligen bezeichmet; wïhend ich nun die 'Zahl der Fïden eines Kiemenbiischels finde, wie or sie angegeben hat, sehe ich die Dreitheiligkeit nicht (Taf. 3, Fig. 7 ) : alle Fäden gehen ron gemeinsamer Basis aus. Mir ist aber auch dieser Unterschied nicht bedeutsam genug, dass ich darauf hin eine nene Art aufstellen möchte.

Zu dieser ganzen Auseinandersetzung fïhlte ich mich verpflichtet, da Nofopyyos crinitu bis jetzt mur von St. Helena bekamnt geworden war; das Vorkommen in Antillenmeere zeigt eine weitere Verbreitung, welche allerdings nichts Auftillendes bietet.

Fundurte: 1, 'Tortugas (Mus. of Comp. Zoül.); 2, Florida (MIus. of Comp. Zoül.); 3, Jan. 16, 1869; W. of Turtugas. Cist No. 1. Depth, 30 fins.

\section{AMPIINOME.}

\section{Amphinomo Pallasii, QTrfas.}

Pleione tetraedra (JFilne-Edwarls, Cuvier, Tiègne animal, Ed. accompagnée de Planches; Les Annélides, P'l. 8 bis Fig. 1).

$$
\text { Taf. 1, Fig. 4. }
$$

Die durch Quatrefages' Beschreibung erginzte Abbildung, welche MilneEdirards von diesem Thiere gegeben hat, passt so gut auf die nir vorliegenden Thiere, dass ich olme Bedenken die Benennung verwende.

Der vierkantige Körper, an dem zumal im contrahierten Zustande die dorsalen Borstenbiindel grad aufrecht stehen, wobei dann die dicht buschigen 


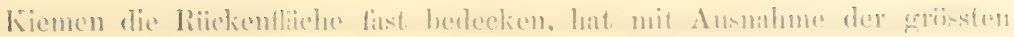

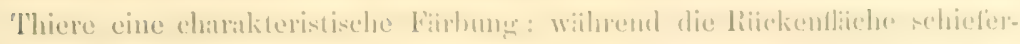

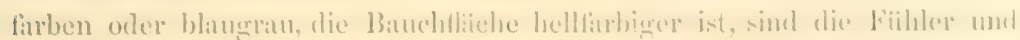

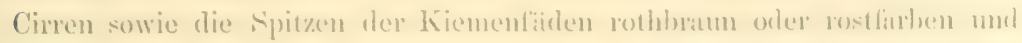
zeichnen sich neben den hellfubigen seidigen liorsten datureh rehatel von

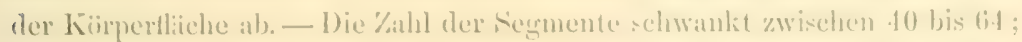

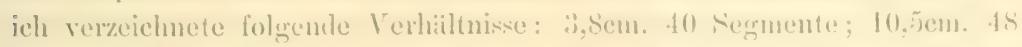

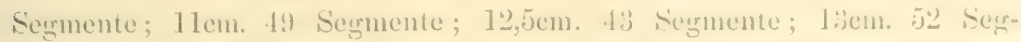

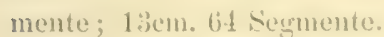

Milne-Edwads zeichnet die Antennen geerliedert; ieh lanle iilmliche Bilder, welche anch ich, aber nicht regelmässig, geschen habe, nehr fïir den Ansdruck einer von Contraktionsatustinden abhängigen Ringelung als ciner wirklichen Gliederung. - Das Bild, welches er von der Ansicht des Mundeinganges giebt, ist zutreffend, sobald das Vorderende des Körpers gestreckt ist; dam rerschwinden die scharfen Begrenzungen der Mundpolster, wolche bei weniger starker Ausklehmug des Vorderendes sich ganz wie bei anderen Amphinome-Arten verhalten.

Zu den Beschreibungen der Borsten fïge ich ergänzend hinzu, dass unter denen des dorsalen Biindels cinfach zugespitzte mit schwachen riickwirts gerichteten Sïgezïhnen rorkommen; die eigenthümliche Form, welehe NilneEdwarls von einer Borste des dorsalen Bïndels alogebildet hat, fiilnre ich nicht, wie Quatrefacges, auf eine durch Bruch verstimmelte Borste zuriick, sondern glaube, dass cliese Abbildung das basale Ende ciner aus der Hant herausgezogenen Borste darstellt.

Fundort: 1, Tortugas-Florida (Mus. of Comp. Zoöl., Cambrilge); 2, Bahia-IIonda.

\section{IERIODICE.}

Hermodice carunculata (P.LL.) Kixbeng.

Diese im Antillenmeere weit verbreitete Art liegt mir von verschiedenen Fundorten vor und giebt mir zu einigen Bemerkungen Teranlassung, welche die Angraben der neneren Schriftsteller, Quatrefnges und Kinberg, die von dieser lang bekannten Art gehandelt haben, ergänzen sollen.

Die Zahl der Segmente nimmt offenbar bei diesem Thiere mit der wachsenden Kürpergrösse lange zu; das grösste von mir gemessene Individuum hatte bei $21 \mathrm{~cm}$. Lïnge 92 Segmente, Quatrefages giebt fiil 22-cm. Linge 117 Segmente an. Aeltere Thiere sind auf der Riickenflïche, während 
Flanken und Banchtliche hellfurbig grau sind, spangriin angeflogen, besonHers lubhat sind die Kiemenbiischel gefirbt; jinngere Thiere sind dagegen hrïunlich gefiitbt, ansgezeichnet aber durch eine auf den Segmentgrenzen der litickentliche stehende, in der Nitte verbreiterte sammitschwarze Querhincle, an deren Stelle seltener ein rundlicher gleich gefïrbter Fleck tritt.

An der hohen ron P'allias zutrellend charakterisierten Carmkel ziilhlte ich bei grossen 'Thieren jederweits sieben der Lüinge nach gefältelte Seitenfalten; zur Seite des umparen lïilhlers stehen jederseits zwei schwarze Augenftecken; Quatrefiges heht zutrefiend hervor, dass der umpare Fiihler die parigen bedentend an Grösse iibertriftt. Diese, wie Kinberg es thut, rom ersten Segmente entspringen zu lassen, scheint mir eine nicht ganz richtige Auflassung der Buccalregion zu sein; ich betrachte als erstes Segment denjenigen Körperabschnitt, weleher zur Seite der Mundpolster stehend das zweiästige, erste l'urapodium trägt; ihm sitzen aber die parigen Fiihler nicht auf, sondern es stehen die vorderen derselben vor dem vorderen Augenpare und am Vorkerrande der Mundpolster; die hinteren weiter nach abwärts verschohen zur Seite des letzteren.

Dann rechne ich die erste Kieme dem ersten Segmente zu, und nicht wie Kinberg dem zweiten. Der hintere Unfang der Mundöfnung liegt auf der hinteren Grenze des tten Segmentes; die Banchfliche des 5ten und 6ten Segmentes ist mit ihrem medianen Theile in die Bildung einer Lippe eingegangen.

Die Rückenfliiche ist bei allen grösseren Thieren netzartig mit rechtwinkeligen Maschen gefureht.

Von den Rudern bestïtige ich die ron Pallas als Eigenthümlichkeit herrorgehobene Bildung, dass die dorsalen Borstenbündel den ventralen altemierend genïhert seien. Die Bildung der Borsten ist von Kinberg charakterisiert.

Ueber die Kieme besteht in den Angaben von Quatrefages und Kinberg eine Differenz, insofern Quatrefages zwei, Kinberg nur einen Kiemenstamm angiebt; ich finde bei den grösseren Exemplaren allgemein ein hinter dem Umfange des oberen Borstenbiindels stehendes, von der Hauptmasse gleichsam abgesprengtes kleineres Kiemenbiischel, welches mit kleinem kurzen Stamme selbstindig entspringt. - Der After steht auf der abgestutzten Endfliiche des letzten Segmentes, ist bisweilen mit dieser dorsalwärts gehoben; ventralwiirts ron ihm stehen, in der Mittellinie an einander stossend, zwei Aftercirren, als kurze dicke, fast knötchenartig erscheinende Fortsätze. 


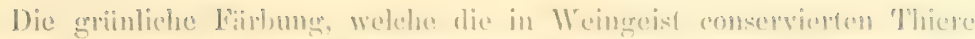

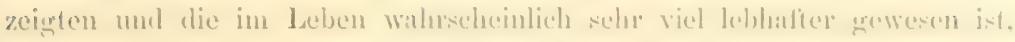

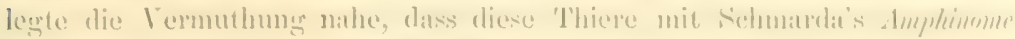

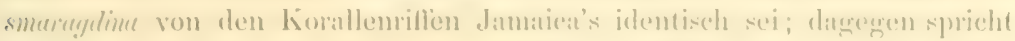

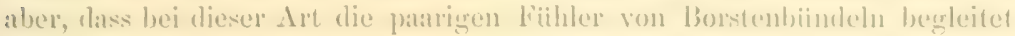
sein sollen - wem hier nicht ein Beobachtungs fehler vorlient — ein sonst

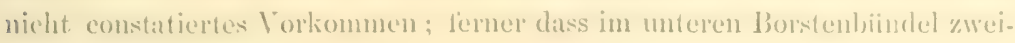
rinkige Borsten stehen.

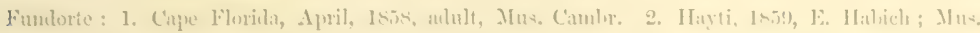

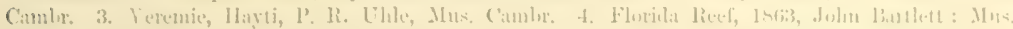

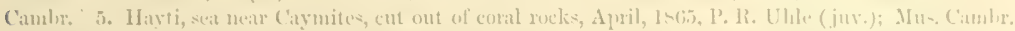

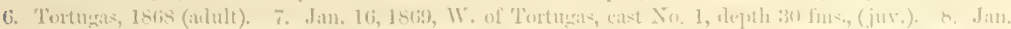

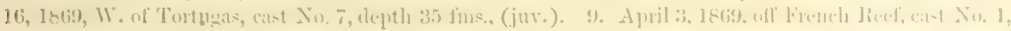

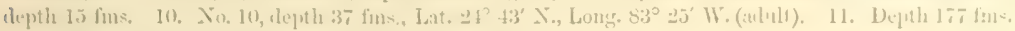
Sigsbee, Lat. $22^{\circ} 9-15^{\prime}$ X., Long. $82^{\circ} 21^{\prime} 11$. (jux.).

\section{EUR YTIIOE.}

\section{Eurythoe complanata, Pist.}

Palles, Miscellanea Znolorica. Ifagac-Comitum, 1766. 4º, pg. 109, Tab. VIII, fig. 19-26.

Die Beschreibung, welche Pallas von seiner Aplwadite complunala gegreben hat, passt so gut nuf eine Anzahl aus dem Antillenneere mir vorliegender Amphinomeen, dass ich nicht zweifle, Pallas habe die grleiche vom gleichen Fundort stammende und dort offenbar nicht selten vorkommende Form vor sich grehabt wie ich.

Den Habitus bezeichnet die Pallas'sche Benennung ganz zutreffend: der Körper ist mehr denn doppelt so breit als hoch, die Rïckenfliche des Kürpers ist stark abgeplattet, so dass sie wie vertieft zwischen den seit- und aufivirts vorragenden dorsalen Borstenbiindeln liegt. Ein 'Thier von $115 \mathrm{~mm}$. Läinge, $10 \mathrm{~mm}$. grösster Breite und $4 \mathrm{~mm}$. Höhe hatte 96 Segmente, ein anderes, welches 145mm. lang, 10mm. ohme, 13mm. mit den Borsten breit und 5mm. hoch war, hatte $11 \pm$ Segmente. Reste ron besonderen Färlungen oder Zeichnumgen waren an in Wreingeist aufberahrten, melur oder minder grau gefurbten Exemplaren nicht vorhanden. Die Riickenflïche ist unregelmässig gerunzelt. Am Kopflppen stehen vor der Carumkel \& schmarze Augrenflecke, die beiden rorteren etwas grüsser als die hinteren; von den 5 kurzen kegelförmigen Fïhlem ist der umpare am kiirzesten, kaum so hoch 
als die Carmbel. Die Canmkel ist ein einfucher glatter Lüngswulst, dessen Ilinterende anf der Mitte des 3ten Segmentes steht. Die langovalen Mundpolster nehmen die Liinge der 3 ersten Segmente ein, dis 4 te Segment bildet den seitlichen, das 5te mit einer lingsgrefurchten Lippenbildung den hinteren Unfing des Mumleinganges.

Die Ruderfortsiitze der 3 ersten Segmente zeigen die von Pallas hervorgehobenen Eigenthiimlichkeiten in derstarken Entwieklung der Cirren; doch kam ich den von ihm angetrebenen Mamgel von Borstenbïndeln an diesen Secrmenten nicht bestiitigen; die Zahl der Borsten ist an diesen Segmenten allerdings eine geringe und es erscheint keineswegs ein Borstenbindel in soleher Miachtigkeit wie es die folgenden Segmente tragen. Das erste Segment trägt den dicken Riicken- und Bauchcirrus fast mmittelbar über einander, am 2ten Segment sind ein dorsiler und ventraler Ruderast durch einen Alstand geschieden, hier wie am 3ten Segment sind die Cirren noch dick; an 2ten Segment trägt dam der obere Ast eine allerdings recht kleine Kieme.

Am ausgebildeten Ruder trïgt der obere kure und dicke Ast ein seitmind aufwärts ragendes grosses Biindel seidig glinzender feiner Borsten, welche theils einfich linear, theils mit rïckwïts gerichteten Sigeziihnen besetzt sind; der untere Ruderast, der um mehr als die halbe Körperhöhe vom oberen entfernt steht, ist stïrker ausgezogren als der obere, schwach kegelförmigr verjüingt; sein Borstenbïndel enthält weniger und nicht so weit rorspringende Borsten als der obere $\Lambda$ st; die einzelnen Borsten sind dicker und haben ein krättiges zweizinkiges Endstiick.

Der dorsale und ventrale Cirrus stehen am hinteren Umfange des zugehörenlen Borstenbïnlels, sind kürzer als diese, entspringen mit einem deutlichen Basalgliede und tragen ein spitz kegrelförmiges längeres Endglied, welches Spuren einer Gliederung zeigt. Die Kieme ist ein hinter dem Rückencirrus stehender auf die Rückenflïche hinauf greifender niedriger Biischel, in dem ich bis zu acht kurze auf gemeinsamer Fläche entspringende Stämmchen zähle, welche sich kurz verïisteln und mit kurzen dicken fast keulenförmigen oder eifürmig zugespitzten Endgliedern ausgehen.

Die Afteröffummg steht auf der Riickenfläche des drittletzten Segmentes; das letzte Segment trägt zwei kleine knürchenfürmige Aftercirren.

Unter dem Namen Amphinome macrotrichu hat Schmarda ${ }^{1}$ eine Eurythoe beschrieben und abgebildet, von welcher ich annelımen möchte, dass sie mit dieser Eurythe complunala (Pall.) zusammenfällt, wenn dem nicht die 1 Schmarda, Nene wirbellose Thiere I, II, 1861, pis. 14t, Taf. XXXIt, Fig. 


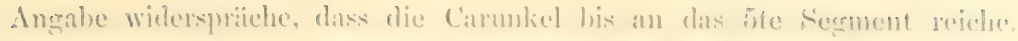

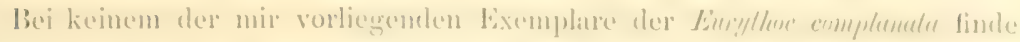

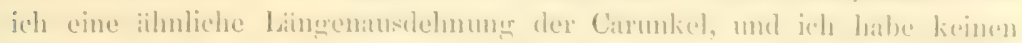

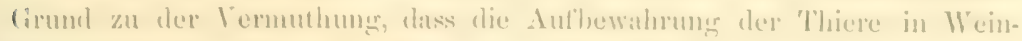

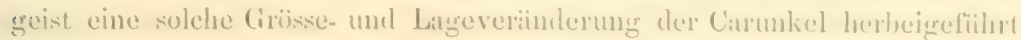
habe.

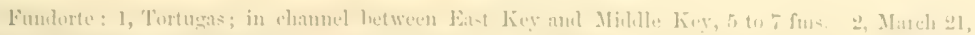

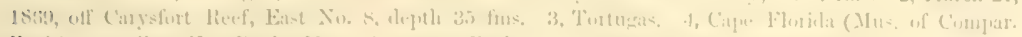

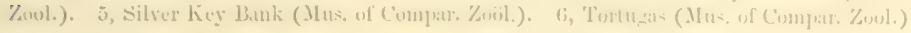

\section{EUPIHOSYNE.}

\section{Euphrosyne triloba, n. sp.}

$$
\text { I'if. } 4 \text {. }
$$

Brevis oratia subtus plana, segmentis 2s. Carmenla 3 lobis eylindmatis inaerualibus trijartita ; tentaculum unicum; oculi bini clorsuales et ventrales. Branchiac singnlorum schmentormm

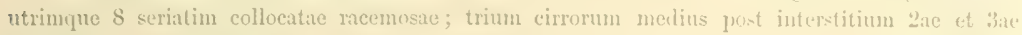

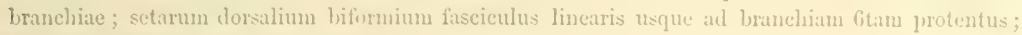
fasciculus setamun ventralium uniturmis.

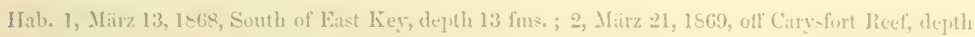

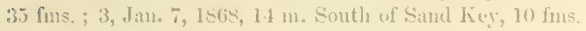

Die Thiere vom gewöhnlichen Habitus der Euphrosyneen (Taf. 4, Figr. 1, 2) hatten $2 S$ Segmente, wobei ein Exemplar $17 m u$. lang, 6mm. breit, ein anderes $23 m m$. lang, $7,5 m m$. breit war; die einzelnen Segmente waren etwa sechsmal liinger als breit; das von Kiemen und Borsten nicht eingenommene Nittelfeld der dorsalen Segmentfläche ist schmäler als jedes der zur Seite stehenden Flankentheile. Die Farbe der in Weingeist offenbar ausgebleichten 'Thiere war grau-srelblich.

Am Kopftheile ('Taf. 4, Fig. 3) erhebt sich dic Carunkel auf dem dritten Segmente und besteht aus drei cylindrisch auslaufenden Fiden, von denen der mittlere der liingste ist und niedergelegrt bis auf das 6te Segment reicht, wïhrend die neben ihm stehenden bis an das 5te Segment reichen. Unmittelbar vor der Carunkel entspringt ron etwas verdickter Basis der kegelförmige fein auslaufencle Fühler; der an Luinge hinter den Seitentheilen der Carunkel wenig zurickbleibt. Etwas unterlalh der Fühlerbasis, etwa am Vorderrande des 2 ten Segmentes, stehen 2 stark gewölbte schwarze Augenflecke; 2 andre schwarze Augen stehen auf der Ventralfläche zwischen den Seitentheilen des ersten Segrmentes hart an einander greschoben (Taf. 4, Fig. 4). 
Die vor dem Mumbleingange grelegenen Platten erstrecken sich ïber das

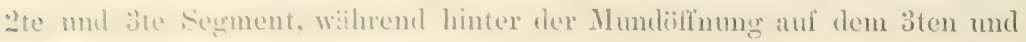
ten segmente vine duch sechs tiefe Linschnitte lingsgefurchte polsterartig vorragente Linterlippe, welche rom jten segmente ausgeht, deren Begrenzumg bilket ('at. 4, Fig. 4). Die vorderen Segmente stehen in dex Entwicklumg. der borsten und Anhänge hinter den folgenden zuriek. Auf der lïickenlliiche des ersten Sogmentes steht jederseit neben dem riemenfürmigen Streilen, wolcher von der Carunkel bis gegen die Mumdiplatten zieht, eine lieihe von 3 knoplartigen Hëekern; vielleicht sind das mentwickelte Tiemen orler Cirren ('Lif. 1, lïg. 3). Als Anomalie, die sich aber anch sonst bei den Amphinomeen finclet, erwihne ich, dass bei einem 'Thiere das fünftletzte Segment anf der emen Körperhiblfte verdoppelt war.

Auf den Flanken des voll entwickelten Segmentes steht eine Reihe ron acht Kiemenbiischen, von denen das 2 te bis 4 te am reichsten verïstelt ist (Til. 4, Fig. 5). Jeder Kiemenbusch erhebt sich mit einem kurzen dicken Stämmehen, welches sehr bald sich gabelt und durch fortgesetzte Theilung vinen l3usch von schlanken, dïmnen Kiemenästen erzeugt, von denen jeder mit einer schwachen knospenartigen Verlickung auslïuft; die meisten dieser Aeste stehen so, dass sie in Ebenen liegen, welehe von der Medinnebene des Körpers nicht oder mur wenig divergieren. Die cylindrisch fadenförmigen Cirren, welehe nicht ganz so lang als die Kiemenbiische sind, stehen hinter der Kiemenreihe; der oberste etwas medianwärts von der ersten Kieme, der zweite hinter dem Zwischenrame der 2ten und 3ten Kieme, der unterste vor der Ventrilliche, die hier zu einem schwachen IÏ̈cker erweitert ist.

Die Borsten treten in 2 gesonderten Büdeln aus: das dorsale Bündcl bildet eine dichte Reihe, welche hinter den Kiemenbiischen auf den Flanken der Segrmente soweit geht, dass sie neben den 6 ersten Kiemen verliuft und ihr Ende etwa neben dem 6ten Kiemenstamme findet. In ihm stehen zwei ungleiche Borstenformen: die Mehrzahl sind schlanke helle Borsten, welche mit 2 ungleich langen 'Linken auslaufen, von denen die kürzere grade, die fast dreinal lïngere geschwungen ist; sie ragen etwas iiber die Kiemen hinaus. Diese Borsten enthalten Kalk in staubartig feiner Vertheilung; sie sind hohl, bis auf die Enden der Zinken (T'af. 4, Fig. 6). Spärlicher stehen zwischen diesen Borsten. welche etwas kiirzer sind und einen diimneren Schaft haben, welcher sich am Ende plötzlich stark verbreitet und hier durch einen Einschnitt in 2 sehr ungleiche Endïste zerfüllt, von denen der kürzere dickere 


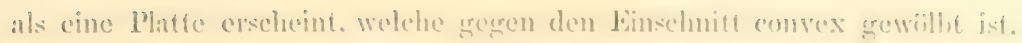

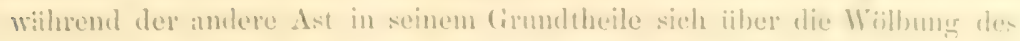

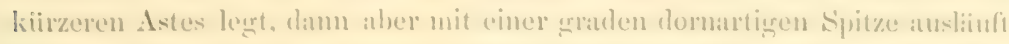
Die den Einselnitt begrenzenden Flidehen beider deste sime quer gerippt (Tiaf. 1, Fim. T).

Von der Banchlliche tritt neben dem ventralen Cirms ein dichtes Bonstenbindel, welches atus den einliteh zweizinkirgen Borsten besteht, von denen die untersten sohr viel kïr\%er als die oberen sime.

Das Aftersegment trïgt 2 Aitereiren, in der Form ron 2 vertical stehenden, dicht an einander liegrenden, am freien Ende etwas verdickten Platten.

Die Art jst sehr kenntlich durch die Bildung des Kopftheiles und der Carumkel. Ton den bis jetzt beschriebenen Arten der Gattung Euphrosyne hat vielleicht die Euphrosyne polybranchue (Schm.) vom Cap der gouten IIollnung eine ïhnliche Bildung aufzuweisen. Die einzige von diesem Thiere vorliegende Beschreibung und Abbildung Schmarda's ${ }^{1}$ gestattet dariiber keinen sicheren Schluss. Dass die Art mit meiner nicht zusanmenfillit, ergiebt sich aus der Differenz der Borsten; was übrigens die von Schmarda in Fig. 270, 271, abgebildeten Borsten darstellen, ist schn zweifuluaft.

1. Schmarda, Newe wirbellose Thiere I, II, pag. 136, 'Taf. XxxIII, Fig. 264, 265-257. 


\section{PALMIYRIDAE.}

Fon Key Wrest aus der 'Tiefe von 1-2 Faden enthält die Ausbeute des "Blake" das Bruchstiick einer zu den P'almyriclen zustellenden Amnelide. Diese Terwandtschaft liisst sich ans der Anwesenheit der so sehr charakteristischen Paleen belegen; genaneres ist aber nieht festzustellen, din dem Exemplare Kopf und Schwanzende fehlen. Wem ich trotzdem dieses Thieres hier gedenke, so geschieht dis, weil der stark aufgekniuclte Körper ungewöhnlich bandartig lang ist und aus ungefïhr 220 Segmenten sich zusammensetzt; die stark entwickelten Paleenfïcher decken die Rïckenfläche vollstïndig. Das Auftreten einer so lang gestreckten Kürperform im Kreise der Palmyriden ist für die Beurtheilung der noch immer nicht ganz sicher gestellten taxonomischen Terhältnisse dieser Familie ron Bedeutung. Grube ${ }^{1}$ hat offenbar in dem von Fr. Mïiller aus Desterro unter dem Namen Pulmyra obscure eingesendeten Wurme ein ähnliches Thier vor sich gehabt, er schlïgt dafuir die Aufstellung einer neuen Gattung, Psectra, vor, olne dieselbe himreichend zu begriinden. Vielleicht hat auch ihm ein verstiimmeltes Thier vorgelegen, da er weder Fïhler noch Augen an ihm gesehen hat.

${ }^{1}$ Grube, Bericht über die Thätigkeit der naturw. Section der Schlesisch. Gesellschaft im Jahre 1866 (rectius 186i), ps. 51 . 


\section{APHRODITIDAE}

Die als Aphroditiden vereinigten Gittumgen derjenigen Borstenwiimer, welehe durch den Besitz von Elytren ausgezeichnet sind, die meistens mit. den Riickencirren der Parapodien alternieren, sind, wenn man den Ciesanmuthabitus der einzelnen 'Thiere in Betracht zieht, seln' von einander veschieden. insofern als kurz gedrungene Formen neben lang gestreckten, secrmentarme neben segmentreichen rorkommen, olnne dass die damit gregelyene Unterscheidung an und fiir sich eine dementsprechende Classification rechtfertigte.

Hiilt man aber zunïchst an dieser Betrachtung der Fomen fest, so ist unverkennbar, dass sich zwei Reihen, wenn man will, Entwicklumgreihen construieren lassen, sobald man von jener Gattung ansgeht, in weleher neben kurz gedrungenen Arten lang wuruförmige enthalten sind. Das ist die Gattung Polynoe in älteren Sime, die Polynoae simplices Sarigny's, welche Grube ${ }^{1}$ in neuerer Zeit mit gutem Rechte als eine grosse axtenreiche Gattung hingrestellt hat. Von hier kommt man einerseits, indem man an die kurzen Polynoinen die Gattung Iphione anschliesst, zu jener Gruple, fiir welche zuletzt von Grube die Bezeichnung der Hernionea gewaihlt wurle, andererseits, die lang wurmfürmigen Polynoinen zum Ausgang wihlend, zu den neben einander stehenden Fanilien der Acoetea, Sigalionina und den noch ungeuägend bekamnten Polylepida.

Für die Hermionea ist dann das Auftreten eines anch bei Iplione vorhandenen Facialtuberkels und die seitliche Anheftung der Elytren kennzeichnend, wihlurend fiir die langgestreckten Acoeten und Sigalionina theils die Vertheilung der Elytren und das Auftreten ron Kiemen, theils die Entwicklung von zusammengesetzten Borsten Bedeutung gewinnt.

Diese beiden Reihen kïmen daneben Uebereinstimmungen aufweisen durch Bilitungen, welche den Polynoinen, denen ich die centrale Stellung anwies, fehlen, so besonders die Acoetea und Hermionea durch die Bildung

I Grube, Demerkungen iiber die Familie der Aphrmiteen. Bericht über die Thätigkeit der naturrissenschaftlichen Section der Schlesischen Gesellschaft im Jahre 1874. 1875. 
ron Augenstielen, sowie durch geb:irtelte Borsten (Aphrodite und Panthalis) und hatrï̈rnige Borsten (Euarche, n. g.). Solche Erseheinungen möchte ich dimn als L'arallelentwicklumgen in iibrigens getrennt verlaufenden Reihen anschen, und bin keineswegs der Meinung, dass die Acoeten, wie sie einerseits an die Polynoinen sich anschliessen, andererseits, von anderen abgesehen, dureh die Kieferbildung den Sigalionima verwandt erscheinen, wegen des Torkommens von Augentrïigern und gewisser Borstenformen eine nähere Verwandtschaft zu den Hermionea besiissen.

Diese Bemerkungen schicke ich voraus, um damit zu kemneichnen, dass die Reihenfolge, in welcher ich die gefundenen und zu beschreibenden Vertreter der einzelnen Gruppen abhandle, nicht der Ausdruck einer linearen Verwandtsehaftsreihe sein soll.

\section{HERMiONEA, Grube.}

Die hier vereinigten Gattungen besitzen, worauf meines Wissens bis jetzt nicht hingewiesen ist, nebeneinander zweierlei Bildungen, welche zusammen bei keiner anderen Gattung der Aphroditeen vorhanden sind. Das ist der rom Vorderrande des Kopflappens zum Mundeingange sich erstreckende Wulst, welchen ich mach Kinbergs Vorgang als Facialtuberkel bezeichne, und die leistenartige vom Rand gegen das Centrum gerichtete Anheftung der Elytren auf dem Elytrentrïger. - Der Facialtuberkel findet sich auch bei der Gattung Iphione, welche im Uebrigen mehr an die Polynoinen sich anschliesst; und es scheint bei einigen Polynoc-Arten als ganz geringe Wulstbildung dieses Organ angedeutet zu sein. Die physiologische Bedeutung des Facialtuberkels ist zur 'Zeit, wo iiber den anatomischen Bau desselben keinerlei Untersuchungen vorliegen, ganz unbeksmnt. So steht es anch ganz dahin, worauf seine Entwicklung zuriickzufiihren ist. Zwisehen den Basalstiicken der Subtentakel oft eng eingeschoben, darf er ohne weiteres mit deren Entwicklung doch nicht in Zusammenhang gebracht werden, da die Sigalioninen, bei denen grosse Subtentakel auftreten, den Facialtuberkel nicht besitzen.

Die eigenartige Verbindung des schuppenförmigen Elytron mit dem Elytrophor, welche ich kurz als laterale Anheftung des Elytron gegenüber der centralen bezeichne, ist meines Erachtens nicht als die ursprüngliche Verbindung beider Theile anzusehen, sondern als eine solche, welche als spätere Entricklung gegenüber der centralen Anheftung erseheint; zu soleher Auf- 


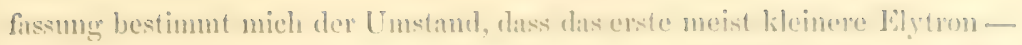
vielledeht immer - eentrale Anheltung besitat, und die tirwibunge, dass die

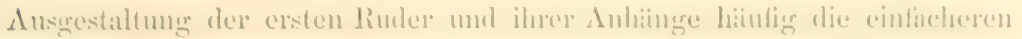
unel wohl urspriinglieheren Verhiltnises anliweist.

Den meisten Ifermioneen kommt eine durch Anfhahme von firemelkïrpern eigenartig ansgeriistete Riiekendecke zu. Sie wird von den Autoren hibuligr als gleichwerthig behandelt, ist es aber kemeswers. Denn an ihrer Bildung nehmen das eine Mal die hatrihmlichen borkten des oberen Ruderastes 'Theil, das andere Mal nicht. Für den ersten labll bietet Aphrorlite das bekamnteste Beispiel, wïlnend die Decke, welehe bei Latetmatonice sich findet, ohne den filz der IIariborsten entsteht. In beiden liallen diurte zum Festhalten der Schlammtheile und sonstigen Fremdkïrper, welche die Decke bilden helfen, ein Druisensekret verwendet werden; das cine Mlal wolnl gleichzeitig mit dem Borstenfilz erzengt - wo dam vielleieht ein weiteres Beispiel eines Ueberganges ron cuticularer zu drüsiger Ausscheidung vorliegt-das andere Mfal als ein ungelormtes Seliret. - Dass der Borstenfilz. nicht immer die klebrige Beschaffenheit besitzt, zeigt sein Verhalten bei der unten beschriebenen Pontogenia, in welcher die dicht verfilzten seidigen Inarborsten keinerlei Fremdkörper aufweisen. Ein diesem ïlnliches V erhalten zeigt dann die unten beschriebene zu den Acoeten gereehnete Gattung Euarehe, und hier machen die haarfürmigen Borsten in Strïngen vereinigt mehr noch den Findruck eines Driisensekretes, und man wird damit eingedenk, dass zwischen diesen Haarborsten und den derberen Borsten ein Verhältniss bestehen müge, wie - weitabliegend - im Federkleide der Vügrel zwischen den Pudertunen und Ferlem.

Das Verhältuiss der einzelnen Gattungen der Hermioneen zu eininder ist ron Kinberg und Grube abweichend aufgefasst. Ich kamn keiner der beiden von ihnen vorgetragenen Anschaumgen ganz beitreten. Kinberg hat bei der Abgrenzung der Gattungen ansser anderen Kemuzeichen die Entwickiung von Augenstielen betont, und sielnt als charackteristisch fuir die Gattung Aphrodite das Fehlen derselben, die oculi sessiles'an. Den von dieser Bildung entlehnten Charakter lasse jch fallen, da sonst eine umnöthir weitgeliende Zersplitterung der Gattungen eintreten wiirde. Die Bildung ron Augenträgern lïsst sich bei den Arten, welche sonst die Charactere der Aphroditen tragen, in ungleich weit gediehener Entwicklung nachweisen; stehen bei der Aphrodite aculeatu die Augenflecke nur auf niedrigen Polstern auf der Oberfläche des Kopflappens, so treten bei der Aplirodite alla Kin- 
beres und bei der unten beschriebenen Anfrodite obtecta solche Polster am Vorklerande des hophlippens bereits so stark hervor, dass sie Augenstielen seln mathe liommen, bis damn die Aphrodite acmminala deutliche vor dem Vorderiand des hoptlappens befestigrte Augenstiele aufweist. So vollzieht sich hier ghtehsim eine Bildung, welche in verschiedener Gestaltung bei den iibrigen Grittumgen der Hermioneen sich wioderfindet.

Grube anderseits hat bei der Zusummenstellumg der Gattungen, welche allerlings zuniichst wohl nur die Bedentung haben soll, leicht eine Uebersicht zu gewinnen, aul' die Form der Borsten im rentralen Ruderaste Riicksicht genommen, und damach Aphrodite und Laetmatonice, bei denen die Borsten des ventralen Ruderastes eine einfuche Spitze, Aplrogenia, Pontogenia und llemione, bei denen die gleichen Borsten eine zwei- oder mehrzinkige Splitze besitzen, zusammengestellt.

Mir scheint es naturgemïsser zu sein, einerseits Laetmonice und Hermione, andererseits Pontogenia und Aphrogenia zusammenzustellen. Die beiden letzteren Gattumgen niblhern sich der Gattung Aphrodite dadurch, dass sie im oberen Ruderaste die harfeinen Borsten tragen, welche unter einander verfilzen ; diese grehen den Gattumgen Laetmatonice und Hermione ab, wenn anch die Arten der Gattung Laetmatonice im dorsalen Ruderaste Borsten tragen, welche als capillar bezcichnet werden können. Die starken mit Widerhaken gezïhnelten spiessförmigen Borsten (setae glochideae) der dorsalen Aeste der Elytrentragenden Ruder kommen in den Gattungen Laetmatonice und Hermione gemeinsam und ausschliesslich vor; eigenartig gestaltete, fast wie die Paleen der Palmraceen gespreitzte Fïcher grosser Bündel starker Borsten, welche an allen Ruderïsten stehen, kennzeichnen und sondern gemeinsam Aphrogenia und Pontogenia von den übrigen Gattungen. - Laetmatonice tritt dann dureh die halb gefiederten Endstiicke der ventralen Borsten denjenigen Arten der Gattung Aphrodite näher, bei welchen die gleichen Borsten am Endabschnitte mit einem Barte feiner Haare dicht besetzt sind; während Hermione an den ventralen Borsten die zweizinkige Spitze zeigt, wie sie bei Aphrogenia und Pontogenia vorkommt. So zeigen sich in mehrfacher Verkniipfung dic Verwandtschaften dieser Gattungen der Hermioneen.

Yon den genannten Gattmoren findet sich in der Sammlung Aphrodite in zwei, Laetmatonice in einer Art vertreten. Auch IIermione fehlt dem durchforschten Gebiete nicht; es liegt mir aber nur ein einziges Exemplar einer zı dieser Gattung gehörenden Art vor; da dasselbe seiner geringen Grösse wegen als ein junges Thier angesehen werden muss und ausserdem wenig 
gut erhalten ist, so habe joh von einer weiteren Bescheilung derselhen

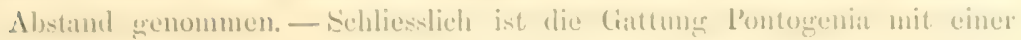
Art vertreten.

\section{Al'ILLOH)I'T.}

Ich rechne die beiden in folgenden bexchriebenen Arten zur Gattumg Aphrodite, wem ich anch einzelne Bildungen an ihnen vorfinde, welehe bis

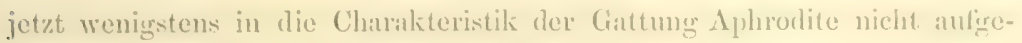
nommen waren. Das sind Bildungen, welche am Koptlappen und in ventralen Ruderaste sich rorfinden. Am Kopflappen ist die Kiirze des dentalicel: und das Fehlen des Augenpigmentes vielleicht noch ron keiner srosen Berlentung. Wichtiger erscheint die eigenthiimliche Bildung, welche ein 'Theil der Borsten des ventralen Ruderastes besitzt, die vor der lindspitze wie mit einem Barte von Hiirchen in ungleicher Miachtigkeit grefranset sind. Sie bieten damit ein Bild, welches, wemn anch in greringerer Aushildung, sich bei der von Kinbergy beschriebenen Apluratite allu vorfindet. Vielleicht ist diese Bartbildung eine Wiederholung dessen, was sich auch an den Borsten in der Gattung Laetmatonice findet, so dass zu deren Charakterisierung die so gestalteten Borsten allein nicht verwerthet werden kïnnen. Hier sind die setae glochidene, welche der Gattung Aphrodite abgelen, kemnzeichnend.

\section{Aphrodite acuminata n. sp.}

\section{I'uf. 5 .}

Corpus latum, postice valde, antice minus attenuatum, in dorso tela tomentosa setis dor:ualibus perforata tectum, segmentis 32 . Lobus cephalicus orbicularis postice transverse dilatatus; tentaculum brerissimum; coulorum jeclunelu non pigmentati in margine anteriore collocati ; subtentaculs valida longissima glaberrima; tuberculum faciale compressum, verruensum. Elytrorum orbicularium glabrorum paria 15. Segmentorum prius utrinque cirris binis brevilus setiacule criniformibus, cetera fasciculis setarum dorsualium validarum spiniformium introrsum curratarum, brumeo-aurearum; et capillarium albarum, elytris aut cirris lorsualibus filiformibus glabris; ramo ventrali brevi setis validis simplicibus minoribusque ad apicem longam filiformum valde barbatis; cirro rentrali setis lureviore.

Irab. I. Jarch 31, 1869, off Carysfort Reef, cnst No. 2, depth 17 fms. 2. May \&, 1869, off Alligator Reef, cast No. 6, depth 88 fms. 3. May 13, 1869, off Pacific Reef, cast Xo. 3, depth 60 fins.

Der Habitus dieser Art erimert an denjenigen kleinerer Exemplare vou Aplerorile aculcata, nur ist der Körper wohl etwas breiter und nach hinten auffalliger zugespitzt, als das bei diesen der Fall ist; aber ein auflallender 
Lnterschiod tritt darin hervor, diss an Stelle der griingoldig irisierenden

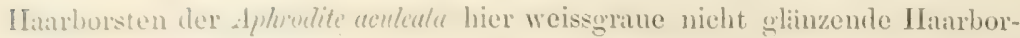
sten den hïrper flinkieren; auch sind die grossen den Rïckenfilz durchbohrenden woldbram glinzenden Borsten bei dieser Art wohl etwas stïrer gekrïmmt, lïnger und reichen näher an die Riiekenlinie heran. Mit IIiilfe der Lupe erkennt man das wesentliche Kennzeichen, die kleineren mit dichtem Bartsaum versehenen Borsten des unteren Bïndels.

Der Koptlappen ist eme milssig gewölbte l'latte, von deren weitans grösston kreisfömigen vorderen Abschnitt sich mit tiefer Einschniirung ein kleinerer hinterer quer halbmondfömiger absetzt. Auf der Wölbung des Kopthapens habe ich Angentlecken nicht gesehen. In der Mitte des Tordermindes entspringt ein ganz kurzer cylindrischer Stummel, ob eine unparre Anteme oder nur das Basalgliel einer solchen, dessen Endstiick abgefallen wïre, blieb umentschieden; alle Exemplare hatten übereinstimmend diese Bildung.

Tor dem kreisförmigen Vorderrande des Kopflappens erhebt sich jederseits ron einer Masse, aus welcher auch die Subtentakel entspringen, ein kleiner Wulst, dessen freies Vorderende als ein kleines queres Polster sich darstellt, bisweilen den Anschein bietet, als erhebe es sich schuppenförmig von der IW urzel der Subtentakel. Ich halte trotz der vorgeschobenen Lage diese Gebilde für die sogenamnten Augenstiele ohne einen Beweis für die Richtigkeit dieser Meinung bringen zu können; und nur die Rücksicht darauf, dass diese Fortsiitze bei Laetmatonice vor den Kopflappen verschoben sind, legt mir diese Auffassung nalre.

Der Facialtuberkel bietet von oben gesehen eine birnförmige, nach vorn verschmälerte Oberfläche, welche von kleinen Warzen bedeckt ist.

Die Subtentakel sind sehr schlank kegelfürmig, glatt; zurückgelegt reichen sie bis auf das 9te Segment.

Das Mundpolster ist eine mit der Spitze nach hinten grerichtete, breit dreieckige Platte, welche auf den Raum der 3 ersten Segmente fällt, so dass die Furchen des 4 ten Segmentes zuerst die ganze Breite der Ventralfliche krenzen.

Das erste Ruder ist einïstig, es trïgt neben einem mässig grossen Bündel graner IIaarborsten zwei fadenförmige Fühlercirren, von welchen der obere etwa ein Drittel der Lüinge des Subtentakel erreicht, während der untere kürzer ist.

Die breitesten Rudertragenden Segmente aus der Körpermitte sind olne 


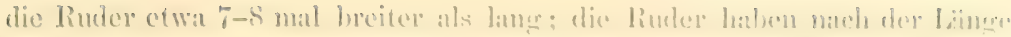

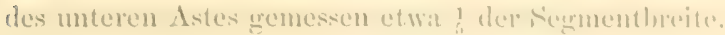

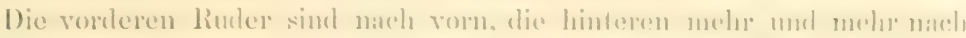

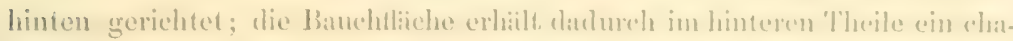

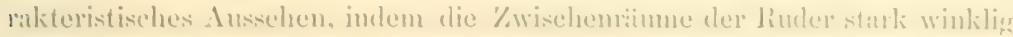
gerenen die semmentfurelien gertellt sind.

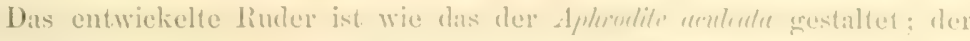

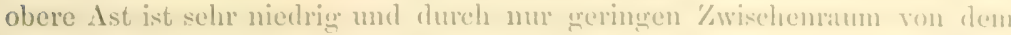
unteren kegeliömigen getrennt. Am oberen Aite treten die Borsten ron der dorsalen Fliehe ab und zwar die hataförmigren an allen liudern, so dass die medianwitits stehenden den dichten, den Rïeken deckenden Filz bilden. wiihrend ein laterales dichtes Biindel an den Finnken des Körpers biischelfömig herabhïngt; diese Biindel sind grau oden weisslich; die einzelnen feinen harförmigen l3orsten sind mit äusserst feinen Hïrehen besetzt, welche wesentlich zu der Verfilzung beitragen. An den Rudern, welche keine Eilytren tragen, treten neben diesen Ifarborsten in zwei gesonderten Gruppen die goldbramen, schwach gekrimmten grossen spieswe hervor; welche den Inarfilz durehbohren, und iiber demselben bis fist an die Mittellinic hinausreichen.

Am unteren Ruderast treten die grossen Borsten in zwei Stufen iiber einander herror; die der oberen Stufe sind selur lang spiessig, einfach spitz auslaufend, die der unteren sind kïrzer, haben einen fast gleichmässig dicken Schaft; dieser lïuft damn aber plïtzlich fudenfömigr zugespitzt aus und ist hier iiber eine lange Strecke bis auf die Lndspitze mit dicht stehenden Hïrchen besetzt, so dass er fast pinsclartig erscheint.

Die Elytren, in 15 Paaren in der gewöhnlichen W eise vertheilt, sind grosse, durchscheinende, glatte, kreisförmige Scheiben, welche iiber die Mittellinie und ihre Nachbarn himansgreifen; so die Rüickenfliche des Körpers ganz decken. Der Elytrenträger ist eine Leiste, welche rom ïusseren Unfange der Scheibe radial bis gegen das Centrum rerlïuft und bei einer Fliachenansicht des Elytron sich scharf kennzeichnet. Der Ruickencirrus entspringt mit kurzem Wurzelgliede hinter dem unteren Theile des Biindels der granen Haarborsten des oberen Astes, ist schlank kegelförmig, rlatt, so lang als diese Borsten. Der Banchcirrus ist einfach kegelfümig, entspringt auf der halben Liinge des unteren Astes und ragt wenig ïber das Ende desselben himaus.

Von der europäischen, auch an der Ostkïste Nord-Amerikas rorkommen- 


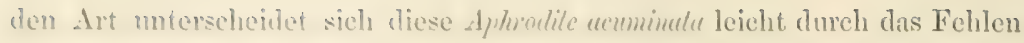
der Angentlectee, den Besitz der Augensticle und die eigenartig bärtigen borsten im ventralen linderast. Die von Quatrefiges erwiihnte siidamerikanische I. celdidm ist zu unvollstindig, nur nach der Rïckendecke bekannt, um Beriicksichtigming finden zu kïmen.

\section{Aplurodite obtecta n. sp.}

$$
\text { liuf. 6, Fing. 1-S. }
$$

Corms suboratum supra altum subtus planum, tela tonentosa crassissima setis non vel perparum perforata in dorso tectum, sermentis 2.5 ; lobus cephalicus segmentaque sicut in Aphrodite acuminute instruta ; diflert anteu ab illa setis rentralibus ante apicem breviter hamatum parum barluntis.

Halh. : 1. Feb, 18, 1869 , of Boca Grande, cist Xo. 2, depth 122 fms, 2. No. 29, ilepth 955 fms, Lat. $21^{\circ} 30^{\prime}$ X.. Lom $81^{\circ} 5^{\prime} 11^{\prime}$.

Das Aussehen dieser Art erimnert an die von Kinberg abgebildete Aphirodile allu. mit welcher anch in den Einzelheiten mancherlei Uebereinstimmungen sich ergeben. Diese Aelmlichkeit ist dadurch bedingt, dass die hoch gewölbte liiickenfläche des ovalen Kürpers von einem durch eingelagrerte grane Schlammtheile gleichförmig erscheinenden Filz gedeckt ist, durch welchen Borsten entweder gar nicht oder nur mit den ïussersten Spitzen durchtreten; seitwärts ragt diese Körperdecke allseitig soweit vor, dass ciie nackte Banchfläche ringram von deren breitem Rande umfasst ist. Das Thier kam allem Anschein nach sich offenbar zum Schutz, so zusammenbiegen, dass die Bauchfläche ganz verdeckt ist, und es dann als ein fast kugeliger Schlammklumpen erseheint.

Fin Thier, an welchem ich nur 25 Segmente zählte, war, an der Bauchfliiche gemessen, ohne die Filzdecke $10 \mathrm{~mm}$., mit derselben $13.5 \mathrm{~mm}$. lang, dabei nicht ganz $4 \mathrm{~mm}$. resp. $8 \mathrm{~mm}$. breit; ein grösseres Thier, an dem ich 20 Segmente, die letzten allerdings nur mit Mühe zählte, war ohne die Filzdecke $15 \mathrm{~mm}$., mit derselben $19 \mathrm{~mm}$. lang bei 11 resp. $15 \mathrm{~mm}$. grö̈sster Breite. Die Haut des Thieres ist an den meisten Theilen des Körpers stark warzig.

Der grlatte Kopfappen ist eine kreisförmige wenig gewölbte Scheibe, auf welcher ich pigmentierte Augenflecken nicht gesehen habe. In der Mitte des Vorderrandes steht ein ganz kleiner Torsprung, der Tentakel ; jederseits daneben zwei fast halbkugelig gewölbte Höcker, vielleicht die Augenstiele. Der Facialtuberkel ist litirzer als der Kopflappen ; seine Dorsalfäche erscheint birnförmig und ist stark warzig. Die Subtentakel sind schlank kegelförmig 


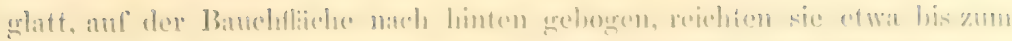

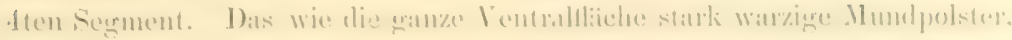

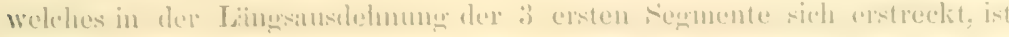
limger als breit, vorn am loreitestem, nateh hinten mu

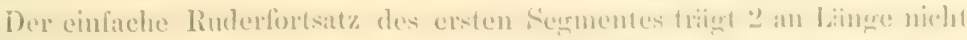

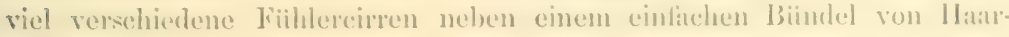
borsten.

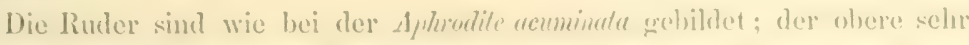
kurze Ast triigrt die breit austretenden dicht verfilaten IIarborsten und lange alicke einfitehe brame Borsten, welche an der iatsersten spitze hakenfömnig gekrimmt sind (Fig. 7,8 ); in einem Falle sale ich diese spitze von einem scheidenartigen Teberzuge gredeckt. Die borsten des unteren hinderastes sind einfach, vor der kurzen stumpfen etwas gekriimmten Spitze aui der cinen Fläche mit einem diehten Bart ron Haren biirstenatig bedeckt (Fig. 6); einzeln kommen daneben spitz auslaulende pinselatig gebirtelte Borsten vor; vielleicht ist dies ein Entwicklungsstadium, bei Aphrade acmminatu danernd erhalten, aus welchen mit $\Lambda$ bwerien der spitze die gewiihnliche Form entsteht. Einnal habe ich zwischen diesen borsten, und zwar an dem kleineren 'Thiere, eine einzelne zweizinkige Borste grefunden; ist das etwa eine dem jungen 'Thiere zukommende Form?

Der schlanke Ritickencirrus ist am Ende sehwach geknöpft, ahgerundet. Die in 15 Paren vorhandenen Elytren sind nicht ganz kreisrund, da sie am lateralen Umfange, an der Terbindungsstelle mit dem leistenförmigen Elytrophor schwach ausgerundet sind; iibrigens diimn, durchscheinend und glatt; die der mittleren Körpersegmente sind die weitaus grössten, aber anch sie ragen nicht viel iber die Medianlinie und ihre Nachbarn hinweg. - Die Bauchcirren sind schlank liegelfürmige Fïden, die kaum so weit als der untere Ruderast vorspringen.

Diese in grössere Tiefe hinabsteigende Art grehört vielleicht in den Terwandtschaftskreis der von Kinberg beschriebenen Apluodile ullu, die bei Rio Jameiro 20-30 Faden tief gefunden wurde; diese stimmt darin mit der Aphroclite abtecla iiberein, dass die Filzdecke des Kürpers nicht durchbohrt ist, dass halbkugelige Augentrïger vorhanden sind, die aber hier Pigmentflecke tragen, und dass die Borsten des rentralen Astes ron einer "vagina papillosa" bedeckt sind, die offenbar dem bärtigen Filz entspricht, welchen ich beschrieben habe. Die Unterschiede zwischen beiden Arten sehe ich darin, dass die Aphroclite alla zahlreiche Segmente (40) besitzt, dass dic 
Pigmentliihrenden Augenträger nicht am V'orderrande, sondern seitlich und hinter dem 'tentakel stehen, der tricialtuberkel mit nur wenigen aber grosen Warzen besetzt ist, dass die Subtentakel nach der Abbildung nicht glatt, sondern mic IHirchen in Reihen besetzt sind, und schliesslich diss die von ratuher Scheide gedeckten Borsten des unteren Ruderastes in der Form doch von den geb:irtelten Borsten der Aphrodite oblecto abweichen; anch ist die eigenartige Gestalt des an der Spitze geknöpften Riiekencirrus der Aphroulite oblectu in Betracht zu ziehen.

\title{
LAETMATONICE KINB.
}

\section{Laetmatonice Kinbergi (B.iro).}

\author{
Taf. \%, Fig. 6; Taf. S, Fig. 1-5.
}

Buirl, Journal of the P'rocecdings of the Limnacan Society, Zoölog., Vol. VIII. p. 180.

? Laetmatonice filicomis Kinberg. - Annulat. Fregatten Eugenies Resa, pg. 7 .

Laetmatonice armata Verril. Notice of Recent Additions to the Narine Invertebrata, Pt. I. Proceculings of Uniter States National Museum, Vol. 1I., 1879. Smithsonian Miscellaneous Collections, Vol. XIA. Washington, 1880. p. 16S.

Fundorte: 1. Off the Sambos, 125 fms. 2. Feh. 17, 1869, S. W. of Sand Key, cast No. 2, depth 125 fms, 3. April 21, 1869, off Key West, cast No. 1, depth 135 fms. 4. May 7, 1869, off Tennessee reef, cast No. 9, depth 174 fuls. 5. May 11, cast No. 16, 138 fms. 6. May 16, 1868, off Sand Key, 120 fms. 7. No, 6, Lat. $24^{\circ} 17 \frac{1}{2}^{\prime}$ N., Lon. $82^{\circ} 9^{\prime}$ W., depth 137 fins.

Diese mir in mehreren Exemplaren von verschiedenen Fundorten vorliegende Art der Gattung Laetmatonice hat durch ihre geographische Verbreitung Interesse. Ich muss die mir vorliegenden Thiere nach der Beschreibung, welche Baird von der Latmatonice Kinhergi gregeben hat, fiir identisch mit dieser halten; ferner ist es mir zweifellos, dass die von Verrill als Lactmatonice armala beschriebene, von der Nordostkiiste Amerikas aus dem Gulf of Maine und der Bay of Fundy stammende Art mit dieser zusammenfiillt. Verrill hat bei der Aufstellung der anfungs von ilım für Lactmatonice filformis Kinb. gehaltenen Art ausser Acht gelassen, dass bereits Baird ron dieser Art die Latmatmice Kinbergi abgretrennt hat und zwar im Wesentlichen auf Grund der gleichen Kennzeichen, welche auch fiir ihn massgebend waren: das sind die Grössenverhältnisse des Tentakels z.u den Subtentakeln und die Anwesenheit von ein oder zwei starken Dornen vor dem Anfange der halbgefiederten Endstrecke an den Borsten der ventralen Ruderäste. Alle die in diesen Beschreibungen angegebenen Verhïltnisse passen num auf die mir vorliegenden Thiere, 
wie diese wiederum iibereinstimmen mit cinem hei lastpont grofuntenen

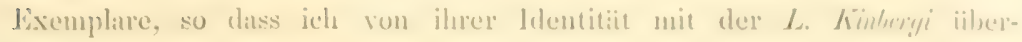
zeunt bin.

Dagegen vermag ich anch jetzt nicht, wie friiher schon, ${ }^{2}$ zu entscheiden, ob die batmetemier himbergi, wie das Malnugren" gethan hat, mit der

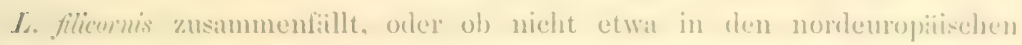

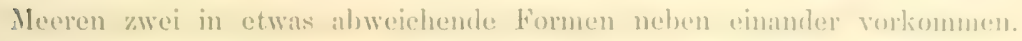
Mit Riieksicht darat ist es wohl erwinseht. \%ul den vorhandenen Nhlildumgen weitere hinzuzufïgen, welehe zur Klarstellung dieser linge helfen kiinnen.

leh finde nirgends die Vertheilung der Elytren auf den Parapodien hervorgehoben, die mit 2, $4,5,7,9) \ldots .23,26,29)$ zu bezeichnen ist; fïr die Bemtheilung der Verwandtschaftverhältuisse kann das ron Bedentung sein. Fiir die geographische Verbreitung ergielst sich das aber unzweitelhaft, dass diese Art von Florida ab an der nordanerikanischen Kiiste und an den nördlichen Kïisten Europas verbreitet ist allem Anscheine nach in den Gebieten, welche in den Golfstrom und dessen Nachbargebiete fallen so zwar, dass die Thiere im rein arktischen Kreise ebenso fehlen wie an den siddlichen Küisten der Nordsee und in der ()stree. Babei ist dam zu beachten, dass im Floridagebiete nach den oben gegebenen Fundorten die Thiere nu unter der IImdertfirdenlinie gefunden sind.

Grube $^{3}$ hat eine an den Kerguelen gefundene Laelmatonice producta beschrieben, welche sich ron der palaearktischen Form in wesentlichen durch die grössere Zahl der Segmente und dementsprechend der Elytren unterscheidet; es bleibt abzuwarten, ob etwa an der Sidostkiiste Amerikas andere Fundorte der Gittung bekannt werden, welche ïber die Gesamutverbreitung derselben mehr Aufklärung bringen. Die von Grube ${ }^{4}$ erwithnte L. violascens muss vorläufigr ausser Acht hleiben, din iln Fundort, angeblich das chinesische Meer, nicht verbuirgt ist; Grube lest fuir die Feststellumg der Art das Hauptgrewicht auf die Grössenverhältnisse der Tentakel zu den Fühlereirren und den Subtentakeln, welche denjenigen nalse kommen, durch welche $L$. Kinberyi ron $L$. filicomis unterschieden sein soll; so dass diese Art der L. Kinbergi sehr nahe stehen muss.

1 Ehlers, Beiträge zur Kenntniss der Terticalverbreitung der Borstenwimer, Zeitsehr. f. wiss. Zool. Bi. 25, pag. 31 .

2 Malmgren, Annulata polychaeta, rg. 3.

${ }^{3}$ Ed. Grule, Annelidenausbente ron S. M. S. Gazelle. Monatsberichte ler Kgl. Akad. d. Wissensch. Berlin, Angust 1si, pag. 512 .

* E. Grube, Bemerkungen üljer die Fauilie der Aphroliteen a. a. 0., 1'6. 45. 
IONTOGEN1A, CLAP, char. emend.

Ans der lieihe der Kiennzeichen, welche Claparède' bei der Aufstellung dieser Gattung in deren Diagnose aufgenommen hatte, ist ron Grube bereits die Vielyliechrigkeit des unpaaren 'Tentakels gestrichen; ich habe hinzuzuliigen, dass auch dasjenige kemnzeichen, welches Grube * in der Tabelle für die Bestimmung der Gattungen aufrenommen hat, wonach die Augren der hierher gehïrenden Thiere gestielt sein sollen, nicht allgemeine Giiltigkeit besitzt, da in der ron mir zubeschreibenden Art die Augen nur auf einem Polster sitzen, nieht aber ton einem Stiel getragen werden. Ich habe schon bei der Gattung A I hhrodite auf das Schwanken dieser Bildung hingewiesen. Die Diagnose wiirle damn lauten:-

l'ontogenia Hermionearum genus tentaculo singulo gracili, flabello setarum simplicium denticulatarum dorstalium et tela tomentosa setarum capillarium in segmentis omnibus, setis perpaucis ventralibus hilentatis.

\section{Pontogenia sericoma, n. sp.}

$$
\text { Tilf. } \% \text {, Fig. 1-i. }
$$

P. chrysocoma similis, difirnt oculis non pelumenlatis, tentaculo cirrisque simplicibus, haud aticulatis.

11:lh, with Havama, s:) fm. (Sigsbee).

Der kurze ziemlich gleich breite, auch nach hinten nur wenigg verschmälerte Körper dieser Aphroditacee erhält sein eigenthïmliches Aussehen durch die fücherförmig gespreizten Bündel der grossen goldbraunen Borsten, welche rlie Riickenfläche nicht so weit bedecken, dass ron dieser nicht ein seidig glïnzendes, weisses oder schwach griinlich irisierendes mittleres Längsfeld zur Schau träte ; die einfarbige helle Bauchfläche zeigt die scharfen Segmentgrenzen und die tiefen Einschnitte zwischen den unteren Ruderïsten. Das einzige Exemplar hatte 33 Segmente, war 17,5mm. lang und olne die Borsten $6 \mathrm{~mm}$. breit.

Der von den ersten Elytren verdeckte Kopflappen ist eine hoch gewölbte mach hinten stark verschmälerte Platte, welche wenig liinger als am vorderen Rande breit erscheint. In der Mitte des Vorderrandes entspringt ron einem durch lange Papillen ringsum rauhen W' urzelghliede der äusserst dünne

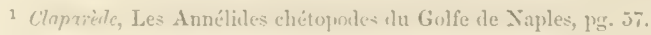

"Girube, Bemerkungen, über dic Funilie der Aphroditeen, a. a. O., 18it, pg. 48. 


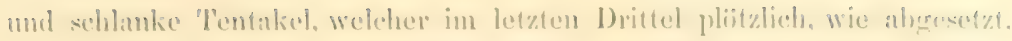

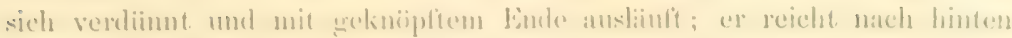

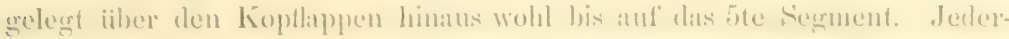

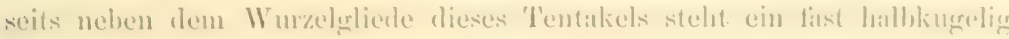
grewiblbtes Polster, welches zavei grose kreisfömige schwarge l’ignent-

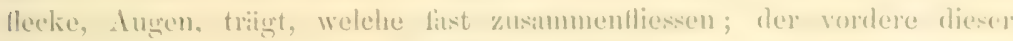
ligmentlecke ist groisser als der hintere. Zawei lange glatte Subtentakel, welche nach hinten grelegt his an das Ste fegment reichen. fiscen den seitlich zusammengerliekten, von Waren rauhen Fiteialtuberkel zwischen sich.

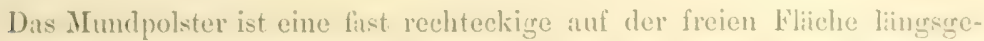
furchte Platte, welche etwa doppelt so lang als breit ist mnd den medianen 'Theil der vorderen vier Segmente deckt ('Taf. T, Fig. 2, 3).

$\Lambda m$ ersten Segment trägt das einistige Ruder ein kileines fiicherförmig von jeder Seite vor dem Kopflappen gespreiztes Biindel groldbrauner Borsten, wie sie, nur grisser, im oberen Aste der folgenten Ruder stehen, und zwei an Form und Grïsse dem Tentakel fast gleichkommende Fiihlereiren auf je einem kleinen warzigen Basalyliede.

Die vollentwickelte Ruder tragenden Segmente sind mit den liudern etwa 12mal, olme dieselben Smal breiter als lang; die 13auchfläche ist fast plan, die Riickenftaiche miissig gewölbt; die Bauchtliache und die Ruder sind schwach warzig.

Das ausgebildete Ruder hat einen niedrigen oberen und einen nur wenig davon getrennten kegelförmigen unteren $\mathbf{A s t}$; aus dem oberen $\Lambda$ st tritt das grosse aufwïts gerichtete, mach hinten geneigte, fiicherfiinig gespreizte Bïndel der grossen goldbraunen Borsten herror, welches nach hinten gelegt mit seinen längsten Borsten etwa ïber drei Segmente reicht; die Borsten stehen in zwei Gruppen iberemander: die obere Gruppe besteht aus den grösseren Borsten, welche fächerförmig gespreizt sind; diese treten auf einer längsoralen Linie aus; so dass sie ein freies Centrum umfassen; ventralwärts von ihmen treten auf einem kleinen Hücker kleinere Borsten aus, cin Bïndelchen bildend; die einzelnen Borsten sind schwach bogenförmig gekrümmt, laufen mit einfacher Spitze aus, und sind an ihrem aufwärts sehenden Umfange mit Zülmchen besetzt, die in grüsseren fast regelmäissigen Abständen stehen (Fig. 5). - Am rorderen oberen Umfange des Borstenfächers tritt ein Strang ron Harborsten ans, welche mit denen der Nachbarsegmente einen feinen seidigen Filz bilden, der eine allerdings nur 
diimne Decke iiber die ganze Riickenfliiche bildet und ron jeglichen Fremdkirpern frei ist.

Aus dem unteren liuderaste treten wenige $(4-5)$ derbe grade braune Borsten aus, welche nit zwei ungleich langen krïtigen Zalunspitzen aiklaufen (Fig. t).

Die Riiickencirren stehen, alternierend mit den Elytren, hinter dem oberen Theile des Borstenfichers auf grossen kegelfömigen Wurzelgliedern; es sind leine, am Ende greknöpfte Füiden, welche an Lünge den grössten Borsten gleichliommen.

Die Elytren sind diinne durchscheinende, glatte, lïngsovale, am lateralen Rande schwach ausgerandete Platten, welche lateral angeheftet sind und dachziegrelförmig iiber einander und über die Mittellinie hinausgreifen.

Die Bauclıcirren entspringen etwas nach aussen von der halben Länge des unteren Astes an einem kleinen warzigen IFöcker, und ragen wenig uiber die Spitze des Astes, nicht aber iiber die Borsten hinaus; dagegen ist der Bauchcirrus des ersten entwickelten Ruders, des zweiten Segmentes, viel linger als alle folgenden, wenig kïrzer als die Fühlercirren.

Am Aftersegment stehen zwei schlanke Aftercirren.

Die Art steht der Pontogeniu chrysocoma (Bairl, Clap.) durch die gleiche Zahl der Segmente nahe, und beide unterscheiden sich dadurch von der Pontorgenic indica (Grube) ${ }^{1}$; von der $P$. chrysocome unterscheidet sich die $P$. sericoma durch ungegliederte Tentakel und Fühlercirren, und stimmt darin mit $P$. indica uiberein; dann dureh die glattrandigen Elytren, da diese, wenigstens am ersten Paare, bei $P$. chrysocoma mit grossen Papillen besetzt sind.

\section{POLYNOINA GRUBE.}

Aus der artenreichen Gruppe der Polynoinen liegen mir verhältnissmässig nur wenig Arten vor; zu den vier auf den folgenden Blättern beschriebenen, von denen ich nur eine mit einer schon frïher - von Schmarda - beschriebenen Art identificieren kann, muss ich noch zwei, wegen des schlechten Erhaltungszustandes nicht zubestimmende Formen hinzufügen - off Tortugats 13 fin. und Nai 16, 1S68, off Sand Key 120 fm. Aus dieser relativ geringen Zahl der gefundenen Arten darf auf das Terhältniss der Polynoinen in der Antillen-Fauna ein Schluss nicht gemacht werden; die Poly-

$$
1 \text { Grulbe, a. a. O. }
$$




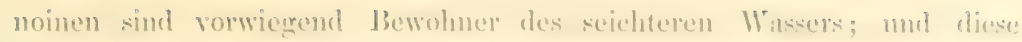

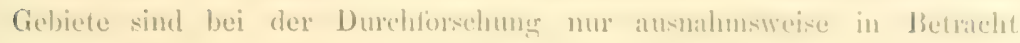
grementent.

Ich belasse die besehriebenen Arten unter dem Collectivnancon Polynoe, mol verweise nur ant ihre stellung in dem kiinstliehen sisteme, welches Grube zuletzt aufrestellt, hat, da ich der Meimumg hin, daks eine naturesemisse Gruppierung von Giattumgen erst zu machen sein wirk, wenn an reichlicherem Materiale der Werth der einzelnen verwendeten Morkmale: orkannt sein, oder ein genetischer Zusammenhang der einzelnen Gruppen in anderer Wreise dargelegt sein wird.

\section{P. (Polynoe S.r.) polytricha Scumstu.}

Schmarda, Nene wirlutlue Thiere. I, II, 1's. 156.

$$
\text { T"uf. 10, Fig. 9, 10; Tuf. 11, Fig. i. }
$$

Ich glaube diese Bezeichnung auf eine Polynoe anwenden zu diirfen, welehe mir nur in einem, nicht ganz vollstindigg erhaltenen Exemplare vorlag. Das $10 \mathrm{~mm}$. lange, olne Ruder $2 \mathrm{~mm}$, mit diesen 4 mun. Jreite 'Thier liatte 35 Elytren an 2. 4.5.7 . . 23. 26 Segmente. Der Kopflappen hat nur 2 Augen, nahe den I Iinterecken; die 'Tentakeln, von denen der umpare felnlte, entspringen unter dem in der Mitte tief eingeschnitenen an den Echen ausgezogenen Vorderrande, sie sind mit kleinen Hïrchen besetzt, wie dic grossen kantigen am Ende fadigg ansgezogenen Subtentakel. Das erste die Fïhlereiren tragende Segment ist in der Ansicht ron oben rerdecht; die Fïhleveirren, zwischen deren Basalstiieken eine grosse Borste hervorragt, sind längrer als die Subtentakel und mit Ausmalime des fadenfömigen Endstuickes dicht mit langen Papillen besetzt.

An den schlinkien Rudern ist der obere Ast schr viel kiirzer als der untere, beide laufen in eine kegelfömig zugespitzte Lippe aus; der obere Ast träigt ein reiches Bündel aufwïrts gerichteter starker gekrininter Borsten, welche auf der convexen Fläche bis zur. Spitze mit gesügrten Blättehen besetzt sind. Aus dem unteren Aste tritt ein zahlreiches Bïndel von Borsten aus; die einzelne Borsie ist an der Spitze zweizähnig; an der Endstrecke erweitert und auf der einen Fläche mit zerschlitzten Blittchen sïgezahnartig besetzt. Diese Bildung der Borsten und Puder Inat anch wohl die Schmarda' sche $P$. polytricha gehabt. An charakteristischsten sind die ovalen Elytren: ihr hinterer Rand ist mit sehr langen fadenfümigen Papillen gefranst, auf der 
Flikhe stuhen lappillen. Welche geren die Flide geneigt sind und alle an freien Endtheile mit spitzon Ziahnchen auslaufen, dabei aber sehr ungleich gross sint; die grössten stęhen auf der hinteren IIïlfte und geben mit ihren spitzen Z/ihnen das dem Aussehen des Elytron besondere Geprïge. Schmardats skizze vom Aussehen eines Elytron lisst sich hiermit wohl vereinigen. Die Rïickencirren ragen iiber die Borsten noch hinaus, ihr schlanker Schalt ist clicht mit langen firdenförmigen Papillen besetzt, ihr nacktes Ende fidenfürnigy zugespitzt. Die Bancheirren sind schlank liegelförmig, kürzer als das Ruder.

Die Art gehört in den Terwandtschaltskreis der Grube'schen Polynoinen der zweiten lieihe und zwar nach dem dafiir gegebenen Schema in die Gruppe II $\Lambda^{*} t^{2}$, wobei die Zweispitzigkeit der ventralen Borsten massgebend ist; mïher schliesst sie sich wohl der (in Il $\Lambda^{*} \mathrm{a}^{1}$ anfgenommenen) Gattung Eunoe (Mlgrn.) an, bei welcher der Koptlappen, seine Anhänge und die Fiihlereirren gleiches Verhalten aufweisen, die getrennten Ruderïste in spitze Lippen auslaufen, und die Elytren, bei Eunoe Oerstedi, ganz ähnlich geformte Papillen tragen. Nit einer der sonst beschriebenen Arten kamn ich sie nicht identificieren.

Fundort : April 3, 1869, ofl French reef, cast No. 3, 34 fms.

\section{Polynoe granulata n. sp.}

$$
\text { Tuf. 11, Fig. },-\% \text {. }
$$

Corpus breve depressum lineare, segmentis $3 \bar{i}$; sordide brunneo rel violaceo transverse in Iorso vittatum. T'entacula lateralia ex angulis anticis lobi cephalici fere rotundati bioculati proUneta, tentaculo impari paullo lreviora, omnia sub apice acuto incrassata glabra; subtentacula magna, tenticulis lonriora, in apice ncuminata, glibra. Segmenti $I^{\text {ni }}$ setis carentis cirri tentaculares magnitudine formaque tentacula aequantes pallum inter se liversi. Pinmarum ramus superior humillimus setis paucis curvatis flavis transwerse spinulosis; ramus inferior crassus obtusus, setis multis validissimis tlavo-anreis ante apicem bispinosum incrassatis et fortiter transrerse spinosis. Elytrorum subreniformium in parte interna et postica livile aut brunneo tinctorum ibidemque granulis dispersis parum scabrorum paria 18 dorsum non nisi antice et postice tegentia segmentorum 2, 4, 5, $7-23,25,27,28,30,31$ - Cirri dorsuales setas inferiores paullum excelentes, tentaculiformes clabri; ventrales, excepto primo tentaculiformi conico, ramo inferiore breviores, glabri: - Papillae rentrales inde ab piuna $11^{\mathrm{m} a}$. Cirri anales sub ano dorsali cirris postremis dorsualibus parum breviores.

Funilort : Tortugas.

Zwei ungleich gefïrbte Exemplare dieser Art liegen mir vor; das vollstïndig erhaltene ist $21,5 \mathrm{~mm}$. lang, ohne Ruder und Borsten 5mm., mit denselben $8,5 \mathrm{~mm}$. breit. 


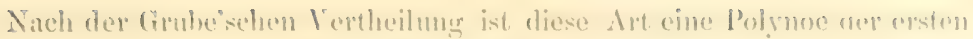

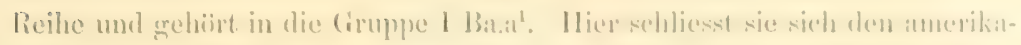

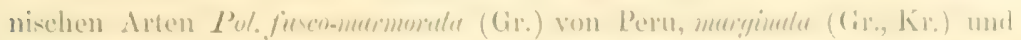

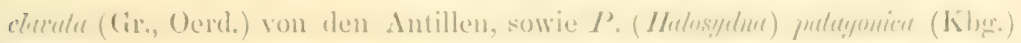
ans Patagonien an, bei denen die Elytren ghaltrandig sind. () lifubar simb

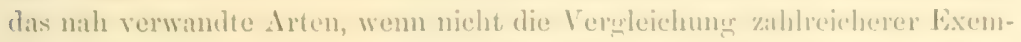

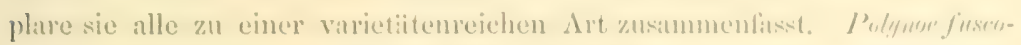

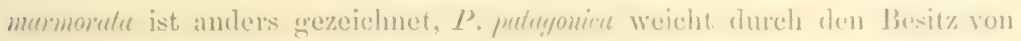
vier Augen, andere fiorm der Elytrenwarzen und der Borsten des oberen

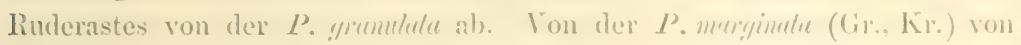

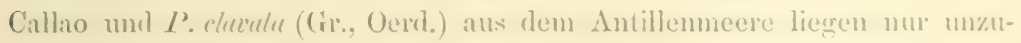
reichende Beschreibumgen vor; bei $I^{\prime}$. marginale decken die Eilytren die gamze Riickenfliche; $P$. cluzatu hat auf den Elytren nur je eine Reihe von 2-3 kleinen Papillen, welche Sehildbuckeln ähmlich sind: das sind Unferschiede, welche sich aus den kurzen, von Abbildungen nicht begleiteten und unzulünglichen Beschreibungen herausfinden lassen. Immerhin ist es moiglich, dass Grube bei der Beschreibung seiner $P$. clazalu ein Thier vor sich gehabt liat, welches zu meiner $P^{\prime}$. gromululu gehört.

\title{
Polynoe taeniata, n. sp.
}

\author{
T'uf. 1U, Fig. 1-S:
}

Corpus breve lineare depressum, sermentis $2 \pi$. Lohus cephalicus paullo longior quam latior, suloquadratus rectangulus, oculis uaioribus anticis, minoribus posticis valde distantibus lateralilus ; tentaculis lateralibus, juxta impar longins infra marginem rectum lobi cephalici productis, hoo illisque ex articulo basali magno prodeuntibus, infra apicen gracillimum filiformem tumichulis, parce ciliatis, brumeo tacniatis; subtentaenlis permagnis, tentacula superantifus conicis serintim ciliatis, in apice subito attenuatis. - Cirri tentaculares forma et longitudine tentaculum implar nequantes. -. Piunae hreves crassae ramis paullum sejunctis obtusis, superiore lumili setis pancis flavis curvatis transterse spinulosis permultisque tenuioribus fereque capillarilus infra apicem acutum plus minusre dilatatis, levibus; inferiore lurevi crassissimo, setis haud ita multis brunneis validissimis lrevibus, in hasi dilatata cuelata apicis simplicis utrimque spinulosis. - Elytrorum reniformium vel ovalinm, margine postien internogne excepto allo brumeo tinctorum nodulis et squamosis et rotundato-conicis variae magnitudinis paullum scabratorum paria 12 totum dorsum inbricatim tegentia, segmentorum 2. 4. 5. 7 . . Cirri dorsuales sefas paullum excedentes tentaculiformes, parce ciliati, taeniati; cirri ventrales, excepto primo tentaculifurmi, glabri in apice tiliformes, pinnam nou superantes. Cirri anales longi tentaculiformes.

Fundort : Xarch 29, 1869, off Carrafort Reef, cast No. \&, depth 35 fm.

Mir liegt nur ein Exemplar ror; welches 12mm. Iang, mit Ruder und Borsten 3,6mm. olne dieselben 2,51mm. Jreit ist. 
In er Grube'schen Vertheilung der Arten wïrde diese Art in die Gruppe I1. A. b. geheïren. Sie ist durch die form des Koptlappens ausgezeichnet, unter dessen grat abgesetzten Vorderande die 'T'entakel entspringen, durch die eigenartige Stellung der vier ungleich grossen Augen fast an den Ecken der oberen lioptlappentliiche und dureh die kurzen stumpfen borstenreichen liuder, deren oberer kleiner Ast zwei ungleiche Borstenformen besitzt. Leber dieses wie iiber die Formen der Warzen auf' den Elytren geben die Abbildungen die beste Auskunft. Hiitte Schmarda ${ }^{1}$ von seiner Polynoe Antillurum, welche er nur in defectem Zustunde gesehen hat, nicht angegeben, dass ein 'Theil der Borsten zweiziilmig sei, so wiirde ich annehmen, dass sie mit dieser zusammenfiele.

\section{Polynoe lactea, ns. sp.}

Taf. IX, Fig. 1-Y.

Corpus brove segmentis 27 , albilum. Lobus cephalicus antice angustatus, caecus; tentaculis externis ex angulis anticis productis paullo impari brevioribus, omnibus sub apice tumidis, glabris; subtentaculis conieis tentacula externa vix aequantibus, glabris. - Segmentum primum setis carens cirris tenticularibus ntrimque 2 magnitudine formaque tentaeulum inpar aequantibns. Pinnae segmentorum sequentiun breves crassiusculite ramis parum sejunctis, stpero inferiore tenuiore in lingulam acutan producto, setis simplicilus eurvatis crassis sermlatis; inferiore crasso in labium brevius obtusum prolucto setis suls apice integro paullum dilatatis curvatisque dense transverse serrulatis; elytrorum paria 15 in segmentis 2. 4. 5. 7. . . 23. 25. 27. 28. 30. 31. 33. imbricata dorsum totum tergentia ; singulum magnum, ovale vel subreniforme, tuberculis duris a basi angulosa conico-acuminatis, papillis cylindratis minutis plus minusve intermixtis scabrum, in margine postico et externo fimbriarum serie clense ciliatum ; cirri lorsuales setis parum longiores infra apicem tumiluli, glabri ; cirri rentrales, excepto priore tentaculiformi, in segmentis anticis apice filiformes, in posticis breviores fusiformes.

Fundort: 1 Feb. 17, 1869. S. W. off Sand Key, cast No. 2, llepth $125 \mathrm{fm}$. 2. Off the Sambos, depth 123 fin.

Ich kann diese Art mit keiner der bekannten, welche die gleiche Zahl und Tertheilung der Elytren besitzen und danach in Grube's Gruppe I. A. b. b. ${ }^{2}$ gehören, identificieren; der Mangel der Angen, die bleiche Farbe sorvie die Ausriistung der derben Elytren und die eigenartige Lippenbildung an den Ruderästen sind sehr kennzeichnend.

1 Schmarda, a. a. O., pag. 158. 


\title{
ACOETEA (Gr:).
}

\author{
EUARCIIE, n. gen. \\ (Eiapxy, Nimen Nereidace)
}

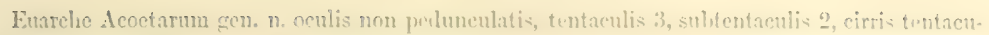

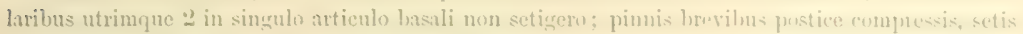
superioribus filiformibus, inferiorihus crassis hervibus et aristatis ; elytris cum cirris altemis mabris imbrieatis dorsum medium non tegentibus; prohoseide paprilla medianit elongata dossali simplici, ventrali tripartita; in oro transverso maxillis dorsali et ventrali validisima liklentatn, lateralilus. grinulosis.

Der hauptsiehliche Charakter dieser Gattumg liegt in der Gestaltung des Kopflappens, welcher von demjenigen aller anderen Acoetiden daturch abweicht, dass auf seiner Oberliiche die Augen, schwarze Pigmentllecke, wie bei den Polymoinen stehen, keinerlei Augenstiele oder auch nur polsterfürmige Erhebungen vorhanden sind; einen Anschluss bildet hier P'mthatis migromaculuta (Gr.), bei welcher die Augenstiele seln kurz sind, und bei welcher neben diesen kleine Pigmentflecke stehen, die als $\Lambda$ ugen gedeutet werden. Drei Tentakel kommen bei Panthalis vor, ihre Stellung erscheint hier aber durch die Entwicklung der Augenstiele eine andere. Der Arancel der Borsten zwischen den Fiililercirren findet sich bei Polyodontes. Die starke Compression der Rucler finde ich in keiner Beschreibung besonders hervorgehoben, glaube aber, dass diese Bildung anch an den Rudern der Punthalis melunonotus (Gr.) rorhanden ist, denn Grube erwibnt hier in seiner ersten Charakterisierung des $\mathbb{T}^{r}$ urmes ${ }^{1}$ ohne bei dessen ausfiilırlicher Beschreibung ${ }^{2}$ darauf zurickzukommen, eine rerticale Lamelle "im Lippenblatt" zwischen dem Riickencirrus und dem Austritt der Borsten, das meines Erachtens nichts Anderes als die First des sturk zusammengedriickten Ruders ist. Die Borsten haben in ihrer Form nichts ron denen der ïbrigen Arten ganz Abreichendes. Eine quere Mundiffhumg und gleiche Kiefer besitzt Eupompe und Polyodontes; die Dreilappigheit der ventralen Medianpapille ist von keiner anderen Art und Gattung beschrieben.

\footnotetext{
1 Grube, Berieht a. a. O., 15. 51.

2 Grube. Arnulata Semperiana a. a. 0., pg. 4 s.
} 
Euarche tubifox, in sp.

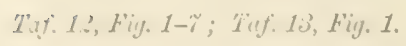

L.mon vermiformis, linearis, antice crassa postice versus complanata paullum attenuata, in florso

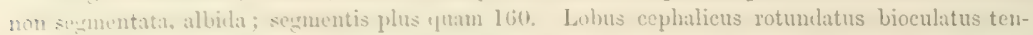
taculis -2 in markin anteriure longitsenlis conicis glahris tentaculo impari e vertice pust ocnlos oriente aracili filifomi maioribus, subtentaculis conicis validis glabris. Cimi tentaculares tentaculis longines conici clatri in articulis basalibus setis carentibus. - Pinne altae breves comprosin, prasertim posticalo sublamellosae; ranis cualitis, superiore acienla et fasciculo setarum

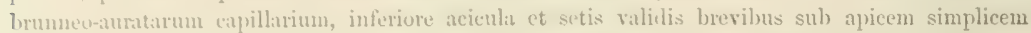

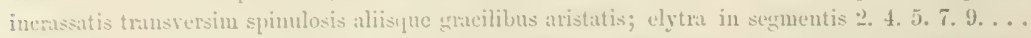
monlariter per totum corpus alterna, mbinknlaria mollia glabra pellueida imbricatim sese, clorsum medium nou texentia; cirri donsiles in pinnis clytris destitutis breves conici, ventrales in pimnis omnibus parvi. P'rubuscis magna alpertura transversa serie simplici inferiore et superiore papillarum conicanum quarum melianae maiores, superior simplex, inferior tripartita, maxilhe mediana dorsalis et ventralis permagn bilentata, laterales utrimane tuberenlis 5 obtnsis conicis parris armatae.

Tubus vermi multo longior crassus, versus aperturam anticam attenuatus postice clansus, limo oli.luetus.

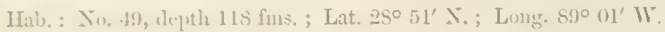

Zur Erginzung der rorstehenden Beschreibung habe ich Weniges hinzuzufïgen. Diese Beschreibung ist nach dem einzigen mir vorliegenden Exemplare entwrorfen, welches ich in der grossen Schlammröhre beim Aufschneiden derselben so gelagert fand, dass das Kopfende des Wurmes der einzigen Oefinung der Röhre zugerrendet war.

Der Wrum, an welchem ich 159 Segmente zïhlte und dessen Länge mit Einschluss des ausgestreckten $9 \mathrm{~mm}$. langen Ruissels $130 \mathrm{~mm}$., dessen grösste Breite im Tordertheile des Körpers 5mm. betrug, war wohl nicht ganz vollst:indig crhalten, da das hintere Kürperende des 'Thieres offenbar etwas maceriert war und, wenn anch wohl nicht viele, Segmente verloren hatte. Auf diesen Erhaltungszustand ist wohl zum Theil, sicherlich nicht allein, das ungleiche Aussehen der vorderen und hinteren Körperstrecke zurïckzuführen. Trihrend die erste derb und fest erscheint und eine im Verhältniss zur Breite erhebliche IÜ̈he besitzt, ist die hintere Köirperstrecke schlaff durchscheinend und völlig platt zusanmengefallen; liegen auf der ersten die Elytren der Rïickenfliiche glatt und regelmässig an, so stehen sie auf der hinteren Strecke vielfach in die Höhe und sind unregelmässig gefaltet und gelinittert. Ein so weit gehender Unterschied, der gewiss mit einer ungleichen Ausbildung des Integumentes oder der gamzen Körperwand zusammenfällt, kann nicht wohl allein auf cine Terunstaltung durch Maceration zuriickgeführt werden, 


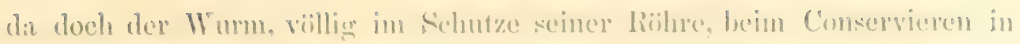

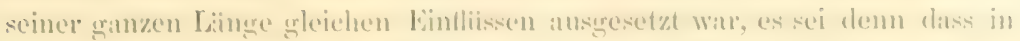

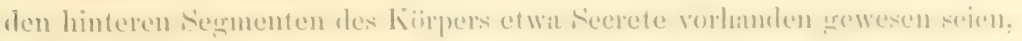

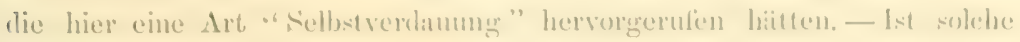
Ammanme aber wenig wathseheinlich und diirfen wir eine anch in Leben vorhandene unghele Beschatenheit in der Kïrperwand der hinteren mol

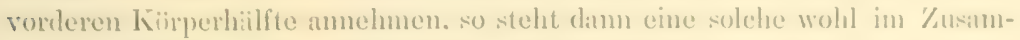
menhang mit. der hei den Aphroditeen nux hiex und bei den niehsten Verwandten rorhandenen Figenthimlichkeit, dass den Wurm Riohren bewolnt. welche er selbst verfertigt. Eine bei den eigentlichen 'Tubicolen weitgehende mit den Lebensverhiiltnissen correspondierende formverschiedenheit der vorderen und hinteren Kiirperstrecke wiirde hier ein Analogron in ungleicher histologischer Ausgestaltung der Körperstrecken finden.

Für den Habitus ist ferner der Umstand wichtign, dass tiefere Segmentgrenzen bei den wenig nur vorspringenden Ruderu fehlen, zumal auf dem mittleren Theile der Riickenfliche des derben Vorderkürpers ganz verwiseht sind. Dabeisind die Segmente kur, im vorderen Körpertheile etwa 10nal breiter als lang.

Ueber die Bildung des Kopfes und seiner Anlüinge habe ich dem in Schrift und Bild dargestellten Niehts hinzuzufïgen. - Wemm in der Beschreibung der kurzen Ruder zwei Aeste unterschieden sind, so ist das mit Riicksicht auf die beirlen Stiitznarleh und die mit diesen verbundenen Borstenbiindel geschehen. In der That ist eine Sonderturg zweier liuderiste nicht zu erkennen. Dem Bezirk des oberen Ruderastes kommen damn die ausserst feinen Harborsten zu, vergleichbar denen, welche bei den Hermioneen den Filz der Riickendecke bilden; solche Borsten sind ron Eupompe und Polyodontes gulo bekame und in gleich zu erwähnender Weise von Polyodontes muxillosus dirch Claparede beschrieben. Allein bei Eupompe ragen diese Haarborsten als kleines Bündel oder Strang mach Kinberg's ${ }^{1}$ Abbildung und Grube's ${ }^{2}$ Angabe nur wenig aus dem Ruder hervor, bei unserer Art treten sie dagegen in den Rudern der vorderen Körperstrecke nur ganz vereinzelt, damn aber sehr weithinreichend aus dem Ruder heraus. - Ton Polyodontes erwilhnt Claparède, dass er beim Oeftinen der Leibeshöhle seines Exemplares darin die grossen grïgoldenen Bor-

1 Kinlerq, Annulati a. a. O. 'Tat'. TII, Fig. 3i F.

2 Grube, Besclireibung nener oder wenig gekannter Anneliden. Archiv für Xaturgeschichte, Jahrg. 21, I, 1855, pg. 87. 
stenstrïnge gefuncten, nicht aber gesehen habe, dass dieselben aus den Rudern hervorträten. In dem hier besehriebenen Wurme schimmerten diese grossen l3orstenstränge dureh die Wand der hinteren Körperstrecke durch, traten aber hier an keinem Ruder atus demselben aus. Vermuthlich liegt hier der Fiall ror, dass die Borstenstränge als Drüsensecrete aufzupassen sind, vielleicht ist ihre Substanz beim Aufbau der Röhre verwendet.

Die Rïhre, in weleher der Wrum lag, ist doppelt so lang als dieser, am vorderen offenen Ende rerjingt, am hinteren geschlossen und hier am dicksten; sie hat eine Lïnge von $28 \mathrm{~cm}$., ist im dicksten Theile $1,6 \mathrm{~cm}$., rorn 0,7 $\mathrm{cm}$. diek. Ihr. Vorderende zeigt eine Anzahl äbereinander gelagerter ungleich weit vorragender Schichten, als wäre eine Anzahl von Röhren hier ungleich weit in einander geschoben. Diese Strecke ist von dem schwarzen Schlamm, der weiterhin die grosse Dicke der Wand bildet, frei, und erscheint von schwach lederartiger Consistenz. Die innere Oberfliiche ist völlig glatt; auf der Schnittliiehe der Röhrenwand sieht man einen Schichtenbau, wie er am Vorderende zu 'Tage tritt, nur wenig deutlich; wodurch die Schlammmassen zusammengehalten werden, weiss ich nicht.

Aus meiner Darstellung erhellt zur Genüge, dass diese Art mit keiner der bisher beschriebenen zusammenfüllt; sicherlich nicht mit dem gleichfalls aus dem Antillenmeere stammenden Acoüles Pleci (Aud. \& M.-Edw. $\left.{ }^{1}\right)$. Dann kann sie aber auch nicht mit der von Stimpson ${ }^{2}$ nur erwähnten, bei SuidCarolina gefundenen Acö̈les lupina (St.) zusammenfallen, da diese von Acoüles Pleci nur dadurch abweichen soll, dass die Elytren die Mitte des Rückens nicht bedecken.

1 Audouin et Milne-Eiducorls, Recherches pour servir ì l'histoire naturelle du littoral de la France. T. II. Annélides. P’arik, 1834. I's. 101.

2I. Stimpson, Synopsis of the Marine Invertebrata of Grand Manan. (Smithsonian Contributions to Knowledge.) Wishington, 1853. $4^{\circ}$. pg. 36. 


\title{
SIG.ILIONINA (GR.).
}

\section{SIGLLIUN (KINBEIR).}

Die Gattung fasse ich lier im Allgemeinen so, wie sic zuletzt von Girube aufgefasst ist, legre neben den amderen Kennzeichen das Haupterewicht anf 2 an Koptlappen stehende 'Tentakehn, und miehte seliaifer, als dits Girube gethan hat, die Arten, bei welehen noch ein unparer klemerer 'Tentakel hinzutritt, aus dieser Gattung fermhalten. - Es wird fiir kommende Untersuchumgen iber die Arten dieser Gattung daraul $z u$ achten sein, wie weit das alternierende Auftreten besonders gestalteter Borsten in den Rulern, wie ich es unten von dem Sigalion P'ourtulesii beschreibe, verbreitet ist.

\author{
Sigalion Pourtalesii nosp. \\ Taf. 15, Fig. 1-4; Tuf. 16, Fig. 1-10.
}

Pallidum, longissimum depressum, in parte anteriore lineare, postice attemuntum in spiram convolutum. Lobus cephalicus longior quam latior, in parte anteriore utrimcque rotundato-4lilatatus antennis 2 minutis, oculis 4 in vertice trapezii instar collocati; sulstentaculis validis elongatis.

Cirri tentaculares utrimque 2, quorum inferior superiove pranllo longior, sul, finem sularticulati, in articulo magno pinuaeformi sub Iobi cephalici margine anteriore producto facciculum setarum: capillarium gerente.

Pimarum longarum rami longitudine fere aepuales parum distantes; muns superior papilla subterminali tereti vel subfoliacen, fasciculo flabelliformi maximn enrvato setarum sericearum longissimarum sursum rergentium capillatium minime ciliatarum in extremo bifilarum; ramus inferior parum crassior quam superior labio postico rotundato papillisque 2 farum minoribus anticis, fusciculis 2 setarum, ynarum superiores et simplices infra apicem seriatim sermato-spinulosae in pimis elytro carentibus non obviae et cormpositae crassiores brevioresque in stipite extremo ant laeves aut seriatim transwerso spinulosae, articnlo terminali brevi simplici vel elongato articulato apice bihamato, inferiores tennissimae longissimaeque, stipite laevi articulo terminali longissimo fere lineari articulato apice bihamato; cirri ventrales, exceptis prioribus, ramo ventrali breviores simplices; elytra in segmentis 2.4.6 . . 24.25 . dorsum tegentia mullia suborbicularia in margine externo pinnato-lohata; tori ciliati in ramo superiore 2 we 3 ; branchiae a pinma 4ta in omnibus, longae hamatae value ciliatne magno spatina ramo sup eriure distantes e margine laterali dorsi propensae rel ex elytrophoro orientes; in primis elytro carentibus in basi frapilam cylindratam gerentes.

.Fumlort: 1 March 21, 1869, off Carysfort Reef, cast 10.5 , 60 fms. 2. March 23, 1869, off Carys. fort Reef, cast No. 1, 63 fms. 3. Off the Sumbos, Floridil, 93 fms. 
Von den 'Thieren, welche mir yon zwei frundorten vorlagen, hatte eines von 143 mu. Linge 185 segmente; ein anderes, dem wenige der allerletzten Seymente fehiten und welehes noch 136 Segmente besass, war $95 \mathrm{~mm}$. lang, im rorderen Kïrpertheil olme die linder, 3,5mm., mit den Rudern 7 mm. breit, gegen dils Kïperende olme die liuder 1,5mm., mit denselben 2,5mm. breit; an den best erhaltenen Lxemplaren war die hintere Strecke des lï̈rpers spiralig aufgerollt.

Yon den bis jetzt beschrichenen Sigalion-Arten sind drei, weil sie ebenfalls ron der Ostkiiste Amerikis stammen, mit der von mir beschriebenen Art gentuer zn vergleichen; von diesen kann die von Grube ${ }^{1}$ unter dem Namen Sigulion Antillarum erwähnte Art ansser Betracht bleiben, da diese einen mparen mittleren Fühler besitzen soll, besser also wohl aus der Gattung Sigalion iiberhaupt ausscheidet. Von den beiden $\Lambda$ rten Sigation Lidhurdsi (Kinb.) $)^{2}$ und Sigution arenicolu (Verr. $)^{3}$ liegen kurze Beschreibungen und rolstindigere Abbildungen vor:

Im Bau des Koptlappens, wie auch sonst, steht nach den Abbildungen das Sigution Pourtalesiï dem S. arenicolu näher als dem Sigution Edurardsi, welehes iiberdies nur' 2 Angenflecken besitzen soll. Bei dieser Art sind die beiden Fïhlercirren gleich lang, während bei Sig. arenicola und Pourtalesii der untere Fiihlercirrus lïnger als der obere ist. Beide Fühlercirren werden bei allen von einem grossen Borstenführenden Grundgliede getragen, welches iiber dem Ursprunge der Subtentakel steht und wohl ein weit nach vorn geschobenes Ruder darstellt, welches nach den Borsten zu urtheilen nur dem oberen Ast der folgenden Ruder entspricht.

Ueber die ausgebildeten Ruder habe ich einiges Weiteres vorzubringen, hebe zunächst hervor, dass in der Form der Elytren Sigul. Edeurdsi von Sig. aremicole und Portulesii abweicht; stimmen darin diese beiden letzteren iiberein, so weichen sie nach den Abbildungen darin von einander ab, dass die Borsten des oberen Ruderastes bei Sig. arenicola stärker als bei Sig. Poutulesii sind und dass erstere Art nur ein Wimperpolster am oberen liuderaste trägt. Leider geben uns Verrill's Angaben über weitere Einzelheiten im Bau der Ruder keinen Aufschluss.

Die dicht auf einander liegenden schlanken Ruderäste sind bei dieser Art

1 Grube, Bericht a. a. 0. pe. 53.

= Kinberg, Fregatten Eugenies Resa Zoolog. Annulat. T'ab. IX, Fig. 41.

3 Verrill, Notice of Recent Additions to the Marine Invertebrata of the Northeastern Coast of North Anerica, Part I., Procecdings of U. S. National Ituseum, Vol. II. p. 167; New England Annelicla, Transact. of the C'onn. Acal., Vul. IV., August, 1881, Pl. VII. 5. 


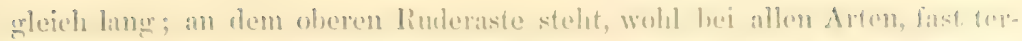

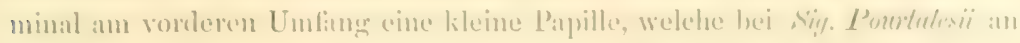

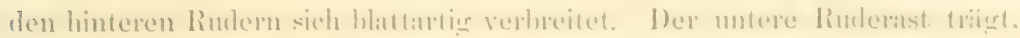

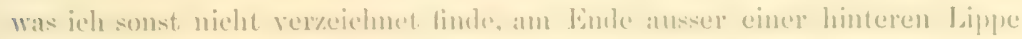

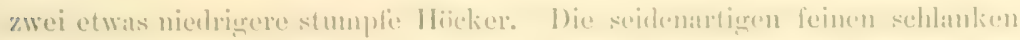

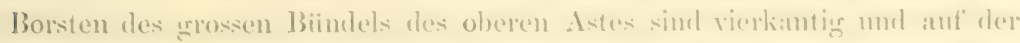

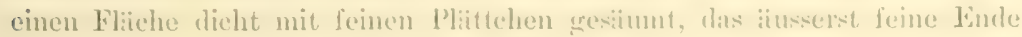
liult mit einer fast zanenenihnliehen Doppelspitze aus.

Das Bündel res muteren $\Lambda$ stes ist an den Elytrentrafenden lindern anders zusammengesetzt als an den ïhrigen. In allen liurlern stehen in diesen

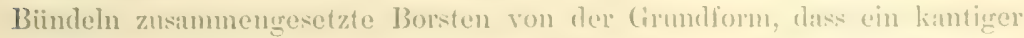
Schaft ein Endglied träigt, welches an dex Spitze in zwei fant zangenlümigr zu einander gestelle Hiekchen ansliunt; diese Form variert so, dass dicke und kurze Borsten neben schlinken und diimmen auftreten; die dickeren l3olsten stehen dam im oberen Theile des Bïndels; die arstere Form iilserwiegrt in den Rudern des vorderen Kürpertheiles und verliert sich nach hinten; bei ihr kamn Schaft und Fndglied einfach scin oder der Schaft ist am Gelenktheil stark quer gerieft; je schlanker diese Borsten werden, um so melı erscheint das lang ausgezorgene Endghlied gegliedert, un so reichlicher wird der Schaft gegen das Gelenkende hin mit quer stehenden Blïttchen besetzt, welche kammfömmig zerschlitzt sind. In denjenigen Rudern num, welche der Elytren entbehren, stehen am oberen Unfange des Biindels renige kïrzere einfache Borsten, welche mit schlanker Spitze auslaufen und fast bis ans Ende mit den kammförmig zerschlitzten Blittehen besetzt sind.

Ton den in bekanntel Weise rertheilten Elytren bemerke ich, dass die Zahl der doppelferlrigen Bliittehen, welche am atusseren Rande stehen, offenbar mit der Grösse der Elytren und also wohl dem Alter des Thieres an Zahl zumehmen; ich habe bis zu zwanzig gezählt.

Vom 4ten Rurler ab steht an allen Rudern die grosse hakenfömigg gekrümmte, auf der Coneavitit mit dichtem Bart langer Cilien besetzte Kieme hoch auf der Ruckenfliche an niedriger Erhebung oder dicht unter dem Elytron am Elytrophor. Diese Kieme trïgt, was ich bis dahin nicht erwähnt gefunden habe, an ihrer Basis eine kleine fingerförmige Papille, aber nur an denjenigen Rudern, welche kein Elrtron besitzen. Dieses Fehlen solcher Papille an den Kiemen der Elytrophoren legrt die Termuthung nahe, dass die Papille ein rudimentïrer Piickencirrus sei, dessen Felılen an den Elytrentragenden Rudern seine Erkliirung dam darin finden würde, 
dass ja das Elytron der ungewamdelte Rïickencirrus selbst ist. Anf diese Verhithnise wirk, wie auf dis oben erwihnte Vorkommen besonders gestalfoter borsten an den Elytrentragenden Rudern, bei ernenerter Untersuchmg anderer Arten besonders za achten sein.

Da Terrill die ron ilm als Sigulion uremicola beschriebene Art als Verwandte des Sigulion Buski (Melnt.) bezeichnet hat, so hebe ich herror, dass Melntosh ${ }^{1}$ von dieser Art den Mangel der Augen erwïhnt, und hervorhebt, dass die 'Terminalpapille des oberen Ruderastes an den hinteren Segmenten verzweigt sei, "like the growing antlers of the stag." Davon ist bei dem Sigution Pontalesii keine Rede. Bei Sigation Muthildue (Aud. \& Edw.) beginnt nach der Angabe der ersten Beschreiber ${ }^{2}$ die ununterbrochene Reihe der Elytren mit dem 27ten Segment; der Kopflappen trïgt keine Augen; dadurch unterscheidet sich diese Art ron dem durch Claparède ${ }^{3}$ beschriebenen Sigution squamutum (d. Ch.), welches sonst dureh Papillen, die neben den gefiederten auf den Elytren stehen, durch den Mangel ron Wimperpolstern und '/weigliedrigkeit der kleinen 'Tentakel gekennzeichnet ist. Foch ist zu erwithnen, dass das ron Grube ${ }^{4}$ beschriebene Sigation amboinensis dureh die fast zusammenfliessenden Augen, dureh ein Läppehen am oberen Ruderaste, Fehlen der Wimperpolster und wie es scheint besondere Länge der Fiedern an den Papillen der Elytren sich auszeichnet.

\section{STIIENELAIS, KBG.}

Grube ${ }^{5}$ hat zuletzt fiir diese Gattung eine Diagnose gegeben; aus der Fassung derselben wird mit Riicksicht auf die nachstehend beschriebene Art zu streichen sein, dass die ununterbrochene Reilıe der Elytren mit dem 23ten Segmente begime, sowie dass der Koplappen Augen trage.

\section{Sthenelais simplex, n. sp.}

$$
\text { Taf. 18, Fig. 2, 8; Taf. 14, Fig. 1-6. }
$$

Linearis, laevis, pallita, postice versus paullum attenunta, fere tetragona antice, subtus subdepressa; segmentis plus 120.

1 W. C. W'Intosh, On British Annelida ; Transactions of the Zoölogical Society of London, Vol, IX., Part TII., p. 391.

2 Annales iles sciences naturelles, T. XXTII, 1832, pg. 395, 441.

3 Claparète, Les Anuélicles chétopodes clu Golfe de Naples, a. a. O. pr. 100.

4 Grube, Annelidenauslente S. M. S. Gaz.Hie; ILnatshericht der Kgl. Akalemie der Wissenschaften 2u Berlin, Aurrust 1877, jw. 520.

5 Gimbe, Anmulata Semperiana, a. a. O. pg. 54. 


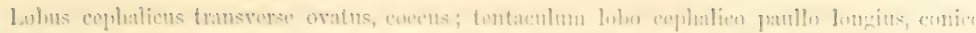

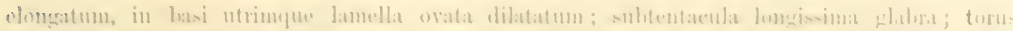

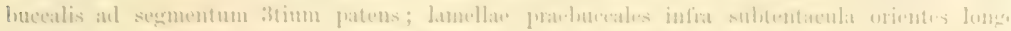

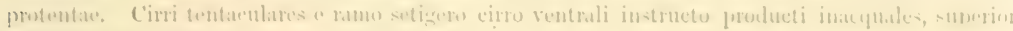
in hasi pupilla filifumi munitus inferione natur.

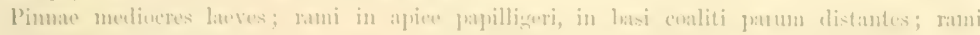

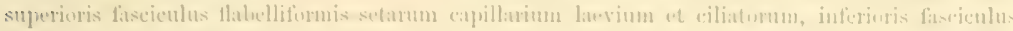

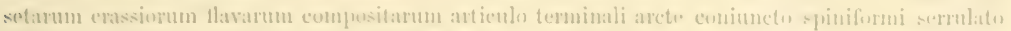

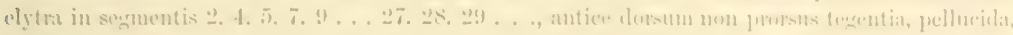

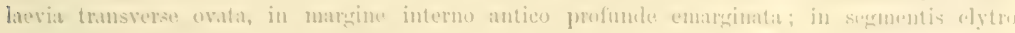

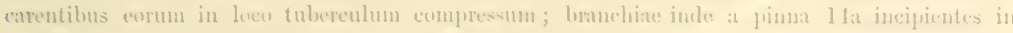

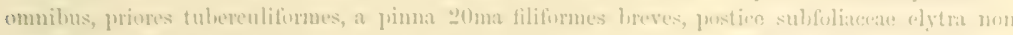
exeenlentes. Cirri ventrales, exeepto segmenti secundi majore, breves lilifurnes, l'apillat filiformis inle a pimma 33 in in momo rentrali sub cirro ventrali.

Proboscis serie papillarum 13 dorsali et ventrali, quarum medianae maiores, aperturam cingente, maxilla dorsali et ventrali bidentata, laminis maxillaribus utrimqqu 2 tuberenlorum obtusorum scrie armatis.

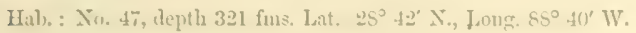

Mir liegt ron dieser Art kein ganz vollständig erhaltenes Exemplar vor; das lïngste aus 123 Rudertmgenden Segmenten bestehende Thier war $92 \mathrm{~mm}$. lang, vorne mit Rudern 4,5mm. ohne dieselben 2,5mm. breit, nach hinten bis aut $3 \mathrm{~mm}$. verschmitlert; ein anderes hatte $12 \mathrm{~S}$ Sermente, war $90 \mathrm{~mm}$. lang, vorn tnm., hinten 3mm. breit; beiden Thieren haben wohl nicht viele Segmente an Körperende gefehlt. Der Kürper ist im vorleren 'Theile auf' der Rüickenfläiche etwas abgeplattet, im Uebrigen im Allgemeinen hoch und auf der Banchseite kantig; die Segmentgrenzen treten an der Ventralfliche zumal im hinteren Kürpertheile stark hervor; die Riickenfliche ist vorn von den Elytren in der Nittellinie nicht bedeckt und erselieint ljien quer gerumzelt. Die Haut ist im Uebrigen fast glatt, nur rereinzelte kleine keulenförmige leicht abfallende Papillen habe ich gesehen; so standen an den vorderen Segmenten auf dem oberen Theile der Flanken je zwei an den hinteren Segmentgrenzen; und fast allgemein sals ich eine derartige kleine Papille auf del Ventralfaiche im Einschnitte zwischen zwei Rudern.

Der querovale Kopflappen ist augenlos; der kurze 'Tentakel, welcher hart hinter dem Torderrande des Kopflappens entspringt, trägt am schwach geringelten Basalgliede jederseits ein kleines, eiförmigres Bliittehen. Die crrossen Subtentakel reichen nach hinten gelegt bis an das 14te Ruder. Sic entspringen vor den Praebuccallamellen (cuillcrons céphaliques, Claparède). Diese gehen als durchsichtige im Allgemeinen vertikal gestellte Blitter jederseits neben dem Mundeingange von dessen vorderem Rande aus, so dass sie mediauwärts von den Subtentakeln stehen. un deren Basalstiick sie sich 
wohl herumlegen. umel nach vorn sich so weit als das erste Borstenbiindel erstrecken; ihre stellumg wirk ron den Bewegungen, welche am Mundeingange zu siancle kommen, sehr beeinthest. - Dis Buccalpolster ist lang gestreckt, doch wenig gewölbt, liings grefureht; es reicht bis auf das 3te Segment. ('lat. 13, Fig. … 3.)

Ein grosser zaplenfömiger Höeker, welcher ein ansehnliches Bïnlel capillarer Borsten liihrt, trägt die beiden Fihhlereiren, von denen der obere den unteren an Gröisse betrïichtlich ïberragt; neben dem gröisseren Fühlercirrus steht eine einfache Papille; ausserdem trüigt dieser Höcker an seiner Basis und zwar auf der. Ventrallible einen fast so weit als der Tentakel rorragenten Cirrus, den man mach seiner Stellung als Bauchcirrus bezeichnen michte.

Fiir die Ruter (Taf. 1t, Fig. 1, 2) ist das Fehlen ron Papillen auf der Flaiche anderen Arten gegeniiber charakteristisch, während die terminalen Papillen sich reichlich zumal an den vorteren Rudern entwickeln; die Papillen haben ein umgleiches Aussehen, insofem als die einen durchscheinend und wie von vacuolenartigen Räumen erfült aussehen, während andere vereinzelte grössere dunkel und undurchsichtig sind; ob diese Unterschiede vielleicht durch ungleiche, vorüber gehende Füllungszustïnde bedingt werden, kann ich nicht entscheiden. - Die Borsten beider Aeste haben die Formen, wie sie sonst ron den Arten dieser Gattung beschrieben sind (Fig. 4, 5). - Die Elytren (Fig. 3) decken den vorderen Theil des Riickens nicht, wie bei anderen Arten; sie nehmen nach hinten an Grösse zu; eine tiefe Ausrandung am vorderen meliamen Rande giebt den querovalen und glatten durchscheinenden Platten eine charakteristische Form, welche besonders stark an denen der vorderen Ruder ausgeprägt ist; dass der aussere Rand der Elytren glatt ist, wird fü die Charakterisierung der Art wichtig; bis zum 26. Ruder fallen alternierend die Elytren aus, an ihrer Stelle steht dam ein niedriger, von vorn nach hinten, fust firstartig comprimierter Hö̈ker. Kiemen habe ich vom 20. Ruder an als fadenförmige Anhäinge am Elytrophor orler an dessen Stellvertreter gefunden, nie iiber den Rand des Elytron hinausragend, an ten hinteren Rudern wohl gering erweitert; dic erste Andentung einer Kieme sah ich dagegen schon am 14ten Ruder als ein winziges Höckerchen. - Der Bauchcirrus ist an allen Rudern einfach, kurz fadenförmigg; nur am ersten zweiästigen Ruder ist er auffallend viel dicker als an den folgenden. Vom 35ten Ruder an steht auf dem ventralen Umfange der Ruderbasis, medianwärts und etwas nach vorn vom Bauchcirrus 


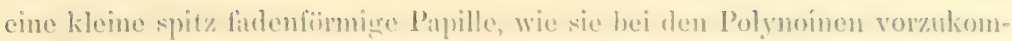
men pollegt. - IVimperpolster habe ich an den lindern nicht greselsen.

An cinem kxemplan mit vormestrektem Riissel zeigte dieser an Eingamere, dessen grösister D) duehmesser dorso-ventral lage, je eine dorsale und ventrale mediane Pippille, von denen die dorsale doppelt so laner als die ventrale war, unt dameben jerlerseits je (i kiirzere l'apillen. Hinter dem l'apjitlenkranze steht im liasseleingange je ein nedinner nit zwei starken dolchartigr spitzen Zïhnen bewelnter Kiefer, grö̈stentheils in einer nischenfömigen Grube geborgen; getrennt davon lateralwirts jederseits je eine lingrovale Platte mit einer Reihe bramer Knitehen.

In der Zusammenstellung, welehe Grube ' ron den beschriebenen Sthenelais-Arten gegeben hat, stellt sich diese Art zu denjenigen, welche glattrandige Elytren besitzen: S\%: laeris (Kogg. $\left.{ }^{2}\right)$ ron Eimeo und S\%. Luimiost ${ }^{3}$ ron den Philippinen; leicht sind beide zu unterscheiden; erstere hat grosse Augen, gegliederte Subtentakel und durchaus andere Borsten; St. Inxuriosa hat Augen, tief gefurchten Kopflappen und einfache nicht tief ausgerundete Elytren; die erste Art gehört jedenfalls gar nicht in den Verwandtschaftskireis unserer Art.

Dagegen scheint eine späiter vou Grube ${ }^{4}$ beschriebene St. incisa vom Congo, welche gleichfalls glattrandige Elytren triigt, der S\%. simplex nahe zu stehen, unterscheidet sich aber durch den Besitz von 4, allerdings undentlichen Augen, etwas kürzere Subtentakel, ein Wimperpolster an der Wurzel des Ruders, durch eine andere Form der Elytren, welche am iusseren Rande zweilappig eingeschnitten sind und durch grössere an den Seiten vorragende Kiemen.

Die ron Verrill ${ }^{5}$ beschriebenen, von Grube in seiner Zusammenstellung noch nicht bericksichtigten Arten St. gracilis, Emertoni, pictu ron der Amerikanischen Küiste unterschieden sich von dieser Art alle durch Elytren mit Papillentragenden Rande.

I Grubc, Bericht a. a. O., pag. 55.

2 Kinberg, Annulata a. 0. O., Tuf. TII, Fig. 40.

3 Grubc, Anmulata Semperiana, a. a. O., prag. 54.

\& Grube, Anneliclenausbente von S. II. S. Gazelle, Monatsber. der Krl. Akad. der Wissensch. Berlin, August 1877, pag. 519.

5 Ferrill, Proceedings of U. S. National Mus., a. a. 0. jo. 166. 


\section{EUNICIDAE.}

Die Familie eler Eunieiden, palaeontologisch als eine sehr alte beglaubigt, ist durch ten eigenartig gestalteten Kieferapparat wohl begrenzt. Die von mir rorgeschlagene Zerlegung dieser Fimilie in labidognathe und prionognathe Lunieiden ist insoweit von den meisten Autoren anerkannt, dass die Gruppe der Lunicene babidognathe und prionognathae, wenn anch theilweise mit anderer benemnung, zwar angenommen sind; aber iiber die 'Lugehörigkeit einiger Gattungen, auf' deren Besonderheiten ich von Anfung an hingewiesen hatte, zu der einen oder anderen Gruppe, gehen. die Meinungen nuseinander; wie beide Gruppen etwa zu verkniipfen sind, oder in welchem Verhiniltniss sie zu einander stehen, das ist bislang nicht eingehender discutiert. - Da ich unter den nachstehend beschriebenen Thieren einige bis jetzt ungeniigend, andere bislang gar nicht bekannte Formen behandle, so hebe ich hier Einiges hervor, was fiir die Systematik der Gruppe Bedeutung haben diurfte.

Dass die Staurocephaliden in der Verwandtschaft der prionognathen Euniceen eine Sonderstellung haben, ist allgemein anerkannt. Zweifelhaft dagegen ist die Stellung der Gruppe Lumbriconereiden, welche ich als E. labidognatha nuda hingestellt hatte, und deren Verhïltniss zu den nackten prionognathen Euniceen (Arnbella u. a.); wïhrend die Beziehung der letzteren zu den Cirren und Fïhler tragenden Prionognathen (wie IIalla u. a.) ebenso klar zu liegen scheint, wie die Zusammengehörigkeit aller derjenigen Gattungen zu einander, welche ich als Eunicea labidognatha tentaculata zusammengefasst liabe.

Diese beiden letzten Gruppen werden nach den Anhängen des Kopflappens, der Buccalsegmente und der liuder in Gattungen zerlegt: die bei Labidognathen und Prionognathen nachgewiesene Anwesenheit der Nackenwïlste, als welche ich auch die eigenthümlichen Anhänge am Koptlappen des Staurocephalus ansehe, ist fiir die Verwandtschaft aller Formen unter einander bedeutungsvoller als die nach Zahl und Form wechselnden Tentakel, Subtentakel und Füllercirren; diese letzteren sind nun bei den Labidogna- 
thatentaculata in soleher Wrise vorhanden, daks sich livihen in der \%acame menstellumgr der Gattungen orhen lasien, welehe bei den driehst contfilteten formen der Reihentulge entsprechen, in weleher diese Anliainge in der (Ontogenie sich einstellen; dabei ist eine Pamallelstellung der formen unverkennbar. Fir die Prionomatha ist das nicht mit gleicher Evideny, durehzufiilnen.

Will man die form des fiuders und seines Anhänge, mnter denen die Borsten hesonders wiehtig erscheinen, fuir dic systematische Gruppierung verwenten, so erhebt sich die Frage, wie das Ruder überall hier anfzufasen ist, ob ein- oder zweïistigg. Die Stamocephaliden haben nach der alten Auffissumg zweiistige, alle iibrigen Euniciden einistige liuder; gregen eine solche Auflassung liesse sich nun die fist iberall nachgewiesene Anwesenheit eines in der Wurzel cines Riickencirrus oder an einem dementsprechenden Orte eingeschlossenen Borstenbindels oder eine: einzelnen Borste anführen, indem man darin das Rudiment eines riiekgebildeten dorialen liuderastes erblicken kömnte; es wäre damn das Rudes der Euniciden mit Ausmalıne der Staurocephaliden als ein rudimentïr zweiästiges aufzufassen; da nun den Staurocephaliden die eingeschlossenen Borsten nicht fohlen, :o miisste man weiter ammehmen, dass das Ruder dieser 'Thiere durch eine Umbildung des ludimentuir zweïistigen Ruders sich derartig entwickelt hiitte, dass seine beiden Aeste nur Theile eines ventralen Rurlerastes wären. Dass die anch sonst ausegezeichnet entwickelte Form dieser Thiere dem nicht widersprïiche, kamn zugegeben werden; zur Zeit fehlt es aber an Material, um die $\Lambda$ uflassung des Euniciden-Ruders als eines ursprïnglich zweiïstigen geniigend zu stiitzen.

Die an dem Ruder weiter sich findenden Anhänge können sich bei morphologiseher Differenz als physiologisch gleichwerthig erweisen; ganz besonders zeigrt sich das in der Ausbildung ron Theilen, welche nach dem Reichthum an Blntgefüssen als Respirationsorgane anzusprechen sind: als solche treten eimmal die mit dem Rückencirrus eng verknippten selbständigen Kiemen auf, Organe, welche in der Ontogenie am spiitesten erscheinen, bei nah rerwandten Formen (Diopatra, Onuphis) vorhanden sind oder fehlen, auch sexuelle Differenzen zeigen (Eunice norergicu u. a.), und dalier meines Erachtens in taxonomischer Hinsicht geringe Bedeutung haben. - Der Riickencirrus selbst kann flïchenhaft sich erreitern und in dieser Erweiterung den Blutgefiissen netzartige Ausbreitung gestatten (Lrsarete, Halla, Oenone) und schliesslich ist eine Ruderlippe so grefissreich, dass sie uns respirationsfähig erscheint (Lysarete brasiliensis); das erreicht die Höhe der Entwicklung damit, dass diese Lippe fast in ähnlicher. Weise in gefässhaltige 
Blittehen oder Fiden zerschlitzt erscheint (Ninoe) wie die Kiemen mancher Eunice-Arten als viscularisierte Fïden oder Strahlen des Rüickencirrus erscheinen.

Die Borsten, welche in den Rudern auftreten, sind für die Systematik her kleineren und grö̈sseren Gruppen sicherlich zu verwerthen, dabei ist aber zu beachten, dass die Borsten ebensowohl nach dem Alter der Individuen (Lumbriconereis) in der Form wechsehn, wie sie in den verschiedenen Strecken des Körpers ungleich gestaltet sind. - leh will hier hervorheben, dass die bei den T'entakeltragenden Labidognathen vorhandenen Meisselborsten mit der kammartig zerschlitzten Schneide eigenthiimlicher Weise bei T'ubificiden sich wiederfinden. - Die mit grossem gekriimmten Endhaken auslaufenden Borsten in den Rudern des Rhamphobrachium bilden eine in der Familie bis jetzt isoliert dastehende Erscheinung, fallen vielleicht mit besonderen Lebensverhältnissen dieser Röhren bewohnenden Thiere zusammen.

Fiir die Gruppe der Tentakeltragenden Labidognathen stellt sich leicht mit der wachsenden Anzahl der Anhänge des Kopflappens für die höheren Formen eine Doppelreihe auf, in welcher parallel neben einander Gattungen mit und ohne Fühlercirren stehen, und bei denen Kiemen auftreten oder fehlen. Eine Uebersicht dieser Gattungen soll das nachstehende Schema geben, welches gleichzeitig als Ausdruck der Construction einer phyletischen Descendenzreihe aufgefasst werden kann, in welcher dann mehrfache Verkniipfung der einzelnen Gattungen untereinander in der Weise ausführbar ist, dass die Gattungen ohne Fiihlercirren als Vorliufer derjenigen mit Fühlercirren angesehen werden; ohne dass sich derartige Verknüpfungen in einer oder der anderen Weise besonders belegen liessen. ${ }^{1} \quad$ Die höber entwickelten Gattungen, besonders Eunice, Onuphis und Diopatra sind die in der Jetztzeit am meisten entfalteten, artenreichsten; vou diesen giebt Diopatra den Ausgany-punkt fiir Heptaceras mit langen Stimfiihlern und Rhamphobrachium mit besonderer Ausgestaltung der vorderen Ruder. Lysidice, Amphiro und Nematonereis sind artenarm.

2 Wie wenig gesichert der Boclen für dic Speculation ist, nb wir die Entwicklung einer Formenreihe bei den Euniciden durch eine Entfaltung oder Verkümmerung der Anhänge des Kopflappens annehmen sollen, ergiebt sich daraus, dass wir einmal Jugendzustände von Euniciden kennen, welche bei fortsehreitender Entwicklung die Anhänge des Koptlappens erhalten, während Ophryotrocha (Clap. Meczn.), nach Kiefer und Brorsten zu den labilosnathen Eunicilen zu stellen, mit fortschreitender Entwicklung eine Rerluction der Anhänge des Kopflappens erleidet. Mörlicherweise handelt es sich allerdings hierbei nur nm Larvalorgane, welche verschwinden, um vielleicht spiter auftretenden Anbängen des Kopflappens Platz zu machen. Das Urtheil über diese Wurmform ist wolı noch in suspenso zu halten. 


\begin{tabular}{|c|c|c|c|c|}
\hline \multicolumn{3}{|c|}{ 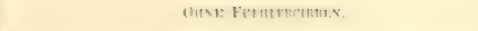 } & \multicolumn{2}{|c|}{ 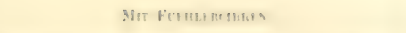 } \\
\hline $\begin{array}{l}\text { Zablither } \\
\text { Teutithel. }\end{array}$ & Olune lifiomess. & Mit Kintuet. & Ohue lílnuen. & Mse lifensens. \\
\hline 7 & $\begin{array}{l}\text { Onmplis sp. } \\
\text { (l'aronuphis). }\end{array}$ & Onuphtis sp. & $\begin{array}{l}\text { Diopratra EIs. } \\
\text { (l'atrudiopatra). }\end{array}$ & 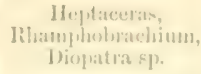 \\
\hline 5 & l'aramarpllyysa. & Marplyysa. & Nikidion. & Eunice. \\
\hline 3 & Lysiltice. & Amplhiro. & $. \quad . \quad$. & 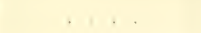 \\
\hline 1 & Nematonereis. & . . . . & . . & . . . \\
\hline
\end{tabular}

Diese Aneinanderreilhung geht nicht, wie man gerne construieren wiircle, von solchen Formen aus, welche keinerlei Anhänge des Kopilappens besitzen, wiewohl dafiir ja die Gattung Lumbriconereis als eine gleichfalls labidognathe sich darbietet. Allein in der Mund- und Kieferbildung aller LumbriconereisArten sind Eigenthïmlichkeiten gegeben, welche allen bis jetzt bekannten Tentakeltragenden Labidognathen abgehen; die paarige Zahl der Stiicke im Oberkiefer, sowie die grossen Reibplatten und die Ausbildung eines dem 2ten Buccalsegmente angehörenden Mundfortsatzes: das spricht dafüir, in dieser artenreichen Gattung nicht eine Form zu sehen, aus welcher unittelbar die Tentakeltragenden Labidognathen herzuleiten sind. Empfehlenswerther erscheint es, dieser Gattung eine besondere Stellung zuzuweisen, damit auszudrücken, dass hier Formzustïnde gegeben sind, welche nicht die Entwicklungsrichtung der Labidognatha tentaculata enthalten. ${ }^{1}$ - Dagegen ist wohl nicht zu beanstanden, dass die Gattung Ninoe aus der Gattung Lumbriconereis abzuleiten ist durch Entfaltung und Lappenbildung der Ruderlippe. Und als labidognathe Form bezeichne ich ferner die Gattung Lysarete (Kinb.) und leite sie, wie unten ausgeführt ist, nicht nur in Hinsicht auf die Kieferbildung, sondem auch wegen des processus oralis von Lumbriconereis

1 Welche Stellung die Gattung Paracticus (Lerins,) cinnimmt, wage ich trotz der eingehenden Darstellung, welche Lerinsen (Videnskaluelire Jeddelelser fri ilen naturhistoriske Forening i hjфluenbarn. 1879-S0, pg. 11) daron gegeben hat, nicht zu entscheiden, da einzelne wichtige Punkte wie die Billung des Mundeing:nges nicht berücksichtigt sind. 
ab: damm nimmt sie allerdings ebensowohl wegen der einfachen Borsten wie wegen dor 'T'ontakel und blattörmigen litickencirren eine Stellung ein, in welcher sie durehans an die Gattung I Ialla erimert; num steht die Entscheidumg ans, ob hier zwischen Halla und Lysarete eine Parallelentwicklung von mgleichen Ausgangrspunkten, oder in der Lysarete eine Uebergangsbildmng von den labidognathen Lumbriconereiden zu den Prionognathen und zwar damn zu den höher organisierten, wie IIalla, anzunehnen ist.

Und hier grestaltet sich fir die speculative Betrachtung und Construction der Verwandtschatten die Siche so, dass man entweder in den prionognathen Euniciden ohne Fiihler und Cirren einfachste Ausgangsformen sieht, von welchen die Fibler- und 'Tentakeltracenden abzuleiten sind, oder dass inan von den hüher organisierten Formen, wie Ifalla, ausggeht, und durch $\Lambda n$ nahme von Rerhetionen zu den emfacheren Formen wie Arabella kommt. Es ist zur Zeit nicht möglich, Beweise für die eine oder andere Auffassung beizubringen; doch möchte ich auf einiges hinweisen. Das ist zunächst das Verhalten der Buccalsegmente zu der Mundöffnung bei einigen der prionognathen Gattungen. So tritt es bei der Oenone diplyyllitic in der Weise auf, dass es ganz an Lumbriconereis erinnert; so kömnte man sich vorstellen, dass die Erweiterung des ersten Buccalsegmentes gegen die Mundöffunng bei Halla oder die Lïngsfurchen auf dem Mediantheile des ersten Buccalsegmentes bei der unten beschriebenen Aracorta mullidentaia, die ganz an die Lingsfurchen eines processus oralis erimnern, gleichsam Ueberreste eines solchen Mundfortsatzes seien, die, während eine ringsum einschneidende Segmentfurche die beiden Buccalsegmente völligr trennte, sich erhalten hätte. Dann wïrde die Reduction der Anhänge des Koptlappens und der Ruder bei der Trennung und Egalisierung der Buccalsegmente sich gleichmässigr mit oder nach der Ausbildung der prionognathen Oberkiefer und des eigenartig gestalteten und gelagerten Unterkiefers eingestellt haben.

Darin dass die prionognathen Euniciden und so auch Lysarete gegenüber den Lumbriconereiden nur einfache und nicht zusammengesetzte Borsten tragen, kïnnte man ein Zeichen aufsteigender Entwicklung sehen, insofern bei den höchst organisierten Labidognathen die zusummengesetzten Borsten weggefallen sind. Dass dann auch in dieser Hinsicht die Staurocephaliden wieder eine ganz besondere Stellung einnehmen, verdient angemerkt $\mathrm{zu}$ werden.

Stellen sich in solcher TVeise für die Erkemntniss der verwandtschaftlichen Bezichungen der Eunicidengattungen zu einander melifiache Probleme ein, 
so verweise ich schliesslich daraut, dass eine Liisung derselhen mon wohl nather gelegrt sein wirkl, sobathl ms von diesen 'Thieren, besomeles von den Prionograthen, die Jugendzustainde bekannt sein werden; hice besteht zur Zeit noch viillige Unlienntuiss.

Ueber die Ferwendung der Formen des Kielerapparates fiir taxumomische Zwoeke möehte inh hier noch ein Wort himaliigen. Zunichst ist mir hei der Musterumg zahlocicher buniciden-kieler entgegengetreten, dass die ungleiche Bildung der P'latten des Unterkielers ein gutes Merkmal sowohl bei der Characterisirumg der Arten, wie bei Kusammenfassumg derselluen zu Gruppen darbieten möchte; bei artenreichen Gattmgen, wie kinice und Lumbriconereis, wiirde das wohl eine gentuere Prifumg rerdienen. - Diese Unterkieferplatten gewilhren aber ankererseits darin ein Interesse, dass sie, wihrend sie bei den in den jurassischen Schiefern Solenhofen's erhaltenen Eunicen in einer Ausbildung, wie bei den jetzt lebenden Formen vorhanden sind, zwischen den von Hinde in den silurischen Schichten gefundenen und beschriebenen Wurmkiefern, unter welchen Stiicke des Oberkieferapparates von Funiceen reichlich sich rorfunden, his jetat völlig rermisst werden. Da nun diese von Hinde beschriebenen Kieferstiicke keine andere Deutung zulassen, als dass wir es in ilmen mit Ammeliten-Kiefern zu thun haben, so ist die Ammahme wohl nicht abzuweisen, dass neben den Kieferstiicken, welche zur Silurperiole dem Oberkieferapparat Eunicilen-artiger Thiere angehürten, solche Platten cines Lnterkiefers: wie sie den mesozoischen und recenten Euniceen zukommen, nicht gebildet wurden. Danach könnte man cine steigende Entwicklung dieser 'Thiere in der Ausbildung des Kieferapparates erblicken, und wïrle eine hïchste Stufe in dieser Richtung darin zu finden haben, dass bei der weiterhin beschriebenen Vicidion brevis (n. sp.) eine unpaare Kieferplatte am dorsalen Umfange des Einganges zum Kiefersack durch Verdickung der Chitinatuskleidung gebildet ist. - Sind wir aber zu der Annahne von Euniciden reranlasst, welche des Unterkiefers entbehren, so ist es von reiterem Interesse darauf hinzureisen, dass bei den Rotiferen, in welchen ich Larvalformen aus dem Kreise der Inmeliden sehe, Formen, wie Asplanchna vorkommen, deren Kaurpparat das getrene Abbild eines labidognathen Euniciden-Oberkiefers darstellt, ohne den dazugehürigen Unterkiefer, wảhrend Larvalformen der Euniciden, als welche ich Ophryotrocha (Clap. Meczn.) auffasse, den Ober- und Lnterkieferapparat neben cinander aufweisen. 


\title{
RLAMPIOBRACHIUM, n. gen.
}

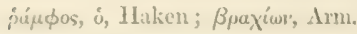

Ditlent a Diopatm pinnis tribus prioribus a ceteris valde discrepantibus foliaceis permagnis antrorsum ulta luhum cephalicum longo provectis, fere imbricatis, setas pancas longissimas pinnas ipsas permultum superantes simpliecs rectas in apico lamato curvatas gerentibus.

\section{Rhamphobrachium Agassizii, n. sp.}

$$
\text { T'uf. 1\%, Fig. 1-5; Tuf. 18, Fig. 1-9. }
$$

Brevius vermiforme in parte antica teres, postice versus paulum depressum, utroque attenntum, brunneum seu pallitum vix iricolor, segmentis plus 54, anterioribus brevioribus minus quam posterioria seiunctis.

Lobus cephalicus coecus, tentaculis maxima parte vecultus; tentacula posteriora ex articulo basuli anmulato conico-elongatia haud longa, impar et media fere aequalia externis paulium longiora, pinnas anteriores vix superantia, al segmentum btum paene protenta; tentrcula anteriora sese tancentia parva subglobosa laevia; subtentacula vicina sessilia globnsa. Segmentum buccale integrum, longituline proxima aequans; cirri tentaculares conico-elongati articulis tentaculorum basalibus longiores, lubum cephalieum non superantes. Segmenta pinnigera anteriora quater, media et postien chuplo longiora quam latiora.

I'innae priores tres inter se fere aequales compresse foliaceae, ter longiores quam latiores, fere imbricatae, sincula in margine libero anteriure lobulos 3 triangulares minutos labiumque cirriforme longius subconicum gerens; cirri dorsales e margine pinnarun superiore articulo basali laevi orientes subconici pimnam paullum vel non excedentes; cirri ventrales sub pinna basim orientes, pinna breviores subconici; setae paucie lungissimae antrorsum convergentes brunneae filiformes graciles, in scapo quadrilatero biseriatim sparse ciliato sub finem oblique striato unguiculi instar lamatie.

Pinnae ceterae parum a latere prominentes conicae obtusae labio postico segmenti 5ti maiore deincle mox omnino evanescente; setae capillares acutae sub apicem late limbo subtilissime striato alatae, pinnarum anteriorum breres, posteriorum multo longiores, corneo-brunneue; scalpratae longae pellucidae acie lata breviter pectinati ; aciculae pinnarum anteriorum obtusae apice parum curvato, posteriorum apice fortiter biclentato obtecto.

Cirri clorsales subconici sen filiformes laeves pinnam superantes. Cirri ventrales, excepto pinnae 4 tre conice elongato, toriformes anteriorum subglobosi deinle transverse oblongi humiliores, a pinna 17 ma evanescentes.

Branchiae in pinuis anterioribus 10 sel 16 nullae, ceterae cirro dorsali paullum longiores, radios, maximas 4 , in rhachile crassiuscula spirae in modum collocatos gerentes.

Maxillae corneae in marginibus partim obfuscatae; fulcra lata; I breviter hamatae; II 8-8, III longa 7 , IV vix eneullatae $6-8, V$ 1-1.

Laninae ventrales corneae, maxillas longitudine aequantes; vix connexae, postice parum divergentes elongatae rectae; partis liberae nitide albidae acie tridentata.

Tubus postice clausus papyraceus tenuis flaccidus cylindratus, limo et foraminiferis aliisque testarum fragmentis parce obductus.

Fundort : 1. Fel,. 11, 1869, off Marquesas, cast Xo. 6, depth 333 fms. 2. March 23, 1869, off Carysfort lieef, cast No. T, depth 351 funs. 3. March 31, 1869, ofl Carysfort Reef, cast No. 4, depth 349 fms.

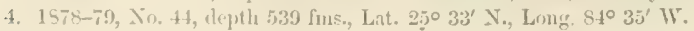




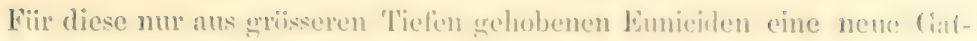
tungr zu errichten, veranlasst mich die eigenatige Ausrestaltume, welele die drei vorderen liuderpatre besitzen. Nach seiner fiesammbilelumg stellt

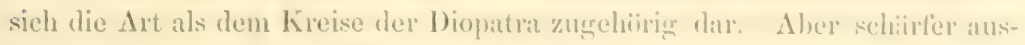
gesprochen als bei diesen Thieren es der Fill ist, zeight der kiirper different grestaltete Strecken, indem einerseits, bei verschiedenen lixemplaren allerdings ungleich stark ausgepriigt, mit dem Auftreten der Kiemen sich die serrmentgrenzen vertiefen, die Ruder weiter von einander getrent archeinen. dabei aber im Allgemeinen die Form, welche sie an den vorhergehenden Segmenten besitzen, behalten, nu dass die queren und flachen Polster, als: welche die Bancheiren erscheinen, almïhlich verschwinden; withend andererseits in viel bedeutsamerer Weise der von den drei ersten Rudertmgenden Segmenten gebildete Körperabschnitt durch die grewaltige Entwicklung seiner Anhänge vor der hinteren Kürperstrecke sich anseichnet. Fine besondere Ausristung der ersten Ruder vor den folgenden ist bei den Diopatra und Onuphis-Arten bekannt und kamn vielleicht mit der Lebensweice der Thiere, mit dem Bewohnen fester Röhren in 'Zusammenhang grebracht werden. Auch eine Verlängerung dieser vorderen Ruder findet sich z. B. bei Diopatra quadricuspis (Sars). So ist die Gestaltung, welche diese Ruder bei Rhamphobrachium besitzen, gleichsam eine Steigerung dessen, was in anderen Arten angedeutet ist; aber diese Steigerung ist eine gewalticge, so dass die grossen von hinten nach vorn blattartig zusammengedrickten Ruder mit ihrem Ursprung den ganzen seitlichen Unfang ihrer hohen Segmente einnehmen, und nach vorn gerichtet weit iiber den Kopflappen, zum Theil iiber dessen Anhänge hinausragen, diesen so ron den Seiten her umfassen, dass sie ihn zum Theil verdecken. Mit solchem Auswachsen der blattfürmigen Ruder ist der Rïickencirus ron seinem gewöhnlichen Standpunkte iiber der Ruderbasis gleichsam verschoben und steht auf rer oberen Kante der Ruder etwa auf deren halber Lïnge. Dass die Bauchcirren hier lïnger als an den hinteren Rudern sind, an welchen sie zu flachen, zuletzt ganz verstreichenden Polstern verkiimmern, ist eine bei der granzen Gruppe wiederkehrende Bildung. Eigenthümlich sind dagegen die grossen weit ïber die Ruder hinausragenden Borsten; dass ich sie nicht in allen Exemplaren finde, erkläre ich aus ihrer Spröde und Bribligkeit; ob ihr Auftreten auch an ein gewisses Alter gebunden ist, kamn ich nicht entscheiden, da die kleineren Thiere, bei denen allen sie fehlten, dieselben anch durch Bruch verloren haben kömnen. Der vierkantige mit zrei Reilıen weitlüufig- 
gestellter IIiirchen bestehende Schaft liiult mit einer grossen lakkenförmig gekriimmten Enelspitze aus: das ist eine Gestalt, welche wenn sie auch an die acieulafirmigen frei rorragenden borsten aus dem ersten Ruder mancher Diopatra, z. 13. der Diopulra Pourtulesii erimnert, doch meines Wissens bis jetzt bei Euniciden nicht beobachtet ist.

Zu der so gekennzeichmeten Gattumg möchte ich damn als eine zweite Art

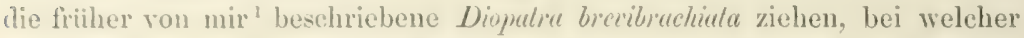
gleichlialls die drei vorderen Ruder stark vergrössert, wemn auch nicht so lang und so stark blattlörmig abgeplattet sind wie bei Rhamphobrachium Agussizï, in gleicher Weise den lïickencirrus und auf der Vorderkante papillenartige Lippen tragen; bei den von Rhamphobrachium brevibrachiatum ron mir untersuchten Exemplaren habe ich allerdings die so charakteristischen langen Hakenborsten dieser Ruler nicht gesehen; ich vermuthe, dass dieselben in ihnlicher Weise wie bei mehreren Exemplaren des $R / h$. Agassizii nur verloren gegangen sind. Im iibrigen verweise ich auf meine frihhere Beschreibung des Rhumphobrachium (Diopatra) brecibrachiatum, aus welcher die habituelle Uebereinstimmung mit die specifische Verschiedenheit ron IRhamphobrachium Agassizii hervorgeht. Die den Kopflappen nicht iiherragenden vorderen 3 Ruder und der Besitz zusammengesetzter Borsten kennzeichnen das Rhumphobrachium brevibrachiatum leicht von der westindischen Art. Dass beide Formen iihnliche Röhren bauen, und dass, was bemerkenswerther ist, beide Arten Bewohner der Tiefsee, Rh. breribrachatum aus 725 Faden Tiefe, sind, will ich zuletzt hier hervorheben.

Weniges habe ich zur Ergänzung der vorstehenden Beschreibung hinzuzufügen; zunächst was die Grösse betrifft. Ich habe kein ganz vollständig erhaltenes Exemplar gesehen, doch vermuthe ich, dass bei einem Wurme, den ich aus seiner Röhre herausschälte, nach der Verjüngung des Körpers und dem Aussehen der letzten Segmente zuschliessen, hier nur sehr wenige Segmente gefehlt haben. Dies Thier war $44 \mathrm{~mm}$. lang, an dem grössten Theile des Körpers nicht ganz 2,5mm. breit und hatte 54 Segmente; dass die Thiere grösser werden, geht aus einem $23 \mathrm{~mm}$. langen aus 20 Segmenten bestehenden Exemplare, ohne IIinterende, hervor, welches $5 \mathrm{~mm}$. grösste Breite hatte, vorn bis auf $3,5 \mathrm{~mm}$. rerschmälert war. Danach kamn man annehmen, dass die Zahl der Segmente auf $60-70$, die Körperlïnge bis auf $80-90 \mathrm{~mm}$. steigen kann. - Die Dimensionen der Fühler und Cirren

1 Beitrïge zur Kenntniss der Vertical rerbreitung der Borstenwürner im Meere, Zeitschrift für wissenschaftl. Zoologie, Bd. 25, 1875, pag. 21-19, Taf. III, Fig. 11-21. 


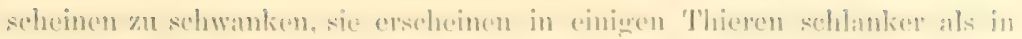

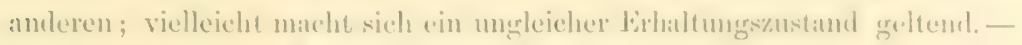
Dis duftreten der kiene varient; bei dem eben erwilunten dickeren Thiere stand die erste Kieme am 17ten Ruder, leci slem um die Jailfr. schmäleren trat sie schon am 11 ten linder anf; bei den fist granz crialtchen Thiere trugen auch die letaten segmente noch einzelne schlanke Kiemenfirlen.

DIOPA'TRA ( IUD. \& M.-EnW.) QTIFGS.

Ich rerwende die Bezeichnumg Diopatra und Onuphis in dem Simne, wie es anch Quatrefinges gethan hat, indem ich auf die Anwesenheit oder das Fehlen der Fïhleremren Gewicht lege; und da ich es füir nicht geboten erachte, füir die Omuphis tubicolu (Miill.), welche Audonin und Milne-Lidwards zu ihrer Gattung Onuphis stellten, eine neue Gattung (Iyalinoecia) zu crrichten, so liegt für mich auch kein formeller Grund vor, von dieser Benennung abzugehen.

Diejenigen Arten, welche keine Kiemen besitzen, kann man wie die gleichen Arten von der Gattung Onuphis, in Untergattungen zusammenfissen, für welche sich dann die Bezeichnung Paradiopatra resp. Paronuphis empfiehlt.

\section{Diopatra Eschrichtii (OFRs.).}

Onuphis Eschrichtii, Oersteel, Grönlants Ammulata torsibranchiata, Kjфbenharn, 18 13, pg. 20.

Fundorte : 1. May 11, 1868, cast No. 2, iepth 152 frus. 2. May 9, 1568, cast No. 14, depth 15t fims.

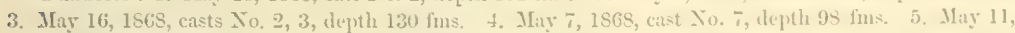
depth 119 fms., 134 fus.; May 16, cast No. 16, iepth 13s fus. 6. April 21, 1869, wil Key IV est, cast No 5,

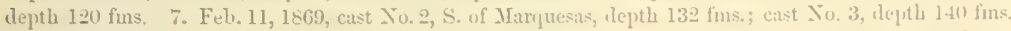

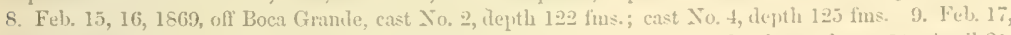
1869, S. IV. of Sand Key, cast No. 2, depth 125 funs., 139 fms.; cast No. 4, depith 325 fmi. 10. A rril 21 , 1569, of Key Test, cast No. 1, depth $135 \mathrm{fms}$, $140 \mathrm{fms}$; east No. 2, depth 140 fims. 11. May 8, 1869, off Alligatur Reef, cast No. 10, depth 118 fins, ; cast No. 13, dejth 136 fims. 12. May T, olf Temuessed Reef, crst No. 3, depth S.J fms. ; cast No. 5, depth 114 fus. ; cast No. (j, depth 115 fums.

Diopatra Eschichtii (Oerd.), wahrscheinlich doch identisch mit der Omphis conchylegu (Sars), ist mit ihren Rölıren an manchen der oben angefïhrten Localitäten sehr häufig, oft in grossen Mengen vorhanden. Dass die durch die aufgeklebten Conchylien-Fragmente so charakteristischen Röhren in der That von diesem sonst aus dem Nordmeere bekannt gewordenen Wurme erbaut werden, davon ïberzeugte ich mich durch Vergleichung der 
Thiere mit Gixmplaren, welche aus Grinland stammen. Aber alle mir vorlienenten libhen orreichen ebensowenig wie die wenigen ganz erhaltenen 'Thiere, welehe ich in ilnen faud, clie Grösse der aus den nordischen Meeren stammenden Exemplare, eine Bestitigung der hïufig gemachten Beobachtung, lass aretische marime Thiere Riesenwuchs erreichen gegeniber den groichen in wïmeren Meeren erwachsenen Individuen. Ein vollstindiges Exemplar aus 34 Segmenten hestehend, war $16 \mathrm{~mm}$. lang, mit Rudern $2 \mathrm{~mm}$, olmo dieselben 1,5mm. breit, und zwar mit Ausnahme des Körperendes ziemlich gleichmissig in der ganzen Linge. - Für die geographische Verbreiturg ist diese Art deshalb von Wichtigkeit, weil wir in ihr eine Form kennen lemen. welche an der amerikanischen Ostkiiste bis nach Florida verbreitet ist und hier in mässiger 'Tiefe hïufig vorkommt, während sie an den europäischen Kiisten nur im nördlichen Gebiete auftritt.

\section{Diopatra Pourtalesii n. sp.}

$$
\text { Tof. 19, Fig. 6-10; Trof. 20, Fig. 1-6. }
$$

Convexa postice versus parum attenuata, segmentis circa 50. - Lobus cephalicus rotundatus; tentacula posteriora in articulo basilari brevi amnulato longissima, simplicia filiformia, impar medianis non ita multum, externis ter longius; tentacula frontalia cylindrata laevia, articulis tentaculortum posteriorum hand Iongiora, vicina; subtentacula sessilia toriformia fere globosa distantia ; ocuii 2 brunuei post tentacula mediana collocati.

Segmentum buccale perbreve, proximo pinnigero triplo fere brevius; cirri tentaculares graciles lobo eephalico breviores a linea mediana remoti.

Segmentum pinnigerum primum proximis dimidio fere longius, hnec quater latiora quam longion.

Pinna prima elongata antrorsum provecta tentacula frontalia fere aequans, labiis 3 crassis rotundatis, cirro dorsali brevi filiformi subterminali, setis aciculaeformibus crassis in apice curvato tridentatis. I'innae ceterie conicne postice versus sensim longituline decrescentes, anteriores antrorsum, posteriores a latere protentae, lahio terminali conico-elongato, anteriorum pinna longiore, posteriorum breviore mox evanescente; setae simplices Iongae in parte terminali brevi curvata alato-dilatatae flavidae, tenerae salpratae; acieulaeformes longae brunneae apice bidentato obtecto. Cirri dorsales filiformes graciles, segmenti latitudinis dinidium aequantes sive superantes in media pinna collocati; cirri ventrales, exceptis 3 prioribus conicis, toriformes fere semiglobosi, deinde huniliores, a segmento $10 \mathrm{mo}$ vix conspicui, - Branchiae in pinnis, 7 vel 9 prioribus posticisque 6 exceptis, omnibus graciles pellucilae, maximae in branchiolis dichotomis fila terminalia 8 gerentes.

IIaxillac corneae in marginibus nigrescentes; fulcra lata ; I. eurvatae II. sinistra apice hamato, in acie 10 , dextra non hamata 9 ; III. longa 9 . IV. cucullatae dextra 13 , sinistra $10 ;$ V. 1.1. Laminae ventrales postice distantes longe triangulares in maxima parte nigritae, in partis liberae albae nitidae acie oblique truncata acute bi- vel triclentatac.

Tubus qunad animal magnus, compressus membranacens candidus, utrimque in margine spongiarum spienlis longinribus, testis foraminiferarum grandium molluscorumque rariorum saepe interris aliisque rebus sparsin obsitus. 


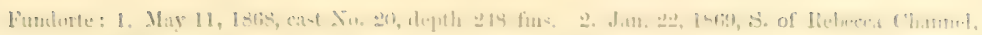

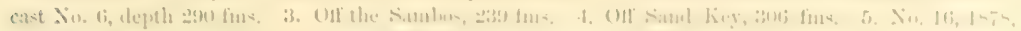

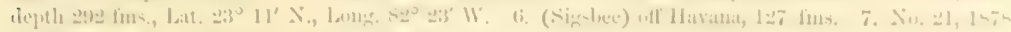

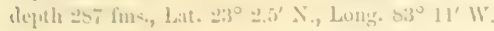

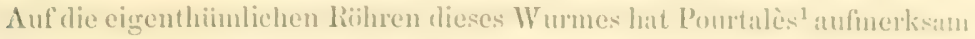
gemacht; doch erhielt er von den Wrimern nur Bruchstiicke; nor liegren wenige ans den libhren heransgenommene bixemplare vor, die meisten von ihnen gleichlalls mit verstimmelten hinteren Kïrperende; ein grumz erhaltenes 18 mm. langes, ohne die liuder 1,3mm. breites 'Thier latte 48 Segnente;

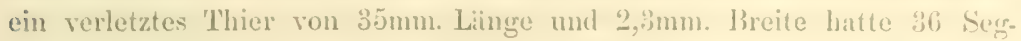
mente. - Aus der 'Zusammenstellung der Fundorte ergiebt sich, dass der Wohnort der Thiere jenseits der Humdertialen liegt.

Mit einer der beschriebenen Arten kamn ich das 'Thiel nicht identificieren.

\section{Diopatra (Paradiopatra) fragosa, n. sp.}

$$
\text { Tuf. 20, Fig. \%-1'; Tuf. } 21, \text { Fing. 1-q. }
$$

Teres, longinscula, flaro-brumea iricolor, segmentis plus 92 , anterioribus minime, posterioribus profundius seiunctis.

Lobus cephlalieus rotundatus coecus; tentacula posteriora ex articulo lasali bresi annulato filiformia, media imprari et externis longiori ad 7 mum fere segmentum patentia; anterion vicina, crassa, articulis basalibus tentaculorun posteriorum breviora; subtentacula pedunculata transversa, sese attingentia.

Segmentum buccale ceteris paullo longits; cirri tentaculares minuti graciles, tentaculorum articulis basalibus breviores.

Segmenta pinnigra priora 3-1 duplo latiora quam longiora.

Pinnae priores baud elongatae antrorsum vergentes, pusticre sensim ad formam tuberculi decreseentes. Pinna 1 ma labio postico magno, cirro dorsali ventraliq̨ue fere aeq̨ualihus sulfuliaceis; setis aciculaeformibus paucis parum protentis apice inciso vaginato. - Pimnarum sequentium labium posticum foliaceum sensin evanescens a segmento IOmo vix conspicnum. Setae lreves simplices infra apicem limbato-dilatatae et sealpratae; aciculae 2- prominentes pinmarum posticarum brunneae ralithe apice bidentato obtecto. Cirri dorsales sulfuliacei pinma longiores, segmenti latitudine multo breviores; cirri rentrales, exceptis 3 prioribus conicis, toriformes, ab segmento $15 \mathrm{mo}$ valde decrescentes, a segmento $30 \mathrm{mo}$ vis conspicui. Branchiae nullae.

Maxillae corneae, parum in marginilus olfuseatae; fulera lata, I longe enrratac, II $\tau-8$, III longa 8 , IV cucullatae $6-7, \mathrm{~V}$ 1. 1 . Laminne sentrales antice in area superne concentrice striata symphysi brevi connexae, postice valde dirergentes, utraque in facie ventrali plaga nigra notata, in parte libera utrimque prominula oblique truncata acie edentata.

Tubus eylindratus tenuis, in superficie externa limo obductus et testarum multiformium fragmentorum angulis prominentibus spisse scabratus.

Fundorte: 1. Off Sand Ker, 366 tims. 2. Feb. 17, 1869. S. W. of Sand Ker, cast Xo. 4, deptlı 325 fms. 3. May 13, 1869, off Pacific Reef, cast No. 7 , depth 233 fms. 4. Otf Bahia Reef, Florila, 413 fms, 5. Feb. 11, 1869, S. of Marquesis, cast No. 5, depth 296 fms. 6. Ent. loen, crat No. 6, depth $33: 3$ fms.

1 L. F. de Pourtales, Bulletin of the Museum of Comparative Zülory, Yol. I. No. 6, p. 109. 
Die Rähren dieses Wrumes sind im durchforschten Gebiet ziemlich weit verbreiter, vonwiegend jenseits der Z/weihundertfaden-Linie. Sie sind dureh die zahlreich dicht gedringt stehenden Schalenfingmente ausgezeichnet, welehe ringsum in solcher Weise quer aufgekittet sind, dass die Bruchkanten der scherben frei herrorragen. Ls ist aber nicht jede so gestaltete Röhre ohne weiteres als ron der Diopulia firgose erbaut anzusehen, dem sehr :ihnliche Rïhren werden ron Sabelliden und verwandten Wiimern angefertigt. - Ich habe viele Röhren durehsucht, ehe ich die Wümer auffand; in den Besitz eines ganz vollstïndig erhaltenen 'Thieres bin ich nicht grekommen. Das Exemplar, mach welchen die vorstehende Beschreibung entworfen ist, war tömm. laug, nicht gimz $1 \mathrm{~mm}$. dick und hatte 92 Segrmente; das Iinterende fohlte, ob in grosser Ausdehnung, kam ich nicht angeben.

Das Fehlen der Kiemen ist eine auftillige Erseheinung; ich bezweifle, dass dasselbe auf die Jugrend des Thieres zurïckzufiihren ist, sowie es höchst umwahrscheinlicì ist, dass Kiemen noch hinter dem 92ten Segrmente rorhanden sind. Die blattörmige Gestalt der winzigen Rüickencirren findet sich bei Diopulra (Iteplaceras) phyllocimu (Schmarda) wieder, von der diese Thiere vielfach abweichen. - Auch die Form des Unterkiefers ist sehr kemzeichmend. - Eine besondere Gattung für die Art zu errichten, halte ich zur Zeit fiur umnöthicr; mit dem Namen Paradiopatra, dessen Bedeutung oben erwähnt wurde, wird man bis auf Weiteres eine, vielleicht kïnstlich abgegrenzte, Gruppe bezeichnen diirfen.

\section{Diopatra (Paradiopatra) glutinatrix, n. sp.}

$$
\text { Tiuf. 18, Fig. 10-15; Tuef. 19, Fing. 1-5. }
$$

Brevis, conrexa, postice multo magis quam antice atteunata, flavida sermentis 47 .

Lobus cephalicus fere semiglobosns, coecus. Tentacula posteriora ex articulo basali brevi annulato filiformia, impar mediaune paene aequalia longissima usque ad segmentum 14 mum protenta, externa multo breviora; teutacula anteriora vicina, sulghlobosa; subtentacula sessilia, late toriformia sese tangentia.

Segmentum huccale brevissimum, trientem longitudinis proximi vix aequans; cirri tentaculares graciles tentaculorum articulis hasalibus haud longiores. Seguentorum pinnigerorum prius proximis triente fere longius, Iuplo latius quam longins, proxima quater vel quinquies lationa quam longion, segmenta trientis cozporis postici iluplo lation quam longiora.

P'inna prima conica elongata antrorsum vergens lobun cephalicum non superans; proximao sensim Inngituline decrescentes, segmentorum posticornm fere tuberenliformes; anteriores labium terminale a segmento 25to evanescens gerentes. Acicula pimae prioris non vel perparum liberae, paulisper curvatae apice obtuse hidentato. Setre pinnarum sequentium simplices, infra apicem tennissimum utringue breviter alatae, denticulatae; scalpratae acie non ciliata; aciculaeformes crassae brunneac apice fortiter bidentato, obtecto. - Cirri dorsales simplices filiformes, primo 


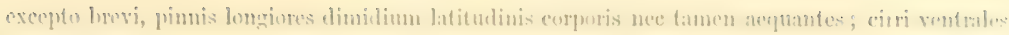

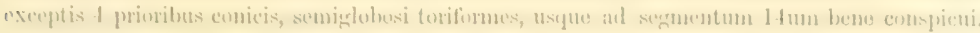
Branchiane mullitr.

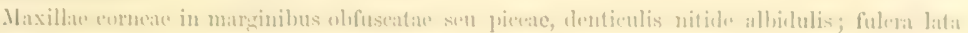

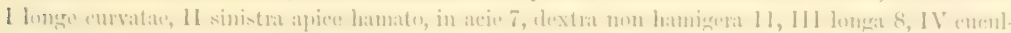

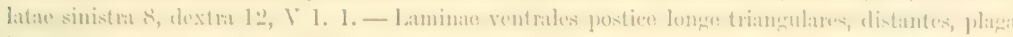

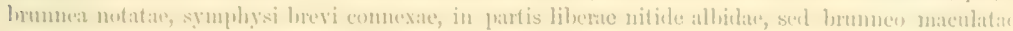
acie ublipge trumeatil tridentatio.

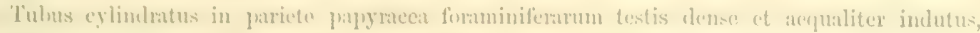
aliisque multifuriis testis clongatis lenge angulatim grominentilons sparsim spieatns.

Fundorte: 1. Off the Samber, depth 237 fms. 2. On Stunl kicy, depth 306 fme.

Die aus grösseren 'Tiefon gehobenen, doch nur vereinzet vorlienenten Rïhren waren aufillent dureh die mamigfaltigen laugen Fremdioipler, welche auf die gleichmissig mit Foraminiferen-Schalen bekleidete Auswenfliiche meist so aufgekittet waren, dass sie sperrig weit abstanden; verwendet waren dazu lange Spongiennadeln, besonders lang gestreckte Polythalamien und arenose Fornminiferen, aber auch kleme Dentalim-Ribhen. I)ic Rïlre selbst aber war völlig cylindriseh; ich hebe das hervor, da hier cin Beweisstiick dafiir gregeben wird, dass man aus der Gestalt der Rïhren nicht auf Terwandtsehaft der Erbauer einen Schlnss ziehen darf. Denn die Diwpatia glutinatrix erimnert in mancher Hinsicht an die Diopatra P'outalesii; deren pergamentartige Röhren sind aber glatt, wemn sie auch darin mit den Röhren der $D$. ghutinatrix iibereinstimmen, dass grö̈ssere Fremdkörper auf sie aufgekittet sind.

Ich habe nur ein unverletztes Exemplar gesehen, und danach die vorstehende Beschreibung entworfen. Das 47 Segmente besitzende Thier war $24 \mathrm{~mm}$. lang, hatte seine grösste 2,3mm. betragende Breite etwa am 20ten Segment, war am Kopftheil 1,5mm. und am Schwanzende 0,6mm. breit. Dass Thier ist kiemenlos wie die Diopatra fragosa; auch hier könnte man geneigt sein, den Mangel der Kiemen auf die Jugend des Thieres, welche man aus der geringen Körpergrösse erschliessen möchte, zurickzuführen. An der Basis des Rückencirrus der hinteren Segmente habe ich einen kleinen Höcker wahrgenommen, da wo die Kiemen zu stehen pllegen. Ist das ein Kiemenrudiment oder das Anfangsstück einer lorrorwachsenden Kieme? Ich lamn keine Entscheidung geben; ist aber ein Analogieschluss erlaubt, so möchte ich hier ein Kiemenrudiment sehen, ausgebildete Kiemen der Art absprechen, da bei Diopatre Eschrichtii. kleinere Thiere von nur $16 \mathrm{~mm}$. Liinge und aus 34 Segmenten bestehend, die ihnen zukommenden Kiemen bereits an allen Segmenten besitzen. 
Aus der Bildung des Kiefers hebe ich die Form des linken 'Zalmes hervor; dieser lïuft wie das gleiche Stiick von Diopatru. Poutulesï in einen grossen Enthaken aus, wiihrend ths grleich lange Gegenstiick eine grmolinige ganz geziihnelte Selmeide hat. Eine allerdings nur schwache Andentung solcher Bilthung ist mir aus dem Kieferapparat der Diopatre Eschrichlie bekannt; hier zog sich in einem Fille die Spitze des linken Zahnes mit besonderer Krimmung zu einem kurzen Iacken aus, doch war dessen von der Schmeide des 'Zahnes ausgehender conciver Rand noch mit zwei kleinen Lügezïhnchen besetzt, zeigte also offenbar eine Uebergangsbildung von der ganz grezilhnelten Schmeide zu dem ungezähnelten Endhaken. Bei Diopatra (Omphis) hyperborec (A. IIansen) dagesgen ist ein solcher Endhaken als ungeziihmelt abgebildet. ${ }^{1}$

\section{ONUPHIS (Aud. \& M.-Edw.) QTrFgs.}

Wregen der Auflassung dieser Gattung verweise ich auf das bei Diopatra Gesagte.

\section{Onuphis (Paronuphis) gracilis, n. sp.}

$$
\text { Taf. 21, Fig. 5-13. }
$$

Brovis, interdum in tentaculis externis pinnisque prioribus brunneo maculata, pallida, antice semiteres, postice complanata, segmentis circa 70 .

Lobus cephalicus quadrioculatus vel coecus; tentacula posteriora ex articulo basali brevi non annulato orientia filiformia, impar trieute fere longius mediis ad segmentum $15 u m$ patens, externis brevibus plus yuam triplo longius; tentacula anteriora inter se distantia globose-ovata; subtentacula sessilia lata parum prominentia.

Segmentum buccale brevissimum, quater latius quam longius, nudum. - Segmenta pinnigera anterion 2 elongatia longiora quam latiora, cetera duplo lation quam lougiora fere aequalia. Pinnae anteriores 2 antrorstum veryentes segmenta longitudine parum superantes labiis superiore subfoliaceo, posteriore cirriformi; setae paucae segnenti prioris falcigerae, falce subrecta bidentata obtecta vel simplices obtusae parum curvatae apice bidentato obtecto, segmenti secundi praeter has simplices acutae limbatae et scalpratae; cirri dorsales a media pinna orientes, pinnam non superantes simplices; cirri ventrales e pinme hasi breves subfusiformes. Pinnae proximae conice procerae, posteriores longituline haul multum decrescentes, setis segmenti praecedentis marginem anticum attingentes, labio postico anteriorum subfoliacen, a pinna 9a nullo. Setae flavae simplices sub) apicem acutum late limbatae, et scalpratae acie breviter pectinato; aciculae pimnarum anteriorum 2 styliformes rectae apice currato acuminato, a pinna circa $17 \mathrm{ma}$ in carum loco singulae crassiores obtusae in apice parum curvato fortiter bidentatae. Cirri dorsales simplices pinnis breviores, ventrales pinnae 3 iae subglobosi, proximi tuberculiformes, deinde evanescentes. Branchine mullae.

Cirri anales filiformes 2 longissimi, 2 multo hreviores.

Maxillae corneae; fulcra oblongata, duplo fere longion quam latiora; I breviter hamatae,

${ }^{1}$ Den norske Nordhars-Expedition, 1876-1878, VII Zoologi. A. Hansen, Annelida, Curistiania, 1882, $4^{\circ}$, Taf. IV, Fig. 7. 


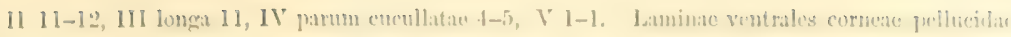

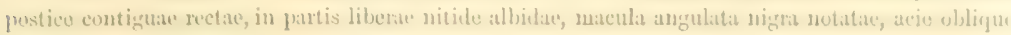
truneatat non dentit:we.

Tubus cylindratus rectus cornens pellucidus.

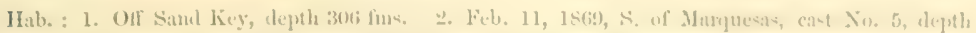

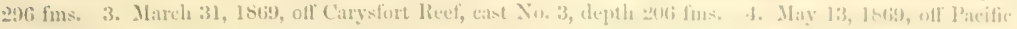

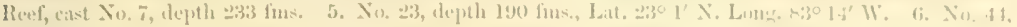

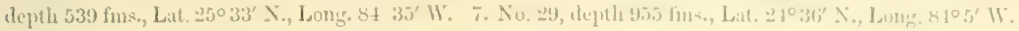

In vorstehender Besehreibung habe ieh Kennzeichen zusammengefassi und für die Charakteristik einer Art vereinigrt, welche vielleicht in zwei Arten zu sontern ist. Vorliiutig halte ich an der Aullassung fest, dass die ron mir beobachteten und angegebenen Unterschiede als solche des Alter's anzusehen sind. Ich habe mich dariber etwas weitliufiger hier zu iuscem.

Aus mehreren Orten grösserer Meerestiefe und allen jenseits der IIundertfadenlinie sind, wenn auch nicht hïufig, diime und schlanke Röhren von dem durchsichtigen glatten Aussehen jener von Omullis tubicola (Miill.) allgemeiner bekannt gewordenen Röhrenform heraufgebracht, welche Malmgren fiir die Charakteristik seiner Gattung IIyalinoecia verwendete. In wenigen dieser Röhren, aber in der aus 95̃ Faden Tiefe stammenden, fand sich der erbanende Wurm, der immer beträchtlich kürzer als die Röhre selbst war. Nur ein Exemplar trug Kopf- und Afterende, aber anch letzeres regeneriert; dieser Wurm war ohne die Fuhler und Aftereiren 21,5mm. lang, und hatte 62 Segmente olne das etwa 1mm. lange regenerierte Hinterende, in welchem die segmentale Gliederung noch nicht zu erkemmen war. Ein zweites Exemplar kam diesem an Breite etwa gleich, alle anderen am Hinterende verletzten waren schmäler. Im Habitus hatten alle Thiere die grösste Aehnlichkeit: das vordere auf der Körperflaiche hoch gewïlbte Körperende trug am Kopflappen die sehr schlanken Fïhler, das nackte Buccalsegment war sehr kurz, die Ruder der beiden folgenden verlängerten Segmente waren, wenn auch in ungleichem Grade, lang ausgezogen und nach vorn gerichtet. Die darauf folgenden Segmente, etwa doppelt so lang als breit, sind anfünglich wenig, im hinteren Körpertheile stark von einander geschieden, aber auch hier mit dem Unterschiede, dass bei dem grössten Exemplare die Segmentgrenzen viel schärfer als bei den schmäleren einschnitten; stets bei der Ansicht von oben viereckig crscheinend, und nach hinten zu etwas abgeplattet.

Die Ruder gehen rasch in die Kegelform über, sind bald mehr seitlich, bald mehr nach vorn gerichtet, ihr ansehnliches gelbliches Borstenbündel 
magt dam bis an den Vorderrand des voranfgehenden Segmentes. - Die Furbe ist bei allen 'Thieren ein mattes Weissgelb, wenig irisierend; bei dem grïssten Exemplare trïgt der iussere Umfing des unteren Theiles der äusseren Fiihler und desgleichen der ïussere Umfing des ersten Ruders einen liinglichen gelbbräimlichen Fleck.

Der Koptlappen ist im Allgemeinen quer oval, bei den kleineren Exemplaren in der Mittellinie schwach nach rorn ausgezogen; nur bei dem grrössten Exemplare ist er villig angenlos, bei allen iibrigen trügt er 4 rothbraune Augenflecke, von denen die grösseren hinter und seitlich von den mittleren Fühlern stehen, wïhrend die kaum halb so grossen vorderen nahe dem Seitenrande auf dem vorderen Drittheil des Kopflappens angebracht sind. Diese Differenz halte ich nicht für ausreichend, um darauf hin die augenlosen ron den augenfiilurenden specifisch zu sondern. Dass das augenlose Exemplar in der griissten 'liefe (95j Farlen) gelebt hat, darf wohl nicht ohne Weiteres in Causalzusammenhang mit der Blindheit desselben gebracht werden. Ob die Augenlosigkeit mit dem grösseren Alter sich einstellt, juingere Thiere rielleicht aus der Larvenperiode Angenflecke heriibernehmen, bleibt weiter zu prüfen. Berleutungsvoll für alle diese Fragen ist die Angabe Claparède's, ${ }^{1}$ dass bei Hyulinocia rigüta in der Regel die Augen fehlen, ausnahmsweise dagegen als schwarze Pigmentflecke hinter den mittleren Fühlern stehen. - Die hinteren Fiihler, übereinstimmend durch das kurze völlig ungeringelte Basalglied, zeigen in den Längenverhältnissen des unpaaren zu den mittleren erhebliche Ungleichmïssigkeiten. Während die äusseren bei allen Exemplaren sehr viel kürzer als die mittleren sind, werden diese bei einigen Thieren, und zwar unabhïngig von deren sonstiger Körpergrösse, von dem umparen Fühler an Länge ïbertroffen oder sind selbst lïnger als dieser; die lïngsten Fühler und zwar das eine mal die paarigen, das andere mal der unpaare, reichten nach hinten gelegt bis zum 15ten Segment, in einem anderen Thiere nur bis zum 10ten Segrment. Offenbar sind diese Verhältnisse taxonomisch ohme Berleutung. - Die vorderen kurz eiförmigen Fïhler waren in allen Thieren weit von einander getrennt, bei den kleineren standen sie frei vorragend auf der vorderen Kante des Kopflappens, bei den beiden grösseren Exemplaren standen sie dagegen auf der Unterfläche des Kopflappens, von dessen frei vorragendem Vorderrande so überdeckt, dass sie bei einer Ansicht von oben her verborgen waren. Ich wiirde diesem Verhalten Gewicht beilegen, wenn nicht diese beiden Exemplare, welche solches zeigten, 


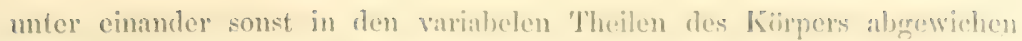
wiren. Vielleicht kamm dep vordere 'Theil des Kophtrppens zeitweiligr saine Ausdehmung und Form :indern und damit zu einer relativen Latgeverimblerumer

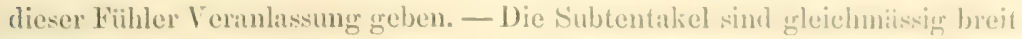
und flach.

Völlige Uebereinstimmung herseht in den Dimensionen des ersten kumen Segmentes; wailnend in den Dimensionen dex ïbrigen segrmente und in dem Grade, wie dieselben und zwar besonders die hinteren von einander fretremit sind, Schwankungen aufreten, welche aber allmaillich in einander iibergrelien.

Das grleiche gilt von den Dimensionen der Ruder; zumal die beiden ersten Ruder, stets verlingrert und nach rom gerichtet, sind nicht gan\% gleichmissigr gross und es bleibt das erste bald mehr bald wenigger hinter dem Vorderrande des Kopllappens zuriick. Uebereinstimmung herrscht in Allgemeinen in den Anhïngen der Ruder; dagegen zeigten die Borsten der ersten Ruder Unterschiede, welche als wesentliche erscheinen könnten. Dic kleineren Exemplare haben nïmlich in diesen Rudern, und zwa in beiden, nur wenige nicht weit vorragende brïmliche, deutlich zusammengesetzte Borsten, bei welchen das gerade zweizähnige sichelfömige Endstiick mit dem Schaftende durch das hiillende Seitenblatt so verbunden ist, dass eine volle Continuitït gegeben erscheint. Bei dem grössten augenlosen 'Thiere fehlten solche zusammengesetzte Borsten, das zweite Ruder fiihrte ausserdem schon Borsten, wie sie den folgenden Segmenten zukommen; neben diesen und im ersten Ruder ausschliesslich allein standen einfache stumpfe etwas greschwungene Borsten nit einer gedeckten zweizähnigen Endspitze, welche annähernd die Form hatten, die man wohl erhalten wïrde, wem man den Sichelanhang an den entsprechenden Borsten der kleineren 'Thiere mit dem Schafte der Borsten fest verbunden sich vorstellt. Das grösste augentragende, in der Stellumg der vorderen Fihler mit diesem letzterwähnten Exemplare übereinstimmende Thier hatte in beiden vorderen Rudern nur zusammengesetzte Borsten, stimmte darin also ganz mit den kleineren Thicren überein. Da wir num wissen, dass auch sonst z. B. bei Lumbriconereis und bei Syllideen die Form der Borsten gerade in den vorderen Rudem mit dem Alter des Thieres wechselt, so möchte ich anch hier diesen Unterschied auf ungleiche Altersentwicklung zurïckführen, das augenlose grösste Exemplar demnach als das älteste ansehen.

Die Borsten der hinteren Ruder stimmen völlig ïberein und auch darim 
herrscht Lebereinstimmung, dass die Borsten derjenigen Ruder, welche auf das zweite folgen, schlanker und weniger breit gesïumt als die der hinteren sind. Aber schwankend ist die Zahl der Segmente, welche derartige Uebergamersorsten tragen.

I on den Anhïngen der Ruder und den bei ihnen vorkonmenten Unterschieden hebe ich Nichts besonderes hervor, da es innerhalb des Kreises der anch sonst rorkommenden Varietiiten grelegen ist. - Kiomen fehlten allen Lxemplaren. - Ieh halte mich mach alledem für berechtigt, alle mir vorliegenden 'Thiere zu einer Art zu rechen.

You St. Vincent (Westindien) hat Baird ${ }^{1}$ eine IIylinoccia v'arians beschrieben, und die Vermuthung liegt nahe, dass meine Thiere mit dieser Art, welcher Baird wegen ähnlicher Variationen, wie ich sie beschrieben habe, den Namen ruriuns gegeben hat, zusammenfillen möchten. Dagegen spricht aber, dass bei der Myulinoecin varians die Grundghlieder der Fühler geringelt, die schlinken Endstiicke gregliedert sind. Das ist aber ein Charakter, den ich nicht auf einen Altersunterschied zuriickführen mag, da die Exemplare, welehe Baird untersuchte, etwa 1" engl., also kaum grösser als die grössten mir vorliegenden Thiere waren. Sonst scheinen die Arten nahe übereinzustimmen, dem auch II. varians (Baird) scheint kiemenlos zu sein, wenn ich Baird's Angabe: "dorsal cirri or branchial filaments" richtig deute.

\section{EUNICE CUV.}

Die grosse Zahl der Arten dieser Gattung habe ich durch die nachstehend beschriebenen noch zu vermehren. Die weit verbreitete Gattung ist offenbar in sehr zahlreichen Arten zur Entfaltung gekommen, deren Feststellung und Wiedererkennung mit um so grösseren Schwierigkeiten zu kümpfen hat, als der Werth der meisten Kennzeichen, mit welchen die Arten abgegrenzt werden, ein sehr geringer ist. Zur Zeit ist es nur die Aufgabe, mit Bild und Wort die different erscheinenden Formen scharf zu sondern; wenn aber, woran nicht zu zweifeln, das brauchbare Material reichlicher, als jetzt angehäuft ist, wird ein Monograph mit Berïcksichtigung auch der geographischen Verbreitung wohl die Wege nachreisen künnen, in welchen die Entwicklung der verwandten Formen stattgefunden haben mag. - Um einen 
Anhalt für die Jinordmung der beschriebenen Arten z.u haben, verwende ieh das von Grube ${ }^{1}$ \%uletzt anfigestelle Schemat, ohne dannit iiber natiorliche Verwandischalten entseheiden zu wollen.

Ein besonderes Interesse diarfen die von diesen Wiirnem erbanten liähren in Anspruch nehmen, welehe bis jetzt nicht oder ganz ungeniigend bekamnt waren.

\section{Eunice articulata, n. sp.}

$$
\text { T'uf: s.' Fig. S, 9, } 10 .
$$

Brevior, semiteres, postice versus attenuata; jlumber vel ochracea iricolor, segmentis plus 110.

Lobus cephalicus bioculatus bilobus; tentaculorum breviter articulatorum vel moniliformium impar mediis et externis duplo longius al segmentum 20mum patens, subtentacula nom partita. Secmentum buecale proximo in lateribus non seiuncto duplo longius, sequentia 3 acyuans, cirri tentaculares longe articulati lobum ceplalicum stzperantes.

Seguenta pinnigera octies lation quam longiora; pinnae melioeres; setae superioris fasciculi capillares paucae non limbatae, tenuissime ciliatae et scalpratao; inferioris crassiores flarae falcigerae falce brevi limbata fortiter bidente; aciculae binae flavidae rectue obtusac; fisciculus acicularum inclusarum pone corpusculum nigrum; cirri dorsales graciles longe articulati in pinnis mediis al segmenti linean medianam patentes; cirri ventrales longitudinem pimne vix aequantes crassiusculi in basi intlata.

Iranchiae a pinna $4 \mathrm{a}$ vel $5 \mathrm{a}$ usque ad pinnan $30 \mathrm{am}$ vel $48 \mathrm{am}$ cirris breviores maximae in rhachide radios 13 parum inter se diversos gerentes.

Cirri anales 2 longe articulati. Maxillae coruene nigrescentes, I elongatire, II $7-8$, III 7 , IV cucullatae 6-11, V 1-1. Laminae ventrales area terminali albida in acie obliqua fortiter dentatie.

Hab. : 1. April 3, 1869, off French reef, cast No. 1, deptly 15 fms.

Ein Exemplar von $46 \mathrm{~mm}$. Lünge hatte 105 Segmente, bei ihm stand die letzte Kieme am 30ten Segmente. Alle iibrigen Thiere waren verstiimmelt; ich zïhlte bei einem der grössten dieser Exemplare 140 Segmente, hier stand die letzte Kieme am 4 Sten Segment.

Diese Art gehört in die Gruppe derjenigen Euniceen, bei welchen die Kiemen auf den vorderen Körpertheil beschrïnkt sind und deren Fiihler und Cirren sich durch scharfe Gliederung auszeichnen (Grube's Leodice I A). Ich kann sie mit keiner hierher gehörenden nach den dartiber vorliegenden Beschreibungen identificieren; sie steht der Eunice Sarrigmyi (Gr. Annulata Semperiana, pg. 150) von den Philippinen rohl am nächsten; diese Art hat aber ungegliederte Fühlercirren.

1 Grube, Bericht üher die Thätigkeit der naturwissenschaftlichen Section der Schlesischen Gesellschaft im Jahre 1877, pg. 56. 


\section{Eunice antillensis, n. sp.}

$$
\text { Tiaf. } \because 4, F i y . \bar{j}, 6, \pi \text {. }
$$

Drevior semiteres pallido ochracea iricolor pimnis cirrisque albidis, segmentis 130. - Lobus cophalicus biuculatus bilobus; tentaculorun longorum parum distincte et longe articulatorum impar mediis quaktriente, externis duplo lungius ad segmentum 20um patens; subtentacula non partit... Spementum buceale proximo in lateribus non seiuncto ter longins, cirri tentaculares longo articulati at marginem anteriorem lobi cephaliei patentes. Segmenta pimigera quater vel quinquics latiora quam longiora. I'imno breves; setae fisciculi superioris incolores capillares tenuissine ciliatae, et scalpmatae; inferionis classiores thavidao falcigene filce ulongata fortiter bidente; acieulae nigrae vel flavae superiores binae rectae, inferiores pinnarum posticarum singulne vel binae apice bidentato obtecto ; fasciculus acicularum inchnsirum parvus prope corpusculum nigrum. C'irri dorsales pinn:arum anteriorum indistincto articulati et longiores qutan posticarum, branchiis uhique longiores, of elongati dimiliam latitudinem segmenti acquantes, of breviores. - Cirri ventrales filiformes basi parum incrassata pinma longiores. Branchiae a pimna ta usque ad pinnam than, maximate 9 5-6-, d 2-tilosae, eirro dorsali breviores.

Maxillate cornea in marginibus vel amplius nigrescentes, I elongata, II $5-5(\overline{7}-\overline{7})$, III longa

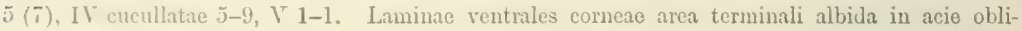
q1ia fortiter tlentatie.

Fumlurt : $18 \bar{i}-78$, No. 45 , depth 101 fms. Lat. $25^{\circ} 23^{\prime}$ N., Long. $81^{\circ} 21^{\prime} \mathrm{W}$.

Ton diesem Fundorte liegren mir drei nach dem. Habitus offenbar zusammengehörige Exemplare vor, von denen ich ein einziges unverletzt erhaltenes $80 \mathrm{~mm}$. langes, aus 130 Segmenten bestehendes als Männchen ansehe, withrent sich die beiden anderen etwas dickeren Thiere durch den Besitz von Eiern als Weibchen answeisen. Dann zeigt diese Art eine sexuelle Differenz, wie sie von Eunice norregica (L.) bekannt ist, und wie sie in der vorstehenden Beschreibung zum Ausdruck gebracht ist. Offenbar gehört diese Form num auch in den Verwandtschaftskreis der Eun. norvegica, und ich habe geschwankt, ob ich die Thiere nicht unter diesem Namen auffihiren sollte. Ton der Emice Norregica unterscheidet sich diese Art durch die bedentend lïngeren Fühler, Fühlercirren und Cirren und durch die etwas geringere Grösse der Kiemen und geringere Zahl der Kiementäden. In den uibrigen Theilen herrscht grosse Uebereinstimmung. Augenscheinlich handelt es sich um eine locale Entwicklungsform, deren geographische Verbreitung noch festzustellen ist. - Das gleiche gilt von der Eunice binominata (Qtrfgs.) (= punetata, Gr., Oerd.). Von dieser unterscheidet sich die E. antillensis gleichfalls durch lïngere Fühler, Fühlercirren und Riickencirren.

Ob die Eunice Guildingi (Baird) aus Westindien hierher zu ziehen ist, geht aus der Beschreibung Bairds nicht sicher hervor. Grube hat in seiner Zusammenstellung der Euniceen-Arten die Eurice Guildingi in den Kreis 
derjenigen gestellt, bei denen die Kienen bis ans binde des Kïrpers "orler fast so weit gehen." Kach Bairdis Angabe hären aber die Kiemen etwa in der halben Lime des Kinpers auf, und damit tritt diese $\Lambda$ rt damm in

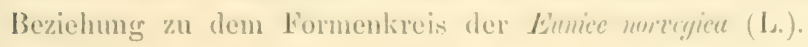

\section{Eunico binominata, (Qtrass.}

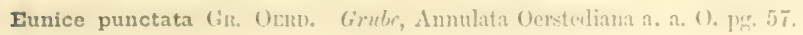

Zwei Wiimer, der eine bei 'T'orturgas gelunden, vermuthlich aus der Litoralzone stammend, der andere in 37 Faten 'Tiefe, stimmten so selur mit der' Grube'schen Beschreibung der Emice pmetutu ïberem, dass ich dieselbe sofort unter dem von Quatrefages geinderten Namen anfiiblute. Die spiitere Vergleichung mit dem Originalexemplare Grube's bestiitigte das. Ich hebe zur Ergïinzung der Grube'schen Beschreibung einiges hervor.

Der verhiiltnissmiissig kurze t5̃mm. lange aus 102 Segnenten zusammenrresetzte Körper des einen 'Thieres ist, wie es in der Grube'schen Beschreibung des lebenden 'Thieres angegeben wirl, gelb nit sehr feiner weisser Punktierung ; das Grube'sche Originalexemplar ist jetzt dunkelfarbig. Die schlanken Fühler sind kïrzer gegliedert als im Originalexemplare. Die Kiemen stehen vom 5ten bis zum 30ten Ruder, haben das Grüssenverhältniss, welches Grube angibt, doch steigt die Zahl der Kiemenfaiden bis auf 12. - Die Bauchcirren werden, was von Grube nicht hervorgehoben ist, an den hinteren Segmenten fadenförmig verlängert und ragen dann über das Ruder hinaus. Darin erimert der Wurm an das gleiche Verhalten bei L. vubra (Gr.), der er im Habitus so ähmlich ist, dass renu nicht die ungleiche Vertheilung der Kiemen vorhanden wäre, man beide Arten vereinigen wïrle.

Die Kiefer zeigen gleichfalls, allerdings nicht bedeutende, Abweichungen von denen der Emice mbra. Alle Stiicke sind licht-hornbraun; die Zangen schlank, die Zühne haben 7 und S Zühnchen, die unpaare Sägeplatte, welche längs der Schneide des gleichseitigen Zahnes sich erstreckt, 7 , die parrige linke 6, die rechte 11 Zähnchen, daneben ist jederseits nu cine Reibplatte. - Die sehr hellfarbigen Unterkieferhälften tragen ein grosses emailleweisses schrïg abgestutztes Schneidestiick mit rellig ausgerundeter aber kaum gezalinter Kante.

Fundorte: 1. Tortugas. 2. Cast No. 11, depth 37 fins. Lat. $24^{\circ} 43^{\prime} \mathrm{N}$, Long. $83^{\circ} 25^{\prime} \mathrm{WV}$. 
Eunico violaceo-maculata, n. sp.

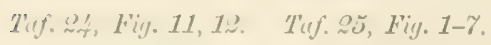

Longa robusti postico rersus sensim attenuatir euprea, lenso violaceo rel brumneo maculata, cirris albilis brnmeo vittatis; segmentis ulus 200. Lolus cephalicus bioculatus profunde bilobus. Tentaculurum simplicium vel indistincto lreviter articnlatorum impar ad segmentum 8 um patens mediis et externis longius; subtentaneula haud vel indistinete partita. Segmentum buecale longitudine seymenta 4 moxima adaequans, a secmento secumlo nou nisi in dorso seinnetum; cirri tentaculares simplices lobum cephalieum attingentes. Segmentr pimnigera anteriora octies, posteriva quinquies latiora quam longiora. - l'inna breves. - Setae flavao fasciculi superioris numernsue capillares haud limbatae et sealpratae paucac; faseiculi inferioris crassiores numerosae falcirerive falee subelongata fortiter bidente Iimbo ciliato obtecta ; neiculae nigrae superioris fasciculi binae rectue, in segmentis mediis et posticis inferioris fisciculi singula oblique collocata apico curvato obtuse hilente; fiseiculus acieularum inclnsarum partim nigrarum.

Cirri dorsales haud artieulati, ventrales, exceptis pinnarum $t$ anticarum conieis, in basi tumida brerissimi. IBmehiae a piuna Ga vel $9 \mathrm{ma}$ incipientes in omuibus segmentis multifilosae, segmentorum mediorum longissinao cirris longiores dorsun paene obtegentes, in rlinchide elongata radios illa multo breviores inter se fere aequales plus quam 20 gerentes.

Iraxillae nigrae, I parum incurvatae, II $4-5$, III-brevis 6 , IV $4-7$, V et VI 1 ; laminae ventrales nigrne area termimali semilumari calcarea albida acie recta edentata.

Hab. : Tortugas.

Alle mir vorliegenden Exemplare, der Sammlung von Cambridge angehörig, stammen von Tortugas; genaueres iiber ihren Fundort ist nicht verzeichnet.

Es sind zum Theil ansehnlich grosse Thiere, metallisch braun, dunkler bram oder violett gefleckt, mit braun quer gebänderten Cirren. Die Kiemen, welche in der Mitte des Körpers länger als die Rüickencirren sind, decken die Riickenfläche fast ganz, dabei tragen sie an einem langen Stamme im Allgemeinen kurze, wenig an Lünge verschiedene Zinken, von denen ich in einem Falle bei einem allerdings sehr grossen Thicre, 40 zählte. Ein vollstïndig erhaltener Wurm hatte 205 Segmente, war $200 \mathrm{~mm}$. lang, und war am Iten Segment $4 \mathrm{~mm}$. breit, erreichte in geringem Abstande davon die grösste Breite mit $6 \mathrm{~mm}$. ohne Ruder, und verschmälerte sich langsam bis $z u$ dem Imm. breiten Afterende. - Im Auftreten der ersten Kieme findet ein Schwanken statt, ebenso in der bald mehr bald minder stark ausgeprïgten Gliederung der Fühler. Als Varietät, richtiger wohl Monstrosität, verzeichne ich hier, dass in einem Falle der linke mittlere Fühler einen Seitenast trug.

Ich habe mehrfach die Kiefer praepariert und folgende Zahlen in den Zỉhnen der Stïcke des Oberkiefers gefunden. 


\begin{tabular}{|c|c|c|c|c|c|}
\hline & II. & III. & IV. & v. & V1. \\
\hline 1. & $5-\overline{5}$ & 7 & $1-4$ & 1 & 1 \\
\hline 2 . & $n-\pi$ & 7 & \{\}$-4\}$ & 1 & 1 \\
\hline 3. & $1-5$ & (i) & $4-7$ & 1 & 1 \\
\hline 1. & $i-1 ;$ & if & $1-7$ & 1 & 1 \\
\hline 5. & $6-6$ & li & $1-\overrightarrow{7}$ & 1 & 1 \\
\hline
\end{tabular}

Der Umstand, dass die Fühler, wemn die Gliederung an ihnen hervortritt, kurz gegliedert sind, muss diese Art zu denjenigen stellen lassen, welche Grube als Leodice II $A \mathrm{a}^{2}$ vereinigt hat, doch mag ich sie mit keiner der dort aufgeführten vereinigen; die grosse Entwicklung der Kiemen zeichnet neben der hier nicht zu vernachliassigenden Zeichnung das 'Thier aus.

Eunice rubra, Gr. Kr.

E. Grube, Annulata Oerstediana. Viclenskabelige Neuldelelser fra den naturhisturiske Forening i Kjöbentuarn for Aaret 1855. Kjöbenluavu, 1856-1857, pg. 59.

$$
\text { Tuf. } 26, \text { Fig. 1-11. }
$$

Brevior, semiteres, postice attenuata, pallihe ochracea cirris branchiisque albidis, secmentis 110 140. Lobus cephalicus bioculatus bilobus; tentaculorum articulatorum fere moniliformium impar meliis triente longius lobum cephalicum longe superans retrorsum ad segmentum lomum patens. Subtentacula non partita. Segmentum buccale a proximo in lateribus non sciunctum, longitudino 4 sequentia aequans. Cirri tentaculares indistincte vel non articulati marginem anticum semmenti buccalis haud attingentes.

Segmenta piunigera quater lativa quam longina. - Pinnae meliocres; setae flarae superioris fasciculi ubique capillares et scalpratae parum dilatatae, inferiores parum crassiores falcigerae falce brevi bidente limbata; aciculie flavae binae rectae rel apice perparum curvato, praeter eas in pinnis posterioribus binae curvatae apice fortiter bi- rel tridentato obtecto. Fasciculus acicularum inclusarum parcus corpore nigro affixus.

Cirri dorsales non articulati pinnam superantes, cirri rentrales pinmarum anteriornm 3 conici, postea ex hasi tumida subulati pinnam superantes, in pinnis posticis seusim filiformes pinnam magis excedentes. Branchiae, in pinnis 5 anterioribus desideratae, pectinatae, radiorum numero mplim ad 17 accrescentes, a segmento circa 360 minores, per omnia sequentia plerumque bi- vel trifilae; maximae cirro dorsali multo longiores dorsum non nisi in lateribus tegentes, radii in rhachicle gracili illa tenuiores, cirrum longitudine stperantes inter se atquales.

Cirri anales superiores longe articulati, inferiores brevissimi.

Maxillae corneae in marginibus nigrescentes, I elongatae, II 5-6, III longa 6, IV cucullatae $7-7$ partim indistincte, V et VI 1. Laminae ventrales corneae area terminali albida oblique truncata acie sinuata non dentata.

Hab. : Key West, 1-2 Faden (una cum Eunice conglomerante). 
Die mir vorliegenden Exemplare zeigen Grüssenuntersehiede in der Weise, dass bei timm. Lïnge 110, bei $62 \mathrm{~mm}$. 118, bei $84 m m$. 140 Segmente vorhanden sind.

lch nehme keinen Anstand, sie auf die von Grube als $E$. rubre bezeichnete Art zu beziehen. Das Grube'sche Original-Exemplar ist allerdings schlanker, zumal weniger breit als alle mir vorliegenden Exemplare; meine Beschreibung weicht von der Grube'schen darin ab, dass in ihr die erste Kieme als am dritten Ruder stehend bezeichnet wird, dass die griosste Zahl der Kiemenfäden höher als die von mir gefundene ist und dass die Kiemen den ganzen Riieken decken sollen. Auf die beiden ersten Differenzpunkte lege ich liein Gewicht, da hierin erhebliche Abweichungen auftreten; die grosse Erstreckung der Kiemen auf die Rïckenfläche hïngt aber vielleicht mit einer starken Schrumpfung des Thierkörpers zusammen, worauf dann auch der Ireitenunterschied der von Grube und mir beobachteten Thiere zuriickzuführen wäre. Darauf möchte ich auch die etras grössere Lünge des unparen Fühlers meiner Exemplare zuriickführen. Durch Länge dieses 'T'entakels ist die E. brasiliensis (Kbg.) ansgezeichnet, unterscheidet sich von $E$. mura aber dadurch, dass sie gegliederte Rüickencirren besitzt.

Als beachtenswerthe Unregelmässigkeit hebe ich hervor, dass ich bei einem sonst normal gestalteten Thiere eine Kieme mit 24 Füden gefunden habe, welche an dem mehrfach gabelig getheilten Stamm befestigt waren.

Das von Oersted gesammelte Thier wurde bei St. Thomas (Antillen) unter Florideen gefunden, es stammte also wie die mir vorliegenden Thiere aus der Litoralzone.

\section{Eunice floridana (Pourtales).}

Marphlysa floridana, Pourtales. Contributions to the Fauna of the Gulf Strean at Great Depths. Bulletin of the Juseum of Comparative Zoölogy, Vol. I. 1863-1869, p. 108.

$$
\text { Tif. } 22, \text { Fig. 1-\% }
$$

Brevior, convexa, postice versus attenuata, segmentis 130. Lobus cephalicus bioculatus bilobus; tentaculorum indistincte et apicem versus longe articulatorum impar usque ad segmentum 12 mum patens mediis et externis duplo longius; subtentacula indistincte partita vel simplicia. Segmentum buccale a proxino brevissimo non nisi in dorso sejunctum $\frac{1}{2}$ latius quam longius, proxima 4 adaequans; cirri tentaculares haud articulati longitudine segmentum buccale aequantes.

Sermenta pinnigera septies latiora quam longion. - Pinnae mediocres; setae fasciculi superioris fure incolores capillares tenerae vix limbatae numerosae, scalpratae paucae acie dentati lata; fisciculi inferioris flavae crassae falcigerae falce valida brevi et parum angustata limbata fortiter bidente; aciculae nigrae 2 vel 3 apice vix incurvo; acicnlarum inclusarum fasciculus mediocris. Cirri dorsales haud articulati breves, cirri ventrales in basi tumida brevissimi pinnam aequantes. 


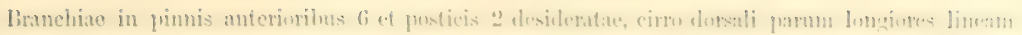

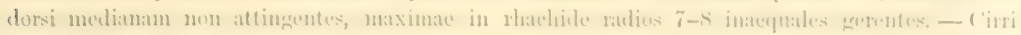
anales 르 lomi haud articulati.

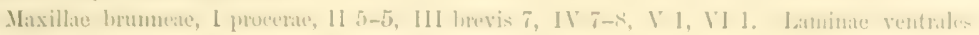
nigrao parte libera whlique truncata whtmes tridentata allat.

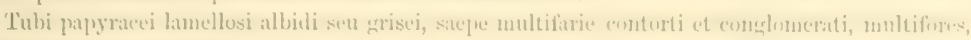
cotiis latemlibus lacintis.

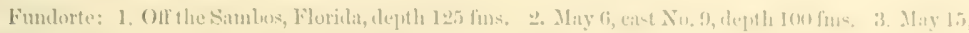

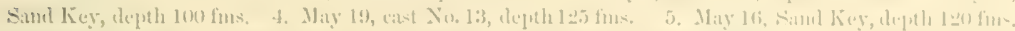

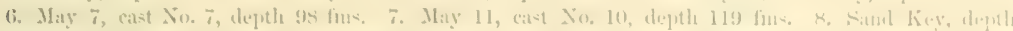

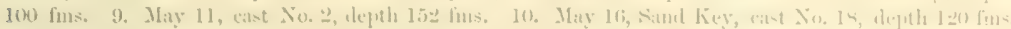

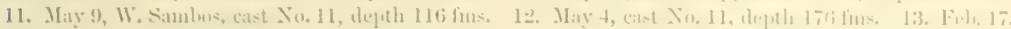

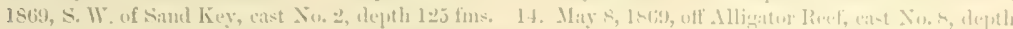

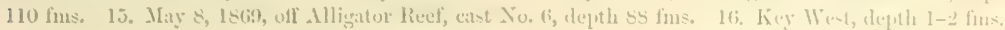

Die Art, welche, wie die Zusammenstellung der vielfachen verzeichneten Fundorte zeigt, im Bereich der Ilundertfudenlinie, und zwar hïitig vorkommt, aber ebenso häufig, wie das unter 16, verzeichnete Vorkommen zeigt, der Litoralzone angehört, erreicht gelegentlich ansehnliche Grösse; das zeigrte mir ein Vorderstiek, welches der Sammlung von Cambridge angehint und das eine Dicke ron $2 \mathrm{~cm}$. besitzt. Ein vollstïndiges Exemplar ron den Dimensionen, wie ich sie am hïufigsten gesehen habe, besass 190 Segmente, war $92 \mathrm{~mm}$. lang und am Vorderende Smm. breit.

Die Art grehört zu denjenigen, bei welchen eine undeutliche Spaltung der Subtentakel vorhanden ist, doch so sering, dass der Vorderrand des Kopflappens nur zweilappig erscheint. Nach der Vertheilung der Kiemen und der Bildung der Fühler und Cirren gelürt sie zu Grube's Leodice II B. $\mathrm{a}^{\mathrm{l}}$; von der dort nufgeftihrten $E$. Guildingi (Baird) unterscheidet sic sich durch die Kiemen, welche nur den letzten Segmenten fehlen, withrend dieselben bei E. Guildingi in der Mitte des Kürpers etwa aufhören. Tiel näher steht sie wohl der $E$. aequerblis Gr. von Cap York auf Neuholland, deren Kiemen aber offenbar viel stärker entwickelt sind.

Auch bei dieser Art habe ich, allerdings nur eimmal, eine reichere Ausbildung der Kieme gresehen, dacturch dass dic 8 Fïden derselben zum Theil dichotomisch sich theilten.

In dem erwåhnten grossen Exemplare hatte im Oberkiefer 4, statt wie oben verzeichnet $7-8$, nur $3-7$ Zïhne; solche grossen Differenzen sind wohl auf Abnutzung der Zahneinschnitte zurtickzufïhnen.

Die Röhren erinnern mit ihren papierartigen weisslichen Wandungen an diejenigen der Emice conglomerans, unterscheiden sich aber ron diesen durch seitliche, von Lappen umstellte Oeffnungen. Dadurch sind sie so 
wohl chankterisiert, dass ich keinen Anstand genommen habe, in der Zusammenstellung der fiundorte auch diejenigen mit aufaunehmen, von welchen nur die lecren, von den Wiirmern nicht mehr bewohnten Röhren vorlagen.

\section{Eunice tibiana (Pourtalis).}

Marphysa tibiana, l'ourtalis. Contributions to the Fauna of the Gulf Stream at Great Depths. Bulletin of the Muscum of Comparative Zoülogy, Yol. I., 1863-1869, p. 108.

$$
\text { Tief. } 27, \text { Fig. 1-13. }
$$

Cuprea iridescens, in parte antica valde convexa, in parte postrema depressa, segmentis 174. Lobus eephaliens lioculatus bilobus; tentaculorum longissimorum gracilinm lacvium impar ad scrmentum 2tum patens, media triente illo breviora, externa dimidiam horum longitudinem vix aérumtia. Subtentacula non partita.

seymentum bnceale sequentia 4 longitudine acquans a proximo brevissimo in lateribus non seinnetum; cirri tentaenlares graciles laces marginem lobi ceppalici anticum attingentes. Segmenta pinnigeria exceptis prioribus nonies latiora quam longiora. Pimne breves; setae flavae superioris fisciculi capillares et scalpratac numerosac, inferioris fisciculi parum crassiores faleigerne filce brevi apice bidentato limbata; aciculae crassae llavidae in pinnis anterioribus binae subrectne, in posterioribus quinae, quarum superiores rectae vel apice incurvo, inferior oblique collocata apice currato rel brevissime bidentato obtecto; fisciculus acicularum inclusus. Cirri dorsales simplices filiformes; cirri ventrales in pinnis anterioribus in basi valde tumida brevissimi, in posticis elongati subulati. Branchiae in pinuis anterioribus 5 et posticis 30 desideratae, cirros dorsales excedentes dimidiam dorsi nusquan attingentes, in pinnis anticis sensim accescentes, maximae in pimm 33a incipientes in rhachicle longa radios 4 graciles gerentes.

Maxilline lucide cornene in marginibus nigrescentes, I procerne, II 8-9, III longa 10, IV cuenllatue $i-11, V$ et VI 1 ; laminae rentrales corneae breviter connatae, arca terminali albida acie ollicine trumeata elentata.

T'ubus comens subpellueidus vel cylindratus rectus vel undatus multiforis ostiis quandoque regulariter alteruatim dispositis laciniosis.

Fumlorte: 1. Off Havana, lepth 123 fms. (Sigsbee). 2. Off Havana, deptlı 175 fms. (Sigshee). 3. Xํ. 3. OIf Havana, depth $213-150$ fms. (Sigsluee). 4. No. 11, Lat, $22^{\circ} 09^{\prime} 30 \mathrm{~N}$., Long. $82^{\circ} 21^{\prime} 30^{\prime \prime} \mathrm{W}$. depth 242 fims. (Sigssuee). 5. No. 16, near Havana, depth 292 fins. 6. No. 20, Lat. $23^{\circ} 25^{\prime}$ N., Lomg. $83^{\circ} 11^{\prime} \mathrm{W}$., depth $220 \mathrm{fms}$.

Das eine mir vorliegende vollständig erhaltene Exemplar, nach velchem die obige Beschreibung entworfen wurde, war bei 174 Segmenten $77 \mathrm{~mm}$. lang. Ein anderes zeichnete sich dadurch aus, dass anf dem hellen Grunde des Vorderkörpers und der Fïhler unregehmässige rothbraune Flecke standen.

Pourtalès (a. a. O.) hat die charakteristisch gestalteten, iibrigens vielfach in der Forın wechselnden Röhren dieser von ihn nicht ausreichend gekennzeichneten Eunicee kenntlich beschrieben und die Angabe gemacht, dass auf sie die Lamark'sche Polypen-Gattung Tibiana errichtet sei. ${ }^{1}$ Daher ist die Artbezeichnung gewiihlt.

1 Cfr. J. Lamouroux, Exposition méthodique des genres de l'oritre des Polypiers, Paris, 1821, 40, Tg. 16, 'Tah. 69, Fig. I. 


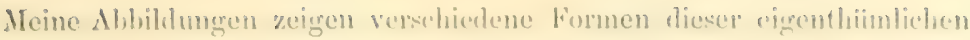
Röhren, und machen eine weitere Bexchreibung iiberdiissig. Nath Pontales sind die Röhren nicht ansewachsen und stecken vermuthlich mit dem diinneren Endstioke in Schlamm.

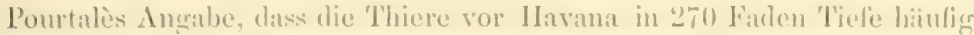
seien, ist nach den uben zusammengestellten Fundorten zu erweitern. I)anach

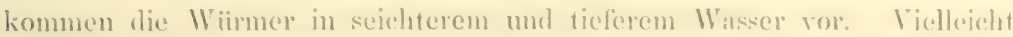
Weehselt die Gestaltung der liöhren mit der Besehafienheit des Wohnortes. Zu dieser Vermuthung veranlasst mich eine lïbhe, welche zusammen mit 2 angenscheinlich dazu gehörigen Thieren in cinem Glase verwahrt war. Der Fundort ist S. W. of 'l'ortugas, cast No. 3, Jan. 1S. IEG9, depth 60 fins. I)ie gelbbriumliche hornartig durehscheinente Röhre ist umregrelnässigg grekriimmt, und erinnert darin an die gewundenen Röhren der E. libirun, weicht num aber von diesen dadurch ab, dass sie auf ihrer Aussenfliche mit mamicrlittigen Fremdkörpern, kleinen Steinchen, Muschelscherben 11. a. weitliufig beklebt ist. Die zu dieser Röhre offenbar gehörigen Wiimer, beide am hinteren Körperende verstïmmelt, weichen nur dirin von der gegebenen Beschreibung ab, dass das die Fühlerciren tragende Segment ringsum von dem voranstehenden getrennt ist, dass die Kiemen am 3ten Ruder dreifarlig begimnen, die Zahl der Kiemenfaiden bis anf 6 steigt und dass die Zahlen fiir die Ziihnchen der Kieferstïcke etwas abweichen. Das alles sind Bildumgen, welche zu einer specifischen Sonderung eine Berechtigung nicht geben. So ist das Wahrscheinlichere, dass diese aus einer geringen Tiefe stammende Röhre ihre Eigenthümlichkeit den Besonderheiten der Lokalität verdankt, während auf gleichmässig schlammigem Grund die Viurmer zur Ilerstellung ihrer Röhren ausschliesslich auf das von ihnen bereitete Secret angewiesen sind.

In Grube's Zusammenstellung grehört die Art, welche ich mit keiner beschriebenen identificieren kann, zu Leodice C. a. ${ }^{1}$

Eunice fucata, n. sp.

$$
\text { Taf. 25, Fig. S-PO. }
$$

Longa postice attenuata, segnentis plus 250 , in parte anteriore rubro vittata, branchiis itidem maculatis, in parte postica transverse rugata. Lobns cephalicus bioculatus bilobus. Tentacnlorum simplicium brerium impar mediis parum, externis duplo longius usque ad segmentum tum patens. Subtentacula haul partita. Seguentum buccale a proxime plus quam dimidio breriore non nisi 
in thetan sejunctum; cirri tentaculures simpliees lobi ecphalici marginem anteriorem peno atrmentus

Sinmenta pinnigern, exepptis prioribus 6 , quater vel quinquies lation quam longiora, anteriora

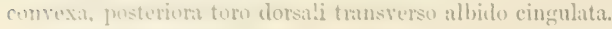

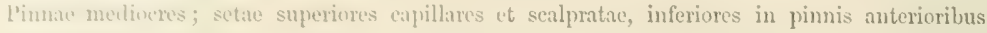
fuldigrae lalce bi- vel tridente hrevi, in pinnis posticis erassa paliformes apice recto vel paullum curvato; aciculate pimarum anteriorum 3 , pimarum posteriorum practer eas 1 oblique collocata apice curvato. Cirri lorsales simplices pimam haud multum superantes, cirri ventules tumiduli cum pima plerum que longriore contluentes. Branehiae in pimis anterioribus 4 et posticis $70-80$ desideratue; maxima plerumpuo in rhachide cirro dorsali longiore radios fraciles apicem versus minores, rurius rulios furcatos red racemosos complures breviores gerentes al dimidium dorsi patentes; ruliorum mumerus in branchia prima fere completus, postico versus sensim decrescens, per Inngam pimnam postienrum seriem singulus. Maxillae I curvatae, II 4-5, III 6, IV 3-8, Y et VI utrimpue 1 ; laminae rentriles acio edenticulata.

Ifah. : 1. Tortugus. 2. Tortugis Chamel between East and Midille Key, depth 5 to 7 fms.

Diese ans seichtem Wrasser stammenden grossen Würmer haben eine fast verloschene im Lehen wahrscheinlich viel stärker heraustretende rothbrame Querbindermmg auf der Riiekenfliche der vorderen Segmente (Fig. 8), wïhrend die hinteren Segmente in auffillender Weise durch einen weisslichen lingwulst ausgezeichnet sind (Fig. 9), dessen auch bei anderen Arten verzeichnetes Vorkommen und Entstehung noch nicht erkliirt ist. Die vorliegenden Exemplare sind oft zerbrochen oder regeneriert, ein Thier von $190 \mathrm{~mm}$. Linge hatte 250 Segmente, ein anderes, welehes $195 \mathrm{~mm}$. ling und vorn ohne die Ruder 5mm. breit war, hatte 246 Segmente. - Von den Eigenthümlichkeiten der Ruderbildung hebe ich besonders hervor, dass in den hinteren Rudem an Stelle der zusammengesetzten Borsten des unteren Bündels, wie sie den vorderen Rudern zukommen, einfache starke dunkelfarbige, stïtznadeliihnliche Borsten hervorragen, welche entweder eine einfache stumpf abgerundete oder schwach winklig gekrümmte Spitze besitzen (Fig. 15, 16). Mir ist eine ähnliche Bildung, ein Ersatz der zusammengesetzten durch einfache Borsten bei einer Eunice nicht bekaunt wohl aber, dass bei anderen Gattungen (Onuphis, Lumbriconereis) analoge Erscheinungen auftreten.

Die Kiemen zeigen gleichfalls besondere, aber gleichsam ausnahmsweis und vereinzelt auftretende Bildungen; während sie wie in einem Falle, der als Regel aufgestellt werden kann, am 5ten Ruder zuerst und gleich mit 7 Kiemenstrahlen erscheinen, am 9ten Ruder schon 12 Zinken besitzen, so eine kurze Strecke verharren, wobei die einzelnen Zinken, kïrzer als der Stamm, von unten nach oben an Länge abnehmen, damn aber allmählich an Zinkenzahl verlieren und ïber eine grosse Reihe nur durch einen Kiementrahl vertreten werden, treten gelegentlich reicher entwickelte Kiemen auf, 


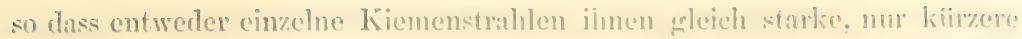
Nobenzinken erhalten (Fig. 12) oder dass von dem Hamptstamm wenige fist gleich dielie Nebenzweige, Wahrselseinlich umgewandelte priniire Kiemenstrablen, abgehen, welehe dimn die diuneren Kiemenstrahlen kammlaimigr angeordnet tragen (lïg. 1:i); eine solehe Kiene wirel litst. Duxchföming und fiihrt cine fiir die Euniceen ungewihuliche Bihlung vor. Doch halbe

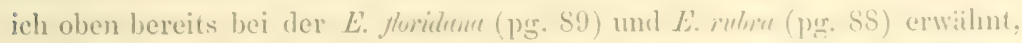
dass hied ansuahmweise eine einzelne Kieme reichere Fatenluildung erhiilt und dadurch das hier hiadigere Vorkommen anfiveist.

Die Art gehört in der Grube'schen Zu*ammenstellung in die Gruppe Ieodice II C. a. 2; doch kamn ich sie mit keiner bis jetzt beschriebenen identificieren.

Eunice conglomerans, n. sp.

$$
\text { Tief. @3, Fig. 1-9; Tue. O4, Fig. 1-4. }
$$

In parte anteriore ralde convexa, postice rersus depressa aequaliter attenuata semment is pins 300 , brunnea cirris branchiisque mediae posticaeque corporis partis nigrescentibus. Lobus cephalicus bioculatus bilobus. Tentaculorm lacrim lobum cephalicum vix vel parum exectentium impar mediis et externis paullum longius. Subtentaculin non partital.

Segmentum buccale a proximo brevissimo non nisi in dorso scimetum longitudine proxima t-5 aequans antice versus paene inflatum; cirri tentaculares simplices brevissimi lobum ecphalicum non attingentes.

Segmenta pinnigera brevissima, anteriora, exceptis prioribus circa \&, et media duodecies, posteriora septies latiora quam longioni. - Pimae conicale; setae flavae superioris fasciculi pinnarum anteriorum capillares late limbatne permultae, pimarum mediarum et posticurum capillares paucae, praeter ens scalpratie multne tenues pectinatne; fasciculi inferioris falcigerae crnssiores pinnarum anteriorum permultae falce anguste elongata limbata ciliata alice minuta bidente, pinnarum posticarum paucae flavidae falce crassa brevi limbata apice fortiter bílente: aciculae pinnarım anticarum singulae, sequentium binae, omnium nigra apice incursa rix dentata; acicularum inclusarum fasciculus numerosus. Cirri dorsules conico-elongati dimidiam segmenti non attingentes, rentrales in piunis anticis tumiduli pima ipsa breviores, in piunis posticis magis magisque elongati filiformes pinuam longitudiue, cirros dorsales crnssitudine superantes. Branchiae in pinnis 23-27 auterioribus et 10-12 posticis uullae, a pinna 50a quadrifilosae procerae, masimae ad dimidiam dorsi patentes, in rhachide brevi radios $5-6$ graciles haud aequales longissimos cirro dorsali longiores gerentes.

Segmentum anale praecedentibus longius inerassatum cirros 2 gerens. Inaillae nigrae,

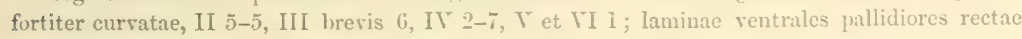
area terminali albida acie integra fere rectr.

Tubi paprracei lamellosi albidi multifurie formati et contorti plerumque congmentati, ostiis singulis.

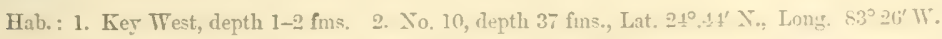

Dieser Wurm ist nach dem mir vorliegenden Materiale ein Berrolner des flachen Wassers und lebt augenscheinlich an seinen Wohnstätten gesellschaft- 
lich, dis die von ihm gehauten, sehr charakteristischen Röhren von demselben Fumblorte in griisserer Nenge, und meist mehtich mit einander verschlungen und rerklebt vorliegren. Diese Rïhren erimnern bei oberllächlicher Betrachtumy an dhejenigen, welche die in tieferem Wasser wohnende abweichend gestaltete F. floridemu (Pourt.) verfertigt; die zur. Herstellung verwendete offenbar dureh eine Drisenausscheidumg erzengte Masse der Röhrenwandung hat die gleiche weisse oder gelbliche Firbung, eine ähnliche papierartige Consistenz und eine blittige Structur; aber es fehlen den Röhren der $E$. conflomernes die vielfachen seitlichen Oefïnungen, welche den Röhren der E. floridenu zukommen. Lïst man aus dem Gewirr der oft sehr stark gewundenen umd verschlungenen Röhren eine einzehne heraus, so erhält man viel. fach ein Bild abnlich dem, welches ich auf'Tit. 23 Fig. 2 wiedergegeben habe; am seitlichen Umfinge der Rïhrenwand sitzen entweder flach auf oder auch auf dem Ende kurzer Abzweignngen rundliche oder ovale, selbst schildförmig erscheinende Stellen, welche durch derberes und glatteres Aussehen von der iibrigen Oberfläche der Röhre sich unterscheiden, und in denen die Röhrenwand meist rerdickt erscheint. Neine anfünglich auftanchende Meinung, dass an diesen Stellen seitliche Oeffnungen, denen an den Röhren der E. floridana und tibum entsprechend, aber verklebt vorhanden seien, musste ich fallen lassen; bei Versuchen, an diesen Stellen die Röhre zu öffnen, geschah das immer nur mit Zerreissen dieser Wandstrecken; eher ist es möglich, dass diese Stellen die Orte bezeichnen, an welchen einmal eine terminale Oefinumg der Rühre bestanden hat, welche in besonderer Weise verschlossen wurde, als der W urm über diese endständige Oeftnung hinaus die Röhre verliangerte und dabei mehr oder minder von der zuerst innegehaltenen Richtung abwich. Dass man R̈̈hren von ungleicher Wandstärke findet, ist wohl auf deren Benutzungsdauer zuriekzuführen. Wie sehr die Thiere ihre Bauten den Umständen auzupassen verstehen, zeigt der in Fig. 3 Taf. 23 abgebildete Fall. Der Wurm hat hier seinen Wohnsitz in der leeren Schale einer Schnecke aufgeschlagen, diese aber auf der äusseren Fläche fast ganz mit der Substanz, aus welcher die Röhre gefertigt wird, iiberzogen, desgleichen die Schalenmiindung mit einer daraus gebildeten diinnen Decke zum grössten Theile iiberspannt und nur an einer Stelle eine Oeffnung gelassen, deren Ründer umregelmässig zipfelförmig zı einer kurzen Röhrenmündung erhoben waren, aus welcher das Thier mit dem Vorderkürper hervorragt.

Ueher die Terwandtschaftsbeziehungen dieser Art besteht wohl kein Zweifel; sie gehört in den Kreis der E. siciliensis, Gr. Mit dieser theilt sie 


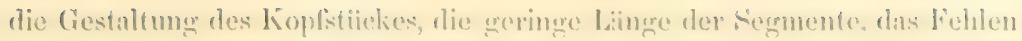

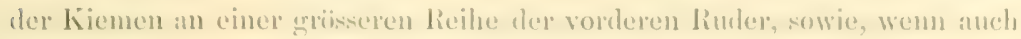
nicht statk ansegespoehen, eine Achulichkeit in der Gestaltumg der lang

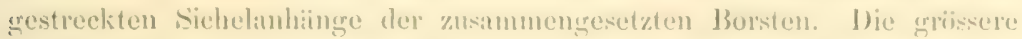
Kahl der Kiementialen, sowie die abweichende Bildumer im (ober- nul Unterkiefor sind hauphäichliche unterscheidende Kenuzeichen. Die Art grehört zu Cirube's Leorlice, 11 C. b.

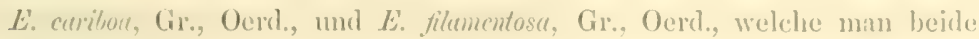
zum Vergleich heranzichen kïnnte, da sie, Bewohner des Antillenmeeres. an einer grösseren lieilıe vorderer Ruder keine Kiemen tragen, unterscheiden sich beide von der $L$. conglomeruns durch weit geringere Soumentzahl ; bei beiden bleibt die 'anhl der Kiemenfiden geringer und erimert an das Verhalten der $E$. siciliensis, keine von beiden besitzt die charakteristich verlïngerten Bauchcirren der $E$. conglomerus; bei $L$. curibou sollen die Bauchciren sogar ganz als selbstïndige Ruderanhänge schwinden.

\section{MARPHYSA, QTRFgs.}

\section{Marphysa Bellii, Aun. \& M.-Evw.}

$$
\text { Taf. } 2 S, \text { Fig. } 1-8 \text {. }
$$

Der Wurm, auf welchen ich die Bezeichnung in Anwendung bringe, hat mir keinerlei Kenmeichen geboten, mit welchem ich einen Unterschied von den europäischen Formen, wie sie an der französischen Kiiste und im Mittelneer (Marenzeller) vorkommen, hïte feststellen lï̈nen. Da ich aber diese Vergleichung nur an der Hand der vorliegenden Beschreibungen ${ }^{1}$ machen kamm, halte ich es für geboten, Abbildungen des 'Thieres zu geben, da solehe ausserdem von dieser Art nur umzureichend vorhanden sind und eine kmre Beschreibung himzuzufügen; damit Material zu liefem zu einer Kritik meiner jetzigen Ansicht, dass Marplysa Bellii eine der wenigen Arten ist. welche das Mittelmeer und die atlautischen europäischen Küsten mit der Fauma von Florida remein haben.

Das einzige mir vorliegende Exemplar, welchem das hintero Kürperende und das Endstiick des umparen Fühlers fehlt, ist mit 72 Segmenten 2 Smm.

1 Audouin u. M.-Edvards, Classification des Anuelés, Annales d. sc. natur., Ser. I, T. 27, 131. 11 ; T. 28, рg. 233 .

Quatrefages, Histoire naturelle des Annelés, T. I, 19. 333.

v. Marenseller, Zur Kenntniss der adriatischen Anneliden, Sitzber. U. Kais, Ak. der Wis., I Abth. Jhrge. 1874, Aprilheft, pag. 59. 
lang. vorn 3mm., in der Kiemenregion 4 mm. und hinten 2,5mm. breit; in den vorderen semmenten drehrund, nach hinten abgeplattet; aufallend hell röthlichlnan gefirbt mit geringem Glinze, die dicht verflochtenen Kiemen wie dic iibrigen Anhänge weiss. Der hoch gewölbte am vorderen Umfange ganzandige Koptlappen ist nicht viel breiter als lang; angenlos; von den ungegliederten Tentakeln, welche iiber den Kopflappen hinausragen, reichen die mittleren, welche etwas lïnger als die ïusseren sind, nach hinten gelegt bis an das the Segment. Fon den nackten Bucealsegmenten ist das erste linnger als dis zweite. Unter den Rudertragenden Segmenten sind die vorderen viermal, die Kiementragenden zehmmal, die dann folgenden achtmal breiter als lang. Die vorderen liuder sind schwach kegelförmig, die hinteren von vorn nach linten zusammengerliuckt; die vorderen haben eine hintere dreieckige Lippe, welche etwa vom 30ten Ruder ab verschwintet. - Wegen der Borstenfurmen verweise ich auf die Abbildungen. - Die Riickencirren sind einfiche Fäden, die der hinteren Ruder länger als die der vorderen, fast so lang als die halbe Segmentbreite; die kegelförmigren Baucheirren ragen iiber die Ruderspitze hinaus, sind an den hinteren Rudern von vom nach hinten abgeplattet. - Es sind 14 Kiemenpaare vorhanden, von denen das erste am 15ten Ruder steht; die Kiemen haben lange Füden, mit denen sie iiber die Mitte des Riickens hinüberragen, mit denen der Gegenseite sich beriihren und die Riickenitiiche völlig bedecken. Hier ist gregreniber den europäischen Arten ein Unterschied zu verzeichnen; dem bei diesen treten nach den iibereinstimmenden Angaben der französischen Autoren, welche v. Harenzeller für die adriatische Form bestätigt, die Kiemen bereits am 12ten Ruder auf, und ist die Zahl der Kiemenpaare, 1525, grösser; allein auf die Unterschierle dieser Zahlenverhültnisse lege ich ebensomenig Gewicht wie auf die abweichenden Angaben über die Zahl der Kiemenfiden, ron denen die adriatische Form 10-1\%, die atlantische 6-10 hatte.

Die Beschreibung, welche v. Marenzeller vom Kieferapparat gegeben hat, passt zu dem, was ich finde: die Trïiger sind lang fast parallelrandig, die Zangen lang hakenförmig, die Zühne haben links 6 , rechts 7 , die unpaare Platte 7 , die folgenden paarigen links 7 , rechts 9 Sïgezïhne, davor jederseits ein einfaches Plättchen. Der Unterkiefer stimmt mit dem grossen weissen am Aussenrande in einen spitzen Zahn ausgezogenen Endstiick gut zu v. Marenzeller's Beschreibung. 


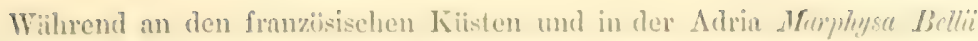
der Strandrecrion angehört, ist sie hier in erheblicher 'l'iefe grefunden.

\section{Marphysa Parishi (B.Anv).}

W. Baird, Remarks on Sereral Genera of Annclids belonging to the Group Eunicen, Journal of the Proceedings of the Limean Society, Zülogy, Vol. X.

In der Sammlung des Museum of Comparative 'Loülogy in Cambridge (Mass.) steht cine bei Key West, Florida, gefingene nicht gut erhaltene Marphysa, die verstummelt wie sie ist bei $130 \mathrm{~mm}$. Liinge noch 251 Segmente besitzt; diese angenlose Form, bei welcher die erste Kieme an $28 t e n$ lunder steht, grehürt vielleicht zu der von Baird unter obigem Namen beschriebenen ron Brasilien stammenden Art.

\section{Marphysa sanguinea (Most.).}

Mit diesem Namen bezeichne ich eine bei Hayti gesammelte dem Museum of Comparative Zoölogry in Cambridge gehörende, und eine andere auf Tortugas gesammelte Eunicide, da ich keinerlei Merkmale an ilnen finde, durch welche sie sich von der europäischen Ifar) $)$ hysa sanguinea unterschieden. Leidy ${ }^{1}$ hat diese Art an der Küste ron Rhode-Island und NewJersey nachgewiesen und Webster, ${ }^{2}$ dem wir interessante Mittheilungen über die Jugendzustände der Art verdanken, dargethan, dass Quatrefages mit Unrecht für die von Leidy beschriebene Form einen neuen Artnamen ( $M$. Leidii) geschaffen hat. Durch Webster's Mitheilungen kemen wir die weite Verbreitung dieser Art an der Ostlüiste Nordamerikas; meine Mittheilung soll auf die nach Siden ausgedehnte Verbreitung aufmerksam machen. Nordwärts scheint der Verbreitungsbezirk an den amerikanischen wie europäischen Küsten ein beschränkter zu sein.

1 F. Leidy, Marine Invertebrate Fauna of the Coasts of Rhode Island and Nerr Jersey, Journ. Acad. Nat. Science, Philadelphia II., Vol. III., p. $14 \bar{i}$.

${ }^{2} H$. E. Wcbster, On the Amnelida Chaetopoda of the Virginia Coast, Transactions of the Albany Institute, Vol. LX., Separat., p. 36. 


\section{NICIDION (KiNBERG).}

\section{Nicidion brevis, 11. sp.}

$$
\text { Tuf. } 2 S, F i g .0-1 \text {; ; T'if. } 29, \text { Fig. 1, 2. }
$$

Brevis, valde convexa, post lobum epphalicum attenuata; antice fulva postice grisea, segmentis $1:-7$.

T.obus cephalicus brevis paullum bilobatus, bioculatus; tentaculorum brevium crassorum fere nequalium indistincte articulatorum lobum cephalicum parum superantium impar segmentum fum non attingens; subtentacula non partita.

Segmentum bnecrle lum altero in dorso tantum scjuncto fere duplo longins; cirri tentaculares hrevissimi simplices, marginem anticum segmenti $1 \mathrm{mi}$ non attiugentes. Segmenta pinnigera octo anteriora octies, proxima 15ies, postice versus 12 ies latiora quam longiora.

Piunac mediocres, anteriores obtusne labio postico rotundato, posticae inde ab segmento circa 340 conice acutae, valde compressac. -

Setae superiores capillares tenerae simplices et scalpratae latae, inferiores falcigerae scopo terminali serrulato falce obtecta bidentata; aciculae pimnarum anteriorum circa 25 flavidae rectae, singulae, posteriorum nigrae, superior recti, inferior oblique collocata apice fortiter bidente. Cirri dorsales simplices pimnarum anteriorum paullum, posteriorum haud longiores quam pinnae; cirri ventrales pimarun anteriorum 7 simplices, conicae 8-28 basi tumida transversa compressa ayice crassiusculo pimnam superantes; posteriorum cum pimun connati brevissimi conici pimam superantes. IBranchino mullice - Cirri anales 2 breves.

Maxillae cornene plerumque pellucidine; fulcra lrevia postice acuminata; I longe hamatre, II utrimque 5; ceterae commatae margine libero edentulo supra et infra I et II usque aul fulcra protentac, III 4 , IV cucullatae nigro-notatae $3-1$, $\mathrm{V}$ laminae rotundatae albidae, VI posticae edentulie; lawina impar clorsalis transversa rufo-brumen in medio margine antico leniter incisa. Laminae rentrales pelluciclae postice angustatae antice dilatatae, in facie ventrali utrimque area concentrice striata margine fere recto edentato.

Fundort: hey West, 1-2 fus.

Fiir den Habitus dieser Art, deren einziges mir vorliegendes Exemplar bei 127 Segmenten $22 \mathrm{~mm}$. lang war, ist die Gestaltung der Ruder an den ungleichen Strecken des Kürpers das Wesentliche, besonders die queren Polster der Banchcirren des Sten bis 28ten Ruders und die starke etwa vom 34ten Segment an auftretende von vorn nach hinten gehende Compression der Ruder, die dadurch fast cristenartig werden.

Solche Bildung zeigt unter den Eunice-Arten die E. siciliensis, Gr., und da ist beachtenswerth, dass diese Art durch die geringe Ausbildung der erst in der hinteren Kirperhälfte auftretenden Kiemen sich anszeichnet; so gleichsam, wie ich ${ }^{1}$ bereits friher vermuthungsweise ausgesprochen hatte, den Uebergang zu den Kiemenlosen Arten macht, welche als Nicidion (Kbg.) zusanmengefasst werden.

1 Ehlers, Borstenwürmer a. a. O. pg. 366. 
Eine etwa anfauchende Vermuthung, die Nicidion-Arten mëchten junge Emiecen-Arten, ans der Ciruppe der l: sieilinxis, sein, bei welehen die Entwicklung der Kiemen noch nicht eingetreten, wird fiir diese $\Lambda$ rt leicht dureh die Betrachtung des Kielerappanates zuriickgewiesen. Die Art und Weise, in weleher die siggeplatten unter einander verbumben sind, so dass die Chitinanskleidung des Kiefersickes auf' den Rïndem der Nische, in weleher Zamge und Kahn liegen, einen scharfén und festen liand bildet, vor allem aber die Ausbilchug der bei keiner anderen Eunicide bis jetzt. beschriebenen dorsalen Medianplatte, welche am Eingange des Schlunclkopfes steht, lassen völlig abweisen, dass dies 'Thier wegren des Kiemenmangels als die Jugendform einer anderen Eunice-Art aulizufassen sei. — In dieser Hinsicht ist an der Aufstellumg der Gattung Nicidion, Kbg., Nichts auszusetzen.

Die von Kinberg beschriebenen Arten dieser Gattung stammen alle aus dem stillen Ocean; Armaner Ilansen ${ }^{1}$ hat eine Nicition incorlu aus der Bai von Rio de Janeïro angegeben, doch so unvollstïndig beschrieben und abgebildet, dass eine Wiedererkenuung nicht wohl möglich ist. — Das Vorkommen von Nicidion Arten an der Ostkiiste Amerikas ist num aber jedenfalls festgrestellt.

\section{PARAMARPHYSA，N. G.}

Differt a genere Marphysa branchiis deficientibus.

\section{Paramarphysa longula, n. sp.}

$$
\text { Tef. } \because 9, F i g .8-12 \text {. }
$$

Teres longissima in parte antica et postice versus parum attenuata, in parte anteriore rufobrunnea iricolor, in posteriore viridule grisea, segmentis plus 244.

Lobus cephalicus bilobus bioculatus, lnggior quam latior, segmenti bucealis $l^{\text {i }}$ longitudinem paullum superans; tentaculorum filiformium lobum cephalicum superantium impar usque ad segmentum 7 mum patens, mediis ad segmentum 5 um patentibus fere triente, externis duplo longius. Subtentacula trunsversa semipartita.

Segmentum buccale prius altero prorsus seiuncto mudo duplo fere longins. Secrmenta pimnigera anteriora decies, posteriora quater latiora quam longiora. I'innae anteriores labio postico brevi longiores quam posticae paullum prominentes simplices.

Setae fasciculi superioris simplices capillares, in pinnis posticis scalpratae latae; fasciculi inferioris falcigerae in pinnis anticis numerosae falce elongata recta bidentata obtecta, in pimis posteri-

1 Armaur Hransen, Recherches sur les Annélites recueillies par ... E. r. Beneiten . . . au Brésil et à la Plata. Jlémoires couronnés et mémoires rles sarants étrangers publ. par l'Acarlémie roy. des sciences de Belgique, t. XLIV. 1881, Extr. l'g. 8. 
oribus pancie filce itilem formata sed breviore. - Iciculite pinnarum anteriorum 33 rectae flavae, menliarum of posticarum nimize simgula reeta et oblique collocata bidentata.

Cirri dowsales filiform's breves, pinnarum anteriorum longiores segmenti proximi marginem anteriorem attingentes, fimal:um posticarum breviores pinnam rix superantes. Cirri rontrales pinnarmm anteriorum basi tumila conici jinnam excedentes, posteriormm breviors. - Branchiae nullixe.

Maxilline corneac, fulcra triangularia postico acuminata, I parum curvatae, II 5-5, III 6, IT" cucullatae nigro signatao $1-8, Y^{*} 1-1$. - Laminae ventrales rectao paullum connatae, areae concentrice striatne marsino antexiore angulato, edentato.

Funlort: Oll IIavana, depth 127 fms. (Sigsbee).

Die Charakteristik der Gattung, welche ich für diese cinzige Art errichte, ist damit gegeben, dass ich sic als cine kiemenlose Marphysa bezeichne; sie verhïlt sich zu dieser Gattung wie Nicidion (Kbg.) zu Eunice.

Das cinzige umegelmïssig gewundene Exemplar, nach welchem die rorausstehende Besehreibung entworfen ist, war mit 244 Segmenten $70 \mathrm{~mm}$. lang, vorn 1,5mm., hinten $1 \mathrm{~mm}$. breit.

Der Mangel an Kiemen kaun bei solcher Grösse nicht auf einen Jugendzustand des 'Thicres zuriickgeführt werden; ich hebe hier hervor, dass die in der Beschreibung erwähnte Lippe der Ruder auffallend reich an Blutgefässen ist; vielleicht ist damit ein Ersatz für fehlende Kiemen gegeben.

Vermuthlich gehört in diese Gattung die von Puntarenas in Costa Rica stammende Eunice quadrioculuta (Gro), da ilır Fühlercirren und Kiemen fehlen sollen; die Angaben, welche Grube ${ }^{1}$ darüber gemacht hat, beruhen aber nur auf einer Zeichnung Oerstedt's.

\section{LYSIDICE (SAV.).}

\section{Lysidice notata, n. sp.}

Taf. 30, Fig. 1-9.

Longa, parallela, subteres, concolor, segmentis 128 ; lobus cephalicus rotundatus integer, triente latior quam longior, segmentis buccalibus paullum longior; tentaculorum lobo cephalico breriorum impar externis paullum longius. Segrmenta buccalia inter se fere aequalia, proximis paullum longriora. Sergmenta pinnigera anteriora 6-7ies posteriora t-5ies latiora quam longiora. Pinnae simplices perbreves paullum prominulae, obtuse conicie; fasciculus dorsalis setis capillaribus anguste limbatis et scalpratis, in pimis anticis saepe desideratis, acicula recta, ventralis setis in scapo terminali falcigeris falce breviuscula bidente obtecta, acicula incurva apice dentato ołtecto ; cirrus dorsalis simplex filiformis pinnam vix aut paullum superaus, cirrus ventralis pinnam fere aequans in basi tumida conicus. Cirri anales 4 , dorsales filiformes ventralibus ter fere longiores. Maxillae corneae flavae excepto margine fulcrorum antico, forcipitis postico laminarum-

\footnotetext{
2 Grube, Annulata Oerstecliana a. a. 0. pag. 60.
} 


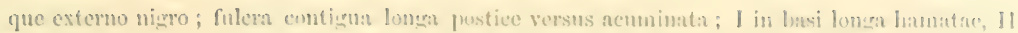

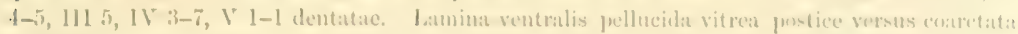

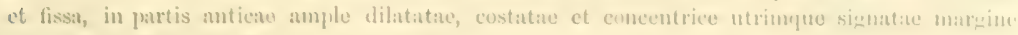
anteriore medio profunde incisa, in lateribus alte surrectis stria nigra lomginyust externit motata.

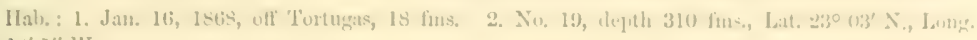
$83^{\circ} 1 \mathrm{U}^{\prime} \mathrm{J}^{\prime \prime} \mathrm{W}$.

Zwei mil vorliegende von den angeführten Fundorten, also aus schr ungleicher 'Tiefe stammende Exenplare, deren Kopfenden ich habe abbiklen lassen, zeigen eine Anzahl von Unterschieden, wegen deren man greneigt sein könnte, sie als specifisch gresondert anfzufissen, meines Erachtens jerloch mit Umecht. Das aus der 'Tiefe von 310 Faden gehobene Thier ist 35mm. lang. etwa $1,3 \mathrm{~mm}$. breit und hat $12 \mathrm{~S}$ Segmente; das aus dem Ylachwaser stammende 'Thier ist nicht völlig erhalten; am 84 Segmente abgerissen, ist es $22 \mathrm{~mm}$. lang und nicht ganz $1 \mathrm{~mm}$. breit; es wird danach vermuthlich auch im Besitz aller Segmente kleiner als das erste, und daher wahrscheinlich auch jiinger als dieses gewesen sein. Dieser kleinere $W^{r}$ urm ist fast braum und zumal in der vorderen Körperstrecke dunkler gefïht als der andere, welcher farblos weiss ist; mahe liegt es, diesen Unterschied auf den ungleichen Wohnsitz beider Thiere zurückzuführen. Gleich greformst ist bei beiden der Kopflappen, dessen Vorderrand nicht eingeschnitten ist; dass an ilım die Fühler ungleich gross erscheinen, möchte ich eincm ungleichen Contractionszustande zuschreiben; darauf ist aber nicht zurïckzuführen, dass das kleinere Exemplar' aus dem. Flachwasser kleine runde, das aus der 'Tiefe stammende grössere und schwach halbmondförmige Augrenflecke besitzt. Diese Augenform ist ja als unterscheidender Artcharakter verwendet; sollte dieser Unterschied, dem ich eine solche Bedeutung hier nicht beizulegen rermag, in diesem Falle auf den Einfluss des ungleichen Wohnsitzes zurückgehen?

Was die Borsten betrifft, so bemerke ich, dass ich die meisselförmigen Borsten in dem grösseren Exemplare rereinzelt schon im 3ten Ruder gesehen habe, dass sie aber regelmässig nur in den hinteren Rudern zu finden sind. Ich hebe schliesslich hervor, dass die Stuitznadeln in den Rudern der kleineren Form gelblich, in denen der grösseren Form mit Ausnahme derjenigen der beiden ersten Ruder dunkelbram, fast schwarz sind, in der Form und Lage aber übereinstimmen; auch darauf hat man, wie zuletzt noch Claparède ${ }^{1}$ hervorhebt, Gewicht legen wollen; sind die beiden Thiere, welche ich vor mir habe, ungleich alt, so diufte der Mangel oder

1 Claparède, Les Annélides du Golfe de Naples, nag. 144. 
die stirkere Anhinutung des Pigmentes in den Stiitznadeln wohl nur einen Altirsunterschied ausdriicken.

Wenn ich diese Unterschiede der beiden 'Thiere hervorhebe, so scheinen sie mir von keinem Belang zu sein, gegenïber den ïbrigen Punkten, in denen die Kïrpergestaltung beider iibercinstimmt, ganz besonders gegeniiber der Uebereinstimmung in der Form der Kiefer. Diese diurfte aber fïr die sonst, leider nur oft ungeniigend, beschriebenen Arten der Gattung Lysidice ein sicheres Unterseheidungsmerkmal abgeben. Der Oberkieferapparat mit seiner fahlen Fïrbung, welche nur an den Rändern einzelner Kieferstücke durch tief schwarze Firbumg verdrängt wird, und in welchem die linksseitige paarige Sigeplatte in einen lingen schmalen Rimd ausliiuft, wie das Fig. 8, Taf. 30 zeigt, in welcher die Stiicke dislociert sind, ist noch nicht so charakteristisch als der fist glasartig durchscheinende Unterkiefer, dessen dorsale Flïche mit longitudinalen Rippen besetzt ist, deren Ausläufer den Vorderrand jederseits wie gesiigt erscheinen lassen, wïhrend die ventrale Fläche die oft auftretende concentrische Zeichnung zeigt, aber besonders gekennzeichnet ist und kemmeichnet durch einen tiefsehwarzen, jederseits am Seitenrande lings verlaufenden Streifen.

Mit den Arten, welche Grube ${ }^{1}$ in seiner Zusammenstellung aufzühlt, kamn ich die Art nicht vereinigen; doch ist allerdings die Beschreibung vieler derselben füir eine Identificierung ganz unzureichend; aus dem hier behandelten Faunengebiete ist keine Lysidice bis jetzt beschrieben ; mit der von Verrill ${ }^{2}$ beschriebenen Lysidice americana fällt meine Art nicht zusammen, da diese Riickencirren hat, welche - im Leben - länger als die Breite des Körpers sind, und an der Basis einen kleinen Lappen tragen.

\section{LUMBRICONEREIS (BLV.).}

$\mathrm{Zu}$ den zahlreichen beschriebenen Arten dieser gut begrenzten Gattung fiige ich drei neue hinzu, von denen die eine vielleicht mit einer oder der anderen bereits beschriebenen zusammenfällt. Bei dem meist so gleichförmigen Habitus dieser Thicre lassen sich schwer leicht zu handhabende Kennzeichen aufstellen. Grube ${ }^{3}$ hat zuletzt auf die Form des Kopflappens

\footnotetext{
1 Dericht über die Thätigkeit der naturwissenschaft1. Section der schlesischen Gesellschaft im Jahre $187 \%$, pag. 61 .

3 Verrill, Report on the Condition of the Sea-Fisheries in 1871 and 1872 , Washington, 1873, $8^{\circ}$, 1. : :is.

3 Grube, in Bericht über die Thätigkeit der naturwiss. Section der schlesisch. Gesellschaft im Jahre 1878, pag. 40.
} 
Gewicht gelegt und dic Burstenformen selhst. fiir die (irmprierung der Arten verwendet. Der Werth atueh iles letzteren Kenmzoichens bleibt noch zn priiten; vielleicht giebt die Form des Unterkielers sute Merkmale ab); leider ist dieselbe in den wenigsten Besehreibumen herickisichtigt.

\section{Lumbriconereis floridana, n. sp.}

$$
\text { T'if. SO, Fig. 10-1.). }
$$

Brevis vermiformis, postice magis quam antice attenuatia, teretiuscule, secmentis plus 110 . Lolus cephaliens conice-ovatus, nulus, coecus; triente fere longior quam latior; longituding scymentr proxima 4 nex̧unus; tori buceales trausversi.

Segmenta buecalia inter se et emm proxinsis longitudine fere acpualia ; procesus oralis latu: sulco meliano et laterali singulo exaratus. Segmenta pimngera t-ijes lation quan longiona. l'imane postice versus aceresecutes labio digitiformi postico, intico tuberculiformi.

Setae capillares acutae infra apicem late limbatae, in pimnis posticis desideratac; situe compositae obtusac articulo terminali brevi dentato acie lenticulata simul cum seapo limlato in pinnis anticis, in earum loco in pinnis mediis et posticis setae simplices apice hamato acie dentata limbatac.

Maxillae brumneo nigrescentes; fulcra duplo fere longiora quam latiora; I loure hamatae, II 1-1, III 2-2, IV I-1, lamine edentatae anteriores oblongae, posteriores elongatice angustie. Laminae ventrales albidae postice aequaliter attenuatne parum divergentes, in fucie dorsali angulatin signatac, in partis liberae facie rentrali semilunari concentrice suleatae acic fere rectit integra in meliana parte oblique truncata, angulo externo brunueo maculatac.

Funlort : Key West, 7 fms.

Ein völlig erhaltenes Exemplar von 110 Segmenten war 25mm. lang, $1,3 \mathrm{~mm}$. dick.

Fs liegt nahe, in dieser Art die Lumbriconereis Junumi, Gr. ${ }^{1}$ (= Brasiliensis, Kbgr.), von Rio de Janeïro zu vermuthen; aus der kurzen Kinberg's schen ${ }^{2}$ Diagnose geht aber hervor, dass bei dieser Art das erste Buccaliegment länger als das zreite ist. - L. ocemica, Kbg., ${ }^{3}$ ron der La Plata Mündumg, die in den Verlültnissen des Koplappens und der Buccalsegmente der L. floridana fast gleich kommt, scheint nur Haarborsten zu besitzen. - L. temix; Verr., ${ }^{4}$ hat nach der Beschreibung andere Borsten als $L$. foriduna.

\section{Lumbriconereis bidens, n. sp.}

$$
\text { Taf. } 31, F \ddot{i} . \tilde{\gamma}-1 \% \text {. }
$$

Longa rermiformis, fere aequalis, segmentis plus $8 t$, pallile brunnea sub pimnis posticis nigromaculata. Lobus cephaliens ovatus, segmenta buccalia longitudine frarum supreruns; tori buc-

1 Grube, Bericht, 1878 , a. a. 0. pg. 47.

* Kinberg, Aumulata nora, a. a. O. pg. 570 .

3 Kinterg, a. a. 0.

4 Verrill, Invertehrate Animals of Tineyard Sound, Feport on the Condition of the Sea-Fisheries, Pt. I., Wishington, 1873, p. 594. 
cules parum prominentes. Segmenta bucealia longitudine inter so et proximis fero aequalia; procesus omlis segmenti secuncli sexies suleatus.

Sumbenta pimnigera anteriora 5-bies, postica duplo latiora quam longiora. Pinnae conicae anteriores loreves, pusteriores longiores; labium posticum anteriorm pimnam vix superans, posticarum filifurme fere elongatum pinnam sed non setarum fasciculum superaus.

Sutue eapillares late limbatae, in pinnis posticis desileratre; falcigerae scapo et falce minute bidentato late limbato in pimnis anticis, in posticis simplices obtusie hamatae, acie serrulatae, lato limbo obtectze; acicula 4 styliformes; fisciculus acicularum tenerrimarum inclusus. Maxillae plerumque brunne-nigrae; fulcra triangularia longion quam lation; I breviter hamatwe, II angustae in acie albild nitilae 2, 111 edentatae, IV plemumque albidae edentatae, exteriores eilentatie singulae breves angustae. Laminae rentrales excepto angulo externo antico albae in parte anteriore comexae dilatatae, in facie ventrali semilunari concentrice striatac, acie oblique truncatal edentulia postice eruribus curvatis divergentes.

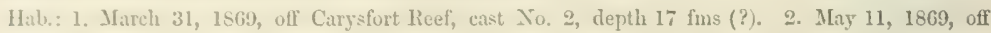

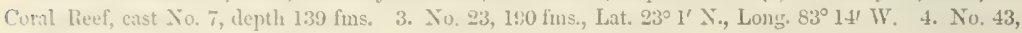
339 fms., Lat. $24^{\circ} 8^{\prime}$, Long. $82^{\circ} 5 l^{\prime}$.

Diese Art ist sehr kenntlich an der Kieferbildung, ebenso wohl durch die Gestaltung des Zahnes im Oberkiefer, wie durch den kreidigweissen Unterkicfer mit der breiten Endplatte und den stark gekriimmten, die Concavität einander zuwendenden hinteren Schenkeh. An einigen Exemplaren war die Nackengegend und die Rüickenflïche der ersten Segmente sehr stark buckelförmig aufgetrieben, der Kopflappen damn platt und längs gefurcht (Fig. T): es ist rohl Ausdruck eines nur zufällig fixierten Contractionszustandes, auf den ich für die Artbeschreibumg darum keinen Werth lege.

\section{Lumbriconereis robusta, n. sp.}

$$
\text { Tuf. 31, Fin. 1-6. }
$$

Longa crassiuscula, valde convexa, antice paullum attenuata, pallide ochracea pimis albidis, segmentis plus 182. Lobus cephalicus acuminate conicus, depressus, nudus, coecus; tori buceales parvi. - Segmenta buccalia Iongitudine inter se et ctm proximis fere aequalia, processus oralis quater sulcatus (!). Segmenta pimnigera brevissima antica 9ies media et postica 16ies latiora quam longiora, postica confiniis profunclioribus sejuncta.

Pinnae postice rersus accrescentes, quadrientem latitudinis segmenti aequantes, fere cylindratae, labio postico priorum subfoliaceo breviore, posticurum digitiformi pinnam sed non setas excedente.

Setae capillares longae flavae acutae infra apicem curvatae et late limbatae; praeter eas in pinnis posticis obtusae apice hamato in acie denticulatae, limbatae. Aciculae nigrae.

Maxillao brunneae partim nigrescentes; fulcra duplo longiora quam lationa; I longe harnatae, II 5-5, III et IV 1-1; laminae edentatae antica oblonga, postica elongata angusta; lamella accessoria iufra I et II. - Laminne ventrales in maxima parte connexae postice versus fere rectae paullisper divergentes; in partis liberae albidac facie rentrali semilunari concentrice striatae, acie oblique truncata integra.

Hiab. : 1. Otf American Shoal, Florila, 75 fms. 2. Sigsbee, off Havana, deptli 175 fms.

Völlig erhaltene Exemplare habe ich nicht gesehen; das grösste, in mehreren Fragmenten vorliegende, hatte bei $68 \mathrm{~mm}$ Länge und $5 \mathrm{~mm}$ grösster Breite 


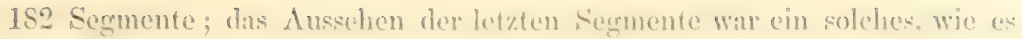

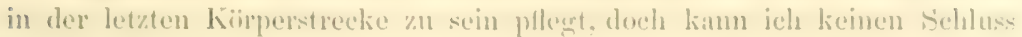
iiber die etwaige Lainge der fehlenden Kiirperstrecke wagen. Jïn zweites gleich breites Exemplar von 50 mm. Linge hatte 1020 segmente.

Im erwachsenen \%ustande ist oin sehr charakteristisches Kemmeichen in der autiallenden li iirze der Segmente gregrelsen; atuch der spitz kegrelfümige lioptlappen, der bei den beiden grosen Exemplaten dureh den etwas vorgedringten Kieferapparat aufwirts gehogen war, ist kemucichnend. Die Angabe mit welcher ich den die Mundölhung auf der V'entralflitehe von hinten begrrenzenden Vorsprung des zweiten l3uccalsegmentes als viomal liingsgefurcht bezeichnet habe, ist nicht ganz sicher. In allen Exemplaren war die Mundüffnug dureh den vordrüngeuden Kieferapparat stark ausgedehnt und dadurch die Furehenbildung des sehr in die lbreite verzogenen Fortsatzes undeutlich geworden. Diẹ Ruder der hinteren Segmente ragren ziemlich weit hervor, ihre Lippe entspringt ganz vou liande der Endfliche und ist schwach winklig nach riickwïrts gebogen; am vorderen Umfange der Fnulläche ist bisweilen eine kleine höckerförmige Auftreibung, fast wie die Anlage einer vorderen Lippe zu bemerken. Borsten- und Kieferform ertellen aus der Abbildung.

\section{NINOE (KBG.). Ninoe Kinbergi, n. sp. Tuf. 32, Fig. $1-9$}

Elougata teres, in parte anteriore pimis magis prominentibus dilatata, postice rersus parum attenuata, segmentis brevibus plus 95 ; pallida. Lobus cephaliens nuflus coecus conicus, in utraque parte sulco dorsali parum profundo exaratus, subtus fere planus, longitudine segmenta priora 4 fere aequans; tori nuchales distantes maculati segmentis buccalibus conditi; tori buccales vicini. Segmentorum bucealium nudorum supra aequalium prius subtus processu buceali alterius carinae fere instar elevato fissum.

Segmenta pinnigera brevia, anteriora sine pinnis decies, posteriora sexies latiora quan lungiora.

Pinnae conicae anteriores maiores, labium posticum superne vergens pinnarum priorum $G$ accrescens simplex, sequentium 20 in lacinias maximarum 5 teretes inaequales pinnam multum superantes divisum, primarum deinde sequentium decrescens obtnsa pima brevius; setro pinnarum anteriorum et laciniferarum plures quam posteriorum, lacinias superantes, brunneae simplices limbatae, aline elongatae acuminatae, aliae breviores obtusae apice minutisime bidentato; aciculae simplices 2 nigrae.

Ifaxillae plerumque nigrescentes; fulcra lorevia et lata; I longe hamatae, II sinistra 7 dextra 6, III 1-2, IV cucullatae granulosae 10-10 ; cxternae edentatae singulae elongatae gramulatae; laminae ventrales postice angustae styliformes fere connexae, antice una triangulariter dilatatae in acie oblique truncata lamella albida semiorata munitae.

Hals.: 1. No. 49, depth 118 fins, Lat. $28^{\circ} 51^{\prime} 30^{\prime \prime}$ X., Long. $89^{\circ} 01^{\prime} 30^{\prime \prime}$ W. 2. No. 43 , denth 339 fmse., Lat. $22^{\circ} 8^{\prime}$ N., Long. $82^{\circ} 51^{\prime} \mathrm{W}$. 
leh beneme die Art nach dem Autor dieser interessanten Gattung. Ob sie vielleicht mit einer der vier bis jetzt beschriebenen Arten zusammenfillt, bleibe spitterer Lintscheidung vorbehalten. Änoe chilensis, ${ }^{1}$ Köb., von Valparaiso hat 2 'Tentakel, oflenbar ausstiilpbare Nackenwiilste, 4 Lïngsfurchen auf dem Kopflappen und bis zu 11 Endfiden an der Ruderlippe; $\boldsymbol{N}$. brasilienvis, Kibg., und ocutulu, Kibg., ron Rio Janeiro, haben beide keine Tentakel wie die $\Lambda$. Tühbergi, vielleicht aber wie diese eingezogene Nackenwiilste, bei 1. In asilicusis trïgt der Kopflappen + Lïngsfurchen, bei $\mathrm{N}$. oculato Augen; dureh diese vielleicht wenig bedeutenden Merkmale weichen diese Arten von der N. Timberyi ab. - Bei Linoe nigripes ${ }^{2}$ (Verrill) aus Vineyard Sound ist schon am 3ten Ruder die Lippe zweispaltig und die Lippenfäden gehen bis zum 2Sten Ruder, auch scheinen die Borsten, "with hooks at the spatulate end" anders geformt als bei meiner $\Lambda$ rt zu sein.

Alle bis jetzt beschriebenen Arten stammen aus thachem Wasser.

Die 'Thiere sind offenbar, wie die Lumbriconereis, sehr leicht zerbrechlich, dem alle mir vorliegenden Exemplare sind verstiimmelt; auch Verrill scheint von der von ihm beschriebenen Art unverletzte Exemplare nicht erhalten zu haben. - Das grösste mir rorliegende Thier hatte bei $13 \mathrm{~mm}$. Lünge 95 Segmente.

Dass wir es in dieser Gattung mit einer besonderen Entwicklung der Lumbriconereis-Form zu thum haben, die sich darin kund giebt, dass, wie bei Lysarete, Halla u. a., der Rïckencirrus, so hier die ausgedehnte, schon bei eimzelnen Lumbriconereis-Arten gross werdende Ruderlippe in fingerförmige, fücherartig gestellte Lappen zerschlitzt, respiratorische Functionen iibernimmt, Kiemen bildet, die in ihrer Beschü̈nkung auf den vorderen Körpertheil analoge, vielleicht durch die mächtige Ausbildung des Kieferapparates berlingte Verhältnisse mit Eunice-Arten vorführt, bedarf keiner weiteren Ausführung.

Der Kopflappen mit den Nackenwiilsten, die eigenartig gestalteten Buccalsegmente, die Mundpolster und schliesslich der Kieferapparat zeigen ganz die bei Lumbricouereis vorhandenen Gestaltungen, auf die ich, da sie bis jetzt nicht beschrieben waren, die Aufmerksamkeit besonders zu lenken habe.

Alle bis jetzt beschriebenen Arten dieser Gattung sind amerikanisch.

1 Kinberg, Annulata nova, a. a. O. pag. 566.

2 Report on the Condition of the Sea-Fisheries of the South Coast of New England in 1871 and 1572, Washington, $1873,60, \mathrm{Yg} .593$. 


\section{LYSARE'L' (KNABERG).}

\section{Lysaroto brasilionsis, kixum.}

Kinberg, Annulata nova, Uefvers. af K. Vet.-1kad, Fürh. 1804, No. 10.

$$
\text { Tiej. S3, Fiig. 1-S. }
$$

Longissima acpundis palliclit, segmentis 490 .

Lohus cephaliens conicus, tentaculorum impar externis paullum longins, lohi cephalief marginen anteriorem vix attingens; oenli externi maiores quam iuterni juxta tentaculum impar enllocati. Segmenta bucealia mula aequalia ; tori buceales simplices; processus oralis semnenti 2i sulcatus; fossa nuchalis triaugularis segmentum tum attingens. Feconenta pinniqura anteriora 4 -5ies, media et postica ter lationa quam longiora et in dorso toro transverso convexa. I'innao inter se distantes sensim maiores dimidiam latitudinem segmenti nequantes, labio postico foliaceo elongato ; cirri dorsales, pimnis anterioribus 34 exceptis, in articulo basali longe foliacei linguaeformes; setae longae thavidae capillares limbatae; aciculac complures nigrac.

Maxillarum nigrarum fulera comexa triangularia autice in lateribus incisa, 1 forcipiformes sinistra in basi tri-dextra unidentata, II $6,1114,1 \mathrm{~V} 4, \mathrm{~V} 1$; laminarun edentatarum anterior brevis, posterior elongata forcipitis basim attingens.

Laminae ventrales maxillis longitudine aequales, postice attenuatae distantes, antice commexae in acie recta areac communis ventralis albidae semicircularis concentrice stritata profuncle incisae.

Hab. : Floricla, Mus. Cambr.

Lysarete brasilinsis wurde von Kinberg kurz, aber so zutreffend charakterisiert, dass ich nicht zweifle, anf die mir vorliegenden Wïmer die von ihm gegrebene Bezeichnung anwenden zu dïren. Bei dem Interesse, welches diese Euniciden-Form auf sich zieht, habe ich Kinbergs kurze Beschreibung mit Wort und Bild ergïnzen wollen.

Die hell weisslich-grauen Thiere erreichen eine ansehnliche Grösse; ein aus 490 Segmenten zusammengesetztes Thier war 685mm. lang. Darin sowie im Gesammthabitus erimern. sie durchaus an Hulle parthenopein, aber die Einzelziige ihrev Organisation lassen andere Verwandtschaftsrichtungen erkennen. Grube ${ }^{1}$ hat offenbar durch die grosse Uebereinstimunug des Habitus geleitet die Gattung Lysarete ummittelbar zu Halla (Costa) gestellt, ja selbst ausgesprochen, dass beide Gattungen zusammenfallen möehten. Dagegen spricht der Unterschied, welcher zwischen beiden im Kieferapparat besteht. Darauf hatte ich ${ }^{2}$ friher rerwiesen, als mir nur Kinbergs kurze Beschreibung vorlag, und eine nähere Beziehung der Lysarete zu Lumbriconereis betont. Grube ist darauf nicht eingregangen und hat meine Angabe

' Grube, Fortsetzung der Mittheilungen über Euniceen, Bericht, etc., Is;8, pag. 38.

2 Borstenwürmer, pag. 422 . 
von dem Yorhandensein plattenförmiger Kieferträger im Oberträger beanstmlet, die Kinberg weder im 'Text erwähnt noch bildlich dargestellt habe. Grube ist dabei entyangen, dass linberg die Gattung Lysarete in die von ihm aufgestellte Cruppe A der Euniciden aufgenommen hat, welche eben durch den gemeinsamen Besitz plattenförmiger Kiefertrïger ausgezeichnet ist.

Die von mir friiher angedentete Bezichung von Lysarete zu Lumbriconereis liisst sich num des weiteren dadurch stïtzen, dass das zweite der ruderlosen Segmente ganz wie bei Lumbriconereis mit einem Fortsatze, welcher die Ventraltliche des ersten Segmentes durchbricht, an den Mundeingang stösst; Halla verhailt sich in dieser Hinsicht wie Arabella. Ferner besitzt Lysarete wie Lumbriconereis die in dem Mundeingange liegenden Polster, welche Arabella und IIalla fehlen. Kommt nun hinzu, dass der Unterkiefer so langr wie der Oberkieferapparat ist, gerade ventralwärts von diesem liegt und durchnus die Form hat, wie sie am Unterkiefer von Lumbriconereis sich finclet, dass ferner die Träger der Oberkiefer platíenförmig gestaltet sind wie diejenigen der Eunice labudornatha, so füllt dem gegenuiber weniger dasjenige ins Gewicht, was an Halla und die prionognathen Euniceen erinnert. Als solches kann man die ungleiche Zähmelung des Grundstïckes der Zangen im Oberkiefer anffassen, dessen iibrige Stiicke am meisten denjenigen von Lumbriconereis ähnlich sind. In der Ausbildung der Ruder ist die grosse hintere liuderlippe in der Entwicklungsrichtung gelegen, welche bei Ninoë ilı Maximum gefunden hat. Besonderheiten bilden der blattförmige Rückencirrus und die drei vor einer Nackengrube stehenden Fühler des mit vier Augen ausgerïsteten Kopflappens, Terhältnisse, welche ganz in gleicher Weise bei Halla vorhanden sind. Ich halte das für Parallelerscheinungen, welche nicht ausschliessen, dass Lysarete an Lumbriconereis, Halla an Arabella anzuschliessen ist; ob dann die Formen mit blattförmigen Rüickencirren als parallele Weiterentwicklungen von Lumbriconereis und Arabella anzusehen sind oder ob die Gattungen mit den einfacheren Ruderformen als spätere durch Verkümmerung von den Rüickencirrentragenden abzuleiten sind, habe ich oben bereits discutiert. 
OHNONE: (S.IY.).

Oonono diphyllidia, scrmard..

$$
\text { Tiuf: Si, Fig. } 1-\text { r. }
$$

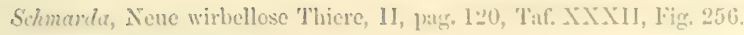

Andromache diphyllidia (S.hm.).

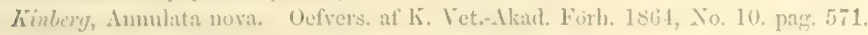

Brevis, supra alte convexa, antice versus pullum, postice in ultima corporis parte mayis attomnati, brumnea iricolor, semmentis 220 brevissimis. Lobis cephalicus mudus olituse oratus paullum latior quan longior, oculis 4 nigris, maioribus externis, minoribus medianis.

Segmenta bucealia nuda, in dorso penitus coalita, in ventre sciuncta; prius processu orali secundi intermptum. Seymenta pinnigera 1 bies lationa quam longiora - Pinnac magnac quadri. entem latitudinis segmenti nequantes, scomentorum pancorum anteriorum ultimorumpue paullum minores; labio postico foliaceo, itidemque formato sed longiore et cmssiore ex articulo hasali oriente cirro dorsali rasculoso; setae superiores paucae flavae lungae ciapillares tencrae labium posticum superantes; inferiores sinqulae vel binae breviores parumque crassiores aciculaeformes apice incurvo vel olutuse dentato obtecto; fiscienlns acicularmu inclusus magnus.

Segmentum anale breve, cirri anales 4 breves acquales fuliacci.

Mraxillac nigrae: fulcra valde styliforme elongatit; series denticularum imacquales, I siuistra maior forcipitis instar uneinata in parte basali 8 , destra plus quam dimidio brevior non uncinata acie recta 8 ; ceterae sinistrue minores quam dextrac, dentatre dente apicali unciniformi, II sinistra 8 dextra 10 , III sinistm 5 destra 8 , IV sinistra 4 dextra 5 , $V$ utrimque 1 ; lamime externae edentatae brumene sinistme 4 dextrac 3. - Laminne ventrales brevinres quam serics maxillarum dentatarum in parte anteriore securiforme dilatata fere sese attiugentes, vigrae in angulo externo albidae.

Tubus teuuissimus cuticulac allac instar corpori indutus, limo calcareo sparsim obductus.

Hab. : 1. Florida Reef, John Bartlett, 1863. 2. Hayti, cut out of Coral rocks, sea near Apt Carymites, P. R. Uhler.

Ein völlig erhaltenes Exemplar ron 226 Segmenten war S2mm. lang. Dass ich auf diese Thiere die Bezeichnung Oenone diphylliclie (Schmarda) antende, ist kaum zu beanstanden. Schmarda fand die von ihm beschriebenen Thiere auf den südlichen Keys von Jamajea im Korallensande, also offenbar in ähmlichen Orten, in welchen wenigstens das eine der vorliegenden Thiere gefunden ist.

Das Habitusbild, welches er giebt, lässt sich auf unsere Thiere anwenden; dass darin 3, nicht, wie Grube angiebt, 2 ruderlose Buccalsegmente gezeichnet werden, ist wohl auf ein Versehen des Zeichners zuriickzuführen, im Text ist darüber nichts erwälnt; die Form des Vorderendes zeigt ofienbar den Kopflappen über welchen ein lileines Stück der wenig vorgestülpten Riisselröhre hinwegragt. Tentacula frontalia, melche Schmarda, selbst an 
deren Anwesenteit zweifohd, mgiebt, sind in der Abbildung nicht grezeichnet; diss sehmarda nur - Augen anfiihrt, erachte ich gleichfills fiir wenig bedeutumgroll, da die inneren kleinen Augenflecke sehr leicht zu übersehen sint. - Sclmmarda's Angaben über den Ruderbau stimmen mit dem von mir

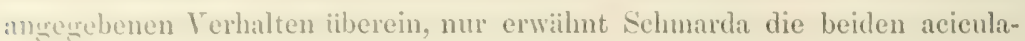
firmigen. lang vorstehenden Borsten nicht; bei den Lumbriconereiden haben jiingere 'Ihiere eine andere Ausriistung der Rucler mit Borsten als ältere; das von schmarda untersuchte Exemplar war nur $50 \mathrm{~mm}$. lang, also wohl ein nicht ansgewachsenes 'Thier und es ist darauf' wohl der Mangel dieser Borsten zuriickzufiihren. Schmarla giebt unter der Uebersehrift "Ocnone lucidu, Savigny," an, eine grosse Oenone von 160mun. Linge gefunden zu haben, welche neben den hatarörmigen Borsten je eine Hakenborste getragen habe. Leider ist nicht eimmal angegeben, wo er dieses 'Thier gofmden hat, so dass es zweifelhaft ist, ob es sich etwa um eine vollwiehsige Ocnone diplygllidia handeln kamn. - Mehr Bedenken iiber die Zusammengehörigkeit der von Schmarda mol mir beschriebenen Thiere könnte man erheben, wem man die von uns gregebanen Abbildungen der Oberkiefer mit cinander vergleicht; doch glaube ich auch hier Uebereinstimmung annehmen zu müssen. Bei der Untersuchumg der Stiicke des Oberkiefers bietet sich nämlich für die Erkennung der einzehnen Formverhältnisse in der tief schwarzen Fäıbung der einzelnen Stiicke eine nicht geringe Schwierigkeit, zumal da, wo solche Stücke über einander geschoben sind; nur bei giinstigster Beleuchtung mit aufillendem Lichte kommt man hier zum Ziele. Wem num Schmarda in der rechten Hiilfte des Obarkicfers nur 4 Stücke, in der linken Hailfte das erste Stiick ohne Endhaken zeichnet, so hat er wahrscheinlich diesen Endhaken, wie das erste Stïck der rechten Mälfte übersehen, weil beide auf dem dunklen Grunde der Folgestiicke lagen.

Ist $n$ m die Oenone thipllyllidia (Schm.) nach meiner Darstellung aufzufassen, so fïllt zunïchst der von Kinberg für die Aufstellung der Gattung Andromache verwendete Charakter und damit diese Gattung selbst fort.

Zu rechtfertigen ist dann aber noch die Stellumg dieses Wurmes zu der Gattung Oeno:e, Sav. Mält man sich dafür besonders an die Abbildung, welche Sivigny ron seiner Ocnone lucidu gregeben hat, so muss gregenüber den Angraben verschiedener Autoren, welche dem Kopflappen 2 sehr kleine oder kaum sichtbare T'entakel zuschreiben wollen, festgehalten werden, dass der Kopflappen hier wie bei der Oenone diphyllidia nackt ist; Savigny selbst sagt dariber: "Antennes point saillantes et comme nulles." Das Buccalseg- 
ment, die folerenden foemmente und deren linder stimmen mit den von mir

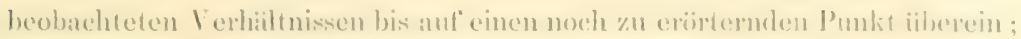

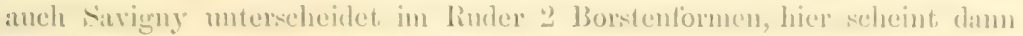
aber cine specifische Diflerenz zu bestehen.

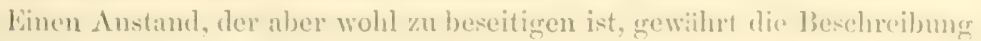
und Abbihlung der 'Zahmstiicke des ()herkiefers; diese sollen aus nux neun Stiicken, und zwar in der rechten lieihe ans 5, in der linken ans 1 Stiicken bestehen. Das erste dieser stibeke in der linken lieihe libuft alser in der Zeichmug mit einem solehen boppelhaken aus, dass jeh vermuthe, es seien hier zwei auf einunder folgende Stïcke nicht aus cimander frehalten, mud es bestehe in der 'That ein Verhalten, wie es auf der gleichen Tafel von den entsprechenden Kieforstieken der Agluera fulgida abgebildet ist. Icls bin daher der Meinung, dass die Gattungsdiagnose so zu erweitern ist, dass 10 \%almstïeke im Oberkiefer zu zihlen sind.

Auf eine Besonderheit des Buecalsegmentes der Oenone diphyllidia, welche jch in den sonst treflichen Savigny'sehen Figuren nicht finde, verweise ich schliesslich. Ich habe in der Beschreibung das Buccalsegment beschrieben, als sei es durch eine auf der Rïckenflïche erfolgte Verschmelzung zwejer Segmente eimheithich gerorden. Die Auffassung geht von der Gestaltung aus, welche dieses Segment auf der Bauchfläche besitzt. Wie bei den echten Lumbriconereiden stüsst hier ein lïngs gefurchter Fortsatz vom hinteren allseitig durch eine Furehe abgegrenzten Bezirk des bucenlen ruderlosen Körperabschnittes so an den Mundeingang, dass hier wie bei Lumbriconereis ein hinteres Buccalsegment das vordere gleichsam durchbricht Solche 'Trennung zweier Buccalsegmente ist an dorsalen Umfange nicht zu erkennen, die Segrmente sind hier entweder verwachsen oder es ist das zweite durch das erste verdrängt. Bedeutungsvoll ist die Bildung deshalb, weil sie auch hier wie bei Lysarete auf eine Verwandtschaft zu den Lumbriconereiden hinweist. Trotz des füllerlosen Kopflappens entfernt sich aber wegen der priono. gnathen Kieferbildung Oenone mehr von Lumbriconereis als Lysarete.

ARACODA (ScImaRd, char. emend.).

Ich fasse diese Gattuner in dem Sinne derjenigen Diagnose auf, welche ich ${ }^{1}$ dafuir friher aufgestellt habe; nur in einem Punkte mache ich noch eine Einschränkung, indem ich auf die etwas grössere oder kleinere Zahl der

1 Borstenwürmer, a. a. O., pg. 397. 
Stiicke des Oberkiefers ebensowenig Werth lege wie darauf, ob neben den pantigen 'Trigern noch cine umpare Platte entwickelt ist. Die Zahl der Kiefurstiicke widchst dachurch, dass der vorderste Sägezahm des vordersten Kieferstiickes sich ablüsen und selbstïndig werden kam; eine Platte neben den paarigen Kiefortrigern kommt mehreren Gattungen zu (Arabella (Gr.), (O)igognathus (Spengel), Maclovia (Gr.)), ist aber vielleicht weit in der ganzen Gruppe verbreitet. - Wenn ieh anf die Kall der Kieferstiicke für die Abgrenzung ler einzelnen Gattungen wenig Werth lege, so trete ich danit der Grube'schen ${ }^{1}$ Darstellung gegeniiber, in welcher die Gattungen, jenachdem 4 oder 5 Kieferstiicke vorhanden sind, gruppiert werden; darin würde die unten beschriebene fracoda mullidentata mit je 6 Stiicken im Oberkiefer nicht Platz fimlen.

Fiir die Abspaltung der Gattung Maclovia (Gr.) von Aracoda (Schm.) scheint mir gleichfalls Veranlassung nicht vorzuliegen, sobald man die Gattung Aricoda in meinem Sime auffasst, $d$, h. dieselben von den Kennzeichen der Gattung Lumbriconereis befreit, welche dadurch ursprünglich hineingetragen sind, dass Schmarda eine echte Lumbriconereis mit einer Aracoda zusammenkuppelte.

Aracoda multidentata, n. sp.

$$
\text { Taf. 34, Fig. 8, 9; Tuf. 35, Fig. 1-4. }
$$

Elongata teres antice paullo attenuata, segmentis fere aequalibus quinquies latioribus quam longioribus plus 114. - Lobus cephalicus ovatus antice acutus postice aeque latus ac longus, nudus ; oeuli 4 nigri in parte postrema transverse collocati. - Segmenta buccalia 2 nuda, magnitudine inter se et cum proximis fere aequalia, prius in ficcie ventrali sulcis + longitudinalibus exaratun. - Segmenta setirgera aequalia quinquies latiora quam longiora. P'inune breves conicae labio postico pinnam longitudine aequante vel in segmentis posterioribus paullum superante; setae paucne flavidae simplices infra apicem curratae et late limbatne spinulose utrimque serrulatne; fasciculus setarum inclusus parvis. - Cirri dorsales minutissime fere squamaeformes; cirri ventrales nulli. - Maxillae nigrae prionognathae; fulcra styliformia longissima antice dilatata, I ntrimque hamatae in parte basali $7-7$, II aequales longiores quam I $10-11$, III $4-4$, IV $5-5$, V 1 ; externae edentatne brumene oblongae ntrimque 3. - Laminae ventrales in parte antica securiforme dilatatac contignae, seriem maxillarum dentatarum aequantes.

Fundort: To. 26 , depth 110 fms., Lat. $24^{\circ} 37^{\prime} 5^{\prime \prime}$ N., Long. $83^{\circ} 36^{\prime} \mathrm{W}$.

Ein wohl fast völlig erhaltenes Exemplar von 114 Segmenten war 33mm. lang und 2mm. breit. Die Furchung der Bauchfliche des ersten Segmentes, auf welche ich friher schon verwiesen, giebt vielleicht einen beachtenswerthen Charakter ab, doch ist in der Beschreibung anderer Arten hierauf bislang

\footnotetext{
1 Grube, Bericht, a. a. O., pag. 36, 37.
} 
nicht Riicksicht genommen. D) re rehe Entwicklung des Kieferappantes ist ferner ein wiehtiges liemuzeichen. Beides finde ich ron keiner Art sonst erwiilınt.

\section{Aracoda dobilis, n. sp.}

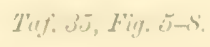

Elongata teres rufo brunnen postice in dorso seymentorum linen nigrita transversa rittatn, segmentis plus 160 . - Lobus cephalicus conicus depressus undus coecus, longitudine segmenta \& proxima nequans, paullum longior quan postice latior. Segmenta buccalia nuda inter se et cum proximis magnitudine aequalia ; us simplex.

Segmenta jinnixera quinquies latiora quam longiora aequalia. I'innae conicao hreves, postice tersus lougitudine creseentes, trientena latitudinis segmenti vix aequantes, lahio pristico pimna haud longiore; setae tlavidae paucae simplices parum curvatae infra apicem limbo scrrulato dilatatae; styliformes apice acutissimo longo; acicula siugula simplex; fasciculus setarum inclusarum parrus. Cirri dorsales et ventrales nulli.

Maxillae prionoguathae nigrae, fulcra longissima postice linearia antice dilatata; I fere nequales longe hamatae in basi $:-3$, II angustae 5-5, III $1, N^{r} 1, \quad$ I, - externae nullne. Lamina rentrales maxillarum dentatarum seriem aequantes, in parte antica securiforme dilatata contiguac.

Fundort: Lo. 23, depth 190 fms., Lat. $23^{\circ} 1^{\prime}$ X., Long. $83^{\circ} 1 \Psi^{\prime}$ W.

Das einzige Exemplar, welches von dieser Art mir vorliegt, war nicht vollstiundig erhalten; es hatte bei $40 \mathrm{~mm}$. Liunge 159 Segmente. - Dic in der Beschreibung erwähnten, in sehr feine lange Spitze ausgezogenen einfachen Borsten finden sich auch an anderen Arten z. B. bei Lrabella planiceps (Gr.). Der Oberkieferapparat, in welchem III, IV und $V$ nur aus je einem Zahn bestehen, ist sonst nicht beobachtet.

1 Grube, Annulata Semperiana, a. a. O., pag. 274. 


\title{
LYCORTDAE.
}

\author{
NEREIS (L. s. str.).
}

Nereis articulata, n. sp.

$$
\text { Tief. 36, Fig. 1-4. }
$$

Subparallela, flavido-brumea in pimmis posticis glandulis cutaneis brunneo notata, segmentis $54+4$-5ies latinitus quam longioribus.

Lobns cephalicus longior quam postice latior, subovatus, tentaculis in basi remotis, lobi cephaliei longitudinem fere aequantibus, subtentacula magna superautibus sexartieulatis; oculis trapezii instar collocatis nigris aequalibus, anterioribus a posterioribus diametrum distantibus magis clutum hi inter se remotis.

Segmentum buecale proximo paullum longins; cirri tentaculares articulati longissimi ad segmentum 5 นu patentes. Pimne fere aequales, posteriores parum elongatae dimidiam latitudinem sermenti vix nequantes; rami pinnarnm aeque proninentes approximati; labiorum rami superioris superius brevissimm, inferius triangulare subfoliacenm, lingula superior brevis triangularis; rami inferioris labia nequalia triangularia, lingula inferior brevior quam labia conica, basi tumidula; ncienlae nigrae; setre superiores pauca spinigerae, inferiores spinigerae et breviores fulcirerae, falce brevi in apice valde incurva ciliata ; spina brevi recta ciliata. - Cirrus dorsalis et rentralis simplex filiformis, dorsalis pinnam paullum superaus, ventralis brevior; glandulae cutaneac lingulac labilique rami superioris pinnarum posticarum maiores brunneae.

Cirri anales 2 longi articulati.

Masillae corneac 9-dentatne; paraguatha maxillaria desunt, oralia pallida, obtuse-conica, seriem simplicem formantia.

Fundert : Oft Sant Key, depth 120 fms.

Die Beschreibung dieser wohl charakterisierten Art ist nach einem einzigen Exemplare von $16 \mathrm{~mm}$. Länge entworfen. Ich habe hier nur einige Punkte besonders noch hervorzuheben.

Im Integument ruft die starke Driisenentwicklung vor allem an den Rudern der hinteren Körperstrecke und zwar in beiden Züngelchen wie in der grösseren Lippe des oberen Astes eine auflillige dumkle Fäbung hervor; aber auch am Kopflappen ist durch derartige Drisen, welche an den Vorderecken und in der Strecke zwischen den Tentakeln eingelagert sind, eine brïunliche Färbung erzengt. - Die hervorragendste Eigenthümlichkeit besteht in der Form der Tentakel und Fühlercirren, welche deutlich gegliedert 
sind; an den T'entakeh zidilte ich sechs schlanke (ilieder; von den diiblescirren fehlen dem Exemplare die oberen des hinteren Patres, welche die

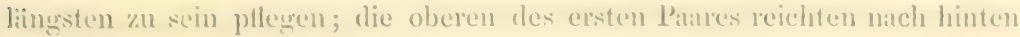

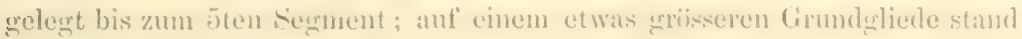

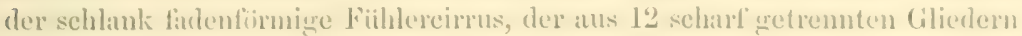
bestand, von denen die mittleren an limgsten und etwa dreimal linger ats breit waren; die unteren kïmeren Fibhlereirren hatten weniger Gilieder, an dem des vorderen Parares sah ich nur 6. - Der Fall. dass Fiblilereirren und 'Tentakel gegliedert sind, findet sich meines Wissens bis jetzt nur noch bei der von Savigny ${ }^{2}$ beschriebenen $\Lambda$. aegypliu des rothen Meeres, es lisist die Savigny'sche Abbildung wenigstens eine, wemn auch mur schwach angedentete Gliederung der 'T'entakel erkennen; bei dieser Art sind dam anch nach den Abbildungen die Rïekencirren gegliedert. Alle iibrigen Arten, deren Fiblerciren gegliedert sind, ausser der hier beschriebenen $\Lambda$ rt, haben ungegliederte 'Tentakel; von ihmen hat, wie ich wiederum nur den Abbildungen entnehme, allem Savigny's Lycoris mutiu ${ }^{2}$ gegliederte Riickencirren. Dic Arten, welche sonst gegliederte Fiihlercirren besitzen, sind nach Kinbergr ${ }^{3}$

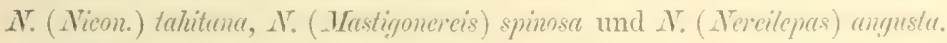

Eine Gliederung der Aftercirren, wie ich sie bei dieser Art geschen, ist von keiner der anderen Arten angegeben; das berechtigt aber licineswegs zu dem Sehlusse, dass den genannten Arten ungegliederto Aftereiren nicht zukämen, da diese Anhänge liäufig duxch Verletzung fortgefillen oder in den Beschreibungen mberiicksichtigt greblieben sind. - I)ass die Riickencirren meistens ungegliedert sind, wihhend die Fühlereiren Giliederung besitzen, ist weniger auflallend, wemn man sich erimnert, dass bei den limiceen dieselbe Erscheinung häinfiger auftritt. - Der Gliederung selbst ist für die Feststellung der Verwandtschaftsveihailtuisse kaum irgend eine Bedeutung beizulegen; diese Bildung wiederholt sich chen bei Arten, welche in anderen und, wie man wohl sagen dàf, wichtigeren Kennzeichen weit aus einander gehen.

Ueber die Beschaffenheit der Ruder brauche ich mich, da die Abbildungen die gegebene Beschreibung wohl hinlänglich erliutern, nicht weiter auszulassen.

1 Sarigny, Srstème des Aunélides, pag. 31, Expédition de l'Égrnte, Histoire naturelle, Zuologie, Annélides, Pl. 4, Fig. 1.

2 Surigny, Exploration, a. a. O., Pl. 4, Fis. 2.

3 Kinberg, Annulata nova, a. a. O., pag. 173, 178, und Fregatten Eugenies Resa. Annulata, Tafl. IX, Fig. 2. 
Dagegen habe ich die Angaben iiber die Riisselbewaflinung etwas zu vervollstimtigen. - Der Riissel des vorliegenden Exemplares war eingezogen; der. Versuch, dureh Glyeerintränkung das 'Thier hinlïnglich autzuhellen, um die Kiefer und Paragnathen zu erkemen, gelang nieht. Ich praeparierte dither den litissel heraus und find num an ihm die beiden schlanken, hell hombrumen Kiefer von der gyewöhmlichen Form mit 9 spitzen Sigezihnen besetzt: dass Paramnathen vorhanden seien, erwies sich erst bei der Anwendung stïkerer Vergrösserungen; da zeigte sich auf den durch Längsfurchen von cinander getremten Feldern des oralen Abschnittes der Riisselscheide je ein nierlerer stumpfer Hüeker von lichthornbramer Fürbung, welcher als Paragnath y bezeichnen ist, da die Chitineuticula durch geringe Verdickung diese Höekerbildung erzengte; der maxillare Abschnitt der Rüsselscheide hatte dagregen keinerlei Paragnathen. - Eine Riüsselbewaffnung wie diese ist . meines Wissens noch nicht beschrieben.

Nereis (Ceratonereis) versipedata, n. sp.

Taf. 36, Fig. 5-10.

Brevis, parallela, flavida, segmentis 5ies latioribus quan longioribus 47. Lobus cephalicus Lexagonalis, triente fere hatior quam longior, segmenta proxima 2 longitudine superans, antennis in basi fere coniunctis, lobo brevioribus, subtentucula crassa non superantibus; oculorum vicinorum paribus valde distantibus. Segmentum luccale froximo vix brevius; cirri tentaculares in articulo basali siuguli simplices, tentacula superantes, longissimi ad segmentum 6um patentes.

Pinnte forma et inagnitudine rami superioris paullum inter se diserepantes; ramorum approximatorum superior in pinnis anticis labiis 2 fere aequalibus, supero rotundato, infero conico-acuminato, ramum inferiorem non excedens, in pimnis posticis labio infero elongato conico, supero brevissimo obtuso ramum inferiorem paullum superans, lingula eonica in piunis posticis parum elongata; ramus iuferior labio posteriore conico, anterioro brevi acuto in pinnis anticis magis quam in posticis provectus, lingula in pinnis anticis obtuse rotundato ramo breviore, in pinnis posticis conico-acuminata ramum aequante; setae superiores et inferiores spinigerae et falcigerae, spina mediocri laevi, falce unidentata in acie ciliata; aciculae pinnarum posticarum nigrae; cirri dorsates simplices pinnas paullun, setas non excedentes; ventrales simplices in pinuis anticis lingulam aequantes, in posticis breviores.

Cirri anales 2 simplices longi.

Maxillac validae nigrae 6-dentatae; paragnatha oralia (V-VIII) desunt, maxillaria I nulla, III 2 unum post alterum, II $5-\bar{i}$ seriatim, IV circa \& aggregatim collocata.

Hal), : No. 11, Long. $21^{\circ} 43^{\prime}$ N., Lat. $83^{\circ} 25^{\prime} \mathrm{W} ., 37 \mathrm{fms}$.

Ich habe von dieser Art nur ein Exemplar gesehen, welches $18 \mathrm{~mm}$. lang trar und 47 Segmente besass; ob diese Segmentzahl als die volle angesehen werden kann, ist mir ungewiss; das Körperende des Wurmes trug allerdings einen Afterzapfen und an demselben 2 lange Aftercirren; doch sass dieses 
Afterserment einem so breiten fecrmente anf, dass es viclleicht als cin dureh liegeneration entstandenes zu betrachten ist. J)er Wurm war im vorderen Kïpertheile ohne linder 2 mm., mit denselben 3,5mm. breit, im linteren 'Theile olme Ruler 1, 5mm., mit denselben 2,20m, hreit.

Die Bewallinung des im ansegestreckten Zustande 2̌, Jmm. langen IRiissels weist die Art in dicjenige (iruppe, fïr welche Kinberg die Gattung Ceratonereis errichtet hat, und offenbar steht die Art der Nereis Costre (Gro) nahe, unterscheidet sich aber von dieser wie von der $\Lambda$. Ehlersimu und Kinbergiana (Clprod.) von Neapel, welche beide besonders in Hinsicht auf die Bildung der liuler, die zumal bei der letztgenamnten Art eigenthimlich gestaltet erscheinen, noch besonders zu prüfen sind, lurch die Vertheilung der Paratgnathen, welche bei diesen Arten auf 111 einen Ilaten oder eine Doppelreihe bilden. Zwei einzelne Paragnathen auf III, wie sie bei meiner Art vorkommen, finden sich meines Wissens bei den Arten, welche zu dieser Gruppe (Ceratonereis) gehïren, nur noch bei der $N$. pectimifer $a$ (Gr.) von den Plislippinen, stehen hier aber nicht hinter, sondern neben einander. Alle iibrigen von Grube in den Annulata Semperiana besehriebenen Arten dieser Gruppe weichen mehr orler weniger von dieser Art ab. - Auf die Ungleichheit der Ruder der vorderen und hinteren Segmente, welche ich von dieser Art beschreibe, möchte ich besonders hinweisen; es wird für spätere Beschreibumgen nöthig sein, bei der Charakterisierung der Arten zu achten, in welcher Verbreitung diese Bildung anftritt; beschrieben ist sie bis jetzt ron keiner der hierher gehörenden Arten. Die Borsten,-welche ich von dieser Art ggesehen habe, waren homogomph und diuner bei gräitenförnigem Endgrliede, heterogomph und dicker bei sichelförmigem Endgliede; diese Borstenformen kommen in gleicher. Weise bei der $\Lambda$. Tinbergiuna (Clprd.) vor.

N. (Ceratonereis) mirabilis, INNBERg.

$$
\text { Taf. 3\%, Fig. 1-li. }
$$

Kinberg, Annulata nora a. a. O. pag. 170.

Fundorte: 1, Key West, 1-2 fms. ㄱ, Key West, 7 fms. 3, To. ii. 37 fms., Lal. $24^{\circ} 43^{\prime}$ X., Long. $83^{\circ} 25^{\prime} \mathrm{W}$.

Es liegt mir eine kleine Zilhl Exemplare einer Nereis-Art vor, für welche ich die obige Bezeichnung in Anwendung bringe. Kinbergs Exemplare sind auf $9^{\circ}$ südlicher Breite vor der brasilischen Küste auf 18 Faden Tiefe gesammelt, also in einer Region, welche mit der Antillenfauna als zusammen- 
hïngend gedicht werden ksmm. Ob diese Ceratonereis mirabilis (Kbg.) nicht

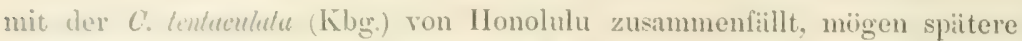
[ntersuchungen entscheiden. Die ron Kinberg getrennt gehaltenen Arten zusimmenzuziehen habe ich vorlitufigg keine Veranlassung; im Allgemeinen aber stimmen die Abbildungen, welehe Kinbergo ${ }^{1}$ von der Coratonereis tentaculutu gegeben hat, abgesehen ron Kleinigkeiten, die gleich zu erwithnen sind, ganz wohl zu dem, was ich an den mir vorliegenden 'Thieren sehe; ganz nahe dieser Art steht die ron Crube ${ }^{2}$ beschriebene $\Lambda$. excisa, welche $F r$. IIïller in Desterro (Brasilien) gesammelt hat; ich werde die Unterschiede hervorheben, auf welche ich bei Prifung der Grubsehen Beschreibung aufmerksam geworden bin.

Ein vollstïndig erhaltenes Exemplar von $37 \mathrm{~mm}$. Lünge, welches vorn $4 \mathrm{~mm}$. breit war, hatte 86 Segmente. Der Körper des 'Thieres ist hoch, doch die Riickenfliiche nicht stark gewölbt; in Bereich etwa der ersten 6 Segmente hat der Körper seine volle Breite noch nicht, erhält sie dam aber durch die grossen weit gerade auswäits ragenden Ruder, und erfährt weiter nach hinten nur eine geringe Verschmälerung. Die einzehnen Segmente nehmen dabsi von rom nach hinten an Lünge zu, die vorderen sind achtmal, die hinteren nur zweimal breiter als lang; die vorderen Ruder sind nicht ganz so ling, die hinteren etwas lainger als das Segment breit.

Der Kopflappen, der etwa doppelt so breit als lang ist und mit seiner Lünge nicht ganz diejenige der drei ersten Segmente erreicht, hat wie in allen im Eingange genamnten Arten seine eigenthïmlichste Gestaltung durch den tiefen Einschnitt in der Mitte des Vorderrndes; seine spitz kegelförmigen, unmittelbar jederseits am Einschnitt stehenden Tentakel iibertreffen ihn an Länge und reichen nach hinten gelegt bis an den Hinterrand des ersten Segmentes; hinter ihnen bleiben die Subtentakel etwas an Lünge zurück, ihr kleines Endglied ragt aus einem undeutlich zweigliedrigen walzenfürmigen, meist etrras nach auswärts gekrïmmten Basalstiicke heraus, welches lïnger als der Kopflappen ist. Vier grosse schwarze Augenflecke stehen zu je zwei nahe dem Rande der mittleren Theile, die vorderen etwas weiter als die hinteren von einander getrennt, das vordere vom hinteren jederseits kaum um die Grïsse seines eigenen Durchmessers entfernt. Der Hinterrand des Kopflappens ist gerade.

Am ersten Segmente sind die oberen Fühlercirren jederseits wohl dreimal

2 Frematten Eumerice Resa, Anmulati, Tafl. XX, Fig. 5.

2 Grube, Bericht über die Thätigkeit der naturw. Section der schles. Gesellschaft im Jahre 18 13 , parg. 46. 
so lang als die muteren; der obere des hinteren Patues, etwas linturer als ded des vorderen, ragt, nach hinten geleget, bis and das 1fte sergment.

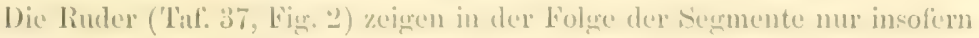
cinen Untersehiod, als diejenigen des hinteren kinjertheiles in ihren Lippen und Kiingelehen etwas kiirmer sind als die der vorderen Semmente, mud dass in den letzteren der obere linderast iber den unteren weiter hinausaget als das in den hinteren liudern der Fall ist. Beide linderaitete sind wengig von einamder getremnt; der obere $\Lambda$ st hat eine spitz kegelfirmige untere Lippe, wihlnend die obere, durch die Spitze der Stiitznadel gekenmzeichnet, kamm vorspringt; das obere Ziingelehen stimmt in Form und frösse framz mit dex unteren Lippe iberein; der obere Rand dieses Astes geht mit jühen Abfall, da wo ihm der Rïickencirrus aufsitzt, in das Züungelehen iiber. Der untere Ast liuft mit einer spitz kegelförmigen und einer breiten gerad abrestutzten dïmnhäutigen Lippe aus; in der ersteren liegt die Spitze der bramen Stiil\%nadel; das Zïngelchen dieses Astes ist kegelfürmigr, entspringt an den vorderen Rudern am ventralen Umfunge der liuderbasis und ragt so weit als die Spitze der kegrelformigen Lippe hinaus; etwa vom 30 ten linder ab ist es aber erheblich kleiner, mit der Ruderbasis stïker verschmolzen und bleibt mit seiner kleinen Spitze weit hinter der Spitze der kegelfömigen Lippe zuriick. Im oberen Aste stehen homogomphe Borsten mit Gritten- und Sichelanhïngen; im unteren Aste homogomphe mit Griten, heterogomphe mit Sichelanhäingen. Die Zahl der Borsten des oberen Astes ist geringer als die des unteren, welche noch weiter biundelförmig gruppiert sind; der Schaft der Borsten, welche Sichelanhïnge tragen, ist etwas stiirker als derjenigen, welche Grätenanhänge haben. Die Grätenanhinge sind schmal, nicht sehr lang und haben eine feine grezihmelte Schneide (Fig. 4); die Sichelanhïnge sind schlank und schmal, laufen an der Spitze mit einem hakenfömig grekrimmten Zahn aus und tragen lïngs der Schneide eine Reihe von ziemlich grossen Härchen, unter denen am Einschnitte ror dem Endhaken eins oder einige wenige die übrigen an Linge ïbertreffen und in auffallenter Weise iiber den Endhaken hinausreichen (Fig. 3). - Der Rüickencirrus ist ein langer schlanker Faden, welcher weit iiber die Borsten himausagt; der Batuchcirrus, unterhalb der Ruderbasis entspringend, lst gleichfalls schlank, ragt aber nicht iuber die Spitze des unteren Zïngelchens hinaus.

Das so gebaute Ruder stimmt im Allgemeinen mit demjenigen uberein, welches Kinberg von der Ceratonereis tentaculata abgebildet hat; die Borsten aber, welche aus demselben gleichfalls abgebildet sind, unterscheiden sich von 
denen meiner Art dadurch, dass der im iibrigen gleich gestaltete Sichelanhang die IIiirchenreihe lïngs der Schneide nicht besitzt. - Auffallende Differenzen ergeben sich dagegren, wemn man die von Grube gegebene Beschreibung der liuder ron Nereis excisa mit der hier gegebenen zusammenstellt: bei dieser Art soll rom 2Sten Ruder ab das obere Zïungelehen gïnzlich verschwinden. Es dringt sich die Vermuthung auf, dass hier ein Druckfehler vorliege und es statt "oberen" Ziingelchen unteres Ziingelchen heissen miisse; damn wïre die Differenz nur eine quantitative, da ja auch bei meiner Art etwa rom 30ten Ruder das untere Ziingelehen erheblich verkleinert ist; als kleines Spitzchen bleibt es allerdings iiberall bestehen.

Die Riisselbewaffnung finde ich fast ganz so, wie sie Kinberg von Ceratonereis tentaculatu abbildet, Grube ron Nereis excist beschreibt; die schlanken braunen Kiefer haben 4 Zïhne auf der Schneide, vor der Spitze damm noch 2 Höcker; am oralen Wulste fehlen die Paragnathen, und ebenso auf dem medianen dorsalen Felde (1) des maxillaren Wulstes; auf den seitlichen Feldern stehen in unregelmässigen Reihen braune Paraguathen, welche lang kegelförmig und dabei klauen- oder hakenförmig gekrïmmt sind, auf II zählte ich 6, auf IV 7 solcher Spitzen; die Paragnathen des rentralen Medianfeldes (III) sind kleiner als diejenigen der Seitenfelder und einfache niedrige Höckerchen. 


\section{GLVCERIDAT.}

Ich kann dem Vorgange Claparède's ${ }^{1}$ fiir die 4 Kiefer tratrenden Glycercen die Bezeichnung Rhynchobolus zu verwenden, den Gattmesmanen Glyeera aber mur aul"kieferlose Arten anzuwenden, nicht folgen aus Grinden, welche ich friiher bereits dargelegt habe, und finde mich in Uebereinstimmune nit Grube, ${ }^{2}$ wemn derselbe die Gattung Glycera in dem Sinne auflisst wie es seit Audouin und Milne-Edwards bis auf Claparede's abweichende Auflasumg allgemein äblich war. Grube hat dementsprechend dem von Savigny für die Gattung aufgesteliten Namen eine erweiterte Diagnose gegreben.

In der terminologischen Sonderung der auf der Spitze des Kopflappens stehenden kleinen Fiihler als Tentakel und Subtentakel kann ich Grube nicht beipflichten, sondern möchte die Bezeichnung der Subtentakel (Palpen) fir die an der Basis des Koptlappens auftretenden retractilen und daher oft schwer erkembaren Anhänge beibehalten.

GLYCERA (Sav. char, emend.).

Glycera oxycephala, n. sp.

Taf. 41, Fig. $7-11$.

Longa rermifurmis postice attenuata, segmentis tripartitis 118 , antice quater, postice duplo latioribus quam longioribus.

Lobus cephalicus conicus clongatus acuminatus, longitudine segmenta proxima 12 fere aequans: annulis bipartitis 23 prae parte basali breri, tentarulis 2 gracilibus.

Pinnae anticae breres partem duodecimam segmenti latitudinis aequantes, posticae elongatae a latere proteutre, segmenti latitudinem aequantes, ebranchiatne; labio postico perbrevi simplici, anticis 2, supero inferiore breriore, in pinnis anticis obtusis, in pinnis posteriorilus acuminatis, setis pancis superioribus capillaribus, inferioribus spinigeris ; cirro dorsali in pimne basi globoso, eirro rentrali magno conico, labium posticum rix excedente; aciculis simplicibus flaris.

Proboscis ter lobo cephalico longior, clavata, papillis filiformilus parum inter se diversis obsessa, maxillis 4 nigris armata.

Hàb. ? (Eine genanere Angabe ïher clen Fundort kunn ich nicht machen, da lie Aufechrift der Etiquette völlig ausgelöscht und đlurch keinerlei Mittel mieler herzustellen war.)

1 Claparède, Anuélides chétopodes du Golfe de Naples, pag. 182 ; Supplément, pag. 3.

2 Grube, Bemerkungen über die Familie der Glycereen. Bericht üb, d. Thätigkeit der naturw. Sect. der schles. Ges., 1869, pag. 29. - Annulata Semperiana, prag. 180. 
Der cinlarbig gelbliche, 4 tmm. liuge, aus 118 Segmenten bestehende Kïrper erhilt ein charakteristiches Aussehen durch die ungleichen Grössenverhibltnisse der Segmente und liuder in der vorteren und hinteren Strecke; demn in der vorderen liërperstrecke, wo in geringem Abstande hinter dem Kioptlappen die grüsste Breite sich befindet, sind die Segmente etwa viermal breiter als lang und tragen dicht an einander gerïckte Ruder, deren Läinge etwa einem Zwölftel der Segmentbreite gleichkomnt; weiter nach hinten nehmen die Segmente, während die Körperbreite abnimmt, an Läinge zu, und gleichzeitig wiichst die Liinge der eimzelnen nun erheblich weiter von einander getremnten Ruder, so dass die Segrmente so lang als breit sind, die Ruder aber schlank gestreckt jederseits so weit über die Körperflanken hinausragen als die Segmente breit sind.

Der Kopflappen ist sehr schlank kegelfömig, und liuft mit fast fadenförmiger Spitze aus; seine Linge erreicht fast die der ersten 12 Segmente; dats Basalstuick ist beinahe um ein Drittel sehmäler als die grösste Körperbreite und etwa doppelt so breit als lang; an dem schlanken kegelförmigen Endstiick ziihlte ich deutlich 23 gleich grosse Ringe, von denen jeder durch eine schwichere Ringfurche noch eimmal getheilt war; mur das fast fadenförmign auslaufende Endstiick zeigte auf eine lingere Strecke keine Ringelung mehr. - Auf seiner Spitze standen zwei feine schlanke Fädchen, die, wie sie dicht an einander lagen, fast den Eindruck machten, als sei die Endspitze des Kopflappens getheilt; das sind die Tentakel, neben denen ich vergebens das 2te Paar, wie es sonst bei den Glycera-Arten sich findet, gesucht habe; immerhin wäre es möglich, dass dieses zweite Paar schr klein gewesen und abgefallen ist, so dass selbst die Ansatzstellen desselben nicht zu finden waren. - Die an der Basis des Kopllappens sonst stehenden Unterfühler habe ich nicht gesehen, vermuthlich sind sie völlig eingezogen gewesen. (Taf. 41, Fig. 7, 8.)

An den dreiringeligen Segmenten stehen die kurzen stets kiemenlosen Ruder der vorderen Körperstrecke ziemlich tief, während am verschmächtigten Hinterende des Körpers das nicht der Fall ist. Die Ruder (Fig. 9) sind abgeschen von den schon erwähnten Grössenunterschieden nur insofern ungleich als an den hinteren lïngeren Rudern alle Theile schlanker als an den vorderen Rudern sind; an allen findet sich eine ganz kurze, wenig über den Borstenaustritt hinausreichende, gerad abgestutzte hintere Lippe, und zwei schlanke vordere Lippen, von denen allgemein die obere linger als die untere ist; an den vorderen Rudern ist der Unterschied dieser beiden hier stumpf 


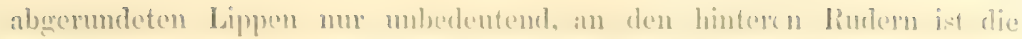

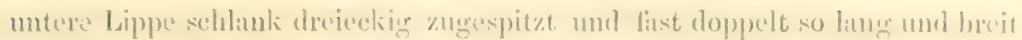

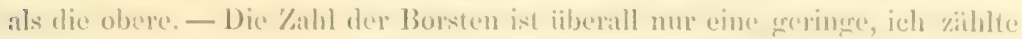
bis zu 10, die scheinbar ein Biinded bildeten, in der 'That aber ansemander zu halten sind, da die griosser. '/ahl der unteren zusammengesetgten J3orsten

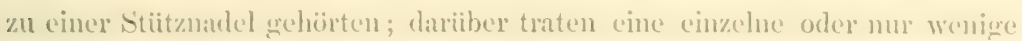
cinfache Capillarborsten aus, zu welchen eine foine einfache Stiitzuadel grehiirt. - Die zusammengesetzten Borsten haben ein etwas verdicktes fellaftende, in welchen zwischen zwei yleichlangen 'Zinken das cinfinche spitz messerformige Endylied eingelenkt ist. (Fig. 10.)

Auf der Basis des Ruderfortsatzes - und nicht an der Seitenflaiche des Segmentes - steht der kugelige Rückencirrus. Der Bancheirrus ist cin breites spitz liegelförniges Blatt, welches mit breiter Basis dem unteren Umfang der Ruderbasis anfistat und kaum so weit oder wenig weiter als der Rand der hinteren Lippe hinnusragt.

Das Aftersegment träigt einen schlank kegelfömigen Aftereirrus, dessen Länge derjenigen der letzten $8-10$ Segmente gleichkommt. Der kenlenfürmige Rïssel ist, mit den anderer Glycera-Arten verechlichen, kur, 4 mm. lang, also nur etwa so lang als ein Zehntel des Körpers, und etwa dreimal so lang als der Koptlippen. Seine Oberfläche ist ganz mit einfachen Papillen bedeckt, von denen die meisten fadenförmig sind, während vereinzelt dazwischen etwas dickere aber gleich lange stehen. (Fig. 11.) - Vier schwarze krïtige Kiefer stehen auf der Endläche des Riissels.

Die Bildung der Ruder weist diese Art in den Kreis der Glycera capilala; von den wenigen hierher gehörenden Arten unterscheidet sich diese Glycera oxycephala leicht durch den spitzen viehringeligren Kopflappen, anch wenn die von mir angegebene Zweizahl der 'Tentakel sich als irrig erweisen sollte; und durch die besondere Ausgestaltung der vorderen Ruderlippen. In allen diesen Punkten ist aber die Differenz als eine nur quantitative zu bezeichnen; das ist dem Umstande gegenüber beachtenswerth, dass die Glycera capitala selbst circumpolar verbreitet ist, und in der Glycera paprillosa (Gr. K.) bereits eine nahe verwandte Forın auf der West-Küste Südamerikas (Valparaiso) aufzureisen hat. 


\section{GONIADA (AUD. ET M.-EDW.).}

\section{Goniada emerita (AUD, ET M.-EDT.).}

Von drei Fundorten finde ich in der Sammlung 'Thiere, auf welehe ich die obenstehende Benennumg mit. Recht glaube in Anwendung bringen zu diirfen. Allerdings ist nur eins der rorliegenden Exemplare, aus der Tiefe ron 321 Faden, ein $225 \mathrm{~mm}$. langer, am Hinterende verstiummelter, aber so noch 202. Segmente besitzender Wurm, so erhalten, dass er alle die Charaktere erkemnen liisst, welche nach der einzig bis jetzt vorliegenden Beschreibung fuir diese Art massgebend sind. Die anderen Exemplare sind kleinere Thiere, von denen mur die vordere Körperstrecke vorliegt; da diese aber volle Uebereinstimmung mit dem grossen Wurme besitzen, so übertrage ich auch auf sie unbedenklich diese Benennung.

Fundorte: 1. No. 11, depth 37 fms., Lat. $21^{\circ} 43^{\prime}$ N., Long. $83^{\circ} 25^{\prime}$ W. 2. No. 9, depth 111 fms., 7 miles $\mathrm{S}$. W. from Sand Kiey. 3. No. 47 , depth 321 furs., Lat. $28^{\circ} 42^{\prime} \mathrm{N}$., Long. $89^{\circ} 40^{\prime} \mathrm{W}$.

Dieses Torkommen gewährt ein gewisses Interesse, demn es gehört danach Goniade emerila zu denjenigen Ameliden, welche im westindischen und Mittelmeer vorkommen. Dem Anscheine nach ist diese Art aber im Mittelmeere nicht häufig, und fuir den Golf von Marseille ist das von Marion und Bobretzky ${ }^{1}$ besonders bestätigt. Daher ist ihr Hauptverbreitungsbezirk wohl ausserhalb des Mittelmeeres zu suchen; wemn hier nun das Vorkommen im westindischen Meere bezeugt wird, so könnte die Vertikalverbreitung des Thieres von 37 bis auf 321 Faden darauf hinweisen, dass auch die Horizontalverbreitung eine ausgedehntere ist. Dafür fehlen aber bis jetzt ausreichende Belege.

3 Marion et Bobretzky, Annélides du Golfe de Marseille, Annales des sciences naturelles, Sér. VI, Zoolog., T. II, pg. 17. 


\title{
NEPHTHYDDAE.
}

\author{
NEPIITIIS.
}

Nophthys (Aglaophamus KïG.) inormis, n. sp.

Taf. 38, Fig. 1-6.

Procera rermiformis alba, segmentis 150 ; lobus cephalicus pentagonus coccus tentaculis nullis, subtentaculis minutis; pimae longae ramis conicis valde distantibus, supero labio postico lanceolato, branchia filiformi inroluta, cirro elongato, setis capillaribus minutissime ciliatis et lyratis ciliatis, infero conico, cirro ventrali pimnam excedente, setis capillaribus. Proboscis nuda maxillis carens.

Hab.: Jai 8, 1869, off Alligator lieef, cast No. 3, depth 53 fms.

Körper schmal und schlank, nach hinten stark verschmälert; im vorderen Theile hoch und rierkantig; im hinteren stark abgeplattet; withrend die vorderen Segmente kurz und eng an einander geschoben sind, und wenig rorspringende Ruder haben, werden die der hinteren Körperhälfte bedeutend länger, sind scharf von einander getrennt, und verleihen dem Körper besonders durch die weit rorragenden Aeste mit den langen Cirren und Kiemen einen Habitus, welcher dem einer Nereis ïhnelt. ('Taf. 38, Fig. 1, 2.) Die Farbe war weiss. Das einzige Exemplar war $62 \mathrm{~mm}$. lang und hatte 150 Segmente.

Kopflappen füfeckig, der vordere Theil bildet eine fast quadratische Platte mit schwach concav ausgeschnittenem Vorderrand, der' hintere 'Theil läuft in eine kurze Spitze aus. Er trägt nur 2 sehr kleine Fuihler, welche vor der halben Länge von der Ventralläche hart am Seitenrande entspringen; ich habe vergebens nach anderen Fiihlern gesucht und keine Stellen gefunden, welche auf eine Verletzung des Kopflappens und damit verbundenen Verlust der Fiihler hinwiesen.

Am Mundeingange fand ich keine Lippen, die wohl durch den völlig aus gestiilpten Rüssel verstrichen waren; ebensorenig habe ich ein längsgefurchtes Mundpolster gesehen; an dessen Stelle fand sich nur cine ganz geringe polsterförmige Erhebung. 
Das erste kurze segment tright jerlerseits 2 selu kurze dicht an einunder stchemle linderiiste, jeden mit einem Borstenbiindel; am oberen Ast stehen 2 sehr kleine lappenfömige Anhinge, ron denen wohl nur der eine als Fiihlereirus, der andere als Lippe zu bezeichnen sein wird; der untere $A$ st trikgt einen etwas lingeren Fühlercirrus. - In der Reihe der folgenden Segmente sind die vorderen etwa j-6 mal breiter als lang, withrend ihre IIöhe etwa der Breite erreicht. Weiterhin verschmilern sich die Segmente, strecken sich und werden niedriger und sind damn etwa um die Hailfte linger als breit. Das dorsile Medianfeld ist unmittelbar hinter dem Koplappen granz schmal, verbreitert sich aber rasch und erreicht etwa am 7ten Segmente seine rolle I3reite; danach verliert es etwas wieder an Breite, bleibt aber immer wohl doppelt so breit als sein Lateralfeld; in der linteren Körperhiilfte lassen die bis auf das Medianfelk einschneidenden Segunentfurchen die dahurch weit getremnten Lateralfelder ganz als Rurlerbasen erscheinen.

Die Ruder der vorderen Segmente ragen etwa mit $\frac{1}{5}$ der Segmentbreite vor, während sie an den hinteren Segmenten so sehr an Lïnge gewimnen, dass sie in dieser Ausdehnung der Breite rles Segmentes gleichkommen. - Die beiden Aeste des Ruders (Fig. 3, 4) sind durch einen Abstand von einander getrennt, der grüsser als die Dicke des einzelnen Astes ist. Die Körperwand dieses Raumes träigt Flimmerhare, welche sich auf den oberen Umfang des unteren Astes fortsetzen. Die Aeste gehen divergent aus einander, der obere Ast mit der Spitze aufwirts, der untere abwärts gewandt. Der obere Ast ist schlank kegelförung, an den mittleren und hinteren Rudern von vorn nach linten zusammengedriickt, immer mit einer Spitze auslaufend, in welcher das Ende der Stiitznadel liegt. Die hintere Lippe ist ein spitz eiförmiges Blatt, wolches mit einer langen Kante längs dem oberen und hinteren Umfinge des Astes aufsitzt, und nit seiner Spitze uiber die des Astes himausragt. Unter und etwas vor der Spitze des Astes springt ein kugelig gerundeter IIücker nicht so weit als die Astspitze vor, zwischen beiden tritt der vordere Anfang des hinteren Borstenbiindels aus. Eine vordere Lippe am Austritt des vorderen Borstenbïndels habe ich nicht gesehen. Kieme und Cirrus entspringen unter und zur Seite des kugeligen Höckers. Die Kieme ist sehr schlank und fidenförmig und reicht so bis zum unteren Ast, mit der Endläilfte eingerollt, dabei mit der Convexität nach anssen grerichtet, so dass sie sich nicht in dem Raum zwischen den beiden Aesten an die Körperwand anschmiegt, sondern nach aussen rorragt und häufig auch weit vorgestreckt ist. An ihrer Basis steht neben einem deutlichen Einschnitt ein star- 


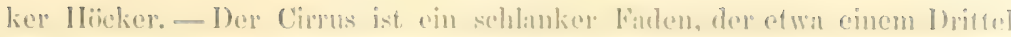
der kiemenlange gleichliommt. - Der untere Ast raget chenso weit wie der

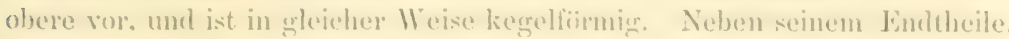
aber weit hinter der spitze zuriickbleibent, steht cin stumpl grerundeter Ilöcker, der an den vorderen Ruder mehr dem oheren, an dem hinteren mehr dem hinteren Umfinge des Astes antsitzt und einen Theil des unteren Borstenhiumels zwischen sich und der Astspitze umlisit. Der launcheirus ist ein schlank liegelfömiger Fortsat\%, weleher mit schwath blattartign erweiterter Basis am unteren Umfange des Astes aufsityt mul mit seiner Spitze weit iiber den Ruderast hinussagt. - Die Borsten sind in beiden Aesten gleich. Sie treten fist in einer Kreislinie um den Unfung der Aeste herats; so dass das hintere Bündel auf die vordere Flaiche hiniibergreift, aber doch von dem gesondert austretenden vorderen Bindel getrennt bleibt. Die Borsten des hinteren Biindels sind dïnn, schlank, ragen weit ïber das Ende des Astes hinaus und sind auf der terminalen Iälfte mit schwachen IIarzihnchen besetzt. '/wischen ihnen stehen in der Nitte des Bündel. einige wenige durchaus anders gestaltete, als Leierborsten (lyratae) zu bezeichnen: bei ibnen, welehe kaum die halbe Liunge der vollkommen ausrewachsenen ibrer Nachbarn erreichen, erweitert sich das Schaftende, indem es sich zugleich abplattet und lïuft dam in 2 gleich lange, schwach geschwumgrene mit Ilirchen besetzte 'Zinken aus, die durch eine äusserst feine Platte verbunden zu sein scheinen. - Die Borsten des vorderen Bündels sind nicht quer gerippt, sondern wie die einfitchen des hinteren Bündels gestaltet, nur kiirzer, so dass sie wenig ïber das Ruderende himausragen, und dunkler. Leierborsten habe ich im vorderen Biindel nicht gretroffen.

Am ventralen Unfinge der Ruder, mit Ausuahme der vorderen, steht eine kleine halbmondförmige dümne IIautschuppe, welche an den mittleren Rudern sich an den unteren Ruderast anlegt; an den hinteren Rudern aber weiter von der Ruderbasis abrickt und vom Seitenrande der Banchfliche des Segrmentes hinter der Ruderbasis frei nach aussen vorspringt.

Das kurze kegelförmige Aftersegment trägt einen kurzen dicken von der Ventralfiache kommenden Aftercirrus.

Der ausgestülpte Rüissel ist kurz und wenig dick; man unterscheidet 3 dentlich von einander getrennte Abtheilungen an ihn: ein kurzes orales Stiick, das grösste Mittelstiick und auf dessen Ende dic 2 den Eingang umfassenden Lippen. Die Rïsselröhre trägt keine Papillen. Dic beiden Endlippen stimmen in ihrer Form und Stellung mit denen der tibrigen Nepl- 
thys-Arten iiberein, allein es fehlen ihnen die gabeligen Endpapillen, welche sich bei diesen finden. Statt deren zeigt die Oberflïche der Endlippen, als eine Antentung einer solchen l'apillenbildung, schwache vom Rimde ausgehende Lingsfurchen, und wird der Lippensaum von einem feineren Gewebe grebildet, dessen Struetur jedoch nicht mehr erkennbar war. - Im. Inneren des Riissels fehlen ferner die Kiefer, welche sonst bei Nephthys vorkommen, und es besass der Riissel einen gerïumigen cylindrischen Hohlraum.

Nach dem alleinigen Auftreten der leierförmig auslaufenden Borsten neben den capillaren wîrde die Art in die von Kinberg ${ }^{1}$ aufgestellte Gattung Aglaophamus gehören. Das Fehlen der vorderen Fühler wie der Papillen und Kiefer des liiissels kennzeichmet die Art vor allen beschriebenen, und kömnte Veranlassung zur Aufstellumg einer neuen Gattung geben. Bei dem augenblicklichen Stande unserer Kemntnisse der Nephthydeen halte ich das nicht fiir angezeigt.

\section{Nephthys squamosa}

$$
\text { Taf. 37, Fig. 7-10. }
$$

Louga, postice attenuata et inter pinnas profundius incisa. - Lobus cephalicus Iongior quam latior, in parte anteriore pellucidus, subtentaculis tentacula superantibus. Pinnae in basi lamellam dorsalem majorem minoremque rentralem gerentes, ramis spatio ramo iuferiore paullo majore distantibus; ramus superior labio postico lanceolato setas non excedente, branchia magna introrsum curvata cirroque dorsali lamelliformi, ramús inferior labio postico ovato-acuminato permagno setas excedente, cirroque ventrali lamelliformi ; nterque setis anterioribus transverse crenatis, posterioribus numerosis longis capillaribus subtilissime ciliatis instructus. Proboscis brevis labiorum papillis bitidis coronata et ordinibus 22 longitudinalibus papillarum $5-6$ simplicium filiformium antrorsum accrescentium singulique cirriformi ventrali et dorsali, maxillis triaugulis armata.

Hab. : 1. Off American Shoal, 55 fms. 2. Off the Sambos, 67 fins, 3. April 3, 1869, off French Reef, 50 fms. 4. April 3, 1869, off French Reef, 103 fms. 5. May 8, 1869, off Alligator Reef, cast No. 6, clepth 85 fms. 6. May 8, 1869, off Alligator Reef, cast No. 9, 113 fms. 7. May 8, 1869, off Alligator Reef, cast No. 10, depth 118 fms.

Körper schlank, nach hinten verschmälert, im vorderen Theile etwa halb so hoch als breit, gregen das Schwanzende stärker abgeplattet. Die Ruder der vorderen Segmente kurz, dicht an einander stehend, an den hinteren Segmenten etwas stïrker vorragend und weiter von einander entfernt. Segmentgrenzen schwach. Fårbung grau oder bräunlich. Bei $50 \mathrm{~mm}$. Lünge vorn $3 \mathrm{~mm}$. breit mit 117 Segrmenten. - Kopflappen lïnger als breit, schwach gewölbt, auf der Rückenfläche eben, auf der Bauchfläche nach vorn zugeschïrft und durchscheinend. Vorderrand convex, Seitenränder gerade

1 Kinterg, Annulata nova. Oefvers af, k. Tet.-Akad. Fört., 1865. No. 4, pag. 239. 
parallel unter einander; die kuren Ifinterainder unter stumplem Wrinkel

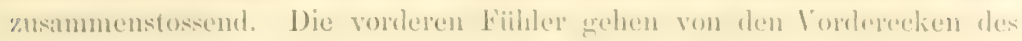
liopflappens aus, sind kïrzer als die and der halben lainge des Kopflappens vou der ventralen filiche hart am Seitenrande entspringenden hinteren Fiihler.

Die seitlichen Lippen des Mundeinganges reichen iiber die 3 ersten Sorrmente, springen mit gradlinigen liandern wenigr gegen die Medianlinie vor; das Mundpolster ist lang gestreekt, schwach prominierend, deutlich grefureht, aber wenig ron der gemeinsamen Bauchlliche abgesetzt.

Das erste Segment mit "2 rudimentairen Ruderisten, in jedem ein kleines Borstenbiundel; der obere Ast mit einem kleinen, dex untere Ast mit einem grösseren Fiihlereirus, welcher linger als die Fiihler ist, und an seiner Basis cine blattartige Erweiterung trigt.

Die folgenden Segmente sind im rorderen Körpertheile 5-Gmal, im hinteren 4mal breiter als lang. Ihr medianes Dorsalfeld nimmt von vorn nach hinten an Breite ab, so dass, wïhrend es an den vorderen Segmenten doppelt so breit als ein Seitenfeld ist, am Schwamztheile das einzelne Seitenfeld breiter als das Medianfeld wird. Hier werden dann anch die Segmentfurchen tiefer und dadurch dass sie tiefer einschneiden, trennen sie die Seitenfelder. welche damm mehr als Ruderbasen erscheinen, schärfer, olne jedoch sperrig von eimander zu stehen. - Die Ruder der 3 crsten Segmente sind unvollstiandig entwickelt.

An den vorderen Segmenten sind die Ruderäste kurz, liommen etwa $\frac{1}{6}$ der Körperbreite gleich, an den hinteren Segnenten gewinnen sie an Länıre, so dass sie etwa $\frac{1}{\ddagger}$ der Körperbreite erreichen. - Im völlig entwickelten Ruder steht auf der hinteren Kante des dorsalen Seitenfeldes der Rïckenfläche (oder der Ruderbasis) ein ovales durchscheinendes Blatt, welches nach hinten niedergelegt schuppenförmig auf die halbe Länge der nüchst folgenden Ruderbasis, oder etwas duruber hinausreicht. Diese schuppenförmigen Bläter der Ruderbasis treten zuerst als wenig vorspringende lappenförmige Erweiterungen der Kante am 15ten Ruder auf, erreichen aber bald die volle Grösse. So wie sie an Grösse zumehmen, nehmen in gleicher Weise die Lippen des oberen Ruderastes an Ausdehnung ab. - Die beiden Ruderäste sind durch einen tiefen Einschnitt getrennt, der aber kaum so hoch als der obere Ast ist; der untere Ast ragt weiter als der obere hinaus.

Der obere Ast läuft mit einer kegelförmigen Spitze aus, in welcher dic Spitze der Stütznadel liegt; vor derselben steht vom unteren Rande des 
Astes auscrehent cine dicke stumpf abgerundete Lippe, welche nicht weiter als die crwilnate spitze hinausreicht und hinter welcher die gerippten kurzen borsten des vorderen Biindels austreten; von der hinteren Flibhe des Astes, und hinter dem Austritte der langen hinteren Borsten entspringt ein diumläutiges lancettfömiges Lippenblatt, welches mehr deun doppelt so ling als breit ist. Von der gleichen likiche, aber unterhalb dieses Blattes gehen die Kieme und der Rüickencirrus aus. - Die Kieme ist stark sichelförmig gekriummt und so gross, dass sie den Raum zwischen den Ruderisten ausfiillt; an ihrer Wurel fehlt der sonst hier stehende Einschnitt und Höcker. - Der mit der Kieme entspringende Cirrus ist ein diumes schmales spitz auslaufendes Blatt, welches etwa halb so weit als die hintere Lippe hinausragt.

Der untere Ast liuft wie der obere mit einer kegelfümigen, die Spitze der Stiitzmadel tragenden '/uspitzung aus; auf seiner vorderen Fläche steht am oberen Rande eine kleine schmale und dïnne Lippe, welche nicht weiter als die Spitze himausragt; und ein zweiter ganz kurzer dümnhäutiger Vorsprung steht hart am unteren Rande nahe der Basis des Astes. Beide Vorspriinge repräisentieren die vordere Lippe, hinter welcher die gerippten Borsten herrortreten. - Die hintere Lippe ist ein sehr grosses diunnes Blatt, welches breiter als der Ast ist, nach anssen in eine lange abwärts geneigte Spitze auslïuft und damit beträchtlich weiter als der obere Ast hinausragt. - Vom unteren Rande des Ruders entspringt medianwärts von der hinteren Lippe und hinter derselben gelegen der Bauchcirrus, ein spitz auslaufendes diumes Blatt, welches wenig weiter als die Spitze des Astes hinnusragt.

Die Borsten sind in beiden Aesten gleich, die des vorderen Bündels kürzer als die Lippen stark quer gerippt; die des hinteren Bündels sehr viel zahlreicher, vierkantig, in mittleren Theile etwas dicker als an der Wurzel, haarfein auslaufend, und etwa auf der halben Länge mit sehr feinen Härchen auf der einen Fliche besetzt. Sie bilden einen noch weit iiber die hintere Lippe des unteren Astes hinausragenden Fächer. ('Iaf. 37, Fig. 8, 9, 10.)

Eine kleine halbmondförmige Schuppe entspringt, vom 5ten Ruder ab, am Segmente medianwärts und hinter der Ruderbasis, und legt sich nach hinten, das folgende Segment kaum erreichend.

Das Aftersegment ist cylindrisch und trägt auf der Ventralfläche einen dicken kegelförmigen Aftercirrus.

Der Riissel ist kurz; die Endlippen tragen schlanke Gabelpapillen; auf der Riisselröhre stehen 22 Lïngsreihen von schlank kegelförmigen Papillen; in jeder Reihe stehen 5-6 Papillen, von denen die hinteren 2-3 beträchtlich 


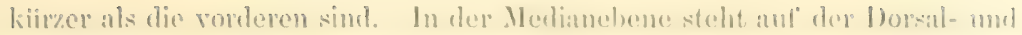

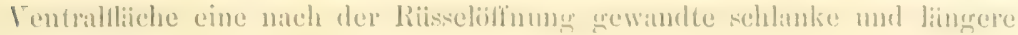
Einzelpatpille.

Diese Beschreibumg ist nach dem best erhaltemen, oben sub) 1 anfogefiilarten lixemplare genacht. Lis finden sich in der simmlung andere lixemplare, welche von dem hier beschriebenen im Ban der Rubler etwas abweichen. Ml̈̈glicherweise handelt es sich hier um gresehlechtliche Diflerenzen ; so dass das Thier, nach dem die roranstehende Beschreibung gemacht wurde, ein Minnchen, die anderen aber Weibehen witren. Lis funden sich aber in keinem der Thiere Geschlechtsproducte, so dass die lintscheidung dariiber noch aussteht. Die Differenzen bestehen in folgrenclen: Die 'L'hiere sind im Allgememen grösser und haben mehr Segmente; allein da keins von ihnen vïllig erhalten ist, so miissen grenamere Angaben dariber fortbleiben. Der llabitus ist ibereinstimmend; der Kopflappen bisweilen lïnger und damn im vorderen 'Theile stïker durchseheinend, eine Differenz, welche bedeutungslos ist, da es sich nur um 'Thiere in Weingeist handelt; die auf der Dorsalfliche der Ruderbasis stehende Schuppe ist schon am 3ten ('Taf. 37, Fig. T) oder am Tten Ruder als ein kleiner Vorsprung der hinteren Ecke des lateralen Feldes zu erkennen; die ventrale Schuppe schon am 3ten Ruder; hesonders ist aber auffallend, dass die hintere Lippe des unteren Ruderastes nicht so weit hinausragt, als es oben angegeben wurde, wennschon sie die gleiche Form behïlt und stets etwas lïnger als die Lippe des oberen Astes bleibt.

Die Art steht der $\mathbf{\Lambda}$. imbrierta (Gr., Oerd.) durch den gemeinsamen Besitz der dorsalen und ventralen Schuppenblätter nahe; unterscheidet sich aber, wie ich durch Vergleichung mit dem Original-Exemplar feststellen konnte, durch andere Gestaltung der Ruderlippen, ganz besonders durch die grosse zweilappige Lippe des unteren Ruderastes. Grube's ${ }^{1}$ Angabe, dass die Ruder der $\Lambda$. imbricata nur glatte Capillarborsten besitzen, ist nicht zutreffend, der untere Ast trïgt wenige (ich sah nur 2) kurze quer gerippte Borsten, der Unterschied zwischen den beiden Arten wird in dieser Bezieliung also verringert.

\section{Nephthys phyllocirra n. sp.}

$$
\text { Taf. 38, Fig. } 7-11 \text {. }
$$

Pallida, postice attenuata, inter pimnas paullum incisa. Lobus cephalicus longior quam latior; tentacula ex angulis marginis antici pellucidi prodeuntia breriora quam sulstentacula in parte postica ventrali lobi cephalici. - Pinnae breves, posticae pandlum longiores; rami paullum distantes

1 Grube, Annulata Oerstediana. Videnskabel. Meddel. fra den nat. Forening. Kjöbenhavn, 1857, pag,. 168. 
conice acuminati; superior labio postico pellucilo transserse ovato maximam marginis superioris partem orenpante, hanchia curvatir cirreque subfoliaceo; inferior labio postico acuminato ramum vix superante, cirroçue ventrali conico; uterque setis longissimis subliliter ciliatis, ranus superior prater ens setis brevioribus crenatis instruetus. P'roboscis labiorum papillis bilidis coronata et unlinibus 2.2 longitutinalibus papillarm antrorsum majorun, maxillisque 2 triangukibus latis :tmitis.

11ah, : 1. March 23, 186 s, Cist No. 6, ofl Carysfort Reef, depth 320 fms. 2. No. 43 , depth 339 fms. L.it. $21^{\circ} b^{\prime}$ X., Long. $82^{\circ} 51^{\prime} \mathrm{W}^{\prime}$.

Ton lieser Art liegen mir mur zwei, leider verstümmelte, Exemplare von verschiedenen Fundorten, aber aus fast gleicher 'Tiefe vor.

Das eine derselben hatte bei $15 \mathrm{~mm}$. Läingre und $2 \mathrm{~mm}$. grösster Breite noch 36 Segmente. Der firblose, weisse Kïrper nimmt hinter dem Kopflappen in der Weise an Breite zu, dass bei eingezogenem Riissel seine grösste Breite ctwa auf der Strecke rom zwölften bis funfzchnten Segmente liegt; von da ab erfolgrt eine allnülige gleichmässige Verschmälerung. Im breitesten Körpertheile ist die Rückentliche hoch gewölbt; weiterhin plattet der Körper auch auf der Rïckenflïche sich ab. Die Kanten des Körpers sind missig abgerundet; die Ruderiiste springen nicht stark vor, wohl aber ragen die grossen grïnzenden Borstenbiindel seitwärts weit himaus.

Der fünfeckige Kopflappen ist etwa um ein Drittel länger als am vorderen Rande breit; seme hintere Spitze wenigs scharf von der Rïckenfläche des folgenden Segmentes gesondert; die Seitenrïinder der vorderen Hälfte untereinander parallel; der Vorderrand wenig gerundet erweitert, durchscheinend. Die ans den Ecken des Vorderrandes hervorgehenden Tentakel sind kurz, kegrelförmigg; die auf der Unterflïche des Kopflappens stehenden, von oben nicht sichtbaren Subtentakel sind grösser als die Tentakel, im basalen Theile keulenförmig verdickt. ('Taf. 38, Fig. 7, 8.)

Die Mundlippen nelımen die Länge des zweiten Segmentes ein; das Mundpolster, welches ïber die Flïche der vorderen fünf Segmente sich erstreckt, ist vorn am breitesten und lïngsgefurcht, nach hinten mässig versehmïlert und glatt. (Fig. 8.)

Die vorderen Segmente sind fünf- bei sechsmal, die hinteren schmäleren dreimal breiter als lang; ein Mittelfeld ist von den gefurchten Seitenfeldern abgesetzt.

Das Ruder des ersten Segmentes ist nach vorn gerichtet und dem Kopflappen dicht angeschmiegt; der obere Ast ist kurz, aufwirts gerichtet, und trägt am iusseren Umfange neben dem Austritt des Borstenbiindels eine ganz niedrige Spitze als Fïhlercirus; der untere nach vorn gewendete 
Ast hat ein groses Borstenbiindel mol an oberen Undinge einen Fïblereirrus, weleher den des oberen Astes otwas an Lingre ibertriflt.

Die dolgenden Ruder nehmen an den himteren semmenten etwas :m Libnge zu, doeh werden sie, ohne die Bursten, liatum so lang als die halhe Breite der Segrmente. Die beiden deste des libulers sind grleich langr der Abstand zwischen ihnen ist greringer als die Hiihe des eimzelnen Astes; jerler Ast liiult mit einer liegelfümnigen, die spitze der Acicula einschliessenden Spitze aus; am oberen Ruderaste ist eine hintere Lippe in form eines quer ovalen Blattes vorhamelen. welches mit seinem Ursprumge fast die ganze Länge des Ruderastes eimmimmt, seitwïrts iilver die liuderspitze hinaus ragt, am freien Raude leicht ausgerandet ist, und schuppenartig aufecht mit geringer Neigung nach hinten getragen wird; die Kieme ist haken, oder auch schwach spiralförmig gekrimmt, und füllt den Raum zwischen den Ruderïsten; der kegelfürmige Rüickencirrus ist sehwach blattförmig abrgeplattet; am unteren Aste ist mureme, die Spitze des Ruderastes wenig iiberragende, spitz abgerundete Lippe rorhanden. - Die Borsten beider Aeste bilden sehr lang hinatusragende Biindel, welche lïnger als die Ruderïste sind; im oberen Aste stehen am hinteren und unteren Umfange des Bündels capillare Borsten mit sehr feiner Zähnelung auf der Schneide der schwach erweiterten Endstrecke; am vorderen Úmfinge stehen kiirzere, auf der einen Flïche der Endstrecke quer gekerbte Borsten; im unteren Aste sind nu Borsten der ersten Form vorhanden. (Fig. 9, 11). 11.1

Die Rüsselröhre erstreckte sich, wie ich am aufgeschnittenen Thier sah, durch die zwölf vorderen Segmente; der Magen lag in den mïchst folgenden acht Segmenten; in der geäfineten Rïsselröhire zählte ich 22 Liingsreihen von Papillen, von denen die oralwiirts stehenden schlank und spitz kegelfürmig sind; am Mageneingange stehen 22 schlanke kegelförmige Gabelpapillen.

Diese Art gehört in den Kreis der Nephthys ciliatr. Bestehen die Ausführungen, welche Wirén ${ }^{1}$ ïber die Variabilität der Nephthys caeca (Fabr.) und die darauf begründete Synonymie dieser Art gemacht hat, zu Recht, so sind auch die Kenmzeichen, welche ich für die Begründung dieser neuen Art verwenden müchte, ohne Bedeutung. Dahin rechne ich die kegelförmige Zuspitzung beirler Ruderäste, welche die Spitze der Stütznadel einschliesst,

1 A. Irivén, Chaetopoder frin sibiriska Ishafvet. Vega-Expeditionens Vetenskapliga Iakttagelser. Bd. II, Stockholm, 1853. P8. 392. 
die Billung der Rulerlippen und des Riickencirrus, sowie das Fehlen der grekerbten Borsten im unteren Ruderaste. Damn wiirde eine weitere Aufvabe darin bestehen festzustellen, ob der nordische formenkreis der Wiphlhys cuecu mit allen seinen Variationen, vielleicht in den 'Tiefen des Meeres, eme soweit siddich reichende Verbreitmo hat, dass er zur Fauma des Florida-Gebietes zu rechen ist, oder ob diese Form, welche ich hier als besondere Art aufführe, als eine geographisch beschrïnkte Localvarietiit aufigefissst werden muss. Den beiden voranstehenden Arten gegeniiber repräisentirt diese Nephllys phyllocirra jedenfalls eine nordische Form im Florida-Gebiete, und da ist es nicht uninteressant zu sehen, dass die beiden gefundenen Exemplare aus einer Tiefe von über 300 Faden stammen, wihrend die erst genannten die Ifundertfadenlinie nicht oder nur wenig iiberschreiten. 


\title{
P'HLLODOCIDAE (Gr.s.str.).
}

\author{
PII LLODOCE (S.IY.).
}

Phyllodoce oculata, n. sp.

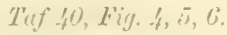

Longa, vermiformis, posteriora rersus attenunta, in dorso subfinseo vitta obseuriore transversia singuli secrmenti notatin, cirris dorsualibus medium fere dorsum terentibus alhidis, segment is 230 ) anterioribus sexies latioribus quam longioribus. - Lobus cephaliens ex triangulo rotundatus margine postico sinuato, postice latior quam longior, longitudine sermenta proxima 5 aequans: oculis 2 magnis transverse ovatis brumeis trientem lobi cephalici latitudinis superantibus; tentaculis $t$ acqualibus lobo cephalico brevioribus.

Cirri tentaculares utrinque $t$ in articulo basali brevi filiformes, longissimi ad segmentum $14 u m$ patentes, anteriores 3 segmento priori, quartus segmento alteri sunra cirrum parrum foliaceum lanceolatum affixus.

Pinnae breres, obtusae, labio parum prominente bipartito; setae tenerae incolures spinigerne, stipite termiuali incrassato spinuloso, spina elongata curvata in acie ciliata; ncicula flava. Cirri dorsales pedunculati lamelliformes, ex orato triangnlares acuminati, anteriores trientem, medii posticique medium fere dorsum utrimųue imbricatim tegentes, singuli per tria fere segmenta postice porrecti.

Cirri ventrales lanccolitt humiles, pinuis late insidentes iisque longius prominentes.

Cirri anales longi filiformes 2.

Proboseis clavata in triente orali utrimq̨ue papillarum foliacearum nigritarum scriebus sex, in apice corona papillarum minutarum siuplici munita.

Hab.: I. No. 11, depth 37 fms., Lat. $24^{\circ} 43^{\prime}$ N., Long. $83^{\circ} 25^{\prime}$ W. 2. No. 5, depth $152-220$ fms., Lat. $24^{\circ} 15^{\prime} \mathrm{N}$., Long. $83^{\circ} 13^{\prime} \mathrm{W}$

Bei der Feststellung des Verwandtschaftsverhältnisse dieser Phyllocloce oculufa zeigte sich mir, dass noch keinesregs eine Uebereinstimmung der verschiedenen Autoren iiber diejenigen Merkmale erreicht ist, welche dabei in Betracht gezogen zu werlen verdienen. Denn wie Möbius ${ }^{1}$ und Tauber ${ }^{2}$ zahlreiche von verschiedenen Autoren aufgestellte Arten als Varietäten einer Art (Ph. maculata Müll.) zusammenziehen, hat sich Grube ${ }^{3}$ zum Theil dage-

1 K. Möbius, Die wirbellosen Thiere der Ostsee. Kiel, 1873, pag. 111. (Ans dem Bericht über die Experition zur physikalisch-chemischen und biologischen Untersuchung der Ostsee im Sommer $18 \% 1$ anf S. M. Aviso D.mpfer Pommeninia.)

${ }^{2}$ P. Tauber, Annulata danica I. K jöbenbarn, 18т9, 8, pag. 87.

arube, Bericht, 1879, a. a. O., pag. 11. 
gen bereits ansgesprochen. Lin Streit, ob Art oder Varietiit, ist ja ein ganz miissiger, wemn nicht die Werthschitzung der Charactere, welche hierbei in betracht kommen, festgestellt werden kam oder dargelegt wird, unter welehen Verhältnissen die Varietiit entsteht. - Das macht sich aber in noch höherem Grale gelten, wem im System die Arten zu Gattungen und Untergattungen zusammengefasst werden mit einseitiger Verwendung von Kennzeichen, wetche wohl nur in enger Beschränkmg Bedentung haben. - Diese Enwiigungen haben mich bestimmt, diese wie die folgende Art als eine Phyllotoce im weiteren Sime zu bezcichnen; in der folgenden Beschreibung hebe ich dam solehe Bildungen hervor, welche als Charactere fiur Gattungen oder Untergattungen Verwendung gefunden haben, oder bei offenbar gleicher Bedeutung umbeachtet geblieben sind.

Der $52 \mathrm{~mm}$. lange, aus etwa 230 Segmenten bestehende Körper ist in der hinteren Iliilfte wenig verschmïlert; er ist vome ohne die Ruder $1,5 \mathrm{~mm}$, mit denselben fast $3 \mathrm{~mm}$. breit; hinten ohne die Ruder fast $1 \mathrm{~mm}$., mit denselben etwa 1,5mm. breit. Seine Riuickenfläche ist brïunlich und erscheint dadurch gebändert, dass am hinteren Rande des einzelnen Segmentes eine dunklere Querbinde steht, dagregen stechen die weissen blattförmigen Riickencirren, welche den grüssten Theil des Rüickens bedecken können, auffällig ab. - Das ron 2 stammende Thier sehe ich als ein junges nicht ausgewachsenes Exemplar an, welches $12,5 \mathrm{~mm}$. lang ist und nur 45 Segment besitzt.

Der Kopflippen, auf dessen Form und Grösse ich weder für die Erkennung noch, wie das Grube zuletzt versucht hat, für die Zusammenstellung der Arten, erhebliches Gewicht legen möchte, ist in der hinteren Hülfte breiter als lang, nach vorn dreieckig zugeschmitten, mit schwach gerundet erweiterten Seiten der hinteren Hälfte und wenig ausgerandetem Hinterrande. Seine Lünge ist etwa derjenigen der ersten 5 Segmente gleich. Zwei quer ovale durch ihre Grösse auffüllige brame Augenflecken stehen, jedes dem Seitenrande ziemlich genähert, auf der hinteren Hälfte. Vier unter einander gleiche Fühler, welche kïrzer als die Kopflappenlänge sind, stehen parweise an den Vorderecken, nur wenig von einander getrennt. ('Taf. 40, Fig. 4.)

Die Segmente des Körpers sind in ihren Dimensionen ziemlich gleich, die ersten, welche die Fühlercirren tragen, von den folgenden kaum verschieden; die vorderen Körpersegmente ïberhaupt etwa sechsmal breiter als lang, die hinteren verhältnissmiissigr liinger.

Die schlanken fadenförmigen Fühlercirren sind derartig vertheilt, das am 
ersten Fegmente, welches andere Autoren als ein ans dem ersten und zweiten verschmolzenes bezeichnen, jederseits drei stehen, jeder atuf einem kmzen Wurelgliede; der liangste von diesen, im ïbrigen wenig an biange verschice

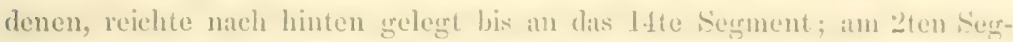
mente steht ein Fïhlercirrus und unter diesem ein kleiner blattfïmierer, seiner Form nach an meisten cinem Bancheirus entsprechender Cirrus aber weder ein Ruderfortsitz noch ein Borstenbindel. Diese Bildung kommt walnseheinlich weiter verbreitet ror, als es bis jetzt beksunt ist, und verdient zur Charakterisiermug der Arten Beachtumg. Ich kenne sie nur an der von mir beschriebenen $P^{\prime} /$. lumelligeru, ${ }^{1}$ deren Synonymic besonders mit Riicksicht auf die nordischen Arten noch festzustellen ist, von Anceitis ceplutules (Clprd.) ${ }^{2}$ und lineatu (Clprd.), ${ }^{3}$ und an der Ph. Mauderiensis (Lugrh.), ron welcher Langerhans ${ }^{4}$ allerdings zu vermuthen scheint, dass das Fehlen eines Borstenbindels oder Ruderfortsitzes ein Jugendzustand sei.

Das Ruder ist ein kurzer stumpfer Höcker, welcher mit 2 Lippen ausliuft, von denen die lintere etwas längere an Rande durch cinen Linschnitt in 2 nicht gan\% gleiche Lappen zerlegt ist; damit stimmt am meisten die Form eines Ruders iiberein, welches Malmgren ${ }^{5}$ von Phyllodoce muculutu, Claparède * ron Anaitis lineata abgebildet hat; Levinsen " hat, wemn ich ihn recht verstanden habe, diese Bildung in die Diagnose von Anaitis aufgenommen, und die von Malmgren ${ }^{8}$ gregebene Abbildung eines Ruders von Anatis Wrhlberyi zeigt solche Gestaltung. In die so begrenzte Gattung Anaitis passt diese neue Art wegen der Riisselpapillen nicht. Ein Einschnitt an der Ruderspitze ist iibrigens häufiger abgebildet, aber seine Lage nie grenauer bezeichnet. (Fig. 5.)

Die zusammengesetzten Borsten von der Form, wie sie in dieser Gattung allgemein vorkommt, deren Zahl nicht gross ist, sind farblos; die terminale Schaftanschwellung, welche das eiugelenkte Endglied träigt, ist jederseits mit kleinen borstenartigen Härchen besetzt und erscheint dadurch rauh. (Fig. 6.) Solche Bildung ist charakteristisch, zunächst jenen Formen gegenüber, bei

1 Borstenwürmer, pag. 139.

2 Claparède, Les Annélisles du Golfe de Naples, pag. 235.

3 Clapuride, iil. Supplément, pag. 94.

4 Langerhans, Zeitschrift für wiss. Zoologie. Bd. XXXIII, pag. 307.

5 Malmgren, Annulata polychaeta. Tab. III, Fig. $16 \mathrm{~B}^{2}$.

6 Claparide, Amuélides chétopodes du Golfe de Xiples. Supplément, par. 94.

' G. M. R. Lerinsen, Systematisk-geoprafisk Orensigt orer de nordiske Amulata, Gephyrea, Chaetognathi og Balanoglossi. Kjöbenham, 1853, pg. 19 (Tidensk. Ieddel fra den naturh. Foren, i Kjöbeuhavn, 1852, pag. 203).

8 Malmyren, Nortiska Hafs-Anunlater, Tafl. XIT, Fig. 31, C. 
welchen das Schattente mit einem oder mehreren grösseren dolch-oder dornartigen Ziihnen besetzt (wie $P /$. budia (Kbrgs.) mucosa (Oerd.), grönlandica

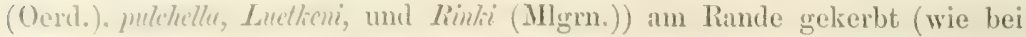

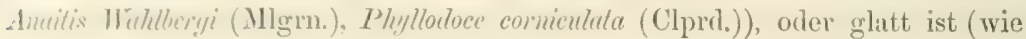
bei Plyflueloe teres). Die bei meiner Art vorkommende Bildung entspricht am meisten dem, was Malmgren ${ }^{1}$ von der Phylloduce maculatu (Miill.) und laminosu abbildet, und dem, was Claparède als eine Rauhigkeit vom Schaftende der Borsten bei Anaitis lineutu beschreibt. - Das messerförmige Endglied liiuft in eine feine, meist peitschenförmig geschwungene, fast fudenförmige Spitze aus; seine Schneide ist mit feinen Hirchen besetzt; seine Form scheint fiir die Artunterscheidung weniger greeignet zu sein.

Der blattfömige Riickencirus steht auf einem etwas oberhalb des Ruderfortsitzes entspringenden, kurzen, quer grerumzelten WVurzelgliede. Es ist ein grosses breit lancettfürmiges Blatt, welches mit seiner schwach ausgerandeten Basalkinte jederseits über den Umfang des Wurzelgliedes vorragt, in der basalen Hailfte gerundet erweitert, gegen die Spitze hin dreieckig zugeschnitten auslïuft; die Rückencirren der vorderen Segmente decken, an den Körper angelegt, jerlerseits etwa ein Drittel der Rïickenfliiche, an den hinteren Segmenten dagegren fast die Hälfte derselben; nach hinten gelegt reichen sie etwa iiber 3 Segmente. Ihre weissliche Firbung hebt sie von der dunklen Riickenfliche ab; in ihrer Haltung war eine bestimmte Anordnung nicht zu erkemen. Malmgren hat in seiner Charakteristik der Gattung Phyllodoce auch die Grösse der Riickencirren aufgenommen, welche hier die Flanken der Rückenfïiche nicht oder kaum decken sollen, und danach würden alle von ihm zu Phyllodoce grestellten Arten mit der hier zu kenuzeichnenden micht zusammenfallen; dieselbe würde sich danach an seine Gattung Anaitis anschliessen.

Der Bauchcirrus ist dadurch in hohem Grade ausgezeichnet, dass er ein im Allgemeinen niedriges vertikal gestelltes 13latt bildet, welches der ganzen Liinge des ventralen Unfanges des Ruderastes angewachsen ist und mit seiner freien lancettförnigen Spitze um mehr als dic halbe Länge des Ruderastes dessen Lippen ïberragt. Ich finde solche Form des Bauchcirrus nur bei der Anaitis lineata (Clprd.).

Das Aftersegment träigt 2 schlank fatenförmige Aftercirren.

Der ausgestiilpte, keulenförmige Riissel, welcher $2 \mathrm{~mm}$. lang und etwa 1,6mm. dick war, ist auf seinem oralen Drittel jederseits mit 6 Längsreihen 
von quer blatfömmigen dunkelfirhigen l'apillen besetnt, in der cinzelnen

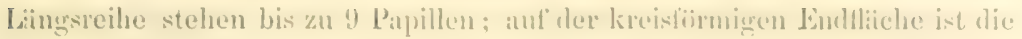

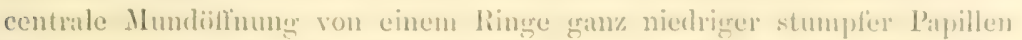
umramlet. - Die Papillenreihen des Riissels weisen die Art nach (ipulare Authassung in die Ciattung Phyllodoce s. str. Mlmgrn., und trennen sie von Anaitis Mgn., deren liiissel der Liingsereihen von l'apjillen enthehren soll im Gegensat\% zu der von Levinsen gremachten Aufstellumg. Dass die Zalhl dep Liingsreihen, welehe bei den meisten beschriebenen diten jederscits sechs

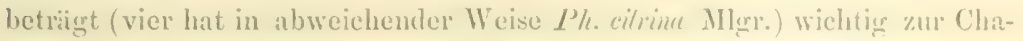
rakterisiermug ist, bezweitle ich nicht, ob aber die '/ahlıl der Papillen in den einzelnen leihen zu benchten ist, bleibt mir zweifellatt. Die den Mundeingang umstellenden Papillen sind meist höher als bei der vorlierrenden Art; es kommen andererseits Arten ror, denen dieser Papillenkranz ganz fehlt.

Die Art erscheint danach. wenn zunichst die am besten bekimnten enropäischen Arten zum Vergleich herangezogen werden, nach der (irösse der Riickencirren als eine Anaitis (Mlmgr.); von der typischen Aneitis Wahlbergi Mlgn. weicht sie damn durch die gestielten litickencirren ats; mit der Anuitis ceplutotes stimmt sie durch den Besitz eines kleinen blattfömigen Cirrus unter dem ten Fiihlereirus iiberein, ist aber durch die andere Form der Baucheirren davon getrennt; zu der Untergattumg Anaitis, wie Grube dieselbe auffasst, und mithin zu allen von ihm dahin gestellten Arten gehört sie nicht wegen der in Lïngsreihen stehenden Rïselpapillen. - Diese weisen die Art in die Gattung Phyllodoce (s. str. Grube); unter den hicrher gestell. ten Arten erreist sich damn die Ph. (Anailis) lineatu (Clprd.) als eine nah verwandte Form, was die grosse Zahl der Segmente, die Form und Stellung der Fühlercirren sowie die Ruder- und Borstenbildung anbetrift. Dagegen sehe ich bei meiner Art nicht die besondere Gestalt, welche bei Anaitis lineata das Fühler tragende Endstiick des Kopflappens hat, remisse bei $\Lambda$. linealu die grossen, meine Art leicht kennzeichnenden Augen und finde eine wenn auch geringe Ungleichheit in der Beschaffenheit des Schaftendes der Borsten. Leider ist von der Anaitis lineala nichts iiber die Stellung der Riisselpapillen bekamnt.

Grube hat die Anaitis cephalotes und lincatu wegen der besonderen Gestaltung der "Stirn" zusammen den iibrigen Arten seiner Gattumg Phyllodoce gegeniiber gestellt; mir scheint das misslich, sobald die Kritik auf in Weingeist conservierte Exemplare angewendet wird, bei denen die Form des Kopflappens leicht verändert wird; ron allen deshalb zusammengefassten 
Arten, zu denen ieh bei beriicksichtigung dieser Gestalt die $P h$. oculuta stellen miisste, unterscheidet sie sich durch die Bildung des Ruders, besonders des bancheirus.

Ich habe noch zu erwilhnen, dass von den Phyllodoce-Arten, welche von den amerikanischen Kiisten beschrieben sind, keine mit dieser $1 \%$. oculutu iibereinstimmt. Die durch den Besitz grosser Augen und quere Bïnderung und grosse den Rïcken deckende Fiihlereiren gekennzeichnete Ph. macrophthumas (Gr., Oerd.) weicht durch die Anwesenheit von 5 Fïhlercirren ab. - Phylloduce longipes (Kinberge ${ }^{1}$ ) von Valparaiso, welche nur durch eine kurze Diagnose bekannt ist, kïmnte hierher gehören, wem deren Rïekencirren nicht als "rotundatine" und "ovales" bezeichnet wiiren. Von der $P h$. catcmult $^{2}$ (Verr.) und grucilis ( Terr.) ${ }^{3}$ von den nördlichen Theilen der amerikanischen Ostkiiste sind Beschreibungen und Abbildungen nicht ausreichend, um deren Beziehungen zu dieser floridmer Art zu sichern; die blattörmigen Riickencirren beider Arten sind zu klein, als dass man von ihnen eine Identitiit mit der $P h$. acululu ammehmen kömnte. - Ph. fragilis Webster ${ }^{4}$ von der virginischen Küiste unterscheidet sich leicht durch Form der Ruder und Borsten.

\section{Phyllodoce (Anaitis s. str. Gr.) papillosa, n. sp.}

$$
\text { Taf. 40, Fig. } 7,8,9 .
$$

Long:n, vermiformis, posteriora versus attentrata, pallide ochracen, segmentis 152 anticis quinquies, posticis quater latiorihus quam longioribus.

Lobus cephalicus triaugularis segmentir proxima 5 longitudiue aequans postice latior quam longior, utrimque rotundato dilatatus margine postico recto, oculis 2 orbicularibus brumeis, tentaculis 4 , superioribus longitudinem lobi cephalici aequantibus, duplo quam inferiores longiuribus.

Cirri tentaculares ntrinque $t$ in articulo basali brevi filiformes, longissimi ad pimnam 7am patentes anteriores 3 segmento priori, quartus segmento alteri supra cirrum parvum foliaceum lanceolatum affixi.

Pinnae breves, oltnsae, labio pellucido inciso; setne numerosine incolores spinigerae, stipite terminali incrassato erenato, spina incurvata; acicula flara. Cirri dorsales supra pinnam in tuberculo insidentes foliacei cordiformes, dorsum non tegeutes, singuli rix per segmentum proximum postice porrecti, pimam parum excedentes. Cirri rentrales lancenlati, liberi pinnam aequantes.

Cirri anales 2 breves conici.

Proboscis longa papillis folinceis triangularibus seriatim dispositis undique obsessa, in apice coroua papillitrum obtusarum munita.

Fundort: Key West, 1-2 fms.

1 Kinberg, Annulata nova a. a. O., pag. 241.

${ }^{2}$ Report of U. S. Commiss. of Fish and Fisheries, Pt. I, pag. 587. Transactions of the Connecticnt Acarlenis, Tol. III, pas. 39, I']. IV. fig. 3.

${ }^{3}$ Ieport of U. S. Commiss, of Fish, a. a. O., pag. 586, Pl. XI. fig. 56.

4T. E. Welster, On the Annelida Chaetopoda of the Virginian Coast (Transactions of the Albany Institute, Tol. IX, pag. 14). 


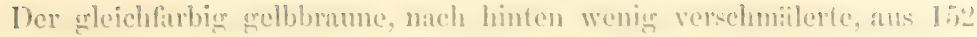

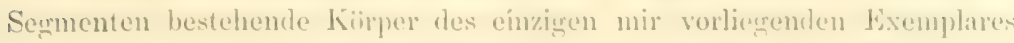
dieser Art war Ifmm. lamy, vorn olme linter 1.5mm., mit denselben 2mm., hinten ohme Ruder lmm., mit denselben, 1, smm. Ireit.

Der im hinteren Theile seitlich grerundet erweiterte, vorn dreieckig zureschnittene Kopflappen ist breiter als lange, sein flinterramel gerade abogestutzt. Auf seiner hinteren Hiilite stehen 2 grosse lireisfömige braun pigmentierte Angenflecke, um wenig meln als ten eignen Durchmeser von einumer entferut; an den Vorderecken des Kopllappens stehen, dureh greringen Abstand ron einander getrennt, jederseits '2 einlazche Fiihler iiber einander, von denen der obere so lang als der Kopflappen und doppelt so lang als der untere Fiihler ist.

Die Dimensionen der Kiirpersegmente weichen wenigr ron einandel ab; im vorderen Kürpertheile ist das einzelne Segment etwa fünf-, in hinteren etwa viemal breiter als lang.

Das erste Segment träigt jederseits 3, an Lüinge nicht erhelblich verschiedene Fïhlercirren, von denen der lïngste nach hinten gelegt bis \%um 7ten Ruter reichte; am zweiten Segmente steht jederseits ein den voranstehenden gleicher Fiblercirrus und unter diesem ein kleiner blattfömiger, den Bauchcirren der Ruder entsprechender Cirrus. Da ich hier werler einen Ruderfortsatz noch ein Borstenbiudel gesehen habe, so entspricht der Wurm in dieser Hinsicht der vorstehend beschriebenen Phyllodoce oculatu und den dort besprochenen Arten.

An den folgenden Segmenten treten die seitlich rorragenden Ruder nur wenig heraus; ilır Endtheil erscheint cylindrisch und liiuft mit einer durchscheinenden eingeschnittenen Lippe aus; im Einschnitte liegt die Spitze der einfachen hellfarbigen Stützmadel; neben der Lippe tritt fiicherförmig gespreitzt ein über die Spitzen der Rïckencirren hinausragendes Borstenbündel aus, in welchem ich mebr als 30 Borsten zaihlte; die einzelne farblose Borste ist auf beiden Flïchen des verdickten Schaftendes, neben der Einlenkung des Endgliedes, vom Rande her gekerbt, ohne Zïhnchen oder Dornen; der Endanhang, vielfach abgebrochen, lïuft in eine feine sehr biegsame und vielfach geschwungene Spitze aus.-Ueber der Ruderbasis erhebt sich auf einem niedrigen Höcker, seitwärts abstehend, der blattartige, im Allgemeinen herzförmig, aber etwas schief zugeschnittene Rüickencirus, der seine grösste Breite etwas über der Basis erreicht, hier fist so breit als ron der Basis bis zur Spitze hoch ist und mit scharfer Spitze auslïnft. Seitlich gelegt ragt er etwas 
uiber die liuderlippe, aber nicht ïber die Borsten hinaus; an den Körper anEclegrt reicht er aufwirts nicht iiber den seitlichen Umfing desselben, sodass die Riiickentliiche von diesen Cirren nicht gedeckt wird, nach hinten meist nicht iiber die gamze Liinge des folgenden Segmentes hinaus. - Der Banchcirrus, welcher hart unter der Ruderbasis auf einer schwachen Erhebung breit anfsitzt, ist ein frei stehendes abwiirts geneigtes lancettfürmiges Blatt, dessen Spitze nicht iiber die Ruderlippe hinausragt. Das Aftersegment trïgt zwei kurze liegelförmige Altercirren.

Da der Riiissel nicht ausgestiilpt war, suchte ich seine Form durch Prïiparation zu erkennen. Hinter der Mundöfhnumg erstreckte sich bis in das 12te rudertragende Segment die in der hinteren Strecke schwach in Falten zusammengeschobene Riisselröhre, daran schloss sich der sehr lange cylindrische, bis in das 4 atte Segment reichende Magen, und auf ihn folgte, fast bis auf die halbe Lünge des Magens unter ihm zuriicklaufend und damm schlingenförmig umbiegend eine Darmstrecke, welche den Anschluss an den gekammerten Darm herstellte. Aufgesehnitten erwies sich die Riisselröhre in ihrer ganzen Ausdehnung gleichmässig mit reihenförmig gestellten Papillen besetzt; die einzelne Papille ist blattförmig breit dreieckig; den Fingang in den Mrgen umstand ein Kranz niedriger stumpfer Papillen. - Der ausgestreckte Riissel muss danach eine erhebliche Lünge haben und auf seiner ganzen Oberflïche mit Papillen besetzt sein.

Das untersuchte Exemplar war, wie aus der Anwesenheit ron frei in der Leibeshöhle liegenden Eiern hervorging, ein Weibchen.

Die Art wïrde nach der Vertheilung der Fühlercirren und dem Auftreten eines ventralen blattförmigen Cirrus unter dem 4ten Fïhlercirrus in dieselbe Gruppe wie die voranstehende Phyllodoce oculata gehören, und mit grösserem Rechte als diese in die Untergattung Anaitis, wie sie von Grube aufgefasst ist, wegen der gleichmäissigen Bekleidung des Rüssels mit Papillen gehören. - Mit einer der bis jetzt beschriebenen Arten kamn ich sie nicht identificieren. Die ungleiche Grösse der Tentakel besitzt anch Ph. Rathkii (Qtrfgs.), von der sich diese Ph. papillosa aber leieht durch andere Form der Rüickencirren und der Borsten unterscheidet, sowie Ph. callaona (Gr. Kr.), bei welcher aber die Fühlercirren an drei Segmenten vertheilt und der untere des zweiten Segmentes lancettfürmig ist. 


\title{
HESIONIDAE.
}

\author{
IIESIONE (SAT.).
}

Hesione vittigera, n. sp.

T'uf: 41, Fig. 1-4.

Brevis, postice vir, antice paullo magis attenuata, subtus plana supra convexn, secmentis pimigeris 15 , ter fere latioribus quam longioribus, in parte dorsali posteriore dense ochraceo Fransverse vittnt is.

Lobus cephalicus trausverse rotundatus, in margine anteriore rectus vel parum emarginatus, quadrioculatus, nudus. Cirri tentaculares utrimque S, paris prioris breviores quam sequentes inter se fere aequales ad segmentum 5 un fere patentes.

Pimac conicae, dimidiam segnenti latitudinem fere aequantes, lobulis minutis terminalibus 2, acicula singula nigra, setis falcigeris, appendice in acie minutissime eiliata apice inaegualiter bidente. Cirri dorsales in articulo basali simplices filiformes, setas excedentes, segmenti latitudinem aequantes; cirri ventrales e pinna orientes camque non superantes, filiformes. Segmentum prenultimum utrinque cirris 2 longis; segmentum ultimum anale cylindratum breve cirris 2 longis.

Proboseis crissa, nuda, inermis.

Fundort: Key West.

Da die Termuthung mir nahe trat, dass die im vorstehenden charakterisierte Art vielleicht mit einer, wenn nicht mit allen aus dem gleichen fumistischen Bezirke stammenden Arten zusammenfallen möchte, mit der IIesione pieta $^{2}$ (Fr. Müll.) von Desterro (Brasilien), Hesione margaritue ${ }^{2}$ (Hansen) ron Rio de Janeïro und Hesione moctochone ${ }^{3}$ (Schmarda) von Jamaica, so gebe ich unter Bezuguahme auf das, was ron diesen Arten bekaunt ist, cine etras ausfïbrlichere Beschreibung der von mir für unbeschrieben gehaltenen Art.

Mir liegren mehrere Exemplare von derselben vor, deren Länge zwischen 20-30mm. schwankte; das stimmt im Allgemeinen zu der Länge von Hesione

1 Archiv für Naturgeschichte. Jhry. 1858, I, pag. 213, Taf. TI, fig. 3.

\& Armaner Hansen, Recherches sur les Annélicles recueillies par . . . v. Beneden . . a au Brésil. (Jém. cour. et des sarants étrang. publ. par l'Acad. roy. des Sciences et de Belles-lettres de Bruxelles, t. XLIV (1881), pag. 6, Pl. I. fig. 18-22.

3 Schmarda, Neue wirbellose Thiere, I, II, pag. 79, Taf. XXVIII, fig. 226. 
mochelumu, welche f(hmm. misst, wïhrend das grösste Exemplar von II. marguritue Tomm. lang war. Bei solcher Linge schwankte die grösste Breite des Kïrpers, ohne die liuder gemessen, "̈-5mm., mit denselben von 6-8mm.

Bei allen Exemplaren besteht der Körper aus dem Koptlappen und dem Bezirk, welcher jederseits vier Patu Fühlereirren trïgt, aus 15 Ruder trageniten Segmenten, einem vorletzten, welehes an Stelle des borstenführenden Ruders jederseits einen langen dorsalen und ventralen Cirrus trïgt und schliesslich aus dem cylinderfürmigen Aftersegment, welches aus einem herzförmigen Einschnitt aus der Riickentäche des letztgenannten Segmentes hervorgeht und unter der Afteröflinmg zwei lange Aftereirren trägt. Für die Thesime proctochone sind ron Schmarda 16 Ruder tragende Segmente angegeben, das letzte dieser Ruder ist aber allen vordergehenden gleich und nimmt clie Stelle ein, an welcher die Cirren stehen, durch welche meine Art ausgezeichnet wird. Hesione murgaritue hat " 17 Ringe;" es ist aber aus der kurzen Beschreibung nicht ersichtlich, was als Ring gezählt ist; sollten dies ansgebildete Segmente zwischen Kopflappen und $\Lambda$ fter sein, so ist dadurch diese Art von den anderen leicht zu scheiden.

In der Körpergestalt herrscht wohl bei allen vier Arten eine gewisse Uebereinstimmung; Schmarda griebt von der Hesione proctochona an, dass die - Bauchfläche eine mediane Furche trage; bei meiner Art ist etwa im mittleren Drittel des Körpers die Ventralfliche median schwach furchenartig vertieft und hebt sich dadurch gegen die wulstigen Seitentheile ab.

Auch in der Färbung und Zeichnung scheinen alle vier Arten eine gewisse Uebereinstimuxung soweit zu besitzen, dass auf der Rïckenfläche eine feine gelbe Querbïnderung steht; im einzelnen scheint sich diese Zeichnung doch ungleich zu verhalten. Bei meinen Thieren ist die Bituchfläche gleichmässig farblos mit schwachem Perlmutterglanz; die Rückenfläche des einzelnen Ruder tragenden Segmentes hat eine vordere kiirzere Querzone, welche farblos ist und eine hintere lïngere, auf welcher feine braune gerade Querbinden auf hellem Grundle stehen; diese quere Bänderung lässt aber auch den grössten Theil des wulstig erhabenen Seitenrandes zum grössten Theile frei und nur auf einer schmalen Zone greift sie hinter dem Ruder abwärts bis gegen die Bauchfliche; die feinen braunen Querlinien sind auf den vorderen Segmenten meist einfach, auf den hinteren dagegen nicht selten gabelig getheilt, im Allgemeinen jedoch gleichmässig breit, so breit als ihre hellen $Z$ wischenräume und parallel zu einander. Der Kopflappen, die Ruder und Cirren siud furblos; das vorletzte Segment ist ganz braun, der aus ihm hervortretende 


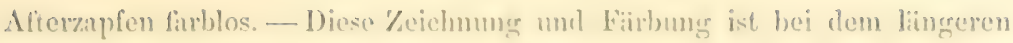
Aufbewahen in Weingeist viilligr greschwunden.

Die Ilesione piche trägt anf schwirzlichem Grumbe weise Querbiuden und

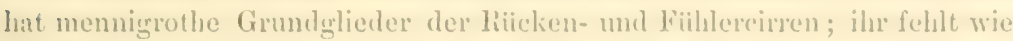
der Ilexione moctochone, welehe im iibrigen tein bram und weiss querebebindert ist, die aufitilige farblose (querzone aul" dem Vordertheile der einzelnen Segmente, wibrend der Abbildung nach zu urtheilen, die Sexmenterenzen, aber auch nur in geringer Aushehnumg hellinbig sind. - In der Abbildung der Hesione muryatue treten die Randwilste der Segmente wie bei meiner Art weiss gegen die gebiinderte litickenfliche hervor, und zwar in voller Lïngserstreckung; die Bïnderung greift nicht ïlser sie himaus.

Der Kopflappen ist bei eingezogenem Riussel eine breit eilörnige l'latte mit gerad abgestutztem oder schwach auscremoletem Vorderrande, ziemlich hoch gevölbt und mehr oder minder deutlich dureh eine Medianfurehe in 2 kissenartige Hïlften getheilt; an Breite bleibt er nicht uncrheblich hinter der des ersten Segmentes zuríck, dessen Lüuge er nicht ganz errejcht; auf seiner hatben Lainge etwa steht jederseits mahe dem Seitemrande ein Pan einander stark genihlierter rothbramer Augen, die vorderen meist etwas grösser als die hinteren und am vorderen Umfinge ansgerandet. Fiilıler fehlen in gleicher. Weise wie bei Hesione picta, marguritue und proctochona; ich habe keine Spuren daron gefunden, dass sie etwa vorhanden gewesen und? abgefallen wïren. Der Kopflappen der Hesione margaritae ist, nach der Abbildung zu urtheilen, in der Mitte des Vorderrandes tief eingeschnitten, seine Augen stehen weit von einander getrennt.

Die \& Paar Fühlercirren stehen jederseits dicht zusammengedrängt an der Seite des Körpers unterhalb des Seiteurandes des Kopflappens, einzeln je auf einem kurzen Wurzelgliede; eine Körperstrecke, die man als verschmolzene Segmente auflissen und auf welcher man diese Fiihlercirren parweise jederseits vertheilen kïmnte, tritt nicht hervor; bei ausgestrecktem Riissel ist die Körperwand, auf welcher diese Cirren stehen, zugleich mit vorgeschoben. Die Cirren des ersten Pares sind wohl um die Hälfte küirzer als die folgenden, von diesen sind die unteren wenig kiirzer als die unter einander fast grleichen oberen, von denen die längsten über den ausgestreckten Rüssel hinaus, uach hinten gebogen bis an das fünfte Segment reichen.

Die MIundöffnumg ist tommenförmigr weit; der Rüssel is ausgestreckt breiter als der Kopflappen, etwas länger als breit, schwach keulenförmig ror dem freien Ende aufgetrieben; eine seichte Ringfurche sondert eine küirzere hin- 
tere von ciner lingeren Torderstrecke. Papillen sind weder auf seiner Flitche noch an seiner lingrungsüfinumg rorhanden; im Immeren stehen keine Kiefer.

Dic Ruter tragenden Segmente sind schr gleichmäissigr gebildet, im Allgemeinen etwa dreimal breiter als lang, ein Seitentheil auf der Riicken-wie Banchlliche etwas wulstig abgesetzt. Die kegelfömigen Rurler, welche ctwa so lang als die halbe Breite des Segmentes sind, nehmen mit ihrer Basis am seitlichen Unfinge des Segmentes und zwar auf der vorderen IJiilfte desselben etwa dessen halbe Lïnge ein. Am oberen Unfange der abgestutzten Flïche, auf welcher die Borsten austreten, stehen 2 kleine, an Grösse verschiedene fast fingertomige Litppehen; unter ihrer Basis liegt die Spitze der einzigen Stiitznadel; vielleicht sind diese Anhïnge als Lippen zu bezeichnen. Von IIesione jidte und proctochone sind solehe Anhïnge des Ruders nicht bekannt; wohl aber finde ich diese auf der Abbildung des Ruders der Hesione marguritue.

Die Form der Borsten kommt offenbar derjenigen sehr nahe, welche Schmarda von der Hesione proctochon, A. Hansen von Hes. margaritae beschreibt; ich hebe hervor, dass, wie solches die Abbildung zoigt, die beiden Zïhne vor der Spitze des Endgliedes ungleichmäissig gestaltet sind.

IIesione moctochon besitzt auf den einzelnen Segmenten an der Seite vor den Rudern einen unvollständigren Höcker; davon finde ich bei dieser Art Nichts, wenn nicht die Wulstbildung an den Flauken der Segmente so bezeichnet werlen soll.

Die Rïckencirren sind bei der Hesione proctochona, da sie die Breite des Segmentes ïbertreffen sollen, wohl länger als an dieser Art; im Allgremeinen jedenfalls wie die Bauchcirren übereinstimmend gestaltet; das gleiche gilt von der Hesione margaritae.

Wie sich durch die besondere Gestaltung des Körperendes meine Art von der IIesiane moctochona unterscheidet, habe ich zum Theil schon oben erwiihnt. Das Segment, welches ich als das vorletzte bezeichne, trïgt an Stelle eines liuders 2 iiber einander stehende Fiiden, welche erheblich länger als die Riickencirren sind und nach hinten gerichtet getragen werden. Dass dieser Körperabschnitt einem Segment gleichwerthig ist, scheint mir trotz der Vertretung des Ruders durch Cirren unabweisbar. Dagegen ist es nicht zu beweisen, dass der farblose Zapfen, welcher aus einem herzförmigen Einschnitte auf der Rïckenfliche dieses Segmentes austritt, und der auf der

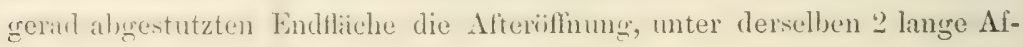


tereiren triggt, gleichlills rinem Segmente voll entspricht. Ich bequehne diesen Zapten seiner Cirren wegen trotzdem als Aftersecrment, mul betrathe

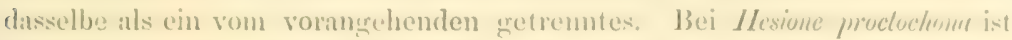

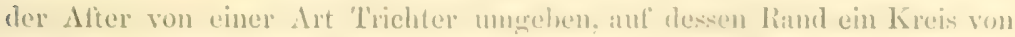
10 kurzen Cirren steht; von dieser besonderen 13ildung, welche in der $A 1$ bildung stark hervortritt, findet sich bei meincr Art keine spur. - Jinen trichterfömigr umrandeten After zeigrt anch die Ilesime murguritue. Weiteres davon lisst die Abbildung, welche dieses zejgrt, nicht erkemen; wohl aber geht ans ihn noch hervor, dass die Cirren der Aftersegmente erheblich kiirzer als bei meiner $\Lambda \mathrm{r}$ t. sind.

Der Mangel allex Fiihler am Kopflappen sowie die eigrenatige l3ildung des Körperendes berechtigen vielleicht zu der Aufstellumg einer besonderen - von der Hesione abzuspaltenden Gattung. Dariber wird die Entecheidung mach Kemntnissnalme eines reicheren Materials zu greben seim. Dann wird sich auch entscheiden lassen, ob nicht, wie ich vermuthe, die 3 Arten, welche ich zum Vergleich herangezogen habe, mit dex von mir beschriebenen zu einer einzigen zu vereinigen sind, die Untersehiede nur in den ungenauen und unzureichenden Beschreibungen begriudet sind; am wahrscheinlichsten ist mir die Zusammengehörigkeit der Hes. margaritue mit meiner Art.

\section{Hesione praetexta, n. sp.}

$$
\text { Tuf. 41, Fig. 5. 6. }
$$

Ifesiona vittigerae simillima, differt praesertim facie dorsili segmentorum anticonum per longitudinem brunneo striolata ; segmento paenultimo albido ; piuvarum magis prorectarum lobulo terminali singulo longiore, cirro rentrali pinnam excedente, setarumque articulo terminali elongato.

Fundort: L้o. 11, deptl 37 fms., Lat. $21^{\circ} 43^{\prime}$, Long. $83^{\circ} 23^{\prime}$

Diese Art steht der vorangehenden sehr nahe, ist aber von ihr durch den Unterschied der in Weingeist allerdings auch schwindenden Firbumg leicht, dann durch die Unterschiede im Bau des Ruders unschwer zu sondern. Die Fürbung ist nur in der vorderen Körperhälfte vorhanden: hier ist die mittlere Rückenfläche der Segmente, deren gelbe Grundfarbe scharf gegen die Wïlste der weissen Ruderbasen absticht, mit feinen längslaufenden braumen Binden, welche vielfach quer unterbrochen sind, grestrichelt. 'Leichnung und Färbung erlischt in der halben Körperlänge allnählich.

Es wird darauf zu achten sein, ob Unterschiede, wic die hier als specifische verwendeten etwa nicht nur die Bedentung sexueller Differenzen besitzen. 


\section{SYLLIDAE.}

\section{BRANCIIIOSYLLIS, n. g.}

Syllidarum genus pimis labia conica et branchiam lamellosam gerentibus.

\section{Branchiosyllis oculata, n. sp.}

$$
\text { Taf. 39, Fil. 1-\%. }
$$

Elongata ralde depressa, postice versus attenuata, brunuea pinuis cirrisque albidis nigroconspersis, segmentis brevibus 112 .

Lobus cephlalicus duplo fere latior quam longior, paullum convexus, in margine anteriore profunde incisus fere bilobus; oculis 4 , anticis magnis convexis, posticis ninutissimis, tentaculis 3 arete articulatis; subtentaculis maguis fere clavatis, approximatis, glabris.

segmentum buccale absconditum eirris tentacularibus utrimque binis, cirris dorsalibus nequalibus.

Segmenta pinnigera sine pimnis Ties latiora quam longiora; prius in parte dorsali mediana supra lobum cephalieum antrorsum lobuli in modum dilatatum; omnia area laterali cirrum gerente alhida distincti.

Pinnae conicae, longae, dimidiam latitndinem segmenti haud attingentes; labiis untico et postico conico-acutis, mineribusque binis rotundatis, setis pancis validis articulo terminali perbrevi fere uncinato, acicula singula simplici; branchia dorsali lamelliformi humili; cirro dorsali in basi ralde tumida crassiusculo sermenti dimidiam latitudinem superante articulis cirea 24 brevissimis nigro maculatis vel cinctis; cirro ventrali simplici media in pinna oriente pinnam non superunte.

Fundort: Key West, 1-2 fms.

Zwei Exemplare dieser Art liegen mir von gleichem Fundorte vor, das eine aus 105 Segmenten bestehend, $17 \mathrm{~mm}$. lang und $2 \mathrm{~mm}$. breit, das andere von 112 Segmenten, $21 \mathrm{~mm}$. lang und 2,8 $\mathrm{mm}$. an der breitesten Stelle breit; in der Färbung der Riickentäche war zwischen beiden eine geringe Differenz, insofern dieselbe bei dem einen braun mit kleinen weisslichen in Querreihen gestellten Pïktchen bedeckt, bei dem anderen im Allgemeinen lichter, aber fein schwärzlich bestïubt war; bei beiden ist die Banchliache hellfarbig, desgleichen die Flanken und Ruder, deren Cirren aber wieder schwärzlich bestäubt oder bald mehr bald minder vollstïndigr geringelt sind. - Das Hinterende des einen Exemplares war entweder neu regeneriert und noch nicht völlig ausgewachsen oder war eine Knospe, deren Kopflappen 
noch unentwickelt: das komnte ich nicht entscheiden. \%u bemerkon ist

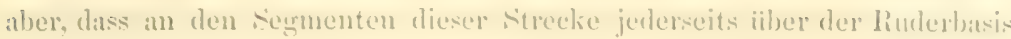
aut der Riiekenlliche ein kreistömiger schwatzer fleck stamb, ob ein Ange

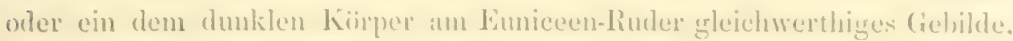
blieb unentschieden. Solche bihlungen erseheinen aber an den atuf dem Wege der Knospumg zu Geschlechtsthieren sich entwickelnden Individuen. und darin könnte man Veranlassumg finden, dieses Lxemplar als ein in Kinospung belindliehes aufzulissen.

Aul besondere Gestaltungen, dureh welche diese Form in Kreise der Syllideen theils an ihmliehe formen sich anschliesst, theils gresondert dasteht, michte ich anfmerksam machen.

Der Kopflappen mit dem stark, fist herzförmigr ausgeschnittenen Vorderrande hat im iibrigen die Form, welehe bei den Syllideen hïufigr vorkommt; auch die Fïhler, welche ich allerdings nicht alle völlig erhalten gefunden habe, mit ihrer kurzen Gliederung, und die grossen kenlenfürmigen Palpen, die nicht mit einander verwachsen sind, finden sich in der Gattung Syllis; abweichend dagegen ist die Augenbildung insofern als die vorderen an den Vorderecken des Kopflappens stehend gross sind und cine convex gewöllote, fast Cornea-iahnlich erscheinende Oberfliche besitzen, waihrend die unmittelbar dahinter stehenden nur schwer erkemnbare punktförmige dunkle Pigmentflecke sind. Dass das erste Segment bei eimer Ansicht von oben vällig verdeckt ist, die Fihlereirren an den Seiten des Kopflappens herrortreten, findet sich auch bei der Syllis brericollis (Ehl.) und Eurysyllis tuberculata (Ehl.). Die auftallende Kürze und Breite der Segmente kommt auch anderen Syllideen (z. B. Eurysyllis tubcrculatu) zu, dagegen ist mir von kiner Syllidee bekaunt, dass das erste rudertracende Segment sich, wie sonst wohl das Buccalsegment lappenförmig, wenn auch nur schwach, iiber den Kopflappen verbreitert, und die Flankentheile des einzelnen Segmentes scharf, felderartig abgesetzt sind, durch die besondere Ausbildung der Basis des Riickencirrus. Die eigenartige Stellung der Gattung in Kreise der Syllideen wird aber vor allem durch die Form der Ruder bedingt. Das kegelförmig zugespitzte Ruder, welches mit seiner seitwärts gerichteten Liingserstreckung nicht ganz die halbe Breite des Segmentes erreicht, wird an seiner abgestutzten Endfläche, an deren oberem Umfang die Spitze der Stiitznadel in einem kleinen Vorsprunge liegt, ron 2 kegelfürmigg zugespitzten Lippen überragt, einer hinteren, welche am Grunde schwach liugelig verdickt ist, und einer vorderen, unter deren Ursprunge noch 2 kleine kegelförınige Zapfen stehen; die 
beiden Lippen sind fast gyleich lang, und erreichen etwa ein Drittel der Linge des Ruderfortsatzes. 'Lwischen den beiden Lippen tritt das kleine Borstenbiintel nur wenig herror; seine Stiitznadel ist einfach, schlank zugespitzt; die einzelne Borste ist im V'ergleich mit den Syllideen-Borsten dick, :m tief ausgeschnittenen Lindstiick des Schaftes ist ein kurzes, fist hakenoder klauenfürmiges Endglied eingelenkt. Vom Flankentheile des Segmentes erhelot sich iiber dem Basaltheile des Ruders von einer ansehnlichen kegrelförmigen Erhebung der Riickencirrus, ein riemlich dicker, aus etwa 24 schr kurzen scharf getrennten Gliedern zusammengesetzter Faden, welcher mit seinem zugespitzten Ende iiber das Ruder hinausragt, und die halbe Segmentbreite an Länge iibertrifft. Der Banchcirrus ist ein einfacher, glatter, auf der halbèn Lïnge des Ruderastes entspringender, die Ruderspitze nicht iiberragender kegelförmiger Fortsatz. - Am dorsalen Umfange des Ruders steht etwas auf die vordere Fläche abwärts verschoben und den mittleren Theil desselben einnehmend ein etwa halbmondförmiges mit langer Basis aufsitzendes Blatt, welches ich als eine Kieme deshalb bezeichne, da die Lichtung desselben wie von einem maschigen Gewebe locker erfiillt ersehien und dats Ganze an das Aussehen erimnerte, wie es wohl die Kiemen einer Gilycera zeigen; eine capillare Ausbreitung von Gefässen konnte ich in remselben nicht erkennen.

Mit solcher Gestaltung weicht nun das Ruder von dem Ruder der Syllideen ab, dem weder Lippen noch ein als Kieme zu deutender Anhang zukommen; die Lippenbildung erinnert viel eher an das Ruder der Hesioneen, und damit wiirde weiter eine Verwandtschaft dieser mit den Syllideen angedeutet; die Borsten ähneln mehr den Syllideenborsten; dahin weist auch das Terhalten des Bauchcirrus, wïhrend der Rïickencirrus, der nach seiner Gliederung an die Syllideen anschliesst, in der Art und Weise, wie er dem Segmente aufsitzt, auf Hesioneen hinweist.

Als Syllidee charakterisiert sich der Wurm aber durch die Form des Anfingsstiickes des Darmkanales, welches aus einer Schlundröhre, einem Driisenmagen und einem Uebergangsstiicke zum gekammerten Darm sich zusammensetzt. Da mit Aufhellung des ganzen Thieres durch Trünkung mit Glycerin die Verhältnisse dieser Theile nicht klar genung hervortraten, tremnte ich die ventrale Decke der vorderen Körperstrecke medianwïrts von den Ruderbasen durch einen Lünursschnitt so dass ich dieselbe wie einen Lappen zur Seite schlagen komnte, und erhielt damit das in Fig. 3, Tat: 39 dirgestellte Bild von dem ventralen Unfinge der vorderen Darmstrecke; 


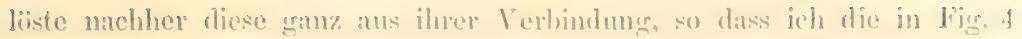
gregebene Riickenansicht derselben strecke erhalten komte. Danach erweist sich die schlundröhre, an deren bingang ein Kram\% von nienleren und, soweit ich beurtheilen kam, weichen l'apillen steht, kiirzer als der diumul' lólgende "Driisemmagen;" ihr Ilinterende liill in der huhelage mit der Ilintergrenze

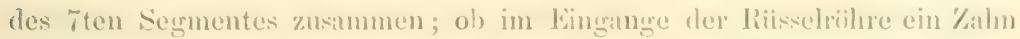
sich befindet, ist mir nieht vibllig klar greworden. Der "D)riisemmagen," scinem Aussehen nach mit dem gleich benamten 'Theil im Dam der Syllideen ïbereinstimmend, fiillt den Risum der niichsten S Segrnente. Jei der Ventralansicht scheint es, als ob an den Driisenmaren sich unmittelbar cin in unrergelmïssigen seitlichen Aussackungen erweitertes Uebergangsitiick anschliesse; die Ansicht der Rïickentläiche (Fig. 4) zeigt aber, dass das nicht der Fall ist, dass viehmehr die mit den rehenfömig gestellten Drisen ausgeristete Wandstrecke zumaichst in eine gleichfalls dickwandige, der Driisenreihen aber entbehrende Strecke ibergeht, welche den Raum von \& folgenden Segmenten eimnimmt, mit einer queren Erweiterumg endet und damit zugleich mach abwirts in den unter ihr gelegenen dimnwandigen 'Theil iibergeht, weleher durch die seitlichen lappigen Aussackungen gekenmzeichnet ist. - Im 18ten Ruder tragenden Segment geht aus diesem der viel engere grekammerte Darm hervor. - Wie die hinter dem Drisenmagen gelegene Strecke bei vielen Syllideen eine wenn auch nicht so stark entwickelte homologe Bildung findet, braucht nicht besonders hervorgehoben zu werden; da aber der Wurm Anklïnge an die Bildung zeigrt, welche den IEsioneen zukommt, so ist in der grossen Ausbildung des lappig erweiterten Uebergangstheiles vom Drỉsenmagen zum grekammerten Darm eine Amüherumg an jene Bildumg gegeben, welche Eisig bei Hesioneen als "schwimmblasenühnliche Organe" kennen gelehrt hat.

\section{TRYPANOSYLLIS, ClaP. char. emend.}

Syllidarum genus tentaculis et cirris tentacularibus dorsualibusque moniliformibus, subtentaculis nou coalitis prominentibus; pharynge corona dentium valida armato.

\section{Trypanosyllis vittigera, $\mathrm{n}$. sp.}

$$
\text { Taf. } 70, \text { Fig. 1-3. }
$$

Elongata, subdepressa, fulva in dorsi parte anteriore segmenti singuli rittis binis transtersis brunneo picta; segmentis plus St. Lobus cephalicus transverse rotumdatus, triente fere latior 
quan longior, tentaculis frontalibus breviter artienlatis, impari externis panllum longiore ad segmentum limm fore patente: subtentaculis inter se distantibus glabris subtus curvatis; oculis mannis lnmmeis vertieis in lateribus trapezii instar collocatis.

seymentum buecale sequeds aequans, prominentia occipitali triangula parva, cirris tentacularibus tentaculis brevioribus, neque articulatis.

Sermenta cetera 1:ies fere latiora quam lengiora, antica trausverse brunneo bivittata. - Pinme simplices, qualrientem segmenti latitudinis aequantes; setae aequales articulo terminali sulvelongato in apice bidentate, in acie ciliato ; cirri dorsales inter se longitudine paullum discrepantes, dimidiam sermenti latitudinem superantes, in articulo basali magno submoniliformes ; eirri ventrales simplices coniei, pimnam paullum excedentes. - Pharyux segmentis 15 anticis inclusus, in parte postica convolutus, antice corona 8 deutium validorum et papillarum mollium armatus; rentrieulus glandulosus ad segmentum $39 \mathrm{um}$ patens; pars proxima intestini infuudibuliformis, autice utrimque sutrorsum paullum clilatati.

Funlort: hey West, 7 frus.

Das Thier lat durchaus den IIabitus der lang wurmförmigen, dabei platt gedruickten Syllideen; das einzige Exemplar, welehes mir vorliegt, ist nicht viollig erhalten, es hat bei emer Linge von $13,5 \mathrm{~mm}$. und einer grössten Breite von 2,5mm. St Segmente; dass sehr viel Segmente mit dem fehlenden IIinterende fortgefillen sein sollten, ist nicht wahrscheinlich. - Die Grundfarbe des Kürpers ist gelbbraum, auf dieser steht im Vordertheile des Körpers eine bei den Syllideen hïufig vorkommende derartige quere braune Bünderung, dass von den beiden Querbinden, welche hier auf der Rïckenfläche eines jeden Segmentes stehen, die eine in der Mitte, die andere vor dem Hinterrande sich befindet. Diese stark hervortretende Zeichnung kommt nur den 46 vorderen Segmenten zu und bricht dann plötzlich ab, das heisst: sie steht anf denjenigen Segmenten, welche den vorderen 'Theil des Darmrohres enthalten und fehlt denjenigen, welche den segmentierten Darm umschliessen.

Der quer ovale Kopflappen trägt die kurz und deutlich gegliederten Tentakel, an denen ich gegen 30 Glieder unterscheiden konnte, auf seiner vorderen Hälfte, so dass der etwas längere mittlere 'Tentakel vor der Verbindungslinie des vorderen Augrenpares, die seitlichen 'Tentakel am Vorderrande selbst entsprangen; diese weit nach rorn geschobene Stellung der Fühler, welche ich als eine frontale bezeichnen möchte im Gegensatz zu einer vertikalen, bei welcher wenigstens der umpanre Tentakel zwischen oder hinter den Augen entspringrt, ist das seltenere Vorkommen; dass es für die Begriindung von Verwandtschaften verwendet werden kamn, bezweifle ich, immerhin wird es fïr die Kennzeichnung der Art von Bedeutung sein kïunen. Die Subtentakel entspringen getrennt von einander, fast unter den Torderecken des Kopdappens, sind glatt, schlank und schwach hakenförmigr grekrümmt. Die grossen Augen sind wenig unter einander ver- 
schieden, ihre 'l'rapezstellung nimmt den mitteren 'Theil des Kopllappens ein.

Aut der Unterlliche ist der tief trichterfirmiere Eingimer des Mumbes von hinten durch einen am liande mit Furehen gelierlsten dreieckig nach vorn erweiterten Lapplen ungeben, man kïmnte fast sagren, zum Theil verdeckt, und auf der Spitze des Dreiecks nagt ein kleiner pappillenartiger Zapfen hervor.

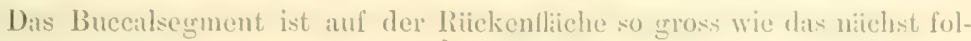
gende, in der Medianlinie mit einem dreieckig zugespitzten Oecipitallappen iiber den hinteren Kophlappemand nach vorn erweitert; duch die Grosse dieses Segmentes stimmt diese Art ron den bislang beschriebenen nur mit der Th. coelue Clprd. überein; die dreieckige Occipitalprominenz kommt weiter verbreitet vor, \%. B. bei Syllis (Typosyllis) Krohnï Ehul. und Oprishosyllis brumen Lghs. - An den wie die 'Tentakel gregliederten Fïhlercirren zählte ich gregen 20 Glierler.

Die folgenden Segmente, welche etwa zwölfinal breiter als lang sind, laben ein cinfach kegelförmiges Ruder, dessen zusammengesetzte Borsten, etwa 10 an der 'Zahl, höchstens in geringen Lïngenunter:chieden des an der Sjoitze doppelzïhnigen, lïngs der Schmeide mit einer Reihe von Härehen besetzten Endgliedes von einander abweichen. Die Riickenciren sind an Lünge etwas ungleich, aibertrefien im Allgemeinen die halbe Breite des Segmentes olme die ganze zu erreichen; alle besitzen unter der Reihe der kurzen Glieder ein grosses Grundglied. - Die Baucheirren sind einfach und ragen wenig uiber die Ruderspitze hinaus.

Die Rüsselröhre liegt im Raume der ersten 15 Segmente, ihre vordere Strecke ist gerade, ihre hintere in Windungen geschlängelt; am Eingrang der von chitinöser Cuticula gefestigten Röhre steht ein geschlossener Ring - von 8 grossen, breit dreieckigen, einfach spitzigen Zühnen, welche an Grösse geringe Unterschiede besitzen; sie sind offenbar von der derben und festen Substanz grebildet, welche die Rïisselröhre auskleidet; diese Zahnkrone wird nach aussen umfasst von einem Kranz 8 weicher stumpfer, lappenförmiger Papillen, welche am Grunde der vorderen weichhäutigen Strecke der Rüisselröhre stehen. - Der Drïsenmagen reicht bis in das 3 Ste Segment; ich zählte an ihm 40 linge von wandstïndigen Driisenschlänchen. An ihn schliesst sich ein trichterförmig verjüngtes Uebergangsstick an, welches etwa einem Viertel der Liinge des Drisenmagens gleichkommt und an seinem Anfangsstücke jederseits eine geringe ohrförmig nach vorn ausgezogene Erreiterung trägt. Daran folgt fast geradlinig anschliessend der gekammerte Darm. 
Diese form des Uebergangsstiickes findet sich bei keiner der bisher beschriebenen 'lypanosylis-Arten. Die nach vorn geriehteten E'weitermgen desselben, oflenbar niedere Entwieklungszustinde der sonst bei den Syllideen inftretenden T-lïrmigen seitlichen Anhänge finden sich nach Langerhans, aber am hinteren Ende des Uebergangsstiickes, bei T'ypunosyllis zebru (Gr.). "*

Ieh stelle diese Art zu der Gattung 'Trypanosyllis (Clprd.), zu der sie zweifellos gehïrt, deren urspriingliche von Claparède ${ }^{2}$ gegebene Diagnose dann einer leichten Aenderung bedarf. Claparède hat in die Reihe der Gattumg:merkmale aufgenommen: "Pharynx rectiligne;" da die Schlundröhre der hier beschriebenen Art im hinteren Theile geschlingelt ist, so wuirde streng genommen dieselbe zur Gattung Trypanosyllis nicht gehören und es miisste für sie eine nene Gattung errichtet werden. Nun scheint mir aber die Verlängerung und die dadureh bedingte Schlängelung der Schlundröhre kein so wichtiger Charakter, dass durch ihn die Aufstellung einer besonderen Gattung zu begriinden wäre oder die geringere Lünge und die Gradlinigkeit dieser Darmstrecke von solcher Bedeutung, dass man daran als wichtigem Gattungsmerkmale festhalten müsse. Verkiirzt man aber in diesem Sinne die Claparède'sche Diagnose, dass man in ihr die Worte "Pharynx rectiligne" streicht, so erweist sich nach der solcherweise geänderten Diagnose die beschriebene Art als eine echte Trypanosyllis, welche dann in der Fïhlerstellung, auch wohl der Bildung des Mundeinganges, in der Grösse des Buccalsegmentes, der Form der Zahnkrone am Eingange und der Schlïngelung der hinteren Strecke der Riisselröhre, sowie in der Bildung des Uebergangsstiickes hinter dem langen Drïsenmagen ihre Artkennzeichen erhält.

Unter den von Grube ${ }^{3}$ beschriebenen Syllis-Arten aus Westindien könnte man wegen der ihr gleichfalls zukommenden, aber ja auch sonst bei Syllideen weit verbreiteten und daher in dieser Hinsicht bedeutungslosen, Querbänderung die Syllis zonata zum Vergleich heranziehen. Dass diese aber mit der Trypanosyllis zittigera nicht zusammen fällt, geht aus Grube's Angaben hervor, wonach Syllis zonutu durch einen nach vorn erweiterten Kopflappen, anders gestellte Querbänder der Rïckenfläche und sehr viel lïngere Rïckencirren von der Tiypanosyllis rittigera abweicht.

I P. Langerhans, Wurmfauna von Madeira. Zeitsch. f. wiss. Zoolog., Bd. XxxII, pag. 57; Tuf. XXII, Fig. 17 b.

${ }_{2}^{2}$ Claparèle, Glanures zootomiques parmi les Annélides de Port-Venilres. Genève, 1864, pag. 98. (Mémoires de la Ścociété d'histoire naturelle de Genève, t. xvii. $2 m e$ partie.)

3 Grube, Aunulata Oerstediana. Videnskabelige Meddelelser fra den naturhistoriske Forening i KjöLenlavn for Aaret 1857, pag. 182. 


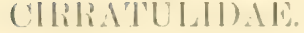

\author{
CIRRA'TULUS' (L.L.).
}

\section{Cirratulus melanacanthus ((ir.).}

Combe, Dic Fumilic der Cirratuliden. Bericht iiber dic 'l'hätigkeit der naturw. Section der schlesischen fiesellsehaft in dahre 18i2, pag. 31.

Von Key-West aus 1-2 Faden 'Tiefe stanmt eine kleine Zahl leider nicht völlig erhaltener Wiirmer, in welchen ich nach der kurzen von Grube gegebenen Charakteristik den Cirratulus melenucanthus (Gr.) wieder zn erkennen glaube, da dasjenige, was ich als Abweichung etwa zu bezeichnen hätte, von keinem Belang ist.

Die Würmer sind im Allgemeinen klein und fast furblos oder gratu. Ich fand bei einem der best erhaltenen Thiere auf $26 \mathrm{~mm}$. Länge 140 Segmente, was zu Grube's Angabe (36mm. 160 Segmente) gut passt. - Der Koptlappen ist bald eifürmig, bald auch kegelförmig zugespitzt, und ragt über die hinter seiner Ventrallaiche stehende, ziemlich weite, quere Mundifftinung ror. Die beiden ersten borstenlosen, in Grösse renigg verschiedenen Segmente sind zusammen etwa so lang, als die uächsten fünf folgenden.

Die Riickenfliiche der darauf folgenden Körperstrecke ist zunächst hoch, nach hinten weniger gewölbt; die Banchtlïche zwischen den ventralen Borstenhöckern fast plan; das einzelne Segment 9-10 mal breiter als lang.

Die Segmente tragen jederseits ein dorsales und ein ventrales, durch grossen Abstand getrenntes Bïndel einfacher capillarer Borsten, die aus einem kleinen Höcker heraustreten. Vom 5ten borstentragenden Segmente ab tritt im ventralen Bïndel zuerst eine dunkle, durch diese Fïrbung sehr auffallende Stiitznadel auf, die in den Segmenten weiter nach hinten stïrker wird und stärker herrortyitt, während die Capillarborsten schwinden; die Stiitznadel ist dann auch woll doppelt vorhanden und bald mehr bald minder stark hakenfürmig an der Spitze gekriimmt. Diese von Grube herrorgehobene, und mit dem Namen des Thieres mekemmeichnete Bildung scheint mir die Identitit der antillischen und brasilischen Wiirmer zu sichern. 
Aber auch die Terhiiltnisse der Kiemen sprechen daffir: Diese sind lange Fiiden, welche mit Ausnilume des 4-Gten borstentragenden Segmentes zu je einem an den Flanken der Segmente stehen, wo ich sie bis zum 51ten Segment grefunden habe, wiihrend Grube angiebt, dass sie bis zum 76 ten Segment rorkommen. Diese Difterenz halte ieh fïr bedeutungslos. - Ifervorheben will ich, dass hinter dem 22ten Segment die Reihe der Kiemenfiden nicht mehr continuirlich ist : in dem nun vorhandenen Auftreten und Fehlen der Fiiden habe ich eine Regehmïssigkeit nicht beobachtet. Zweifelhaft muss ich es lassen, ob die fehlenden Kiemen etwa abgerissen oder abgeworfen waren. Auffïllig ist, dass die hinteren Kiemenfiiden mit ihren Ursprïngen höher auf die Rïckentlïche treten; Grube lässt das vom 40ten Paare an erfolgen; ich notirte dafuir das 42te Segment. - Die wie bei vielen Arten den Kiemenbiischel bildenden Fïden versetzt Grube auf das 5te Segment und giebt 12 Fïden an ; die Zahl wechselt wohl; ich habe wenigstens bei einem, scheinbar unverletzten 'Thiere in dem Bündel der rechten IIälfte 12, in dem der linken 9 Fïden gezïhlt; und was die Stellung am 5ten Segmente betrifft, welche Grube hervorhebt, so finde ich auf diesem allerdings die grösste Zahl der Fiden, sehe aber auch auf der Flïche des 4 ten und 6ten Segmentes einige der Fäden entspringen. Bisweilen hatte es den Anschein, als lägen die Urspriinge dieser Kiemenfïden in hintereinanderstehenden Querreihen, von denen die mittleren die grösste Zahl besässen; doch liess sich nicht iiberall das Bündel zu solchen Querreihen auseinander legen. Kinberg hat bekanntlich in der reihenweisen Vertheilung dieser gehäuften Fïden den Charakter seiner Gattung Timarete gefunden. Ich erwähne schliesslich, dass under diesen im Bïndel stehenden Fïden Differenzen der Dicke vorhanden sind, und dass hier Fäden vorkommen, welche ihre Nachbaren sowohl wie die Einzelfäden der Segmente fast um das Doppelte ïbertreffen. Eine Regelmässigkeit habe ich aber auch hier nicht beobachtet. 
OPHELIIDAS.

TRAVISIA (JOIYST.).

Travisia carnea (Ternule) ?

Ferill, Report upon the Invertebrate Animals of Tineyard Sound. Uniterl States Commission of Fish and Fisheries. Pt. I., lieport on the Condition of the Sea Fisheries, 1873, pg. 604.

Nicht olme Bedenken bezeichne ich die hier zu erwihnende Opheliide. welche auf Lat. 260 $3 \mathrm{I}^{\prime} \mathrm{N}$., Long. 850 3' W. ton 119 Faden Tiefe erhalten wurde, als Tirurisu curnea (Verr.), da sie, wie diese, in einem Punkte ron der europäischen L'urisiu Forbesi (Johnst.) abweicht: das ist der Mangel ron höckerförmigen Erhebungen an den Seiten der hinteren Segmente; wenigstens erwihnt Verrill solehe in seiner kurzen Beschreibung nicht, und hat sie auch in der später ${ }^{1}$ gegebenen $\Lambda$ bbildung nicht gezeichnet.

Der Körper des Wurmes, welcher bei $16 \mathrm{~mm}$. Länge $4 \mathrm{~mm}$. urrösste Dicke besitzt, ist spindelförmig, olne besonders abgesetzte Abplattung der Banchflïche. Der Kopflappen ist spitz kegelförmig, nackt; das erste Segment emfach, borstenlos. Darauf folgen 25 borstentragende Segmente, während Verrill für Trarisia carnea nur 24 angiebt, die wie bei Travisia carnea dreiringelig sind, und deren Haut von äusserst feinen in Querreihen stehenden Pünktchen besetzt ist. Auf der Grenze zwischen dem ersten und zweiten borstentragenden Segmente liegt als querer Spalt die Mundiffnung, nach himten von einer leicht gefurchten Unterlippe begrenzt. - Fadenförmige Cirren oder Kiemen, von denen die längsten etwa einem Drittel der grössten Körperbreite gleich kommen, treten am 2ten Borsten tragenden Segment zuerst auf; ich habe davon nur 14 gezählt, und das wïrde einen Unterschied von der Trarisia carnea ausmachen, bei welcher nach der Beschreibung rom 3ten nach der Abbildung rom 2ten borstentragenden Segment bis zum 20ten diese Anhänge sich finden; ich mag aber diesen Unterschied nicht für die Aufstellung einer neuen Art betonen, da ich nicht sicher bin, ob die mir vorliegenden Thiere nicht einige dieser Anhängre verloren haben.

1 A. E. Verrill, Ners England Annelida. Transactions of the Connecticut Academy, Tol. IV. Pt. 2, Pl. VIII. Fig. 1. 


\section{CHLORAEMIDAE.}

Die Vertheilung der wenigen hier zu besprechenden Arten in Gattungen und die Benennung der letzteren habe ich im Anschluss an die zuletzt von Grube $^{3}$ vorgenommene Revision der Familie der Chloraemidae gemacht, nicht als ob ich dieselbe als eine abschliessende ansehe, sondern weil in ihr dis bis dahin bekannt gewordene Material zusammengefisst und geordnet ist.

\section{SIPIONOSTONUM (OTTO).}

\section{Siphonostomum cariboum, Gir.}

Grube, Annulata Oerstediana. Tidenskabelige Meddelelser fra den naturhistoriske Forening i Kajubenlarn for Aaret, $185 \overline{8}, \mathrm{pgg} .108$.

$$
\text { Taf. 42, Fig. 6-9; Taf. 43, Fig. } 1 .
$$

Die von Grube ${ }^{1}$ als Siphonostomum carboum kurz charakterisierte Art glaube ich sicher, in den von Key-West in 1-2 Faden 'Tiefe gefundenen 'Thieren wieler zu erkennen, und bin darin durch eine Ansicht des im kopenhagener IIuseum aufbewahren Original-Exemplares bestälit. Grube's kurze Beschreibung kann ich in manchen Punkten ergänzen.

Das grösste der mir vorliegenden Exemplare ist 20̃mm. lang, an ihm zihle ich 64 Segmente; an kleineren 'Thieren betrug deren Zahl nur 52; der von Grube kurz als wurmförmig bezeichnete Körper ist durch die am Vorder- und Hinterende wenig unterschiedene Verschmächtigung spindelfömig gestaltet, immerhin erscheint das Hinterende etwas schlanker als das Torderende, doch sind hier ungleiche Contractionszustände von grossem Einfluss. Diesen ist es wohl auch zuzuschreiben, dass bei einigen Exemplaren rler mittlere Kürpertheil zumal schwach kantig erscheint. - Die mittleren Körpersegmente sind etwa $5 \mathrm{mal}$, die hinteren 8 mal breiter als lang.

Grube's Angabe, dass die vorderen Segmente röthlich seien, stïtzt sich vielleicht anf eine nach dem Leben entworfene Abbildung, am Originalexem.

1 Grule, Jittheilungen üler die Fumilie der Chloraeminen. Bericht über die Thätigkeit der naturwisesenschaftlichen Section der schlesischen Ge-ellschaft in Jahre 18i6, par. $3 \overline{7}$. 
plar war davon nichts zu erkennen; es stimmte dies im Allereneinen nit den mir vorliegenden 'Thieren äberein. Bei starker föchlumblerleckung waren die 'Ihiere hellgrau, lag die Kïrperdecke nackt vor, so war sie grleichfill.

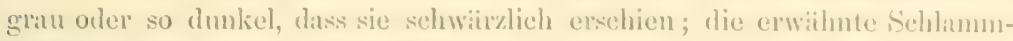
bedeckung war in ungleicher Michtigkeit vorbanden, ans,er den feinkïnigen Sehlammtheilen hafteten zumal am vorderen Körpertheile zerstrente Sandkömehen der IItut an; Grube ${ }^{1}$ erwiihnt spiiter, dass solche Körner anch bei dieser Art eine Nackenplatte bildeten; ich kam dem nur insoweit zustimmen, dass ieh allerdings bei einigen 'Thieren auf der Rïekentlitche der vorkeren Segmente eine Anhäufung von Sindliörnem gretroften habe, aber bei anderen 'Thieren nicht, und nie in solcher Ausdehmung, dass Incrustationen ron der Ausdehnung und Mäichtigkeit wie bei Sylurvides purmulus (Gr.) oder sentiger (Ehl.) entstanden wäiren. - Ein sammtartiges, von Grube erwähntes Aussehen der Körperdecke kamn ich nur in dem Auftreten kleiner weicher Hantpapillen erkennen, zwischen denen grössere vertheilt stehen; diese werden dam an den hinteren Segmenten besonders gross und erscheinen neben den Borsten als kleine Cirren. - Die Seginentfurchen treten wenig hervor, neben ihnen sind feine Querrumzeln, bisweilen zu Ifalbringen ausgedehnt, vorhanden; bei einigen Exemplaren war die Batuchliache der mittleren Segmente fust regelmaissig fein quer gefureht.

Die nach rorn gerichteten Borstenbiindel des ersten und zweiten Segrmentes ïbertreffen die folgenden erheblich an Länge und ragen weit nach vorn hinaus; in ihnen wie in denen des 3 ten und 4 ten Segmentes stehen nur capillare gegliederte Borsten. Diese Borstenform erhiilt sich in den dorsalen Bündeln der nächsten Segmente, doch werden die Borsten in den Segmenten der mittleren Körperstrecke sehr kurz, nehmen dagegen an den hinteren Segmenten wieder etwas an Länge zu. Vom 5ten Segment ab) treten in den ventralen Bïndeln dickere einfache hakenfürmigg gekrimmte Borsten auf, in den vorderen dieser Segmente noch fist capillar, damn aber stiirker und kürzer, in einer Reihe stehend, selten mehr als fünf. - Ventrale und dorsale Bïndel sind am ersten Segment zu einer Reihe zusammengeflossen, am 2 ten Segment bereits deutlich von einander getrennt, in den folgenden Segmenten fust um die Höhe des Körpers von einander entfernt. - Die Stellen, an denen die Borsten austreten, sind bei einigen Exemplaren am mittleren und hinteren Körpertheile unter der Form kleiner ovaler Felder ausgezeichnet, bisweilen mit dunkler Färbung von der übrigen Fläche ab-

2 Grube, Amulata Semperiana a. a. O., pag. 200. 
stechend, weil auf' ihnen die Aullagerung weissen Kälkschlammes ganz fehlt; die Anstrittsstelle der ventralen Borsten sah ich bisweilen schwach kristenartig erhoben; das mag durch eine vorgeschobene Stellung der liorsten bedingt sein. - An den hinteren Körpersegmenten tritt neben dem dorsalen liorstenbiindel je eine fidenförmige verlingerte Papille anf, die neben der oberen Ecke des hinteren Randes des Biindels sich erhebt ('Taf. 42, Fig. 9); vine solche Papille fehlt auch den mittleren und vorderen Segmenten nicht, nur ist sie absolut und relativ kleiner als diejenige der hinteren Segmente, liisst sich aber bei grenauem Nachsuchen an der bezeichneten Stelle unschwer nachweisen; in den Fällen, in welchen ich sie vermisste, glaube ich annehmen zu diirfen, dass sie abgefallen war. - Line andere Beschaffenheit zeigten mir vereinzelte neben dem rentralen Bündel stehende Papillen, welche hinter den fadenförmigen an Grösse zurickblieben, immer aber noch die kleineren sonst auf der Körpertlïche zerstrenten Papillen an Grösse iibertrafen. Diese Papillen sind eiförmig und besonders dadureh auffallend, dass auf der abgestutzten Endfliche ein heller durchscheinender 'Zapfen hervortrat (Taf. 43, Fig. 1). Vielleicht liegen hier besondere Tastapparate vor.

In fast allen Exemplaren ist der am Vorderende des Körpers befindliche Apparat von Anhüngen völlig eingezogen, wie in dem von Grube untersuchten Thiere. Nur bei einem meiner Exemplare ist dieses Kopfstiick zum Theil vorgestreckt (Taf. 42, Fig. 8), bei einem anderen suchte ich es durch Prïparation frei zu legen (Taf. 42, Fig. 7). Der Apparat besteht aus zwei dicken 'Teutakeln und einem Kiemfäden tragenden Blatte. Die fast drehrunden, allmählich gegen die Spitze zu verdünnten Tentakel sind mehr oder minder stark gekrümmt oder schwach spiralig gewunden, auf ihrer unteren Fläche von einer Rinne gefurcht und von hier aus an den Rändem mehr oder minder stark gekräuselt. Ihre Länge dïrfte die des Kiemen tragenden Blattes um reichlich ein Drittel ïbertreffen. Das die Kiemenfäden tragende, vielleicht als Kopflappen zu bezeichnende Blatt, ist zungenförmig, dreimal länger als breit, anf seiner Unterfläche eben, in der Mitte der Länge nach vertieft, auf der Oberfläche schwach gewölbt, an den Rändern wie stumpfgezähnelt. Bei dem 25mm. grossen Thiere war es herauspräpariert $2 \mathrm{~mm}$. lang. Die drehrunden schlanken Kiemenfäden, wie ich sie vermuthungsweise nenne, sind mehr als doppelt so lang als ihr Träger breit, die am basalen I'Theile desselben stehenden etwas länger als die gegen die Spitze hin gestellten. Sie entspringen von der Oberfläche des Blattes längs des Randes desselben, wie es scheint in Reihen angeordnet, so dass sie die Mitte des Blattes 
wenigstens am Basultheile freilassen; ob die Stellung der einzehon etwa mit den limndeinschnitten zusammentällt, kam ich nicht entscheiden. Wenn ich diese Fialen als Kiemen bezeichne, so gerehicht das, weil die unter stairkeres Vergrösserung geringelt erseheinenden fïhlen oflenhatr schlïuche sind und weil in der $\Delta$ xe des sie tragenden Blattes grose Blutgelisse verlaulen.

\section{S'I'YLARIOIDES (d. Chr.), C'rar.}

Stylarioides collarifer, 11 , sp.

$$
\text { T'uf. fr, Fiy. : }:-7 \text {. }
$$

Griseus vel subnigricans plerumque limo calcareo olductus; fusiformis, papillis filiformibus in parte anteriore plus minusre in cingulos congluminatis cinctus, antice arenato obductus ; segmentis 2t, quorum duo anteriora a ceteris forma setisque longissimis discrepantia. Fusciculi sctarum dorsales et ventrales sermenti prioris confluentes, cetcrorum distantes; sethe dorsales eapillitres articulatae, segmenti prioris lougissimac, mediorum posticorump̨ue perbreves ; setne ventrales segmentorum anticorum qquattuor dorsalibus aequales, sermenti $5 \mathrm{ti}$, $6 \mathrm{ti}$, $7 \mathrm{mi}$ breviores, brumneac, articulatac, articulo terminali parum hamato ; segmentorum ceterorum breres aciculaeformes paullum curvatac, articulatae, flahellum fingentes.

II:b. : 1. Fetb. 16, 1869, off Boca Grande, cast No. 4, depth 369 fims. 2. Feb. 17, 1869, sontluwest of Sand Key, enst No. 4, depth 325 funs. 3. MIreh 31, 1869, ofl Carysfort Reef, cast No. 3, depth 206 fins. 4. Lo. 43 , depth 339 lims, Lat. $24^{\circ} 8^{\prime}$ N., Long. $83^{\circ} 51^{\prime} 11^{\prime}$.

Der im Allgemeinen spindelfömige Leib dieser Würmer erhïlt sein besonderes Aussehen, abgesehen von den grossen Borsten der vorderen Segrmente, welche dem ganzen Kreise der Verwandten zukommen, einmal durch mehr oder minder ausgedehnte Incrustationen der Körperwandung theils mit einem weissen Kalkschlamm, theils mit festeren Kömchen, das andere Mal durch eine ringförmige Anordnung ron lïngeren Hautpapillen, welche verbunden mit diesen Incrustationen im Bereich des vorderen Körpertheiles Giirtel erzeugen, die in sehr ungleicher Ausbildung auftreten, bald scharfkantig erscheinen, bald breite Ringwiilste darstellen. Fallen die Incrustationen fort, so tritt anch diese Ring- oder Wulstbildung zuriick; die nackte Kürperoberflïche zeigt damn eine feine quere Ringelung. - Die Segmentierung des Körpers tritt bisweilen im Zusammenhang mit der Wulstbildung sehr deutlich heraus; dann besonders in der mittleren Körperstrecke. - Das hintere Körperende ist meist nackt. Im rorderen Körpertheile tritt eine besonders zu beschreibende Ausgestaltung ein (Taf. 43, Fig. 2, 6, 7 ).

Ein völlig erhaltenes Exemplar von 12,5mm. Lünge und einer grössten Breite von nicht ganz 2.5mm. hatte 24 Segmente; bei einem $7 \mathrm{~mm}$. langen 
'Thiere fand ich dargegen nur 17 Segmente, bin aber' unsicher dariber, ob das Kïrperende hier nicht verletzt war.

Die beiden ersten Segrmente sind bisweilen in sehr auftallender Weise vor den folgenden dureh eine besondere Art der Incrustierung atusgezeichnet; bei emem Exemplare war die der ibrigen Hattliche gegeniiber glatt erscheinente Inutlliehe vollstïndig von einer gleichnässigen Schicht aufgekitteter Sandkïnchen bedeckt (Fig. 3, 4).

Beide Segmente bilden gleichsam ein zusammengehöriges Ganzes, dessen segmentweise Ghederung nur aus der Vertheilung der Borsten erkamnt wird. Dieses Vorderstiick geht mit einer cylindrischen Strecke halsartig aus der von einem Papillenkranze ungiirteten kindliiche des 3ten Segmentes hervor, erweitert sich kegrelfömigr nach vorn besonders dadurch, dass hinter den beilen ihm angehörenden Borstenbindeln je ein kegelfümniger Höcker stcht; zwischen den beiden ventralen Höckem steht auf der Banchflïche eine quere Firste mit undentlich gezackten Riundern, die Rïckenfliche dagegen ist zwischen den dorsalen seitlichen Ḧ̈̈kern eben. Ḧ̈̈ker und Querfirst sind wohl auf Papillen zuriickzufiiluren, und in diesem Simne liesse sich sngen, diss das 2te Körpersegment ron einem auf der Bauchfliche unterbrochenen Papillenkranze ungiurtet sei. - Das erste Segrment ist schmäler und kuirzer als das 2te, kegrelfümig mach vorn verjuingt, auf der dorsalen und ventralen Fläche abreplattet, anf der ventralen Fliche steiler als auf der dorsalen geneigt; beide Flächen fillen somit gegen die terminale querspaltige Mundoffnung ab; der Torderrand der ventralen Fläche ist gerade abgestutzt, während die dorsale Fliche mit einem dreieckigen Zipfel auslïuft; hinter dem seitwirts entspringenden Borstenbiindel stehen jederseits zwei dicht an einander grerïckte kegrelfürmige Höcker; dadurch erscheint bei einer Ansicht von oben der Vorderrand dieses Segmentes dreilappig. Ein Papillengiirtel ist nicht rorhanden.

Die Borsten beider Segmente sind capillar und gegliedert. Diejenigen des ersten Segmentes sind zum Theil so lang ( $8 \mathrm{~mm}$.), dass sie $/$ weidrittel der Körperlinge erreichen, solcher ziihle ich bis $\mathrm{z} \| 6$; daneben treten ventralwärts sehr viel kïrzere in geringer Kahl auf; alle Borsten stehen so nahe an einander, dass sie ein einziges Bündel darstellen. - Die Borsten des zweiten Segrmentes treten dagegen vor den genanuten Höckern in zwei gesonderten Biindeln aus; die dorsalen sind etwas zahlreicher und länger als die ventralen, erreichen aber kaum die halbe Lünge der Borsten des ersten Segmentes.

Aus der Mundöfnumg ist bei einigen Exemplaren ein dünn- und glatt- 
wandiges, firlenfömig imd hohl erseheinentes Gebilde hervorgetreten, iiber

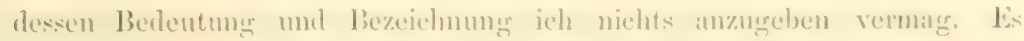

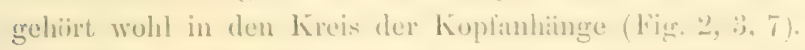

Die Sermente, welche die mittlere und hintere Kiorperstrecke bilden, unterscheiden sich von einamler in ilnen Dimensionen und in der Ausbildum von Pipillenkrïnzen; ein damit nieht zusimmenfillender Untersehierl besteht in dem Verhalten der ventralen Borsten.

Die Segmente der vorderen und mittleren Kïrperstrecke sind etwa dreimal breiter als laug, auf der verjüngten hinteren Strecke werden sie dagegen sechsmal breiter als lang. Die Papillenkrinze sind nur an den vorderen dieser Segrmente vïllig entwickelt, und zwar am rollständigsten, ein vollen Ringkratgen bildend, am šten, ften und 5ten Seggmente; an den folgenden Segmenten tritt diese Anordnumg meln zurick, am hinteren Körperende fehlt sie granz; ich bilde ein Exemplar ab ('L'af. 43 , Fig. (6), an welchem ringförmige breite Incrustationen mit Schlammkïnern, welche durch das Auftreten grösserer Papillen bedingt sind, bis zum 11 ten Segment hervortreten. - Die ganz entwickelten Papillenringe des 3 ten bis 6ten Segmentes stehen auf einer hinter dem Austritt der Borstenbündel liegenden Linie; es sind Kinme, deren ron den Papillenenden gebildeter freier Rand meist gleich lange Zaibne, die freien Papillenenden, trägt. Die Papillen, welche diese Ringe bilden, sind nur durch ihre erheblichere Grösse von den fadenförmigen Papillen der folgenden Segmente unterschieden; auch die Segmente des hinteren Kürperendes enthehren die Papillen nicht ganz, nur sind dieselben lier bedeutend kleiner. Der Torgang, der zur Bildung der Schlammdecke und der Incrustierung fiilnt, ist wohl mit einer 'Thïigkeit ron drüsigen Orgranen in oder an diesen Papillen in Verbindung zu bringen, und das ungleiche Aussehen der Incrustierung wohl bedingt durch ungleiche Thätigkeit dieser Gebilde. Bei cinem Exemplare, an welchem ich durch Behandlung mit Essigsiiure die Schlammdecke völlig entfernt hatte, zeigte dic Oberfläche der Haut ein grob genetztes, fast wabiges Aussehen.

Die Unterschiede in der Ausriistung der Segmente mit Borsten betreffen die rentralen Borsten. Denn mährend die Borsten der dorsalen Bindel alle capillar und gregliedert sind und nur in der Grösse insoweit ron einander unterschieden, dass diejenigen der mittleren und hinteren Segmente seln' kurz sind, sind nur die rentralen Borsten des 3ten und 4ten Segmentes wie diejenigen des 2 ten den dorsalen ähnlich, capillar und gegliedert; diejenigen des 5ten, 6ten und 7 ten Segmentes sind etwas dicker als die roranstehenden, 
gecrliedert und briiunlich gelïrbt, vor allem aber dadurch ausgezeichnet, dass sie eine vom Schnft albgesetzte schwach gekrimmte Endspitze tragen und mithin zusimmengesetzte Borsten dirstellen (Fig. 5, b.); vom Sten Segment ab sind alle rentralen liorsten einfach kuz nadelfömigg schwach gekrümmt, hraun gelïrbt und gegliedert, und bilden meist 3-4 an Zahl ein fïcherförmiges Biindel (Fig. 5, a.).

Die terminal stehende grosse kreisförmige Afteröfinung trägt keine Anhi:in.:-

Ieh habe lïingere 'Zeit geschwankt, ob diese Thiere nicht zu dem Siphonostomun cingututum (Gr., Kr.) von Rio Janeïro zu stellen seien. Das thier, auf welches Grube's ${ }^{1}$ Beschreibung zuriekgeht ind welches in dem kopenhagener Museum sich nicht befindet, hat bei einer erheblich grïsseren Lünge (12 Linien) cine sehr viel grössere Segmentzahl (59) als alle mir vorliegenden thicre. Ian wïrde die darin gelegenen Unterschiede auf Altersunterschiede zurïckfiihren und deshalb umbeachtet lassen können; dann aber besitzen nach Grube's Beschreibung alle Segmente eine dorsale Querreihe von Papillen, das 3te bis 11 te Segment auch eine ventrale und damit einen vollständigen Papillengriirtel; das ist eine Eigenschaft, welche ich bei meinen Exemplaren nicht finde, weder trägt das erste noch die letzten Segmente diese dorsale quere Papillenreihe. Andererseits erwähnt Grube von seinem Siphonostomum cinguIntum nicht die eigenthïmlichen zusammengesetzten Borsten, welche ich am 5 ten bis 7 ten Segmente finde und welche einen Uebergang von den einfachen capillaren der ersten Segmente zu den gekrïmmten nadelförmigen der hinteren Segmente machen. Die Möglichkeit ist allerdings nicht ausgeschlossen, dass auch in dieser Form der Borsten ein Jugendeharakter vorliege, und dass mit grösserem Alter, wachsender Körperlïnge und Segmentzahl die Thiere an allen Segmenten die dorsale Querreihe von Papillen, in allen hinteren Segmenten einfache capillare Borsten erlalten.

Bis aber ein solcher Nachweis grebracht wird, glaube ich die mir vorliegenden Thiere als eine mit dem Siphonostomum cingulatum wohl verwandte, aber sicher zu unterscheidende Art um so mehr bezeichnen zu müssen, als alle diese Thiere aus grösserer Tiefe von ungleichen Fundorten stammen.

\footnotetext{
1 Grube, Annulata Oerstediana a. a. O., pag. 108.
} 


\section{Stylarioidos scutiger, n. sp.}

$$
\text { Iitf. \& } \therefore \text {, Fin. } 1-i
$$

Cimnmomeo-bmonens, brevis fusifurnis, antice depressne, lingulatus, supra concavens ntrimenu. serratus: papillis mollibus in parte majore pusteriure minutis filiformibus dense chsitus, anties multo majorilus cingulatim et collaris instar collonetis fimbriatus, in parte lingulata flatier are

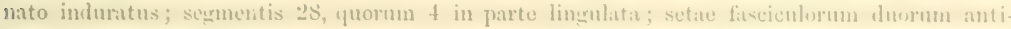
corum longissimae iridescentes aequales dorsales, ceterorum dersales et ventrales, inde al, fancicule nono inter se discrepantes; anticornm fasciculorum setae onues capillares articulatue, ceteromu dorsales itidem formatae, ventrales aciculitermes bicurrae bruuneae flabellun complonentes.

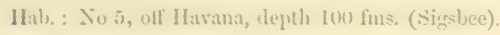

Von diesem meines Wissens bisher nicht beschriebenen Wurme liegt mir nur ein Exemplar vor. Bei der Aufgabe, dieses zu beschreiben, stosse ieh insoweit auf Schwierigkeiten, als ich bei dieser eigenthimlichen Körpergestaltung für die Bezeichmung der Körperregionen volle Sicherheit nicht erlangt habe. Der Versuch, durch anatomische Zerlegrumg hier Sicherheit zu erhalten, scheiterte daran, dass die im Inneren der Leibeshohle greborgenen Organe zu schlecht erhalten waren, als dass man mit Aussicht auf Hrfolg eine Zerglierterung hiitte vornehmen diirfen, bei welcher eine Erhaltung der Gesammtform ausgeschlossen war. Meine Beschreibung, welche in Rücksicht auf andere Wurmformen entworfen ist, wird daher spiter vielleicht eine Correctur zu erfahren haben.

Der im Allgemeinen zimmtbraun gefïrbte, im ganzen 15mm. lange Körper lïsst zwei ungleiche Strecken unterscheiden: eine grössere lintere und eine viel kleinere, nur $3 \mathrm{~mm}$. lange vordere.

Die hintere Körperstrecke stellt einen nach hinten schwach keulenförmigr erweiterten, stumpf kegelfürmig abschliessenden Schlauch mit überall kreisfürmigem Querschnitt clar; eine in seiner vorderen Strecke gelegene ringförmige Einschnürung stellt wohl einen nur individuellen Contractionszustand ror; abgesehen ron dieser Strecke ist dieser hintere Kürperabschnitt am vorderen Theile am diinusten, 3mm. dick, während die Anschwellung vor. dem Hinterende bis auf $5 \mathrm{~mm}$. steigt. Die zimmtbraune Oberlläche ist auf der bei weitem grö̈sseren hinteren Strecke von kleinen fadenförmigen gleichmässig dicht stehenden Papillen derartig bedeckt, dass sie ein fast sammtartiges Aussehen gremihrt; auf der vorderen Strecke treten höher werdende kegelförmige Papillen auf und diese rerden auf der ventralen Fliche mit einer Reihe sehr viel grösserer Kegel da abgeschlossen, wo mit scharfem Ab- 
sitz die vorlere Strecke gleichsam ans der hinteren hervorgeht. So entsteht hier ein den lalben Unfimg des Kïrpers umfassender Rand, der durch die ghich hohen kegrelfümigen Papillen wie gesiigt erscheint. Man kamn ihn einem Krigen verghleiehen, welcher den Ursprung des vorderen Kärpertheiles umgiebt, um so mehr als die '/acken desselben steif und hart sind dadurch, dass sie ron eingekitteten Fremdkörpern, besonders Sandkörnern, starren.

Bei scharfer Beleuchtung erkennt man auf der so beschaflenen Oberfiiche Sermentfurchen, welche als feine Linien in gleichmässigen Abstanden von einander ten Kïper giirten. Ihnen entsprechen Borstenbindel, welche als ein dorsales unt ventrales schwer wahnehmbares Bïndelchen ohne einen Borstenhïicker aus der IIut hervortreten. Solcher Borstenbiindel stehen an dieser Kürperstrecke jederseits 24 dorsale und ventrale; alle Borsten sind cinfich und in ren vorderen nach hinten almaihlich kleiner werdenden Biindeln sind die rentralen und dorsalen Borsten gleich gestaltet; von da ab, mit dem 9ten Borstenbindel der ganzen Reihe, sind die ventralen Borsten kiirzer und dicker, dunkler gefärbt und erscheinen als hakenförmig geschwungene brame Nadeln mit heller Spitze, in einer Reihe neben einander anstretend; die Spitze ist dann solide, die Mitte des Schaftes allein gegliedert, die Endstrecke ror der soliden Spitze fein schrïg gestreift. Am Körperende nehmen anch die dorsalen Borsten etwas dunklere Fürbung an. In der Haut geborgen liegen neben den hervortretenden Borsten andere einfach grerade, meist ungefürbte Borsten, wie sie in der Abbildung (Taf. 42, Fig. 5) mit dargestellt sind; ich muss es unentschieden lassen, ob dies Stiitz-oder Ersatznadeln sind.

Auf dem kegelfümig zugespitzten Ende steht die einfache Afteröffnung olne Cirren.

Der vordere Körperabschnitt ist vor dem hinteren ebensowohl durch seine Form wie durch die Beschaffenheit der Körperwand und durch den Besitz sehr langer Borsten ausgezeichnet. Seine Form (Fig. 2, 3) ist die eines zungenartigen, hohl gebogenen eifömigen Blattes mit grob gesïgten Seitenrïindern, das etwa doppelt so lang als im gekriummten Zustande breit ist. Die concave Blattfliche betrachte ich als die dorsale, die convexe als die ventrale Fliiche; die drei grossen Zacken, in welche jederseits der dorsal gewendete Seitenrand zerschnitten ist, entsprechen segmentalen Grenzen, da die Einschnitte zwischen den Zacken mit den Austrittstellen der Borsten zusammenfallen. Der Torderrand des Blattes ist conver gerundet. Er träigt eine quer stehende Spaltüfinung, welche ron einer etwas lïngeren dorsalen 
und kïmeren ventriten lippe unfisst wird; ich sehe darin den Mumderngang und wie dieser dureh den etwats lingeren Lijpentand, weleher von des

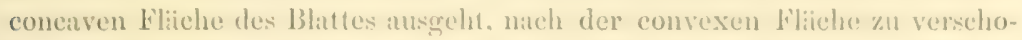
ben erseheint, fasse ich diese als die ventrale filiche and, Auf dieser fliche steht jederseits neben der Seitenecke der halbmondliomigen Mundspalte eine kure liegelfermige Paypille, welehe nicht iiber den Vordermand hinansragt; der obere Lippenrand ist jederseits mit einer Reihe weniger tanz niederer P’ipjillen geframst.

Die besondere Beschaffenheit der. Wamd dieses Körperabschnittes ist datdureh erreicht, dass beide Fliichen mit anf- und eingekitteten Fremdkïrperm, zumal kleinen Sindkömchen, dicht bekleidet sind; dardurch sind, wie der ganze Körperabschnitt, so besonders diese Fliiehen hart und fest geworden.

An den gezalkten Seitenrïulern treten mit dex Richtung nach rorn weit vorragende fächerfürmig grestaltete Biindel von Borsten aus, von denen die lïngsten der Gesammtlïnge des Körpers grleiehkommen. leh zïlıle jederseits 4 solcher Biindel: das hinterste, welehes umittelbar vor dem Kragen hervortritt, ist das kiirzeste; das zunïchst meh vorn sich anschliessende hat ungleich lïngere Borsten; beiden gemeinsam ist, dass man in ihnen eine getremute Gruppe dorsaler und ventraler, iibrigens gleich gestalteter Borsten unterscheidet. Die beiden vordersten dieser Borstenficher stehen viel dichter hinter einander als die hinteren; sie tragen die besonders langen borsten und zwar übertrifft hierin das 2 te Büindel bei weitem das erste; eine 'Tremmung in dorsale und ventrale Bïndel sehe ich hier nicht; zwar finde ich neben den langen Borsten des ersten Bïndels an der einen Seite zwei abgebrochene stäkere und dumklere Borsten, doch halte ich dieselben nicht fiir besondere ventrale Borsten. Die Zahl der Borsten in den einzelnen Biindeln ist immer eine geringe, ich zählte im einzelnen Fïcher bis gegen 8 Borsten; die schlanken Borsten sind firblos oder brïunlich, irisieren aber nicht unbedeutend; sie sind gegliedert wie die dorsalen des Rumpfes; und es liegrt kein Grund vor sie von diesen zu tremnen, da die Grösse, welche sie auszeichnet, im allmählichen Uebergang erreicht wircl.

Die Austrittstelle dieser Borstenbindel ist nicht zu einem besonderen Köcher umgebildet; wie aber die Borsten im Grunde der Einschnitte austreten, erscheinen diese dadurch um so tiefer, als auf der dorsalen Ecke derselben eine besonders entwickelte Papille, fast einem Cirrus vergleichbar, aufsitzt.

In der Mundöffnung wird, wenn man die beiden lippenförmigen Ründer 
aus einander biegt, eine diume fist farblose chitinös erscheinende spitz dreieckige l'latte sichtbar, deren Riinder mit einzehen fadenförmigen Verlingerungen besetzt sind. Das diirfe darauf hindeuten, dass hinter dieser Mundiffinumg im Körper geborgen ein ausstreckbarer Abschnitt der Körperwand oder ein liiissel liegt.

Das 'Thier erimnert in der Ausgestaltung des vorderen Körpertheiles, sorrie in der Form und Vertheilung der Borsten an den von Grube' beschriebenen Stylurioilles parmutus; dass Grube von dieser Art 2 grössere Tentakel und feine Kiemenfïden beschreibt, stört die Verwandtschaft der beiden formen kaum, din diese Anhänge bei dem mir vorliegenden Exemplar eingezogen sein kümen. Dagregen trïgt der Slylurioides parmutus auf der Riiekenfliiche der vorderen Segmente eine schildförmige Incrustation von Sandkürnchen, und damit offenbar in geringerer Ausdehnung die Bildung, welche bei meiner Art das ganze Vorderende starr macht; dass dann die vordersten Borstenbiindel aus sehr langen Borsten, die folgenden in dorsale und ventrale geschieden ans kiirzeren gegliederten Capillarborsten gebildet werden und die hinteren Segrmente im dorsalen und ventralen Bündel äbereinstimmend verschiedene Borsten besitzen, zeigt die Zusammengehörigkeit der Arten, welche im übrigen durch die Zahlenverhältnisse in der Vertheilung dieser Borsten, besonders aber durch die eigenartige Ausriistung des Vorderendes, die Kragenbildung sowie die starke Papillenentwicklung bei meiner Art von einander getrennt werden. 


\title{
SCALIBREGMIDAL.
}

\author{
EUMENIA (OERD.).
}

\section{Eumenia glabra, n. sp.}

$$
\text { Tiuf. 15, Fig. 1-4. }
$$

Subfusiformis, antice parum attenuati, in extremo corpore maxime coarctata appendicen fingens, deuse annulata subtiliterque reticulata, albida ; in superficie ventrali parum applanata sulco mediano per longitudinem leniter exarata, segmentis 36 , quorum 6 in parte postica caudacformi. - Lobus cephalicus parvus, subquadratus, antemis duobus ipso haud longioribus conicis ad angulos anticos munitus. - Os inferum in confinio segmenti setigeri 2 di et 3 ii rugis circumdatum. Segmentum prins nudum; cetera fasciculos flabellatos e cute emergentes linos spatio magno laevi disjunctos setarum capillarium simplicium breviorumque furcatartm gerentia. Anus postremus terminalis in area sulcati dorsum versus elongatia.

Hab. off Havanna, depth 175 fins. (Sigsbee).

Das einzige mir vorliegende Exemplar dieses eigenthümlicheu Wurmes ist $30 \mathrm{~mm}$. lang, gleichmässig weisslich gefürbt, fast glänzend. Der bei weitem grösste Theil des weichen, fast schlaffen Körpers, welcher aller hervortretenden Anhïnge entbehrt und keine tieferen Segmentfurchen zeigrt, ist fist ralzenförmig, auf seiner dicksten Strecke $7 \mathrm{~mm}$. im Durchmesser stark, mit einer nur geringen Abplattung auf dem mittleren Theile der Bauchfläche; eine geringe kegelförmige Verjüngung erfährt das Vorderende, welches mit dem zwei kleine Fühler tragenden, übrigens fast verstecktem Kopflappen ausläuft; und in dessen Bereich auf der Bauchfäche die Mundöfnnung steht. - Dagegen ist das hintere Körperende in sehr auflallender Weise, und wohl nicht zufällig, plützlich derartig versehmälert, dass es wie ein hakenfürmig mit der Richtung nach vorn auf die Bauchfläche umgeschlagener Körperanhang erscheint, auf dessen Endspitze in einem matt weisslichen, längs gefurchten Felde der After steht. - Die Oberflüche ist zum bei weitem grössten Theil eng geringelt und erweist sich inter stärkerer Vergrösserung fein reticulirt; diese Sculptur thut aber dem bei bestimmter Beleuchtung auftretenden schwachen Atlasglanz keinen Abbruch (Taf. 45, Fig. 1). 
Der am Torderende stehende Koptlappen, weleher zum grössten 'Theil im niichsten Fumente verborgen bleibt, ist eine fast quadratische, auf der freien Oberliiche wenig gewoilbte Platte, deren grad abgestutzter Vorlerrand jederseits auf der Ecke einen kleinen, mit unbewallietem Auge noch eben wahrnehmbaren kegrelförmigen Fortsatz trägt, den ich als einen Fühler deshalb bezeichne, weil er an sciner Basis dureh eine, wenn auch nur leichte, Einschnürung derartig rom Koptlappen abgetrennt ist, dass er danach mehr als eine rerlingerte Kopflappeneclie darstellt. Der einzelne Fỉhler ist etwa so lang als der Kopflappen, kaum halb so lang als an der Basis breit. Die zwischen den Fiihlem liegende Strecke des Vorderrandes des Koptlappens ist gerade, olme Eimschnitt (Fig. 2).

Der Körper besteht aus 36 Segmenten, ron denen 6 auf die anhangartige Endstrecke liommen. Diese 'Zahl ist, da schärfere Segmentgrenzen, mit Ausnahme des vordersten Abschnittes, kaum zu erkemen sind, nach der Anzalil der Borstenbindel festgestellt.

Das erste den Kopflappen tragende und mit ihm vielleicht retractile Segment ist borsteu- und anhanglos; eine ringförmige Furche trennt es ringsum gleichmïssig rom nïchsten Segmente. Der Kopflappen steht auf seiner Forderfläche wie in einer seichten, grubenartigen Vertiefung. Die beiden ersten borstentragenden Segmente haben in ler ventralen Medianlinie zwischen sich die kleine, fast kreisförmige Mundöffnung, doch so, dass dieselbe zum grössten Theil auf dem hinteren Theile des ersten Segmentes liegt; ringsum führen in sie hinein kurze, radïir gestellte Furchen (Fig. 2).

Hinter der Nundöfnumg ist die Bauchfläche der Segmente etwas abgeplattet und mehr oder minder glatt, so dass die den Körper umfassenden Ringfurchen an ihren Rïndern auslaufen. Sie vertieft sich in der Medianlinie zu einer schwachen Lïngsfurche, welche bis an die schwanzähnliche Endstrecke verläuft.

Die Borstenbiindel sind an allen Segmenten fast gleich, nur durch eine schwache grelbliche Färbung weichen die vorderen von den hinteren ab. Sie treten olne die geringste Parapodien-Bildung als weit von einander getremnte dorsale und ventrale, aus nur wenig Borsten zusammengesetzte Bïndel, welche die Form von in der 'Transversalebene ausgebreiteten Fïchern liaben, aus der Haut hervor, sind aber im Allgemeinen so dïnn und wenig vorragend, dass man sie ohne Hiilfe von Vergrösserung auf der glatten Körperoberfliiche kaum wahrnimmt. Jedes Bündel enthält neben einfachen capillaren Borsteu kürzere, bei welchen der dünne glashelle Schaft mit einer 


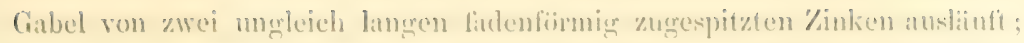

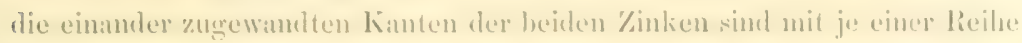
feiner Hairehen besetzt. (Ob) diexe (iabelhorsten in allen Borstenbiendehn vorhanden sind, weiss ich nicht (Fig. 4). - Deb antiallige Manget der L'araporlien sowie aller anderen Anlainge kïmnte die Vermuthung nalie lexgen, dass solehe Gebilde in Wirklichkeit vorhanden, aber retrietil und eingezoren seien. Ich habe dafiir, allerdings ohne das einzige Exemplar zu zerschneiden, irgend cine Andeutumg nicht wahrenommen. - Der \%wischentum zwischen dem ventralen und dorsalen Borstenbindel ist glatt, von lieiner liurehe eingुenommen.

Wrie weit die an diesem Wurme beobachtete eigrenthïmliche Ausurestaltung des hinteren Kärperendes auf' individuellen Zustinden beruht, muss dahin gestellt bleiben. Die Strecke erscheint gegeniiber dem iibrigen Kärpertheile erheblich derber, und man könnte darin den Ausdruck einer starken, die geringen Dimensionen herbeifiilnenden Contraction der Körperwand sehen. Damn wiirde aber mit einer solchen Amalnme die eigenartige Lagerung dieser Körperstrecke nicht erklärt; und diese scheint dafiir zu sprechen, dass diese ganze Bildung nicht eine individuelle, oder nur zeitweilig rorbandene ist ( Fig. 1, 3).

Die kreisfïmige, terminale Afteröfinung steht in der Mitte einer mat weissen Flïche, welche sich etwas nach der Rüickenflïche hinauf verlingert, und rom Rande her mit radiü laufenden Furehen derartig gekerbt ist, dass sie den Anschein eines Kranzes nieder liegender Papillen erreckt (Figr. 3).

Ich stelle diese Art vorlïufig in die Gattung Eumenia (Oerd.), in welcher sie allerdings wohl Vertreter einer besonderen Gruppe ist, welche zu ciner selbständigen Gattung erhoben werden künnte; zu einer endgiiltigen lievision der beiden eng zusammen gehörenden Gattungen Eumenia und Scalibregma, welche dabei vorgenommen werden muisste, fehlt das nöthige Material.

Das characteristische Kemnzeichen fü diese Art bleibt der Wangel der Parapodien und Kiemen. Sie stellt in dieser Hinsicht eine Weiterführung dessen vor, was bei Scalibregma longisetosum (Théel) ${ }^{1}$ und Scalibregma prareum (Arm. Hansen $)^{2}$ sich darin zeigt, dass die Parapodien der vorderen 11 oder 12 Segmente unentwickelt sind.

1 Thél; Les Annélides polychètes des mers de la Nourelle-Zemble. Stockholna, 1879. to. Kgl. Srensk. Yetensk. Akad. Handlingar. Bul. 16. Yoo. 3, pag. 49 .

${ }^{2}$ G. Armauer Hansen, Anpelida. Det norske Nordbars-Expedition, 15iG-157s. VII, Zoologi. pag. $34,35$. 
Fiilsleribuliche Anhänge besitzt der Kopflappen bei allen Arten dieser

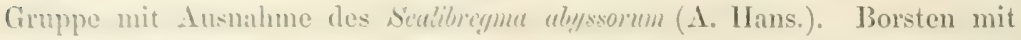
grabeliger lindspitze sind bei Émmia crassa (Oerd.), Scalibreqma abyssoram (A. Mans.) und Sculihegma lonnixetosum (Théel) vorhanden. - Dass die Afterïlnung aut einer mit strahlenförmigen Furchen versehenen Papille steht, hat Tevinsen ${ }^{1}$ in der Charakteristik der Eimmenin crussa besonders hervorgehoben; wihhend II. Sars² das Analsegment dieser Art als röhrenförmigr und viel schmaler und liinger als die vorhergehenden Segmente beschreibt; wie weit das an die ron mir bei Eumenu glubru beobachtete Bildung, dass mehrere Segmente einen Afterzapfen bilden, anschliesst, bleibt unbestimmt.

1 Leminsm, Systematisk-greografisk Oversigt, a. a. O. pag. 134.

2. M. Surs, Geolog. ong zoolog. Tagttagelser anstillede pan en Reise i cn Deel of Trondljems Stift. Christiania, 1853. pag. 51. 


\section{ISTTHUSA}

\section{ARENICOLA (LAM.).}

\section{Arenicola antillensis, LTw.}

Ich erwilhne diese $A$ rt, fiir welehe Lïtken ${ }^{1}$ die Aufstellung einer nenen Gattung, Pteroscolex, vorgeschlagen hat, da ich sie in der Sammlumg des Museum of Comparative Zoülogy als bei filorida und Captiva-Key gesammelt rorfinde, und damit die grössere Verbreitung dieser bisher nur bei St. Croix gefundenen Art im Antillen-Neere belegt wird.

Das hat ein weiteres Interesse dadurch, dass Levinsen" diese drenicolu antillensis (Ltk.) mit der im Mittelmeer vorkommenden, als Arenicole marim (d. Ch. Clprd.) beschriebenen Art in nähere Beziehung bringt; diese mediterrane Art aber als Arenicolu Claparedi von der nordischen Arenicolu marinu tremnt.

1 Chr. Lü̈then, En ny restindisk Sandorm, Arcnicolet (Pteroscolex) antillensis Ltk. Vitenskabel. Meddelelser fra d. maturhist. Foren. i Kjöhenharn for Aaret. 186t. pag. 1:20.

2 Levinsen, Systematisk-geografisk Oversigt, a. a. O. pag. 137. 


\title{
C.APITELLIDAE.
}

\author{
DASYBRANCIUS, GR.
}

Dasybranchus lunulatus, 11. sp.

\author{
Tuf. fis, Fig. 5-9.
}

Pallide ochracens, antice crassus qundrangulus, postrema versus sensim attenuatus, subtercs, cute pellucida indutus; segmentis setigeris 145 , anticis 7 ies posticis 5ies latioribus quam longioribus, - Lobus epphalicus segmento buccali undo biannulo plus minusve absconditus, supra e margine antico recto ad cristam humilem compressus utrinque maculam senilunarem brumeam. gerens. - Segmenti buecalis proxima aequantis aunulus prior os e latere, alter postice circumiens. Sermpnta sequentia 13 fisciculos binos setarum capillarinm anguste limbatarum valde inter so remotos utrinutue grerentia, sicut proxima fere quadrangula, sulco laterali inter setarum fasciculos exarata. Sermenta cetera sensim rotundata, inde ab Ifo toros uncinigeros fere aequales utrinque 2 gerentia, rentrales subtus in medio sese pacne tangentes, dorsales inter se et ab illis remotos; uncini seriem simplicem formantes nanubrio longo subrecto, rostro bidente late limbato. Branchine pancre filiformes vel subclavatae e margine superiore tori rentralis orjentes, torum longitudine fore aequantes, retractiles.

Hab. : Key West, ilepth 1-2 fins.

Der missig lange Körper der mir rorliegenden Thiere ist mehr oder minder aufgerollt, von bleicher Fïrbung und besonders dadurch auffälig, dass in seiner mittleren Strecke die Wandung so dünn ist, dass der ans weisslichen Kömern und Ballen bestehende Darminhalt durchscheint, eine auch ron anderen Arten, D. calucus (Gr.) und umbrims (Gr.) beschriebene, vielleicht von ungleichen Contractionszustiinden abhïngende Bildung. — Eine genetzte Oberfläche, wie sie von $D$. caducus und umbrims beschrieben ist, fohlt hier wie bei D. cirratus (Gr.) und lumbricoides (Gr.); vielleicht ist aber auch das durch roribergehende Zustände bedingt. - Der Körper hat nahe linter dem Kopfende seine grösste Dicke, verschmälert sich gegen das Hinterende hin langsam, aber nicht unbeträchtlich. Ein aus 125 Segmenten bestehendes, $49 \mathrm{~mm}$. langes Exemplar war auf der dicksten Strecke des Vorderendes $3 \mathrm{~mm}$. hinten kaum $2 \mathrm{~mm}$, dick. Dabei erseheint die vordere Körperstrecke schwach vierkantig besonders dadurch, dass zwischen den weit aus einander stehenden Borstenbïndeln jeder Seite eine Längrsfurche verläuft; 
nach hinten wird der Kinpes mit dem Verliechen dieser Furehe drehrund; hier träigt dam die Jintwieklumg der die Jakenborsten tragenden Querwiilste viel zum Gesimmmtbilde bei. Auf dieser hinteren Kinperstrecke verlinfi anch eine nach vorn verstreichende mediane bauchlurche ('latt. 45, lige. 5).

Der Kopllappen, weleher rom Bucealsegment ganz alugenommen werten kamn, ist ein dieker nach rorn verjüngter, hier aber mit grater Kante abgestutzter Lappen; seine ventrile liliche ist platt; seme dorsale filaiche ist zu einer von vorn nach hinten ansteigenden Firste erloben, an deren seitlichem Ablall jederseits aul' der hinteren Itallte ein mit der Concavitit nach rorn grewendeter halbkreis-, oder hufeisenfömiger, aus bräunlichen l'igmenthäufchen gebildeter Fleck steht. - Mit dieser Darstellung fasse ich als Koplappen den vordersten, ungetheilten Auslïufer des Körpers auf, und weiche damit ron der Beschreibung und Abbildung ab, welche Grube " von dem Kopflappen des Dusybranchus cirratus, und, was hier wohl heranzuziehen ist, Langerhans ${ }^{2}$ von dem gleichen Gebilde des Notomustus rosens gegeben hat; in beiden Fïllen wird zum Kopflappen eine basale Strecke gerechnet, in welche die Kopflappenspitze eingezogen werden kann, und diese trägt bei Dasybranchus cirralus jederseits einen punktfömmigen augenïhnlichen Fleck, bei Lotomastus roseus an gleicher. Stelle jederseits über 20 kleine Augen. Bei diesen 'Thieren ist, wie es scheint, das Buccalsegment einfach; das kïnnte zu der Vermuthung Veranlassung geben, dass der abgesetzte Basaltheil des Kopflappens der gemannten Wïmer dem ersten Ringe des Bucealsegmentes des Dusybranchus lumulatus entspreche; dann wiirde die Differenz in der Stellung der Pigmentflecke zwischen dem letzten Thiere und den erstgenamnten eine bedentende sein, da bei diesem $D$. lumulutus die erwailinten Pigmentflecken auf dem Kopflappen stehen und mit diesem unter den Rand des Buccalsegmentes eingezogen werden. - Ich nehme Anstand diese Pigmentilecken als Augen zu bezeichnen; bei der Lage der Gebilde auf der Grenze zum Buccalsegment wäre zu erwïgen, dass an diesem Orte in der mit Dasybranchus verwandten Capitella ein Nackenorgan liegt, welches bei Dasybranchus bis jetzt nicht beobachtet ist (Figr. T).

Das an Liinge den folgenden Segmenten fast gleichkommende borstenlose Buccalsegment besteht aus zwei Ringev, ron denen der vorhin bereits erwïhnte auf der Bauchflïche insofern unvollständig ist, als er im seitlichen Umfange der grossen Mundüfinung sich verliert, während der hintere Ring

1 Gmbe, Reise der... Norara, Zoolog. Th. Bl. 2. Anneliden, pg. 28, Taf. III, Fig. 4.

2 Langerhans, Zeitschr. f. wiss, Zoolog. Bd. IXXIV, pag. 99. 
villig geschlosson ist und die hintere Ummondung des Mundes bildet (Fig. 6).Die horstentragenten segmente sind im vorderen Körpertheile etwa sieben-, im hinteren etwa fünfmal breiter als ling. Wenn für andere Arten, wie $D$. umtwinus (Gi:), angegeben wird, dass die Segmente zweiringelig seien, so kam ich das fuir $D$. lumulutus nicht obne Weiteres behaupten: im vorderen Körpertheile erscheint die Obertliiche der Segmente gegen die Segmenterenzen hin ringsum wulstförmig erhoben, auf der Höhe des Wulstes findet sich daun auf' den '/wischenräumen zwischen den Bündeln der Itarborsten, und zwar der gegenseitigen wie der gleichseitigen, eine scharf geschnittene Furche, welche aber, so weit ich gesehen habe, niemals einen solchen ringförmigen Zusammenhang hat, dass dadurch die Oberllïche des Segmentes zweiringelig wiirde; an den ersten Segmenten, welche IIakenborsten tragen, dehnen diese furchen sich weiter aus, ohne jedoch auch hier an den Körperflanken zum Ring geschlossen zu sein. An den hinteren Segmenten ist eine ringförmige Wulstbildung nicht mehr vorhanden.

Die Reihen der Hakenborsten stehen auf abgegrenzten Querwiilsten; diejenigen, welche der Bauchflïche angehören, fliessen in der Medianlinie von jeder Seite her fast zusammen; die Wiilste, welche die dorsalen Borsten tragen, sind von den ventralen Wïlsten entfernt; in ihrem Bereich zumal ist die Leibeswand der mittleren Körperstrecke bis zu grosser Durchsichtigkeit verdïnnt, und dann künnen die Wiilste wie verwiseht erscheinen.

Ueber die Borsten habe ich dem, was in der Diagnose und Abbildung (Fig. 9) enthalten ist, Nichts hinzuzufuigen.

Heine Angabe über die Kiemen beruht auf dem, was ich an einem einzigen Exemplare gesehen habe, denn nur bei diesem waren Kiemen, und zwar nur an einem Theile der hinteren Segmente ausgestreckt; vermuthlich besitzt wenigstens der grössere Theil der hinteren Segmente retractile Kiemen. Die Kiemen treten an diesen Segmenten über dem scharf begrenzten dorsalen Rande der rentralen Wuilste ans, der hier meist eine kleine grubige Vertiefung begrenzt. Während an einigen Segmenten, und zwar bisweilen nur auf der einen Körperhälfte, ein einzelner, wohl etwas keulenförmig am Ende verdickter Faden hervorragte, zeigten andere Segmente zwei solcher Fäden neben einander; selten nur war die Zahl grösser. Ob diese Fäden am Grunde von einem gemeinsamen Stamme ausgehen, mithin ein Bündel vorstellen, habe ich nicht sicher entscheiden künnen, glaube aber, dass man wohl allgemein von Kiemenbïndeln hier sprechen darf (Fig. 8).

1 Grube, Annulata Semperiana, a. a. O., parg. 189. 
In dem abgebildeten Wurme ist dits hintere, auf der Tafel mach oben gerichtete, den After trigende kïrperstiack plitzlich stakk verjingt, und erscheint list wie alogesetzt; ich habe so ausgepriigt die Bildung nur an diesen Exemplare gevehen, mol weiss nicht, ob es sich um ein rïhrenfirrmiges normales, oder um ein etwas prolibirtes Aftersegment himdelt. 


\title{
MALDANIDAE.
}

\author{
MALD ANE, GR. \\ Maldane cuculligera, n. sp.
}

Tuf. 46, Fig. 1-3.

Teres, fulva, segmentis 21, quorum 19 setigeris. Lobus cephalicus cum segmento bucenli mulo biamnulato coalitus, oratus, valde convexus, antice breviter bisuleatus et brunneo lituratus, margine frontali obtuso, limbo utrinque senel plicato postice encullato limbatus. Segmenta setigera anteriora 5 biannulinta, media elongati, postica breviora. Setae superiores capillares anguste limbatae longae; inferiores in segmento setigero priore nullac, ceterne uncinatie in rertice transverse serrulatae; segmentum setigerum prius limbo brevi integro, quintum limbo majore utrinque inciso einetum. Segmentum anale breve undum. Anus dorsalis; area postanalis limbo utrinque semel inciso cinetr.

Hab. : No. 48 , depth 533 fms., Lat. $28^{\circ}+\vec{\imath}^{\prime} 30^{\prime \prime}$ X.; Long. $88^{\circ} 41^{\prime} 30^{\prime \prime} \mathrm{W}$.

Der lang grestreckte drehrunde Körper von bräunlich gelber oder in der mittleren Körperstrecke anch graugelber Färbung besteht aus 21 Segmenten, von denen 19 Borsten tragende sind; bei $68 \mathrm{~mm}$. Lïnge betrug die gleich bleibende Körperdicke etwa $2 \mathrm{~mm}$.

Das borstenlose erste oder Buccalsegment, welehes den Kopflappen und die Mundöffnung trägrt, ist wie alle folgenden zweiringelig, mit Einschluss des Kopflappens etwas länger als das erste Borsten tragende, und etwa um ein Drittel länger als breit. - Der Kopflappen ist eine hochgewölbte Platte, welche nach hinten steil in die Riickenflïche des Buccalsegmentes abfiillt and fast die hintere Grenze desselben erreicht, vorn in einen durch zwei fast parallele die Scheitelhöhe des Kopflappens nicht ganz erreichende Furchen begrenzten Schnauzentheil ausläuft, der zwischen den Furchen zu einer abgerundeten Firste erhoben ist, vorn mit einem lappenförmig zugeschärften verbreiterten Rande endigt. In jeder Furche steht ein lang gezogener brauner Pigmentfleck. - Von der durch die einschneidende Furche erzeugten Ecke des Vorderrandes des Kopflappens erhebt sich jederseits der den ganzen Kopflappen umfissende, hohe durchscheinende Randsaum, der, so Techsehnd auch seine Ausdehnung je nach der Schrumpfung ist, welche der 
conservierente $\Lambda$ leohol erzonerte, immer zu ciner ansehnlichen llible nelsen

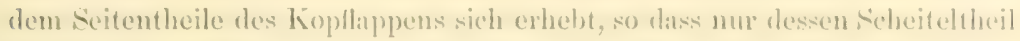
den Randsatum ïberragt, zwischen diesem und der Kopllappenfliche stets eine tiefe Rimne besteht; um den hinteren 'Theil des Koptlappens endeift alser

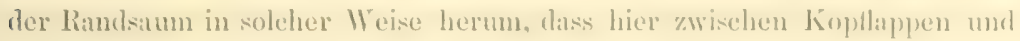
Ramdsaum eine tiefe Titsehe gehildet wird, deren boten die math hinten abfillende Flidche des Kopllappens bildet. Der freic land des situmes ist jederseits hat vor dem Einminge in die 'l'asehe sehart' winkeligr eingekniekt. so dass er hier in der Prolilausicht wie eingeschnitten erseheint. Dicht unter dem nach vorn ïberhingenden sehmauzentheile des Kopllappens steht in der ventralen Mittellinie die lireisrunde Mundüfnumer, zu welcher cine $\mathbf{A l}$ zahl ron kleiren wurchen fiihrt. - Auf der Ventralliache stehen weiterhin bei den verschiedenen Exemplaren ungleich starke quere furchen, welehe halbringförmig an den Seiten des Segmentes hinaufreichen. Unter ilnen zeichnet sich die Grenze, welehe den hinteren, kimu ein Viertel der Giesammtlïnge eimnehmenden ling vom vorderen 'Theil scheidet, als eine feine Linie aus, welche auf den hinteren Theil des taschenförnigen Kopthapensaumes fuihrt. Die Furche, welche das Buccalsegment vom niichsten tremt, ist auf der Rückenfliche stiurker als auf der Banchlläche nach hinten verschoben und dementsprechend jederseits am seithehen Unfing geschweilt (Fig. 1-4).

Das erste Borsten tragende Segment ist etwa so lang als breit. Sein Vorderrand, welcher den eben geschilderten Verlauf hat, erweitert sich auf der Ventralfliche zu einem frei vorspringenden Saum, der je nach dem Erhaltungszustande flach dem Körper anliegt, oder-zumal bei Schrumpfungen - in solcher Weise abgehoben ist, dass er kragenförmig vorragt und eine taschenförmige nach rorn offene Grube begrenzt, welche am Seitenumfang des Segmentes geschlossen ausläuft. Der mit einficher Ringfurche abgetrennte hintere Ring hat etwa ein Drittel der Gesammtlänge. Am vorderen Ringe steht etwa auf seiner halben Liinge jederseits ein Biindel von Capillarborsten, welche nur durch etwas geringere Lïnge von den gleichen Borsten der folgrenden Segmente unterschicden sind (Fig. 1, 2, 4).

Die folgenden Segmente sind zunïchst durch Grössenverhältnisse unter einander verschieden, insofern als gegen die Körpermitte him die einzelnen Segmente an Länge zunehmen; das zweite Borsten tragende Segment ist nur wenig längrer als breit, das 3te etwas kiirzer, das 4te dem zweiten gleich und dann begimnt vom 5ten, auch sonst ausgezeichneten Segmente ab eine 
Streckumg derart, dass die zuniichst folgenden doppelt so lang als breit sind, weiterhin das einzelne Segment vier bis finfmal linger als breit wird; vor dem hïrperende tritt dam wieder eine Verkiirzung ein und es sind die hinteren seymente nicht ganz doppelt so lang als breit.

Das fünfte Borsten tragende Segment ist besonders ausgezeichnet und bildet in bestimmter Weise eine Grenze zwischen vorderen und hinteren Segmenten. Alle ror diesem Segmente gelegenen sind ausgesprochen zweiringelig, der hintere Abschnitt hat ein Drittel oder ein Viertel von der Gesammtlïnge des Segmentes; der vordere Abschnitt trägt etwa auf seiner halben Lünge jederseits cin Biindel Capillarborsten und mit Ausnahme des ersten darunter eine Reihe ron Hakenborsten; ein besonderes Borstenfeld ist nicht ausgezeichnet. Am Buccalsegment und den 3 folgenden ist die Furche, welche die beiden Abschnitte von einander trennt, eine feine in gleicher Höhe den Körper unspannende Linie. Am 4ten Borsten tragenden Segmente weicht diese Furche auf der Ventralläche in starken Bogen nach linten ans. Das 5te Segment num ist allerdings zweiringelig wie die vorangehenden, aber an Stelle der Ringfurche erhebt sich kragenförmig ein nach vorn gerichteter niedriger Saum, weleher an der Ventralflïche etwas höher als an der Dorsalläche ist und jederseits am Seitenumfang zu einem kleinen gerundet frei vorspringenden Läppehen sich erweitert. Wo auf der Ventralfliiche der Körper des vorangehenden Segmentes aus dieser Kragenbildung hervortritt, zeigt er jederseits neben der Medianlinie ein kleines nach vorn scharf umgrenztes halbmondförmiges Feld, die Andeutung einer besonderen Organisation. - Die Borsten dieses Segmentes stehen wie auf den vorhergehenden jederseits auf der halben Lünge, aber es macht sich um sie herum ein besonderes Feld in der Haut geltend (Fig. 1, 2).

Hinter dem 5ten Borsten tragenden Segmente erfolgt rasch die oben erwïhnte Lüngenzunahme; dagegen fehlt die durch eine scharfe Furche ausgepräigte Zweitheilung der Segmente. Dafür macht sich an diesen Segmenten eine vordere kurze Strecke kenntlich durch ein stark hervortretendes Borstenfeld, und die bei weitem lïngere hintere Strecke durch eine quere in der Medianlinie meist unterbrochene Ringelung der Ventralfläche. Das Borstenfeld steht, mit Ausnahme des 6ten Segmentes, des ersten dieser Reihe, auf welchem es in der vorderen Hälfte des Seggmentes Platz findet, unmittelbar hinter dem Vorderrande des Segmentes; sein Aussehen ist ein ungleiches: bei prallem Kürper ein ebenes nur durch hellere Färbung von der Umgebung abgesetztes Feld, bei geschrumpftem Körper ein in gleicher 


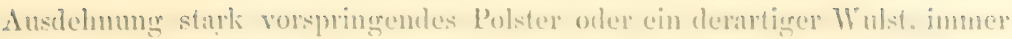
wohl eine durch Drisenzellen berlingte Bilduner. Nur an den letzten rop dem dier stehenden mol verkïmten segmenten tritt diese bildumer wioder zuriick.

Die Capillarborsten stehen dorsilwiirts von der Reilse der llakienborsten oder am dorsalen höchsten Umlinge der Borstenfülles; es sind rehr schlanke

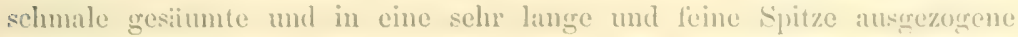
Borsten, welche bei grösster Entwicklung in den mitteren segmenten ein ficherfömiges Bindel bilden, dessen Linge wenig hinter der Broite des Segrmentes zuriickbleibt (Fig. 7). Unter starker Vergröserung zeiert sich die sonst fadenfömig erscheinende Endstrecke mit scitlichen spitzen dornartigen Zacken besetzt (Fig. 7, a). - Die Hakenborsten stehen mit Ausmahne des ersten nur Capillarborsten führenden Segmentes an allen Segmenten in ciner Querreihe, die in den mittleren Segmenten am lingsten ist und die meisten Borsten besitzt. Die einzelne Borste hat iiber dem Scheitel des Inuptlakens in mehreren lieihen stehende Zishme und die chnrakteristischen Fiederchen. Die Form dieser Hakenborsten ist in den verschiedenen Sergmenten nur in geringem Grade ungleich (Fig. 8, 9).

Das borstenlose Aftersegment ist sehr viel kïrzer als das vorangehende, etwa doppelt so breit als lang. Die Afteröfinung steht in der dorsalen Medianlinie auf einem kleinen foin lïngs gefurchten Ringrulste. Die End1lïhe dieses Segmentes zeigte die wechselnde Form, welche ich abgebildet habe; in dem einen Falle war diese Flïche kreisförmig uml von einem ringsum gleich hohen schwach trichterförmig nach aussen geloogenen homartig braumen Randsaum umgeben, der vor der Afteröftnung vorbeizog (Fig. 5); in dem andereu Falle erschien die Endfläche oval und schüg zur Lingsaxe des Körpers gestellt; der sie umfassende älnnlich aussehende Hautsaum erniedrigte sich gregen die Afteröfinung, gegen welche er so verzogen war, dass er aus dieser herrorzugehen sehien (Fig. 6). In beiden Fällen trïgt dieser Saum auf seinem freien Rande der Afteröfinung genahlrext jederseits einen Einschnitt, welcher etwa bis auf die halbe Höhe des Sammes himunter reicht. - Ich vermuthe, dass die Diflerenz im Aussehen der Analplatte auf ein ungleiches Lagerungsverhalten des Enddarmes zurỉckzuführen ist; damit wïrde es passen, dass in den beiden errähnten Fïllen auch.das Ansehen des Afterwulstes etwas ungleich war.

Die Würmer waren zum Theil frei in dem Glase, in welchem ich sie erlielt, und daun vielfach grekrümmt, zum Theil staken sie in Röhren, und 
waren dam grestreckter. Diese Röhren waren in mehreren Fiillen so lang oder etwas kiimer als das Thier und liefen dimn an beiden Enden in eine diimhlïutige 11 ind ats; die mittlere Strecke hatte eine dicke, einzig aus dunkelfirbigem Schlamm verfertigte glatte Wand ohne ein-oder aufgekittete Eestkïjrper.

Die Art fïgt sich in die Gattung Maldane, wie dieselbe zuletzt von Grube ${ }^{1}$ im Anschluss an Malmgren begrenzt ist. Das Auftreten von kragenartigen Hautsiimmen bei der ron mir beschriebenen veranlasst mich nicht zur Aufstellung einer neuen Gattumg, da diese bei Rhodine so ausgezeichnet vorhandenen Bildungen offenbar bei verschiedenen anderweitigen Entwieklungsrichtungen vorhanden und mach ihrer Bedeutung moch unklar sind. - Unter den beschriebenen Arten der Gattung Maldane besitat die Muldane marsupiulis $\left(\mathrm{Gr}^{1}{ }^{1}\right)$, einen Koptlappen, der dem der M. cuentligere insoferm ähnlich ist, als der Hautsaum auch hier in Nacken eine tiefe Tasche bildet, und die Vordertlïche desselben gleichfalls vou kurzen pigmentierten Furchen eingeschmitten ist.

\section{CLYMENE (SAF.). \\ Clymene cirrata, и. sp. \\ Tuf. 46, Fig. $10-13$.}

Lobus cephalicus declivus subcarinatus et bisulcatus, limbo utrinque semel plicato, lobulo antico acuto excepto, omnino limbatus, cum segmento setigero priore coalitus; segmenta plus minusve elongata, excepto anali setigera; setae dorsales capillares limbatae ventrales uncinatae in vertice rostri $3-1$ - dentatae in segmentis anterioribus $t$ singulae, in proximis uniseriales. Segmentum anale praecedenti longius, limbo integro infundibuliformi cirros 4 longos gerente anum eleratum amplectens.

Hab. : off Carysfort Reef, . Iarch, 1869, depth 351 fms.

Von dieser Art finden sich zusammen in einem Glase zwei uibereinstimmende Vorderstrecken und ein gleich langres hinteres Körperende; ich zweille nicht, dass diese Stiicke zusammengehören, habe aber keine Gewisslheit dariber, dass nicht eine Mittelstrecke fehle, und kann daher iber die Gesammtzahl der Segrmente Nichts aussagen. Jedenfalls ist aber der ganze Körper drehrund, nirgends durchscheinend und von grauer Farbe; in seiner granzen Lïnge 1mm. dick. Die vordere Körperstrecke war 22 mm. lang und hatte 9 Segmente, die hintere war $21 \mathrm{~mm}$. lang und hatte 3 vollständige und ein halb zerstörtes vorderes Segment. - An der vorderen Körperstrecke 
nehmen die Sermente ron rom nach hinten an Lianre ab; die droi rorderen

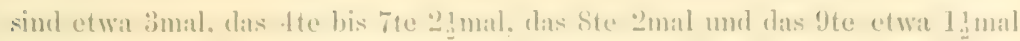
lingrer als breit; an der hinteren Kibrperstrectie sind die vorderen sexmente erheblich linger; die drei ersten erhaltenen sind etwa 5-tmal, das naichst-

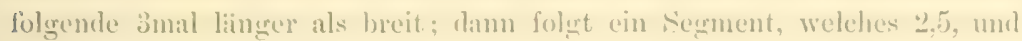
zwei weitere, die nur 1,jmal breiter als laner sind, worald das Altererment wieder verlingert und dreimal linger als breit ist (Figr. 10, 11).

Das erste der Borsten tragenden Segmente ist in beiden kxemplaren am Vorderende sehwach ventralwirts grekriumnt und etwas verdickt. Es endet vorn mit der Platte des Kopllappens, unter weleher aul' der Ventralthiche die Mundöfhumg steht, und ist, wenn man die Stellung seiner Borsten mit derjenignen der niichst folgenden Segrmente vergleicht, wohl aufunfissen, als sei ein borstenloses Buccalsegment völlig mit ihm verschmolzen. Der Kopflappen ist eine von der dorsalen zur ventralen Fläche stark abschüssigr gencigte Platte, hinten etwa doppelt so breit als lang, nach rorn dreieckig zugeschnitten, rings umsiiumt von einer aufrecht stehenden diumen I_anelle, welche nur eine vordere dreieckig vorspringende Spitze der Kopflappenplatte frei lisst. Dieser Ilautsaum erscheint etwa auf der Grenze des hinteren Drittels an scinem freien Rande jederseits durch eine scharf winklige Einknickung wie eingeschnitten. Auf der Scheiteldäche des Kopflappens zieht von der Basis der freien Endspitze jederseits nach hinten eine Furche, zwischen denen die mittlere Strecke erista-artig erhoben ist (Fig. 10. 12).

Die auf der Ventralfliche unmittelbar unter der freien Vorderspitze des Koptlappens stehende Mundöflinung ist von einem längsgefurchten Wulste umgeben.

Die Borsten stehen an diesem Segmente jederseits etwa auf seiner halben Länge, stimmen sonst mit den Borsten der drei nächsten Segmente überein.

Diese sind gegen einander stäker abgesetzt als das bei den hinteren Segmenten der Fall ist, und zmar gilt das besonders von der Verbindung des ersten und zweiten, sowie zweiten und dritten Segmentes unter einander; bei ihnen ist der Vorderrand des Segmentes wulstig aufgetrieben und dicker als der daran stossende Hinterrand des rorangehenden Segmentes; zu einer eigentlichen Kragenbildung kommt es jedoch nicht. Die Borsten dieser 3 Serrmente stehen jederseits auf dem vorderen Drittel des Segmentes, umweit des Vorderrandes; es ist ein fïcherförmiges Bündel von nur wenigen und kurzen schwach gresäumten Capillarborsten und hart darunter steht je eine einzelne starke gelbbraune Hakenborste, welche von der gleich geformten 
der hinteren Segmente dadurch unterschieden ist, dass die Seheitelliache nur 3 Zilhneinschnitte träigt. Die Richtumg dieser Borste schien mir wechselnd zu sein, insolorn als die Spitze des Hakens bald nach hinten, bald ventralwärts gewendet war:

Mit dem jten Segmente beginnt eine Reihe von solchen, die das gemeinsame haben, dass ihre Segmentgrenzen einfache Ringfurchen sind, dass in der ventralen Nittellinie eine schwache Kielbildung continuierlich bis zum Analsegment liiuft, und diss an allen Segmenten an Stelle der einzelnen ventralen Borste der rorderen Segmente cine Querreihe rou solchen erscheint. In ïbrigen bildet sich an den ersten derselben ein in der Stellung der Borsten gregebener Unterschied aus, in der Weise, dass die Borsten, wie dic Sermente sich verkiuzen, an deren hinteren Rand riicken und diese Stellung dam an allen Segmenten, auch an den gestreckten der hinteren Körperstrecke beibchalten; das achte Segment zeigte zuerst deutlich diese Stellung der Borsten. - Der Platz, an welchem die Borsten stehen, war ferner vom 5ten bis Sten Segmente in besonderer Weise ausgezeichnet; die drei ersten dieser Segmente tragen jederseits hinter dem Vorderrande ein fast die granze Seitenhülie einnehmendes quadratisches oder oblonges Feld von hellerer weisslicher Firhung; am Sten Segmente fand sich statt dessen ein dreieckigres mit der Spitze nach vorn gerichtetes, gleich gefuirbtes helles Feld, welches in seiner Lïnge den grössten Theil der Segmentflïche deckte (Fig. 10). - Die Querreihe der Hakenborsten stand iiberall hart am Hinterrande dieser Felder, das Bündel der Capillarborsten an der hinteren oberen Ecke. Diese weisslich gefiubten Felder waren glatt und prominierten nicht; sie sind wohl auf eine Entwicklung von Hautdriisen zurückzuführen und stellen vielleicht unter anderen Zuständen vortretende Polster vor, welche zu der Einpflanzung der Borsten in Beziehung stehen. - Ich habe an den weiterhin folgenden Segmenten übrigens keine Spur dieser Felder, noch etwa denen entsprechende Polster gefunden. - An den drei letzten Borsten tragenden Segmenten zeigte sich in geringer Entwicklumg ein Borstenhöcker als ein kleines jederseits vorspringendes Kegelchen; die in ihm stehenden Capillarborsten waren alle kurz abgebrochen, so dass ich Nichts dariber aussagen kann, ob etwa hier auch die Capillarborsten stïrker entwickelt waren.

Die dorsalen schwach gesiiumten Capillarborsten bilden auch an allen hinteren Segmenten eimen nur kleinen Fächer, der kaum mit der halben Segmentbreite volspringt.

Die ummittelbar darunter stehende Querreihe der Hakenborsten hatte 
wohl nicht mehe als $S$ soleher Borsten, an einigen der vorteren fiegmente des hinteren Stiiekes weniger als an den letzten Borstentragenten; doch ist. das vielleicht zulaillig entstanden. Die form der einzelnen llakenborste ist, wie aus der Abbihlumg ersichtlieh, die grewöhnliche, anf der Scheitellaiche mit vier Kalmeinschniten (Fig. 1:3).

Das borstenlose Analsegment, welches das vorhergehende so seln an Lïnge ïbertrifit, diss man vermulhen kï̈nte, es sei durch Verschmelzung von zweien entstanden, trïgrt aul" der Lindläiche einen gerieften Kegel, ant" dessen Spitze die Afteröflnung steht. Die Basis des Kegels ist von einem niedrigen ganzandigen Inutsame umgeben. Aus ihm entspringen jederseits in der llöhe der dorsalen Borsten zwei lange fadenförmige Aftercirven dieht neben einander; ihre Lingre ist etwa der vereinigten Liinge des analen und vorletzten Segrmentes gleich (Fig. 11).

Die Thiere staken in Bruchstücken von ziemlich diimmwandigen glatten granen Schlammröhren.

Ich stelle diese Art in die Gattung Clymene, welche ich in ihnlichem Umfange aufasse, wie es Levinsen ${ }^{1}$ gethan hat. Damn ist die Verschmelzung des Kopflappens, ohme ein besonders abgegrenztes Buccalsegment, mit dem ersten borstentragenden Segmente, sowie der Umstand, dass die dem Aftersegment vorangehenden Segmente Borsten tragen für weitere Charakterisirungen wichtig; dass vielleicht das Analsegment als mit vorangehenden nackten Segmenten verschmolzen aufgefasst werden kann, bleibt für Weiteres zu beachten. Die Ausrïistung des Aftersegmentes mit den vier langen Cirren und dem ganzrandigen Trichter wird für die Arterkenmumg ron Werth sein. - Ob die eigenthïmliche Ausgestaltung am Seitenumfange des achiten Segmentes etwa mit einer Kragenbildung, wie sie sonst in dieser Familie an einzelnen Segmenten vorkommt, im Zusammenhang steht, kamn nur bei besserer Erkenntniss des Baues und der Bedeutung dieser Theile entschieden werden.

\section{Clymene cingulata, u. sp. \\ Taf. 47, Fig. $2-5$.}

Teres, antice subinflata et pellucida. Lobus cephalicus declisus, margine frontali triangulo vix lihero, limbo angusto utrinque semel inciso limbatus, cum segnento buccali et primo setigero coalitus. Segmenta anteriora 3 elongata fere coalita, quartum collari antico subtus triangulatim producto instructum, sequentia bipartita valde inter se distiucta. Setae in parte anteriore seg-

1 Levinsen, Systematisk-geografisk Oversigt, a. a. O., lg. 145. 
menturum donsales caprillares nnmuste limhatic breves, rentrales in sugmentis 3 anterioribus

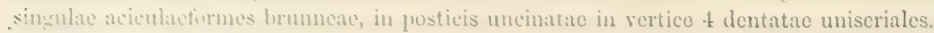

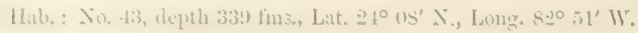

Ton dieser Art liegen mir zwei Exemplare ror, welchen beiden das hintere Kïrperende fehlt. - Es sind drehrunde, fast ladenförmige, bräimlich gelbe Thiere, das best erhaltene nur ats 7 Segmenten bestehende Thier bei einer durehsehnittichen Dicke von $1 \mathrm{~mm}$. 2tmm. lamg; beide im Habitus darin in kemntlicher Weise ïbereinstimmend, dass das grleichmässige Vorderende hell durchscheinend, die scharf segmentierte hintere Körperstrecke dagegen undurchsichtigr war.

Die vorlere Körperstrecke umfasst mit Eiuschluss des Buccalsegrmentes vier segmente, zwischen denen Segmentfurehen kaum zu erkennen sind; das erste dieser Segmente ist als Buecalsegment, das vierte durch Kragenbildungr und Borsten ausgezeichnet, wie sie an den folgenden Segmenten vorhanden sincl. Uebrigens lassen diese Segmente, allerdings nur in seln geringer Andeutumg, eine Gestaltung erkennen, welche an den 3 folgenden Segmenten stark ausgeprïgt ist: das ist, dass die einzelnen durch tiefe Furchen ron einander gesonderten Segmente einen vorderen kiirzeren und schwach erweiterten glatten Abschnitt, welcher die Borsten trügt, vor einer doppelt so langen geringelten Strecke haben; die vorderen Segmente tragen allerdings in ungleich starker Auspräinumg eine ähnliche Ringelung, und bei dem Mangel der Segmentfurchen lïsst sich danach der vordere und hintere Bezirk je eines dieser Segmente abgrenzen. - Die hinteren Segmente sind absolut und relativ kuirzer als die vorderen; von diesen ist das erste etwa dreimal, das 2 te und 3te viermal so lang als breit, das vierte etwas kiirzer als das vorhergehende, die folgenden etwa 2.- mal so lang als breit (Taf. 47, Fig. 2).

Das erste Segment ist mit dem Kopflappen orler mit einem nackten Buccalsegmente so enge verschmolzen, dass eine Abgrenzung beider gegen einander nicht anzugeben ist. - Der eigentliche Kopflappen ist eine von der Dorsalfläche steil nach der Ventralfläche abfallende hochgewölbte Platte, welche gegen das abwirts geneigte Vorderende dreieckig zugeschnitten ist. An dem Seitenrande dieser Platte steht jederseits ein ganz niedriger und darum nicht leicht wahrunehmender Saum mit einem winkligen Einschnitt in seiner Mitte; an hinteren Umfange greht die Platte unmittelbar in die liochgewölbte Riickenfliiche res Segmentes iiber; eine besonders ausgezogene rordere Spitze trägt der Kopflappen nicht. - Die rentrale Fläche des freien Vordertheiles des Kopflappens wird von einer breiten Längsfurche 


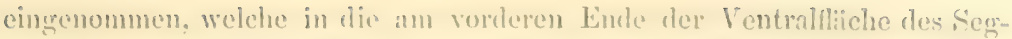
mentes gelegene Mundiblinmer fiihnt. Sie ist an den Seston und hinten ron

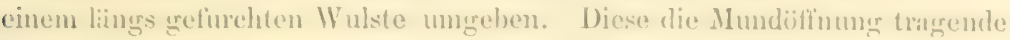
und die zunächst nach hinten daran sich schliessemde Strectie des Soumentes ist in beiden Exemplaren etwas andgetrieben, diunwandig mand durchseleinent, vielleicht stellt sie den Bezirk eines Bucealsegmentes vor, welches nach hinten dam olne eine Grenzmarke in das erste Borsten tragende Serment hinibertiihrt. Dessen hinterer Abschnitt besitzt die rorhin erwïhnte Queringelung. - Etwa anf der halben Iïnge zwischen dem Scheitel des liopllappens und der hinteren Segmentgrenze stehen am Seitentmung des Segmentes die Borsten: dicht iiber einnder das dorsale fiicherförmier gespreitzte Bïndel ron wenigen und kurzen, schwach gesiumten Capillarborsten, und die ventrale aciculaförmige einfache kegelförmig zugespitzte Borste (Fig. 2, 3).

Dis zweite Segment, welches nach hinten rom dritten nur wenigr dentlich gesondert ist, hat eine vordere etwa ein Drittel seiner ganzen Lïnge einnehmende Strecke, welche cin matt getriibtes, von der darauf folgenden geringelten Strecke abweichendes Aussehen besitzt, vielleicht beringt dureh IIautdrisen; auf der halben Lïinge dieser Strecke stehen jederseits die Borsten, welche wie im vorangehenden Segment gestaltet sind (Fig. 2).

An dritten Segmente befindet sich vor der mehr als zwei Drittel der gamzen Länge einnehmenden hinteren Strecke eine glatte vordere Strecke; auf der Grenze ron beiden stehen jederseits die wie vorhin gestalteten Borsten (Fig. 2).

Abweichend ron allen anderen Segmenten ist das 4 te Segment grebildet. Seine hintere geringelte Strecke geht allmählich in die vordere glatte Borsten tragende Strecke ïber. An deren Vorderrande erhebt sich kragenartig ein dümhliutiger Saum, welcher am dorsalen Umfinge niedrig ist, nach der Tentralseite hin sich zu einem mit der Spitze nach vorm gerichteten dreieckigen Lappen erweitert. Das Aussehen dieses Kragens, welcher den hinteren Theil des rorangehenden Segmentes umfasst, und der zunïchst dahinter liegenden Körperstrecke, ist matt weisslich-rrau, vermuthlich auch hier durch die Entwicklung von Drüsenzellen. Unmittelbar hinter diesem Bezirk, etwa auf der Grenze rom ersten zum zweiten Drittel der Segmentlänge stehen jederseits die Borsten abweichend ron denen der vorangehenden, ibbereinstimmend mit denen der folgenden Segmente: ein dorsaler Fïcher kurzer gresäumter Capillarborsten (Fig. 4), und unnittelbar darunter eine Querreile 
ron Ilakenborsten; diese tragen auf einer geringen Auschwellung des stabartigen Schaftes den starken Lndhaken, weleher bei Profilstellung auf der Seheitelliiche vier Zalmeinschnitte, ror dex Ilauptspitze die fïcherfürmigen Fiedern träist; die Spitzen der IIaken sind nach vorn gerichtet (Fig. 5).

Die drei folgenden Segmente sind fast granz gleichförmig gestaltet, durch tiefe Ringfurehen scharf ron cinander abgegrenat; ihr glattes vorderes Drittel, welches jederseits nahe dem IInterrande die Borsten trägt, ist etwas grorundet erweitert und dadurch etwas dicker als die hintere geringelte Strecke. Die Form der Borsten ist die gleiche wie diejenige der am vorangehenden Segmente stehenden; auffillig war mir, dass die Spitzen der Inakenborsten des ersten dieser Segmente mach vorn, diejenigen der beiden folgenden Segrmente nach hinten grerichtet waven. Sollten diese Borsten im Leben eine solche Beweglichkeit besitzen, dass sie derartig ihre Stellung zu wechseln vermüchten? Daun würden wir es in diesem Verhalten nur mit einem individuellen Zustande zu thun haben.

Die Endflïche des letzten dieser Segmente trug einen kurzen Anhang, den ich für einen durch Zerreissung entstandenen Fetzen halte. Ich vermag leider iber die Zahl der etwa fehlenden Segmente so wenig, wie iber die Bildung des Aftersegmentes cine Angabe zu inachen.

Die Würmer staken in dickwaxdigen, glatten, grauen Schlammröhren.

Mit der erweiterten Auffassungr der Gattung Clymene, welche ich bei der vorhergehenden Art besprochen habe, wird es gestattet sein, auch diese Art vorläufig darin unterzubringen, wemn ich auch über das entscheidende Merkmal, welches das Aftersegment bietet, Nichts angeben kann. Dann schliesst sich diese Art an die voranstehende insofern an, als auch bei ihr der Kopflappen vom ersten borstentragenden Segment nicht getrennt ist. Als neu kommt die beschriebene Kragenbildung hinzu. Nach Levinsen's Darstellung wirde das nicht in die Begrenzung der Gattung Clymene passen; ich habe aber schon oben ausgesprochen, dass diese Kragenbildungen bei sonst nicht näher verwandten Formen auftreten, und sehe zur Zeit darin kein Hinderniss, auch diese Art als eine Clymene zu bezeichnen. 
RIODINE, MLMG, char. emend.

$$
\begin{gathered}
\text { Rhodino sima, w. sp. } \\
\text { Teff. fi, Fig. } f-10 \text {. }
\end{gathered}
$$

Differt ab lihodine Loreni sergmento huceali perbrevi cum primo setigero non conlito sermentis setigeris primo et secundo limbo infundibuliformi muitis, uncinis restrat is in semmentis setigeris 3 anticis desilerat is, in segmentis proximis 7 biscrialibus, in ceteris nuserialibus.

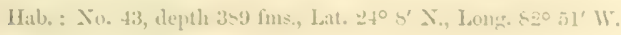

Von dieser interessanten Art liegt nur ein Exemplar mir vor, dessen vorderes Kärperende allein ich abbilden lasse, weil das hintere Eunde durch Maceration oder Quetschung vermstaltet und wohl an Körperende verstiimmelt ist.

Das weisslich gefïrbte Thier erhïlt seinen eigenthiimlichen IIabitus durch die kurzen, scharf von einander abgesetzten, zum 'Theil Kragen tragenden und durehscheinenden Segmente der vorderen Körperstrecke, an welche sich langgestreckte hintere Segmente anschliessen. Der Körper ist etwa $24 \mathrm{~mm}$. lang und abgesehen von den tiefen Segmentalfurchen durchschnittlich nicht ganz 1,5mm. dick. Ich zïhle ausser dem Buccalsegment nach der Zahl der Borstenbiindel noch 12 erhiltene Segmente.

Das Buccalsegment mit dem Koptlappen ragt als ein kurzes dickes Glied, welches höher als lang ist, ans der kragenförmigen Umfassung des nïchsten Segmentes heraus. - Ein eigentlicher Kopflappen ist kaum vom iibrigen Theile des Segmentes abgesetzt und nur daran zu erkemmen, dass ïber die steil abfallende Vorderfläche, welche eine durchscheinende W andung besitzt, eine kleine weissliche Crista verläuft, und dass diese Fläiche selbst in eine schnauzenartig frei rorspringende dreieckig zugeschnittene Spitze aulliuft. Von einem seitlichen Hautsaume des Kopflappens, wie er sonst bei den Naldancen vorkommt, ist keine Spur vorhanden. - Unter diesem Schnauzentheil liegt der Eingang zur Mundöfnung; diese ist von der Tentrallikiche her von einem dünnen frei vorspringenden Hautsaume umfasst, welcher als eine ventrale Kragenbildung des Buccalsegrmentes aufgefasst werden kanm. Hinter diesem Saume ist die Ventraltäche dieses Segmentes kielfürmig zusammengedriickt. - Die beiden ersten Borsten tragenden Segmente stimmen durch den Besitz eines rom Vorderrande sich kragenartig nneh vorn erhebenden ganzrandigen und trichterförmig geschlossenen Hautsaunes iiberein. Das erste dieser Segmente hat durchscheinende Wandung; ist etras länger 
als d:s nitchste, und den Kingen mit einbegriflen etwa doppelt so lang als breit: die Ilibe des Krigens beträgt etwa cin Viertel der grumen Lïnge; diıs nïhluste sexment stimmt abgesehen von den etwas geringeren Dimensionen. diunit iiberein. Beide Segmente tragen ein Biindel schlanker, grlasheller, kitum gesitumter Citpillarborsten, die aus einem legrelförmigen Ilïcker hervortreten; Bündel und Ilücker sind am 2ten Segment grösser als am ersten. Die zunäichst folgenden drei Segmente sind dureh tiefe Segmenturehen, fist rosenkinzfömig von ihren Nachbarn getrennt. Das 3te Borsten tragende Segment ist breiter als lang, das the so lang und das 5te etwas liinger als breit. Die nun folgenden Segmente sind länger als breit, im Allgemeinen wohl doppelt so lang als breit, doch kann ich bei dem Erhaltungszustande des 'Thieres genaue Angaben dariber nicht machen. Die Segmentfurchen zwischen ihmen sind wenig tief. Zwischen dem 6ten und Tten Borstenbïndel habe ich eine Segmentgremze nicht gesehen. An den hinteren Segrmenten ist eine greringe ventrale Kielbildung zu erkemmen (Fig. 6). - Die Borsten stehen an den vorderen Segmenten jederseits etwa auf der halben Länge, an den hinteren Segmenten dagegen vor der hinteren Segmentgrenze. Dieser Wechsel der Stellung erfolgt rom Gten bis zum Tten Borstenbindel, zwischen denen ich die Segmentfurche vermisste. Am 3ten Borsten tragenden Segmente sehe ich nur das dorsale Bündel capillarer Borsten, welche wie die an den vorangehenden Segmenten gestaltet sind, und wie an den folgenden fächerförmig, ohne besondere Höckerbildung anstreten. Unter den Capillarborsten stehen vom 4ten Borsten tragenden Segmente ab die eigenthiimlich gestalteten Hakenborsten, welche den Borsten der 'Terebelliden insofern ähneln, als auf dem Schaft die an der Hatutoberfläche vortretende Platte sitzt, welche auf der Scheide eime stark zahmartig vorspringende Basalecke, ihr gegenüber den auf der Scheitelfäche mit einer Querreihe von Zähnen besetzten Hauptendhaken, und zwischen beiden einen spitz dreieckigen trägt (Fig. S). Diese Borsten bilken auf den ersten sieben der damit ansgeristeten Segmente eine parabolische Doppelreihe (Fig. 9); auf den dahinter noch erhaltenen zwei Segmenten eine einfache Reihe (Fig. 10). Die Endhaken dieser Borsten sind in der einfachen Reihe und in der linteren Strecke der Doppelreihe nach vorn gerichtet. Die Fläche, auf welcher diese Borsten in ansehnlicher Zahl stehen, ist an den hinteren Segrmenten polsterartig erhoben; an den vorderen Segmenten zeichnet sich nur durch hellere Färbung und wenig bestimmt ein Borstenfeld aus.

Der Körper endete mit einem Wulste jederseits, auf welchem IIakenbor- 


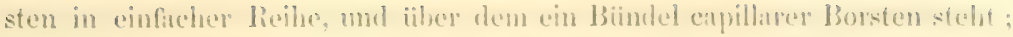

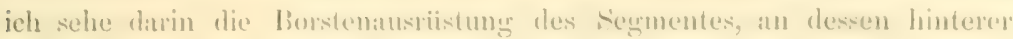
Grenze cin Bruch erlolgte.

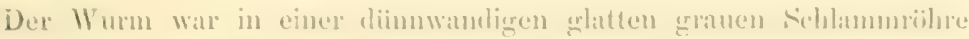
enthalten.

leh stelle diese Art zu der Gisttung Rhouline (Mhmer.), und zwar besonders mit Rücksicht anf die in einer Anzahl von segmenten doppelreihigr stehenden IIakenborsten. Aus der Fassumg, welche Malmgren der Gattungsediagnose gegeben hat, werden dam einzelne P'mkte answeheiden mitsen, welche Werth für die Artunterscheidung behallen: das ist die Versehmelzung des Buecalsegmentes mit dem ersten Borsten tragenden, denn diese simd bei meiner Art völlig getrennt, und dis Fehlen der ventralen Borsten an den vier ersten Segmenten, welehe Capillaw Art nur die drei ersten dieser Segmente der rentralen Borsten ermangeln. Es fehlt der Rilodine sima das lang gestreckte erste borstentragende Segment, welches nach Malmgren's ${ }^{1}$ Abbildungen bei Rhodine Loreni zwisehen dem wit dem Koptappen verschmolzenen Buccalsegment und dem ersten der beiden mit trichterförmigren Hautsäumen ausgestalteten Segmenten liegt.

Der Hiuptcharakter der Gattung wird durch die eigenthiumlichen in Doppelreihe stehenden Hakenborsten gebildet, welche bei lihodine Loxeni (Mlgn.) an allen hinteren Segunenten vorzukommen scheinen, während sie bei Rhodine sima auf eine Anzabl vorderer Segmente beschrüukt sind. Daneben ist der Mangel eines Hantsaumes am Kopflappen wohl ron Bedeutung, sowie das dem Orte nach allerdings ungleiche Auftreten von trichterfömigen Hautsïumen an den Segmentgrenzen. Fïr die Rhodine Loreni (Mlmg.) ist die Anwesenheit solcher nach hinten gerichteter Ifautsïume an den hinteren Segmenten eine höchst eigenthümliche Bildung, iiber die, wie uiber das Analende von Rhodine Loreni wir durch Tauber ${ }^{1}$ unterrichtet sind. Danach unterliegt es denn auch lieinem Zweifel, dass das mir vorliegende Exemplar einen wahrscheinlich grossen Abschnitt der hinteren Körperstrecke verloren hat. Tauber berichtet Nichts iher das Verhalten der ventralen Haken an den hinteren Segmenten; man darf danach wohl ammehmen, dass Malmgren's Beschreibung von der zreireihigen Stellung derselben hier ïberall zutrifit.

Rhodine Loreni (MImg.) ist an den schwedischen und dänischen Küsten aus geringer Tiefe gesammelt; dass der Wurm Röhren baut, wie Rhodine sina ist bis jetzt nicht bekannt gemacht, doch sehr wahrscheinlich.

1 Malmgren, Annulata polyehaeta, pg. 99. Taf. X. Fig. 61. - Nordiska Hafs-Anuulater, pag. 189.

2 Tauber, Annulata danica, pag. 122, 123. 


\title{
NICOMACHELLA (LETINSEN).
}

\author{
Nicomachella (?) picta, n. sp. \\ Taf. 47, Fig. 1.
}

Unter diesem Namen erwílume ich das auf 'Taf. 47 Fig. 1 abgebildete vorlere Körperende einer Maldanee, um die $\Lambda$ ufmerksamkeit auf diese Form zu lenken, welche durch eine auflillende Firbung und Zeichnung, wie sie im Kireise der verwandten Wiirmer selten ist, an Nicomachella temis (Théel) erimmert, welche bis jetzt nur in je einem unvollstindigen Exemplar von Novaja Semla und ron Hellebaek (Dänemark) bekamnt geworden ist. Zu beachten bleibt, dass der hier beschriebene Wurm aus grösserer Tiefe - 339 Faden - stammt.

Das 'Thier ist gestreckt $17 \mathrm{~mm}$. Iang und $1,5 \mathrm{~mm}$. breit, urspriinglich wohl drehrund, jetzt seitlich abgeplattet, und besteht aus einem mit dem Kopflappen rerschmolzenen Buccalsegment und 10 Borsten tragenden Segmenten, von denen das Buccalsegment etwas linger als die folgenden ist, diese aber gleichförmig und etwa so lang als breit sind. Die Farbe ist ein helles Gelb, auf dem Buccalsegment stehen zwei etwas schwächere, auf den folgenden Segmenten je eine tief zimmtbraune Querbinde, welche unmittelbar am Torderrande sattelförmig iiber die Dorsalfläche an den Seiten des Segmentes bis etwa tiber die halbe Höhe herabgreift. - Die Haut erscheint überall derb und dicht quer gerunzelt.

Das Buccalsegment endet mit einer einfuchen, in keiner Weise ausgezeichneten, steil vom Riicken zur. Butuchflïche abfallenden Endflïche, welche den Kopflappen darstellt. Auf der Ventralfläche liegt vorn eine grosse kreisförnige Mundöffnung, über welcher der Vorderrand des Kopflappens schwach wulstig verdickt ist. - Beim Einblick in die gerüumige Oeffnung zeigen sich einige häutige Lappen, welche ich nicht weiter deuten kann. Dies Segment ist borstenlos.

An allen folgenden steht jederseits hart am Vorderrande ein weisslicher querer Wulst, welcher etwa von der halben Körperhöhe zur Ventralläche zieht und hier an einem medianen schwachen Längskiel endet. An der oberen Begrenzung des Wulstes stehen die Borsten, ein oberes kleines Biindel einfacher schwach gesäumter Capillarborsten und darunter aus einer kegelförmigen Erhebung hervorragend eine - ausnahmsweise zwei - hornbraune dicke einfach zugespitzte stiitznadelartige Borste. 


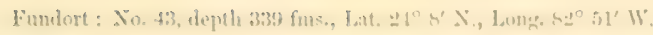

Die Firbumg erinnert an diejenige, welche Levinsen ${ }^{2}$ von der Sicanuchellu temis beschrieben hat; von dieser Art weicht aber die hier beschriebene durch die Borsten ab, besonders daturch, dass in allen Segmenten mur eine stiitzuadelartige Borste vorhanden ist, wiihrend bei $\Lambda$. lemis das nur an den 3 ersten borstentragenden segmenten stattindet. Deshalb ist es auch zweifelhaft, ob man die Art in der Gattumg Nicomachella belassen wird.

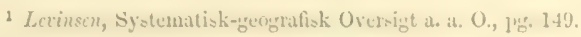




\title{
AMPHICTENIDAE.
}

\author{
PECTINARIA (LIN.). \\ Pectinaria (Petta, MLGx.) pellucida, n. sp. \\ T'uf. 44, Fig. 1-9.
}

P. prsillue (IIGRx.) persimilis, diflert ab illa limbo urene oris sub palmulis in laciniam acutam prolucto; processu triangulari pone articulum lasilarem cirri tentacularis prioris; margine inferiore scirmenti prioris medio profunde inciso utrimque sexdentato.

Hab. : Suntarem Channel, iepth 270 funs.

AIs Pellu pusillu (Mlmg.) 1 hat Malmgren eine Amphictenide kurz charakterisiert, welche in einem einzigen Exemplare einst von S. Loven an der Kiiste you Bohusliin aufgefunden war. Malmgren's Beschreibung ist in einzelnen wichtigen Punkten durch von Marenzeller ${ }^{2}$ ergïnt, welcher 5 von v. Frauenfeld an der schottischen Kíiste, bei Great Cumbray, gefundene Exemplare vor sich hatte.- Mir liegen mit ihren charakteristischen Rühren 2 Thiere vor, welche alle Kemmzeichen der Malmgren'schen Gattung Petta besitzen, ju der Pelle pusilla oftenbar sehr nahe stehen und nur in solchen weiter zu erwïhnenden Punkten von dieser Art abweichen, welche auf ihre Beständig. keit und Bedentung bei reichlicherem Material zu prïfen sein werden.

Beide Thiere sind fast gleichmissig gross, das besterhaltene $16 \mathrm{~mm}$. lang, rorn 2,5mm., hinten $2 \mathrm{~mm}$. dick; der übrigens drehrunde nach hinten also nur schwach kegelfürmig verjüngte Körper verdankt das charakteristische Aussehen, ausser den besonderen Bildungen, welche das Kopf- und Hinterende der 'Thiere in dieser Familie auszeichnen, der dünnhäutigen Beschaflenheit der Kürperrandungen, dureh welche der von weissem Kalkschlaunm stark gefuilte Darmtractus hindurchscheint. Die Segmentgrenzen sind, abgesehen von der vorderen ventralen Strecke, so wenig entwickelt, dass der Körper bei oberflïchlicher Betrachtung ungegliedert erscheint, und nur die nach hinten gerichteten, wenig grossen und meist der Kürperwand anlie-

1 . Mralmaren, Jorliska ITafs-Amulata, pag. 361. Taf. XVIII, f. 43.

2E. von Marenseller, Leber Lagis (Pectinariu) Koreni IJgm. aus dem Mittelmeer und die Hakenborsten der Amphieteneen. Terhandlungen der k. k. zool. bot. Gesellschaft in Wien. Jhrgg. 1874. 


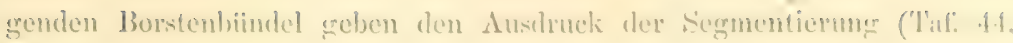
lig. 1).

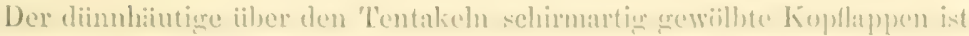

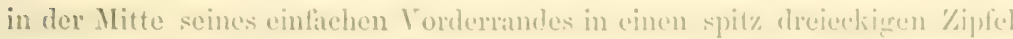

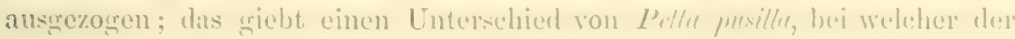

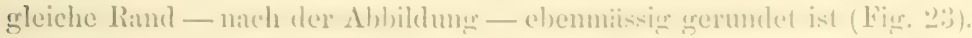

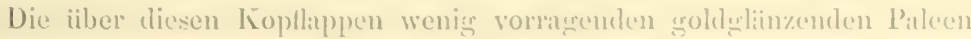

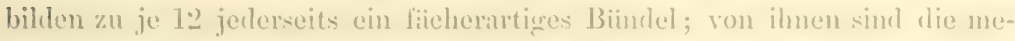
dianen die kiiresten, die Ite und lote, von der Medianlinie ans grezihlt, die

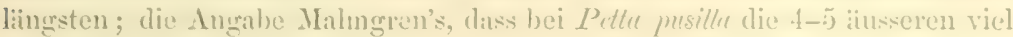
breiter und stiirker als die iibrigen seien, lässt sich auf' die Pelle prellucidu nicht iibertragen; die Grïsenabnahme erfolgt gegen die medianen zu allmählich. Die einzelne Palee ist etwas abreplattet und gegen das Encle hin greichmitsig zugespitzt; die grösseren dorsalwiirts concay geschwungen (Fïg. 3t).

Die halbmondfömige nach vorn geneigte Nackenfliche, unter deren Torderande die Paleen austreten, hat einen scharfen, völlig glatten Iinterrand, der in Form einer kleinen scharfen Falte vorspringt; der Vorterrand erscheint schwach gezihnelt, dieses Bild wird durch die Austrittstellen der einzelnen Borsten hervorgebracht (Fig. 3t).

Unter dem Kopflappen stehen kurze, am Ende schwach kolbig verdickte oder auch kegelfümig zugespitzte Tentakel, einen in der Mitte leicht getheilten Gürtel bildend; mit der Nadel konnte ich an dieser Theilungstelle die Tentakel in der Weise leicht aus einander legen, dass sie sich als zwei getrennten Gruppen von je 11 Fïden angehörig erwiesen. - An der seitlichen hinteren Ecke des Kopflappens steht etwa in gleicher Höhe unit der Austrittlinie der Paleen jederseits der vordere Fühlercirrus, der von emem kurzen Wurzelgliede entspringt und peitschenförnig so weit als die L'aleen vorragt. Etwas hinter seinem Wurzelgliede steht medianwirts greriekt ein anderer kegelfümiger aber etwas blattartig compresser IIjeker, desien Bedeutung ich nicht kenne; diesen funde ich in keiner der tregrebenen Beschreibungen ron Petla msillu erwibint. Er steht offenbar mit dem IVurzelgliede des Fühlercirrus auf gleichem Boden, so dass man versucht sein lïmnte, in ihm einen zreiten rentralen Fiihlercirrus zu sehen : allein seine Blattform lässt auch die Deutung zu, dass es sich hier um eine Hantbildung, wie an dem gezackten Hantsaume des 1ten Segmentes handele.

Die beiden ersten Segmente - nach der Auffissung Malmgren's - zeigen die für die Gattung charakteristische Ausgestaltung der Bauchfläche; der 
kimmartig zerschlitzte freie liand des ersten Segmentes ist durch einen schmalen tiefen - und nicht wie bei Petta millu weiten ausgerundeten Einschnitt in zwei Hiilften zerlegt, von denen jede 6 lange, spitz dreieckige Ziilume trïigt; für Pella pusillu werden 4-5 solehe Zïhne angegeben. - An der lateralen Ecke dieses Sammes steht jederseits der zweite Fühlercirrus, weleher etwas kiirzer als der vordere ist, aber wie dieser anf einem kurzen IV urzelgliede entspringt. Am ventralen Vorderrande des zweiten Segmentes erhebt sich jederseits neben der Medianlinie ein frei vorspringender rechteckiger Lappen ron opaker weisslicher Fïrbung. Beide Lïppehen, von denen jedes etwas lïnger als breit ist, springen über den Vorderrand des Segmentes nicht ganz so weit vor, als dieses Segment lang ist und decken bei der Ansicht der Ventralliiche den hinteren 'Theil des Einschnittes im Randsaum des ersten Segmentes. - An dem seitlichen Umfange dieses Segmentes steht weit himaf nach der Rïckenfläche geschoben die vordere Kieme, und ummittelbar hinter ihr, doch augenscheinlich dem folgenden Segrnente angehörend, die hintere Kieme; beide Kiemen sind kleine Lïppchen, an denen ich 6-7 Kiemenzähmchen zählte (Figr. 23).

Das zweite Kiemen tragende Segment ist wie die vorangehenden borstenlos. Nit dem 4ten Segmente beginnt die Reihe der borstentragenden Segmente, von denen 17 vorhanden sind, im Allgemeinen ron gleichem Grössenverhältniss, etwa viermal so breit als lang. Die beiden vorderen dieser Segrmente tragren jederseits nur das dorsale Bündel der so charakteristischen capillaren Amphictencen-Borsten, nur sind diese Bündel, wie auch das zunächst folgende, erheblich kleiner und schwächer als die weiterhin folgenden. Unter dem 3ten dieser Büschel steht die erste, nur erst mässig ausgedehnte Reihe von Hakenborsten auf kaum vorspringender Wulstbildung; etwa rom 10ten der Capillarborsten tragenden Segmente ab beginnt die Flösschenbildung, ohme irgend eine grosse Ausdehnung zu erreichen; überall sind die Flösschen auf der durchsichtigen Körperwand nur schwer zu erkennen; viel leichter die lang ausgedehnte Querreihe der glänzenden dicht gedrängt stehenden Hakenborsten. Gegenüber der Petla pusilla ergiebt sich aus dieser Beschreibung der Unterschied, dass während bei beiden Arten die Hakenborsten erst am 3ten, statt wie bei den iibrigen Gattungen am 4 ten Borsten tragenden Segmente auftreten, die Ausbildung der Flösschen bei Petla pusillu nach der Abbildung ${ }^{1}$ Malmgren's zu urtheilen viel stärker ist

1 Diese Abbildung ist insofern mit dem Texte nicht übereinstimmend, als auf ihr die Hakenborsten zuerst unter dem vierten Borstenbündel gezeichnet sind. 
und frïher an den Segmenten einsetzt, als hei Pellu pelluedutu. - Die Capillarborsten haften merleiche formen, die vielleicht anf versehientene Lutwicklumgsstulen zuriekzufiilıen sind; die cinen trugen an dem spit\% anslatufenden lingsstreifigen Schaft jederseits einen cinfachen foin lataförmig geribunelten Saum. Die anderen stimmen im Allgeneinen mit den von Malmaren alugebildeten iiberein: der brame fein lïngsstreifige Schaft trïgt am spitz auslanfenden Endtheil einen blattürmigen quer grestreiften und gezilhnelten Samm; dieser geht da, wo die brïunliche Spize des Schaftes sich verliert, ziemlich plitzlich in eine glattrandige blattatige dreieckige lerbreiterung iiber (condée en beïomette, Claparède), welehe dann in die glashelle mit feinen Ilärchen besetzte Endspitze auslïuft. Eine nicht ausgewachsene Borste dieser Art, wie sie in Fig. 6 auf 'Taf. 44 mit abgebildet ist, erweckte die Vorstellung, als sei dieser Saum eine Art von Scheide, welche das Schaftende ungebe; vielleicht entsteht mit Verhust dieser Scheide die zuerst beschriebene Form dieser Capillarborsten. Aus der Nebenemanderstellung einer ausgewachsenen und unausgewachsenen Borste ergiebt sich, dass das Lïngenwachsthum dieser Borsten allein im Bereich des Schaftendes erfolgrt, da die mit Situmen versehenen lindstrecken bei beiden gleich lang sind.

Die Hakenborsten, welche mit den Spitzen nach vorn gewendet in cinficher Reihe und grosser Zahl - ich zühlte auf einem Flösschen aus dem mittleren Körpertheile 175 Iaken - stehen, haben einen kurzen Stiel, zwei starke Ziihne und zwischen dem letzten derselben und der Basisceke (Meisselzahn [v. Marenzeller]) eine mit feinen Sägezïhnen besetzte Strecke. Diese fein gesärnte Strecke fehlt nach Malmgren's Zeichnung der Pellu pusille, die damit auch von den übrigen Amphicteniden abreichen wïrde, allein hier hat bereits v. Marenzeller von den Würmern, welche er für Petlu msilla anspricht, die Angabe gemacht, dass diese feinen Zähnchen vorhanden und Malmgren wohl entgangen seien; auffallend ist es jedoch, dass Malmgren über diese Bildung hier nichts erwähnt und in der Zeichnungr den Rand ganz glatt zeichnet, da er sonst auf diese Sägezähne besonders eingelıt, und wie bei Lagis und Cistenides ihre geringe Grösse oder ihre Abresenheit besonders herrorhebt. - Die mir vorliegenden Thiere zeigen diese Bildung und zwar, wie das v. Marenzeller angiebt, in Form einer Doppelreihe, oder wie es noch genauer auszudrïicken wäre, in Form einer U-förmigen Reihe, deren Schenkelenden gegen die Kammzälne gerichtet sind, in jedem Schenkel 4-5 Zähnchen, auf der Verbindungsstrecke 1 oder 2.

Die Borsten variieren in ein und derselben Reihe in Bezug auf die groben 
Kimmzilhne; ats Regel gilt das oben angegebene, dass die beiden Zithne cincr. Reihe angehören; in der Kantenansicht findet sich damn aber hier und dit cine Schneide, welche am Scheitel zwei oder drei, selbst vier, Zahnspitzen nehen einander zeigt, in der Weise, dass zwei grössere Kammzïhne neben cimander den Scheitel eimnehmen, oder dass dieser von einem oder zwei kleinen Spitzen grebillet wird, welehe sich vor und zwischen zwei Kammzïhne einsehieben. Es handelt sich dabei also um eine Bildung, mit welcher von der einfichen Reihe der Uebergang zur Doppelreihe gemacht wird. v. Marenzeller hat diese Bildung nicht gefunden, da er bei seinen besonders hierauf gerichteten Untersuchungen fïr P'ettu pusilla angiebt: mu 2 grobe Zühme in cinfucher Reihe. - Bei der Profilansicht ist diese Bildung nur schwer nachzuweisen (Fig. $7,8, \mathrm{Su}$ ).

Am Afterende des Körpers stehen vor der schrïg abfillenden Endfläche die der ganzen Gruppe zukommenden Analborsten; hier sind es jederseits 6 braune stumpfe Nadeln, die auf dem Wurzeltheile eines liingeren zugespitzten, flïsschenïhnlichen Anhanges stehen (Fig. 5).

Das an der Ventralflïche vorspringende Analblatt (scrpha) ist gleichmässig abgerundet, in der Mitte des freien Randes mit einem unpaaren längeren Faden, jederseits daron mit drei in gleichen Abstïnden stehenden stumpf dreieckigen Zacken besetzt (Fig. 5).

Die Röhren, etwa doppelt so lang als die Thiere, sind gerade oder sehr schrach gekrümmt; von der vorderen weiteren zur hinteren Oeffnung gleichmässig kegelförmig rerjüngt. Ihre imnere Oberfliche ist glatt, ihre äussere höckrig rauh, dadurch dass in eine scheinbar aus Schlamm bestehende feste Grundlage kleinere, abgerundete, an Grösse wenig unterschiedene Steinchen eingekittet sind, Darin stimmen die Röhren mit den von v. Marenzeller beschriebenen überein, während die von Malmgren beobachtete Röhre aus kleinen Schneckenhäusern aufgebaut war.

Die Unterschiede zwischen der Pella pusilla und der Petta pellucida, welche stichhaltig erscheinen liömten, bestehen in der fadenförmigen Zuspitzung des Kopflappens, dem Höcker nehen dem vorderen Fühlercirrus, und dem tiefen schmalen Einschnitt im Vorderrande der Ventralfläche des ersten Segmentes. Alle ibrigen sonst etwa zu nennenden Untersehiede, wie die so wechselnde Zahl und Grösse der Paleen, die stïrker ausgebildeten Kammzähne an Randsaume des ersten Segmentes und die geringere Flössehenbildung bei Petta pellucida sind ebensowenig wie die in der Zahl der Randzähne von Pelta pusilla abweichende Scapha von Belang, sondern gehören 
wohl mu den variabeh Bildmengen. - Liigen nieht v. Marenzoller's Angraben vor, so kïmnte man and die Diflerenz in fer kïhrenbildmer dewicht legen; da aber v. Marenzeller die von ihm beobathteten Thiere sicher als Preth msille bezeichnet, deren Riohren aber keine schneckenhïuser in der It:undung tragen, so ist danus ein Unterschied nicht almzuleiten.

Die mamiglaltigen Untersuchumgen im arktischen (ichiet halben bisher von dort Vertreter der Gattung P'etta nicht kennen grelehrt; das Aultreten an der südlichen norwegisehen und schottischen Kiiste sowie dats Vorkommen im Florida-Giebiet spricht zu Gunsten der Ansicht, dass wir hier cine, vielleicht mit dem Golfstrom, im wiirmeren Neere weit verbreitete Untergattung zu schen haben; ob vielleicht nicht ein und dieselbe, dann von mir irrthïmlich zerlegte, Art, mag die Untersuchung eines reicheren Materials von europäischen und amerikanischen Kïsten lehren. 


\section{AMPHARETID AE (MLMGX.).}

Für die Familie der Ampharetidae haben die Florida-Expeditionen einen Zuwachs ron Arten eingetragen, und gezeigt, dass diese Gruppe, welche bis dahin die Hauptzahl ihrer Vertreter in den vieldurchsuchten nordeuropäischen sowie nordamerikanischen Meeren besass, wohl in gleicher Weise wie die 'lerebellaceen verbreitet ist; zu den von den Philippinen und Madeira genamer bekannt gewordenen Arten fïge ich eine kleine Anzahl anderer dem tropischen Gebiete zukommender Formen hinzu. Nur eine dieser Arten, Auchenoplux crimila, erscheint als eine solche, welche zum Theil neue Zïge fiur die Familie aufzuweisen hat, alle iibrigen schliessen sich den bekannt gewordenen Arten recht nahe an. - Die Untersuchung dieser Arten bleibt in einem Punkte lückenhaft; wir haben erfahren, dass die Ampharetiden zum Theil lebhaft gefairbt und auffallend gezeichnet sind, wiewohl sie Röhren bewohnen; ob das auch von den von mir untersuchten Würmern, die meist aus grösserer liefe stammen, gesagt werden kamn, muss ich, beschränkt auf die Untersuchung der in Weingeist conservierten Exemplare, unentschieden lassen. - Anderseits bin ich bei der Untersuchung dieser Arten auf einige Punkte aufmerksam geworden, welche wohl für die ganze Familie von Wichtigkeit sind, und diese möchte ich hier zunächst bei einer Zusammenstellung der der ganzen Familie gemeinsamen Formverhältnisse verwerthen.

Es gehört zu Malmgren's Verdiensten, dass er die Ampharetiden aus dem Verbande der Terebelliden und dem der Amphicteniden gelöst hat. Doch wird man bei Annahme dieser Sonderung nicht ausser Acht lassen können, dass die Ampharetiden nur eine bestimmte Entwicklungsrichtung neben oder mit den Terebelliden darstellen und stets enger als andere Familien an diese anzuschliessen, beide als Entwicklungsformen von gemeinsamem Ausgangspunkt aufzufassen sind.

Ist die Aufstellung dieser Familie allgemein gut geheissen, so hat die Zerlegung derselben in mehrere Gattungen einen zum Theil gerechtfertigten Widerspruch erfahren, so von Langerhans ${ }^{1}$ und Théel, ${ }^{2}$ welche beide aller-

1 Langerlans, Die Wurnfauna von Maleira. Ztechr. f. wiss. Zoolog. Bd. XXXIV, pag. 105.

- Thécl, Les Annélides polychètes des mers de la Nontvelle Zemble, a. a. O., pag. 60. 
dings nur eimelne Punkte hervorheben, cine Diskussion der gresammten Verhibltnisse nicht gegeben haben. Antererseits hat Tevinsen ${ }^{1}$ nach ilnen noch andere Cattmengen anfestellt und eine Charakteristik der framilie gogeben. Hlieran amschliessent mïhte ich anf einige P'unkte von besonderer Bedeutung hinweisen.

Der Kïrper aller bis jetzt bekamnt gewordenen Anpharetiden setzt sich aus den beiden, als thomeale und abdominale liegrion bezeicheten Strecken zustmmen, welche durch die Anwesenheit und den Mangel von capillaren Borsten gekennzeichnet sind. Diese Sonderung, offenbar in l3ezichung zu dem Umstande stehend, dass die Thiere Röhren bewohnen, fïllt durchaus nicht immer mit cinem Dickenunterschied einer vorderen und hinteren Koirperstrecke zusammen; in einzelnen Arten z. B. Amage tumide ist allerdings die vordere Strecke der abdominaien Region noch erheblich gegeniber dem Kürperende verdickt. - Die Sonderung der Regrionen ist im Uebrigen die gleiche wie bei den 'Terebelliden. Hier aber liegt die Amnalne nalse, dass diese letzteren von gleichmässig segmentierten Wiirmern abzuleiten sind; dem unter den Terebelliden sind ja Gattungen wie Lepraea, Grymaca ı. a. bekannt, in deren Arten Capillarborsten an allen Segmenten, mit Ausnahme der Kopfregion, auftreten; solche Formen wïrden also in dieser Hinsicht einer als gleichmässig gegliedert gredachten Ausgangsform mahe stehen. Fiir die Ampharetiden ist zur Zeit eine dem parallel gehende Form nicht bekannt geworden, und in dieser Hinsicht erscheint mithin. fiir die Gesammitgruppe der Ampharetiden die Entwicklung als die rorgeschrittenere. Es ist bis jetzt aber auch nicht gestattet, und ich komme später darauf zurück, für die Terebelliden und Ampharetiden einen gemeinsamen Ausgangspunkt der Entwicklung mit einiger Bestimmtheit zu kennzeichnen. Aber dass in beiden Familien Reductionsvorgänge zunächst zur Sonderung der thoracalen und abdominalen Region geführt haben, und Reductions- wie Dislocationsvorgänge in dem thoracalen Abschnitte weiter gewirkt haben, wie derselbe alleiniger Träger besonderer Organe und Verrichtungen geworden ist, kamn wohl angenommen werden.

In der thoracảlen Region bietet bei den Ampharetiden die Gestaltung der vorderen Körperstrecke einer gleichmässigen morphologischen Ausdeutung Schwierigkeiten. Allen Formen kommt am Torderrande der dorsalen Flïche eine sehr ungleich ausgebildete Strecke zu, welche als Kopflappen bezeichnet wird. Ueber die Abgrenzung dieses Kopflappens scheinen die Ansichten

\footnotetext{
1 Levinsen, Geografisk-s5stematisk Orersigt, a. a. O., pag. 156.
} 
der Antoren unter cinander abzuweichen. Unzweifelhaft verdient bei den I'entakeltragenden Arten als Kopilappen derjenige Abschnitt bezeichnet zu worlen, wolcher hinter diesen 'Tentakeln gelegen derartig beschafien ist, dass diese wie unter einem Vordermale desselben angeheftet erschemen. Nun sind aber diese 'Tentakel wohl in allen fïllen retractil, so dass sie im Imern eines geräumiggen Mundeinganges geborgen werden können, und treten daher bald mehr bald minder weit hervor, zeigen bisweilen selbst nur ihre Spitzen in der Mundöllinumg. Mit den 'Tentakeln zugleich aber entfiltet sich oder wirl eingezogen ein hïufig in Filten gelegtes oder der Liinge nach wellig gekriuseltes 13latt, welches am leichtesten einer Lippe rergleichbar ist. Ob dieses Blatt num als ein Abschnitt der Schlundwand, odler die vortere Strecke des Kopflappens zu bezeichnen ist, das ist mit Sicherheit erst durch eine amatomische Untersuchung festzustellen. Ich rechne diese die 'Tentakel tragenle Lippe vorläufig zum Kopflappen, mit Riicksicht auf den offenbar gleichwerthigen Absehnitt des Kopflappens, welcher bei den Terebelliden vor den Tentakeln steht. — Wie dieses Blatt bei den tentakellosen Ampharetiden, Glyphanostomum und Auchenoplax, sich verhält, ob es in Rudimenten wenigsten vorhanden ist oder ganz fehlt, bleibt moch festzustellen. Dagegen ist bei diesen Gattungen der posttentaculare Koptlappentheil nicht zu verkemnen.

Die hinter den Tentakelurspriingen liegende Platte des Kopflappens zeigt ungleiche Auscrestaltung, insofern sie bald durch Längs- und Querfurchen cine verschiedcne Felderung erhiilt, bald bei Mangel solcher Furchen nur diinnere Seitentheile neben dem derben gewölbten Mitteltheil zeigt, oder schliesslich bei den tentakellosen Gattungen ganz ungefurcht ist. Ich habe nicht die Ueberzeugung frewiunen können, dass die stärkere oder greringere Ausprägung solcher Furchen für die Systematik grössere Bedentung habe. Ueber die hintere gleichmässige Abgrenzung der Kopflappenplatte kann man in einzelnen Fiallen in Zweifel sein, da hier vielleicht Verschmelzungen mit der Riickenfläche des auf den Koptlappen folgenden Segmentes eingetreten sind. Das füllt mit der Auffassung des als Buccalsegment zu bezeichnenden Körperabschnittes zum Theil zusammen. Auf eine besondere Bilrlung möchte ich an dieser Stelle hinweisen, welche ich an Ampharetiden aus dem Florida-Gebiet gesehen habe, die leider so verstïmmelt waren, dass eine genauere Beschreibung unthunlich ist: das mittlere Feld des gefurchten Kopflappens trug hier eine fast die halbe Länge desselben cinnehmende rechteckigre und schwach gewöllute Platte, von blass 
hornbriunlicher Finhe und fester Comsisten\% oflenbar eine derbe Chitin-

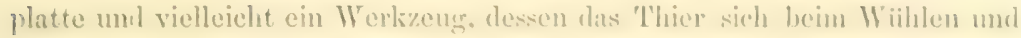
bei der Besehathung des Materiales bedient, welehes es zur Ilerstellung der IVandung seiner lioilnen bedart.

Die das Vorderende des Kïrpers zusammensetzenden Segmente, welche bei allen Ampharetiden dureh den Besitz von ribekenstïndigen Kiemen. meist anch durch Paleen und durch das Fehlen der Haken tragenden Polster oder Fläsechen vor den folgenden sich auszeichnen, sind ron firube und Malmgren in ungleicher Ireise gezilitt worden. Der Unter-chied in der Auffassung tritt darin hervor, diss das Paleen tragende Segment, welches wohl unweifelhalt bei allen Ampharetiden das greiche ist, ron Grube als das 2te, von Malmgren ${ }^{2}$ als das dritte angesehen wird. Ich schliesse mich dier ïlteren Auffassung Grubes an, wihhrend Levinsen Malmgren gefolgt ist. Die Differenz in der Auftassung ist, wie das ans Levinsen's Darstellung kilar hervorgeht, dariuf zuriekzuführen, dass Malnggren das liaufig in grosser Entwicklung auf der. Ventrallikiche hinter der II undüftinung grelegene und diese wie eine Lippe begrenzende Stiick, welches aber eine Continuitait mit der Rückenfliiche nicht besitzt, als seibständiges Segment anffasst und zählt, während ich, der Grubeschen Darstellung folgend, als Buccalsegment dasjenige ansehe und als erstes Segment zähle, welehes auf der Ventral- und Dorsalfläche als ein continuirlicher Körperring erscheint. Welche dieser Auflassungen morphologisch grössere Berechtigung hat, bleibt noch zu erreisen. Der lippenïhnliche Fortsitz oder das erste Segment im Simne Malmgren's verdient wohl diese letztere Bezeichnung, wenn der Beweis gebracht wird, dass der zu ihm gelürende dorsa? Theil mit dem Koptlappen oder mit dem ron mir als erstes gezïhltem Segment verschmolzen ist. Letztere Deutung köunte man den Verhältnissen geben wollen, welche bei Auchenoplax vorliegen. Ein Berreis für die eine oder andere Auffassung fehlt zur Zeit. Wenn ich mich in den folgenden Beschreibungen Grube's Auffassungen anschliesse, so geschieht das, weil der lippenförmige Fortsatz, Malmgren's erstes Segment, fehlen kann, und nan damn nach Malngrens Auffassung das in Wirklichkeit mun erste Segment als das zweite zählen müisste.

Will man die Ampharetiden auf homonom segmentierte Ameliden zuriickführen, so wird man zu der Ammame genöthigt, dass in der thoracalen Körperregion ein Zusimmenschieben urspriinglich getrennter Theile stattge-

1 Grube, Beschreibung nemer oler wenig bekinnter Anneliden. Archir für Vaturgesch., Jahrg. 26, 1860. pag. 105.

2 Malmgren, Nordiska Hofs-Annulater, a. a. O. pag. $363 \mathrm{f}$. 
limen lube. Amstïksten tritt solehes in der Stellung der Kiemen hervor. -Diese sind in allen Fïllen cintache von der Kegelform abzuleitende Fïden, welehe meist zu vier Pataren, seltener zu drei (Ampluerele putagonica) (Glyphanostomum) oder zwei (Auchenoplax) vorhanden sind. Der angenommene Verschiebungsvorgang hat damn an ilmen, ohne dass eine Concrescenz oder ein Ausfillen von segmenten angenommen zu werden braucht, in doppelter Richtung stattgefunden; wemn man als Ausgang eine Form amninmt, in weleher solehe Kiemen in segmentaler Ordnung je ein Paar auf den Flanken der Segmente gestimden habe, so erfolgte von dieser aus eine Concentrierung, das einemal durch ein Verschieben der Ursprungsstellen in der Richtung von hinten nach vorn, wodurch die Kiemen der gleichen Körperhälfte zusanmengerückt wurden, das anderemal in der Richtung von den Flanken des Kürpers medianwïts, wodurch die Kiemen in der Medianebene des Körpers an cinander rücken. Diejenigen 'Thiere also, bei welchen die Kiemen zwei in der Mittellinie des Körpers sich beriihrende Haufen darstellen, wïrden den rorgeschrittensten Fall darstellen (z. B. bei Melinna), während die Stellung wenigstens eines Theiles der Kiemenfüden hinter einander (wie bei Amphicteis, Gr.) ein urspringlicheres Verhalten zeigt. Zwischen den getrennten Kiemenfiden erhebt sich aber bei einer Anzahl von Formen (Amphicleis procera) eine crista-artig vorspringende quere Hautfalte; in ihr könnte man, wenn man die Vorstellung eines hier angedeuteten Entwicklungsganges festlaalt, die Bahn sehen, auf welcher es gleichsam zu einer Vereinigung der noch getrennten antimeren Kiemen kommt. Solches ist in ansgezeichneter Weise bei Amphicteis Vega (Wirén) der Fall. Schliesslich würde eine Verkümmerung der Kiemen mit einer Ausbildung der Criste zu der Bildung führen, wie ich sie von Auchenoplax beschreibe. - Für einen Terschiebungsvorgang in der Richtung von hinten nach vorn und für die Lageänderung, welche damit zweifellos die die Kiemen speisenden Blutgefässe erleiden müissen, ist es zu beachten, dass auf der Dorsalflïche dieser Körperregion Segmentgrenzen nicht zu erkennen sind, damit die 'Zeichen von Schranken fehlen, welche solcher Verschiebung entgegenständen. - Wird ein soleher Verschiebungsvorgang der Kiemen zugelassen, so darf das Ergebniss desselben doch noch nicht ohne Weiteres als ein Kennzeichen für nühere oder weitere Verwandtschaft der einzelnen Gattungen verwendet werden.

Seitliche frei vorragende Hautsïume, wie sie an den vorderen Segmenten von Auchenoplax rorhanden sind, in besonderer Ausgestaltung die Borstenbündel tragend und nach vorn verschoben die kragenartige Beklei- 
dung des Vorderendes bei Melimu bilden, sind bei den Terebelliden in ähmlicher Wrese vorhanden. Ieh verweise im Vergheich mit Melinna besonders

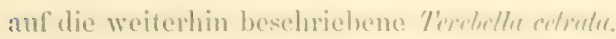

An dem Seitemmfing der thoracilen Kïpperstrecke verlangt die Stelluner und Zahl der Borstenhüeker Beachtung, und in erster Linie sind es die in der einen Gruppe der Ampharetiden aufretenden P’aleen. I)ass rlieve (iebilde als 13orsten iiberhaupt anfgefisst werden miisen, kann nielst bezweilelt werden; aber in welcher Beziehmeg sie zu den Capillarborsten der Thoracalregion stehen, das ist noch darulegen; dem es ist ebenso denkbar, dass diese Paleen besondere, in Neubildung entstandene Borsten sind, wie dass sie aus einem Bindel eapillarer Borsten abzuleiten seien. Ich neige mich rer ersten Ansicht zu, allerdingrs zunïchst nur in Riicksicht auf die besondere Gestaltung, welche diese Paleen hïufig haben. - In denjenigen Fällen, in welchen die getrennten antimeren Kiemenpare durch eine Inutfilte verbunden sind, stehen die Paleen seitwärts an dieser Falte und oflenbar mit ihr in Verbindung. Bei Amplicteis procera finde ich num unmittelbar hinter dem Paleenbïndel ein kleines Bündel capillarer Borsten, ohne dass zwischen beiden eine Furche wïre, welche hier eine 'Trennung in zwei Segrmente anzeigt, und ich rechne daher diesen Bezirk zu einem Segment, welches also Paleen und Borstenbiindel träigt; eine Auflassung, welche zulässig ist, sobald man Paleen und Borstenbïndel als nicht gleichwerthig ansicht. Allein einwurfsfrei ist diese Auffassung nicht; denn nach ihrer Stellung gehören Paleen und Borstenbündel hier einem Segment an, welches jederseits zwei neben einander stehende Kiemen trägt, und da die 3te ma fte Kieme dahinter jederseits nach ihrer Stellung zum Borstenlü̈cker als je einem Segmente zuggehörig erscheinen, so wiirde die Auffassung nicht olne weiteres abzuweisen sein, dass die jederseits zwei Kiemen tragende Strecke auch zwei Segmenten entspreche, die Paleen aber das umgewandelte Borstenbündel des ersten dieser Segmente darstellen. - Vielleicht bringt eine anatomische Untersuchung, welche ich leider aus Mangel an Material hier nicht anstellen kann, über diese Frage Aufschluss.

In welchem Verhältuiss wir uns die Paleen tragenden Ampharetiden zu denen, welche Paleen nicht besitzen, denken sollen, ist allgemein nicht festzustellen. Wemn eine Form wie Melimna, bei welcher die eng zusammengeschobenen Kiemen und die weit gehende Umbildung des vorderen Körperendes auf einen weitesten Fortschritt in der von mir vorausgesetzten Richtung hindeutet, die Paleen nicht besitzt, so liegt die Auffassung nahe, 
diss hier eine Reduction zur Abschaftung der Paleen gefuiht habe; Glyphanostomum und Auchenoplax schliessen sich weiter hier an; allein hier wie bei den amleren formen kümte man auch an einen Nichterwerb denken; gemeinsam ist allen die Paleen entbehrenden Formen, dass die Kiemen stark zusimmengeschoben oder an Zahl reducirt sind.

Allen Ampharetiden kommt an der vorderen Körperstrecke eine kleine Zaihl ron Borstenhückern mit Capillarborsten zu, unter welchen Polster oder Flöschen mit Hakenborsten fehlen; die Zahl derselben wechselt von 2 (Auchenoplax) zu $t$ und es bleibt der ungleiche Ort des Auftretens der ersten Hikenreihe ein für die Systematik gut zu verwendendes Merkmal. Fiir die morphologische Auflissung ist aber die Entscheidung noch nicht getroffen, ob der Borstenhöcker, unter welchem die erste IIakenreihe steht, bei allen Ampharetiden gleichwerthig ist. Denn wemn wie bei Amphicteis die Zahl der Borstenhöcker, unter welchen die IIaken fehlen, grösser ist als bei den anderen Formen, so bietet sich ebensowohl die Annahme, dieser Unterschied sei dadurch bedingt, dass die kleinere Zahl entstanden wäre, indem bei vorschreitender Reduction ein Borstenhöcker ausgefallen, wie diejenige, dass die grössere Anzahl dieser Borstenhöcker nur dadurch entstanden sci, dass die Bildung der Haken um ein Segment weiter nach hinten sich verschoben habe. Dass dieser letztere Vorgang angenommen werden darf, ist nach den Mittheilungen, welche Langerhans ${ }^{1}$ iiber das mit dem Alter wechselnde Verhalten der Haken tragenden Polster bei Polycirrus, und nach der zuletzt ron Salenski ${ }^{2}$ vertretenen Auftissung, dass diese Haken bei tubicolen Amneliden als Neubildungen und nicht als umgewandelte Borsten eines ventralen Ruderastes aufzufassen sind, nicht zu bezweifeln. Nur spricht für die erstere Annahme der Umstand, dass diejenige Form, Amphicteis, bei welcher die Stellung der Kiemen dem als urspriinglich angenommenen Verhalten am nächsten steht, einen Borstenhöcker ohne darunter stehende Haken melır besitzt, und dass der erste dieser Höcker kleiner ist, als rie folgrenden, gleichsam als stände hier der bei den übrigen Formen eingetretene Wegfall bevor. Die Consequenz solcher Auffassung wäre, dass man für Auchenoplax den Ausfall zweier Segmente annehmen müsste; bestimmte Anzeichen dafiir liegen kaum vor.

Die in der Gattung Melimna hinter den Kiemenbiischeln stehenden Haken

I Langerhans, Die Wurnfauma von Makleira, Ztschr. f. wiss. Zoolog. Bt. XXXIV, pag. 109.

- W. Salcnsli, lEturle sur le déreloppement des Annélides. Arehives le Biologie publiées par E. ran

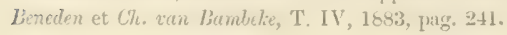




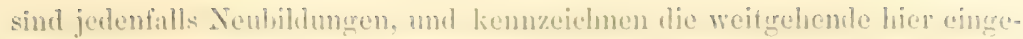
tretene Umerestaltumer iles Vorderendes.

Die thoracale hegrion hesizat weiterhin eine bei den verschientenen Arten

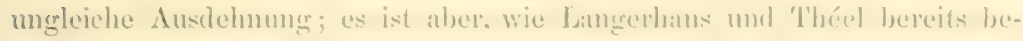

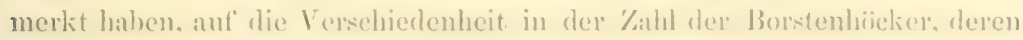
Auftreten die 'Thoracalregion bestimmt, nur ein grevinges Gewicht zu lengen, und dieses Verhältniss fiir die Alygrenzung der Gattungen ebenso wenig von Werth, wie die Gesammtzahl der secrmente, oder die Zahl der in der abdominalen Regrion enthaltenen Kiorperglierler.

Fiir die Gittung Sosane hat Milngren ein meines Wiscens sonst weiter nicht beobachtetes Verhalten, das IIerausriicken eines Borstenhöekers aus der Reihe, bekumnt gemacht. Dem wiirde die mediane Verschiebung der beiden ersten Haken tragenden Wülste bei Anchenoplax entsprechen. Sollten hier Ausbildungen im Geschlechtsapparat Einlluss gehaht haben?

Die Form der anf den Flösschen stehenden Haken besitat cine, wie ich glaube, bei den Ampharetiden weit verbreitet rorkommende Eigenthiimliehkeit, auf welche meines Wissens noch nicht hingewiesen ist: das ist die in Bereich der abdominalen Körperregion allmählich eintretende Umwandlung der Form, durch welche bald ohne, bald mit Abnahne der Crösse an Stelle der Plattchen, welche an der thoracalen Region nur eime Reihe ron Siigezähnen auf der freien Kante tragen, solche treten, welche dicker werden, und dementsprechend auf der freien Kante mehrere Reihen von Sïgezihmen neben einander führen. Diese Bildung weist auf die nahe Verwandtschaft der Ampharetiden mit den Terebelliclen, bei denen die gleichen Verhïltnisse vorliegen. Auchenoplax und Melinna weichen in dieser Himsicht ab, indem die Irakenform, welche sonst den hinteren Segmenten zukommt auch auf den Querwiilsten der vorderen Segmente, bei Melimna allerdings etwas abweichend sich findet; ein Beweis, dass diese Gattungen in der Entwicklung weit vorgeschritten sind.

In ihrer Stellung rerhalten sich die einzelnen Haken wie die der Terebelliden, insofern sie die Basalecke und die Spitzen der Sägezähne nach rorn wenden; eine gebogene Reihe der Haken kommt vielleicht bei Ampharetiden nicht vor:

Ob, wie im letzten Flösschen von Melimn, sonst Stiitznadeln, die bei den 'Terebellen bekannt sind, bei den Ampharetiden weiter verbreitet auftreten, bleibt noch zu untersuchen.

Für die Abdominalregion exweist sich schliesslich das Knötchen charakter- 
istisch, in welchem ich wegen seiner Bezichung zu dem Aftercirrus bei Amplacteis mocem einen rudimentiren Cirrus sehe. Es ist von anderen Antoren wohl als ein borstenloses Riickenparapodium bezeichnet. Die Stellung deselben schwankt insoweit, als derselbe durch die Körperdicke vom Flïschen getremnt ist (Amphicteis), orler mit ihm in nahe Verbindung tritt (wie bei Amuge tumidu). Ich muss mich vor der IFand auf den Hinweis beschrïnken, dass dieses Gebilde nicht allen Ampharetiden zukommt. In wie fern diejenigen Arten, welehen dieser Fortsatz fehlt, näher zusammen grehören, kam ich zur Zeit nicht beurtheilen, und der Umstand, dass bei Glyphanostomum und Auchenoplax, den am weitest abweichenden Gruppen, dieser Mangel vorhanden ist, liisst sich mit Riicksicht auf die anderen Gattungen noch in keiner. Weise für eine Deutung verwerthen.

Wenn es sich herausstellen sollte, dass die urspringlicheren Gattungen dieser Familie diesen rudimentären Cirrus besitzen, und derselbe nicht als ein in der Gruppe neu erworbenes Organ aufzufassen ist, dann würde er als ein Anzeichen dafiir zu verwerthen sein, dass die Ampharetiden nicht von den Terebelliden abzuleiten sind, sondern für beide nur ein gemeinsamer Ausgangspunkt zu suchen ist.

\section{AUCHENOPLAX, n. g.

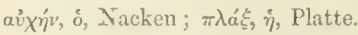

Ampharetidarum genus lobo cophalico brevi in area frontali haud sulcato; tentaculis nullis; ore postice labio tecto; branchiis segmenti $2 \mathrm{i}$ utrinque binis longissimis in basi coalitis; segmentis 2 anticis nudis, 14 sequentibus pinnigeris, sericbus uncinorum a segmento setigero 30 incipientibus, duobus primis submedianis, deinde lateralibus, in pinnulis segmentorum posticorum ralde dilatatis.

Diese Gattung, deren einzige Art ich im Folgenden beschreibe, schliesst sich in einigen Punkten an die Gattung Glyphanostomum (Levins.) an. Das ist die einfache, nicht gefurchte Kopflappenplatte, die augenähnlichen Pigmentflecken auf derselben, und der Mangel der Tentakel. Im übrigen ist Auchenoplax von Glyphanostomum wohl zu trennen. Ich habe in die Characteristik der Gattung die Bildung der freien Hautsiume an den vorderen Segmenten, die scharfe Begrenzung. der Bauchfläche der zunächst folgenden Segmente nicht aufgenommen, da ich ïber den Werth derselben kein Urtheil habe, und besonders nicht weiss, in welchem Verhältniss diese Hautsäume zu den ähulichen Bildungen an den ersten Segmenten von Nelinna sich verhalten. 


\section{Auchenoplax crinita n. sp.}

$$
\text { Tuif. Yh, Fig. 10-16. }
$$

Teres, longa vermiformis bipurtitu, sermentis 16 unticis postice versus longiorihus, sequentibus plus quam 12 brevioribus, valde inter se sejunctis. Lahns eephalieus trigenatus sultus planus, supra convexus, subenrinatus; branchiae 4 secomenti di lomgissinne filifumes e limina prodeuntes. Segmenta 2 antien margine laterali cutance elevato munita, 11 sequentia setipera et, exeeptis duobus anterioribus, uncinigern; fasciendi setamm cippillarium in piunis dorstalihus nequiles; uncini segmenti $5 \mathrm{i}$ et bi seriem submedianam magnam, ceterorum literalem minorem formantes, segmentorum posticorum in acie pimnulae humilis latae seriem formantes, ubique crassi post apicem terminalem triserrati.

IInb. 1. No. 43 , depth 339 fms., Lat. $21^{\circ} 8^{\prime}$ N., Long. $82^{\circ} 51^{\prime}$ II. 2. No. 47, depth 321 fims. Lat. $25^{\circ} 42^{\prime}$ ㅊ., Long. $58^{\circ} 40^{\prime} 11$.

Mir liegen von dieser Wurmart mehrere Exemplare vor, welche ich aus ihren Rühren herauszulösen hatte, leider keines davon vollstiindigr erhalten, demn allen fehlt das Afterende und mit ihm vielleicht eine grössere Anzahl der hinteren Segmente.

Der Körper erscheint, wenn man von der Besonderheit des Kopfendes absicht, drehrund, da Rücken- und Bauchfliche fust gleichmässig hoch grewölbt sind, und abgesehen von einer geringen Verdickung der vorderen Kürperstrecke, die Breite in der ganzen Lïnge fust die gleiche ist. Der zugespitzte Kopftheil mit den vier langen fadenfömigren Kiemen, die aus der Nackengegend entspringen, bildet den Anfing der vorderen Kürperstrecke, welche vor der hinteren nicht allein durch den Besitz von Borstenbüudeln, sondern auch die geringe Tiefe der Segmentfurchen ausgezeichnet ist; so erscheint der Körper wie aus zwei ungleichen Theilen zusammengesetzt: der vordere glatt mit den nach hinten zu weiter aus einander greriickten Borstenhö̈kem, der hintere fast rosenkranzförmig durch die tiefen Sermentfurchen eingeschnitten, aus welchen die Haken tragenden Flösschen nur wenig hervorsehen (Taf. 44, Fig. 10).

Ein $25 \mathrm{~mm}$. langes, durchschnittlich $1 \mathrm{~mm}$. dickes Thier hatte 24 Serrmente; bei einem etwas längeren Thiere hatte das Hinterende 4 Segmente mehr; beide Exemplare waren ohne charakteristisches Aftersegment und sicherlich hier verstiimmelt.

Nach der Vertheilung der Borsten lassen sich die Segmente in solcher Weise zusammenfassen, dass die zwei vordersten Segmente, welche zusam. men mit dem Kopflappen das Kopfende bilden, keine Borsten tragen. Die 
1t lolwenden Segmente tragen dorsale Ilöcker mit einfichen gesiumten Borsten, und, mit Ausmithme der beiden ersten, jederseits cine ventrale Reihe ron Haken. Welche wiederum in den beiden ersten eine von den folgenden abweichende stellung haben. - In der hinteren Körperstrecke mit den tiefen Segmentfurchen treten die Haken nur an Fliisschen stehend anf:

An Kopfende bezeichne ich als Koptlappen eine dreieckig zugespitzte Platte, welche aut' der ventralen Seite platt, auf der dorsalen Flaiche aber im doppelten simne gewölbt, ist, in der. Weise, dass sie in der Medianlinie zu cinem abgestumpften Lingskiel sich erhebt, der von hinten nach vorn mit der gamzen Fläche steil abfillt, so dass die hintere Hailfte in dieser Richtung convex, die vordere concav ist; die ganze Fläche wird dadurch annähernd sattelfürmig ( Fig. 11, 12, 13).

Bei einem Exemplare fiud ich auf der Unterfliche des Kopflappens aus der Aundioflinung eine flache membranöse Ausstïlpung hervorragen. Mir schien dieselbe der vorderen Strecke des Darms, also einer Rüsselbildung anzugehören, und nicht einem bei anderen Arten der Ampharetiden vorkommenden, mit 'Tentakehn, welche hier fehlen, in Zusammenhange stehenden Blatte.

An diesen Kopflappen schliesst sich nach hinten auf der Dorsaltiäche eine hoch convexe Platte an, welche etwa um ein Drittel breiter als lang ist und einen greraden Vorder- und Hinterrand besitzt; unter ihrem vorderen steileren gradlinigen Abfall geht der Kopflappen hervor; nach Behandlung mit Glycerin und der dadurch hervorgerufenen Aufhellung der Körperdecke zeigten sich im Bereich dieses Abschnittes auf der Höhe nahe hinter dem Torderrande und hart am Seitenrande zwei dumkle augenartig erscheinende Pignentflecke; ob diese auf der Oberfliiche eines Hirnes oder auf einem eingezogenen 'Theile des Kopflappens sitzen, konnte ich nicht entscheiden; und damit ebensowenig, ob es sich um Augenflecke oder eingezogene Nackenorgane handle (Figr. 12, 13).

$\mathrm{Zu}$ dieser dorsalen Platte rechne ich, als in deren Bereich gelegen, zwei Strecken der Tentraltiiche, welche ich, trotzdem dass sie durch eine dentliche Querfurche von einander gresondert sind, zu einem Segment mit grosser Lippe zähle. Der vordere lippenförmige Abschnitt des Segmentes ist eine im Allgemeinen quer ovale, nach vorn etwas verjüngte und am freien Vorderrande mit medianem Einschnitte versehene Platte, welche in der ventralen Medianlinie der dahinter gelegenen Segmentstrecke an Liugre fast gleichkommt; ilıre Seitenräinder sind wie diejenigen der folgenden Segmente zu scharfen frei vorspringenden und durchscheinenden Randplatten erhoben; 
unter ihnen steht ant dem Seitentheile der Lipne cine Anzahl von Wulstbildumgen, welehe alser nicht iibereinstimmend und constant zus sein scheinen.

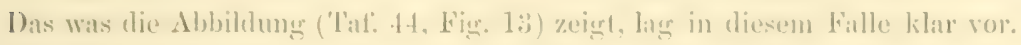
Die Furche, welehe diese lippe von der hinteren segmentstrecke trennt, ist im medianen 'Theile der banchifiche als quere furche am weitesten vorgeschoben, weicht an den Seitentheilen nach hinten aus. Hier erhebt sich damn der freie Rand der im iibrigen shatten Segmentfliche zu cinem diinnen freien Hautsume, weleher nach vorn convex abgerumdet ist.

Nach meiner Ziihlumer bezeichne ich das an diese sich anchliessende noch borstenlose Sergment als das zweite; seine Eigenthiimlichlieit besteht in einer Quertheilung der Bauchfliche und in den Anhangsgebilden der Ritickenfliche, welche ich als Kiemenapparat bezeichne. Das Segment ist auf der Ventralfliiche etwa so lang als dis vorhergehende, mehr als dreimal so breit als lang; die Querfurche anf der Ventralfliche liegt nicht ganz auf der halben Liinge, und so ist die vordere der beiden durch sie getremuten Strecken etwas kiirzer als die hinteren. Der seitliche Segmentumfung lïuft mit cinem dorsalwiirts frei vorspringenden, durehscheinenden Hautsaum aus, der einen S-fömig geschnittenen Rand trägt (Fig. 11, 13).

Auf der diesem IIautsaume gegeniiber vertieft liegenden Riickenfliiche steht der Kiemenapparat, welcher aus einer Basalplatte und vier Kiemenfuden besteht. Diese Zusammensetzung habe ich nur an cinem einzigen Exemplare gefunden, an den iibrigen war nur die Basalplatte vorhanden, die offenbar leicht hinfilligen Kiemenfiden fehlten hier. Die Basalplatte ist ein unmittelbar hinter der vorderen Segrmentgrenze sich erhebendes Blatt, welches in seinem Grundtheile nicht ganz die Breite der Rïckenfläche des Segmentes besitzt, gegren den Rand hin sich zu dieser Ausdehnung rerbreitert und niedergelegt die Lïnge des Segmentes deckt. An den Seitenstrecken des nach hinten oder aufwärts gerichteten Randes sitzen jederseits die beiden Kiemenfïden, wïhrend die mittlere Strecke zwischen den Ursprïgen der Kiemenfäden halbmondförmig ausgeschnitten ist. An denjenigen Basalplatten, deren Kiemen abgefallen waren, erschien der kiemenlose Rand und die zunächst dahinter gelegene Fläche des Blattes von einer Anzath paralleler Furchen oder Einschnitte wie zerschlitzt, so dass ich, ehe ich die Kiemenfäden gesehen hatte, eine Bildung wie die des Nackenorganes ron Capitella zu sehen glaubte. Eine streifige Zeichnung zeigrte das Basalblatt auch in dem Falle, in welchem die Kirmenfäden noch an ihm befestigt waren. - Die Lage des Basalblattes war meist eine solche, dass das Blatt der Rückenflïche 
anlay und nach hinten gerichtet war, doch habe ich es auch aufgerichtet und etwas nach rorn gerichtet gelunden. - Die Kiemenfiden, welche jederseits zu zwei an den gefurehten Seitentheilen der Basalplatte entspringen, sind drehrumle, in der gamzen Linge gleichmässig dimme, glatte Füden, welche nach hinten gelegt bis ïber das 12te Borsten tragende Segment hinausreichen (Fig. 12, 13).

Die aus den $1 \pm$ Bzorstenlü̈ker tragenden Segmenten gebildete Körperstrecke, welche an das geschilderte Kopfende sich anschliesst, ist im Allgemeinen drehrund mit einer geringen Anschwellung im Bereich ihrer vorderen Segmente. Die Grössenverhältnisse dieser Segmente ändern sich von vorn nach hinten, denn während die vorderen dieser Segmente fast Treimal breiter als ling sind, beginnt etwa rom sten Segmente an eine Lïngsstreckung, bis das 13te und 1tte Segment mehr als doppelt so lang als breit sind. - Rüicken- und Batuchfliiche der Segmente sind fast gleichmässig hoch gewülbt; die Rüickenfläche erscheint an den Seitenrändern der Segmente scharf begrenzt; denn die Randbildung, welche als durchscheinender Saum die Segmente des Kopfendes flankierte, erhält sich in geringer Ausbildung noch an den Seiten des ersten dieser Segmente, erscheint dann weiterhin auf einen immer mehr zuriicktretenden Rand reduciert, mit welchem die Flanken des Körpers die gleichsam hoch hinauf sich erstreckende Ventralfläche gegen die Rüickenfläche abgrenzen. Mit der Verlängerung der einzelnen Segmente erlischt diese Bildung. Sie erinnert wohl an die Bauchplatten, welche bei Terebelliden auftreten. Die Segmentgrenzen sind zwischen den vorderen Segmenten auf der Ventralfliche lineare scharfe Furchen, auf der Dorsalfläche renig ausgeprïigt; zwischen den hinteren verlängerten Segmenten ringsum sehr viel schwächer (Fig. 11, 12, 13).-Diese 14 vorderen Segmente tragen dorsale kurze kegrelförmige Borstenhöcker, welche jederseits am Seitenrande der Rïickenfläche nahe der vorderen Segmentgrenze so stehen, dass sie hier in einem kleinen Ausschnitte des scharf geprägten Seitemrandes Platz finden und aufwärts gerichtet sind, an den sich streckenden Segmenten die nahe Stellung zur vorderen Segmentgrenze beibehalten, aber mehr seiträrts gerïckt sind. Die in ihnen stehenden Borsten sind bräunlich, einfach, wenigg lang, vor der scharfen Spitze jederseits mit einem breiten gleichfalls spitz auslaufenden Saum versehen; sie bilden ein zusammenliegendes oder wenigg gespreitztes Bündel, welches auf der abgestutzten Endfläche des Borstenhöckers austritt und wenig mehr hervorragt, als dessen Länge beträgt (Fig. 15̃). 
Mit Ausmalme der zwei vorderen Borsten tragenden Sommente traten

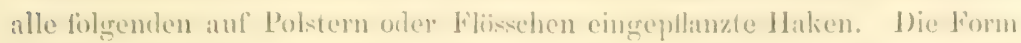

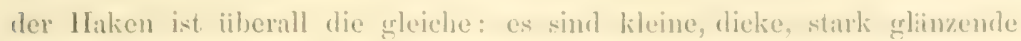
Platten, welehe so lang sind als die Basis breit ist; das gezillnele Endsibck nimmt wenig mehr als die Irillte der Ciesammtlinge ein; die Kante triigt drei heihen von sitgezihnen neben einander, die benten Seitenreihen enthalten hinter dem gemeinsam terminalen je ${ }^{3}$ fist gleich grosse Zïhne und begrenzen eine Mittelreihe, in welcher ich hinter dem 'T'erminalzahn 2 Zaihne untershied. Die Iaken stehen im Alleremeinen in einer Reihe so, dass sie die Basalkante und die Spitzen der Zïhne nach vorn weuden; von ihrer Basis grelıt eine zarte Stiitzlamelle in die Körperwand (Iig. 16). - Eine von allen uibrigen abweichende Stellung nehmen die beichen ersten Iakenreihen ein, das sind die des 5ten umd 6ten Segmentes. Am 5ten Segmente steht auf der Ventralfliiche jederseits neben der Mittellinie ein von anssen nach imen und hinten schräg gegen diese gerichteter schmaler Wulst, welcher auf jeder Iälfte der Segmentfliche iiber diese zum grösseren Theil sich in der Weise erstreckt, dass er mit den Enden fust gleichweit ron der Mittellinie wie rom Seitenrande entfernt bleibt; ich zïhlte auf ihm gegen 40 IIaken. Auf der Tentralfläche des 6ten Segmentes steht ein etwa um die Hälfte kleinerer Wulst, jederseits hart neben der Nittellinie und nahe hinter der vorderen Segmentgrenze (Fig. 11, 13). - Von dem Tten Segrmente an sind diese IIaken tragenden Polster erheblich kleiner und airmer an IIaken; das Polster am 7ten Segmente ist in der Querrichtung liaum doppelt so gross als in der Richtung von hinten nach vorn, ich zählte auf ihn nus S Haken. Weiter nach hinten nimmt die Grösse in der Querrichtung zu, und es erfolgt nun allmählich der Uebergang zum Flösschen. Die Stellung bleibt im Allgemeinen die gleiche; abreichend von derjenigen der beiden ersten Polster stehen alle diese Polster von der Medianlinie so weit mach aussen geriickt, dass sie bei einer Ansicht der Ventralfläche deren Seitenrand erreichen, dabei nahe oder ummittelbar an der rorderen Segmentgrenze und somit etwa in gleicher Höhe mit den Borstenhöckern stehen.

Die hintere der Borstenhöcker entbehrende Körperstrecke ist durch die fast rosenkranzförmig von einander abgeschnürten Segmente auffallend ausgezeichnet. Diese sind so breit, aber kaum halb so lang als die voraufgehenden Borsten tragenden Segmente; die Läuge des einzelnen dieser Segmente erreicht die doppelte Breite derselben nicht ganz. Das einzelne Segment ist dabei drehrund, Bauch- und Rückenfläche gehen ohne Grenze 
in einanter iiber. An den vorteren Segmentgrenzen, oiter auch wohl in denselben, steht jeterseits ein Flisschen, welehes wenig hoch ist und daher kaum vorspringt, digegen in dorsoventraler Richtung an der Flanke des Kïrpers weit atlegedehnt, und dabei wellig gekräuselt ist (Fig. 14); auf scinem treien liande stehen sehr zahlreiche Itaken, auf ihren Stiitzlamellen bisweilen frei vorgeschoben; hier und da hat es - an diesen in Weingeist conservierten Exemplaren - ren Anschein, als ständen die IIaken in mehrfachen leihen oder grehïuft; in der That ist aber doch wohl iiberall nur eine lang ausgedehnte leihe vorhanden, und die Abweichung ron der linearen Anordnung kommt durch die Krïuselung des Flösschens zu Stande.

Ueber die volle Zahl dieser Segmente sorrie iiber die Bildung des Aftersegmentes kamn ich Nichts aussagen.

Die Thiere staken in diinnwandigen, meist collabierten, hier und da auf kiirzere oder lïngere Strecken mit leicht abfallender Schlammschicht bekleideten Röhren, deren Länge die des darin sitzenden Wurmes um ein Vielfaches ihertraf.

\section{MELINNA (MLMGR.).}

\section{Melinna parumdentata, n. sp.}

$$
\text { Taf. 50, Fig. 1-9. }
$$

Differt a IYelinna cristala (Sars) tentaculis 10, dnobus medianis longioribus; labio os attingente transterso; segmentis tribus anticis setigeris brevioribus; tuberculo ad basim ragiuae nullo; crista $\&-10$ dentibus scrrata; branchiis non sulcatis arcte coactis.

Hilb. No. $4 \overline{7}$, depth 321 fms, Lat. $25^{\circ}, 42^{\prime}$ X., Long. $85^{\circ}, 40^{\prime} W^{\prime}$.

Der Wrum, dessen Beschreibung ich hier zu geben habe, ist der Melinu cristafu (Sars) sehr nahe verwandt, immerhin in charakteristischen Zïgen von ihr unterschieten; um das hervortreten zu lassen, beziehe ich mich bei meiner Darstellung dieser westindischen Art zugleich auf diejenige der norwegischen Kuiste, ron welcher die güttinger zoologische Sammlung Exemplare besitzt, welche theils von Malmgren, theils aus dem Museum von Bergen stammen; und auch eine bildliche Darstellung dieser Art habe ich gegeben ('Taf. 49, Fig. $7-10$ ), da die von der Melinna cristata bislang vorhandenen Abbildungen eine wenig grute Torstellung des Thieres zu geben vermögen.

Melimu panmdondata stimmt im IIabitus im Allgemeinen mit der Mclinna cristatu iberein. Beide sind ziemlich lang gestreckte, an vorderen mit Kiemen, Fïhlern und den eigenthümlichen Kragenbildungen ausgeriisteten Körperende verdickt, gegen das hintere Fnde hin um mehr als zwei Drittel 
versehmilert, in der vorderen kiirperstrectic durch die langrortretenden Borstenbiindel, an der hinteren strecke dureh die schmalen rlöschen auserezeichnet.

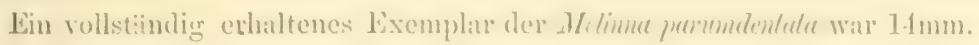
lang und hatte jS Borsten tragende Sogmente; bei cinem S5mm. lamenen

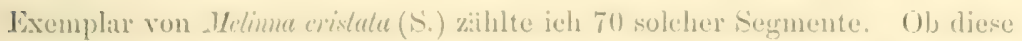
Diflerenz durch ungleiches Alter der untersuchten 'L'hiere bedingt ist, liam ich nicht entscheiden.

Bei beiden Arten ist die vordere Körperstrecke mit 18 l3orstenbindeln ron der hinteren gresondert, und in :ihnlicher fiir die Gattumg charakteristischer 17 eise erfolgt bei beiden die Ausgestaltumg des vorteren Kïperendes im Bereich der vorderen fïnt' l'are von Borstenbiindeln, doch mit solehen Unterschieden, dass hiernach die Arten zu tremen sind.

Bei Melinna cristuta ist diese Körperstrecke verhittnissmissig linger als bei $\boldsymbol{M}$. parmdentuta; der Hantsaum, weleher den trei ersten Borsten tragenden Segmente zugeschrieben wird und den Mialmeren als eine Scheide "vagina" bezeichnet, trï̈gt bei Melina cristata ('Tal. 49, Fig. 8) an seinem Ursprunge ïber und hinter dem dritten Borstenbündel jederseits einen kergel-

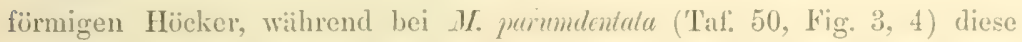
Bildung fehlt. - Die Crista, nach weleher M. Sars die ron ihm gefundene Art benamnte, und welche in der Höhe des dritten Borstenbindels quer ïber die Rïckenlliache lïuft, ist bei Melimu cristutu niedrig und am freien Rande zu 18 Zïhnchen eingeschnitten, von denen bisweilen je 2 näher beisammen stehen oder als Einschnitte eines gemeinsamen Basalstiickes erscheinen (Iaf. 49, Fig. 8); bei Melima pumdentute ist sie höher und trïgt am freien Rande nur $S$ oder 10 grössere Ziiline, welche als dreicckigre, selbst ziptlig auscgezogene Lippchen erscheinen (Taf. 50, Fig. 3, 4).

Auf der Dorsalfläche vor der Crista entspringen auf der IÏ̈he des 3ten an der Seite des vorderen Hautsaumes stehenden Borstenbindels die zu zwei Bündeln vereinigten Kiemen, welche nach allgemeiner Auffassung wohl dem 2 ten Segment-zuzuschreiben sind. Zwischen deren Ursprungsstellen ist bei Melima cristuta die gewölbte Rückentiiche spitz hinein ausgezogen (Tatf. 49, Fig. S), wïhrend bei Melima parmudentuta diese Strecke kiirzer ist und kaum gewölbt erscheint (Taf, 50, Fig. 3). Hinter dem Ursprunge jedes Kiemenbiischels steht der charakteristische nach hinten sehende Haken, welcher in cine nischenförmige Hautfalte zurückgezogen werden kamn; er ist bei M. parumdentala hell hornfarben; bei $\boldsymbol{M}$. cristata wohl meistens dunkler. 
Die im Allgemeinen schlank kegrelfümigen und schwach geringelten Kiemen weichen in Stellung und Form bei beiden Arten von einander ab: bei Melimu eristulu stehen die kiemen eines jeden Bïndels zu je zwei über cinander; bei Melimu parmutentulu stehen sie auf der gemeinsamen Basis in solcher II eise neheneinander, dass sie fast den Abschnitt eines Halbkreises bilden. Bei M. cristulu sind diese Kiemen amnïhernd gleich gross, und zeigten - bei cinem Exemplare sehr deutlich - auf ihrem ventralwärts gerichteten Unfing eine breite von scharfen Rändern begrenzte Lüngsfurche. - Bei Melinna purumdentata waren die Kiemen ungleich lang, jedoch in rerschiedener Weise, demn bei cinem Exemplare war die mediane Kieme wenig lïnger als die ïbrigren, bei einem anderen ïbertraf dagegen der am woitesten lateralwärts stehende Kiemenfaden jederseits die übrigen Kiemen sehr erheblich. Danach sind diese Unterschiede auf ungleiche Contractionszustiunde zuriickzufiilnen. Von ëmer Rimnenbildung am ventralen Umfange habe ich bei den Kiemen der mir vorliegenden Thiere Nichts gresehen; dagegen waren bei einem Exemplare diese Fïden besonders gegen die Spitze hin stark abgeplattet. Die lïngste der Kiemen reichte zuriickgelegt bei Melina parumlentata bis zum 11ten Borsten tragenden Segment.

Der vor dem Ursprung der Kiemen gelegene Theil der Rückenflïche des Vorderendes erscheint mir bei Mclinna parumdentata durch 2 Querfurchen dreitheilig, bei Melima cristuta zweitheilig zu sein; die von Surs bei Mclinn cristala beschriebenen 2 longitudinalen Furchen, welche die vorderste dieser Strecken feldern, sehe ich nur in einem Falle bei Melinna parumdentuta ganz schwach angedeutet. Malmgren hatte der Gattung Melinniı einen durch Furchen getrennten Frontaltheil des Kopfluppens abgesprochen; das ist gewiss nicht zutreffend, unter besonderen Verhältnissen tritt aber diese Furchenbildung vielleicht zuriick, und solche Formen mag Malmgren vor sich grehabt haben. Fïr mich ist das ein Grund auf diese Gestaltung des Kopflappens für die Unterscheidung der Arten kein grosses Gewicht zu legen.

Dass die Fühler bei Melinn cristata, wie Sars ancriebt, in zwei Reihen geordnet sein sollen, finde ich bei keinem der mir vorliegenden Thiere. Diese haben, wie die Exemplare der 1 . parumdentata, bei welchen die Fühler ausgestreckt sind, diese in einer Querreihe stehen, und zwar so, dass die medianen läuger als die lateralen sind (Taf. 49, Fig. 7, Taf. 50, Fig. 1, 2.) Dagegen ist ein Zahlenunterschied zu bemerken; ich finde bei einem grut erhaltenen Exemplar von Mctimu cristata 12, bei Nclima parmatentata 10 solcher Füden; bei ersterer Art sind die 4 medianen, bei lezterer nur die 
2 medianen Fïden linger als die äuseren Füden. Alle Fïiden sind eylindrisch und am linde stumpen alygerundet.

Auf der ventraten Flike tragen beite Arten hinter der Mlundiffinung ein

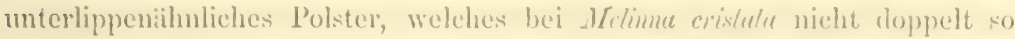
breit als lang und am Vorderimde hallymondfïmir convex grerandet (Tat:

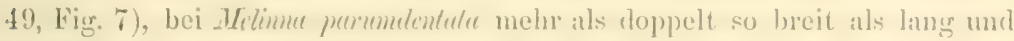
an Vorderrande selhwach ausgerandet, dem Hinterrande parallel war. (Tax: 50, Livg. 1, 2).

Die Borsten dieser vorderen Kürperstrecke sind dergestalt und awar bei beiden $A$ rten nahezu grleich rertheilt, dass, wie solehes bereits in den frihleren Beschreibungen erwïhnt ist, an dem Hantsaume, welcher danach den drei ersten Segmenten zufillt, muterhalb der freien Kante hinter cinander :3 ron rorn nach hinten an Grösse zunchmende I3iindel jederseits so gestellt sind, dass sie ohne Bildung eines Borstenhü̈kers über die Wliche sich erheben, ihre Spitzen nach vorn wendend und der Körperflïche platt anliegend; hinter diesen folgt, der Höhe nach etwa der Basis der Crista entsprechend, jederseits ein dorsales und rentrales Borstenbiindel, beide ohne einen Borstenhöcker nur aus wenigen kurzen Borsten bestehend, welehe wie die vorangehenden und die folgenden dorsalen eapillar sind, mit gresïumter Endspitze. Am 5ten borstentragenden Segmente erscheint damn die Borstenbildung mal Stellung, welche sich an der Reihe der nächsten Segmente findet: unter einem dorsalen Bündel capillarer gesüumter Borsten, welchem bei MI. parkmdentuta ein ausgesprochener Iï̈ker noch fehlt, steht eine kurze Querreihe von Haken, wie sie weiterhin auf den Flïsschen sich finden.

Die Segmente, welche den folgenden Körpertheil zusammensetzen, haben

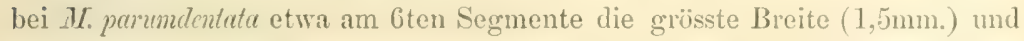
nehmen von da bis zum (etwa $0,6 \mathrm{~mm}$. breiten) Schwanzende gleichmässig ab. Damit stimmt auch der Habitus der $\boldsymbol{M}$. cristala überein. Nun zeighten mir einige Exemplare der M. parumdentata ein Grössenverhältniss in den Segrmenten, welches ich bei der M. cristuta nicht beobachtet habe. Waihrend die vorderen der Segmente mit Capillarborsten etwa sechsmal breiter als lang sind, strecken sich die folgenden, bis die letzten dieser Categorie etwa so lang als breit sind; das habe ich bei Melina cristata nicht gesehen und muss unentschieden lassen, ob dies Grössenverbältniss nur ein individuelles Auftreten ist oder grössere Bedeutung hat. In beiden Arten verkiirzen sich hinter dem letzten der Borsten tragenden Segmente die nur mit Haken bewehrten Segmente rasch, so dass sie schmäler werden, etwa sechsmal breiter 
als lang sind. Bei Afelinna prommentule tritt dieses Verhialtniss durch den Geyensit\% zu den vorangehenden Segmenten stark hervor ('Taf. 50, Fig. 1).

Die segmentyrenzen treten im Allgemeinen auf der ventralen Fläche stïrker als auf der dorsalen hervor, schairfer auch an der vorderen mit Bosstenbiindehn versehenen Körperstrecke als an der hinteren Flössehen tragenden; die quantitativen Unterschiede, welche sich dabei zwischen beiden Arten bemerklich machen, so dass diese Segmentfurchen bei Mr. cristata schïirfer als bei $\%$. purmmpuctula ausgeprägt sind, halte ich fïr von untergeordneter und individueller Bedeutung. - Auf' der ventralen Fliche der vorderen Segmente tritt bei beiden Arten ein schmaler quer über die Mitte verlaufender durch lichtere Füirbung ausgezeichneter Streif auf, welcher wohl einem Giirtel von Driisenzellen entspricht; auch diese Bildung ist bei den Exemplaren der Melimu cristula schärfer als bei denen der M. parumdentata ausgepriigt; bei beiden beginnt sie am 5ten borstentragenden Segment, und ist bis in die Gegend des 14ten Segmentes zu verfolgen, an den hinteren dieser Segmente allmählich schwächer werdend und so sich verlierend.

Die Borsten dieser Streeke sind in Hijekern stehende capillare Borsten und auf Flösschen stehende Haken. Borstenhöcker und Flösschen nehmen ron vorn nach hinten an Grösse zu, erstere brechen mit dem 18ten Borstenbiindel in allen mir vorliegenden Exemplaren beider Arten ab, während die Flösschen an den folgenden Segmenten weiter gehen.-Die Borstenhücker sind in beiden Arten kegelförmig, an der Spitze abgestumpft, nach hinten gerendet; mit denfrei vorragenden Borsten treten sie bei grösster Ausbildung fast so weit vor, als die halbe Breite des Segmentes beträgt. Die in ihmen stehenden Borsten sind einfach capillar mit schwachem Saum auf jeder Seite der Endstrecke.

Die Flösschen treten zuerst unter dem 5ten Borstenbündel als kaum prominierende quere Polster auf, nehmen dann, indem sie etwas von dem dorsalen Borstenbïndel sich entfernen und mehr der Bauchfläche nähern, die nusgesprochene Form der Flosse an, welche aber an allen diesen Segmenten breiter als lang ist, die halbe Lïnge des Segmentes nicht iibertrifft und kaum iiber die Segmentgrenze nuch hinten ragt. Mit der wachsenden Breite nimmt gleichmässig die Zahl der eingepflanzten Haken zu; diese haben die frewöhnliche in der Abbildung dargestellte Form mit Zïhnen, deren Spitzen wie der basale Rand des Ifakens nach vorn gerichtet sind (Taf. 50, Fig. 7).

Die hinter dem 18ten Borstenbündel beginnende Strecke des Körpers ist bei beiden Arten durch die Abnahme des Breitendurchmessers und die 


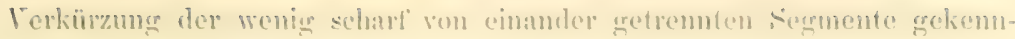

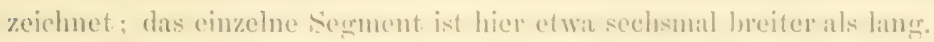

An stelle der Borsten diihrenten Heicker hesitzen diese sermente in greicher llähe mit den Borstenhïekern der vorhergehenten Senmente cin kleines, bisweilen durch weissliche Firhung stirker herrortretentes Küitchen, dem ersten $\Lambda$ nselieine nach das Rudiment eines borstenlos gewordenen Borstenhëekers, wahseheinlieher jerloch einen rudimentiiren Cirrus; dafir

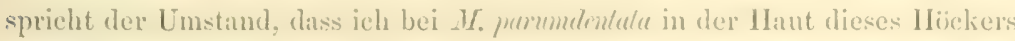
dicht gedräingte kleine Yellen mit grossen Kernen fimd, wie sie wolsl an den Orten einer Nervenendausbreitumgr vorkommen. Genaneres wa bei dem Erhaltumgsustande der Exemplare nieht zu ermittehn (Taf. 50, Fig. S).- D) ie Flösschen, die noch weiter als an den vorderen Segmenten ventralwäts geriekt sind, sind durch einen niedrigen, oft schwer wahnehmbaren Hautwulst, welcher vou der dorsalen Ecke ihrer Basis ausgreht, mit diesem Küitchen verbunden. Damit ist eine Bildumg regeben, welche in viel stäkerer Auspräigung in anderen typischen Gattungen der Ampharetiden sich findet. - Die Flösschen selbst werden an diesen Segmenten zu mach hinten gerichteten mehr oder minder abstehenden Platten, welche doppelt so lang als breit sind, die Lünge ihres Segmentes aber nicht ganz erreichen. - Die auf der Endkante stehenden Haken sind an Zahl betrïhtlich rerringert, sinken bis auf 8 herunter. Ton Mclima parmulentata habe ich dargestellt, wie die Form dieser Borsten in der Reihe der Flösschen allmählich zu derjenigen wird, welche auf dem letzten Flisschen als erheblich klemere aber dickere Haken stehen. bei welchem ror der Basalecke ein grosser stumpfer Sigezahn, vor diesem zwei oder drei Querreihen Klemer Zahnspitzen stehen (Taf. 50, Fig. 8, $8^{3}$ ). Diese Flösschen sind aber dadurch ausgezeichnet, dass in ihnen 2 aciculaartige feine und schlanke Borsten liegen, die mit einer Scheide versehen weit iiber das Flösschen hinaus in den Kürper hineinragen (Taf. 50, Figg. 8, y).

In beiden Arten ist das Aftersegment am Ende wulstig rerdickt, und trägt keine Cirren. Die in den Abbildungen daran auftretenden Unterschiede zwischen $\boldsymbol{M}$. cristata und parumctenlata halte ich für berleutungslos.

Die Exemplare der Metima parmetentatu staken in derben dickwandigen Schlammröhren.

Mclima cristalu (S.), deren Verbreitung von den europäischen Küsten bis in den arctischen Kreis hinein nachrewiesen, ist nach den Angaben Verrill's ${ }^{1}$ an der Ostküste Nordamerikas (Küste von New England, Vineyard Sound,

1. Cir. A. F. Vorrill, New England Annelitia Pt. I. (Transact. of the Connecticut Acadenry, Vol. IV, Pt. 2). New Haren, 1881. 
Casco Bay (ieorge's Bank) weit verbreitet, dameben hat Webster ${ }^{1}$ eine zweite Art. Methmu muculutu, unterschieden, welche an der Kïste Virginiens gesammelt wurle. Aus der kurzen Beschreibung ist nicht zu ersehen, wie diese Art etwa zu der Melinna parmutentulu steht; in der Zathl der Segmente der hinteren Kïrperstrecke (55) steht sie der $\boldsymbol{M}$. cristate nîher als der $\boldsymbol{M}$. purmulentuta; es wird iiberhaupt einer genaueren Untersuchung dieser Form bediirlen, welehe im Leben wie andere Verwandte auffillend gefïbt ist, um sie von der nordischen M. cristule zu unterseheiden. Damn wird sich vielleicht herausstellen, dass hier ein, auch geographisch interessantes, Vermittlungsglied zwischen den beiden Arten vorliegt, welche ich geschildert habe. - Weiter ist aber dam zu vergleichen die von v. Marenzeller ${ }^{2}$ beschriebene Mel. atrialicu, die in ganz geringer Tiefe lebt, und die dieser wohl nahe stehende Melima pulmala, Gr. - Fïr die Mr. adrüutica wird neben der Form der Lippe des Bucealsegmentes und den feinen auf Kopflappen und Buccalsegment stehenden bramen Punkten, vielleicht auch die Zähnelung der Haken und die geringe Ausbildung des gezïhnelten Stumes der queren Nackenfalte wichtig; allein das ist ein noch zu prifender offenbar sehr schwankender Charakter, da v. Marenzeller dessen ungleiche Ausbildung mit wachsendem Alter bereits angiebt, und andererseits Levinsen ${ }^{3}$ _ auf die hier herrschende Variabilität hingewiesen hat. Auch die von mir aus der Ausbeute der Porcupine-Expedition erwähnte Melima cristetr, welche aus beträchtlicher 'Liefe stammt, zeigt hierin einen Unterschied; denn nach meinen darüber gremachten Aufzeichnungen besassen diese Thiere 12-14 schmal dreieckige Ziilune an dem Hautkamme, also weniger als typische Exemplare der $\boldsymbol{M}$. cristata (S.), aber mehr als die M. parumdentata. Alles weist wohl darauf hin, dass es sich in einer sonst wohl abgegrenzten Gattung um zahlreiche Formen mit flüssigen Unterschieden handelt.

\section{AMAGE (MLgN.) \\ Amage tumida, n. sp.}

Taf. 48, Fig. 10-19.

Pallida, antice crassa tumida, postice attenuata, segmentis 25. - Lobus cephalicus in area frontuli mediana antice longitudinaliter sulcatus, tentacula laevia plerumque brevia tegens. Seg-

III. E. Welster, On the Annelida of the Virrinian Const (Transact, of the Albany Institute, Vol. IX), parg. 61. S. A.

2 v. Marensoller, Zur Kenntniss der alriatischen Anneliden. (Sitzgsber, der k. Akad, der Wiss. in Wien, I Abth., Bu. LXIX, 1874), pag. 6G, Tuf. VII, Hig. 6.

${ }^{3}$ Levinsen, Systematisk-geografisk Oversigt, a. a. O. pag. 163. 


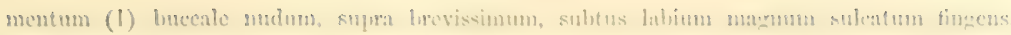

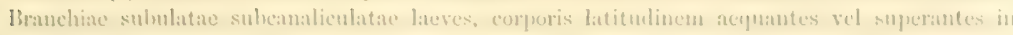

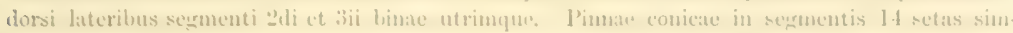
pliees mugnste limbatas gerentes, prima mimeissima, seemula et qertia paulo majores a latere

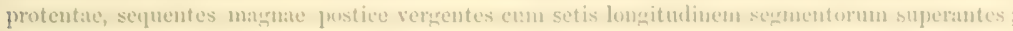

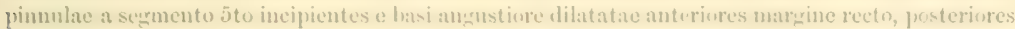
emaryinatate in lacinian eirrifurmem superiorem productae, seriem simplicen uncinorum dentibns 5 uni-vel pluriseriatim pectimatorm gerentes. Śrmentum analu cirros 22 anales gorens.

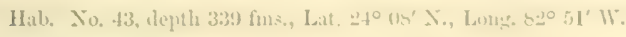

Der schwach gelbliche diimmandige Körper dieser Würmer zeigt in allen Exemplaren einen ziemlich scharf ausgesprochenen Gegensatz zwischen einer rorderen dickeren und einer erheblich schmileren hinteren Körperstrecke, ohne dass die Grenze dieser beiden Strecken mit dem durch den Enterselnied der Ruder bedingten Gegensatze zusammenfiele. Bei einem etwa 17mm. langen Exemplare war die grösste Breite des vorderen anf der Ritickenflaiche hoch gewölbten Körperabschnittes 6mm., wïhrend das Körperendstiick fist auf ein Viertel dieser Höhe und Breite reduciert wird; die Verschmailerung des Körpers erfolgt auf dem Uebergang rom 11ten zum 12ten Segment und erreicht bald ihr Maximum (Taf. 48, Fig. 10).

Der Körper lrat im Ganzen 25 Segmente, von denen das erste und das Aftersegment borstenlos sind, während das 2 te bis 14te Segment in kegrelförmigen Höckern Capillarborsten, das 5te bis vorletzte Hakenborsten auf Flösschen tragen.

Ueber die Auffassung und Benennung der Körpertheile, welche den rorderen Körperabschnitt bilden und die Mundöfnung umgeben, kamm man in Zweifel sein; für das Verständniss meiner Beschreibung bemerke ich folgrendes. Als erstes Segment fasse ich denjenigen ringförmigen Kürpertheil auf', welcher auf der Rückenfläche als schmale Binde vor dem Ursprung der vorderen Kiemen sichtbar ist, an den Flanken des Körpers sich rerbreitert und auf der Ventralfïiche zu einer grossen lippenartig nach vorn sich erstreckenden Platte sich erweitert, welche durch eine nicht immer gleich stark ausgeprägte Querfurche in einen hinteren kïrzeren und vorderen längreren längsgefurchten Theil gesondert ist (Fig. 13, 14).

Die auf der Rückenfläche vor diesem Buccalsegment gelegene Platte fasse ich trotz der an ihr auftretenden trennenden Furchen als eine einheitliche auf, und bezeichne sie als Kopflappen, vielleicht richtiger nur als einen Theil desselben, unter dessen Torderrande die meist kurz erscheinenden oder ganz eingezogenen Tentakel stehen. Auf dieser gewölbten Platte ist durch eine hufeisenförmige Furche ein mittleres Feld so ausgeschnitten, 
dass dieses die mittlere Strecke des Vordermules dieser Platte bildet, von deren Linge es etwa die Hailfte eimimmt; dieses Feld ist weniger hoch gewïlbt als der übrige 'Theil des Kopllappens unl fiillt mach dem Vorderrande hin schrig ab; drei lingslaufende durch gerade Furchen von einander gesonderte gleichbreite Wüilste lassen die rorlere Hälfte dieses Felfles eigenthimlich sculptiert erscheinen (Fig. 1t).

Die einen Bïschel bildenden 'Tentakel sind cylindrische, glatte und stumplie Fïden, welche unter den Vorderande des Kopflappens hervortreten, in einem fialle etwa so lang als die Lïnge des Kopflappens ist (Fig. 13); in einem anderen Falle ragten die Enden iber den Vorderrand desselben nicht hinans. In einem dritten Falle waren Tentakel iberhaupt nicht sichtbar; als ich aber die oben erwïhnte "Unterlippe" aufhob und nach hinten zurickbog, was in der ventralen Querfurche des Bucealsegmentes leicht von Statten ging, sah ich in der num frei gelegten kreisförmiggen Mundüffnumg am dorsalen Umfange in zwei Gruppen vertheilt die Spitzen weniger Fäden kam hervoragen. Offenbar sind also wie bei den verwandten Arten auch bei dieser die 'l'entakel zuriickziehbar. - Von einem Blatte, das bei anderen Arten dieser Gruppe mit den Tentakeln so verbunden ist, dass sie an ihm zu entspringen scheinen, habe ich hier Nichts gesehen. Es ist möglich, dass solch ein Blatt in der That vorhanden, aber in allen mir vorliegenden Thieren völlig in den Schlund eingezogen ist; dann aber ist es wahrscheinlich auch im vorgestreckten Zustande von nur geringer Grösse.

Mit solcher Auffassung des Kopflappen und des Bucealsegmentes zähle ich nun die folgenden Segmente derartig, dass ich dem 2ten bis 4 ten Segrmente den Besitz von Flösschen abspreche, dem 2ten und 3ten denjenigen von Kiemen zuschreibe. - Das 2te bis 4te Segment sind im Allgemeinen kürzer als die folgenden Segmente; ich fand sie etwa 5-6mal breiter als lang; doch wechseln diese Dimensionen offenbar nach dem Contractionszustande; ihre durch die Kiemen meist ganz bedeckte Riuckenfliche ist wie die der folgenden Segmente hoch gewölbt, glatt und ohne deutlich heraustretende Segmentgrenzen; die Bauchfläche erscheint polsterförmig erhoben, ohne dass eigentliche Bauchpolster gebildet werden, und ist zum Theil durch Querfurchen, welche in ihrer Ausbildung wohl von den Contractionszuständen abhängen, sekundär getheilt. Die Ruder dieser 3 Segmente sind kleine kegelfürmige Iöcker nit je einem kleinen Büindel feiner farbloser capillarer Borsten; das erste Borstenbindel ist so klein, dass es nur schwer gefunden wird. - Paleen fehlen (Fig. 11, 13, 15). 


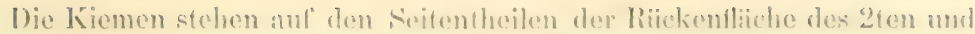

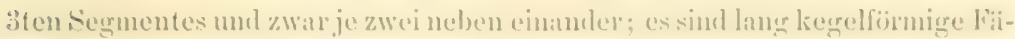

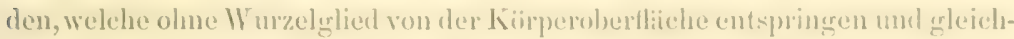

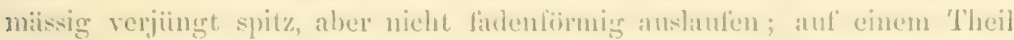
ihres Unfunges sind sie der Libnge nach rinnenfoimg vertictt; wie weit anf diese Bildung die durch Aufbewahrung in $1 \mathrm{~T}$ eingeist erfolghe Schrumptung grewirkt hat, bleibt festzustellen weiteren Beobachtungen vorbehalten. Die lainge der Kienen übertrifh die grösste Körperbreite. (Fig. 11, 13, 14).

Tom üten Segmente ab tragen alle folgrenden Segmente ventrale Flüss. chen unt einer Reihe von Hakenborsten; neben diesen steht his zum 15ten Segment ein kegrelfürmiger Häcker mit einem I3iindel grosser nach hinten gerichteter Borsten. Diese Ruderfortsiitze sind mit denen der drei rorderen Segmente gleichwerthig und nur durch die erheblich berlentendere Grösse des IÏ̈kers und der Borsten von ihnen untersehieden; sie stehen ummittelbar iiber dem oberen Rande der Flösschen; das einzelne Borstenbindel reicht bei grösster Entwicklung nach hinten angelegt fust bis zur hinteren Grenze des folgenden Segrmentes; die Borsten sind einfach, schlank zugespitzt und schwaelı gesïint.

Die ventralen Flösselien an den Ruder tragenden Segmenten sind dex Segmentfläche dicht anliegende Blättchen, welche an dem mach hinten gerichteten geraden oder schwach convexen freien Rande breiter als an der Basis und im Ganzen breiter als in der Richtung von vorn nach hinten lang sind; die vorderen Flösschen sind etwas kiurzer und schmäler als die folgenden, sowie, wenn auch nicht in gleichem Masse, die letzten dieser Flösschen etwas kleiner als die mittleren sind. Parallel dem freien liande lïuft auf dem Flösschen die einfache Reihe der Hakenborsten, von denen ich auf einem der grösseren Flösschen gegen 130 zïhlte; diese stehen alle in gleicher Richtung und tragen auf der schmalen freien Kante 5 nach rom gerichtete spitze Säigezïhne vor der abgerundeten Ecke der Basis. (Figr. 18).

An den 9 Segmenten, welche vor dem Aftersegment stehen und keine Capillarborsten tragen, weicht die Form der Flösschen von denen der vorderen Segmente ab. Das Flösschen erscheint bei oberflächlicher Betrachtung allerdings kaum verschieden zu seim, und der als solches sich darstellende Fortsatz an den Seiten dieser Segmente, welcher die gleiche Lagerung wie die Flösschen der vorderen Segmente hat, ist so gross wie diese, ja scheint, da die Segmente nach linten an Grösse abnehmen, cher vergrössert zu sein. An seinem freien Rande aber macht sich auf der dorsalen Ecke eine nicht ganz 
gleichmilssigg gestaltete ziptellömige Verlingerung geltend, und eine genaue Besichtigung dieses Roudes liisst erkemen, dass derjenige 'Theil, welcher die Haken trïgt und als soleher dem ganzen hande der vorderen Flüsschen entspricht, auf einen kleinen ventrilwäirts stehenden Abschnitt des Flösschens beschnänkt ist. Der an einzelnen der Flisschen scheinbar an einer dorsalen Eecke des Ramles stehente Zipfel steht an anderen Segmenten auf dem basalen 'Theile des Flüsschens oder' erscheint auch, wie ganz vom Flösschen abgetrennt, unmittelbar iiber dessen Basis, damn aber wohl durch eine Wulstbildung mit dieser verbunden (Fig. 12, 16). Dieses Verhalten dentet an, dass diesem Ziptel eine besondere, wenigstens morphologische Bedeutung zukommt, und da ist es unzweifelhaft, dass er den rudimentiiren Cirrus anderer Amphareteen darstellt, der hier dem Flüsschen bis zur Vereinigung nahe rüickt, während er sonst, wie bei Ielima, un die Körperdicke von ihm getrennt bleibt. Es entspricht dis der engen Nachbarschaft, in welcher an den vorderen Segmenten der Borstenhöcker und das Flösschen zu einander stehen; an dem ersten der borstenlozen Segmente steht der Höcker ganz in gleicher Höhe mit dem vorangehenden Borstenhöcker; eine morphologische Gleichwerthigkeit derselben ist daraus wohl nicht ohne Weiteres herzuleiten. - Die Hitkenborsten auf diesen hinteren Flösschen bilden in nur geringer Zahl eine kurze Reihe; sie sind etwas kleiner als die der vorderen Flösschen, dicker und tragen kleine Sägezähnchen in mehrfachen Längsreihen auf der breiten Schneide (Fig. 19).

Das Aftersegment ist sehr kurz; es trïgt jederseits neben der terminalen Afteröffnung einen Aftercirrus, der die Form eines kurzen und stumpfen Hückers hat, welcher die Lünge des Segmentes nicht überschreitet. (Fig. 17).

Die Thiere wurden zusammen mit Amplicteis procera und Auchenoplax crinita gefunden, zum Theil in glatten, mässig dickwandigen Schlammröhren.

Die Art ist augenscheinlich der Amage auricula (Mlgn.), ${ }^{1}$ welche an der Kiiste von Bohuslin in einer Tiefe von 100-120 Faden gefunden wurde, sehr nahe verwandt. Ich unterscheide sie zunächst nach der ungleichen Zahl der nur Flösschen tragenden Segrnente, bei Amage auricula 8, bei Amage tumida 9 . Wichtiger als das ist die Differenz in der Bildung des Kopflappens, denn Malmgren erwälnt weder in Wort noch Bild, dass A. auricula die Lüingsfurchen des Koplappens besitze, welche bei A. tumide so auffallend sind, dagregen spricht er (in der Diagnose der Gattung, welche in Bezug darauf wohl zu ändern wäre) von zwei kleinen Vorspriingen auf dem hinteren Theile des 
Kopflappens, welehe ich bei meiner $\Delta$ t nicht gerehen halse. Levinsen ${ }^{2}$ fat

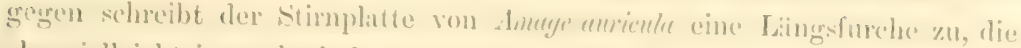

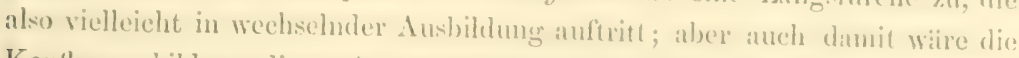
Koptlappenbildung dieser Art ron derjenigen bei Amuge lumild almweichend.

Was im Uebrigen als cin Unterschied in den Bescheihungen Matmerens von der A. anvicule und der meinigen von A. lumilu erscheinen kionnte, ist wohl nur von formaler Bedeutumg, insofern Milmgren die Zusammensetzung des Koptendes anders als ich atuftasst. Fir liisst cin erstes Sergment, welches aul der Ventraltliche die Lippe bildet, mit einem zweiten natekten granz verschmolzen sein und weist danach die Kiemen dem Sten und 4 ten Segmente zur. Ich riehe die Lippenbildung zum ersten Sermente, welches mit rlem 2ten nackten Malmgren's offenbar identisch ist, und rechne die Kiemen zum 2ten und 3ten Segmente. Die Malmgren'sche Abbildung Fig. 72 auf 'Taf. XXY giebt eine Darstellung, wie ich sie acceptieren kann; in Fig. T2 D scheint unter den 'Tentakeln der bei anderen Amphareteen gefundene retractile Lappen gezeichnet zu seim, welchen ich bei Amuge tumidu nicht gesehen lnabe. Die Segmenteintheilung aber, welche in Malmgrens Fig. $72 \mathrm{~A}$ in der Ansicht der Rückenfliche eines Thieres ron dem Kopftheile desselben gegeben ist, kann ich auf die mir vorliegenden Thiere nicht übertragen, und das bestïrkt mich in der Meinung, dass die Bildung des Kopflappens bei Amage andiculu eine andere als bei Amage tumidu ist.

Ich nehme die Gattung Amage im Malmgren'schen Sime an, und kamn der Correctur nicht zustimmen, welche Levinsen damit vorgenommen. Malmgren hat das 3te Segment als ein borstentragendes bezeichnet, wähend Levinsen ${ }^{2}$ dasselbe als borstenlos, im ausgesprochenen Gegensatz zu Malmgren's Angabe hinstellt. Da das 3te Segment Malmgren's nach meiner Zählung das zweite ist, so muss ich fuir Amage tumida die Malmgren'sche Angabe durchaus bestätigen, denn dieses Segment trägt ein, wenn auch kleines, so doch dentliches Borstenbindel in einem Parapodium. Sollte die Differenz in den Angaben auf emen Altersunterschied der untersuchten Thiere zurückzufülren sein?

1 Levinsen, Systematisk-geografisk Orersigt a. a. O., pag. 162.

2 Lerinsen, Systematisk-geografisk Orersigt a. a. 0., pag. 162. 
AMPHICTLLS, Grube.

Amphicteis procera, 11. sp.

T'uf. 4s, Fig. 1-?.

Longa postice versus sensim acuminata, segmentis eirca 45 ; lobus cephalicus lacvis in margine recto utrimque in tuberculum parvum productus; tentreula simul cum labio plicatili retractilia mumerosi laevia; seguentum buecale subtus labium mediocro fingens; flabellum palearum eirea 50 haud ita longarum. Tubercula setigera utrimque 14; branchiae utrimque 4 subulatae elongatae, prima et secunda juxta cristan cutaneam dorsalem transversam supra fasciculum setarum primun, tertia suprn secundum, quarta supra tertium fasciculum setarum insidentes. - Pinnula a tuberculo setigero tto incipientes latitudine inaequales, in segmentis posticis breves crassae; uneini anteriores denticnlis 5 uniseriatim, posticae bi- rel triseriatim serrati. 'l'uberculum cirriforme a pinnula prorsus remotum in segmentis posterioribus, nltimis exceptis. Segmentum anale prae margine lobato cirros anales 2 filiformes longos gerens.

Hhab. : دo. 43 , lepth 339 fms., Lat. $21^{\circ} \mathrm{S}^{\prime} \mathrm{N}$., Long. $83^{\circ} 51^{\prime} \mathrm{W}$.

Der fuhlgelbe oder weissliche Körper ist lang gestreckt und bei den verschiedenen Exemplaren ungleichmïssigr stark nach hinten verdiinnt, bei keinem war durch den Unterschied der Dicke eine Sonderung des vorderen vom linteren Körpertheile ausgesprochen; der im Allgemeinen schlanke Habitus des Thieres ist durch die grosse Länge und Zahl der Segmente der hinteren Körperstrecke hervorgerufen. Ueber das Kopfende ragen die beiden um die Körperbreite von einander entfernten Bündel der starren an den Enden aufgerollten Kiemenfïden hervor; die glïnzenden Bündel der langen Capillarborsten zeichnen die vordere, die Flösschen die hintere Körperstrecke aus; beide sind fast drehrund, an den Segmentgrenzen nicht, oder nur unbedeutend eingeschnürt. Dass die Segmentierung des Körpers hervortritt, bewirken die Borstenbündel, mehr noch am hinteren Körpertheil die Flösschen, welche oft eckig hervorspringen und wie sie am hinteren Rand der Segmente stehen, die Anwesenheit einer tieferen Segmentfurche vortïuschen. - Ein Exemplar von 33,5mm. Lïnge war rom 3,5mm hinten $1 \mathrm{~mm}$. dick und hatte 42 Segmente, bei einem anderen Exemplare zählte ich 45 Segmente; der Unterschied liegt in der ungleichen Anzahl der Segmente der hinteren Körperstrecke. - Die Dimensionen der einzelnen Segmente verändern sich von vorn nach hinten derart, dass die vorderen etwa sechsmal breiter als lang sind, im Bereiche der vorderen Körperstrecke aber bereits sich bei abnehmender Breite strecken, so dass die letzten der Capillarborsten tragenden etwa $\frac{1}{2}$ mal breiter als lang sind; die vorderen der nur Flösschen tragenden 
Segmente simel edwa so lang als breit, bis vor dem deterente die Sermentgremzen sich so mahe rieken, dass and der Austehmung von der Breite des Livipers 5 bis 6 sergmente stehen ('Tat. 48, Wig. 1).

Als hoptlappen bezeichne ich die dorsale vorderste allscitig abregrenzte Fliche, unter deren lrorderrande vor und iiber einem grefalteten und einzichlotren Lappen die 'lentakel entepringen, und verbinde damit dats Buecalsegment, welches anf der Ventrallaiche die Mundiblinung oder die in diese einzichbare Oberlippe begrenzt, aul" der. Dorsallliehe aber als quere l'atte erseheint, welehe danach auch als eine hintere Strecke des koptlappens bezeichnet werten kamn. Die Formen und Verhailtnisse wechseln sehr nach den Contractionsverhältnissen; so ist der retractile Mundlappen in einem Falle weit ausgedehnt, faltig der Linge nach zusammengelegt umd iiber der Mundieflnung fast bis zur Beriihrung seiner gegeniberstehenden Ribuder hohI zusammengebogen, in einem anderen Falle so weit eingezogen, dass kaum cin Rand daron sichthar ist. In diesem Falle ist auch die granze Reihe der 'T'entakel soweit eingezogen, dass nur deren Spitzen eben im Eingange der Nundöftumg herrorragen. Bei entfalteter Lippe ragen die Tentakel weit heraus, ich zithlte dann etwa 20 Fiden, welche in einer queren Doppelreihe iiber dem Lappen und unter dem Torderrande des Koptlappens so stehen, dass die in der Vorderreihe kurz sind, einzelne kaum ibber den Lappenrand hinausragen, diejenigen der hinteren Reihe zum 'Theil sehr viel länger, mannigfaltig gekrimmt und zusammengedreht sind, ausgedehnt iiber die Spitzen der Kiemen eine gute Stracke weit hinausragen; die Fäden sind drehrund und glatt, die kïrzeren oder stark contrahierten an der Spitze wohl schwach kolbig aufigetrieben (Fig. 2, 3).

Buccalsegment und Kopflappen wechseln gleichmässig mit den Contractionszuständen; die ventrale Fliiche des Buccilsegmentes bildet hinter der Nundöffnmg einen schmalen Giirtel, welcher in der Mitte des Torderrandes bald mehr bald weniger stark convex nach rom gegen den Mundeingang erweitert ist und dadurch nach den Seiten hin verschmälert erscheint; zu einer durch eine Querfurche scharf gesonderten Lippenbildung kommt es an den von mir gesehenen Thieren nicht. Ein weiss oder gelb gefïrbter Streif, oftenbar ein Gürtel von Drisenzellen, läuft quer uiber seine Fläche.

Die Gesammtheit der dorsalen Fläche des Buccalsegmentes mol Kopflappens ist stark abschuissig nach rorn geneigt und etma so breit als lang. Der durch eine Querfurche rom Kopflappen abgesetzte Theil des Buccalsegmentes ist kürzer als der Kopflappen, stark convex gewölbt; die nach rorn abfallende 
Koptlappenfliche ist in der grleichen Richtung etwas verschmillert, fast eben oder bei grewisem Contractionszustande in der Mlitte der Liinge nach rinnenlirmig vertieft; ih. Vorderrand gerade abgestutzt, die :insseren Ecken desselben etwas höekerartig ausgezogen; bei starker Contraction und bei dur Rimenbildung aut" der lilähe springen diese Eeken wie zwei kleine Ilömehen ror; der ganze Vorderrand mitsammt den Ecken bildet eine rorspringende Kante, unter weleher die Urspringe der Tentakeln stehen, und welehe zumal bei eingezogenem Mundlappen einen scharfkantigen Vorderrand bildet.

Die vordere Körperstrecke umfasst den Bezirk, welcher 4 Paar von Kiemenfiiden, jederseits einen Paleenfïcher und 14 Bïndel capillarer Borsten träigt. Die Feststellung der Segmentzahl dieser Strecke ist insofern nicht ganz sicher, als ich, wie oben bereits erwïhnt, ungewiss dariber bin, ob der Paleenfächer und das erste Borstenbündel auf ein oder zwei Segmente zu vertheilen sind; ich entscheide mich für die erstere Auffassung.

Der Bezirk, auf welchem die Kiemen stehen, umfasst damn drei Segmente. Er ist auf der Rückenflüche hoch gewölbt, fast glatt und ohne deutlich ansgeprïgte Segmentgrenzen, roru durch einen scharf vorspringenden an den Ecken etwas erweiterten und dadurch im Ganzen schwach concav ausgerandeten Hautsaum begrenzt, trïgt auf dem Uebergang zu den Seitentheilen die Kiemen und unter diesen hinter einander die Paleen und Borstenbündel, anf der Ventralflikche die dicht auf einander geschobenen Grenzen der Segmente, welche hier wie auf den folgenden Polsterbildung zeigen, bei starker Contraction allerdings weniger deutlich.

Die Kiemen sind schlank kegelförmige Fäden, welche fist peitschenförmig in einen Endfaden auslaufen, der in mannigfaltigster Weise aufrerollt oder gekräuselt ist; ein erheblicher Luingenunterschied der Fïden ist kaum zu bemerken; zurïckgelegt reicht ein Kiemenfaden etwa bis zum 11ten Segmente. Die Füden stehen, durch die ganze Rüickenbreite von einander getrennt, jederseits so, dass die beiden vordersten neben einander in der Verlängerung des häutigen Vorderrandes des ersten Borsten tragenden Segmentes, dahinter nuf dem zweiten dieser Segmente die dritte Kieme, und hinter dieser, dem nächstfolgenden Segmente angehörig, die vierte Kieme steht.

Der Fächer der Paleen steht jederseits unter und etwas vor dem ersten Kiemenpar auf einer wenig vorspringenden Ecke hinter dem seitlichen Umfange des Buccalsegmentes. Er enthält zahlreiche - ich zählte in einem 
Fille gregen 50- leine messingrainzende Borsten, welche in ihrer breit ficherfömigen spreitumg meist in kleinere (iruppen vereinigt stehen, nach vorn gerichtet bis anf die Ilïhe des Vorderrames des Kopllappens reichen. - Dicht hinter der Austritsstelle des Paleenfibhers, unter dem vorderen Kiemenpare steht als ein kileiner Kergel der erste liuderfortsat\% mit cinem kleinen, von nur wenigen Borsten gebildeten Biindel, das an Ijinge um meln als das doppelte hinter den l'aleen zuribkbleibt. Hinter ihu folgen anf einer schräig zur lïïchenfliiche aufsteigenden Linie das 2te und Bte lBorstenbündel, die aus je einem denthehen Höeker als ein zusammenliegendes Biindelchen von grimzenden Borsten austreten; an Grösse amnähernd unter cinander gleich, das erste wohl um das Doppelte ïbertreffend; das 2te dieser Bïndel steht unter der 3 ten, das dritte unter der ften Kieme. - Zwischen dem Paleenfitcher und dem ersten Borstenbindel habe ich weder auf dem Seitenumf:ung noch weiterhin auf der Ventralliiche eine Segmentfurche geschen; die hinter dem ersten Borstenhöcker gelegene Furche trennt hinter dem Buccalsegment ein Segment ab, in welchem man ein aus zweien verschmolzenes sehen könnte, weil an seinem Seitenumfange jederseits ein Paleenfïcher, ein Borstenhöcker und zwei Kiemenfïden stehen; bei solcher nicht sicher zu begrïndenden Auffassung wiirde dex Paleenfücher ein umgewandeltes Borstenbiudel darstellen. - Die ventrale Segmentfurehe zwischen dem zweiten umd dritten Segmente ist einfich; auf derjenigen zwischen dem dritten und vierten Segmente steht jederseits neben einem medianen Bezirke eine bald mehr bald minder tiefe, quere Grube, in welche bei grösserer Entwicklung ein erheblicher Theil der Segmentflichen aufgenommen werden kann; dann springt der zwischen den beiden Gruben gelegene Theil wohl firstenartig hervor.

Vom 4ten Borsten tragenden Segmente ab beginnt die Reihe derjenigen, welche Hakenborsten und Flösschenbildung besitzen. Von diesen tragen in ungleicher Entwicklung die sieben ersten, also das 11te der ganzen Reilhe mit eingeschlossen, quere schmale Banchpolster, die an den vorderen dieser Segmente deren ganze Tentralfläche eimehmen, nach hinten, während die Segmente sich strecken, kiirzer werden und dann als weisse Querstreifen wohl von Driisenzellen gebildet - auf rem dunkleren Grunde stehen. In cinem Falle sehe ich auch noch auf dem 12ten Segmente eine ganz schwache derartige Querbinde.

Die dorsalen Borstenbiindel aus Capillarborsten bestehend, uehmen wie die Borstenhöcker ron vorn nach hinten an Grösse zu; bis etwa zum 9 ten 
oder 10ten Segrment sind sie seitwïrts gerichtet, ihre IIöcker nur wenig answebildet, an den letzten 1 oder 5 dieser Segmente werden die Ḧ̈̈cker schlanker, die Biindel lingrer, sind nach hinten gerichtet und reichen num dem Seitenumfange des Kïrpers anliegend bis zur nïehsten Segmentfurehe.

Die rom ften Segmente an auftretenden Haken stehen an diesen vorderen Segmenten auf einem dimnen der Körperfliche anliegenden plittehenartigen Schiippchen, welches hinter der hinteren Seitenecke des rentralen Polsters oder Driisenstreifen steht und im Allgemeinen breiter als lang ist. Am 4ten Segmente ist die Reihe dieser IIaken nur kurz, an 5ten und 6ten bedeutend ausgedehnter, nimmt an den nächst folgenden nur wenig ab, ist aber vom Oten oder 10ten Segment ansehnlich schmiler geworden. Immer ragt dabei das Flüsschen als ein schuppenartiger querer Fortsatz vor, der von der Austrittstelle der Capillarborsten oder der Basis des Borstenhückers deutlich getrennt bleibt. Die Capillarborsten sind schlank, an der Endstrecke doppelt gesiiumt; der Saum bisweilen eigenartig unterbrochen (Fig. 7). - Die Haken tragen 4 oder 5 Zïhne in einer Reihe vor der Basalecke (Fig. 8).

An den Segrmenten der hinteren Körperstrecke ist das Flüsschen nicht mehr schuppenartig diinn, sondern ein wenn anch breiter und platter, doch immer dicker Fortsatz, welcher auf oder an der hinteren Segmentgrenze am Seitenrande der Ventralfäche mit der Richtung nach hinten frei vorspringt und auf seiner abgestutzten, meist etwas wulstigen Endfläche die kurze Reihe der Haken träigt, an der Basis bald mehr bald weniger geschwollen oder aufgetrieben erscheint; seine Länge bleibt, wenn von den letzten verkürzten Segnenten abgesehen wird, hinter einem Drittel der Segmentlänge zurïck, uibertrifft aber etras die eigne Höhe. - Die Hakenborsten bilden in geringer Anzahl eine Querreihe auf der Endtäche; sie stehen an Grösse den Haken der vorderen Segmente nicht nach, tragen aber auf der Schmeide Sägezähne in 2- bis tfacher Längsreihe ror dem unpaaren der Basalecke zunächst stehenden. Diese IJaken sind dementsprechend dicker als diejenigen der rorderen Sermente (Fig. 9).

An der Seitenflïche der dorsalen Fläche steht auf oler vor der hinteren Segmentfurche, so dass es von dem Flösschen um die Körperdicke getrennt ist, ein kleiner kugeliger order auch fadenförmig ver]ängerter Höcker, der mit dem Flüsschen wohl durch einen auf der Segmentgrenze am Seitenumfange des Körpers laufenden Wulst verbunden ist (Fig. 5). Dieses Höckerchen, scheinbar eine winzige Wiederholung der Borstenhöcker, nimmt nach hinten allmählich an Grösse ab, aber nur an den verkürzten letzten 10-12 Segmen- 
ten wird er unkenntlieh oder ist mit dem lilisschen zusammongerehnolzen; als gresonderte Bildumg ist er jedentills nicht mehr zur erkennen.

Dits Altersegment ist etwas dieker und limger als das zumiehst voranstehende; an der bindliche triagt es einen kranz niedriger, selseinbar moregelmissiger Lïppehen, and zwei lange futenfürmige Cirren, welche an den seitlichen Unfinge des Surmentes vor dem terminalen Wrulste und höher als die Flisschen entspringen, so dass sie in grleiche Ilöhe mit den dorsalen Ilöckern der hinteren sermente oder den Borstenhüekern der vorderen Körperstrecke zu setzen sind: ein fïr die morphologrische Ausdeutung wichtiges Verhiiltniss (Kig. 6).

Die 'Thiere bewohnen lange eylindrische Rühren, welche eine grleichmissign glatte und dicke Wand von Schlamm lraben.

Diese Art stelle ich zur Gattung Amphicteis (Gr.), indem ich dieselbe nach Grube im weiteren Sime auffasse. Damn lege ich zunaichst der Anzalil der Capillarborsten tragenden IIöcker, welche bei dieser Art greringer ist als diejenige, auf welche Malmgren boi der Aufstellung seiner Diagnose fiir diese Gattung Werth legt, eine besondere Bedeutumg nach Langerhans' Vorgang nicht bei. Auch iiber die abweichende Gestaltung des Koplappens sehe ich hinreg. Dagegen scheint mir bedentsam zu sein, dass die erste Reihe der IIakenborsten erst unter dem 4 ten Borstenhöcker erscheint, dass also hinter dem Fücher der Paleen है Borstenhöcker ohne Hakenreihen auftreten. Dass diese eine solche Beziehung zu den Kiemen haben, dass ïher dem ersten derselben zwei Kiemen jederseits nebeneinander, iiber den beiden folgenden Borstenhöckern jederseits nur je eine Kieme steht, wie es bei Amplicteis pocer" der Fall ist, stellt vielleicht ein ursprïngliches Verhailtniss dar, weiter verbreitet bei den Arten der Gattung Amplnicteis ist dasselbe wohl nicht, da es wenigstens in den Beschreibungen und Abbildungen von A. Gumeri (Sars) und Sundevalli (Mlgn.) nach Nalmgren ${ }^{1}$ und A. Phitiprinanum nach Grube ${ }^{2}$ sich nicht findet. Dagegen zeigt mir Grube's Abbildung der Amphicteis gröntandic $=$ Amph. Gumner (S.) eine Stellung der einzelnen Kiemen zu einander, wie ich sie bei der A. mocera sehe: d. h. die beiden ersten Kiemen neben einander, die 3te und 4 te hinter diesen und hinter einander, die 3te zugleich medianwärts rerschoben. Für die Gattung ist auch die Iautfalte charakteristisch, welche auf der Riickenfliche zwischen der Basis der vorderen Kiemen quer gespannt ist; Grube hat sie ron der

\footnotetext{
1 Nordiska Hafs-Annulater, pag. 365, 366.

2 Annulata Semperiana, pag. $20 \%$.
} 
Amphictcis grimtendiour ${ }^{2}$ sehr grut abgebildet; anch bei der A. Sunderalli (Mlgn.) scheint sie vorhanten zu sein; doch wird hier auch eine iihnliche Bildung wut der torsalen Strecke zwischen den P'aleenfïchem abrebildet. Grube hubt die Anwesenheit einer solehen Vialte auch fïr die Amph. incalidu Gr. aus dem kiappischen Iteere und für seine Amplicteis aculifions hervor; letztere ist aber, dil dis erste Flössehen schon unter dem 3ten Borstenbiindel erscheint, aus der Gattung Amphicteis auszusondern, und damit wird diese Falte als ein exclusiver Charakter nicht aufufissen sein, so lange man dem Verhältniss der Flüsschen zu den Rudern Bedeutung geben will. Dazu kommt, das Grube's Amph. intulita aus dem kaspischen Meere diese Falte wahrscheinlich nicht besitzt. So ist wolil das Auftreten dieser Querfalte immerhin zu beachten, ihre Abschiitzung vielleicht aus dem Gesichtspunkte zu beurtheilen, dass sie eine Verbindung zwischen den getremnten Kiemenbiindeln jederseits darstellt, ïber welche wir sicherer urtheilen wiirden, wenn wir Sicherheit dariber hiitten, ob die Trennung der beiderseitigen Kiemenbiindel von einander oder deren Vereinigung zu einem medianen Haufen das ursprüngliche fiir diesen Verwandtschaftskreis ist. Will man das erste als das ursprünglichere ansehen, wie das aus allgemeinen Erwägungen sich empfehlen künnte, damn liesse sich dieser Falte die Bedeutung beilegren, dass sie gleichsan die Bahn vorstelle, auf welcher die Vereinigung der Kiemenbündel erfolge. Andererseits künnte man amnehmen, dass die Falte den letzten Rest einer früheren Verbindung darstelle. Von solchen Gesichtspunkten aus würde man dam eine Terwandtschaft dieser Querfalten mit dem gezähnelten Querblatte auf der Rüickenflïche der Mrelima cristata abweisen.

Die Ausbildung von zwei fadenfürmigen Aftercirren, welche bei der hier beschriebenen Art das Maximum der Länge erreichen, kam vielleicht als Gattungscharakter verwendet werden.

\section{Amphicteis nasuta, n. sp.}

$$
\text { T'af. 49, Fig. 1-6. }
$$

Subpellucida pallida, antice crissa alta, postice attenuata, distincte articulata; segmentis folus quam 22. Lobus cephalicus suljcristatus antice paullum productus utrinque alatus. Tentacula laevia. Segmentum bucenle subtus magnum labium disjunctum non fingens; segmentum 2 rum subtus angustum, supra utrinque flahellum palearum cirea 17 in pinna conica, fusciculum branchiarum 4 elongatarum articulis basalibus arcte conjunctarum gerens. Segmenta proxima 14 setas capillares in pinnis et, exceptis duobus primis, uncinos simplices quinque dentatos, a seg- 


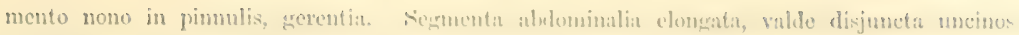
minores crassos pluriseriatim dentatos in pinmulis bevilus ferentia.

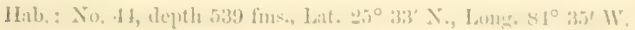

Alle mir vorliegrenden Exemplare sind klein. Keines derselben ist vollstindig erhalten; das besterhaltene war, ohne die Kiemenfiden, 14mm. lang, vorn nicht ganz 2mm., hinten $1 \mathrm{~mm}$. Breit. Bei allen war der iibrigens farl)lose orler dmehseheinent weisse Kïrper im vorteren Theile, wohl von durchscheinenden Fingeweiden, gelblich grelïbt. Der Kinper ist hinter dem weit vorragenden Schopf der. Kienenfiden hoch gewölbt, verschmälert sich nach hinten und wird abgeplattet; am Körperende sind die grestreckten Segmente scharf von einander abgesetzt, währent in der vorderen Kïrperstrecke serrmentgrenzen auf der Rückenfliche katum wahrnehmbar sind.

Der Kopllappen, welcher etwa so lang als die beiden folgenden Segmente ist, ist $u m \frac{1}{3}$ breiter als lang. Seine Dorsalfliche ist in der Mitte zu einer stumpf grerundeten Lïngsirste erhoben, welehe nach vorn fist schnauzenartig ausgezogen mit abgrerundetem Ende den Vorderrand bildet; die Seitentheile sind neben dem erhobenen. Mitteltheil fliigelartig gerundet erweitert und diim, dadurch bei geeigneter Beleuchtung durchscheinend und dann mit radiüirer Streifung gezeichnet, vermuthlich durch derartig gestellte in dev Körperwand eingelagerte Drisenschlïuche. Tiefere Furchen, welche den Mittel- von den Seitentheilen tremen, habe ich bei keinem Exemplare gesehen; sie deshalb für die Art ganz in Abrede zu stellen ist nach den bei anderen Arten in dieser Beziehung gemachten Erfahrung nicht zulässig (Taf. 49, Fig. 1, 2).

Auf der Ventralfläche des Kopflappens steht bei allen Exemplaren, aus der Mundöfhinung hervorragend, ein wenig ausgedehntes, gefaltetes Blatt, bei zwei 'Thieren darunter eine kleine Zahl kurzer Fiden, welche in dem einen Falle nicht, in dem anderen nur wenig iiber den Kopflappenrand himausragten. Das ist der offenbar hier gleichfalls retractile Lappen mit den Tentakeln. Die Tentakeln waren glatte, an der. Spitze kolbig verdickte Fïden (Taf. 3).

Das Buccalsegment hat auf der Ventralfliche, wo es den Nundeingang von hinten umfasst, eine in der Form wechselnde Platte, welche das einemal ein Rechteck, das anderemal ein mit der Spitze nach hinten gerichtetes Dreieck bildete, stets aber in der Läingenausdehnung grösser als die beiden folgenden Segmente war (Fig. 3); der Vorderrand ist bisweilen leicht mregelmïssig eingekerbt, der hintere Rand eine scharfe Furche; ich habe in keinem Falle eine von der ïbrigen Fläche abgetrennte Lippe gesehen. Die Dorsalfäche 
des Segmentes fillt mach vorn ab, ist glatt, wenig vom Kopflappen wie vom nitclist folgenten sergmente gesondert.

Dits nibichst folgende durch den Pallenfäicher atugrezeichnete Segment ist nuf der Ventraltliche ein granz schmaler von scharfen Furchen vorn und hinten begrenzter Gürtel, erweitert sich am seitlichen Unfange in der Lüingsausdehnung erheblich und trägt hier mahe am Vorderrande in einer höckerartig rorspringenden Ecke den Paleenfïcher. Auf' der glatten Rïickenfliiche, deren Segmentgrenzen kaum zu erkemnen sind, steht jederseits das Kiemenbiindel. - Die Paleen bilden ein grosses ïber den Koptlappen nach vorn hinausragendes breit fücherförmig gespreitztes Bündel; ich zählte in dem einzelnen Biindel 17 goldbraune, einfach capillare, geschwungene und in feine Spitzen auslaufende Borsten (Fig. 1-3).

Die Kiemen, welche an den Seitentheilen der Riickenfliche etwas hinter dem Austritt der Paleen stehen, bilden zu vier jederseits ein dichtes Biindel, inden ihre grossen cylindrischen Basalglieder hart an einander geschoben, im unteren Theile vielleicht sogar verwachsen sind. Ob die Ursprünge nicht etwa auf die Rückenflïche des ersten Ruder tragenden Segmentes hinübergreifen, komnte ich nicht sicher entscheiden. Die Kiemenfäden sind äusserst lange und diinm auslaufende, unregelmässig quer gekerbte oder geringelte Fiiden, welche in ihrer granzen Linge grewunden oder fast lockenförmig gerollt sind; die beiden äusseren Fäden sind etwa um ein Drittel länger als die inneren und anch etwas dicker als diese; einer der äusseren Fäden reichte, als ich ihn müglichst gestreckt nach hinten bogr, bis auf das 13 te Ruder tragende Segment (Fig. 1-3).

Mit dem zunäichst folgenden Segment, mit Einschluss des Buccalsegmentes dem dritten, beginnt die Reile der mit Capillarborsten tragenden Ruderhöckern ausgestatteten Segmente, rou denen 14 rorhanden sind. Die rorderen dieser Segmente sind 5 bis 6 mal breiter als lang, die Linge nimmt zu, bis rom 9ten dieser Segmente die Längsstreckung derselben deutlich hervortritt; das 10 te und 11te ist etwa so lang als breit; vom 12ten Segmente ab sind diese lïnger als breit.

Die beiden ersten dieser Segmente tragen nur Capillarborsten; die Borstenhöcker sind niedrig, deren Borsten nach vorn gewendet; rom aten dieser Segmente an, dem 5ten der ganzen Reihe, nehmen die Borstenhücker an Grösse zu, und die schliesslich der Segmentlïnge an Lïnge gleichkommenden Borstembindel richten sich nach hinten; an diesem Segmente tritt zuerst unterhalb der Capillarborsten nahe vor der hinteren Segmentfurche 


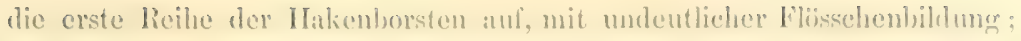
die Flisschen werden erst vom gten der borsten trugenden fegmente ab deutlich als schuppenartige noch wenigg vortretende quere Blaitter.

Die Capillaborsten sind, von den Griissenuntersehieden abgesehen, als. grleich zu bezeichnen; Intumgelle schlamke Jorsten, deren spitz anslan-

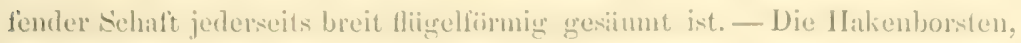
welche in riemlich grosser 'bahl (60) dicht gedränert in eines lieihe stehen, die Basis nach vorn wendend, sind lang-ovale diinne P'latten mit stark hakigr vorspringender Basalecke und 5 schlanken, einreilig stehenden Kammz:ihmen, von denen der unterste bisweilen etwas grösser ist als die nach der Spitze zu folgenden (Fig. 5).

Die Ventralfliche dieser Segmente zeigt schnrfe Segmentfurchen und eine Polsterbildung, welche je weiter nach hinten um so weniger scharf ausgepright erscheint. Das erste dieser Segmente, das drifte der ganzen Reihe, lat auf der halben Linge eine quere furche, welche sich vor der seitlichen Begrenzung der Ventralliiche erweitert und vertieft, dadurch hier eine quer ausgezogene Grube darstellt. Der Vorderrand dieses Segmentes war im mittleren 'Theile mit einer Reihe kleiner niedriger süigezahmartiger Ilïcker besetzt.

Die Segmente der hinteren Körperstrecke, an welcher nur Hakenborsten stehen, sind doppelt so lang als breit, anf der Ventrallläche abgeplattet, mit hoher Seitenwand und mïssigg gewölbter Riickenfliche und durch deutliche Einschniirung auf den Segmentgrenzen von einander gretiennt. Ich ziilılte an dem lïngsten Exemplar deren nur 6, und muss anmehmen, dass hier die letzten dieser Segmente verioren gegangen sind. Kurze und dicke Flösschen stehen an dem seitlichen Umfange vor der hinteren Segrnentgrenze gegen die Bauchfliiche him geriickt, und tragen auf der Endfliche eine Reilse nicht sehr zahlreicher (25) von Fäden gestiitzter Hakenborsten. Diese sind abgesehen von denjenigen, welche auf den beiden ersten dieser Flösschen stehen, kaum halb so lang $(4: 9)$ als die IIakenborsten der vorderen Segmente, aber dick, und auf der Schneide mit mehrfachen Reihen spitzer Sägezälıne besetzt (Fig. 6).

Von einem rudimẹntären Cirrus oder einer dementsprechenden Bildung habe ich bei besonders darauf grerichteter Aufmerksamkeit nichts .gefunden.

Die Thiere staken zum Theil in dickwandigen Schlammrölnren.

Ich rechne anch diese Art zu der Gattung Amphicteis in der weiteren Auffassung, von welcher ich bei der vorhergehenden Art gesprochen habe. 
Mlit dieser stimmt sie dureh den Besitz von 14 Paaren Capillarborsten tragender Panapodien iiberein, unterscheidet sich aber in dieser Minsicht dadurch, dass inr die bei Amphicteis procera hinter dem Paleenfïcher stehenden Capillarborsten fehlen; dadurch kommt es, dass bei beiden Arten die Zahl der IIakenborsten tragenden thoracalen Segmente die gleiche (12) ist. die erste Inakenreihe bei Amphicteis mrocera aber unter dem 4ten, bei Amluphicteis nusuta unter dem 3ten Borstenbindel steht.

Unter den besehriebenen Arten steht diese offenbar der von Malmgren beschriebenen dimphurete gracilis nahe. Sie unterseheidet sich von dieser zunïchst durch die röllig glatten 'Tentakehn, und darf, wemn man auf diesen Charakter Gewicht legt, danach iiberhaupt nicht in der Gattung Ampharete nach Malmgrens Auftassumg, oder in der fuir Ampharete gracilis ron Levinsen aufgestellten Gattung Anobothrus unterzubringen sein. Femer durch die Gestalt des Kopflappens, der mit dem von Malmgren abgebildeten eben so wenig im äusserem Umriss ïbereinstimmt, wie in der Furchenbildung und in den eigenthïmlichen Flecken, die Malmgren hier zeichnet. Die Paleen sind bei Ampharete nasuta grösser und zahlreicher als bei Ampharete gracilis; die Kiemen stimmen in der Vertheilung auf die Segmente bei beiden Arten iiberein, weichen aber durch die Stellung zu einander und dadurch ron einander ab, dass die Kiemenursprïnge bei Ampharete gracitis nach der Abbildung die volle Riickenbreite einnehmen, bei Amphicteis nasula einen mittleren Theil frei lassen. 


\section{TEREBELLTDAE.}

Bei der Darstellung der wenigen 'Terebelliden, welche alle aus der LitoralZone von Key-West stammen, bin ich nu beniiht gewesen, die 'Thiere so zu kemmeichmen, dass sie wiedex zu erkemnen sein werden. Ich habe dabei es unterlassen, die einzelnen Arten unter die zahlreichen Gatungen zu vertheilen in welche in den letzten. Jahren die alte Gattung Terebella zerspalten ist, und zwar aus dem einfachen Grunde, weil bei der engen Charakteristik, welche die meisten dieser Gattungen erhalten haben, kaum eine dieser Arten in diese hineingepasst haben wïde, vielmehr die Errichtung neuer Gattungen für sie nöthig geworden sein würde. Deshalb bin ich dem Vorgange Grube's, ${ }^{1}$ gefolgt, und habe zunäichst die Gattung 'I'erebella in dem weiten Sinne beibehalten, wie er dieselbe begrenzt hat.

TEREBELLA (L.) s. str. Grube.

Terebella bruneo-comata, n. sp.

$$
\text { Taf. 51, Fig. 1-5. }
$$

Longa, antice modice incrassata, albida, segmentis 120. Lobus cephalicus antice amplificatus, postice in laminam parvam erectus, tentrcula numerosa longa filiformin, paullum circinnata partimque brunnea gerens. Segmentum buccale subtus magnum bipartitum. Segmenta anteriora Sies, postica ultimis exceptis ter fere latiora quam longion; duo anteriora nuda. branchifera ; 27 proxima pinnigera et excepto primo setigero uncinifera; segmenta 16 antica scuta rentralia postice versus angustata gerentia, sequentia per longitudinem profunde in medio sulcata. Branchiae laterales fere aequales e stipite crasso ramis ramulisque brevibus arborescentes; sub branchia postica tuberculum conicum pinnaforme. Pinnae 27 , mediae majores; setre capillares longae limbatre, in apicem longum flexilem ciliato-scrratum productae. Tori uncinigeri postice rersus minores, priores sex uncinos in serie simplici, ceteri in serie parabolica alternos gerentes; uncini denticulo suprabasali minuto, supra dentem terminalem validum denticulis biseriatis muniti. Segmentum anale lobo ventrali brevi.

Hab. : Key West, 1-2 fims.

1 Grube, Annulata Semperiana, a. a. O., pag. 221. 
Diese Art liegrt mir in zahtreichen, allerdings nur zum theil gut erhaltenen bxemplitren vor.

Der weissliche Körper ist lang gestreckt mol durch den dichten Schopf der langen gegen dis linde hin meist braun gefürbten T'entakel ausgezeichnet; im vorderen theile ist er nur missig erweitert, in der weitaus lingeren hinteren strecke, abgeschen ron der tiefen rentralen Medianfurehe fast drehrund. Bei einem der grö̈sseren Exemplare fitnd ich bei einer Lüinge des lï̈rpers von Stmm. 120 Segmente, dabei war der Körper vorn 5mm., hinten 2 mm. breit; die Abnahme der Breite begann etwa vom 15 ten Segment ab.

Der Kopflappen ist gross und filtig, sein Lippentheil deckt schirmartig von oben den Eingang in die Mundöffnung; sein Nackentheil erhebt sich als eine diumhäutige aufrecht stehende Platte; zwischen ihr und dem Lippentheil stehen dicht gerträngt in gleichmissiger Vertheilung iiber die ganze Fliche die 'Tentakeh. Dies sind lange diunne, gleichmässig dicke, gegen das Ende hin meist gekräuselte Fïden, welche mit einer wenig tiefen Lüngsrimne versehen sind. Die bei weitem meisten dieser 'Tentakeln sind gegen das Ende hin auf eine lïngere oder kiirzere Strecke braun gefärbt; doch kommen daneben ganz farblose vor. Vielleicht fällt dieser Unterschied in der Fïrbung mit umgleichen physiologischen Zuständen zusanmen. Die medianen Fïden sind länger als die lateralen und kommen wohl einem Drittel der Körperlïnge gleich. - Augenflecken fehlen dem Kopflappen. (Taf. 5̋. Fig. 1, 2.)

Das Buccalsegment stellt sich auf der Ventralflïche als ein breites Polster dar, welches zweitheilig ist, indem vor der hinteren IIälfte, welche an Länge das folgende Segment etwas iibertrifft, ein bisweilen recht kurzer, dann saumartig erscheinender, in anderen Füllen ausgedehnterer Gürtel liegt, welcher am Seitenumfange in den Kopflappen übergeht. - Vor diesem Theile des Buccalsegmentes liegt hinter dem Mundeingang, seitlich vom Lippentheile des Kopflappens umfasst, ein queres durch dicht stehende Längsfurchen gekenuzeichnetes Polster. Ich kann nicht entscheiden, ob dieses Stiick dem Buccalsegmente zuzurechnen ist, oder ein Stiick der Schlundwand, welche dann vielleicht ausstreckloar ist, darstellt. (Fig. 2.)

Die folgenden Segmente sind auf der Ventralfläche theils durch die Bauchpolster und Borstenwülste, theils durch letztere allein gekonnzeichnet, auf der Rückentläche durch Segmentfurchen nicht von einander geschieden. Das einzelne Segment der vorleren Körperstrecke ist wohl achtmal breiter als lang; die hinteren Segmente nehmen an Lünge zu, und sind mit Aus- 
nuhme derer des Keirperendstickes. Wolche ku\% und dicht zusammengedringrt sind, etwa dreimal breiter als lang. Am vorderen liöpertheile zeigrt sich anf der Ventrallliche im Bereich des Sten bis bten semententes eine tiefe meist mit Knickung verbundene grubenartige Einziehume, lluch welehe bisweilen die hier grelegenen Banchschilder ganz in die 'l'iefe grezogen und verdeckt werden. (Fig. 2.)

Die beiden auf das Buccalsegment folgenden Segmente haben keine Borsten, sie tragen dagegen jederseits je eine Kieme, mel das zweite von ihnen unter dem Kiemenstamm einen kleinen kegelfömmigen Hïcker. - I)ie nïchsten 27 Segmente tragen kegelfömige Ruderfortsiitze mit langen Capillarborsten; am 2ten Borsten tragenden Segmente steht der erste ventrale Wulst mit Hakenborsten, die vou hier an allen folgenden Segmenten sich finden. - Banchschilde stehen an den vorderen 16 Segnenten hinter dem Buccalsegment und führen zu einer tiefen ventralen Medianfurche hinïber: (Fig. 2.)

Die an den borstenlosen vorderen Segmenten stehenden Kiemen entspringen am Seitenumfunge des Segmentes etwa in gleicher Höhe, wenig höher als die Borstenhö̈ker der folgenden Segmente, sind fast gleich gross und erheben sich anfwirts wenig über die hüchste Wölbung der Dorsalliaiche. Sie besitzen einen kurzen und dicken Stamm, der sich unter Abugabe kurzer und dicker Zweige auflöst, die sich damn bald in feine Endzweige vertheilen, so dass die ganze Kieme als kurzer Busch erscheint. - Der kegelfömige IÏ̈cker, welcher unterhalb und etwas vor der zweiten Kieme steht, entspricht den folgenden Borstenhöckern, ist aber kleiner als diese. (Fig. 1.)

Die kegelfümigen Höcker der folgenden 27 Segmente führen ein amsehnliches Bündel langer capillarer Borsten, welche ihre grüsste Entwicklung an den mittleren der Borsten tragenden Segmente erhalten. Der Schaft dieser Borsten erweitert sich, bevol er scharf zugespitzt ausläuft, ein wenig und wird jederseits schwach gesäumt, dann aber geht er in eine schlanke blattartigg diume lange Endspitze aus, welche an der als Schneide zu bezeichnenden Kante einen Saum feiner Härchen trägt; diese Strecke ist offenbar selır biegsam und daher oft mannigfaltig rreschwungen; ihr Längenverhältniss wechselt, wie ich das an den abgebildeten Borsten zeige, oft recht erheblich. (Fig. 4, $4^{\mathrm{a}}$.)

Die Wülste, welche die Hakenborsten tragen, nehmen von rorn nach hinten an Breite ab; in vorderen Körpertheil bedecken sie, soweit sie durch breite Bauchpolster von einander getrennt sind, etwa ein Drittel der 
rentrulen Flithe, mit dem Schwinden dieser Polster stossen die gegenseitigen $1 /$ iilste jederseits an die Mledianfurche, und decken die ibrige ventrale Fliche (Fig. 2); gegen das Kïperende hin nehmen sie erheblicher an Breite ab; hier indert sich ihr Verhalten auch insofern, als die hinter einander stehenden Wiilste dureh Zwischenriume von einander getrennt sind umd so allseitig frei vorspringen, waihrend die Wiilste der vorderen und mittleren Segrmente nur um die Breite der Segmentfurche von cinander abstehen, Verhiiltnisse, welche selbstverstïndlich von Contractionszustïnden erheblich beeinflusst werden (Fig. 3). - Die Hakenborsten nehmen die ganze Breite der Wiilste in querer Reihe ein, und zwar stehen sie vom zweiten Borsten tragenden Segment ab auf den ersten 6 Wiilsten in einfacher, auf allen folgenden Wülsten in parabolischer Reihe altemierend cinander gegeniiber. - An der Platte der Inkenborste ist die freie Basalkante an der der Hakenspitze zugewendeten Ecke zu einem spitzen Dom erweitert; der Endhaken ist gross und kräiftig, seine Scheitelhöhe mit 2 Querreihen kurzer Säigezälne besetzt. (Fig. $5^{\mathrm{a}}, 5^{\mathrm{b}}$.)

Die Bauchpolster sind an den ersten Segmenten sehr kurz, aber so breit, oder selbst etwas breiter als an den zunächst folgenden; etwa vom 6ten Polster tritt eine Lüngenzunahme cin, ohne dass die Breite sich vermindert; so kommt es, dass während diese Polster etwa ein Drittel der Bauchfläche eimnehmen, die rordersten etwa sechsmal so breit als lang, die grössten, etwa am 10ten, doppelt so breit als lang sind; dann nimmt die Breite rascher ab als die Lünge, bis dieser Theil der Bauchflïche in der Ventralfurche verdeckt liegrt.

Gegen das Afterende verkürzen sich die Segmente und verschmälern sich die Borstenwiilste selır erheblich, bis der Körper stumpf abgeschnitten endet, auf der Ventralflïche von einer kleinen lappenförmigen Verlïngerung überragt. (Fig. 3.)

Die einzelnen W vielleicht bauen sie mit Hülfe eines derartigen Materiales leicht zerfallende Rïhren.

Nach der Gestalt der Capillarborsten gehört die Art in die Gruppe, welche Malmgren ${ }^{1}$ als Amphitrite (Miill.) bezeichnet hat; die hierher gezogenen Arten sind aber durch den Besitz von 3 Kiemenparen ausgezeichnet. Sieht man ron diesem wohl nicht hoch anzuschlagenden Unterschiede von der nur 2 Kiemenpare tragenden Terebelle brumeo-comata ab, 
so finten sich in dieser Gruppe Arten, welehe mit der hier beschriebenen

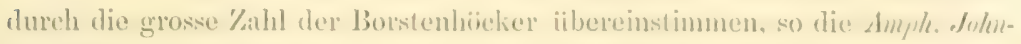

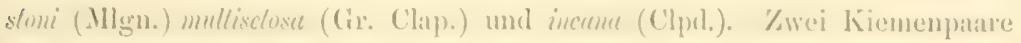

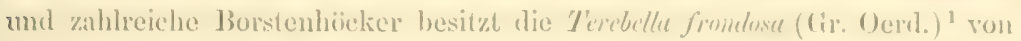
Puntarenas, bei dieser sind aber die Kiemenfihtnenden sourmente in Lappen erweitert; andere hier noch in Betracht zu ziehende Arten sim mir niehr bekamnt greworden.

\section{Terebella turgidula, n. sp.}

$$
\text { 'taf. E.2, Fig. 1-4. }
$$

Pallida subpellucida, haud lougn, supra alta antice paullum incrassata, segmentis 53 . Lobus cephalicus in parte postica tentacula longa crassa flexuosa canalieulata et utrimque vittam punctorum brumeorum gerens, antice in labium amplum vix plicatum os superne cincens dilatatus. Segmentum buccale in dorso et lateribus perbreve, subtus in cristam semilunarem os postice cingentem eleratum. Segnenta cetera brevin $\xi$ antica tria branchiforil, exceptis duobus prioribus 18 pinuigera, omnia torigera et a segmento 5 to umcinos in toris 6 anticis in seric simplici, in ceteris in serie parabolica alternos intercalatos gerentia; sogmenti postica suleo mediano ventrali per longitudinem sulcata uncinos uniseriatin in extremis pinunlis crassis brevibusque gerentia. branchiae e stipite crasso ramulis illo brevioribus scopateformes, anteriores majores; sub luranchin secunda pinuisque duobus anticis tuberculum conicum. Scuta ventralia postice versus attenuat:a in segmentis anterioribus 16 , prius in marginem cutaneum anticum productum. Setae capillares mediocres angustissime limbatae; uneini ubique denticulo suprabasali et in vertice dentis terminalis denticulo sivgulo vel perpaucis armati. Segmentum anale couicum sulcatum.

Hab. : Key West, 1-2 fms.

Der farblose Kïrper dieser mir nur in einem Esemplar vorliegenden Art ist $31 \mathrm{~mm}$. lang, vom $4 \mathrm{mmn}$, kur vor dem Ende 2, $5 \mathrm{~mm}$. breit und besteht aus 53 Segmenten; leicht abfallende dicke vielfuch gewundene Tentakeln stehen auf dem weiten Koplappen des erweiterten Vorderendes und sind wie die hochgewölbte Rüickenflïche zumal der hinteren Körperstrecke und wie die kurzen dicken Flösschen der hinteren Körperstrecke mehr oder minder durchscheinend. (Taf. 52. Fig. 1.)

Der Kopflappen besteht aus der hinteren die Tentakel tragenden Strecke und dem vorderen lippenartigen 'Theile. - Der hintere Theil bildet auf der Rïckentläche eine derbe quere Platte, welche mehx als doppelt so breit als lang ist, in der medianen Strecke am läugsten, nach jeder Seite etwas verkiirzt; sie erhebt sich wulstförmig und springt mit gerundetem Rande sowohl gegen das vordere Lippenblatt, wie gegen die Rïickenfläche des

1 Grube, Annulata Oerstediana, a. a. 0. 1859, jag. 110 
Bucealsegmentes vor; ihre mittlere liliche ist lïngs gerieft; an den Seitentheilen entepringen jederseits die 'T'entakeh; hier erhebt sich der hintere liand der Platte am seitlichen Unfinge des Körpers zu einem niedrigen aufrecht stehenden 13latte, an dessen hinterer Fliche eine dichte Reihe von dunklen Pigmenttleckehen steht; neben der hinteren Ecke der Oberlippe zur Seite des Mundeinganges liuft es niedrig aus; eine feine liurche zeigt seine hintere Grenze gegen den Bezirk des Buccalsegmentes. - Die. Tentakeln entspringen in 2 von einander gesonderten Gruppen jederseits an dieser Kopflappenplatte - wemn nicht ron dem mittleren jetzt nackten 'Theil der llatte 'lentakel abgefallen sini. Die meist sehr stark gewundenen und knïnelförmig verwickelten T'entakel sind dick, aber zum grössten Theil durehscheinend; die längsten von ihmen kamen wohl der Körperlänge gleich, und waren im Leben gewiss sehr dehnbar. Sie besitzen eine tiefe Längsfurche, deren hohe durchscheinende Ränder gewellt und grekräuselt sind. Der lippenartige Vordertheil des Kopilippens ist eine glatte ziemlich dicke und nur schwach gefältelte Platte, welche hohl gekrummt den Mundeingang auf der Ventrailäche von oben und scitwïrts schimartig deckt. (Fig. 1, 2, 3.)

Hinter dem Kopflappen ist ein Bucealsegment nachzuweisen; auf der Rückenfläche liegt es im Grunde einer tiefen Furche hinter dem gewulsteten Hinterrande des Koplappens, am seitlichen Unfunge ist es als schmaler Streif vor dem ersten Kiemen tragenden Segment zu erkennen und auf der Tentralfliche zeichnet es sich durch einen frei rorspringenden hyalinen Saum aus, welcher concav nach rorn gekrümmt von hinten in solcher Weise den Mundeingang umfasst, dass die nach vorn gerichteten Ecken jederseits an die Ecken der Lippe des Kopflappens eng sich anlegen, und dass dieser Saum solchergestalt mit dieser Lippe zusammen eine scheinbar ununterbrochene trichterförmige Umrandung des Mundeinganges bildet. In der Mundüffnung wird ein kurzes queres Polster sichtbar, welches wohl der Schlundwand angehört. (Fig. 1, 2.)

Die Körpersegmente sind alle fast gleichmässig kurz, aber an Breite verschieden; ummittelbar hinter dem Kopflappen haben die Segmente etwa dessen Breite, und sind achtmal breiter als lang; etwa vom dritten Segment ab erfolgt die Verbreiterung, welche am 8ten Segment ihr Maximum, das zrö̈lffache der Länge erreicht; mit dem 16ten Segment etwa tritt dann eine deutliche Verschmälerung ein, so dass die hintere Körperstrecke ziemlich gleichmässig breit bis zum After hin ist und dabei nicht ganz auf die halbe Breite der vorderen Körperstrecke herabsinkt. — Die Bauchfläche ist abge- 
plattet, die litickentliche hoch grewilht mol zumal in der hinteren Kiirper-

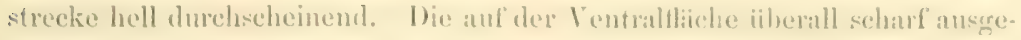
sprochenen Segmentgrenzen sinet anch anf der l)orsalliache als feine Iinien an erkennen.

Von den anf das Bbuealsegrment. lügrenden Segrmenten besitzen mit einer nacher zu schildernden Unregrehiissigkeit die drei ersten Kiemen; von diesen sind die beiden ersten horstenlos, an den Sten dieser Segmente tritt jederseits der erste Borstenhidick auf und 15 Segrmente tracren dorsale Borstenhöeker mit Capillarborsten; quere Wiilste nehmen die Flanken aller dieser Segmente ein, und mit Ausnahme der 4 volderen tragen die Wialste Reihen von Hakenborsten. Am 2ten Kiemen trigenden Segment steht unter der Kieme, an den beiden zuniehst folgenden unter den Borstenhücker ein kleiner kegelfürmiger Zapfen. (Fig. 3.) Anf den ersten 16 Segmenten hinter dem Buccalsegment stehen quere Bauchpolster, welche, wihrend die Borstenwälste an Breite zumehmen, in soleher Weise sich nach hinten zu verschmiileru, dass ihre Gesammtheit auf der Ventralfliche dieser Segmente eine nach hinten dreieckig zugespitzte Flïche bildet. Die beiden letzten Segmente, welche Capillarborsten tragen, haben kein Bauchpolster, an ihnen begimnt die mediane Längsurche, welche sich iiber die ventrale Fläche der hinteren Segmente erstreckt. (Fig. 1.)

An diesen Segmenten stehen statt der queren Hakenwülste kurze und dicke Flösschen.

ron Einzelheiten ist herrorzuheben, dass das anf das Buccalsegment folgende Segment ein auf der Fläche unregelmässig quer gefurchtes Bauchpolster hat, dessen Vorderrand sich zu einem frei vorragenden Hautsaum erhebt; seine durchscheinenden seitlichen Ecken ragen etwas stirker hervor, reichen jedoch seitlich nur wenig weiter als die Ecken des vom Buccalsegment kommenden Hautsaumes. - Allen folgenden Segmenten greht diese Bildung ab.

Die Kiemen besitzen eine wohl auch sonst beobachtete, für die taxonomische Werthschätzung dieser Organe nicht unwichtige Unregelmässigkeit. Bei einer Ansicht der Riickenfliche hat es den Anschein, als trüge die linke Hälfte der vorderen Segmente zrrei hart an einander stossende gleich grosse, und dahinter einen kleineren Kiemenstamm, wïhrend auf der rechten Hälfte, den 2 getremnten Kiemenstämmen der linken Seite entsprechend, ein grosser und breiter Kiemenstamm und dahinter, ganz wie auf der Gegrenseite, ein kleiner Kiemenstamm steht. (Fig. 2.) Eme genauere Betrachtumg zeigt jedoch ein anderes Verhalten. Danach trägt das dem Buccalsegment folgende 
Sogment joderseits cinen grosen Kiemenstamm, das nächste Segment rechts den kloinen Kiemenstamm unl darunter einen kegelfömigen Ilöeker, links den zweiton grossen Kiemenst:umm und darunter einen Höeker wie die Gefrenscite. Das dritte Segment trïgt jederseits einen Höcker mit Capillarborsten und dirunter eimen kleineren kegelö̈migen Ilöcker, über dem liuder aber auf dex linken Seite einen kleinen stumpi kegelfürmigen Höcker, rechts den kleinen Kiomenstamm dieser Seite. Ich halte den linksseitigen iber dem linder stehenden Ilöcker für einen unentwickelten Kiemenstamm, und schreibe dem Thiere daher jederseits drei Kiemenstimme zu. Die mangelhafte Entwicklung des dritten Kiemenstammes der linken Hälfte ist durch die stïrkere Entwicklung der vordersten Kieme dieser Seite compensiert, orler es ist auch anzunehmen, dass eine Störung in der Entwicklung auf der linken Seite den zweiten Kiemenstamm hat kïmmern lassen, den dritten aber fust völlig unterdrickt hat. Nach der ursprïnglichen Anlage aber stimmen die Gegenseiten der drei Segmente völlig überein. - Die einzelne Kieme besteht aus einem grossen dicken Stamm, der an seinem Endtheil sich in ein kurzes dichtes Endbiischel von Kiemenfiiden auflöst, das kïrzer als der Stamm ist.

Das zweite Borstentragende Segment träigt unter dem Ruderfortsatz einen liegelfürmigen IÏ̈cker, der den vorangehenden beiden durchaus ähnclt.

Die Borstenhöcker sind kurze und dicke, am freien Ende stumpf abgerundete Höcker; die aus ihnen hervortretenden Capillarborsten sind an keinem Segmente auffallend ling. Die von hinten nach vorn auf Kosten der Bauchpolster an Breite zumehmenden lateralen Wiilste tragen unter dem dritten Borstenbindel die erste Querreihe von Hakenborsten, und zwar stehen diese auf den ersten sechs Wülsten in einfacher Reihe, die Spitzen nach vorn gewendet; auf den folgenden Wiilsten mit der Richtung altemierend in einander verschrinkt eine einfache Reihe bildend, welche wohl durch eine Zusammenschiebung und Verschrinkung der beiden Zeilen einer parabolischen Doppelreihe entstanden gedacht werden muss. (Fig. 4.)

Die Flösschen, welche an den Segmenten der hinteren Körperstrecke plötzlich an Stelle del Borstenwiilste treten, sind kurze und dicke, frei vorragende zapfenfömige Vorspriincre mit abgeplatteter Endläche, in gewisser Weise die Form der Afterfïsse einer Raupe darstellend; auf der freien Endfliche steht eine kurze und nun wieder einfache Querreihe von Hakenborsten mit den Spitzen nach rorn gerichtet. - Der einzelne Haken ist eine schmale Platte, bei welcher die Basalecke zu einem stumpfen Zahn ausgezogen ist; 


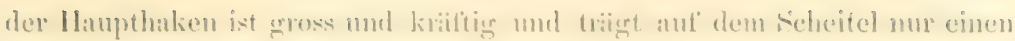
oder in einer Qnerreile nur wenige spitze sitgerilme.

Das letate Borsten tragende forment bat and der bmelliiche eine niedrige,

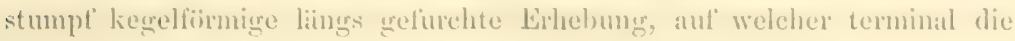
runde Alterïlnumg steht. (Fig. 1.)

Diese Art besitzt alle diejenigen Kemmeichen, ant' welche Malmeren die Gattumg 'Terebella s. str. begribulet hat, mit der alleinigen Lusmahme, dass sie statt 17 Borstenbindel deren IS besitzt. Ich kam sie mit keiner der bis jetzt kemntlich besehriebenen Arten dieser Gruppe identiliciren. Dis Verhalten der Banchsehilde zu den Borstenhöckern, oder die (irenze, bis an welche nach rom die Banchfurche dea abdominalen liörperstrecke reicht, bildet für diese Thiere vielleicht ein bequemes Erkennumgsmittel.

\section{Terebella reticulata, n. sp.}

$$
\text { Taf. ji, Fig. } \tilde{\nu}-\mathrm{s} \text {. }
$$

Termifurmis, antice subinflata, scgmentis plus quam 80 . Lobus cephalicus paullum dilatatus tentaculis subelougata filiformia canaliculatir puuctaq̨ue brumea pluriseriatim collocata gerentia.

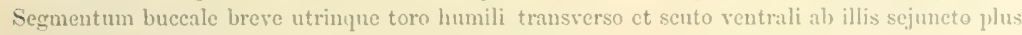
minusse inflato instructum. Secmenta cetera in dorso biannulata plerumcue reticulata ; tria anterium branchifera, exceptis duobus prioribus sequentia 32 piunigera, a secundo pingigero uncinos in toris 6 anticis in serie sinplici, in ceteris in seric parabolica alternos intercalatos gerentia 13 anteriora scutis rentralibus postice decrescentibus munita, cetera postica per longitudinem in medio ventre sulcati. Branchine in stipite brevi valde ramosae, prima et tertia aequales, secundi is minor magis ventrem versus collocata. Segmenta uncinis carentia ntringue torulo transverso, primo cum seuto rentrali conlito munita; tuberenla subbranchialia mulla. Setao capillares simplices limbatro; uncini ubique denticulo suprabasali obtuso, in vertice dentis terminalis deuticulis pluriseriatis armati.

Halı. : Key West, 1-2 fuss.

Die Art ist in der Sammlung in 3 Exemplaren vertreten.

Das besterhaltene etwas schlaffe Exemplar war fast cylindrisch, abgesehen von einer geringen Erweiterung im Bereich der rorderen Segmente, hatte so Segmente, womit die ursprüngliche Gesammtzahl nicht erreicht wird, da am Körperende eine wenn auch wohl nur kleine Zahl von Segmenten fehlt, und war bei einer durchschnittlichen Breite von $1 \mathrm{~mm}$. $39 \mathrm{~mm}$. lang. - Ein kleineres Exemplar von nur $12 \mathrm{~mm}$. Liinge und nicht ganz $1 \mathrm{~mm}$. breit hatte 75 Segmente.

Der Kopflappen ist nur mässigg gross und sowohl in seinem Lippen- wie in seinem Nackenblatte nur wenig gefaltet; am Grunde der hinteren Fläche 
des anficeht stehenden Ninckenblattes findet sich ein querer Streifen von dicht stehenden kleinen dunklen Pigmentflecken, welche unregelmäissign meist in melneren lieihen angeordnet sind. - Die 'Tentakeln find ich in 2 median von einanter getrennten Gruppen vertheilt, doch oflenbar nicht mehr in voller Zalıl vorhanden; urspringlich nehmen sie wohl mit ihren Wureh die samze Breite ein, tem bei einem Thiere habe ich fast median einen ganz kuren Fiden gesehen; es sind diime, im Allgemeinen kure Fïden, da die lïngsten von ilnen etwa der Limge der 12 vorderen Segmente gleichkimen, alle mit einer deutlichen Lingsrime versehen.

Das Buccalsegment trägt auf der Ventrallläche hinter der Mundüfnung ein querorales hoch kissenfömig gewölbtes Polster, welches in einem Exemplare blasenförmig aufgetrieben war, und getrennt daron jederseits einen rentralwirts spitz auslaufenden Wulst ('Tif. 52, Fig. 5).

Die folgenden Segmente sind in der rorderen Körperstrecke etwa sechsmal, in der hinteren dreimal breiter als lang. Hhre Grenzen treten auch auf der hochgewölbten Rückenfliche als scharfe Furchen dentlich hervor; hinter der vorderen Segmentalfurche verliuft parallel mit ihr eine zweite, welche diese Fläche des Segmentes derartig trennt, dass ein vorderer Ringabsehnitt von einem hinteren bisweilen wohl doppelt so langen geschieden ist. Die abgeplattete Buuchfläche ist fast glatt, dagegen ist die Rücken- und Seitenfläche besonders in der hinteren Körperstrecke zu kleinen meist rechtwinkligen Felderchen metzartig fein gefurcht. - Die 3 auf das Buccalsegment folgenden Segmente tragen jederseits je eine Kieme; die beiden ersten Kiemen trigenden Segmente sind borstenlos; am 3ten dieser Segmente steht der erste Ruderhöcker und von hier ab sind weiterhin die dorsalen Borsten an den rorderen 32 Segmenten rorhanden. Am 2ten Ruder tragrenden Segrmente steht die erste Reihe von Hakenborsten. Bauchschilde finden sich an 13 auf das Buccalsegment folgenden Segmenten, an ihre Stelle tritt Teiterhin eine tiefe Medianfurche (Fig. 5).

Die Kiemen sind insofern gleich, als jede aus einem kurzen Stamm besteht, der sich in einen dichten Busch ron kurzen Fäden auflöst; ungleich aber verhalten sie sich darin, dass die vordere und hintere, die an Grösse einander gleich sind, hoch an dem seitlichen Unfange der Segmente entspringen, waihrend die mittlere kleiner ist und weiter ventralwirts, etwa auf der Höhe der dorsalen Borstenhöcker entspringt (Fig. 6).

Die Ruder sind kume kegelförmige Höcker, die in ihnen stehenden Capillarborsten sind in den vorderen Segmenten länger als in den hinteren. Die 
einzelne Borste scheint mir eine schwnch gresiumte einfitche Cippillathorste mit geringer Verbreiterung ror der Jindspitze \% sein. Ich drieke nuch umsicher aus, da an allen Exemplaren die meisten Borsen kur, al)gebrochen watren, in den Biindeln dam aber cinige Borsten sich fanden, bei denen der Schalt plötzlich mit einer schrig abestutzten grezihnelten an einer beke mit fadenfömiger spitze aushufenden kimte versehen was. Ich bin reneigrt diese form als eine solehe anfzulissen, welehe durch Bruch und Splitterumg entstanden ist.

Am seitlichen Umfinge der Semmente finctet sich auch an den 3 auf das Bnecalsegment folgenden Segmenten jederseits ein sehmales plattenartiges Feld, welches am ersten dieser Segrmente aus dem ventralen Banclipolster hervorgeht, an den beiden niichsten von ihm dureh eine fiurehe gretrennt ist; diese Felder reichen dorsalwirts bis anf die Iöhle der dorsalen Borstenhöcker, von einander sind sie durch die Segmentfurchen geschieden. Auf dem Bezirk dieser Felder treten rom 2ten Borsten tragenden Segmente ab die Wiilste auf, welche die Hakenborsten tragen. Der erste dieser. Wiilste nimmt diesen Bezirk nicht ganz ein; es ist ein querovales Polster, dessen dorsaler Umfang hart unter dem Borstenhöcker steht, während der ventrale fast um ebensoviel von der medianen Bauchplatte entfernt bleibt, als der Borstenwulst in dorsoventraler Richtung lang ist. Die nïchst folgenden Wülste vergrösseren sich dann in der eben angegebenen Richtung, bis der siebente dieser Wuilste den Raum zwischen dem Bauchpolster und dem Borstenhöcker völlig einnimmt. Damit ist die grösste Ausdehnung dieser Wülste erreicht; an den Segmenten, bei welchen die ventrale Medianrime auftritt, erfolgt eine allmähliche Grössenabnahme der Hakenwülste, und an den Segmenten der hinteren Körperstrecke sind dieselben auf die Bauchfläche beschränkt, stossen medianwärts an die Bauchrinne, lateralwärts aber greifen sie nicht über die Bauchnäche auf die Seitenwand des Körpers hinaus. Mit der Streckungr, welche die hinteren Körpersegmente erfahren, wird der Abstand zwischen den unter einander benachbarten Wiilsten ein grösserer, so dass er grö̈ser ist als der Durchmesser des einzelnen Polsters in der Richtumg von hinten nach vorn (Fig. 5 ). Nur an den letzten Segmenten ror dem Aftersegmente sind auch diese Wülste wieder eng an cinander geschoben. Die Hakenborsten haben überall die gieiche Form; das basale Stiick ist fist so hoch als breit, seine Ecke nur stumpf höckerförmig ausgezogen; der Hauptzahn ist schlank und spitz, nur mässig gekrümmt, auf dem Scheitel mit 3-t Querreihen kleinerer Zähnchen besełzt (Fig. 8). Darin sind die Haken 
aber unterschieden, dass diejenigen der vorderen Segmente mehr als doppelt so gross als die der hinteren Segmente sind. Die Inaken stehen auf den 6 vorderen Wülsten in einer Querreihe, alle die Spitzen der 'Ziilme nach vorne gewencte auf allen folgenden Wuilsten ist eine verschrinkte Querreihe vorLanden, so dias die Stellung der IIaken num regelmäissig alternierend nach vorn und hinten gewendet ist. Im Allgemeinen stimmt die Grösse der Querreihe und die Zahl der llaken mit der Grösse des Wulstes iiberein; auf den hinteren Segmenten sind aber die Reihen etwas gelockerter, und ist die Zahl der Haken ein wenig rermindert.

Bauchpolster mit scharfer Ausprägung finden sich auf der ventralen Mediantliiche der 13 hinter dem Buccalsegment folgenden Segmente; dahinter stehen im Anfange der medianen Bauchfurche noch einzelne undeutlich algregrenzte. Abgesehen von dem ersten dieser Polster stehen die zuniehst folgenden derartig, dass je zwei und zwei enger an einander angeschlossen und stiirker von den benachbarten getrennt sind; doch ist das bei den letzten der Bauchpolster nicht mehr vorhanden. Die Polster nehmen je weiter nach hinten um so mehr an Breite ab, dagegen an Lünge zui, die vorderen, welche mehr als ein Drittel der Banchflïche in der Breite einnehmen, sind etwa viermal breiter als lang, wïhrend die hinteren fast quadratisch und etwa doppelt so lang als die vorderen sind (Fig. 5).

Die Art stimmt mit keiner der beschriebenen zusammen und passt in keine der Gattungen, in welche die dreikiemigen T'erebelliden unter gebracht sind. Alogesehen von der characteristischen Zweiringeligkeit der Segmente und der reticulirten Ruickenhaut ist die Stellıng der Kiemen, die grosse Zahl der Borstenhöcker neben der geringen Zahl der Bauchpolster, die an der ganzen Lünge des Körpers vorhandenen Hakenwülste, auf denen mit Ausnahme der ersten sechs die IIaken alternirend verschränkt stehen, von Bedeutung.

Terebolla cetrata, n. sp.

$$
\text { Trif. 5i, Fig. 2-14. }
$$

Sordide bmunea vel behraeen subtiliter albide conspureata, vermifurmis, subparallela segmentis plus quam 63. Lobus cephalicus paullum dilatatus in parte postica brevi tentacula filiformia caualiculata haud longa gerens. Segmentun buecale a proximo nou distinetum, lobo cutaueo laterali rotundato bases tentaculorum partemque corporis oralem ab utraque parte amplectens. Segrmenta froxima duo coalita, sulutus scuto transverso utrimqque lobo eutaneo inciso munita, in dorso ntrimque branchiam et post illım tubereulum in cristam transversam humilem productum gerentia. Segmenta proxima 17 pimigern ct, excepto corum primo in dorso margiuem anticum 


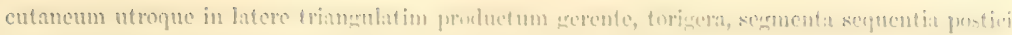

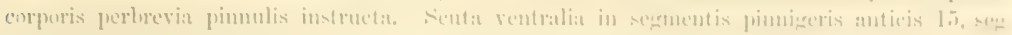
menta proxima in superticie ventrali per longitudinem non suleata. Branthia estipite crasen

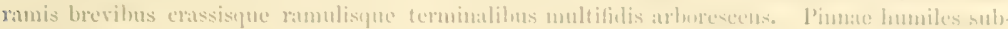

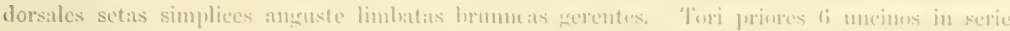
simplici, ceteri in serie parabolica alternes interealates, pimulate in serie simplici larevi forentes.

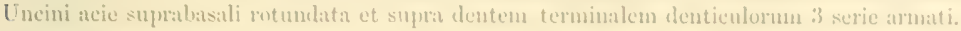

Hislo: key West, 1-2 lins,

Die Buschreibung dieser nu in einem und dibei nicht unverletwten Exemplare vorhandenen I'erebellide rechtfertight sich ramit, dass durch sie Orratnisationsverhälnisse in weiterer Entwicklung bekannt werken, welche eine bestimmte Entwicklungsrichtung imneihalb dieser fimilic kennzeichnen.

Der durch Verstimmelmug des IInterentes wohl nicht viel von des urspringlichen Liinge verkïrte $\mathbb{H}$ urm war $2+\mathrm{mm}$. lang und bei einer gleichmässigen Dicke in seiner ganzen Lïnge 2mm. breit; ich ziihlte an ihm 63 Segrmente. Die vordere Körperstrecke war völlig drehrund, an der hinteren Körperstrecke dagegen die Ventraliliche abgeplattet. Mit Ausnahme an den vorderen schmutzig bram grefirbten Segmenten war die Körperwand durchscheinend und dam gelblich grau; iiberall an dichtesten aber auf den vorderen Segrmenten mit kleinen kreidigweissen opaken Piinktchen besiiet, welche an einigen der Segmente aus dem mittleren Körpertheil an den Segmentgrenzen in Querlinien standen. Diese Fleckchen verdanken vielleicht Hautdritsen und deren Secret ihren Ursprung.

Der Kopflappen, das Buccalsegnent und die beiden näichsten Segmente, wie ich sie auffasse, bilden zusammen eine Einheit, welche durch eine besondere Ausgestaltung des Vorderrandes des ersten Borsten tragenden Segmentes von der dahinter folgenden Reihe der Segmente scharf alogegrenzt werden. Seitliche mehr oder minder weit nach der Ventralflaiche sich erstreckende nach vorn gerichtete Hautlappen der 3 vorderen Segmente umfissen die Seitentheile, and zum Theil die Ventralfläche dieser Region. Wie diese Lappen mit freien Kanten dorsalwärts rorragen, lassen sie die Rüickenfläche dieser Region, auf welcher das eine Kiemenpar steht, um so mehr vertieft und eingesunken ersclieinen, als die hintere Grenze derselben durch den gleichfalls saumartig frei vormagenden Vorderrand des ersten Borsten tragrenden Segmentes gebildet wird (Taf. 52, Fig. 9). Damit scheint cine Parallelentwickluno gegeben zu sein mit derjenigen, welche unter den Ampharetiden in der Gattung Melimua den dorsalen geziilnelten Hautsaum hervorgebracht hat. 
1) Iñuflippeni besteht aus einer Nacken- und Lippenplatte. Die Xitekemplatte ist die schmiilere von beiden, nicht blattartig erhoben, sondern piatt und mit kuren Lingsfurchen, vielleicht den Ursprumgstellen abgefallener Tentakel bedeckt. Gegen das Bucealsegment ist sie durch eine tiefe Furelse alogegrenzt. Iuf ihr stehen in 2 lateralen Biindeln, bei völliger Erhaltung vielleicht durch cine uedime lieihe verbunden, die meist kurzen mit tiefer Lïngsurehe und welligen lïndem versehenen, theilweise durchscheinenten T'entakeln, von denen die lingsten, wie sie jełzt vorlagren, etwa der Lïnge der vorderen S Segmente gleichkamen. Das Lippenblatt, welches kaum rou der Nackenplatte getrennt erseheint, ist wenig ausgedehnt, grosswellig gekrïuselt, und deckt nur ron oben her die Region des Mundeingimgers.

Dis Buccalsegment ist von den zuniichst folgenden Segmenten durch Furchen nicht geschieden; der ihm gehörende Bezirk ist auf der Riickenfliche eben, an den Seitenflaichen erhebt sich jerlerseits ein nach vorn grerichtetes straffes IIautblatt, welehes mit abgerumdetem Vorderrande seitwairts die Ursprungstheile der am Kopflappen entspringenden Tentakel umfasst, und auf der Tentralfliche gregen die Medianlinie soweit herumgreift, dass nur ein schmaler medianer Streif der ventralen Fläche nicht bedeckt wird.

Die auf das Buccalsegment folgende, ein Kiemenpaar tragende Strecke betrachte ich als aus 2 Segmenten, die völlig verschmolzen sind, zusammengesetzt. Auf der ventralen Flikche liegt hier eine Platte, welche gegen das Buccalsegment wie gregen das nach hinten folgende erste Borstentragende Segment durch scharfe Furchen abgesetzt und doppelt so breit als lang ist. Der seitliche Uufang der Strecke, zu welcher diese ventrale Platte grehört, greht in ein IIautblatt iiber, welches nach vorn gerichtet sich iber den hinteren 'Theil des Seitentheiles jenes Blattes legrt, welches dem Buccalsegment zugerechnet ward; dorsalwäits aber reicht dieses Blatt weiter als das voranstehende, wird aber dabei verkiirzt und geht mit einem schrïg nach hinten und medianwärts abfallenden Rande bis zur hinteren Sergmentgrenze. Etwa an der Stelle, wo beim Uebergang von der Seiten-auf die Bauchfläche die Verkiuzung dieses Blattes erfolgrt, sehe ich vom freien Rande gegen den Ursprung einen Einschnitt verlaufen, durch welchen von dem grösseren Theile des Blattes ein oberer kleiner wie cin selbstindigrer Lappen abgetrennt wird; vielleicht ist aber diese Abtrennung lieine natürliche, sondern durch Bruch enstanden; das habe ich nicht entscheiden können (Fig. 10). 
Anf der dorsiden Flidehe stehen nun die beilen greich zu beschreibenden Kiemen und hinter jealer dersefloen grewaht man einen kleinen selarfkantigen Hëicker. Diever lleicker aber ist, wie ich mich iiberzengte, als ich rlie betreflenden theile von einander hoge, die frei anslatende, scharfwinklige Eeke eines niedrigen Hantsammes, der sich jerlerseits lateralwairts gregen die mediane Elaiche des eben beschriebenen Ilatblattes verlolgen liisst, und etwa an der seitlichen Grenze der Riickentliche in dieses IIathlatt iibergeht (Fig. 9). Dieser kleine Inutsaum, der, da er zum grössten 'Theil von dem grossen Seitenblatte verdeckt wird, nur sehwer wahmehmbar ist, bezeichnet vielleicht eine Grenze zwischen 2 Segmenten, deren Verschmelzung ich anzunchmen geneight bin, da alsdann in der Vertheilung der Borsten auf die einzelnen Segmente eine Ueberemstimmung dieser Art mit anderen I'erebellen erreicht wird. Fs wïrde dann dieser kleine Hautsam einem zweiten, das grüssere Hautblatt aber dem 3ten Segmente zuzuschreiben sein. Damn aber gehört das einzig vorhandene Kiemenpar demjenigen Bezirke an, releher hinter dem Buccalsegment, ohne auf der lïickenlläiche von diesem gesondert zu sein, das erste derjenigen Segmente darstellt, welehe bei anderen Terebellen die Kiemen tragen. Diese Auffassung andert sich anch nicht, renn man in dem Hïcker eine nicht zur Tollendung gekommene oder rudimentär gewordene Kieme sehen will. Die Entwicklung der bammförmigen 'Terebellenkiene von einer leistenförmigen Erhebung giebt solcher' Anschauung eine gute Grundlage.

Die einzelne Kieme ist baumförmig; ein kurzer dicker Stamm giebt eine Anzahl (6) ron Zweigen ab, welche an Dicke wenig hinter dem lualben Durchmesser des Stammes zurïckbleiben und entweder unmittelbar oder durch Vermittlung kurzer und diuner Aeste die terminalen einfachen oder gabeligr getheilten, immer aber kurzen, Kiemenfäden tragen (Fig. 12). Die Kieme ragt mit ihren Endverzweigungen ïber die Rïuder der seitlichen IIantlappen hervor, nach vorne gelegt ïber die Ursprungstrecke der 'J'entakel, aber kaum bis an den Vorderrand des labialen Koptlappentheiles.

An diesen Kiemen tragenden Tordertheil schliesst sich dic Reihe der Borsten tragenden Segmente, in weleher die ersten 17 Segmente jederseits einen niedrigen kegelförmigen \#̈̈cker mit bräunlich refäibten Capillarborsten, und, mit Ausnahme des ersten dieser Sermente, einen Querwulst mit Hakenborsten tragen, während die dahinter folgenden Segmente jederseits je ein kurzes Flösschen mit FIakenborsten besitzen. Von den Segmenten, welche ein dorsales Borstenbiindel besitzen, tragen die 15 vorderen deutlich 
kenntliche mediane Ventralplatten, doch sind die 4 letzten derselben nur schwach alswepriigt; an den folgenden Segmenten ist die Ventralfliche cben: eine mediane Furche fehlt. An den Sermenten der hinteren Körperstrecke sieht man in der medimen Strecke der einzelnen Segmente weissliche amiähernd oblonge l'lecke, welche wohl anf die durchscheinenden Nerrenknoten zuriickzufïihren sind (Fig. 11.). Die einzelnen Segmente sind auf der Ventraltliche alle dureh Querfurchen von einander getrennt; auf der dorsalen Flähe sind nur die vier vorderen in dieser Segmentreihe durch scharfe Furchen von einander geschieden; weiterhin fehlen hier die Segmentygrenzen völlig.

It as die Dimensionen dieser Segmente betrifft, so sind die beiden vorderen kiirzer als die zunäehst folgenden; denn während die mit Capillarborsten versehenen Segmente im Allgemeinen viermal breiter als lang sind, hahen die beiden ersten im Breitendurchmesser etwa das Sechsfache der Lïnge. Die Flösschen tragenden Segrmente der hinteren Körperstrecke verkiirzen sich erheblich, und sind durehschnittlich achtmal breiter als lang.

Zu Einzelheiten ibergehend hebe ich zunïchst die bereits oben erwähnte Bildung des Vorderrandes des ersten Borsten tragenden Segmentes hervor. Der merliane Theil dieses Vorderrandes, welcher nicht ganz ein Drittel der Segmentbreite einnimmt, erhebt sich als ein nach vorn convex abgerundeter Saum, welcher frei iiber die dadurch vertieft erscheinende Fläche der vorderen Körperstrecke vorragt. Diese Saumbildung des Vorderrandes erstreckt sich jederseits ron dem medianen Lappen weiter, und zwar derartig, dass der Saum hier zu einem mit der Spitze nach rorn gerichteten dreieckigen Lappen ausgezogen ist; die Spitze dieser jederseits stehenden Lappen ragt etwas weiter nach vorn als die hüchste Wölbung des convexen Vorderrandes der mittleren Strecke. Auf der Ventralläche fehlt die Saumbildung völlig (Fig. 9, 10).

Die Höcker, welche an den erwähnten vorderen 17 Segmenten Capillarborsten tragen, sind ganz niedrige stumpfe Kegel, welche am seitlichen Umfange der Segrmente, aber fast auf dem Uebergange zur Dorsalfäche stehen, von den unter ihnen stehenden Haken tragenden Wuilsten völlig getrennt. Die aus ihnen hervorragenden Borsten, welche zumal an den vorderen Segmenten, so lange sie zusammenliegen, brïunlich erscheinen, sind kurze, gerade, auf der Endstrecke jederseits gesïumte, mit einfacher Spitze auslaufende Capillarborsten (Fig. 13). 
Die Wiilste, welehe die Hakenhorsten traten, sind anf den ersten ihree Segmente wenig, weiterhin dagegen allseitig schat' mmandet. - Dic Flüsschen, welche hinter dem letaten Capillarborsten tragenden semmente pliit\%lich in der Grösse mol Ausbildumer anfreten, welehe sie weiterhin behalten. sind mässig dicke, fast panallelwandige blitter, welehe seitlieh gremaleats. gerichtet nicht ganz soweit vorspringen, als die sie tragemben segnente lamg sind; ihr Durchmesser von vom nach hinten bleibt hinter der habben Segrmentlinge zuriick; ilıre Höhe entspricht etwa ihrer grössten seitlichen Erstreekung; ihre Endiliiche ist geracle al)gestutzt (lïg. 11).

Die Ilakenborsten, deren Kathl auf den Flisschen erheblich kleiner als aul den Wïlsten ist, haben eine völlig abgerundete Basalecke mnd einen schwach hakenfürmigg gekrimmten Hauptzahn, auf dessen Scheited in einfacher Qnerreihe 3 Nebenzihne stehen (Fig. 14). - Die IIaken bilden auf den 6 vorderen Wülsten eine einfache Querreihe, die Spitzen und Basalecke nach rorn wendend, auf den 10 folgenden Wiilsten stehen sie regelmiissig alternierend rerschränkt in einer Reihe; auf den Flösschen ist die kure Reihe wieder cinfuch mit der normalen Stellung:

Die medianen Bauchpolste: sind am 3ten bis 5ten Segmente wenig ausgebildet, entsprechend der Kürze der Segrmente viel breiter als lang, weiterhin treten sie schärfer hervor und sind dam fast quadratisch.

Das Thier steckte in einer leicht zerbrechenden mässig dicken glatten Schlımmröhre.

Die Verwandtschaftbeziehungen dieser Art liegen klar vor: sie schliesst sich an diejenigen an, für welche Malmgren die Gattungen Axionice und Scione errichtet hat, gehört aber bei der Characteristik, die diesen Gattmugen gregeben ist, in keine derselben. Ich halte es zur Zeit fiur nicht geboten, eine neue Gattung für diese einzelne Art zu errichten, oder die zusammengehörenden Arten schon in einer neuen Gattung zusammenzufassen. 


\section{SABELLIDAE.}

\section{BRANCHIOMAi (Koell.) Clap.}

\section{Branchiomma lobiferum, n. sp.}

Taf. 53, Fig. 10-15.

Subparallelum depressum, brunneum postico versus fulrum, toris et raris in branchia maculis nlbidis; segmentis 81. - Branchia utraque in lamina basali brevi semiorbiculari radios 21, subnequales, in rhachide mula filis hranchialibus sub apicem paullum minoribus, singnloque oculo composito subterninali pedunculato sulghoboso, meliorum dorsalium mijore, a foliolo terminali superato munitos gerens. Lamina buccalis lobo impari carneo compresso albido bruneo-signato et utrinque lacinia plicata triangulari acuta. Segmentum buccale proximum nequans, collari integro humili in dorso paullum hinate, in superficie rentrali lobulis parvis productis contiguo, scuto ventrali transverso et in pimn fere dorsali setis capillaribus munitum. Segmenta sequentia thoracalia $\overline{7}$, priora quinquies latiora quam longiora, deindo breviora, ultima abdominalia 10 I2ies latiora quam longiora. Pimme humiles anticae subdorsales, tori thoracules serie uncinorum duplici sub pinna hamati usque ad scutum ventrale protenta muniti, abdominales uniseriales pinna vix duplo latiores. Setae capillares anguste limbatre. Uncini aviculares in vertice dentis terminalis mitella limato-crenata tecti, manubrio longo, abdominales minores; setre falcientes thoracales capillares in apice subcordate dilatatie. Scuta ventralia rectangula subquadrata, anteriora 8 sulco stercorali ventrali non dirisa.

Tubus rectus niger glaber, limo frustulis raris intermixtis indutus.

Hab.: Ker West, 1-2 fnis.

Das einzige Exemplar welches ich von dieser Art gesehen habe, ist durch einen queren Bruch in der vorderen Körperstrecke getheilt, doch lassen sich die Bruchfächen in solcher Weise an einander legen, dass die gegebene Abbildung (Taf. 53, Fig. 10) gefertigt werden konnte, und dass die Sicherheit bestand, es sei durch den Bruch kein wesentlicher Theil fortgefallen.

Das Thier war ohne Kiemen $40 \mathrm{~mm}$. mit diesen $56 \mathrm{~mm}$. lang, die grösste fist in der ganzen Länge des Körpers gleiche Breite betrug 5,5rnm., so dass der Körper im Allgemeinen 9mal so lang als breit ist; Rücken- und Bauchfläche sind fast gleichmässig abgeplattet, der Körper vorn etwa halb so hoch als breit, am Hinterende ziemlich rasch sehr viel stärker abgeplattet und zugespitzt. - Die bräunlich gelbe Färbung der grössten Strecke des Körpers geht nach rom in ein dunkles Braun über, welches an dem Kragen des 
ersten Segmentes und an den Sehnden der Kiemenstrahlen am tiefsten ist. Auf der brämulichen Grumblinbe der vorderen segmente treten weisslich die Jisken tragenten Wiilste heraus.

Der Kïrper besteht aus 8 !) Segmenten, von denen mit lïinschluss des bucealen. 8 thoracal, und 73 abelominal simt.

Aut der steil abfillenden Kopflitiche bildet die nïhlste Umgebung der Mundoffnmg das nach innen vou der Kiemenbasis stehende Buecalblatt. Dasselbe besitzt bei dieser Art eine Bildung, welche meines Wissens bis jetzt nicht beschrieben ist, indem man einen umparmen Lappen von parigen zu umterscheiden hat. Der mediame umpare Lappen steht dorsalwaits rom Mundeingang: zwischen den dorsalen Basalecken beider Kiemenblïter, ganz nur dann zu übersehen, wem diese auseinander gebogen sind, liegt plattenartig cin durch grö̈sere Festigheit ausgezeichnetes Feld, welches fast quarlratisch ist, einen nach rom convexen Vorderrand besitzt und auf' seiner freien weiss gefürbten Oberflïche mit zwei feinen bramen Linien grezeichnet ist, welche jederseits in geringem Abstande von der Medianlinie in ihrer Mitte schwat convex gegen dieselbe gekrimmt sind. Seitwirts schliesst sich jederseits an dieses Feld der Basaltheil des Kiemenblattes an, nach hinten stösst es an die braun gefïbte Dorsalliiche des ersten Segmentes; unter seinem Vorderrande aber erhebt sich frei vorspringend der umpare Lappen, welcher seitlich comprimiert eine obere und untere Kante besitzt, die, wie der Lappen nach vorn sich zuspitzt, am abgerundeten schmalen Vorderende desselben in einander übergehen; die Grundfurbe dieses zungenfümigen Lappens ist weiss, auf der dorsalen Kante aber verläuft eine feine brame Längslinie und von dieser zweigen sich feine Querlinien ab, welche etwas unregrelmässig, schwach wellig gebogen, auch wohl einmal gabelig sich theilend über die seitlichen Flächen des Lappens zur unteren Kante verlaufen. Die Lïnge des ganzen Gebildes, gemessen von dem hinteren Rande der Platte bis zur freien Spitze des Lappens, beträgt 2,5mm. ; der freie Lappen selbst ist etwa $1,75 \mathrm{~mm}$. lang; seine Länge ist also etwa $\frac{1}{9}$ der Kiemenlänge gleich (Fig. 14).

Die parigen Seitenlappen stellen eine braun grefärbte diume Hautplatte vor, welche derartig zu einem medialen und lateralen Blatte zusammengefaltet ist, dass der geschlossene Scheitel der Falte dorsalwairts gewendet und unmittelbar neben dem unparen Lappen jederseits zu einem dreieckigen spitz auslaufenden Zipfel ausgezogen ist, wïhend der schmale Eingang zwischen die beiden eng an einander liegenden Faltenblätter ventralwärts geöffnet ist (Fig. 14). 
Das mediane Blatt endet mmittelbar unter der Basis des mparen Lappens, das laterale Blatt aber erstreckt sich neben dem Mundspalt und iiber diesen hinaus bis an die Ventralfliiche des ersten Segmentes. Jede derart zu einem Doppelblatt gefiltete Platte ist dex Flaiche nach in eine Anzahl, wie es scheint, umegelmissiger Falten rom oberen Scheitelrande her zusammengelegt, che sie in den spitz dreieckigen '/iplel ausliuft; vor dessen Basis war cin kleiner zahnartiger Ausschnit des einen Randes auffallend benerkbar. Die fialenfömigen Zipfel, die 'Tentakel oder Tentaknlareiren mancher Autoren, ragen fast um ein Drittel mehr als die Spitze des unparen Lappens. hervol,

Das Kiemenblatt jeder Seite ist halbkreisförmig grekrimmt; die dorsalen Basalecken etwas von einander getremnt, die ventralen schwach eingerollt und so, in dem mir vorliegenden Zustande, einander berihrend. Jedes Kiemenblatt hat eine sehr niedrige Basis, welche iiber den Rand des Kragens des ersten Segrmentes kaum hinwegragt, und trägt '21 gleich- oder fast gleichlange Kiemenstrahlen mit langen Kiemenfiiden und je einem subterminalen halbkugeligen zusammengesetzten Auge. Die Farbe der Kiemenstrahlen ist pupurbraun, an einigen der ventralen Kiemenstrahlen findet sich als Andentung eines Querbandes auf dem inedianen Umfang der Strahlen und dem Wuzeltheile ciniger Fäden ein weisser Fleck, der nur bei Entfialtungr der Kieme sichtbar wird. Der schlanke Sehaft der Kiemenstrahlen ist fist gleich breit in seimer granzen Läinge; die Kiemenfäden stehen dicht gedrängrt, sind lang und schlank und nehmen nur erst kurz vor der Spitze der Strahlen etwas an Lïnge zu. Ich schäzte ihre Zahl an einem der mittleren Kiemenstrahlen auf gegen 200 Pare. Ueber dem letzten Kiemenfarlen erhebt sich am medialen Umfang des Strahles wie mit einem kurzen dicken Stiele das subterminale Auge, welches an den dorsalen Strahlen grösser als an den ventralen ist; und zwar sind die Augen der beiden medianen dorsalen Strahlen vor ituren Nachbaren durch plötzlichen Grössenzuwachs ausgezeichnet. Das einzelne zusammengesetzte Auge stellt den grösseren Theil des Abschnittes einer Kugel dar, deren Durchmesser an den grösseren Augen grösser, an den Augen der ventralen Strahlen kleiner als der Querdurchmesser des Schaftes ist; es ist durch blauschwarzes Pigment dunkel gefärbt, aus dem dunklen Grunde sehen hell die lichtbrechenden Kürper, von gemeinsamer feiner Cuticula gedeckt, heraus. Die Kahl der einzelnen Augenkegel, welche gegen eine aus dem Augenstiel zu der höchsten Wölbung des Auges gezogene Achse gerichtet sind, wechselt mit der Grösse des ganzen 
Auges. - In den Augenstiel sells tritt die knorpelige Achxe des strables neht hinein; hier rerlinlt, von hohen Ephlhelien ungehen, ein Stuang von Fasern. welehe wohl zum gröisten 'Theil nervös sind. - Leh halbe das Augre, dem Gebranch folgend, als suhteminal bezeichnet; diese bezeichmum ist nur insoferm zutreflend, als sich iiber das Auge hinwer ein vom iusseren Umtang des Kiemenstrahles abgehender etwas ahgeplatteter Faden erhebt, der fist doppelt so lang als das Auge mit seinem stiele und 1-Gmal linger als breit ist. Diesen Faden fisse ich als einen Anhange des Kiemenstrahles anf, der jenen Fididen zu vergleichen ist, welshe augenlidartig an den Suhaftstïndigen Augen der Kienenstrahlen anderer Sabellen stelen, und zwar sehe ich in ilm nicht das Endstiick des Strahles, sondern einen Anhang desselben, weil die knorpelige Achse des Strahles hinter dem Auge zugespitzt endet, und nicht eimmal, wie in die Kiemenfiden hinem, in diesen Anhangr einen Auslaiufer sendet. Dagegen liegt in der Achse dieses terminalen Anlianges eine Fortsetzung des Blutraumes aus der Axe des Strahles; von den Kiemenfiiden unterscheidet sich dieser Anhang schliesslich durch den Mangel von Wimperharen (Fig. 12, 18).

Die Körpersegmente unterscheiden sich unter eimander zunäichst in ilıen Dimensionen: die thoracalen sind 5mal breiter als lang, die ersten der abdominalen etwa 6mal, diejenigen des hinteren Körperdrittels dagegen 10-12mal breiter als lang.

Das erste Segment trïgt den niedrigen nach vorn gerichteten Kragen, dessen beide von cinander getrennte, übrigens ganzrandige Hälften in der rentralen Mittellinie sich berïhren, auf der Rüickenfläiche digegen durch einen kleinen Zwischenraum ron einander getrennt sind. Seine Höhe, melche die Linge des Segmentes nur wenig iibertriftt, ist in der ganzen Erstreckung fast die gleiche; nur die vorderen Tentralecken jeder Hälfte sind zu einem kurzen aufrecht stehenden stumpf dreieckigen Lippchen erweitert; die medianen Dorsalränder sind ein wenig eingerollt. Das Segment trägt jederseits an der Flanke, aber der Rïckenfliche sehr genähert, einen niederen stumpf kegelfürmigen Borstenhöcker mit gesiumten Capillarborsten, wie sie in den folgenden Segmenten stehen. Auf der Ventralläche steht ein queres medianes Bauchpolster, das etwa doppelt so breit als lang ist, dessen Seitenränder schmach winklig nach aussen grebogen, während Vorderund Hinterrand gerade und parallel sind (Fig. 10, 11).

Die folgenden 7 thoracalen Segmente tragen jederseits den Borstenhücker, welcher je weiter nach binten, um so mehr gegen die Ventralfäche riickt. 
Suine Capillabborsten siml kur. und lings der Endstrecke jederseits mit einem wenig verbreiterten, fein schrig grestrichelten Blitte gesiiumt. Unter ihmen steht der weisse quere Wrust, weleher vom seitenramle des Bauchpolsters bis an die Bisis des Borstenhöeker's sich erstreckt. Die Doppelreihe der Borsten zieht sich quer iiber seine ganze Ausdehmung hin und biegt an der Basis des Borstenhöckers hakenartig nach hinten um. Die zahlreichen Bolsten der hinteren lieihe sind sehlanke aviculare die Iauptspitze nach vorn wendende IIaken, deren Ścheitel kappenartig wie mit dichten Feilkerben gedeckt ist, welche bei Eimwirkung von Salpetersiure in feine IJärchen anseinander weichen; die Seitenflächen des Hakens sind lingsstreifig (Fig. 15). In der vorderen Reihe stehen, zu den einzelnen Haken gehörig, Borsten, welche theils stumpt nadelfömig sind, theils an der Spitze ein fast herzfömiges diinnes Blatt tragen; die erstere form ist wohl ans der zweiten hervorgegangen. - Die umparen medianen gut ausgeprägten Bauchpolster sind wenig breiter als lang, ihre Seitenrinder sind concav ausgrerandet, Vorler- und IInterrand gerad und parallel unter cinander; die benachbarten Polster stossen dicht auf einander.

Mit dem 9ten Segment beginnt mit dem Borstenweohsel die Reihe der Abdominalsegnente; die kleinen stumpf kegelförmigen Borstenhöcker sind bis auf das Niveati der Bauchfliche gerückt und tragen ein kleines Biindel capillarer Borsten, welche soviel ich an den erhaltenen gesehen habe, von denen der thoracalen Segmente in der Form nicht abweichen. Dorsalwïrts ron diesem Hücker steht, ohme ihn zu berihhren, doch nahe iiber ihm der quere weisslich gefürbte Wulst, etwa doppelt so lang als die Basis des Borstenhöckers gross, mit nur einer Reihe von IIakenborsten, welche in der Form mit denen der thoracalen Segmente iibereinstimmen, aber erheblich kleiner als diese sind. Von den medianen Bauchpolstem ist dasjenige des ersten abdominalen Segmentes unpaar; an allen folgenden Segmenten trennt die mediane Kothfurche ${ }^{1}$ diese Polster in 2 gleiche Hälften, welche durch etwas wulstförmig aufgeworfene Ränder allseitig, mit Ausnabme gegen die Kothfurche scharf begreuzt sind. Dic Bauchpolster behalten in der ganzen Liinge des Kürpers, mit Ausnahme der letzten Segmente, an denen sie undeutlich werden, fast die gleiche Breite; da aber die Segmente sich verkiirzen, so wird dann das einzelne Bauchpolster fast doppelt so breit als lang.

${ }^{1}$ Ich nebme Claparede's Bezeichnung dieser Furche an, bemerke dazu, Ilass das Verhalten dieser Furche lee ein und derselben Art selır wechseln kimn; von Spirogray,his Spallanzanii kenne ich Exemplare, bei denen - im Leben - sämmtliche Bauchpolster der thoracalen Segmente durch diese Furche getheilt waren. 


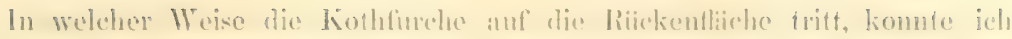
wergen der Verletzmng des Thiores nicht entichediden.

Dex Alter steht and einem winzigen Katplen, an welehem bosondere Anliinge fehlten.

Ku dem 'Thiere gehoirt eine glatte diumwandige mit feiner Schlammschichte bedeckte und von nur ganz vereimzelten festkïrpern incrusticrte liöhre, wenigh linger als der Wrum.

Die Art steht nach der Grïse und Segmentzahl dem Jirenchimma Köllikeri (Clip.)' nalie, unterseheidet sich von diesem dadureh, dass die beiden ventralen Kiemenstrahlen an Linge von den ïbrigen haum abweichen und wie alle iibrigren Strahlen Augen tragen. Beides ist bei brunchiummu lubifinm nicht der Fall; hier ist, auch abweichend ron dem Verhalten bei unserer Art, das Auge nicht rom 'lerminalbliittehen iiberragt; so zeirgt es wenigrtens Claparède's Abbildung. Ferner soll Branchiomma Köllikeri:2 Par von T'entakeln besitzen, wihrend bei dieser Art nur ron einem solehen die Rede sein kamn. Ich finde in Claparede's Beschreibung nichts erwiihnt, was ich auf den Carunkelartigen Lappen beziehen kömnte; und schliesslich ist bei der neapolitanischen Art der Kragen in 6 Lappen zertheilt, wiihrenr hier ja jede Hiilfte ganzrandig ist.

Niiher steht vielleicht das Branchiomma resiculosum (Mont.)." Sehe ich dabei, wie bei der vorigen herangezogenen Art, von den Unterschieden der Färbung und Zeichnung ab, da diese wohl umbestiindig sind, so stimmt die Art mit unserer durch den ganzrandigen 2theiligen Kragen iiberein, weicht aber durch ein anderes Verhältniss der Kiemenlïnge zur Körperlänge ab und durch das sehn kurze Terminalblättchen über den Augen; die Erwithmung zweier membranöser Lappen in dem dorsalen Zwischenraum der Kragenrïnder passt nicht zu dem spitz ausgezogenen Lappen und der umparen Cirumkel, welche das Brunchiomma lobiferum auszeichnet; das Branch. vigiluns, melches Claparede ${ }^{3}$ beschrieben hat, fällt ausser Betracht, da es eine sehr viel grössere Zahl von Segmenten und einen vierlappigen Kragen besitzt.

Sabella acrophthulnos (Gr.) von den Philippinen, welche dem Branchiomma resiculosum nahe stehen soll, unterscheidet sich durch andere Kragenbildung und sehr kurze Buccallappen; auch ron ihn ist ein medianer Lappen nicht erwähnt.

\footnotetext{
1 Claparède, Les Anuélides poltrchètes du Golfe de Nap̣les a. a. O. pag. 423.

2 Cfr. Clapuride, a. a. O. pas. 424.

3 Claparède, Lés Annélides dn Gulfe de X̃aples. Supplément a. a. O. pag. 137.

1 Grube, Amulata Semperiana, a. a. O. pag. "2ss.
} 


\section{Branchiomma bioculatum, n. sp.}

$$
\text { T'ty is, Fiy. 1-9. }
$$

Sulteres, paullum depressum; pallide ochracenm, in branchin vitta transrorsa singula lata bruneum: sementis DS. Branchia climidia corporis longitudine brevior, in utraque lamina basali humili semiorbiculari radios 16 , molios longissimos, dorsalem singulum oculiferum panllo, rentrales hinos multo iis breviores, tilis bramehialihus in rhachide nuda brevibus, apice, excepto oculifere, simplice acuto instruetos gerens. Oeulus compositus in apice radii supremi dorsalis subclubosus vel prrifurnis, foliolo termimali perbrevi vix superatus. Segmentum buccale collari in durso late hiante, utrinque accrescente, ad superficiem ventralem in lohum trigonatum producto, contigno, in pinua subdorsali fasciculo setarum capillarim, et seuto ventrali proximo duplo fero majore munitum. Laciniae buceales utrinque 3 plientac triangulice, superjores longissimne neutac. Sexmentin sequentia thoracalia $\vec{t}$, anteriori ter fere lation quam longiora, posteriora bresiora, ultima 1 ties fere latiora quam longion. Mutatio pedum in segmento 9no. Pinnae humillimae setas eapillares utrinque late limbatas gerentes. Tori thoracales biseriales scuta rentralia non attingentes, ablominales uniscriales perbreres; uncini ariculares in rertice dentis terminalis mitella limato-crenata tecti, ommes manubrio elongato. Setre fulcientes thoracales sub apice spatulato-dilatatac. Scuta veutralia rectangula transversa, 9 anteriora sulco stercorali non divisa.

Tubus rectus albidus, fragmentis variis spissatus.

Hab.: 1. ํo. 26 , 110 fms., Lat. $24^{\circ} 37^{\prime} 5^{\prime \prime}$ X., Long. $83^{\circ} 3^{\prime} 6^{\prime \prime} \mathrm{W}$. 2. May 4, 1868, 5th Dredging, 91 fathoms.

Ein völlig erhaltenes aus seiner Röhre herausgrelöstes Exemplar dieser Art hatte eine Gesammtlinge von $73 \mathrm{~mm}$., wovon $47 \mathrm{~mm}$. auf die Läinge des Körpers, $26 \mathrm{~mm}$. auf die der Kieme kamen; seine mit Ausnahme der Körperendspitze in der gamzen Kürperlïnge grleiche Breite betrug 3,5mm.; dabei erscheint der Körper fast drehrund, da Rücken- und Bauchfläche eine fast gleiche, nur umbedeutende Abplattung besitzen. Der Körper bestand aus 97 Borsten tragenden Segmenten. - Die Farbe des Körpers ist ein fahles gelbliches Weiss, ohne besondere Zeichnung; die Grundfarbe des Körpers geht auf die Kieme über, wird aber hier durch ein breites queres Band von braungelber Farbe unterbrochen, welches auf den Kiemenstralilen liegt, und von diesen etwa das mittlere Drittel derartig deckt, dass die basale und terminale Strecke farblos ist.

Das buccale Blatt ist viollig paarig gretheilt; eine dorsale unpare Carunkel fehlt. Jede Hälfte des Buccalblattes bildet 3 ungleiche Lappen; von diesen sind die der Ventralfläche am meisten genährten, dreieckige in der Medianebene fast sich berührende platte Blätter, deren Spitzen kaum über den Rand des Collare hinausragen. Dorsalwärts von ihnen stehen jederseits zwei in solcher Weise gefaltete Blätter, dass der Scheitel der Falte dorsalwärts gewendet, der Eingang zwischen die Faltenblätter ventralwärts geöff- 


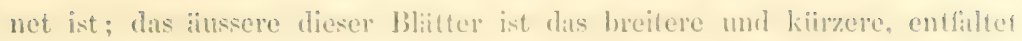

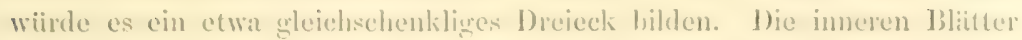
jeder Seite, welche zugleich am meisten dorsalwiits stehen met sich unter cinander in ihren basilen Theilen fist beriihen, sind durch eine schlank ausgezogene spitze um ein enhehliches ibher das lorderende der ausseren Blitter hinaus verlingert; ihr fialtenscheitel ist fast cristenatig zusammengedriekt, ihre Bliitter sind, ungleichnissig allerdings, der Fläche mach noch cimmal cingerollt. In cinem 'Thiere, dessen Kieme 2..), 5nmm. lang war, betrug die Linge dieser zugespitzten Buccalziplel 3,5mm. ('Taf. 533, Fïg. (i).

Die Kieme besteht aus zwei halbkreisfömigr grebogrenen Jlikttern, ron denen jedes auf einer niedrigen, wenig ïber das Collare himausragenden Basis 16 Kiemenstrahlen trïgt. Die einzelnen Strahlen sind ungleich lang: in jedem Blatte ist der am meisten dorsalwärts stehende fiaden um ein geringes kiirzer als seine Nachbarn; die mittleren Farlen eines jeden IBlattes sind am liungsten, und bedentend verkiirzt sind die beiden letzten Stralılen nach der Ventrallitiche zu, sodass der vorletzte etwa um litirzer als seine dorsalwärts stehenden Nachbarn, der letzte aber kaum so lang als dieser vorletzte ist. An den grössten Strahlen zählte ich etwa 110 Parre ron wenig langen Kiemenfiiden; die Riiekenfliche eimes jeden Strahles ist nackt; jeder Strahl lïuft mit einer kurzen nackten Endspitze aus. Der etwas verkiizte dorsale Strahl ist durch den alleinigen Besitz eines grossen subterminalen Auges ausgezeichnet. Es ist das ein kurz birnförmiger dunkel pigmentierter Körper, der bedeutend breiter als das Terminalstiick des Stralıles ist, und dieses in der Breite beträchtlich überragt, während der Endzipfel desselben ein renig ïber das Auge himausreicht (Fig. 1).

Die Fläche, mit welcher das Auge angeheftet ist, erscheint gegenuiber der hoch gewölbten freien Fläche, etwas abgeplattet, und iiber sie läuft damn, fast rinnenartig schmal, das Terminalstiick des Fadens limweg. Ton ihm gilt das Gleiche was bei der Besprechumg des Brunchiomma lobiferm gesagt wurde.

Von der Basis des pigmentierten Auges gelit eine durchscheinende fast membranös und flügelartig ausgespannt erscheinende Hautstrecke auf den Schaft des Strahles über. Aeusserst zahlreiche Einzelaugen, deren Menge die Zeichnung andeuten mag, sind in der Gesammtheit des Auges vereinigt (Fig. 4, 5).

Die Segmente des Körpers nehmen ron rorn nach hinten an Breite ab, und zwar sind diejenigen der vorderen Körperstrecke etwa dreimal, die der 
hinteren etwa 7mal, die letaten aber wohl $14 \mathrm{mal}$ breiter als lang. Das erste Semment, welches um die llillte linger als das zweite ist, träigt einen ans zwei IViilten bestehenden ganzandigen Kragen; derselbe erhebt sich jecterseits an den seitentheilen der Dorsallikiche rom hinteren Theile dieses Segmentes als cin niedriger; nach vorn gerichteter IIautsaum, so dass also der grösste 'Theil der medianen Dorsallibche völlig frei liegt; jede Kragenliillte wird dam, wie sie, ihre Ursprungshinie nach vorn sehiebend, nach der Ventralfliche herumgreift, hïher und liuft auf dieser mit einem uach vorn grerichteten, spitz dreieckigen Jappen aus, der etwas liinger als an seiner Basis breit ist; die medialen Kanten dieser beiden Kragenlappen berihren sich fast der ganzen Lïnge nach. Die freie dorsale Flïche des Segmentes ist in rler Medianlinie der Lïnge nach schwach vertieft; aus ihrem Vordertheile grehen ohne scharfe Grenzlinie die basalen 'Theile der Kiemenblïtter hervor (Fig. 1, 2) . - Am seitlichen Unfiange träigt dieses Segment nur den dorsalwirts stark rerschobenen kleinen Borstenhöcker mit Capillarborsten, auf der Ventrahiailfte ein grosses medianes Banchpolster, das an Länge und Breite die folgenden iibertrifft, und doppelt so breit als lang ist.

Die nithst folgenden 7 Segmente sind als thoracal zu bezeichnen, insofern als sie das dorsal gestellte Biindel Capillarborsten und den ventral davon stehenden queren Wulst mit Haken sowie das ungetheilte Bauchpolster besitzen. Am 9ten Segment erfolgt die Umstellumg der Borsten, das Bauchpolster dieses Segmentes ist noch einfach. Vom zehnten Segment ab halbiert die Kothfurche alle Banchpolster (Fig. 1).

In allen Segmenten sind die Höcker, welche die Capillarborsten tragen, so klein, dass sie nur wenig herrorragen. Die Borsten sind an der winklig rom Schaft abgebogrenen Endstrecke mit einem breiten Saume versehen (Fig. 7). Die queren Wiilste der thoracalen Segmente sind nicht gross, da sie alle nicht bis an den Seitenrand der Bauchpolster sich erstrecken. Sie sind doppehreihig, da vor der hinteren Reihe der Haken die mit einem spitzen spatelförmigen Blatte auslaufenden Borsten der vorderen Reihe stehen (Fig. 8). An den abdominalen Segmenten sind die dorsalen Haken. wiilste selı liurz; die eimreihig gestellten wenigen Haken, deren Form von derjenigen der thoracalen nicht abweicht, besitzen ein stabförmiges langes Basalstiick, und ein kurzes Hakenende, dessen Scheitellläche feilenartig grekerbt erscheint (Fig. 9).

Die einfachen Bauchpolster der thoracalen sowie die getheilten der abdominalen Segmente sind iiberall scharf abgegrenzt; sie nehmen ein Drittel 


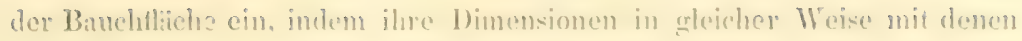
der seamente von vorn nate hinten sich indern.

Am Ilinterende des Kinpers steht die weite, von cinem feinen liandwulst

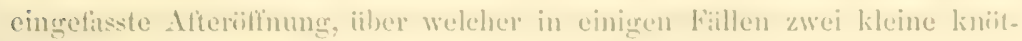
chenatige Anhïnge zu erkemuen waren ( kigig. 1).

Die Thiere erbanen Rähren. ileren gleichnassigr hell gran grefäbte Aussenfliche durch atul- und eingekittete Fragnente der merleichsten Art, aher der Grösse nach wenig verschieden, rauh war; dic meisten der noch besetzten höhren waren wenigr lïnger als der cingeschlossene Wrum ( lig. :3).

Die Art rechne ich zur Gattung Branchiomma, in welcher sie die Eigene thimblichkeit aufweist, dass allein die beiden medianen dorsalen Kienenstrahlen subteminale zusammengesetzte Angen tragen. Angrenleutet ist diese Bildung bei anderen Arten, wie bei Brunthomma Köllikeri (Clap.) und Lubiferum dadurch, dass hier die grenamnten Kiemenstrahlen Augen besitzen, welche diejenigen der tibrigen Strahlen an Grösse übertreffen. Ich habe keinerlei Anhalt gefunden, dariber zn entscheiden, ob der Besitz von nur zwei zusammengesetzten Augen den Anfang oder das Ende einer Entwicklungsreilie bezeichnet.

SABELLA L. (s. str. Sav. nec Mllmgr.)

Sabella melanostigma (Schmarda).

SchMard, Xene wirbellose Thiere, 1, I1, 1861. pag. 30.

Ein bei Tortugas, vermuthlich in Flachwasser gefundener Röhrenwurm lïsst in den meisten Beziehungen die Beschreibung, welche Schmarda von der bei Jamaica gesammelten Sabclle melunostigma giebt, auf sich anwenden, so dass ich annehme, das mir vorliegende Thier gehöre zu dieser Art. Dam ist es geboten, die unzulängliche Darstellung Schmarda's durch eine genatuere Beschreibung zu ererüuzen.

Das Thier ist $59 \mathrm{~mm}$. lang, von welcher Länge $20 \mathrm{~mm}$. auf die Kieme kommen, rorn $4 \mathrm{~mm}$. breit und etwa gleich hoch, in der hinteren Körperstrecke um $\frac{x}{3}$ verschmälert und abgeplattet; der zumal im vorderen und mittleren Theile ausgeprägt vierkantige Kürper hat 135 Segmente; Schmarda griebt nur $7 \pm$ Segmente an; da das von ihm beschriebene Thier nur $29 \mathrm{~mm}$. lang war, so ist der Unterschied in der Segmentzahl wohl lediglich als ein Alterunterschied aufzufassen. Die von Schmarla hervorgehobene ochergelbe 
Finbe fintiet sich an meinem Exemplar in gleicher Weise wie die auffallenden schwarzen Pigmentflecken an den libunken des Kürpers; doch ist nicht ein Fleck an jeder Seite eines Segmentes, sondern es steht jederseits ein Fleek je an der ventralen und dorsalen Kante; das erste dieser Fleckenparte steht bereits auf dem Basalblatt der Kieme, dahinter trägt die dorsale Bisallecke des Kiemenblattes einen grossen schwarzen Fleck neben den F'lecken des Buccalsegmentes; an den vorderen Segmenten ist der dorsale Fleck jederseits grösser als der ventrale, an den hinteren Segmenten ist das Verhältniss umgekehrt und es werden die dorsalen Flecke bis zum Verlüschen gering; hier scheint bei oberflächlicher Betrachtung jederseits am Körper nur eine Reihe von sehwarzen P'unkten vorhanden zu sein.

Die Kieme, welche in diesem Exemplar einfarbig und nicht, wie es Schmarda angiebt, brïunlich quer gebïndert ist, hat ein jederseits etwas mehr als halblieisfürmigg eingerolltes Basalblatt, welches iiber den niedrigen Kragen herrorragt, und auf diesem jederseits 19 gleichlange Strahlen; Schmarda griebt 17 an; dieser Unterschied ist bedeutungslos; dagegen scheint mir wesentlicher der Umstand zu sein, dass jeder Kiemenstrahl in weiten Abstiinden von einander vier oder fünf Paar schwarzer Augenpunkte trägt, welehe Schmarda ron seinem Exemplar nicht erwähnt; ich mag bei der sonstigen Uebereinstimmung diesen Unterschied für Aufstellung einer besonderen Art nicht verwerthen, da in diesen Bildungen offenbar erhebliche Variierungen eintreten können und Schmarda's Schweigen in Bezug auf diesen Punkt auch noch nicht umbedingt als Negation aufzufassen ist. Der Kiemenstrahl trägt eine Doppelreihe von Kiemenfïden, welche 10-12mal breiter als der Strahl, und ron einander um ihre eigne Dicke entfernt sind. Der Strahl läuft mit einer kurzen nackten Endspitze aus, welche einem Kiemenfaden :ihnelt; die Kiemenfüden treten fast unverkürzt bis da hinan. Blïttchen am äusseren Umfang sind nicht vorhanden. - Zwei schlanke spitz auslaufende Buccalzipfel, welche einem Viertel der Kiemenlïnge etwa gleichkommen, sind von einer derartig gefalteten Membram gebildet, dass der Eingang zwischen deren Blätter dorsalwïrts sieht.

Ton den Segmenten, welche den Körper zusammensetzen, sind unit Einschluss des Buccalsegmentes 15 thorncal; die vorderen Segmente sind etwa 6-Timal, die hinteren 10 mal breiter als lang.

Das Buccalsegment, länger als die folgeuden, trägt einen niedrigen Kragen, dessen Hälften auf der dorsalen und ventralen Fläche weit klaffen; der ventrale Rand des Kragens reicht bis auf die Höhe der ventralen Borsten; 
ich war anfinghlich der Meinmes, dieser Rand grehiere einem seitlichen Einselunitt an, und es sei der dazu grehörembe ventrale Lappen etwa abgefallen; doch komme ich eine dahin weisende Bruehstelle nielst sehen, sondern find die ventrale Flitehe des Buecalsegrmentes frei nach vorn anslatufen. An der dorsalen Basalecke träight der Kragen einen grossen dunklen lileck. - Die Riiekenllibhe des Bucealsegmentes fiilnt an vorkeren 'Tlheile mit einer

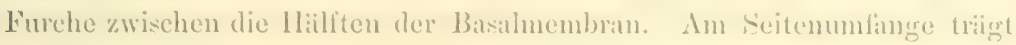
das Buccalsegment nur ein mit den dorsalen Biindeln der folgenden Serrmente in form und stellung iibereinstimmendes Borstenbiindel.

An ten folgenden thoraculen Segmenten sind die dorsalen Borsten, wie das von Schmarla hervorgehoben ist, zu einem ansehnlieh weit vorspringenden, groldgelb gefiirbten Bimdel veremight, welehes mit der Richtung nach hinten aus einem kegelfümigen liuderfortsatz hervorragt, der zwei häutige Liippehen trïgt; die Borsten, capillar, sind theils schmal, theils breit gresiimmt, letztere im Spitzentheil wie etwas verbogen; auch das hebt Schmarda her: ror; einen Ucbergang ron der schmalen frorm zu dler breiten, welche Schmarda als paleenartig bezeichnet, sehe ich nicht; aber dass diese Bezeichmung zutrifit, geht auch daraus hervor, dass die breiteren Borsten in mehreren Reihen neben einander den ventralen Theil des Biindels bilken. an dessen dorsalen Umfang die schlankeren, schmal gesïumten stehen. Unter diesem Borstenbindel steht eine einfuche Querreihe von Haken auf einem Wulste, der an seinem hinteren Rande membranös, fist flösschenartig verbreitert ist; die Querreihe ist, von den ersten abgesehen, so breit, dass sie sich über die ganze Flanke erstreckt; die Haken in ihr wenden die Spitzen nach rorn. Der einzelne Haken hat nur eine greringe stielartige Verlingrerung; iiber seinem spitzen Endhaken steht auf dem Scheitel eine kleine Kappe von Zähmchen. - Hinter der grossen Bauchplatte des Buccalsegmentes tragen die folgenden 9 Segmente eine rechteckigre Banchplatte, welche fast die ganze Segmentbreite deckt; von da ab sind die Bauchpolster der thoracalen Segmente um wenig mehr als $\frac{1}{3}$ der Segmentbreite quer ausgedehnt. - Der Borstenwechsel erfolgt am 16ten Segment. Die num rentral stehenden Borstenbündel bleiben gross und ragen aus ruderihhnlichen Höckern hervor; aber nur eine Borstenform, welche den kiirzeren breiteren Borsten der thoracalen Segmente entspricht, steht in ihmen, und bildet ein geschlossenes, ringsum zusammengelegrtes Biindel. - Der clorsale Haken tragende W ulst ist erheblich verkiirzt, weist aber noch den Flossensaum auf; die Haken sind wenig lileiner und von derselben Form als an den thoracalen Segmenten. 
Eine dentrehe liothfirche fehlt auf' den Bauchplatten, welche etwa $\frac{1}{3}$ der Segmentbreite decken.

1)as dftersegment ist einfach.

Der IV urm steckte in einer aus festem Schlamm verfertigten Röhre, entspricht auch darin dem von Schmarda gekemmeichneten Verhalten.

Funlort : Turturis.

Die Art gehïrt wohl in den Verwandtschaftskreis der Sabella manicata (Gr.). ${ }^{1}$ welcher sie in Färbung und Zeichnung nahe kommt, und mit der sie durch den Besitz von Lüppchen an den Rudern sowie ungetheilter Bauchpolster iibereinstimmt. - Wenn dieses letztere Kennzeichen - was ich bezweille - von Bedeutung ist, so ist die Subelle melenostigma auch von S. viola $(G r .)^{2}$ zu trennen. Dass ich diese nicht ohne Weiteres als Synonym mit S. melunostigma bezeichne, davon hält mich nicht sowohl die Anwesenheit nur eines Pigmentfleckes an den Rudern ab, als der Umstand, dass Grube von dieser S. violu Lïppehen an den Rudern nicht angiebt; weitere Unterschiede; wie eine ungleiche Lünge der Kiemen, und etwas abweichende Dimensionen der Segmente und Bauchpolster sind wohl von keinem grossen Belang.

Die Bezeichnung "Sabella" behalte ich fïr diese $\Lambda \mathrm{rt}$ in dem iilteren, weiteren Sime bei; in rler Begrenzung, welche Nalmgren der Gattung gegeben hat, passt dieselbe nicht fuir Sab. melanostigma, da sie auf den Hakenwülsten nur eine Reihe von grleichgeformten Haken trïgt. Sie wiirde danach und bei dem Mangel äusserer Kiemenanhänge in die Gattung Laonome (Mlmg.) zu stellen sein, passt aber nicht dazu, weil ihre Haken kurz gestielt sind und in den Borstenbuindeln die für Laonome characteristischen Paleen fehlen.

\title{
DASYCHONE (II. SARS).
}

\section{Dasychone conspersa, n. sp.}

\author{
Taf. 54, Fig. 1-C.
}

Elongatula, antice in dorso conrexa, postice subdepressa, attenunta, fusca nigro aspersa, branchiis dimillio corporis brevioribus rubro vittatis, segmentis 81 . Branchine in lamina basali brevi utrinųue radios 19, exceptis duobus rentralibus minoribus, fere aequales, filo nudo terminatos, fila branchialia permulta brevia, maculas oculares et foliolos externos 16-20 inacquales grerentes; laciniae buccales 2 breves superiores triangulae et inferiores 2 elongatae angustac. Segmentum luecale breve fasciculo setarum parvo et scuto ventrali munitum; collare humile bipartitum utrinque integrum, in dorso late hians, in ventre lobis paullum clongatis triangulis

1 Grube, Annulata Semperiana a. a. O., pg. 255.

2 Grube, Archiv fur Naturireschichte, Jhrg. 29, I. 1863, pog. $5 \mathrm{~S}$. 


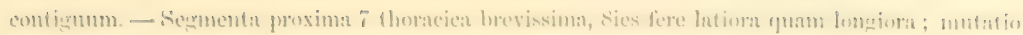

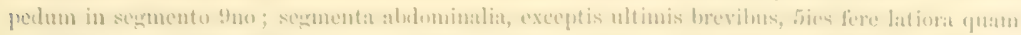

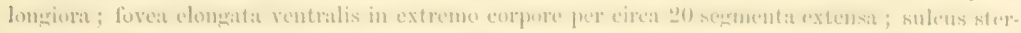

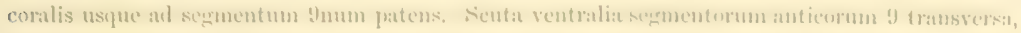

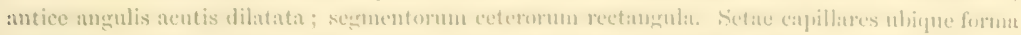

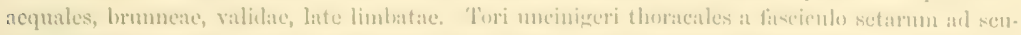
tum ventrale extensi; alulominales multo minores; meini nbique eatem format, abluminales vero minores, avienlates in vertice dentis pancis dentienlis hiseriatis armati, in seric simplici.

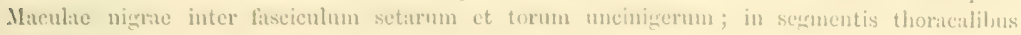
majores.

'Tuhus rectus temuis fianilis, intus pallide ochracens, extrinsecus limo obductus.

Ilab, : liey Wost, 1-2 fms.

Das einzig vollstiundig erhaltene lixemplar dieser $\Lambda$ rt hatte bei 87 Segmenten eine Gesammtlinge von $26 \mathrm{~mm}$., wovon $10 \mathrm{~mm}$. auf die Liinge der Kieme kommen. Die etwa am šten Segment gelegrene gröiste breite betrug $3,5 \mathrm{~mm}$, nach rom ist der Körper wenig schmïler, nach hinten nimmt er allmählich bis auf nicht ganz 2,5mm. Breite ab, verbreitert sich aber vor dem kurz zugespitzt endenden Aftertheil noch eimmal ein wenig. In Allgemeinen ist der Körper abgeplattet, nur im Bereich der mittleren 'Thoracalsegmente ist die Rüickenfliiche, gregenüber der fast ebenen Bauchfläche hoch gewölbt. Auf der hinteren Körperstrecke findet sich eine in der ventralen Medianlinie gelegrene lang ausgrezogrene muldenförmige Vertiefung. (T'af. 54, Fig. 1.) - Die Firbung ist bei allen Exemplaren ein bald helleres bald dunkleres fuchsiges Braun, auf dieser Grundfarbe sind in der vorteren Kürperstrecke kleine runde schwarze Fleckchen wie unregelmässig verspritzt vertheilt. An den Kiemen, bei denen die gleiche Grundfarbe vorherrscht, stehen auf den Kiemenstrahlen ziemlich dicht und unregelmäissig rothe Querbäinder, die Kiemenfaden sind streckenweis alternierend roth und bram. die ïnsseren Blättchen iiber den schwarzen Augempunkten im Basaltheil der Kieme an der Spitze braun gefürbt, weiterhin völlig roth.

Zum Buccalblatt zähle ich zwei kurze in der Merlianlinie sich beriihrende dreieckige Lappen, welche von dem zwischen den beiden Kragenhälften freigelassenen 'Theile des ersten Segmentes frei nach vorn gerichtet ragen, nicht so weit als die benachbarten Iappen des Kragens. Etwas tiefer, dureh die eingerollte Kieme bei nicht ansgrebreiteter Haltung durselben verborgen steht jederseits ein schlank dreieckig ausgezogrenes und zugespitztes einfach gefaltetes Blatt, den Faltenscheitel dorsalwärts, den Eingang zwischen die schmalen Blätter ventralwärts richtend. Diese schlanken Zipfel der Buccalmembran erreichen fast $\frac{1}{3}$ von der Länge der Kiemenstralılen. (Fig. 4.)

Die beiden Hälften der Kieme haben ein sehr niedriges Basilblatt, welches 
am ventralen Kande ein wenig cingerollt ist. Jerles Blatt träigt 19 Kiemenstrahlen. die mit Ausuahme der beiden zumeist ventral stehenden Strahien untereinmuler fist grleich limg sind. Von den beiden genamiten ventralen Strahlen hat der tiefst stehende kaum ein Viertel von der Lünge der vollentwickelten Strahlen, der zuniichst benachbarte ist doppelt so lang. - Die an der spitze mit einem dimnen nackten Endfaden auslaufenden ungegliederten stralulen tragen gegen 200 Par von Kiemenfïden, welche im Allgemeinen kurz, kaum dreimal so lang als der Strahl dick sind und an der Endstrecke des Strahles allmiblich an Lünge abnehmen. Am änsseren Unfinge des Kiemenstrahles stehen parweise in ziemlich regelmässigen Abstïnden von einander schwarze Augenflecken und schlanke Blittchen; im Allgemeinen hinter einem Piar von Augenflecken in einem bald grösseren bald kleineren Abstand ein Paar dieser Bliittchen, doch ist die Regelmässigkeit dieser Stellung mehrfich unterbrochen; so labe ich an einem Strahl 16 Paar Augenpunkte und 20 Par dieser Bliittchen gezïhlt. Der Abstand dieser Gebilde von einander ist derartig, dass auf ein Intervall zwischen je 2 Paaren der Blittchen etwa 10 Paar Kiemenfiden kommen. Die paarweis stehenden Bliittchen, deren Breite derjenigen der Kiemenfïden gleich ist oder sie um ein geringes iibertrifft, sind an Länge recht erheblich verschieden; indem sie bald das Intervall zwischen zwei Augenpunkten üherragen, bald kaum über den zunïchst vor ihnen stehenden Augenpunkt hinausgreifen. Solche kürzere und lingere BJät.tchenpaare wechseln mit einander ab, so dass, jedoch ohme Regehnissigkeit, ein lingreres Pitar meist zwischen mehreren kürzeren Patren steht, (Fig. 3.)

Das erste Segment hat einen aus 2 Hïlften bestehenden ganzrandigen Kragen; derselbe lïsst die dorsale Fläche dieses Segmentes fast völlig frei, erhebt sich jederseits am Seitentheile desselben mit einem frei vorragenden abgerundeten Lappen, setzt sich mit gleicher Höhe un den Seitenumfang des Körpers fort und läuft d:unn an der ventralen Medianlinie mit einem etwas längeren stumpf dreieckigen Zipfel aus; diese rentralen Zipfel der Kragenhälften liegen mit den medianen Rändern hart an einander und sind nach vorn gerichtet. - Am Seitenumfange des Segmentes, aber hoch gegen die Rückenfläche verschoben, steht ein kleines Bündel capillarer Borsten, welche mit denen der folgenden Segmente der Form nach übereinstimmen. Das mediane Bauchpolster ist rorhanden, aber nur schwach ausgeprägt. (Fig. 1, 2.)

Die folgenten 7 thoracalen Segmente sind sehr kurz, etwa achtmal breiter 
als lang; ihre Sermenterenzen sind anch and dem dorsalen Umfange gnt anserepright. Die dorsalen borstenhröker riicken je weiter nach hinten um so

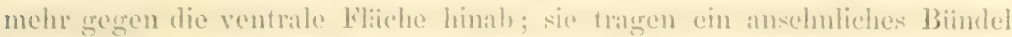

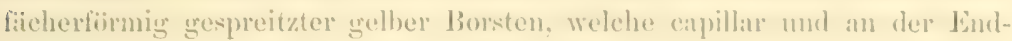
strecke jerlerseits mit cinem breiten l3latte fliigelartig gresiumt sind. (lïg. 5.) - Der IIaken tragende Wrulst tritt nur missig hervor, erstreckt sich aber von dep basis des Borstenhäickers bis an den Seitemand des medianen 13anchpolsters; er trïgt eine einfiche lieihe von Halien, deren Zahl ich bis auf 60 schïzte. Die IIaken haben eine cinfache, nicht stichtigr verlingerte Basis, und eimen mach vorn gerichteten spitzen IIaupthaken, auf dessen Seheitel wenige Zïhnchen in zwei Querreihen stehen. (Fig. G.) Zwischen dem oberen Raurle des IIaken tragenden Wulstes und dem unteren Unfaner des Borstenhückers steht ein augenïhnlicher, kreisfömiger schwarzer P'igmentlleck: (Fig. 2.) - Die medianen Bauchpolster sind trapezfürmig dadurch, dass ihr Yorderrand erheblich breiter als der. IInterand ist, welcher etwas mehr als ein Drittel der Bauchfläche eimimmt; dabei erseheint die Vorderecke eines jeden Bauchpolsters seitwirts stark, fast riemenartig, atusgezogen; und hinter dieser verlingerten Vorderecke stösst dam der Haken tragende Wulst an den Seitenrand des Polsters. Diese Bildung ist an den hinteren der thoracalen Segmente schärfer als an den vorderen ausgeprägt. (Fig. 1.)

Die abdominalen Segmente nehmen wie sich der Kärper verschmälert etwas an Längre zu, so dass das einzelne Segment etwa fünfmal breiter als lang ist; nur auf der letzten Koirperstrecke sind die Segmente wieder selir verkiurzt und fast $10 \mathrm{mal}$ breiter als lang.

Der Borstenwechsel erfolgt am 9ten Segmente, hier steht zuerst der Wulst mit Haken dorsal voun Borstenhöeker; das ungetheilte Bauchpolster hat aber noch die Form derjenigen, welche an den thoracalen Segmenten stehen.

Die dorsal stehenden kurzen, quer ovalen Wülste, welche von der Lïnge des Segmentes etwa ein Drittel eimehmen, in dorsaler Richtung sich nicht über die Seitenfläche hinaus auf die Rückenflïche erstrecken, tragen eine einfache Reihe von Hakenborsten, welche in der Form mit denen der thoracalen Segrmente übereinstimmen, nur etwas kleiner sind. Ich fand auf den mittleren der abdominalen Polster 20 Haken in normaler Stellung. Das aus einem kurzen Ḧ̈̈ker austretende Bündel der Capillarborsten, welche wie die der thoracalen Segmente gestaltet sind, ist hier nicht fücherförmig gespreitzt; sondern es liegen die einzeluen Borsten in ihm zu einem geschlossenen Bün- 
del vereinigrt. wetches damn seitlich oder nach hinten grewendet soweit vorspringent als dils Segment lang ist, unter der terminalen Zuspitzung eine Anftreibung besitzt, welche durch die Aneinanderlagerung der Fliigelsiume der einzelnen Borsten hervorgebracht wird.

Der an den thoracalen Segmenten unter dem Borstenbiindel stehende P'gmentfleck sitzt an allen abdominalen Segmenten über demselben, behält insofern sein Lagerungswerhiiltniss, als er zwischen den eapillaren und Hakenhorsten eingeschoben ist. (Fig. 2.)

Die merlianen durch die Kothfurche getrennten Banchpolster sind mit Ausnahme des schon erwïhnten ersten recliteckig, zusanmen doppeit so breit als lang und decken etwa das mittlere Drittel der Ventralfäche. - Die vor dem Afterende auf der Ventralfliche stehende im Grunde von der Kothfurche durchzogene grubenartige V'ertiefung, erstreckt sich iiber etwa 20 Segmente. Hinter ihr ist das Körperende nur undeutlich in sehr kurze mit geringen Borsten alusgeriistete Segmente zerlegt.

Die terminale schwach umrandete ziemlich weite Afteröffnung besitzt keinerlei Anhinge.

Die Thiere steckten in kurzen, wohl meist zerbrochenen, papierdünnen Röhren, deren äussere Oberfläche einen weisslich grauen äusserst dünnen, etwas feinkïmigen Ueberzug, wie von einem Kalkschlamm herrihrend trug, während die innere Oberfliche schwach gelblich gefärbt war.

Die Art steht der Dusychone Dulyelli (Köll.) (Das. argus M. S.) nahe, ist aber durch schlankeren Habitus, grössere Zahl der Kiemenstrahlen, andere Form der äusseren Kiemenblättehen und der Haken unterschieden. - Sabellct Lunncens ( $\mathrm{Kr}$.) aus dem westindischen Meere weicht schon durch ganz andere Bildung der äusseren Kiemenanhünge ab.

\section{HYPSICONUS (Gr.).}

Grube, Archir. für Naturgeschichte Jhrg. 36. 1. 1870, pg. 348 .

$\mathrm{Zu}$ den wenigen characteristischen Merkmalen, welche Grube für diese Gattung angegeben hat und unter denen die Längsreihe der Borsten des Buccalsegment wohl das auffallendste ist, hat v. Marenzeller ${ }^{1}$ eins, die Anwesenheit von Paleen an den abdominalen Segmenten, hinzugefïgt. Die machstehend beschriebene Art gehört jedenfalls in diese Gattung, nur muss dann ans der von Grube gegebenen Characteristik derselben die Kürze des Kragens gestrichen werden.

$$
1 \text { v. Marenzeller, Siidjapanische Anneliden, II. 1881. S. A. pg. } 15 \text { (pg. 211). }
$$




\section{Hypsicomus circumspicions, n. kp.}

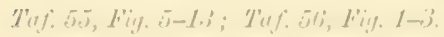

Longus, fore filiformis, plemumue pallidus maculis minutis in lasi brunchiali adspersus, rarim

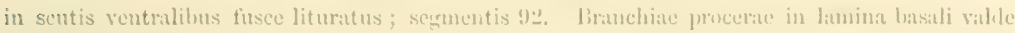
clongata, constricta et in lubulum dorsalem anguste anuminatum libermm producta rudios branchiales utringue l:2, dorsales paullo longiores, ommes in parte medianal oculus lentigeros foli. olis non tectos cirea 50 per praria collocatos, undique versus spectantes, et filit branchialia longa sub apicem ralii hamatum deereseentia gerentes. Laciniae luecales 2 elonsatae acutae quint:m hranchiac longitudinis partem superantes. —Segmentum buceale proximo dipplo fere longins, collare in dorso hians, in lateriłns incisura profundia fere dimidiatum, subtus lobis trigonatis in lasi medi:na continuis antice versus productum, utrinque keriem lon ritudinalem setarum capillarium late limbatarum brumearum, et scutum ventrale paullum distinctum transwerse bipartitum gerens. - Segmenta cetera duplo lation quam longiora; anteriora thoracalia 11, mutatio jedum in segmento 130. Setae capillares in omnibus biformes, in segmentis thoracalibus plerumque in serie parabolica inferiores sub) apice acuto brevi orbiculatae, superiores sub apice elongato utrinque late limbatac; in segmentis abdominalibus pauciores in serie recta inferiores sub apice longo orbieulatae superiores simplices late limbatac. Segmenta thoracalia in serie du. plici currata uncinos et setas fulcientes, abdominalia in serie simplici multo breviore uncinos gerentia ; uncini aviculares manubrio thoracalium clongato, abdominalium brevi, dente unico in vertice glabro; setae fulcientes in apice cursato brevi orbiculatim fere dilatatac. Scuta ventralia paullum distiucta, abdominalia sulco stercorali in segmento 1 to devio divisa.

Tubus longus, teres, parum curvatus, brunuens subpellucidus corneus glaber.

Hab. : Jareh 21, 1569, off Carysfort Reef. Cast No. 8, depth $3 J$ fms.

Der Körper dieses Wurmes ist schlank, in seiner ganzen Länge, mit Ausnahme des Aualendes, fast gleich breit, dabei etwa so hoch als breit, bisweilen dureh eine Abplattung der Seitenflïche deutlich vierkantig. Em völlig erhaltenes Exemplar hatte 92 Segmente, dessen Gesamntlïnge betrug 46,5mm., wovon 9,5mm. auf die Kieme, 37mm. auf den Körper kamen, die Breite war durchschnittlich $1 \mathrm{~mm}$, in der hinteren Strecke um ein geringes vermindert. (Taf. 55, Fig. 1.) Die meisten Exemplare hatten eine gleichmässige weisslich grelbe Färbung, von welcher auf dem äusseren Umfunge der basalen Strecke der Kiemenstrahlen Reihen kleiner in gleichmässigen Abständen stehender brauner Pïnktehen abstachen; in einem Exemplare waren aber auch die hinteren thoracalen Bauchpolster fuchsbraun gefärbt.

Die schlanke Kieme besteht aus den beiden völlig getrennten gleichen Hälften, von denen jede auf einem hohen Basalblatt 12 Kiemenstrahlen und 1 Buecalzipfel träigt.

Das Basalblatt ragt auf der dorsalen wie ventralen Fläche weit über den Rand des Kragens hinaus; seine Länge erreicht fast ein Zehntel der ganzen Kiemenlänge; es ist farblos und durchscheinend hell, vor dem Ursprunge 
der. Kiemenstrahlen schwach ringlömig eingeschnirt; am dorsalen Kiemenstrahl zicht vou ihm ein freier membramiser Situm, welcher den Strahl etwas an Breite ibertrilt, so weit nach rorn, dass sein Vorderende fiat bis auf die Hiihe der Endspitze des Buccalziplels reicht. Jederseits am seitlichen Unfamge schimmert ein brimnlicher Pigmentlleck, einem Ange vergleichbar, muter der Oberlliche hervor: bei dem beschräinkten Material liess sich die Stellung dieses Pigmentfleckes, ebensowenig wie sein sonstiges Verhalten, genauer bestimmen.

Die ron dem Vorderrande des Basalblattes frei nach rorn sich erstreckenden Kiemenstrahlen sind an Lïnge etwas ungleich, die dorsalen die lingsten. Ihr Schaft träigt am äusseren Umfange die in 2 Parallelreihen stehenden bramen P'igmentflecke, weiche auf der terminalen Hiilfte der Kieme fehlen und auch eine kurze Basalstrecke nicht eimnehmen. An den grössten Kiemenstrahlen fund ich in einer Reihe 50 solcher Augenflecke, an den kiirzeren etwas weniger; die Flecken stehen in dem mittleren Theile der Strecke sehr viel gredringter als an den beiden Endtheilen; sie stehen dort um etwa die Dicke ihres eignen Durchmessers von einander entfernt; wihhend sie in den Endstrecken der Reihe drei-bis viermal so weit von cimander entferut sein kïmnen. (Taf. 55, Fig. 10.) Die Flecken sind in den Lingsreihen meist parrweis geordnet; doch erleidet auch das Störungen. (Fig. 11.) Ein einzelner Fleck giebt unter stärkerer Vergrösserung ein Bild, als sei die kugelige Pigmentanhäufung im Grunde einer tiefen trichterförmigren Grube gelagert; und es ist zutreffend, dass das Pigment nicht unmittelbar unter der Oberfäche, sondem in einem gewissen Abstande von derselben in der Tiefe liegt. Die grubenförmige Vertiefung aber, deren Grund das Pigment zu füllen scheint, ist in der 'That ein langer kegelförmiger, das Licht etwas stärker als die Ungebung brechender Körper, welcher mit seiner schwach convex gekrümmten Basalfläche um ein ganz geringes iber die Hautoberfläche sich erhebt, mit seiner Spitze in der Tiefe des Integumentes in der Pigmentanhäufung steckt; oft ist die Kegelspitze schwach hakenförmig aufwärts gegen die Oberflïche des Integrmmentes gekrimmt, und damn erscheint die pigmentierte Endstrecke ähnlich dem Kolben einer Retorte. Fast immer finde ich, dass die Körnchen des Pigmenthaufens von der kugeligen dicken Masse aus in einer allmählich auslaufenden dïnnen Schicht scheidenartig die Kegelspitze des lichtbrechenden Körpers umgeben. ('Taf. 55, Fig. 13.)

Die Stellung der Aurgen zur Längsaxe des Strahles wechselt in sehr bemerkenswerther Weise der Länge nach an demselben. Diejenigen Augen, 
welche in der grissoren distalen strecke des Sehaltes stehen, wenten ilne Linsen mah answen und gegen die Spitze des Kiemenstrithes, so dass die Axe des Aures einen spitzen 17 inliel mit der Axe des Straliles bilelet; geht man an der lieihe der Augenflecke gegen die Kiemenbasis hin, so sicht man, dass dieser Winkel der Augenaxe an Cirözse zunimmt, bis man in der batalen Ilibte der Augenreihe Angen findet, welehe senkrecht in die Obsuläche des Schaftes einrrelassen sind, und noeh weiterhin solehe, welche unter spitzem Wrinkel nach aussen und gegen die Kiemenbasis sich wenden. Die Zahl dieser letzterun ist aber inmer eine leschrankte, der Winkel. welehen ihre Axe mit der des Kiemenstrahles bildet, ist viel grojser als der Neirmugswinkel der distalen Augen. ('Till. 55, Fig. 10, 11, 12.) Die Gesammtheit der Auren bildet mithin anf dem :usseren Umfinge der Gesammtkieme einen Giirtel, in dessen vorderem Bereich die Augen nach vorn; in dessen hinterem Abschnitte sie dagegen mach hinten gewendet sind, oder zu schen vermögren.

Es handelt sich hier um cine fiu physiologische Betrachtumgen nicht unwichtige Ausgestaltung der Kiemenaugen einer Sabellide, sowohl was die Form des einzelnen Auges als die fiir eine allseitige Umsicht bedeutsame Stellumg der Reihen betrifft; ich muss mich hier auf die Mitheilung dieses Thatbestandes beschränken, denselben aber betonen, da von anderer Seite derartige Augen beschrieben sind, als lägen die Pigmenttlecke im Crunde einer tiefen grubenförmigen Eimziehung. Das Bild, welches diese Augenflecke gewähren, kamu, da der helle lichtbrechende Körper nur schwach conturiert erscheint, und daher leicht iibersehen wird, wohl in dieser Weise gedeutet werden; oder es mag die erwähnte Angabe nach Prneparaten gemacht sein, an denen der Kegel ausgefallen war; anf alle Fialle ist es mir in hohem Grade wahrscheinlich, dass da, wo die grubenfürmigen Augenflecke beschrieben sind, eine Bildung wie die hier geschilderte vorgelegen hat.

Augenlidähnliche Blätter fehlen am äusseren Umfange der Kiemenstrahlen, für die angenommene Leistunırsfäligkeit der Augren erscheint das verstiindlich.

Der imnere Umfang trägt die in zwei Reihen gestellten schlanken, vor der nackten und meist etwas hakenförmig gekrümmten Endspitze des Strahles allmählich an Lünge abnehmenden Kiemenfüilen. Ich schätzte deren Zahl an den grössten Strahlen auf gegen 200. - Der einzelne Kiemenfaden ist wohl zehmmal so lang als der Schaft des Strahles breit ist und etwa ein Viertel so dick als dieser; er ist mit langen Wimperhaaren dicht bekleidet; vielfach verkleben diese Kiemenfäden unter einander und er- 
scheinen dam als zusammenhängende, ohne Verletzung nicht zu tremnende Massen. Im terminalen Ende der Reihen der Kiemenfiden nehmen diese allmiilnlich so an Lïnge ab, dass die iussersten nu niedere, kaum vorspringende Höeker bilden; die kïrzer werdenden Fïden erscheinen auffallend dick und entbehren des Besatzes der grossen Wimperhane, doch bleibt es zu prifien, ob der Mangel der Wimpern hier nicht durch die Art der Conservierung der Thiere herbeigeführt ist. (Taf. 55, F'ig. 10 a.)

Im Grumde der auseinandergebogenen 'T'entakelkrone steht ein Paar sehr schlanker Buccalzipfel; es gelang mir nicht, deren Verhalten zu einer etwa vorhandenen Bucealmembran festzustellen. Der einzelne 'Zipfel hatte etwas mehr als ein Fiunftel ("mm. lang bei einer Gesammtlïnge der Kieme von 9mm.) von der Läinge der Gesammtkieme, in seinem Basaltheil war er verbreitert und hatte angenscheinlich die Form eines gefalteten Blattes; die grüssere Endstrecke war dagegen einfach lang nadelförmig.

Der fast gleichmässig breite Körper setzt sich aus Segmenten zusammen, welche mit Ausuahme des etwas verlängerten Buccalsegmentes alle etwa doppelt so breit als lang und dabei so hoch als breit sind; zudem erscheint dieser hohe Körper vielfach vierkantig durch eine Abplattung der Seitenflichen; allerdings tritt rlies Bild nicht an allen Exemplaren gleichmässig hervor, da ich es aber an den Thieren finde, welche aus den cylindrischen Rühren herausgeschält waren, so halte ich diese Körperform für eine primär rorhandene und nicht durch Schrumpfung in Weingeist entstandene.-Die Segmentgrenzen sind im Umfange des ganzen Körpers als scharfe Furchen gezogen, auf der Rückenfläche der vorderen Segmente wenig ausgeprïgt, besonders tief oft am Seitenumfange. Melirfich fand ich diese Grenzen schräg nach hinten oder vorn geneigt, die durch sie bestimmte Transversalebene bildete damn einen spitzen oder stumpfen Winkel zur Hauptachse. Da diese Gestaltung an der Vorder- und Hinterstrecke desselben Körpers ungleich vorhanden ist, so halte ich sie für ein Artefakt, für dessen Zustandekommen allerdings wohl besondere Torbedingungen im Körper der Wïrmer gewesen sein mögen. (Taf. 55, Fig. 6.)

Das Buccalsegment, welches mit Eiuschluss des Kragens das nächst folgende an Lüinge etwa um die Hälfte übertrifft, trägt den mit dem freien Rande nach vorn ragenden, auf der Dorsalfliche völlig getrennten am Seitenumfang cingeschnittenen und auf der Ventralfäche zusammenstossenden Kragen, der auf der ventralen Fläche viel weiter als auf der dorsalen Flïche nach vorn reicht. Auf der dorsalen Flïche, welche in der Median. 
linie gefurcht erscheint, erhebt sich jederseits nehen dieser in einem rolehen Abstande, dass etwa ein mittleres Drittel der Riiekenfliehe unberleckt heibt, der Kragen mit einem iber die ganze segmentlinge sich erstreckenden oval gerumdeten hïutigen Blatte, an dessen basaler Sitrecke die grleich zu erwähnende Liingsreihe von Borsten steht; der Vorderrand des Kragens umgreilt damn frei vorragend den seitlichen Unfing des Könpers mol wird etwa auf der halben Iöhe jederseits durch einen tiefen dreieckigen Ëinschnitt derartig zerlegt, dass seine zur Ventrallliiche zichende Vortsetzung fast als ein selbstiundiger Lappen erseheint; dieser ist dreieckig zugeschnitten und ragt mit seiner Spitze sehr viel weiter als der dorsale Rand an Basalblatt der Kiemen nach vorn; an ihrer Basis berihren sich die beiden Lappen in der ventralen Medianlinie, mit dem dreieckigen 'Jusehnitt divergieren ilare fireien Endstiicke. Ich habe diese Lappen des Kragens nach unten und hinten umgeschlagen, wie es bei anderen Sabelliden rorkommt, nicht geschen. ('Taf. 5\%, Fig. 6-9.)

An den Flanken des Buccalsegmentes lïuft jederseits entlang der Wurzel des Kragenlappens etwas höher als die dorsalen Borsten der folgenden Segmente eine dorsalwärts schwach convex gekrimmte, fast die ganze Lïnge des Segmentes einmehmende Reihe von Borsten. (Fig. 6, T.) Ich zählte in der Reihe 21 Borsten. Diese sind einfach, breit linear und gesïumt, bram und glïnzend; sie wenden die Spitzen nach aufwäts vorn und medianwïrts, so dass diese in beiden Reihen gegen einander convergieren.

Auf der ventralen Fläche steht ein wenig ausgepräigtes Bauchpolster, welches hinter den ventralen Kragenlappen durch eine Querfurche zweigetheilt erscheint.

Die nächst folgenden 11 Segmente sind thoracale; an ihnen steht ein Bïndel capillarer Borsten dorsalwärts von einem Wulste mit Hakenborsten, sie tragen einfache Bauchpolster; am 13ten Segment findet die Umstellung der Borsten statt, das Bauchpolster ist hier aber noch einfach; am 14ten Segment theilt die Kothfurche das Bauchpolster in schrïger Richtung und ron da ab sind alle folgenden Segmente voll als abdominale gekennzeichnet.

Die capillaren Borsten sind an allen Segmenten in doppelter Form vorhanden: solche, welche gelb oder braun gefïbt auf einem dickeren Schaft ein kurzes fast spatelförmig breites aber in eine kurze lanarförmige Spitze auslaufendes Endblatt tragen (Paleen), und solche, welche farblos liinger und dünner als die erstgenannten sind, capillar mit mässig breitem Flügelsaum. An den thoracalen Segmenten bilden die Paleen eine $U$-förmige oder 
parabolische Reihe, deren Schenkelenden 'dorsalwäits gewendet sind, in einzelnen Fillen trat eine einzehe Borste zwischen die Schenkelenden, so dass damm die lieihe in Oral geschlossen erschion. An das dorsale Einde dieser Reihe schliessen sich die feineren lïngeren breit gesäumten Capillarborsten an. ('laf. 56, Fig. 1.) Von Paleen zihlte ich in einem solchen Bündel 12-16; die 'Zallal der einfachen Capillarborsten war erheblich kleiner. - An den abdominalen Segmenten ist die Zahl der Paleen bedentend verringert, sinkt bis auf 4 oder 3 , dementsprechend bilden sie hier nur eine einfache Reihe; in ihrer form unterscheiden sie sich von denen der thoracalen Segmente dadureh, dass sie in eine lange feine Spitze auslaufen ('Th. 56, lig. 3); die Capillarborsten stehen ventral ron dieser oder hinter ihr, im Vergleich mit denen der thoracalen Segmente sind sie sehr schwach gresiumt.

Auf den Haken tragenden Wülsten der thoracalen Segmente steht eine grosse Doppelreihe ron Borsten, auf denen der abdominalen Segmente eine nur kurze einfache. Die Borstenreihe ist an den thoracalen Segmenten so gross, diss sie, wenigstens an den vorderen derselben, vom dorsalen Bündel bis zum Rande des Banchpolsters reicht, an den hinteren derselben sind sie bereits verkiirzt. Die längeren sind meist ein- oder zweimal geschwungen; das ist jedoch wohl ein wechselnder Zustand; am Sten thoracalen Polster ziihlte ich in jeder Reihe noch 25 Borsten. An den abdominalen Segmenten nimmt die Lïnge der Borstenreihen sowie die Zahl der in ihnen stehenden IIaken erheblich ab. Die Haken haben an allen Segmenten eine fast gleiche Form und Stellung, nur sind die der abdominalen Segmente etwas kleiner als die der thoracalen; am Basalstiick des Hakens ist das Manubrium nur kurz; der grosse Endhaken hat keine Nebenzähne und eine einfache Scheitelfliche. Die Spitzen der Haken sind nach vorn gewendet. In den thoracalen Segrmenten bilden sie die hintere Reihe, die vordere wird von Borsten gebildet, welche den Paleen der Capillarbündel sehr ähnlich sind. (Taf. 56, Figs. 1, 2.)

Die Bauchpolster treten bei den versehiedenen Fxemplaren ungleich stark hervor; im Allgemeinen bedecken sie das mittlere Drittel der Ventralfläche nicht ganz.

Am plötzlich kegelfürmigg verjiingten Hinterende trägt das Aftersegment auf der etwas wulstig gerandeten Endfläche die grosse Afteröffnung.

Die Thiere wolmen in glatten hornartigen, durchscheinend braunen, cylindrischen, wenig gekrimmten Rïhren, die erheblich länger als sie selbst sind, und deren Wandung aus einer harten, fast spröden Substanz 
hesteht. Die Oeflimngen der Riihren sind einfach, die innere Oberfliche einfach shlatt.

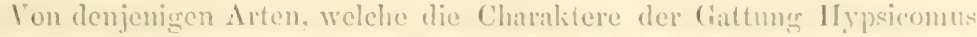

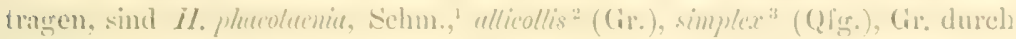

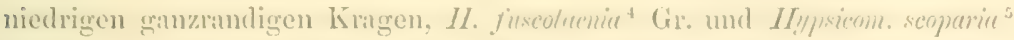
Gr., ebentills threh den nieslrigen liragen, der an lentralrande bei des ersteren kitum eingeschnitten, bei dex letzteren auf der 13auchlliche in einen umparen dreieckigen Lappen rerlingert ist, leicht ron dem $\mathbf{H}$. ciremnspicins

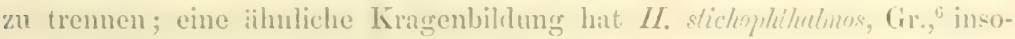
fern der Kragen zweitheilig ist und jederseits zweilippigr, allein dass der Kragen dieser Art niedrig ist, unterscheidet sie ron lem II. cirennspreicns. Weitere Unterschiede zwischen beiden Arten ergeben sich aus der Zahl der Segmente, 190 bei $H$. slichophlhatmos gegon 92 bei $I I$. chrcumspieions, und der anderen Begrenzung der 'Thoracalregion; denn der Borstenwechsel findet bei $I I$. stichophthulnos mit $\frac{n}{10}$ oder $\frac{10}{1}$, bei $I I$. circumspricicns bei $\frac{1}{1} \frac{2}{3}$ statt. In der Zahl der Kiemenstrahlen ist kein erheblicher Unterschied, wohl aber in der Stellumg der Augenflecken, da nach Grube die Augen des Iy/psie. stichopilthatmos in zrrei nicht neben einander, sondern vor einander gelegenen Reihen stehen. Schliesslich möchte ich hervorheben, dass bei $H$. circumspicions die Paleen der abdominalen Segmente anders als die der thoracalen grestaltet sind, wïhrend sie bei $H$. stichophthatmos übereinzustimmen scheinen. Treten so cine Anzahl Unterscheidungsmerkmale zwischen beiden Arten hervor, so ist andererseits nicht zu rerkennen, dass beide gegeniiber den uibrigen aufgeführten Arten näher zu einander gehören müchten. Hyjssic. stichophlhalmos erbaut sich eine Röhre aus Schlamm, wïhrend Hypsic. circunspriciens in brauner hornartiger Röhre rohnt.

1 Schmarda, Neue wirbellose Thiere, I, II, und v. Marenceller, Sürjapanische Annelinlen, II, 188t, pag. 16.

${ }^{2}$ Grube, Beschreibungen einiger . . . A Anneliden und Gephyreen. Verbandl. der k. k. zoologischbotan. Gesellsch. in Wien, Jhrg. 1869, pag. 638.

s Grube, Bemerkungen über Anneliden des Pariser Mruseum, Arch. für Naturg., Jhrg. 36, 1870, p. 318 .

4 Grube, Descriptiones Annulatorum nororum mare ceylonicum habitantium. Proceedings Zoolog. Soc. of Londou, 1874, pag. 325.

s Grubc, Bericht über die. Thätigheit der natur. Section der schlesischen Gesellschaft, 1870, pag. 34.

6 Grube, Archiv für Naturgeschichte, Jhrg. 29, 1863, I, 19. 62, Taf. VI, fig. 3. 


\section{POTAMIS n. ‥}

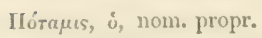

Differt a genero Potamilli: (Mllyn.) bnsi branchiali subinvoluta, lacinia buccali impari, collari subtus longissimo integro, setis abiominalibus biformibus.

Potamis spathiferus, n. sp.

$$
\text { Tuf. 5̌, Fig. 7-11; Taf. 55, Fig. 1-4. }
$$

Fulvidus, subfiliformis, posteriora versus depressus et subtus canalieulatus; segmentis 54 . Branchia dimieliam corporis longitudinem non plane attingens, in lamina basali elongata et constricta, subinroluta, subtus ex angulo dextro in lobulum liberum anguste linguaeformem producta utrimque radios 9, exceptis 2 rentralibus brevioribus, aequales, graciles, in rhachide nuda filis branchialibus laxe collocatis, sub apicem filiformem elongatum nudum minoribus munitos gerens. Lamina bucealis impar semel plicatir non laciniata. Segmentum lnecale maguitudine proximum aequaus, faseiculo setarum munitum, collare in medio dorso paullum contigum, utrimque angulatim postice versus plicatum, subtus in laminam longam integram non reflexam productum gerens. Segmenta moxima $i$ thoracalia priora dimidio latiora quam longiora, posteriora longitudine accrescentia, in superficie dorsali lateribus elevatis depressa; segmenta abdominalia priora elongatia sequentia sensim decrescentia, ultima ter latiora quam longiora. Scuta ventralia non distincta. Pinnac minntac, in segmentis anterioribus anticae, deinde mediae et posticae; tori rix prominuli breves. Mutatio pedum in segmento 9no.

Setre thomeales in serie parabolica capillares superiores sub apicem acutum late limbatae inferiores breviores et crassiores, magnitudine decrescentes, sub apice brevi orbiculatae; setae abdominales inferiores in flabello capillares simplices sub apic̀m longum limbatae; superiores subgeniculatae in parte terminali utrinque late limbatae. Uncini aviculares in vertice dentis terminalis mitella denticulorum alta, thoraeales manubrio longo, abdominales in serie decrescentes mamubrio breviusculo muniti. Setae fulcientes thoracales solum in apice ovato dilatatae et acuminatac.

Tubus fragilis limo obductus.

Hal, : off the Samhos, 275 fins.

Nur ein einziges allerdings in ganzer Lünge erhaltenes Exemplar dieser Art habe ich gefunden. Der durch keinerlei Zeichnungen ausgezeichnete Körper ist fist gleichmässig in seiner ganzen Ausdehnung gelblich braun, an der Kieme zicht diese Färbung ins Grauliche über; seine Gesammtlänge betrïgt 4 Smm., von welchen $20 \mathrm{~mm}$. auf die Kieme kommen, welche also nicht viel kürzer als der Rumpf ist. Die zusammengelegte Kieme ist mit Ausnahme einer geringen im Bereich des Basalblattes liegenden Einschnürung so dick als die vordere Körperstrecke und drehrund wie diese; die hintere Körperstrecke, etwa im Bereich des hinteren Drittels verjüngt sich allmählich und wenig; in der hinteren Hälfte plattet der Leib sich in dorso- 
ventmaler Richtung ab und wirl gregen das Kïperende hin allmiblilich vollstiindig platt. In dieser Regrion ist dam die Banchflaiche der Lä̈nge nats fast in cler gramzen Breite furchenartig vertieft; diese, vielleicht durch die in Wreingeist erfolgte Contraction so stark auscgepriigte, Rime libuft erst in der vorderen Küperhailfte, etwa gegen das 20 Segrment him, vïllig ans. [)er Körper besteht aus 54 Segmenten, von denen S, mit Einschluss des luseculen, thotacal sind. ('Tit. 54, Fig. T.)

Dic Kieme besteht aus einem hohen Basalblatte und zwei nicht ganz gleichen aus je 9 Kiemenstrahlen gebildeten IIiilften. Das Basalblatt, welches an Liinge seinen Querdurehmesser um meln als das doppelte ibjertrillt, und darin wohl der Linge der ersten drei Segmente gleichkommt, ragt auf der dorsalen Fliiche weit aus dem Kragen hervor, wiilurend der weit nach vorn ansgezogene ventrale Iappen desselben bis an scine vordere Grenze etwa hinanreicht. (Fig. 9.) Auf seiner dorsalen Flitche ist es bis an den Ursprung der Kiemenstrahlen ungetheilt, wïhrend auf der ventralen Flïche die 'Theilung in die beiden Hïlften erfolgt; bei zusammengelegrter Kieme umfasst lart hinter dem Ursprunge der Kiemenstralılen cine ringfömige Einschüirung den dorsalen und seitlichen Umfang; biegt man, wie das in Fig. 11 auf' 'T'at. 54 dargestellt ist, die beiden Kiemenhilften auseinander, so erscheint dis Basalblatt im Bereich der Einschniurung seitlich dergestalt comprimiert, dass in der dorsalen Medianlinie eine schwache Crista hervortritt. - Iuf dem hinteren Theile des dorsalen Umfanges sehe ich da, wo das Basaiblatt aus dem Kragen hervortritt, jederseits eine weisslich unter der Kürperdecke hervorschimmernde, strang- oder wulstförmige lingslanfende Masse, über deren Wesen ich nichts anderes angeben kanm, als dass sic den Eindruck einer grösseren schlauchförmigren Drüse macht. (Taf. J̃t, Fig. 9, 10.)

Die Kiemenstrahlen entspringen am Rande des Basalblattes auf einer Linie, welche am dorsalen Umfange weiter als am ventralen nach hinten greift, also mit schwach spiraler Drchung von der dorsalen Mittellinie mit der Richtung nach vorn gegen die ventrale lïuft; am ventralen Rande ist dann an der zusammengelegten Kieme die rechte Hälfte des Blattes ein wenig nach inmen eingerollt, was am linken Blatte in weit greringerem Grade hervortritt. Mit diesem Unterschiede zwischen den beiden Hälften der Kieme verbindet sich der auffälligere, dass am ventralen Rande der rechten Hälfte das Basalblatt mit einem hautartig diimen frei vorspringenden Zipfel auslüuft, welcher schmal zungenförmicg gestaltet frei nach vorn gerichtet neben dem benachbarten kürzesten Kiemenstrahl hervorragt, ohne ganz die 
lnalbe lainge desselben zu erreichen. Ein solehes Randblatt fehlt der gegeniiberstehenden Kiemenhiillte. ('Taf. 54, Fig. 8.)

Jevle Kiemenhailfte enthailt 9 grefiederte Strahlen, welehe mit Ausnahme der bei den an meisten ventralwiits stehenden gleich lang sind; ron den verkiüzten hat der tiefst stehende etwa der Lünge der rollentwickelten Strahlen, während der dameben stehende Strahl die halbe Länge derselben nicht ganz erreicht. Alle Strahlen sind einfarbig, ohme Augenflecke und ¿̈ussere Anhänge, und laufen in ein langes fein zugespitztes nacktes Endstick aus. Die am immeren Umfing der Strahlen stehenden lang bewimperten Kiemenfiden sind, mit Ausnahme der vor der Endstrecke stehenden rerkïrzten, ïber zehnmal so lang als der Schaft breit; sie stehen in zwei Reihen am Schafte, nicht sehr nahe linter einander, sondern um mehr als ihre eigne Breite ron cintuder entfernt; auffallender Weise sind die Fäden in den beiden Liingsreihen am Schafte nicht paarweise gestellt, sondem stehen alternierend, und an einzelnen Stellen hatte es den Anschein, als seien die Strahlen der beiden Reihen ungleich lang; doch habe ich ein abschliessendes Urtheil dariiber, ob dies als die Regrel anzusehen sei, bei dem Erhaltungszustande des Exemplares nicht erhalten können.

Im Grunde der Tentakelkrone steht eine Buccalmeubran, ein einziges Blatt, welches so geknickt ist, dass es eine dorsalwärts gewendete mediane Faltenkante bildet; es ragt wenig weiter als der ventrale Ursprung der Kiemenstrahlen nach vorn; seine Stellung zur Mundöffnung kenne ich nicht. Buccalzipfel fehlen. (Taf. כ̌t, Fig. 11.)

Die vordere Körperstrecke sondert sich durch die Form der thoracalen Segmente ziemlich stark von der hinteren längreren Strecke. (Fig. 9.) Diese sind nicht granz um ein Drittel breiter als langr, ihre Höhe ist etwa der Länge gleich. Das erste derselben, das Buccalsegment, welches von den folgenden durch den Mangel der Hakenborsten sich unterscheidet, träigt den in ausgezeichneter $\mathbb{I}^{r}$ eise entwickelten Kragen. Dies ist ein auf der Ventralfläche ungetheiltes, lang zungenförmig ausgezogenes und über den Vorderrand des Basalblattes der Kiemen noch hinausreichendes diinnes Blatt, welches, wie es die Tentralliache des Basalblattes deckt, beim Aufsteigen gegen die Dorsalfliche niedriger werdend, dessen Seitenumfang nur zum kleineren Theil umfisst, auf der Rüickenfläche des Buccalsegmentes jederseits eine tutenförmige nach vorn geiiffnete Falte bildet, deren hintere den Schluss dieser Falte bildende Spitze in solcher Weise den Vorderrand des nächsten Segmentes berührt, dass zwischen den beiden hinteren Spitzen die Dorsaltliche des 
Segmentes fist in laalber Breite desselben liej ist, willuend die medialen Blitter dieser balte nach vorn grengen die Mittellinie so weit eonverericten, dass ihre an Höhe abnehmenden vorileren sipitzen sich fiast berihren. Die Gesammtform des Kragens erinnert in efwas an die Gestalt, welehe das Seheidenblatt, die Sipatha, am Bliitenkolben siner Aroidee hesitz. Ich

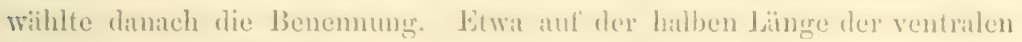
Flibhe stehen der Mittellinie grenilhert und von hinten nach rorn convergierend schrifig zu ihr grestellt zwei lingrovale wie von einem walstigen hande derartig umfasste lifecke, dass sie fist wie Siugreruben erscheinen; da ich das einzige Exemplar einer Untersuchung nicht opfern wollte, kimm ieh über deren Bedentung nichts weiteres aussigen. ('Titt. jut, Fig. S, 9, 10.)

Die dorsale Mittelliache des Bucenlsegmentes ist in der Lüngsrichtung schwach rimenartig vertieft; am seitlichen Umfange steht jerlerseits nahe dem Vorderrande des Segmentes und in gleicher IJ̈̈he mit den Borstenbïndeln der folgenden Segmente ein kleines nach vorn gerichtetes Bündel; seine Borsten stimmen wahrscheinlich mit den dorsalen Borsten der folgenden Segmente granz iberein; ich kam nichts anderes dariber aussargen, da diese Borsten auf beiden Seiten des Wurmes so abgebrochen waren, dass nur die Schïfte herausragten. (Fig. 8, 9.)

Die folgenden thoracalen Segmente sind durchschnittlich um die Hälfte breiter als lang; sie unterscheiden sich von einander wesentlich wohl nur durch eine geringe nach hinten anftretende Lingenzumahme und eine etwas zumehmende Zahl der Borsten; an den letzten dieser Segmente waren allerdings die dorsalen Borstenbiindel stärker hervorgestreckt und fäicherfürmig gespreitzt; doch kann das ein individueller Zustand sein. Ziemlich scharf ausgeprägte Segrmentgrenzen tremnen die einzelnen Segmente von einander; deren Rückenfliche wird von einer läugs laufenden medianen Rime gुefurcht; die Fläche selbst erscheint fast vertieft zu liegen, da die Flanken des Körpers mit scharfem etwas erhobenem oberen Rande in der Weise vorspringen, dass sie auf den Segmentgrenzen durch die Segmentalfurchen unterbrochen werden. (Fig. 9, 10.) - In die ventrale, nur wenig abgeplattete Flïche grehen die Flanken des Segmentes in gleichmässiger Wölbung über; scharf ausgeprïgte Bauchpolster sind nicht vorhanden. - Das dorsale Borstenbiindel steht an den vorderen der thorncalen Segmente hoch an der Seitenflüche fast dicht hinter deren vorderer Ecke; an den hinteren Segmenten bleibt es fast in gleicher Höhe, rïckt aber mehr anf die halbe Lïnge des Segrmentes, Das Bündel wird von dickeren kïuzeren Borsten, bei denen 
der Schalt zn einer liingsstreiligen scheibenfürmigen Endplatte mit kurzer Spitze anslinft, und von schlimkeren diimeren vor der langen Endspitze beiderseits Aligelfürmig gesilumten Capillarborsten zusammengesetzt; diese liorsten stehen auf ciner loppelreihe, welche dorsalwïrts durch die kleine Ciruppe der sehlanken Capillarborsten abgeschlossen ist, wïhrend in den ventralwiirts von einander getremten Reihen die kurzen spatelförmig erweiterten lBorsten derart angeordnet sind, dass wem man von den Borsten der vorderen lieihe aufviilts zu denen der hinteren ïbergeht, eime Grössenabnahme der Borsten bemerkt wird, gleichsam als stinden an den beiden Enden einer U-f̈̈rmig gekrimmten Reihe je die grössten und kleinsten dieser Borsten. ('Tif. 5.5, Fig. 2.) - Ventralwiirts von diesem Borstenbiindel steht die doppelte Querreilie ron Borsten, deren Zahl innerhalb einer Reihe an den hinteren thoracalen Segmenten abnimmt, deren Grösse inmerhalb einer Querreihe aber yleich ist. - Die hintere dieser unmittelbar an einander stossenden Querreihen besteht ans Hakenborsten. Die einzelne Hakenborste, welche mit der Spitze des IJakens nach vorn gewendet ist, zeichnet sich durch eine sehr lange nach hinten gewendete schaftartige Verlängerung der Basis und einen iiber dem Scheitel des Endhakens hoch aufgethürmten, leicht in zwei Hälften zu spaltenden Besatz von mehreren in Reihen gestellten gleich grossen Nebenzïhnchen aus; die Basis des Hakens ist dick, hat keine besonder's stark entwickelte Vorderecken, die Hauptspitze des Ifilkens ist nur mässig entwickelt. $-\mathrm{Zu}$ einem jeden Ilaken gehört eine Borste, welche mit einem langen schmalen gekrimmten Schafte unter der gleichmaissig verlïngerten Basis des Hakens, fast mit dieser sich beriihrend, liegt, vor dem Vorderrande der IIakenbasis ans der Körperwand hervortritt und hier im Niveau der Hautdecke mit einer eiförmig zugespitzten Platte ausläuft; ich hatte bei der Untersuchung dieser Borsten mehrfach den Eindruck, als ob die Ränder dieser dünnen Endplatte in die Chitindecke der Körperwand iibergingen. (Fig. 55, Fìg. 1, 1 a.)

Die abdominalen Segmente der hinteren Körperstrecke sind im vorderen Abschnitte auffallend länger als breit; das orste abdominale Segment ist fist um cin Drittel länger als das letzte thoracale; im hinteren Körpertheile nimmt aber die Lünge wieder etwas ab und schliesslich so erheblich, dass auf der letzten stark abgeplatteten Körperstrecke die Segmente dreimal breiter als lang sind. Die Sergmentfurchen sind weniger scharf als in der thorncalen Strecke und der vorspringende Rand, mit welchem die Flanken in der thoracalen Region von der Rïckenfläche sich absetzten, ist nur an den vorderen 


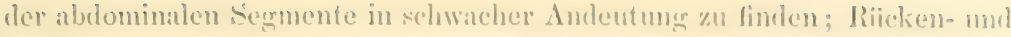
Banchlliche ersehemen fist glatt; das dlles giebt der abdominalen Regrom ein gleichmissigeres Ansehen.

Dic am 9ten semmente aufretente "mutalio pedum" ist von einer Verschiebung der Borstenbindel begleitet; beide Borstengruppen stelen anf der hinteren Ilailfte des segmentes meist unweit der hinteren Eeke des oberen Elankenrantes. Die num dorsal stehende Querreihe ist kur\%; sie enthiilt nur Itakenborsten, diese sind in ein und derselben lieihe ungleich sross, die Grösse der einzelnen Ifaken nimut in der Richtungr von der Banch- zur liiickenlläche gleichmissig ab derartigr, dass der IIaken, welcher in der Querreihe der Riiickenfliche am nïchsten steht, die halbe Grösse des an ventralen Ende der Reihe stehenten Ifakens nicht erreicht; dieser selbst ist nicht ganz so gross wie die ILaken der thoracalen Segnente. Die Form des einzelnen IIakens stimnt im Algemeinen mit derjenigen der thoracalen Haken überein, nur ist die stabförnige Verlingerumg der IIakenbasis erheblich verkïmmert. (Iaf: 55, lig. 4.) - Tentralwïrts von dieser einfirchen Querreihe steht ein kleines fächerförmig gespreitztes Biindel von wenigen Borsten, welche einander ähnlich sind, aber doch zwei zu trennende Formen darstellen. Ventralwärts in diesem Bündel stehen einfache schwach gesïumte lange und schlanke Borsten, welche zumal an den hinteren Segrmenten oft sehr weit mit der Richtung nach vorn vorrargen. Dorsalwairts davon stehen Borsten, welche um die Hälfte kiirzer sind, als die eben erwähnten. Sie erscheinen im ersten Anblick als nux kiirzere Capillarborsten; demn ihre Endstrecke, welche jederseits fliigelartig breit gesïumt ist, linft in eine kurze Spitze aus; diese gesïumte Endstrecke steht aber oft ausgeprägt winklig zu dem Schafte. Der Form nach möchte ich daher in diesen Borsten die Wiederholung der mit breiter Endplatte auslaufenden thoracalen Borsten sehen, und sie von diesen durch eine Verschmillerung und Streckung der dort als breite Platte erscheinenden Endstrecke ableiten. (Taf. 55, Fig. 3.)

Das Aftersegment liuft mit zwei kurzen dreieckigen Läppchen, Aftercirren aus.

Der Wurm stak in einer nur theilweise erhaltenen, sehr brüchigen Schlammröhre. 


\section{SERPULIDAE (BLV.).}

Für die Erkentniss der systematischen Verhältnisse der Serpuliden ist seit der Erfahrung, dass weder die Röhren noch die Deckel ron hervorragender Bedentung fiir die Feststellung der Merkmale und der Verwandtschaftsbeziehungen sind, von Claparède und Langerhans besonders die Gestaltung der Borsten betont, und gewiss mit Recht. Wieweit aber hier die Borsten des Buccalsegmentes, oder die in den Thoracal- und Abdominalsegmenten vorhandenen Capillarborsten für diese Zwecke besonders zu beachten sind, das bleibt auch gegeniiber den oft so auffïlligen Gestaltunterschieden, welche die Hakenborsten zeigen, noch eingehender zu prüfen. Den damit erwachsenden Auforderumgen gegenïber erweisen sich die meisten der älteren Serpuliden-Beschreibungen als ungenïgend und werden vielfach noch kritischer Sonderung bediurfen. Ich möchte daneben darauf hinweisen, das die Ausbildung der, leider in den Sammlungsexemplaren dieser Würmer oft wenig gut erhalten, und schwer zu untersuchenden Thoracalmembran eine sorgfältigere Beachtung verdient als es meistens geschehen ist. Ich habe in den folgenden Beschreibungen den vorderen Ventraltheil dieser Membran als "collare," den an den Flanken des Thorax mehr oder minder weit entrickelten Theil als "pallium" bezeichnet um eine kürzere Ausdrucksweise zu erhalten. Derselbe ist meist durch einen tiefen Einschnitt vom collare getrennt; doch kommen Ausnahmen davon vor, wie bei Pomatostegnes stelletus Abgd.

Fiir die Vertikalverbreitung der Serpuliden ergiebt sich aus dem Nachstehenden eine bereits von Arm. Hansen gebrachte Bestätigung meiner früheren Vermuthung, dass Serpuliden im tieferen Meere nicht fehlen. A. Hansen hat auch die interessante Mittheilung gemacht, dass Serpuliden auf weichem Meeresgrunde mit freien Röhren vorkommen. 


\title{
EUP(OAL'TUS (PHI.).
}

\author{
Eupomatus uncinatus (P'mL.). \\ (Archis für Naturgesch., Jhrg. 1816, I, pag. 195.) \\ Tuj: 5s', Fig. (i-11.
}

In den mil von zwei Fundorten vorliegenden lïhren find ich einen leider nicht grut conservirten Wurm, der nach allen Merkmalen, welche ich feststellen konnte der mediterrane Eupomatus uncinatus ist. Ich gebe kur eine Beschreibung des 'Thieres, in welcher ieh ïber die Beschaflenheit des Kragens und der 'Thoracalmembran leider nichts aussagen kam; die, wie mir scheint, geringfügrgen Abweichungen, welche sich darin von den kurzen Beschreibungen der Mediterranform finden, sind dam später anderweitig in Betracht zu ziehen.

Die ganze Länge des Thieres betrug, der Deckelstiel abgerechnet $22 \mathrm{~mm}$. davon kommen smm. auf die Kiemen, ïber welcher der Deckel weit hinausragt, 3mm. auf den 'Thorax, der Rest auf das Abdomen. Der Thorax hat 7 , das nach hinten verschmälerte Abdomen etwa 50 Segment. Die Kieme war schwach gebändert; an den Flanken des Thorax waren schwarz pigmentirte Querstreifen, wie sie Grube auch von der Mediterranform hervorhebt, vorhanden, welche mach dem Abdomen zu sich fortsetzten, hier, in der Stellung den Borstonbiindeln entsprechend, kürzer und zu geringen Flecken rerkleinert werden.

Die Kieme hat jederseits 15 Kiemenstrahlen, welche mit kurzer nackter hakenartiger Endspitze auslaufen, rechts einen rudimentären, links den röllig entrickelten Deckelstiel, welcher mit dem Deckel weit iber die Kieme hinausragt. Der Deckel ist unregelmässig gefleckt, den schwarzbramen Ring, der nach Grube bei allen ron ihm gesehenen Exemplaren aus dem Mittelmeere sich findet, habe ich nicht gesehen. Der Rand der Kegelbasis, von welcher die Hörner sich erheben, ist mit 30 kleinen, etwas nach aussen umgebogenen spitz dreieckigen Zühnchen besetzt; zwischen je zwei Zähnchen läuft auf der Aussenfläche eine Furche fast über die laalbe Lïnge des Kegels gegen dessen Spitze; die um das Centrum der Kegelbasis kreisförmig gestellten, unter einander gleichen Hörner sind 11 an Zahl, Philippi griebt für die Mittelmeerform 8 an; das einzelne Horn ist fast so lang als der kegrel- 
fïmige Deckeltheil, in der basalen etwas abgeplatteten Ilialfte nur wenig geeren die spitze hin verschmïlert, dann rasch in die hakenförmig einwïrts sekriimmte viel schmilere und zugespitzte Endstrecke iibergehend. Vor den Basalthsilen dieser Hörner bildet je eine kleine kegrelförmige Spitze einen inneren, concentrischen, leicht zu iibersehenden Spitzenkranz; diese spitzen Iröckerehen finde ich von der Mittelmeerform bis jetzt nicht beschrieben. (Tit. 55, Fier. 7, S.)

Das Bucealsegment hat in seinem Borstenbiindel starke vor der plötzlich aus dem Sehaft verjiingt hervorgehenden Lindspitze drei kurze, stumpf kegelförmige llüeker. (Figr. 9.)

Die Capilliuborsten der folgenden thoracalen Segment sind schwach gesitumt, die zu etwa 60-70 in einer Reihe stehenden Haken sind gegen die Spitze verschmiilert, an der Basalecke ausgrezogen, auf der Schneide mit 6-7 Zïlumen besetzt. Die abdominalen Haken sind :ihnlich gestaltet aber kleiner. Die ziemlich dicken Capillasborsten der abdominalen Segmente, welche zu $6-\hat{\tau}$ ein Bïndel bilden, sind schief meisselförmigg am Ende erweitert, auf der Schneide schwach gezïhnelt. Ich verweise im übrigen auf die Abbildungen. (Fig. 10, $10 \mathrm{a}, 11$.

Die vielfach unregelmaissigg gewundenen und zusammengeballten kalkigen weissen Röhren sind im Allgemeinen cylindrisch mit wellenförmigen Zuwachsstreifen, bald ohne bald mit einem schwachen medianen Kiele; einzelne, wahrseheinlich nicht von diesen zu trennende Rühren waren mit drei nahe an einander geriickten Lüngsfirsten besetzt.

Fundort: 1. off Tr. down Cape Dear Rio, depth 7 fass. 2. Inside fishing ground Cape Rear, depth 7 fms. (leere Rölire).

\section{SPIROBRANCHUS, BLV.}

\section{Spirobranchus giganteus (PALL)}

Serreta giglised, Pallas, Miscellanen Zoologica. Hag. Comit., 1766, pag. 139.

Sarigny, Systeme des Annélides a. a. O., pag. 74.

Crmospirs gigliste (Pall.), Schmarda. Teue wirbellose Thiere, I, II, 1861. pag. 31, Taf. xxi, Fig. 180.

Spirobraxchus gigaxteus (Pall.), Mörch. Terisio critica Serpulidarum. Taturhist., Tidskr., 3 P., 1 B., 1863, pag. 56 (S. A.)

$$
\text { Taf. 5\%, Fig. 1-\%. }
$$

Mit der Benemnung "gigantea" ist, seit Pallas eine wohlcharakterisierte grosse Serpulide aus dem Antillenmeere beschrieben hat, eine Anzahl von 
Aen grleichen Orten stammenter grosser Serpuliden beschrieben, welche wie ich weiter zn zeigen labe, von cinander zu tremen sind. Kmmal Mirch hat in seiner fleissigen und verdienstlichen lievision unter dem Nimen grigrntens Formen, die er als Varietiten bezeichmet, \%usimmengefisst, oftenhar von der an und für sich nicht mberechtigten Meinung ansgehend, dass Unter. schiede, welche in der Form der Rïhre und Giestalt des Deckels hervortreten, zu einer specilisehen Sonderung nicht ausciehten. Wie diese IIartgebilde allein in den sammlungen, anch der Conchyliologen, aufbewahrt und mehrfiteh beschrieben wurden, ist msere Kemutniss vom Körper der 'Thiere selbst so unvollstimrlig geblieben, dass es gerechtfertight ist, wenn ich das Wesentliche daraus hier kuz dasstelle und daran die Beschreibung der bis jetzt mit dieser zusammengeworfenen, aber sicher davon zu tremnenden Art gebe.

Ein gut erhaltenes, dureh die Conservierung wohl in allen seinen Dimensionen gleichmässig verkleinertes Exemplar war ohne die Kieme $79 m \mathrm{~m}$. Jang, wovon $9 \mathrm{~mm}$. auf die Lïnge des Thorax kamen; die Linge der eingerollten Kieme war $15 \mathrm{~mm}$, der 'Thorax war $8,5 \mathrm{~mm}$., das sehmiilere und nach hinten gleichmässig an Breite abnehmende Abdomen vorn 6mm., hinten $4 \mathrm{~mm}$. breit. Der Thorax hatte 6, das Abdomen etwa 260 sehr kurze Segmente; ersteres ist auf der breiten Ventralfläche deutlich abgeplattet, letzteres hier ausserdem, mit einer tiefen ïber die granze Länge laufenden Furche versehen.

Der Körper des Thieres war gleichmïssig röthlich grelb; an den vorderen Theilen des Kragens, anf der Kiemenbasis und weiterhin an den Kiemen ist tiefviolette, ins Braune oder Blaue ziehende Färbung, ohne bestimmte Zeichnumgen zu bilden. Scharf markiert treten dagegen auf den nachlıer noch zu schildernden ventralen Kragenlappen und vor diesen auf der Kiemenbasis kreidig weisse Flecke hervor. (Taf. 57, Fig. 1, 2.)

Die Kieme bildet zwei im eingrezogenen Zustande kurze, fast besenfürmig erscheinende Büschel, deren Fürbung sehr wechselte, indem sie bald in grösster Ausdehnung weiss, bald braun oder violett mit weissen Spitzen erschienen; im einzelnen war das Bild auf eine ungleiche Ringelung der einzelnen Fïden mit weiss und bram oder violett zuriickzuführen. Die äussere Fläche des Basalblattes war in ungleicher Weise mit kreidigem Weiss gezeichnet, in einzelnen Fällen derartig, dass schmale weisse Streifen auf dunklem Grunde liefen. Jede Kiemenhälfte besteht aus dem niedriggen Basalblatt, welches leistenförmig und zu fünf engen Spiraltomen zusammengreglegt ist. An ihn entspringen die Kiemenstrahlen, welche gegen die Spitze hin an 
Limine abnehmen. so dass sie hier nur ein Viertel der Lïnge besitzen, welehe die am Grumbe des Basalblattes stehenden Strahlen besitzen. Diese Kiemenstrahlen sind an ihrem Ursprungstheile, etwa auf ein Drittel ihrer gamzen Linge, nicht frei, sondern durch eine Membrau verbunden, wenn man das rerhalten nicht derartig anshricken will, dass die Strahlen auf der inneren Flitehe des Basalblattes als vorkpringende Leisten entstehen. Der einzelne Kiemenstrahl ist mit zwei Reihen von Fiiden besetzt, welche etwa 4-5mal so Iang als der Strahl breit, und ron einander um ihre eigne Breite getrennt sind. Ior der kurzen mackten lindspitze des Strahles nehmen die F'idden allmiklich an Lïnge ab. - Hinter der Basis der linken Kieme entspringt von der Dorsalliliche des Bucealsegmentes der Deckelstiel. Derselbe ist bandartig platt, reicht mit seinem die Deckelscheibe tragenden Vorderende bis auf das Torderende der eingerollten Kieme und hat in seiner proximalen Irilite etwa ein Drittel der Breite der thoracalen Rückentliehe; in seiner distalen IIïlfte rerbreitert er sich durch einen membranösen fast flügrelartigen Samm jederseits, welcher jetzt meist mamigfaltig grekräuselt und gefiltet, offenbar im Weingeist geschrumpft vorliegt, und dann hinter der Breite der basalen Strecke des Stieles jederseits zurückbleibt, im Leben aber nach Schmardit's Angabe so ansgedehnt sein kann, dass die eingezogenen Kiemen sich in ihm bergen kïnnen.

Die Deckelscheibe hat Pallas ganz zutreffend in seiner kurzen Beschreibung charakterisiert, weniger gut ist die von ihm gegebene Abbildung; es scheint fast, als sei die abgebildete Scheibe mit Pflanzen bewachsen gewesen, wie das offenbar hïufig rorkommt, und sei dadurch dem Zeichner die Darstellung der charakteristischen Hömer weniger gegliickt.

Die eigentliche kalkige Deckelscheibe ist breit eiförmig, kaum länger als breit, auf der oberen schwach rosenroth gefärbten Fläche dellenartig vertieft und zwar so, dass diese Vertiefung nach der schmalen Hälfte hin am tiefsten ist. Hier erhebt sich aus ihr, wie es Pallas ganz zutreffend schildert, ein niederer Höcker, der zwei - und nicht wie Schmarda es ausdrückt vier — geweihartige über die Fliiche sich hoch erbebende, der Lünge der Scheibe fast gleichkommende Zinken trägt. Der einzelne Zinken läuft in zwei ungleich lnnge Zacken aus, einen inneren kiirzeren, einen nach aussen gegen den Rand der Deckelscheibe gerichteten längreren; der kürzere innere trägt nur an seinem Ende einige kurze dornartige Höcker, der äussere längere ist der Lïnge nach in wechselnder Weise mit solchen besetzt. ${ }^{1}$ (Fig. 3.) Die

1 Schmarda hat ofienbar die beiden von mir zu einem Zinken grerechneten Zacken als selbständige Bildungen aufgefasst, und ist dadurch veranlasst, vou vier Hörnern zu sprechen. 
untere Flitche der Deckelscheile ist exentrisch mit dem versehmilerten

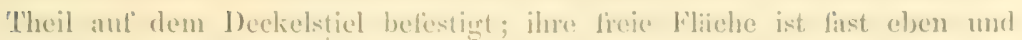
meist derartig gezeichnet, dass aul der blan-violetten filiche weise schmale Streifen rom hande her radiar gregen die Inlueftumg, dabei spit\% anslanfend zichen. Bei Macerationsvorgingen lijst sich die J)echelecheibe rom Stiel und

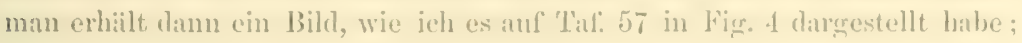
daraus ist ersichtlich, dass die beckelscheibe in ihrer Kalkmasse ausgedehnter als die Endfliche des Stieles ist, dass aber von dieser von weicher Gewebsmasse gebildete Fortsiitze in die Deckelaufäitze himeintreten.

Am 'Thorax zieht jederseits dorsalwïrts von den Austrittstellen der eapillaren Borstenbündel in der ganzen Läinge eine Thoracalmembran, welche an der hinteren Grenze desselben von jeder Seite her zusammentretent einen frei vorspringenden Lappen bildet. Die Membran ist jedenfalls am Buecalsegmente am höchsten und bildet hier einen nach vorm frei vorspringenden Lappen. In allen mir vorliegenden 'Thieren ist die Membran unter dem Linfluss des Weingeistes offenbar geschrumpft und damit verdickt und meist unregelmissig gekrüuselt, am Vorderrande auch in tiefe Falten gelegr, welche ohreniihnlich abstehen. (Fig. 1, 2.) In diesem Zustande wiirden die Lappen niedergelegt die Rückenflïche kaum bedecken und sich gregrenseitig nicht ïberlagern. Und doch dürfte das Bild, welehes Schmarda giebt und auf dem die thoracale Nembran eng dem Kürper anliegend mit ihren Lappen ibbereinander greift, ganz zutreffend sein, da rom $S_{p}$ ). incrussalus, welcher sonst gleiche Terhültnisse der Thoracalmembran aufreist, mir ein, allerdings aus der einschliessenden Röhre herausgenommenes, Exemplar vorliegt, welches das gleiche Terhalten der Thoracalmembran zeigt, wie es Schmarda ron dieser Art abbildet.

Die hinteren Theile der Thoracalmembran sind nicht besonders gezeichnet, dagegen trägt bei allen Exemplaren die Torderfläche des Torderrandes einen ungleich grossen kreidig weissen Fleck, der sich auf die Basis des Kiemenblattes ausdehnen kann. - Ton dieser Thoracalmembran ist der ventrale Lappen des Kragrens durch einen etwa auf der halben Kïrperhöhe stehenden Einschnitt gretreunt. Er reicht mit seinem nach vorn grleichmässig abgerundeten Rande weiter nach vorn als der vordere Rand der Thoracalmembran und deckt niedergelegt den zunächst vorliegrenden Theil des Basalblattes. In der ventralen Mittellinie theilt ein linearer Einschnitt den Kragen in zwei gleichmässige Lappen, von denen jeder auf seiner Vorderfliche einen kreidig weissen Fleck trüigt; Haltung und Grösse dieser beiden 
Latpen sind wohl nach dem Eintluss, welchen das conservierende Mittel auf sie ansigeiibt hat, versehieden; clas Bild, welches lig. 1 bietet, zeigt diese Lappen kïnstlich zuriickgebogen. Ich habe mir mit Riicksicht auf die Bildung, welehe ich von symubrunchus tricomis weiter unten ron dem gleichen $\mathrm{Abschnitte} \mathrm{gebe,} \mathrm{die} \mathrm{linge} \mathrm{vorlegen} \mathrm{miissen,} \mathrm{ob} \mathrm{diese} \mathrm{Lappenbildung}$ nicht etwa durch eine Verletzung, durch eine Zerreissung des sonst ganz randigen Theiles entstanden sei; allein da ich bei allen Exemplaren dieser Art, wie bei denen des Sp. incrussutus dieselbe Bildung ohne besondere Anzeichen einer stattgehabten Verletzung fand, so muss ich diese Lappenbildung für dis Normale ansehen.

Ion den thoracalen Segmenten ist das buccale so breit, aber etwa doppelt so lang als die folgenten. Es trägt jederseits ein bisweilen in den Filten der Thoricalmembran verborgenes, meist wenig hervorragendes Bündel ron ziemlich starken braungelben Borsten, welche einfach capillar und an iler spitz auslaufenden Strecke an der einen Fläche gleichmüissig mit kurzen Iiirehen fast bürstenlömig besetzt sind. (Fig. 5.)

Die folgenden thoracalen Segmente sind etwa sechsmal breiter als lang. Dis characteristische Geprïge der von ilınen gebildeten Körperstrecke entsteht durch die Ausgestaltung der Ventralfläche dadurch, dass, während die dorsalen Borstenbiindel, je weiter nach hinten um so mehr ventralwärts verschoben austreten, die IIaken tragenden Wiilste gleichmässig der ventralen Mittellinie mit ihren ventralen Enden sich nähern; so bleibt auf der Bauchflïche zwischen den 8 letzten Hakenwiilsten nur ein schmaler rinnenförmig rertieft erscheinender Raum, wïhrend zwischen den vorderen ein viel breiterer Raum ist, der seiner Form entsprechend von einem platten Polster eingenommen wird, welches den Umriss eines fast gleichseitigen, die Spitze nach hinten wendenden Dreieckes hat.

Die dorsalen Borstenbündel treten aus einem kurzen Höcker derartig hervor, dass sie in 2 parallel gerichteten, längs laufenden Reihen stehen, und so cinen breiten, aber wenig gespreitzten Fïcher bilden; sie sind dabei aufwärts und nach hinten gerichtet und ragen un wenig mehr als das Segment lang ist hervor. Die einzelne Borste ist braungelb glänzend, an der zugespitzten Endstrecke jederseits fliigelfürmig gesïumt; der Rand des quergestreiften Saumes ist glatt. Unmittelbar unter dem Borstenbïndel erhebt sich, mit einem flossenförmigen dïnnen Irautsaume an seinen freien Rändern iiberall besctzt, der platte Querwulst, dessen ungleiche, ventralwärts gehende Erstreckung bereits erwähnt wurde. Auf seiner Flïche steht parallel dem freien 
hinteren Saume die einfuche Reihe der dicht an einander gredringten Haken. welche am dorsalen Ende der Reihe sich plïtzlich mol erheblich, wohl bis anf ein Viertel ihrer grössten Aushehmung verkleinern. Der einzelne vollontwickelte Haken, der die sitzen seiner Zaihne und die Jassalecke nach vorn wendet, ist eine Platte, welehe linger als breit, und an der fieien Kante lianger als an der basis ist; ihre filichen erselsemen gefurcht; die freie Kante träigt je nach der Grösse der Platte eine ungleiche '/allıl - bis gregen 20von spitzigen Sägezilhnen; die Basalecke ist über dlen ror ihr stehenden Zahn in Form eines hohl grebogenen 13lattes ansgezogen; die Vorderkante erscheint etwas wulstig verdickt. Die Verhïlnisse, welche ich von den kleineren, am Eunde der Reihe stehenden Platten des Sprobrunchus tricomis abgebildet habe, finden sich in gleicher WV eise hier. (Fig. 7.)

Das Abdomen, welches, wie es nach hinten zu schmiller wird, sich auch abplattet und anf seiner Ventralliache bei in Weingeist erhïrteten Exemplaren von einer tiefen Furche iiberzogen wird, besteht aus sehr zahlreichen Segmenten, welche fast gleichmässig kurz sind, sodass ihre Breite das Fiinfzehn- bis 'Zwanzigfache der Länge betrïgt; ein geringer Unterschied ist zwischen den vorderen längeren und hinteren Seginenten wohl zu erkennen. Ueberall sind die Segmentgrenzen an den Flanken des Abdomen scharf gezogen, dagegen auf Rücken- und Bauchfliche oft kaum ausgepräigt. Dic dorsal von den Capillarborsten stehenden Haken tragenden Querwïlste sind an den vorderen abdominalen Segmenten so kurz, dass sic etwa nur ein Drittel der Flankenhöhe bedecken und dabei ventralwïts verschoben erscheinen, während sie in den hinteren Zweidrittheilen dieser Körperstrecke über die ganze Flanke sich aushehnen; dabei bleiben sie in der Lügsrichtumg des Körpers wenig hinter der Länge der Segmente, auf denen sie stehen, zuriick. Die Haken stimmen in ihrer Form unit denen der thoracalen Wiilste iberein; sind aber im Allgemeinen kleiner als diese; die am ventralen Ende der Reihe stehenden Haken sind auch hier plötzlich rerkleinert.

Ventralwärts vom Haken tragenden Querwulste treten an allen Segmenten weit hervorragende Capillarborsten aus, meist nur je eine, die dem Körper angelegt iiber mehrere Segmente sich erstrecken, und durch seidigen Glanz ausgezeichnet sind; sie nehmen an den hinteren abdominalen Segmenten an Länge zu. Die einzelne glashelle Borste hat einen feinen Schaft, dessen freies Ende plattgedriickt und mit rund g̀eschmeifter Hohlkante in einen schlanken von der einen Kante ausgehenden Faden ausläuft. Diese 
Ilohlkante des abgeplatteten Endstiickes ist mit einer Reihe feiner blattartiger kumer Ziihnchen besetht. (Fig. 6.)

Dals detersegment trïigt keine Cirren. Leber die Form der Röhre kamn ich keine Angaben machen. da diejenigen 'Theile, welche mir, durch die neben oder in ilmen liegenten Wiirmer sicher identificiert, vorlagen, vollstiundiy von Corallen umschlossen waren. Nach diesen Bruchsticken zu schliessen, hat die wohl unregehüssig gewundene Röhre ein völlig drehrumles Lumen; ihre glatte immere Oberlläche ist brïunlich gelb gefirbt; in der Dicke der Wand erscheint ungleichmissig vertheilt violette Fürbung; eine besondere Cristenbildung habe ich auf den Bruchstellen im Imneren der Corallen nicht erkemen kümen. Weder die Angaben von Pallas noch von Schmarda enthalten Sicheres ïber die Form etwa frei wachsender Röhren, wemn solche iiberhaupt zur Ausbildung liommen.

Fundort: Florida (Jfus, of Comp. Zool., Cambridge).

Spirobranchus tricornis (Mürcn), char. emend.

Spinonixcires GIgANteı var. B. Triconis, Mörch. Revisio eritica, pag. 58.

Serplla Biconsis, "Sar." r. d. Hoeven, Handbuch der Zoologie, Bd. I, 1850, t. 6, fig. 4, A. B.

$$
\text { Taf. 5\%, Fig. } 8-15 \text {. }
$$

Die von Mörch als $S_{P}$. gigantea var. tricomis beschriebene Form ist nicht nur durch die Gestalt der Deckelscheibe, welche Mörch betont, sondern auch durch die Grössenverhältnisse des Körpers, die Gestalt des Kragens und die Form der buccalen Borsten so gut von der eigentlichen Sp. gigantea gesondert, dass sie als besondere Art aufunführen ist. Ich darf mich hier darauf beschränken, neben den gegebenen Abbildungen die Hauptunterschiede kurz hervorzuheben.

Der Kürper des Wurmes hat ein Ablomen, welches kürzer ist und weniger Segmente besitzt als dasjenige von Sp. gigantea: ein Exemplar, dessen Thorax $9 \mathrm{~mm}$. lang war, hatte ein Abdomen von $48 \mathrm{~mm}$. Läinge und an diesem 185 Segmente; der Thorax war $9 \mathrm{~mm}$, das $\Lambda$ bdomen vorne $5 \mathrm{~mm}$., hinten 7mm. breit; diese Zahlen geben die Differenz, wenn man sie mit denen vergleicht, welche ich von einem $S$ p. giganters von gleichfalls $9 \mathrm{~mm}$. 'Thoracallänge verzeichnet habe; die eingerollte Kieme dieses Exemplares war 12mm. lang.

Vom Kiemenapparat ist als das Abweichendste die Deckelscheibe zu 


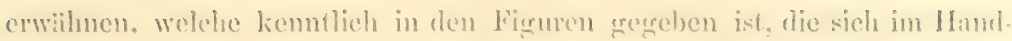
buche v. l. Hoevens finden, nur ist hier in aler 'latelerklitrung eine Verweehselung der Banch- mol Riiekenseite gremacht. Die Scheibe ist nicht so

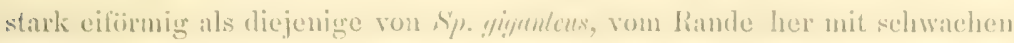
radioir laufenden Leisten besetzt, und trïgt zwischen den parigen Stangen eine umpare; alle drei stangen entsprimgen anf einer gemeinsanen buckelfömigen Frhebung der scheibe, die umpanae mitten zwischen aber etwas vor den parigen; alle drei ragen mit den butspitzen etwa gleich weit ror, sind im Verhältniss zur Seheibe länger als diejenigen der Sy. gryanlens, schliesslich sind alle etwas grekrimmt. Jede der parigen Stangen träigt, wie die des Sp. gigunteus, einen iiber der IVurzel am hinteren Unfang entspringenden grö̈sseren, an der Spitze gerlornten Zacken, ist der Liinge nach mit drei etwas kïrzeren gedornten Zinken besetzt und läuft an der Spitze grabelig mit zwei /acken aus. Die unpare Stange lat eine viollig glatte drehrunde Basalstrecke, welche convex gregen die Seheibenfliche gekrïmmt und etwas niedergelegt ist, und liiuft mit zwei gedornten, an ler Spitze gegabelten Aesten aus, welche etwa die halbe Jiinge der glatten Basalstrecke haben. Die untere Flïche der Deckelscheibe hat ähnliche Keichmung und Fïrbung wie die des Sp. giganteus. (Taf. 57, Fig. S, 9, 15.)

Der Kragen besitzt eine, auch bei van der Hoeven abgebildete sehr charakteristische Gestaltung darin, dass er auf der Ventrallikiche in der Medianlinie nicht in Lappen zerlegt ist, wie bei Sp. giganteus und incrassutus, sondern vielmehr zu einem langen und schlanken spitz dreieckigen Zipfel ansgezogen ist, der sich längs gefaltet zwischen die beiden Kiemenhälften einlegrt und hier über die halbe Lïnge der Kieme hinaus nach vorn ragt. (Fig. S, 10.)

Die capillaren Borsten des Buccalsegmentes tragen den gleichen Bürstenbesatz wie diejenigen des Sp.giganteus; an der Stelle aber, an welcher die sich rerschmälernde Endspitze winklig vom Schafte abbiegt, steht zwischen. den bïstenartigen Härchen eine Anzahl grösserer spitzer dornartiger Zähnchen, so dass in der Seitenansicht diese Strecke wie mit spitzen Zähnchen gesägt erscheint. (Fig. 11.)

Aus der Bildung am 'Thorax hebe ich hervor, dass die dorsalen Torderecken der flossenartigen Sïume der Hakenrülste als kleme zungenförmige Läppchen ausgrezoren erweitert sind; ob diese Bildung nicht aber etwa nur durch besondere Umstände der Conservierung in diesen Thieren stark herrorgreschoben scheint, muss ich dahingestellt sein lassen. (Fig. 8.) Die Borsten und Haken zeigten keine bemerkenswerthe Abweichungen ron 
denen des S\%. giymentes. Tom Abromen hebe ich nur hervor, dass die schlinken cippillaren meisseliomig erweiterten borsten in der doppelten Form rorkinmen, diss bei den einen die eine Eeke der gezihnelten Sehneide in eine schlanke fadenförmige Spitze ausgezogen, bei den anderen stumpl war (Fig. 13): dass die cine durch eine Verstïmmelung der anderen entstanden, ist mïglich; aber danin erscheint es anfiallend, dass ich diese Verstiummelung bei den gleichen Borsten der beiden andern Arten nicht gesehen habe.

Fundort : 1. March 3, Fast hey, depth 13 fms. 2. Tortugas, in tubes on coral.

\section{Spirobranchus incrassatus.}

Mürch, licvisio critica, a. a. 0., pag. 59.

Taf. 5\%, Fig. 10; Taf. 58, Fig. 1-5.

Da mir ron dieser mit Recht abgesonderten Art unzweifelhafte Exemplare vorliegen, will ich den ron Mörch gegebenen, nur die Röhre und den Deckel unfistenden Beschreibungen kure den Wurm betreffende Erginzungren hinzufiigen, un so mehr da das Thier nach seiner geographischen Verhreitung Interesse gewïhrt.

Der Wrurm schliesst sich durch die Kürze seiner Kürperstrecken und die Zallt sciner abdominalen Segmente näher an den Spirobranchus tricomis als an Spriobr. gigunteus an. Bei einem Exemplar von $39 \mathrm{~mm}$. Gesammtlänge war der Thorax 7 mm. das Abromen $22 \mathrm{~mm}$. lang; der Thorax 6mm., das Abdomen rom Jmm. breit; letzteres hatte 140 Segmente.

Die Deckelscheibe weicht in den mir vorliegenden Exemplaren etwas von Tei. Beschreibung ab, welche Mörch davon gegeben hat; doch schlage ich diese Unterschiede nicht hoch an. Ich finde die Scheibe kreisförmig, oder nahezı kreisförmig; den Rand schwach gezackt; auf der Fläche, wie bei Spriabr: tricomis, drei Stangen, aber in soleher Stellung zu einander, dass gleichsam mit einer Verfachung der buckelförmigen Erhebung, welche ich in deren Beschreibung erwïhnte, die Urspriunge der Stangen auseinander riicken; die parigen, mit ihrem Ursprung gegen den hinteren Rand verschobenen, sind den gleichen des Sprobr. tricomis sehr ähnlich; die umpare Stancge aber ist, wie das Mörch schon hervorgehoben hat, durch die Verkiirzung der Basalstrecke ausgezeichnet; ich finde dann auch die beiden Zinken der Endgabel weniger gedornt und weniger von einander divergierend. (Taf. 57, Figr. 16.) 
Der Kragen zeiert ant der. Ventrallitehe nicht die Bildung wie bei symebr.

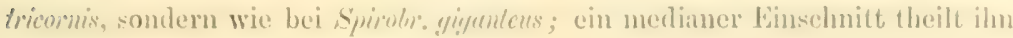
in zwei kurge dreieckige Litpren.

Die Borsten des buccalen Sermentes haben dargegen wieder die fiorm der-

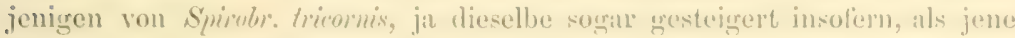
Strecke des Schaftes, von welcher das zurespitzte Endstiick aboreht und welche statt mit biirstenförmigen Ilïrehen mit '/iilunchen besetzt ist, anf dieser Flikche etwas polsterfirmig verdickt erseheint ('lat. 58, Fig. 1, 2) ; an einigen Borsten war diese Giegend von einer homogrenen, wie aufigelagert erscheinenden Substanz bedeckt, deren WVesen mir unbekamnt geblieben ist.

Die capillaren meisselfömigen Borsten der abdominalen Segmente hatten einen im Verhiiltniss zur Enderweiterung breiteren Sehaft als in den beirlen anderen Arten. (Fig. 4, $4^{\text {n }}$ ) Bruchstücke der Röhren, welehe nir neben den 'Thieren vorliegen, passen abgesehen von der Firbung, welche cine bräunlich gelbe ist, zu der Beschreibung, welche Jürch gegeben hat. Lis ist wohl zu beachten, dass diese Röhren nicht in Corallen eingeschlossen sind, sondem frei liegen; die von Mörch erwïhnten Stiicke waren auf Muschelschalen angewachsen.

Fundort: Acapulco.

Die Art gehört den pacifischen Küsten Centralamerikas an; das Volkommen bei Acapulco dürfte den bis jetzt bekanntesten nördlichsten Punkt der Verbreitung, Puntarenas (Oersted) einen centralen und die Westkiiste Columbiens (Mörch) vielleicht den südlichsten Punkt bezeichnen; die grenannten Grenzpunkte gehören einem durch gleiche Isokrymen (Dana) bezeichneten Gürtel an. Innerhalb dieses Bezirkes finclet sich also eine Spirobranchus-Art, welche mit z⿰те丿і dem Antillen-גeere angehörigen Arten eine Anzahl von Kennzeichen gemeinsam hat. Da zweifelsohne eine Verbindung zwischen dem pacifischen und dem Antillen-Meere bestanden hat, so ist die Vermuthung einer nicht weit zurückliegenden genealogischen Verknüpfung dieser jetzt räumlich durchnus getrennten Arten selur wahrscheinlich, weun auch die Art dieser Verknüpfung nicht festzustellen und in ungleicher Weise zu construieren ist. Vielleicht sind die Antillen-Arten die am weitesten ostwärts vorgedrungenen Vertreter einer Gattung, die, wie es scheint, ihre Existenzbedingungen am besten neben riffbruenden Corallen findet. Grube hat von den Philippinen Spirobranchus-Arten beschrieben, welche augenscheinlich den Arten des Florida-Gebietes nahe stehen. 


\section{DOMLATOSTEGUS (SCHMr.).}

\section{Pomatostegus stellatus (Animg.urn)}

Termated strulda, Abilkgaard, Scluriften der Gesellschaft naturforsch. Freunde zu Berlin. Bid. 9, Berlin, 1784, pay. 14:.

Ponstosteges stblates, Mïrch, lievisio critica, a. n. 0., prg. 50.

Mörch hat nachgewiesen, dass Grube fiir einen von der pacifischen Küste Central-Amerikas stammenden Pomatostegus mit Unrecht den Abildgaardschen Namen verwendet hat, und hat die Grube'sche Art als Pomatostegus Kröyeri abgesondert. Da eine genanere Beschreibung des bei Abildgaard bereits kemntich abggebildeten Wumes zur Zeit noch fehlt, so grebe ich eine solche, nach dem einzigen gut erhaltenen, von East-Key stammenden Exemplar, welches mir ohne seine Röhre vorliegt.

Der Wurm hat einen Körper, der, wenn die Liinge der Kieme und des Deckels ausser Betracht bleiben, $24 \mathrm{~mm}$. lang ist, wovon $20 \mathrm{~mm}$. auf die Lïnge des Ablomen kommen; die Kieme ist im Allgemeinen niedrig und ragt etwa Jnm. lang vor; iiber sie tritt weit hinaus der grosse eine fünfach etagirte Scheibe tragrende Deckelstiel ror, der zurüickgebogen nach hinten die hintere thoracale Grenze iberragt; Deckel und Deckelstiel sind zusammen etwa $11 \mathrm{~mm}$. lang, daron entfallen auf die Deckelscheibe $4 \mathrm{~mm}$. Der Thorax ist am hinteren Rande, seimer breitesten Stelle, $5 \mathrm{~mm}$. breit, das daran sich schliessende Abrlomen hier nicht ganz 4 mm, nach hinten allmïhlig um mehr als die Hailfte verschmälert. Dic Deckelscheibe hat in der Basis cinen Querdurchmesser von etwa 4mm., in der Aufthiumung nimmt sie etwas in den einzelnen Sclieiben an Breite ab; der Deckelstiel ist ummittelbar hinter der Deckelscheibe durch den breiten flossenartigen Saum etwas breiter als der Querdurchmesser der Scheibe, an seiner Basis etwa 3mm. breit. - Der Thorax besteht aus 7 , das Abdomen aus etwa 140 Segmenten, die in der hinteren stärker, zuletzt fast spatelförmig abgeplatteten Strecke sehr kurz sind. Der Körper ist röthlich gelb, die Lappen des Kragens und die Hakentragenden Polster weisslich; die Kieme ist fast farblos mit wenig hervortre. tenden griunlich-schwiirzlichen Bändern, welche durch unvollstïndige RingeImyg der dorsalen Kiemenstrahlen hervorgebracht werden; ihnlich geförbte Flecken stehen auf dem sonst weisslichen Grunde der Flügelmembran des im Axentheile röthlich gefürbten Deckelstieles. 
Die Kieme ist in ihrem niedrigen IBasalblatte spibalig mit dem ventralen Ente jederseits medianwints eingerollt, doch nut so gering, diss sie liaum anderthalh, Windungen macht, welehe fast in einer Ebene liceren; dandureh bleibt die ganze Kieme niedrig. Am einzelnen Basalblatte zählte ich etwa 40 Strahlen, welehe von diesem derartig auseringen, dass die granze Auscenfliche des Blattes den Strahlen entiprechend kanellirt war. Die mäisige langen Strahlen waren wieder stark gerollt und gekriimmt, der Jäinge nach mit den ziemlich langen Kiemenfiirlen besetzt, welche nur eine kurze bindspitze des Strahles nackit liessen.

Der frrosse Deckelstiel entspringt in rlem dorsalen /wischenrame der beiden Kiemenblïtter; sein axialer 'Theil, der nach rom von einem an Breite stark zunehmenden hiiutigen Blatte jederseits flïgelartig gesiumt wird, ist auf' der Ventralliache platt, aul' der Dorsalflïche dagegen kissenartig gewöllt. Er trägt den Deckel derartigr, dass dessen untere Scheibe nach der Ventralflïche hin dachförmig vorspringt; hier legt sich dann von jeder Seite kommend der seitliche Fliigelsaum des Deckelstieles unter diese unterste ścheibe, so dass deren hintere Flïche völlig davon bekleidet wird; damit erscheint der Deckelsticl auf der Ventralfliche seines Vorderendes wie rinnenartior vertieft, und jederseits ron dem aufyebogenen Fliigelsamme hoch umrandet. Die hornig brame Deckelscheibe war von kalligen Bryozoen zum grössten Theil bedeckt; sie besteht aus 4 kreisförmigen Scheiben, welche von der gemeinsamen durch alle hindurchgehenden centralen Süule gretragen werden; die einzelnen Scheiben sind wohl etwas unregehmässig verbogen; der Rand der unteren gekerbt, der der folgenden mit kleinen Zälınchen besetzt; die Endfläche der Säule, welche über die letzte Scheibe hinweg ragt, träigt einen Kranz kleiner hakenförmiger Zähne, eine Wiederholung der Bewaffnung der Scheibenrïnder.

Der Thorax, welcher aus dem buccalen und 6 folgenden thoracalen Segmenten besteht, ist auf der dorsalen Fläche gewölbt und jederseit rom Rande her durch die nach hinten an Ausdehnung zunehmenden Segmentfurchen gekerbt, auf der Ventralfäche platt, abgesehen von den Grenzen der Hakenwülste, durch eine einfache Medianfurche getheilt, ohne ein vorderes dreieckiges Feld wie es bei Spirobranchus sich findet. Das Bucealsegment ist so lang als die 4 folgenden zusammen, so viel beträgt der Abstand zwischen dem buccalen Borstenbïndel und dem nächsten thoracalen. Dieses buccale Borstenbündel, bereits im Bereich der Thoracalmembran liegend, springt nur wenig, mit der Richtung nach vorn vor; seine Borsten sind glashell, einfache kaum 
gesïumte. diumere Capillarborsten, und stïlkere, welche den Buccalborsten des spirobranchus entsprechen, indem der Schaft an der Basis der etwas winklig alogebogenen spitze aul' der einen Flïche stark polsterartig verdickt ist, viel stïlier als ich dis von Spirobranchus beschrieben babe, und hier d:mu dicht mit ku"zen stachelartigen Hirchen kammartig besetzt ist; ein gleicher Hairchenbesatz zieht sich gleichmissig iiber die eine Fläche der zugespitzten Endstrecke hin.

Die 'L'horacalmembran besitzt die Eigenthümlichkeit, dass Kragen und Mintel durch keinen Einschnitt ron emander gesondert sind; der Kragen. alsschnitt ist in den seitlichen Theilen sehr hoch und lïuft in der ventralen Ifedianlinie zu einem lang und spitz dreieckigg ausgezogenen Lappen aus, der sich mach rorn zwischen die beiden Hällen der Kieme hineinlergt; der Abschmitt, welcher an den Seiten des 'Thorax sich als Mantel ausbreitet, ist dagegen in der Ausbildung zuriickgeblieben, indem er nach hinten nur gerade iiber das zweite der thoracalen Borstenbiindel sich erstreckt.

Die folgenden thoracalen Segmente sind etwa zwölfmal breiter als lang mit Ausnalne des letzten, welches linger als seine Vorginger und etwa so lang als das 4 te und jte thoracale Segment zusammen ist.

Die dorsalen Borstenbïndel treten aus einem niederen Höcker zwischen zwei häutigen Lippen desselben aus, zu denen sich ein kleines unteres selbstïndiges Liippchen, nach Art eines Cirrus, gesellt. Die Borsten bilden ein ansehnliches, weit nach hinten rorragendes zweireihiges Bündel; die stark gelb grefäbten und glinzenden Borsten unterscheiden sich durch eine ungleich lange Endspitze, sind sonst gleichmässig capillar, mit breitem, am Rimde fein gezihhnelten Fliigelsaume. Die Polster, welche die Reihen der Hakenborsten tragen sind alle am oberen Umfange schwach hautartig erweitert, und haben mit Ausnahme des letzten eine nur geringe flossenförmigge Ausbreitung; medianwäts reichen sie so weit, dass sie von jeder Seite her an der schmalen ventralen Medianfurche endigen. Davon weicht das letzte grössere thoracale Segrment dadurch ab, dass der hintere Rand des Polster zu einem nach hinten weit vorspringenden membranösen Saume sich erweitert, der in der ventralen Medianlinie nicht eingeschnitten ist; dadurch springt die hintere Grenze des Thorax stark iiber die ventrale Flïche des Abdomen ror. - Die Haken, welche in ihrer Form denen von Spirobranchus durehaus entsprechen, bilden eine einzigre iiber die ganze Breite der Polster parallel dem lïutigen Saume sich erstreckende Reihe.

Das Abdomen, welches schmäler als der Thorax von diesem scharf abge- 
setzi hervorgeht, mor nach hinten meln und mehr sich abplattet, setzt sich ans iiberall deutich gesonderten sermenten zustummen, von denen die vordern etwa siebemmal, die letzten hundert, dagergen wohl viermelzwanzignal breiter als lamg sint. Die Segrmente tragen Polster, welche an den vorderen zwölf Segmenten ron den Flanken her nicht anf die Dorsalfliehe hinanfgreifen, weiterhin diese Fläche erreichen und anf der Ventrallliche bis zur Medianfurche ziehen. Die IIakenreihe, welche ant diesen Lolstern steht. erstreckt sich aber nirgends iiber die kiankenhiöhe der Sermente hinaus; die IIaken sind wie die thoracalen gestaltet, aber kleiner als diese. Lor dem ventralen Ende der Hakenreihe steht ein kleines, nur sehwer wahzmmehmendes Bïndel von wenigen eapillaren Borsten, welche der Segmentllïche platt anlagen; die einzelue Capillarborste ist glashell, ilu Schaft linut in eine anfings etwas breitere dann spitz auslaufende Lndstrecke aus, deren eine schmeidenartige Kante zum grössten Theil mit rechteckigen Einschnitten, zahmradähmlich, eingekerbt erscheint.

Das Aftersegment träigt die weit lilaffende Afteröffnung, olne Anhäinge. Hab. : Mrarch, 3 (1868), East Ľey, 13 fms.

Die von Schmarda ${ }^{1}$ beschriebenen Pomatostegus macrosoma und brachysoma sind allem Anscheine nach von diesem Pomatostegus stellatus verschieden. - . Die Characteristik, welche Schmarda für die von ihm aufgestellte Gattung gegeben hat, muss veründert werden, und wohl in anderem Sime noch, als Mörch ${ }^{2}$ es mit Rïcksicht auf die Deckelbildung gethan hat. Doch vermag ich nach alleiniger Keuntnissnahme nur dieser Art, nicht anzugeben, worauf das Hauptgewicht gelegt werden muss. Ton der Gattung Spirobranchus, mit welcher diese Art in der Bildung der einen Gruppe der Buccalborsten, der thoracalen Capillarborsten und der Haken ibereinstimmt, weicht sie durch die abdominalen Capillarborsten ab, welche mit ihrer gekerbten Schneide jene Bildung besitzen, welche sonst den Borsten zukommt, welche Langerhans als "Salmacinaborsten" bezeichnet hat. Das diirfte viclleicht als ein Gattungscharacter zu verwenden sein, womit die Gattung ron Spirobranchus sich sondert. Daneben mag man die besondere Form der Deckelscheibe beibehalten und wird in der Form des breit gesäumten Deckelstieles ein Merkmal sehen, welches mehrere Gattungen verkniipft. Die geringe spirale Aufwicklung der Kieme zeigt, dass dieser Bildung für die Abschäitzung der Verwandtschaften wenig Werth beizumessen ist. Ueber die Bedeutung

1 Schmardit, Nene wirbellose Thiere, I, ii, pag. 31, 32.

2 Mörch, Rerisio criticn, a. a. O., parg. 49. 
der hesonderen Ansgestaltumgr der Thoracalmembran habe ich zur Zeit kein Tritheil. da dieselhe bei den meisten Arten von den Autoren zu wenig beriicksichtigt ist: wichtig ist dagegen wohl die Ausbildung welche die rentrale Fliiche des Thorax und deren Ifinterrand erhalten hat; damit nimmt Pomatostegus auch zu Spirobranchus in besonderer Weise Stellung.

\section{PLACOSTEGUS (PHH. ). \\ Placostegus incomptus, n, sp.}

Tief. CO, Fig. 1-9.

Albidus, breris, postcriora rersus depressus et subtus canaliculatus segmentis 36 . Branchia trientem corporis longitudine aequans in lamina basali semicirculari utrinque radios 18 subaequales, filis branchialibus suls apicem radii nudum vix brevioribus paullum inter se remotis munitos, operculum nullum gerens. Segmentum buceale proximis paullum longius, setis carens, ab utraque parte cingulo lato lenticulorum in ventrem protento instructum ; collare medium antice versus clongatum, pallimn antice dilatatum corporis timidio latius, postice omnem per thoracen decurrens angustatum. Segmentia 6 sequentia thoracalia 5-6ies latiora quam longiora, setns simplices capillares utrinque limbatas flavas, in toris margine cutaneo dilatatis seriem numeresam uncinerum in neie recta lata limae instar subtiliter crenato-lentatorum gerentia. Abdemen a thorace incisura sejunctum postice rersus aretius articulatum attenuatum, subtus depressum et canaliculatum; setao capillares segmentorum singulae simplices geniculatae et dilatatae, posticae multo longiores latitudinem corporis aequantes. Tori breves postici paullum majores uncinos thoracalibus similes sed minores gerentes. Juxta auum lobulus suborbicularis.

Tuhus ritrens hasi omni affixus irregulariter flexuosus in parte antica dilatatus glaber, fortiter carinatus et in carina media deutatus, postice angustatus supra transverse crebre et fortiter crenato-costatus.

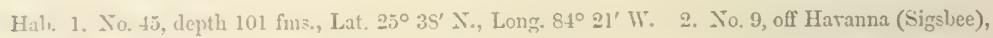
depth 1 으 frus.

Diese Art, deren sehr charakteristische glashelle Röhren an zwei Orten in annähernd gleicher Tiefe gefunden sind, liegt mir nur in einem leider auch etwas verletzten Exemplare vor. Ich habe die Untersuchung desselben hauptsïchlich nach einer Durchtrïinkung des Thieres mit Glycerin ausgefiihrt. danach ist auch die nur in linearen Umrissen gehaltene Abbildung angefertigt. (Taf. 60, Fig. 1, 2.)

Der völlig farblose $\mathbb{T}$ urm war, mit Einschluss der zusammengelegten Kieme, 9mm. lang, von denen $3 \mathrm{~mm}$. auf die Kiemenlänge kornmen; er hat 7 thoracale und 39 abrominale Segmente.

Die Kieme hat jederseits ein niederes iiber den Kragen nicht hinausragendes, nur halbkreisförmig gebogrenes Basalblatt und im Ganzen 18 fast gleich lange Kiemenstrahlen, welche mit je einem nackten, den Kiemenfäden 
gleichenden Endfuten anshuten; die in zwei lieihen stehenden Kiemenfäten entspringen un mehr, als ihre eigne Dicke betright, von einander getremnt

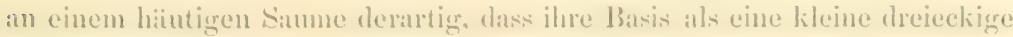
Anltreibung erseheint; wo sic sich entwiren liesen, erwiesen sie sich als

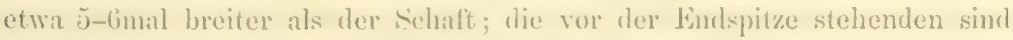
nur wenigr verkiiszt. - Deckelsticle fehlen.

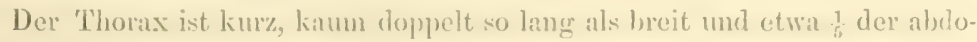
minalen Linge gleich. Die als pallium und collare sehr gross entwickelie thoracale und ventrale Kragenmembran war verletht, so dass ich dieselbe nicht ganz vollkommen beschreiben kann. Die Thoracalmembran verläuft an der ganzen Lainge des 'Thorax, nimmt aber mach hinten an Breite ab, so dass nur am vorderen theile ihre niedergrelegten lïinder iiber einander greifen; der Vorderrand erhebt sich dam abex zu einem frei voragenden Lappen, dessen Liinge der des Thorax fast gleich kommt und dessen freier hand zum 'Theil leicht rundlich ausgebogt erschien. Der ventrale kragenförmige Lappen, der von der thoracalen Membran durch einen Einschnitt getrennt war, schmiegte sich, wie sich bei der Entfaltung zeigte, eng an die Kieme an, war aber verletzt und es liess sich, wie das in der Zeichnung, in welcher der vordere Theil der Kieme abgebrochen und der Kragen entfaltet ist, an einem erhaltenen Lappen nur erkennen, dass derselbe beträchtich weiter als die Ränder der thoracalen Membran nach vorn gereicht haben musste. (Fig. 1, 2.)

Die mit Ausuahme des etwas längeren buccalen Segmentes fast gleichmässigen thoracalen Segmente sind 5-Gmal breiter als lang. Das buccale Segment ist zumächst durch das Fehlen des Borstenbündels, welches ilım bei den Serpuliden sonst zukommt, ausgezeichnet; des weiteren aber durch eine grosse quere rechteckige Platte, welche fast in der Linge des Segmentes von der Höhe der Capillarborsten der folgenden Segmente weit nach der Bauchfläche sich vorschiebt, so dass eine nur schmale Strecke derselben davon nicht eingenommen wird. Das Feld trägt, in der Haut eingebettet, mässig dicht stehende, das Licht stark brechende kegel-oder keulenförmige Körper, deren dickere gerundete Enden im Nireau der Oberhaut stehen, wihrend die spitzen Enden in der Tiefe des Integumentes eingebettet sind; zu jedem derartigen, stark lichtbrechenden Körper schien ein grrosser', am Grunde desselben gelegener Zellkern zu gehören. (Fig. 1, 3.) Plucostegns tridcutalus besitzt nach Armauer Hansen ${ }^{1}$ und Placostegus tricuspidutus nach Langerhans ${ }^{2}$

1 Armaner Hanscn, Oversigt over de norske Serpula-Arten. Areliv for Mathematik og Naturridenskab. Kristiania 1578, pag. 43.

2 Langerhans, Die Wurmfauna von Madeita, IV, Zeitsebr. f. Wiss. Zoolog. Bel. XL, pag. 275. 


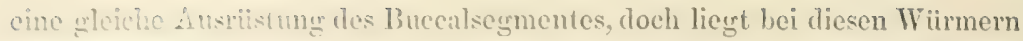
wischers den lichtbrechenden Kïrperm, die ron beiden Autoren als Linsen bondehret werden, ein rothes l'igment. Dies, bei meiner Art fehlende, Pigment spricht allerilings sehr zu Gumsten der Ansicht, dass es sich bei dieser Platte um cine Augenbilutung handelt. Dass diese zum grössten Theil auf der Tentrallikiche grelagert ist, muss dabei auflitlig erscheinen, und die von Langerhans betonte Beziehung der Augenplatte zur Durchsichtigkeit der Rühre verliert dadureh an Wichtigkeit. Es ist daher vielleicht nieht ausgeschlossen, lass die granze Platte eine driksige Bedeutung lat; jedenfalls ¿ihmeln die einzelnen grlüuzenden Körper, worauf zu achten ist, den gleichen Gebilien in den Terminalorganen an den Kiemenstrahlen der Filograna im hohen Grade. Fine Iintscheidung wird crst mit der Erkenntniss des nervösen Apparates grebracht werden können.

Die dorsalen Biundel der folgrenden Thornealsegmente enthalten zahlreiche gelhe Capillarborsten, welche an der spitz anslanfenden Endstrecke gesäumt sind und etwa so weit himausragen, als das Segment lang ist. (Fig. 4.) Die muter ihnen an den Flanken des Körpers stehenden flossenartig erweiterten 'Tlïiger der Inkenreihen sind amnïhernd gleich gross; die äisserst zahlreich und dicht in cincl Querreihe stehenden IIaken sind dadurch ausgezeichnet, dass ihre frei vollegente Kante stumpf abgerundet und gleichmässig breit, in ranzer Ausdehumg wie mit Feilkerben bedeckt ist. (Fig. 6, T.)

Das Abrlomen, welehes mit einer geringen Einschnürung aus dem Thorax herrorgeht, ist in vorderen Theil fast drehrund, plattet sich, wie es nack linten an Breite abnimmt und zuspitzt, erheblich ab und wird auf der Batichliche breit rimmenförmig vertieft. Die Segmentgrenzen treten nur an diesem hinteren Theile zumal an den Flanken deutlich hervor. (Fig. 1.)

Der Abstand der einzelnen Borstenbindel von einander, wodurch die Linge der Segmente ausgedriickt wird, nimmt von vorn nach hinten dergestalt ab, cliss die ersten Abdominalsegmente etwa dreimal, die letzten fünfbis sechsmal breiter als lang sind; die Verkiirzung der Segmente tritt an den letzten zwanzig hesonders heraus. - In allen abdominalen Segmenten steht jederseits nur eine Capillarborste, welche in den vorderen Segmenten kaum die Länge des zugehürigen Segmentes erreicht, in den letzten 12 Segmenten aber beträichtlich verlängert ist und damn der Körperbreite fast gleichkommt; die einzelne feine glashelle Borste läuft mit einer vom graden Grundtheil winklig abgebogenen und an dem Knie erweiterten Spitze aus. (Fig. J.) - Die Hakenborsten, welche sich von denen des Thorax durch 
geringere Grösse unterscheilen, sind an den ersten ablominalen Sorruenten nur in greringer Kalhl vorhanden, und bililen damit ein granz kin\%es (buerpolster.

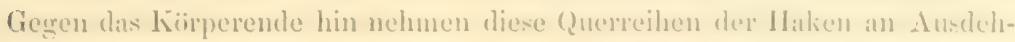
nung zu, bleiben aber, anderen Arten greneniiber, immer nur kum, und greilen lanum iber die Flanken des Körpers lomans.

Am After steht jerlerseits ein scheibenfömiger Latppen als Analcirrus.

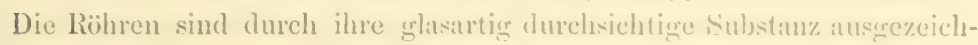
net; sie liegen einzeln, in ganzer $\Lambda$ usdehnung aufgewachsen, und sind unregelmässig, oflenbar der Unterlage angepasit, gewniden. Von hinten nach vorn nehmen sie an Durchmesser zu, ihre Linge iibertriftit die des Wrumes um ein Vielfaches. Die hintere grüssere Strecke ist von dicht stehenden, gleichmässigen queren abgerundeten Wülsten geringelt; diese fehlen dem vorleren 'Theil, der kantig, unegelmäissig prismatisch eine obere Firste trägrt, an welcher sich 2-3 grössere zahmartige Einsehnitte befinden. (Fig. S. 9.)

Die Art gehört in die Gattung Placostegus, sobald man ron dem rollstimdigen Mangel eines Deckels oder Deckelstieles bei iln absieht. Ich liamn mich der Meinung nicht hingeben, dass dieser Mangel hier ein zufiulliger oder durch Verletzung herbeigefülıter sei, denn als ich den Wurm aus seiner Rühre herausnahm, erwies sich die zusammengelegte Kieme in jeder Hinsicht unverletzt, so dass, wenn ein Deckel überhaupt vorhanden gewesen wäre, dieser wohl nicht so vollstïndig, ohne irgend einen Rest zu hinterlissen, hätte rerloren gehen künnen. Die Verletzungen, welche ich vom Kragen erwïhnte, sind wahrscheinlich entstunden, als ich die Kieme auseinander bog; um ihren Bau zu iibersehen; bei dieser Präparation kam erst der grosse vordere Lappen des Kragens zu Tage und wurde wahrseheinlich dabei verletat.

Von den durch A. Hansen ${ }^{1}$ und Langerhans ${ }^{2}$ genauer bekannt gewordenen Arten $P$. tricuspidutus und tridentatus unterscheidet sich $P$. incomptus, ausser durch den nicht schwer wiegenden Mingel des Deckels, durch die Pigmentlosigkeit des Linsenguirtels am Buccalsegment. Dass das Pigment an dem ibrigens gut conservirten Wurme durch die Aufbewalnumg in Weingeist verloren gegangen sei, ist nicht wahrscheinlich; die Pigmentlosigkeit auf den Wolnsitz des Wurmes in grösserer Weerestiefe zurickzufülnen, ist da die Fundorte nur wenig jenseits der Humdertfarlenlinie liegen, wolnl nicht zulïssigr. - Nach der Form der abdominalen Capillarborsten steht Plucostegus

1 A. Hansen, Orersigt orer de norske Serpula-Arten. Archir fur Mrathematik og Xaturridenskab. 3 Li., 1578 , pag. 43 .

${ }^{2}$ Langerhans, Die Wurmfauna ron Marteira. III, Ztschr. f. wiss. Zoulug. Bd. XXXIY, pag. 120. IV. Ztschr. f. wiss. Zoolog. Bul. XL, pag, 275. 


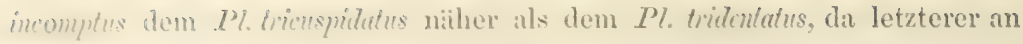
den vorderen der Ahdominalsegmente meisselförmig erweiterte Capillarborsten besitzt. In keiner der bis jetzt mitgetheilten Beschreibungen anderer Arten fimi ich dits Verhalten der 'Thoracalmembran erwïhnt; das ist aber wohl eine duslassung, welche nicht auf ein Fehlen dieser Membran gedeutet werlen darf. - Schliesslich erwähne ich, dass die Querrippung der hinteren Röhrenstrecke sehr auffillig und ron keiner der ibrigen Arten erwähnt ist.

\section{HYALOPONATUS (MARZ).}

\section{Hyalopomatus Langerhansi, n. sp.}

$$
\text { Tuf. } 60, \text { Fig. 10-15. }
$$

Pallidus, antice teres postice versus depressus et canaliculatus, segmentis 47 . Branchia in basi subinvoluta radios 13 dextros, 11 lieros et operculum dorsale gerens; radii erassiusculi, pellucili, filis sub ap̣icem breven undum protinus abbreviatis muniti; stylus operculi subaunulatus branchias longe superans earum radies crissior; operculum pyriforme molle resiculare. Thorax sermentis 6 ; seguentum buccale proximo duplo fere longius; pallium alatum segmentum proximum vix transgrecliens, collare in lobum mediumm longum triangulare productum; setac buceales antice vergentes capillares ante apicen longum ntrinque limbatum serie brevi denticulorum spiniformium armatie. Segmenta proxima duplo fere lation quam longiora, setarum fasciculos distichos gerentia : setae longae brumnene capillares sub apicem leniter curvatum utrinque limbo subtiliter dentato alatae et capillares tenuiores simplices; tori postice versus paullum minores, pimne in modum dilatati, uncinos permultos tenues in acie crebre et subtiliter lentatos ferentes. Ablomen anticum non articulatum, medium maculis albis setarumque distributione, ultimum sulcis etiam transrersis articulatum; segmenta posteriora versus longitudine decrescentin; setae cippillares simplices singulae, ultimae elongatne corporis latitudinem aequantes; tori parvi series uncinorum thoracalibus similium sed minorum perbreres ferentes, - Seg. mentum anale subdilatatum, cirris nullis.

Tubus calearens albidus subnitidus, postice subdepressus, basi et margine paullum dilatato affixa, deinde rectangulatus erectus teres, ostiu integro.

Hab. 1. No. 16 , near Havanna, depth 292 fms. 2. No. 41 , depth 860 fris., Lat. $23^{\circ}, 42^{\prime}$ N., Long. $53^{\circ}, 13^{\prime} \mathrm{W}$.

Zur Beschreibung dieser Art dienen mir zwei in völlig gleich grestalteten Rïhren enthaltene Thiere, beide zerbrochen, doch so, dass an der Länge kein Stück fehlt.

Der Wurm ist völlig farblos; die Kieme in zusammengelegten Zustande 3̂mm., der Leib $8,5 \mathrm{~mm}$. lang, wovon $2 \mathrm{~mm}$. auf die Thoraxlänge kommen; der Thorax ist durchgehend $1,3 \mathrm{~mm}$. breit, das Abdomen, mit Ausnahme einer kurzen verschmälerten Endstrecke, $1 \mathrm{~mm}$. breit; der Körper im vorderen 
Theile drehrumd, die hintere Hiille des Ablonen hat aber cine abreplattete

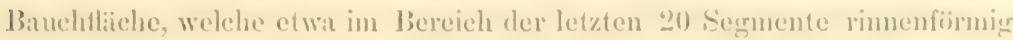
vertiefi ist. ('lit. 60, Fig. 10, 11.)

Der 'Thorax hat 6 Segmente, am Mblomen zaihlte jeh 41, doch ist diese Zahl vielleicht zu grering, dat ich an der vorderen Strecke desselben, welche etwas lïnger als breit ist, iussere Merkmale einer semmentierung nicht gefunden habe, deshalb aber nicht das völlige Fehlen ciner Segmentierung hier behaupten mïchte. Die schlanke Kieme hat jederseits ein kures grleichmiissigg hohes IBasalblatt, welches stiurker als im IIalbkreis cingrerollt ist. Das rechte Basalblatt trug bei dem einen Thiere 13 Kiemenstrahlen, das linke 11 und den Deckelstiel. Die dicken hyalinen Kiemenstrahlen sind fast gleich lang und mit Ausnahme einer ganz kurzen nackten Endspitze ron zwei lieihen Kiemenfüden besetzt; diese, welche in den vorliegenden Exemplaren fost mit einander rerklebt waren, entspringen ummittelbar neben einander, sind schlank, etwa 5-6mal lïnger als der Schaft breit und nur kurz ror der Endspitze des Schaftes, damn aber raseh abfillend verkiirzt. - Der Deckelsticl gehört dem linken Kiemenblatte an und entspringt am dorsalen Ende der Kiemenstrahlemreihe; es ist ein platter, vielleicht aber erst durch Collabieren platt grewordener, in seiner Liinge gleich breiter Faden, dessen Breite fast das Dreifache eines Kiemenstrahles erreicht, und der mit Einschluss des Deckels fast um die Hälfte der Kiemenlänge iiber deren Ende himausreicht; nuf seiner distalen Strecke ist er durch feine, in gleichen Abständen stehende Ringfurchen deutlich geringelt. Eine dicke, von Knorpelzellen gebildete und von einem Plattenepithel gedeckte Wand umgiebt einen engen Centralcanal. - Der an seinem Ende stehende Deckel hat keine Deckelscheibe: es ist ein birnenförmiges Hohlgebilde, welches offenbar nur durch Collabieren abgeplattet ist; in diesem Zustande betrïgt der grösste Querdurchmesser des Deckels etwa das Vierfache der Breite des Deckelstieles, und kommt der eigrenen halben Läuge nicht ganz gleich. (Fig. 10.)

Der Thorax besteht aus 6 Segmenten, ron denen das vorderste, das buccale, etwa doppelt so ling als die folgenden ist, diese aber etwa doppelt so breit als lang sind. - Die Thoracalmembran erstreckt sich jederseits von den Flanken des Buccalsegmentes nach hinten etwas ïber diejenigen des nächsten Segmentes hinaus und reicht nach vorn etra so weit als das Buccalsegment lang ist; abgebogen erscheint sie als ein grosser, fügelfürmiger gerundeter Lappen, welcher niedergelegt ron jeder Seite her über die Mittellinie hinausreicht; der unpare ventrale Lappen, welcher durch einen tiefen 
Finschnitt etwas dorsalwairts vom buccalen Borstenbiundel von der thoracalen Membran wetremnt wirl, ist an seinen seitlichen 'Theilen, etwa in der Ausdehnung der queren IIakeneihen, niedriger als die 'Thoracalmembran, erhebt sich dam aber zu einem unpataren medianen langen und sehlanken spitz dreieckigen zungenförmigen Zipfel, so dass in dieser Ausdehmung der Kragen wenig kituer als der 'Thorax ist. (Fig. 10.)

Dits jederseits am Buccalsegment stehende mach vorn und dorsalwiirts gerichtete Borstenbiindel ist kaum halb so gross als die folgenden Borstenbïndel; seine grlashellen Borsten tragen da, wo der grade Schaft mit scharfer J3iegmug in ten gesïumten spitz auslaufenden Endtheil iibergeht, eine kurze Reihe kleiner fist dornartiger spitzer Zälmehen. (Fig. 12.)

An den folgenden thoracalen Segrmenten treten die dorsalen Biindel capil. larer Borsten hinter einanter auf einer von der Riicken-zur Batuchfliche ziehenden Linie aus. Das einzelne Bïndel ist ansehnlich gross, so dass es nach hinten gelegt auf das je folgende Segment weit hiniibergreift. Die grossen gelbbramen capillaren Borsten haben an der schwach geschweiften Endspitze jederseits einen Samm, dessen Rand fein gezillnelt ist. (Fig. 13.) Neben diesen Borsten stehen einfache capillare, wie es scheint so, dass neben jeder der ersten eine eimfache capillare steht. - Die ventralen Querreihen der Haken stehen vor dem freien Rande der flossenartig erweiterten dïnnhäutigen Wiilste; die Reihen nehmen von vorn nach hinten etwas an Ausdehnung ab. In ihmen stehen sehr zahlreiche Haken dicht gedrängt, die Spitzen der Zïhne nach rorn wendend; der einzelne Haken ist eine selır dünne Platte, deren freier liand mit zahlreichen sehr kurzen 'Zïhnehen besetzt ist. (Fig. 14.)

Am Abdomen erschien mir die vordere Strecke in einer Ausdehnung, welche etwa der Körperbreite gleichkam, unsegmentiert; in der mittleren Strecke war eine Segmentierung, welche der Vertheilung der Borsten entsprach, durch weisslich durchscheinende viereckige Flecken angedeutet; das hyaline Körperende trug an den Rändern gut ausgeprägte Segmenteinschnitte. Die einzelnen Segmente waren in der mittleren abdominalen Strecke am längsten, etwa dreimal breiter als lang, davor fünfmal, und dahinter sechsmal breiter als lang. Die ventral stehenden Capillarborsten stehen zu je einer jederseits in einem Segment, sind einfach haarförmig, an den letzten 17 Segmenten so lang und länger als der Körper hier breit ist. Darüber stehen hart vor der hinteren Segrnentgrenze die an allen Segmenten nur ganz kurzen, auf kleinen Polsterchen sitzenden Querreihen der Haken, welche kleiner als die entsprechenden thoracalen sind. (Fig. 11.) 
Das Alersegment ist etwas erweitert; dentliche (Grren habe ioh an ilum nicht erkennen kïmnen.

Die weisse kalkige Rïhre besteht aus "2 Abschnitten: der hintere der Unterlage aut- und anliegende ist etwas platt gedriekt, an den Seitemrändern mit sehwacher kँmte erweitert : an seinem Vorderende erheht sich liss rechtwinklig abbiegend und vïllig fiei vorragend der griissere vordere $A l$ ). schnitt, welcher schwach gekriimmt, dabei völlig drehrund und glïnzenri glatt ist; die terminale kreisfömige Oefhumgr ist von einer etwas verdimnten, uibrigens völlig ganzrandigen Wandstrecke umgeben. (Fig. 15.)

Von dem Hyalopomatus Clupuredï, welche v. Marenzeller ${ }^{1}$ beschrieben hat, weicht diese Art durch die Bildung der 'Thoracalmembran al, welehe dem II. Claparedii ganz fehlen soll: die gegebene Abbildung scheint mir allerdings für eine solche Auffissung nicht zu sprechen, ich möchte die dort dargestellten den Kiemenursprung umfassenden Hautlappen für Theile einer Thoracalmembran halten; leider wissen wir nichts von der Kragenbildung dieser Art. Nach der Abbildung ist der Deckelstiel des H. Claparèdii kiirzer als der von H. Langerhansi, der Deckel selbst weicht durch die am freien Ende vorhandene Abplattung ab. Mit Hyalopomatus Murchzelleri, welchen Langerhans" beschrieb, stimmt die Art wie $H$. Claparedii durch den Besitz von nur 6 thoracalen Segmenten iiberein, auch in den Borsten herrscht im Allgemeinen Uebereinstimmung, nur giebt Langerbans für die von ilum beschricbene Art nicht die Anresenheit einfacher neben gesiumten Capillarborsten in den Thoracalsegmenten an. Das wïde wohl einen Unterschied andeuten, welcher grösser ist als der aus der ungleichen Zahl der Kiemenstrahlen und dem wechselnden Verhalten des Deckels sich ergebende. Uebereinstimmend bei allen scheinen die Röhren zu sein.

Dass nach dem, was ich über die Thoracalmembran des II. Langerhansi angegeben habe, die v. Marenzeller'sche Diagnose der Gattung Hyalopomatus eine leichte Abänderung erfordert, ergiebt sich von selbst.

1 v. Marenzeller, Coelenteraten, Echinorlermen und Würmer der k. k. oester. ung. Nordpol-Expedition. Denkschriften der k. Akademie der Wissenschaften. Math. naturw. Classe. Bu. 35, pag. 393; Taf. IV, Fig. 2. Fig. 49.

2 Langerhans, Die Wurmfauna von Madeira. Zeitschr. f, wiss. Zoolog. Bd. IL, pag. 278; Taf. XYII, 
VERIII,I Phil, char. emend.

Vermilia annulata (Schmarda), char. rev.

Schmad, Nene wirbellose 'Thiere, I, II, pag. 28, Taf. 21, Fig. 176.

$$
\text { Tif. 5s, Fig. 12-16. Taf. ร9, Fig. 1-s. }
$$

Pallida, subelongata, antice subteres, posteriorn rersus dimidio fere attenuata et depressa, semmentis 85. Intanchia in laminae basalis crassulac, vix involutae subtus prolongatae dextra parte -1 , in lacra 20 tadios et operenlum gerens; radii antice fere acque protenti, crassuli, subpellucidi, annulatim crenati, filis branclualibus sub apice attentiato hamato undo vix brevioribus numiti; strlus opercularis radio branchiali crnssior, in medio attenuatus, annulatim crenatus cum opereulo branchiam rix superans; opereulum conicum molle in linsi libera disco comeo orbiculato dupliei vel triplici tectum. 'lhorax ttam abduminis partem longitudine fere aequans segmentis 7 ; sergnentum buccale proximo paullum longins utrinque fasciculum parvum setarum eapillarium simplicium, pallium segmentis 3 proximis aflixum alatum triangulum corporis latitudinem aequa:us, et collure integrum margine recto antice aeque ac pallium protentum gerens. Segmenta proxima ter fere latiora quam longiora utrinque fasciculos distichos sctarum capillarium Havazum sub apicem cursatum late utrinque limbatarum et series uncinorum in aeie serrato-dentatorum ante marginem dilatatum cutaneum tororum postice versus in superficiom reutralem magis prodnctorum gerentia. Segmenta abdominalia priora teretia, duplo fere latiora quam longiora, posteriora versus breviora et angustiora, ultima 7ies latiora quam longiora ; setae capillares tenues simplices geniculatae, anteriores singulae, posticae elongata flabella latitudinem corporis fere acquantia formantes. Uncini thoracalibus similes antici series perbreres postici latissimas fingentes.

Tubus caleareus albidus scaber irregularis, pro parte affixus, carinis 5 longitudinalibus, antice quasi ex infundibulis sese recipientibus conflatus, ore patulo.

IIab. 1. No. 16, depth 292 fms. Near Morro Light. 2. No. 19, depth 310 tims., Lat. $23^{\circ} 03^{\circ} \mathrm{N}$, Long. $83^{\circ} 10.5^{\prime} \mathrm{Wr}$.

Fiir die Beschreibung dieser Art dienen mir zwei Exemplare, welche ungleich gross sind und in einigen Punkten von einander abweichen; diese spiiter hervorzuhebenden Unterschiede scheinen mir untergeordnete Bedeutungr $\mathrm{zu}$ besitzen.

Beide Thiere sind mit Ausnahme der hornbraunen Deckelscheibe farblos; ziemlich schlank, in der Vorderregion so dick wie die zusammengelegte Kieme und fast drehrund, nach hinten allı̈ihlich auf weniger als die Hälfte sich verschmälernd und dabei abgeplattet; Segmentfurchen treten erst in fler hinteren Körperhälfte dentlich hervor. Das Vorderende hat durch den die Kiemen etwas überragenden Deckel und durch die genauer zu schildernde Thoracalmenbran sein besonderes Geprägre; das Hinterende zeichnet sich im Gesammthabitus durch die ansehnlichen weit vorragenden Bündel der Capil- 
larhorsten ans. - Am kleineren lixemplar wa der Körper 10,5mm. lang. wovon aut den ans 7 Segmenten bestehenden Thorax 2, Jmm. kanen, wih. rend dats Smm. lange Abdomen fi: Segmente hatte; das zusammengelerrte Kiemenbindel war 4mm. lang; der Körper des gröiseren Kxemplares war 12,5mm. lang, wovon 9, Jum. auf das aus s.j segmenten bestehende Abto. men kamen; sein Kiemenbindel war 5, Jmm. lang. Dies zweite Exemplar erwies sich durch den Besitz von Jiern als Ireilochen.

Die im Weingeist ganz fublose Kieme besteht jederseits ans einem von der Riicken- nach der Batuchlikiche hin hoch ansgezorenen wenig eingerollten dicken Basalblatt, welehes etwas iiber die zusammengelegte Thoraealmembran himausrant; bei dem kleineren Exemplar trïgt das linke Basalblatt 12 Kiemenstrahlen, das rechte 11 und den Deckelstiel, wihluend die Kieme des grö̈seren 'Thieres 42 Kiemenstrahlen und den Deckelstiel hat. Die einzelnen Strahlen sind fast gleich lang, die am ventralen Unfange stehenden reichen nicht ganz so weit als die dorsalen hinaus; der einzelne Strahl ist dick durchscheinend, am äusseren Unfange bald mels bald minder ringförmig gekerbt. Jeder Strahl lïuft mit einer sehr viel diuneren mackten schwach hakenfürmig gekrimmten Endspitze aus, welehe länger ist als der Schaft breit; am inneren Umfange des Schaftes stehen die Kiemenfïlen in zwei Reihen mmittelbar an einander, cinen dichten Besatz bildend; wo ich die Fiiden isolieren konnte, waren disselben $4-5 m a l$ länger als der Schaft dick; vor der nackten Endspitze des Schaftes sind sie nur wenig verkürzt.

Der Deckelstiel, welcher dem rechten Basalblatte angehört und hier dem ersten dorsalen Kiemenstrahl semer Stellung nach entspricht, ist drehrund, sehr viel dicker als ein Kiemenstruhl, an seiner Basis und ror dem Deckel dicker als in seimer Mittelstrecke, fast durchscheinend, und an dem kleineren Exemplar stark, an dem grösseren nur schwach von Furchen geringelt. Dieser Stiel ist kiirzer als die Kiemenstrahlen, so dass der von ihm getragene Deckel mit seiner Fndscheibe nur wenig aus dem zusammengelegten Kiemenbündel hervorsieht. Der Deckel ist bei den beiden Exemplaren in der Form der Deckelscheibe ungleich. Die Gesammtform des Deckels ist die eines geraden Kegels, welcher linter der halben Linngre des Stieles an Lânge wenig zurückbleibt, an der Basis fast so breit als hoch und etwas mehr als doppelt so breit ist als an seiner Spitze, mit welcher er von einer stärkeren ringförmigen Einschnürung an der Spitze des Deckelstieles abgeht; scine Oberfläche ist glänzend glatt; im Innem scheint ein ron Flïssigkeit (oder einem sehr weichen Gewebe) erfüllter Raum zu sein, da der Deckel leicht fast platt 
collabiert. Die auf der Kegelbasis aufsitzende Deckelscheibe ist in beiden Thieren von hornartig brumer Chitinmasse gebildet, im kleineren Exemplare dunkler als im grösseren. Im kleineren Wurme hat diese Scheibe das Ausschen, als wïre anf der basalen schwach concaren Scheibe eine Anzahl (3) kleinerer Schnlen dicht iiber einander, aber schief excentrisch aufyesetzt, dathei solchergestalt mit einander verschmolzen, dass nur die Randtheile der einzelnen Schalen ron einander gesondert blieben; die oberste, kleinste dieser kreisfürmigen Schalen bildet dam die freie schwach concrve Endfliche, welche wohì um ein Drittel weniger als die tiefste Schale im Durchmesser hiilt. (T'uf. 5S, Fig. 13.) - An dem grösseren Wurme ist die Endscheibe des Deckels etagiert: auf der Endfliche des Deckels liegt eine hellbrame an Rande etwas verdickte Scheibe, aus deren Centrum sich eine kurze dicke solide Säule erhebt, welche eine zweite der unteren ähnliche, aber etwas lileinere schwach concare Endscheibe trïgt. (Fig. 14.) Die hier beschriebenen Unterschiede in der Gestalt der Deckelscheibe sind, soviel Werth man auch bisher in taxonomischer Beziehung auf die Gestalt der Deckelscheibe gelegt hat, in meinen Augen nicht von solchem Belang, dass ich um deswillen die Träger dieser Deckel als Vertreter verschiedener Arten amsehen möchte; ob diese Unterschiede aber als individuelle Variationen oder als Auslruck ungleicher Altersstufen, worauf der Grössenunterschied der heiden Thiere hindeuten könnte, aufzufassen sind, bleibt festzustellen für später vorbehalten.

Am Kürper des Wurmes sind Thorax und Abdomen scharf von einander getremnt. (Taf. 58, Fig. 12.) Die nach den Borsten und deren Trägern zu sondernden 7 Segmente des vorderen Körperabschnittes sind etwa dreimal breiter als lang; das erste derselben, welches nur ein Bündel capillarer Borsten trägt, ist etwas länger als die folgenden; mit einer schmäler werdenden Fortsetzung setzt es sich auf der Rückenfläche zwischen die beiden Kiemenblätter fort, ohne eine besondere als Kopflappen zu deutende Bildung zu erzeugren. - Die vorderen drei thoracalen Seg̈mente nehmen an der Bildung der Thoracalmembran Antheil. Diese, welche im zusammengelegten Zu-

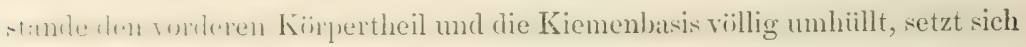
aus zwei seitlichen Lappen zusammen, die durch einen tiefen Einschnitt von einem unpaaren auf der Ventralfliche des Buccalsegmentes kragenförmig quer verlaufenden Lappen völlig getrennt sind. Ausgebreitet stellt jeder der dann flügelförmig erscheinenden dünnhäutigen seitlichen Lappen ein dreieckiges Blatt dar, welches an den Seitentheilen der Rückenfläche oberhalb der 
dorsalen Borstenbindel entspringert, am vorderen Kïrpertheile am Scitentheile der Kieme vorbei nach der Ventralfliche zieht. wo es etwa in der llibhe des unteren Endes des ersten Ilaken tragenden Wulstes an dem Kinschnitte, weleher den unparten lappen sondert, endet. Am ansegebreiteten Bblatte liegt die Spitze der dreieckigen Platte etwas vor der Grenze zwischen dem eristen und zweiten Segment und hier kommt die Breite des Blattes der Kärperbreite gleich. Der umpane ventrale Lappen ragt mit gexade abgestutztem Vorderrande an der Kiemenbasis so weit als die Nachbartheile der Seitenlappen vor und erzengt zusammen mit diesen das Bild eines Kragens, der die Riickenfliiche frei lassend an deren Seitentheilen sich nach hinten erstreckt, jederseits seitlich den linearen Einschnitt besitzt und auf der V'entralliiche mach vorn gerichtet ganzrandigr das die Mundöfinung tragende Körperende umfissst.

Das Bündel der Borsten, welches das Buccalsegment träigt, steht mit den dorsalen Bündeln der nächsten Segmente in gleicher Ilöhe; die Borsten desselben sind aher schwïcher als die der folgenden Bündel, farblos und einfach capillar, ohne breiteren Randsaum. (Taf. 59, Fig. 2.)

An den folgenden sechs thoracalen Segmenten ist das jederseits stehende dorsale Bündel aus Capillarborsten gebildet, welche hoch am Seitenumfinge des Körpers in einer längslaufenden Doppelreihe austreten. Die Borsten sind braungelb, so lang, dass sie nach hinten angelegt auf das folgrende Segment übergreifen, stark geschwungen und vor dem spitz auslaufenden Ende jederseits breit blattartig gesïumt. (Taf. 59, Fig. 1.) Ventralwiirts von diesem Bündel steht die Querreihe der Haken, an den Flanken des Kürpers abwärts reichend, je weiter nach hinten um so mehr auf die Bauchfliche iibergreifend, so dass am 7 ten 'Thoracalsegment die unteren Enden beider Hakenreihen nur durch einen geringen 'Zwischenram von einunder getremnt sind. Jede Hakenreihe bildet einen nach hinten convexen Bogen und steht auf einem flossenartig erweiterten Hautsaume vor dessen parallel mit der Hakenreihe verlaufendem freien dïnnhäutigen Randtheile. Die sehr zahlreichen dicht aneinander gedrängten IIaken stehen in einer Reihe und sind kleine Platten, welche die freie mit einer Reihe von Sägezïlnen besetzte Kante nach vorn wenden. (Taf. 58, Fig. 15, 16.)

Die das Abdomen bildenden Segmente ändern in der Länge desselben ihre Dimensionen und die Ausristung mit Borsten. Die fast drehrunden ersten Segmente desselben, zwischen denen Segmentfurchen kaum wahrgenommen werden, sind etwa doppelt so breit als lang; wie der Körper nach 
hinten sich verschmillert, riicken die deutlicher werdenden Segmentfurchen

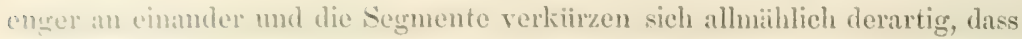
diejenigen der hinteren Kïrperstrecke siebemmal breiter als lang sind. Die am Abdumen ventral stehenden Capillarborsten treten, mit Ausnahme derjenigen der letzten 17-1S Segmente, jederseits nur zu ein oder zwei aus, und reichen kaum so weit ror als das Segment lang ist; an den bezeichneten letzten sermenten bilden sie dagegen jederseits ein Bindel, welehes bedeutend weiter, fist der Körperbreite gleich, vorragt und diese Körperstrecke wie gebiitelt erscheinen liisst. Die einzelne Borste ist furblos, dium, einfach capillar; inre Endstrecke etwas kniefümig gebogen. - Die Haken, dorsalwärts von den Capillarborsten stehend, bilden an den vorderen Segmenten nur eine ganz liure, schwer auftindbare Querreihe; diese queren IIakenreihen nehmen an den hinteren Segmenten derartig an Ausdehumgr zn, dass sie in der hinteren Körperstrecke jederseits an den Flanken auf die dorsale wie ventrale Fläche hinübergreifen. Der die ILaken tragende Bezirk der Lö̈perwand ist wulstfümigg erhaben; an den vorderen dieser Segmente allerdings in kaum bemerkbarer Weise. Die Form und Stellumg der einzelnen iiberall kleinen Haken ist derjenigen der thorncalen Segmente gleich.

Am Afterende habe ich kemerlei Aftereiren gesehen. Bemerken will ich, dass an dem kleineren Exemplare die dorsale Fliiche der letzten Segmente bräinnlich, und unter stïrkerer Vergrösserung derartig gekörnelt erschien, dass es aussah, als sei hier eine Schicht von Hautdriisen entwickelt. Aehnliche Bildungen hat Langerhans ${ }^{1}$ von Vermilia infundibulum, clarigera und ruyose erwihint.

Die 'Thiere leben in dickwandigren weissen Kalkröhren; diejenige, in welcher das kleinere Exemplar stak, ist nur ein kurzes, wahrscheinlich vorderes Bruchstiick; dasselbe ist abgesehen von den Rauhigkeiten und Krümmumgen drehrund, mit einer Anzahl kragen- oder manchettenartig ringsumgehender, frei in ungleichen Abstiinden vou einander vorragender battartiger Leisten versehen, und auf einem Theil des Umfunges mit füf feinen längslaufenden Leisten besetzt. In dem Glase, welches das grössere Exemplar enthielt, lag eine offenbar zu diesem gehörende gerad grestreckte Röhre, welche ron der eben beschriebenen sich durch den Mangel der Querleisten, durch die Abplattung, eine an den Rändern schwach fliugelförmige Ausbreitung des einen Umfanges und schliesslich dadurch unterschied, dass von den fünf Längsleisten die beiden iiusseren niedrig und glatt, die drei 


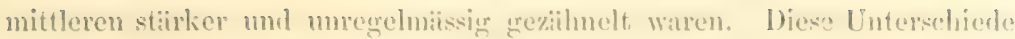
diirften von keinem Belang sein, da die Abplattumg fiir die an- mod aullie-

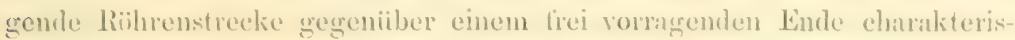
tisch ist, die Querdeisten dagegren friber Mïndumgsö̈uder und romit anch Anwachsstreifen rorstellen.

Ich bezeichne diese Art als Vomilie ammlulu (Schm.), weil die wenigen Kemmeichen, welche Schmarda fuir den von ihm so genamten Wrum amgriebt. sich alle bei ihr vorfinden. - Wem ich diese Art dam muter der Gattung Vermilia auffiihra, so sehe ich zumiichst davon ab, dass nach der Charakteristik, welche Plilippi fiir diese Gattung anfrestellt hat, der 1)eckel kalkigr sein miisste. Das ist num nicht der Fall, aber anch wohl ron keinem Belangr; für Vermilia infundibulum hat Langerhans ${ }^{1}$ schon angegeben, dass hier die Kalkablagerung ganz ïnsserlich und sekundiir sei. Eine Identifieirung der von iilteren Autoren aufgestellten, von Mörch" unter Vermilia zusammengefassten Arten, bei denen die Gestalt der Röhre und des Deckels berücksichtigt ist, wird mit Sicherheit sich kaum ausfiihren lassen; auf keine derselben kann ich die Vermitia amuluta zuriickführen; soll die Form der genamnten Theile von Belang sein, so wäre an die Vermiliu multivaricosa (M.) zu denken, zu welcher Mörch ${ }^{3}$ eine aus Wrestindien stammende, von Gmelin als Vomiliu infundibulum bezeichnete Art rechnet. - Mit eingehender Berïcksichtigung der Borstenformen hat Langrerhans ${ }^{4}$ eine Anzahl ron Arten, die er zur Gattung Vermilia stellt, beschrieben; von diesen weichen $I$. imfundibulum und $T$. spirorlis wegen der doppelten Form der buccalen Borsten, letztere auch durch den Besitz von Kiemenaugen, $V$. cluvigerc ind multicostuta durch anders gestaltete Deckelscheibe, $V$. rugosa schliesslich durch die Form

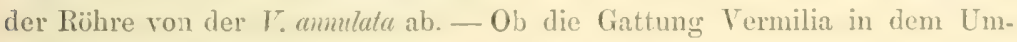
funge, welchen sie zur Zeit durch die in ihr aufgenommenen, besser bekannten Arten erhalten hat, wird bestehen bleiben können, wird sich erst entscheiden lassen, wenn unser Urtheil iiber den taxonomischen Werth der zu verwendenden Merkmale sicherer als zur Zeit geworden ist.

\footnotetext{
1 Langerhans, TTurmfauna ron Madeira, IV, Z. f. wiss. Zoolog. Bd. XL, pag. 278.

2 Mürch, Revisio critica Serpulidarum, a. a. O., pag. $41 \mathrm{f}$.

\& Mörch, a. a. O., pag. 43.

1 Langerhans, a. a. 0 .
} 
FITGRANA (OKEx), char. emend.

Filigrana Huxleyi, n. sp.

Tivi. 56, Fig. $4-9$.

Albita, brevis, longitudine et parvo seymentorum numero rarians; branchia ct thorace pamalleli subterete, ablomine paullum angustiore, posteriora versus depresso. Branchia variae lonzitudinis in lamina basali humili utrinque radios aeque protentos $t$ in apice nudo clavato pulvinari cellulutum et filis sub apicem vix brevioribus instructos ferens. Segmentum buecale iluplo proximo longins, utrinque fascieulum ceteris majus setarum capillarium simplicium breviorum aliarumn̨u ad basim apicis simplicis in laminam mucronato-dentatam dilatatarum ; pallium per ommen thoriecm et supri decurrens antice dimidio corpore latius postice paulum angustius; collare sulitus elongatum et in medio incisum gerens. Segmenta thoracalia 4-5ies latiora quam longiora, in fasciculis longis setas capillares simpliciter limbatas et, excepto segmento priore et ultimo, singulam capillarem geniculatam sub apiecm crenato-dentatam; in pinnulis humilibus postice subtus magis protentis uncinos parvos in acie elongata subtiliter crenato-dentatos gerentia. Semnenta abdominalia postice versus breviora setas singulas capillares subrectas vix sub apicem dilatatas, ultimas longiores, et in pimulis perbrevibus uncinos thoracalibus similes sed minores; ultima subtus pulvinar glandulosum divisum gerentia. Segmentum anale lobulis 2.

Tubi multifarie coaliti molem fiscieulatam fingentes, singuli paullum contorti, subcylindrati albilit.

IIab. : 1. Tortugas, 1868. 2. May 4, 1868. Cast No. la. depth 19 fms. 3. No. 11, 1868. S. W. Loggerhead Key. Cast No. 8, depth 19 fms.

Von mehreren Orten des durchforschten Gebietes liegen mir grüssere oder kleinere IItufen der Länge nach zusammengekitteter feiner, kalkiger und weisser Röhren vor, welche vermuthlich alle ihren Ursprung dem gleichen Erbauer verdanken, als welche ich aber nur in zwei Fällen mit ganzer Sicherheit die hier zu erwähnende Serpulide constatiren konnte.

Die Würmer, welche ich aus diesen Röhren herauslöste, stimmten in vielen Punkten mit der von IIuxley als fissipar beschriebenen Protula Dysteri iberein, und waren, wie diese, zum Theil am hinteren Körperende mit je einer ungleich weit entwickelten Knospe versehen. Die Meinung, dass ich die wahre Protula Dysteri vor mir hätte, war nicht zu halten, da in einigen Punkten sich Abweichungen von der durch Iuxley beschriebenen Bildung dieser Wïrmer herausstellten.

Beim Durchsehen einer grösseren Anzahl dieser Würmer war leicht die grosse Tariabilität derselben in der Grösse und Segmentzahl zu erkennen, wie sie anch von anderen Arten dieser Gattung erwïhnt und mit Recht zum Theil mit der Knospenbildung in Beziehung gebracht ist. Auf die Bildung

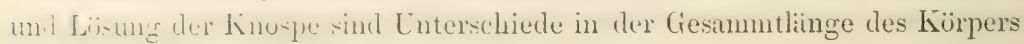


wie in der Zahl der abdominalen segnente ja ohne 11 eiteres zuriickzufiihren,

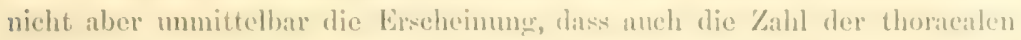
Segmente bei verschiedenen Individuen eine ungleiche ist. Dieses Verhalten, welches auch bei anderen Arten der Gattumg sieh findet, kiinnte zu der Vermuthung führen, dass Knospen bildende und bier wie bamen erzengende 'Thiere in einem Generationswechsel stinclen, weleher an den einzelnen Thieren durch die ungleiche '/ahl der thoracalen segmente zum Austruck kime. Allein das ist nicht der liall : bei Thieren mit deutlich erkembaren Eiern waren am hibufigsten 8, damn 7 , und am seltensten 9 thoracale Serrmente vorhanden. Die von mir gesehenen Knospen tragenden Thiere latten alle 8 thoracale Segmente. Die 'Zahl der abdominalen Segmente schwankte bei den Eier erzeugenden Thieren in solcher. Weise, dass neben 8 thoracalen Segmenten 12, 13, 15, 18, 20 abdominale Segmente sich finden. Bei Kuospen erzeugenden Thieren fand ich das cine Mal bei geringer Ausbildung der Knospe 7 abdiominale Segmente des Mutterthieres, und daran angeschlossen die Knospe, welche $7 \mathrm{kam}$ diflerenzirte Segmente erkemnen liess, das andere Mal gleichfalls 7 mitterliche, abdominale Segmente und darauf folgend cine Knospe mit Kiemen, 6 thoracalen und 7 abdominalen Segmenten. Sicher ist, dass in den Leib der Knospe nicht eine grössere Anzahl muitterlicher Segmente eintritt, sondem dass dieser durch Neubildung auswiichst. Wahrscheinlich ist auch, dass ein Knospen erzeugendes Thier zu gleicher Zeit nicht Eier und Samen harvorbringt, wenigstens habe ich einen solchen Fall nicht beobachtet. Dass aber ein und dasselbe Thier nicht nach einander Knospen und Eier und Simen zu erzengen vermagr, kann ich aus meinen Beobachtungen weder ableiten noch abreisen.

Die Gesammtliurge der Wümer wechselt dementspreehend; meine Messungen geben Differenzen von 2,6mm.-3,9mm., doch ist die Grösse dieser Differenz zum 'Theil auf ungleiche Streckung der Wïrmer zuriickzufïhren. Bei diesen Thieren war das Längeverhältniss des Thorax zum Abdomen ein verschiedenes, im ersten Falle der Thorax 0,66 mm., das Abdomen 0,525mm., im zweiten Falle der Thorax 0,6 mm., das Abdomen 1,5mm. lang. - Dass die Länge der Kieme, welche ja die Gesimmtlänge des Körpers mitbedingt, sehr ungleich sein kann, geht daraus herror, dass das grössere dieser Thiere eine Kieme von 1,0כ̃mm., das kleinere eine Kieme ron 1,12mm. Länge hatte. Die zusammengelegte Kieme und der Thorax sind gleichbreit und drehrund, das Abdomen schmaler als der Thorax (0,33-0,3tmm.) mit Ausnahme der Endspitze fast gleichmässig breit, gegen hinten zu in dorsoventraler Richtung abgeplattet. 
Dic Kience ('l'al. jo ein eylindrisches grathinges Gebilde, in welehem die acht Kiemenstrahlen solchergestalt spiraligr zusammengedreht sind, dass die durchscheinenden Schälte die Ansendliche des Ganzen bihden, wihtend die Kiemenfäden nach vorn reriehtet und den Kiemenstrahlen angeschmiegt den Bimnenxam einnehmen. Die Gesammtlinge ist im Vergleich zur Körperlänge wechselnd, jeh habe sie fitst so lang (1,25mm.) als den Körper (1,5mm.), aber auch wenig mehr als halb so $\operatorname{lnng}(1, \tilde{m} m \mathrm{~m}$.) als den Körpar (2,4mm.) gefunden; stets war sie liinger als der 'Thorax, meist, aber nicht immer, anch länger als das Abdomen. - Die Kieme besteht aus 2 gleichen Hiilfen, von denen jede vier gleich lange Kiemenstralılen auf' einem kam entwickelten Basalblatte trïgt. Jeder Kiemenstrahl hat einen dieken durchscheinenden, nach aussen völlig glatten Schaft, welcher aul dem inneren Umfange die in zwei Reihen stehenden Kiemenfïden trïgrt. Diese mit langen Cilien besetzten Fiiden, deren Zahl um 25-2S schwankt, sind 4-5mal lïnger als der Schuft dick ist, und stehen so, dass die benachbarten an ihren Basen sich beriihren; ihre Länge nimmt gegen die Spitze des Strahles nur wenig ab. Jeder Kiemenstrahl läuft wie bei Filigrana (Prolulu) Dysteri (IIux].) in ein birnförmig oder keulenartig verdicktes, ïber die Kiemenfïden vorragendes 'Terminalorgan aus. Diese terminale Anschrellung entsteht ebensowohl durch die Vergrösserung der die Fläche deckenden Epithelien, wie durch eine, wenn auch nicht bedentende Erweitemung des Hohlrames, welcher aus dem Schafte des Kiemenstrahles in das Endorgan eintritt. Das Terminalorgan hat die Birn- oder Keulenform um so stäker ausgepräigt als das Endstiick des Kiemenstrahles, bevor sich derselbe terminal erweitert, eine Verschmälerung erfihrt. Die terminale Erweiterung ist ferner nicht allseitig im Umfange des Organes gleichmässig erfolgt, sondem die nach aussen gewandte Fliiche des Gebildes ist platt oder auch schwach concav eingezogen, und von einem einfachen niederen Epithel gedeckt; dagegen besitzt der der Längsaxe des Körpers zugewendete Unfang und die dem jederseits sich anschliessende Strecke, eine starke kissenartige, die Birn- oder Keulenform veranlassende Wölbung. Diese Wölbung ist durch die zu hohen keulenfömigen Zellen umgewandelten Epithelzellen herheigefithrt, welche derartig neben einander stehen, dass das verdickte Ende jeder einzelnen Zelle der Oberfliche des Terminalorganes angehört, während das zugespitzte Ende in der Tiefe der ganzen Schicht der Körperwand aufsitzt. (Fig. 5.) Der Zustand der Erhaltung gestattete eine genauere histologische Untersuchung nicht, doch war immerhin noch einiges zu 
erkennen, welches vielleicht auf' die Bedeutung dieser 'T'erminalorgane einen Riickschluss zu michen gestattet. In einzelnen fiillen zeigten nimblich die keulenfömigen an der Oberditiche liegenden 'Theile der Kollen ein kïmiges Ausselien, als sei die Zelle hier von dieht gredrïngt liegenden Kiiggelehen erfüllt; damit bot die einzelne \%elle das Aussehen einer Drüsenzelle orler einer einzelligen Drïse dar. Ku solcher Auflissumg berechtigh auch die Angabe Huxley's, dass bei der nah verwandten $F^{\top}$. (Protulu) Dysteri der kürnige Inhalt dieser Zellen bei Druck leicht austrete, und damn mit Wasser gemischt in diesem sich lïse. - Ueber' das Nivenu dieser '/ellen sprang aber in grüsseren Abstäulen von einander und nieht regehmässig vertheilt anf der kissenartig gewölbten Fläche eine Anzahl von staren, geraden Härehen hervor, dem Aussehen nach Simeshïrchen zu vergleichen. An einem tingirten l'räparat war damn noch zu erkennen, dass zwischen die keulenförmigren Drüsenzellen Kerne eingebettet waren, und ich hege die Vermuthung, dass diese Kerne zu Zellen, welche die Sinneshïrchen tragen, gehören müchten.

Sind diese Deutungen, welche durch Nachuntersuchungen eines besser conservirten Materiales zu bestïtigen sind, richtig, so stellt das 'lerminalorgan vielleicht einen für Sinneswahrnehmung eingerichteten Fangapparat dar, welcher zu einer Beurtheilung der im Wasser zugeführten Nahrung befähigt mnd durch einen von den Driisenzellen stammenden, vielleicht reflectorisch entleerten Klebstoff dieselbe festzuhalten rermag. Ich kam zu dieser Deutung, da ich im Innem der zusammengelegten Kiemenkrone einmal zwei ron den Kiemenfäden fest umschlossene Nauplius find, und mich fragte, durch welche Mittel der Wurm wohl im Stande sei, soleher beweglichen Beute sich zu bemächtigen. Vielleicht ist der Reiz, welchen die Bewegungen eines Thieres, wie ein Nauplius, auf die Simeshïrehen des Terminalorganes ausüben, schon im Stande, die Ausscheidung eines Drisensecretes hervorzurufen, welches das bewegliche Thier so festhält, dass es dann durch die Flimmerbewegung auf den Kiemenfäden dem Schlunde zugeführt wird.

Huxley hat ron der F. (Protula) Dysteri an der Basis der Kiemenfäden kleine Warzen beschrieben und abgebildet, in wehchen ähnliche Zellen wie in den Terminalorganen vorhanden sind; bei der mir vorliegrenden Art finde ich an der bezeichneten Stelle derartige Wirzchen nicht, dagegen bei gefärbten Thieren hier wenig auffallend stärker gefärbte Zellen, welche wohl die von Huxley erwähnten Warzen, nur in geringerer Entwicklung

I Th. Huxley, On a Lermaphrodite and fissiparous species of tubicolar Annelil. The Edinburgh New Philosophical Journal. New Series, Vol. I, 1855, pag. 120. 
darstellen. Digegen vermisse ich bei allen untersuchten Thieren an den spitzon der Kiementiulen ähuliche Bilhumgen, wie sie bei $r$. (Protula) Dysteri mach Huxley hier an manchen Kiemenfitlen sich finden. Dieses Vorkommen ist dagegen von Langerhans ${ }^{1}$ bei $F$ '. (Sulmacina) inerustans beschrieben. - Es butart mach dem allen keiner besonderen Darlegung, dass diese Organe weder als Deckel, Opereula oder Pseuloopereula zu bezeichnen sind, noch in Ilomologie dazu gebracht werden können. - Welehe Stellung die Terminalorgane zu den zusammengesetzten Augen der Branchiomma-Arten einnehmen, mit denen sie leicht in Beziehung zu bringen sind, etwa mit der Annahme eines functionrechsels, bleibt noch sicher zu stellen. Dass die an den Kiemenstrahlen bei anderen Serpuliden und Sabelliden am äusseren Umfange auftretenden Augen schon durch diese ihre Stellung von den Terminalorganen oder den :ihnlichen kleineren Zellanhiunfungen sich unterscheiden, braucht nur erwihut zu werden, um die Zweckmïssigkeit dieser anderen Augenstellumg hervortreten zu lassen.

Die Thoracalsemmente sind, mit Ausnahıne des buccalen, 4-5mal breiter als lang, dieses ist ohme den Kragen etwa doppelt so lang als das folgende Segment. (Fig. 4.)

Die Thoracalmenbran greift am ersten Segmente, wenn sie dem Körper angelegt ist, mit ihren Räudern auf dex dorsalen Fläche ein wenig über einander; weiterhin bleiben in solcher Lage die beiden Riander in der ganzen Liinge des 'Tharax etwas von einander getrennt; nach hinten erstrecken sich die Lappen derselben so weit, dass sie noch die Anfangstrecke des Abdomen umfassen. - Hhr den Kragen bildender Vorderrand greift auf der Dorsalfliche mit seinen beiden Lappen kaum halb so weit nach vorn als auf der Tentralfliche; am seitlichen Umfange trügt er jederseits einen tiefen Einschnitt; auf der Ventralfikiche ist er in der Mittellinie ziemlich tief eingeschnitten, doch nicht bis auf den Grund getheilt.

Das Buccalsegment triigt jederseits ein nach vorn gerichtetes Borstenbündel, welches ebensowohl durch seine Grösse die folgenden Borstenbïndel uibertriff, wie es vor ihnen durch die Form der ungleich gestalteten Borsten sich auszeichnet: neben 2-3 einfach capillaren und kiirzeren Borsten enthailt das Bündel 4-5 längere glashelle Borsten, bei denen der Schaft vor der scharf zugespitzten Endstrecke jederseits eine breite flïgelförnige Erweiterung trägt, deren liand mit spitzen, dreieckigg zugeschnittenen, nach vorn an

2. P. Langerhans, Die Wurmfauna von Madeira. III. Ztschr. f. wiss. Zoolog., Bd. XXXIV, pag. 122; Tuf. VI, Fig. 45 b. 


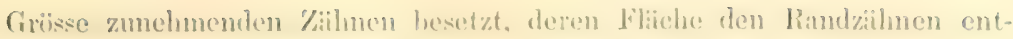
sprechend gefurcht ist. (lig. (i.)

Die auf das Buccalsergnent folgenden thoraculen Sermente tragen im dorsalen Bïndel, mit Ausnahme des ersten und letzten dieser Sergmente,

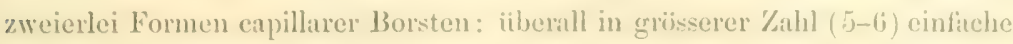
Borsten, deren Endstrecke nur schwach erweitert, wenig winklig abgebogen und glattrandig ist, und daneben in der angegebenen Verbreitung je eine etwas grössere Capillarborste, deren stïker winklig abgebogene und breitere Endstrecke mit queren feilenartigen '/ahnkerben besetzt ist. ( Fig. 7.) Die ventralen Borsten stehen auf niederen Flïsschen, welche je weiter nach linten $u$ so mehr ventmalwirts versehoben sind und bilden in ansehnlicher Zahl hier eine dichte Querreihe. Die einzelne feine und diinne Hakenborste ist ein Pliittchen, dessen freier liand breiter als die Basis ist, dadurch dass derselbe nach hinten gerundet erweitert und an der Basalecke etwas ausugezogen ist; die Schneide ist feillerbenartig gezihut. (Fig. 9.)

Die abdominalen Segmente wechseln in ihren Dimensionen sehr bedeutend, besonders durch die Entwicklung der Geschlechtsproducte. Grosse, wohl reife, Eier habe ich mit Ausnahme der vordersten und hintersten Abdominalstrecke in allen diesen Segmenten gefunden; diese sind dann erheblich in die Liinge grestreckt, fast halb so lang als breit, wiihrend sonst die Breite das Fünf-bis Sechsfache der Lünge betrïgt. Davon macht jedoch die Anfungstrecke des Abclomen eine Ausnahme, indem diese als ein langgezogenes Segment-oder als eine nicht segmentirte Strecke-erscheint, und das Endstück, in welchem die Segmente bisweilen sehr stirk rerkïrt und eng an einander geschoben sind. Die dorsalen Reihen der Hakenborsten stehen auf nur schmalen Flösschen in greringer, auf den hinteren Segmenten etwas steigrender Zahl; die Haken haben die gleiche Form wie die der thoracalen Segmente, siud aber kaum halb so gross als diese. Die Capillarborsten, nur in einer Form vorhanden, haben einen langen Schaft und eine kurze winklig abgebogene, nur schwach erweiterte Endstrecke mit ghatter Schneide. (Fig. 8.) Sie stehen meist nur einzeln in den Segmenten und sind, wo keine Knospe sich findet, an den letzten Segmenten erheblich verliingrert.

Auf der Tentralfliche der letzten $4-6$ Abdominalsegmente liegt bei nicht knospenden Thieren ein durch die Mfedianfurche gretheiltes Drüsempolster von körnigem Aussehen und oft tief gelber Färbung.

Das Analsegment trägt zwei kurze breite Läppchen.

Die jüngsten Knospen, bei denen die Kieme auszuwachsen begann, hatten 
mur Sesmente von abdominalem Charakter. An einer nach der Bildung der Kieme fist reifen Knospe war der Untersehied zwischen abdominaler und thoracaler Strecke villig vorhanden, letztere hatte auch beide Formen von Cipillarborsten, digegen vermisste ich noch die besonderen Buccalborsten, so dass diese als die juingste Bildung zu bezeichnen sind.

Die weissen glatten lïihren waren zu Büscheln vereinigt; die einzelne Röhre etwas unregelmiissig wellig gekrïmmt, ohne besondere Auszeichnung der (Oberlliche.

Die Art steht der von Huxley als Protuld Dysteri genauer beschriebenen Art oftenbar sehr nahe, unterscheidet sich aber von dieser, abgesehen von den bereits oben hervorgehobenen Punkten, leicht dadurch, dass die F. Dysteri zwei Augrenflecken besitzt, welche unserer Art, die aus dem Flachwasser stammt, abgehen; vielleicht weist eine genauere Untersuchung der curopäischen Art noch weitere Unterschiede von der westindischen mach. Beide Arten gehören zusammen und trennen sich von den iibrigen hierher zu stellenden Arten durch den Besitz vou 'Terminalorganen an allen Kiemenstrahlen. Nachdem Levinsen ${ }^{1}$ die Borsten der Filigrana implexa, Berk ( $F$. Schliidcni, O. Schm.), besser als vorher kennen gelehrt hat, ist für mich kein Zweifel, dass die von Claparède ${ }^{2}$ unter dem Namen Salmacina vereinigten Arten, zu denen Langerhans ${ }^{3}$ andere hinzugefügt hat, alle an Filigrana anzuschliessen sind; will man auf die Zahl der Terminalorgane an den Kiemen Werth legen, so stehen $\boldsymbol{F}$. Dysteri und $F$. Huxteyi allen ïbrigen Arten gegeniiber; auf diese letzteren die Bezeichnung Salmacina zu übertragen würde nach dem herkömmlichen Verfahren nicht zulässig sein, da die hierher gehörenden Thicre längst als Filigrana bezeichnet wurden ; die beiden erst genannten Arten aber zu einer besonderen Gattung zu erheben, erscheint, zur Zeit wenigstens, mir nicht nothwendig zu sein.

1 Lerinsen, Systematisk-geografisk Orersigt, a. a. O. pag. 200.

2 Claparède, Les Annélides du Golfe de Naples, pag. 436 ; Supplément, pag. 154. Wenn Claparède scine Gattung Salmacina von Filigrana danach sondern will, dass die letzere Deckel tragen soll, so liegt hier ein Jisverständniss vor, welches durch die unpassende Bezeichnung der 'Terminalorgane als Deckel entstanden ist.

3 Langerhans, Wurmfatna von MLadeira, a. a. O. III, pag. 122; IV, pag. 276. 
PROTULA (Risso), (2Trig., char. emend.

Protula antonnata, 11, sp.

$$
\text { Tif. } 59, \text { Fig. } 4-9 \text {. }
$$

Pallida, antice subteres, postice versus depressit et subtus canaliculata, secrmentis 89. IBranchia trientem fere corporis longitudinis aejuans, subinvoluta, in lamina basali supar humili, suhtus antice versus acute et anguste ad dimidian branchiate longitudinem elongatit utrinque madios 23 gerens; ratlii exceptis binis ventrallibus brevioribus aeque longe protenti filis branchialibus sub apice radii brevioribus, dense collocatis muiti ; operenlo nullo. Antemute 2 ventrales styliformes, dimidia lamina branchiae basali ventrali breviores. - Thorax quintam fere corporis partem longitudine aequaus, segmentis $\bar{\tau}$. Segmentum buceale longius quan latius, segmenta :3 proxima fere aequans, fisciculum parvum setarum capillarim simplicinn anguste limbatarum, collare longum et amplum, plicatum, integrum, pallium utrinque corporis latitudinem superans alatum, in segmenta proxima non continuatum gerens. Segmenta cotera thoriealia ter latiora quam longiora fisciculos magnos setarum eapillarimm flararum, late limbo striolato non dentato alat:urum, uncinorum series longas pone marginem cutmeum pimnafornem tororum gerentia, posteriora 4 utrinque maculam albidam ventralem, ultimum post uncines utringue lobulum rotundatum gerens. Uncini apice rotundato elongati, in acie acute dentati, processu basali brevi bidente muniti. - Abdomen thorace humilius postice subspatulatum, suleis transversis articulatum, subtus cinaliculatum; segmenta anteriora 5ies, ultima loies latiora quam longiora. Ĺneini thoracalibus aequales, sed minores, panci scries perloreves formantes; setne plerumque singulne capillares simpiices, posticae non elongatae. Segmentum anale nudum.

Tubus calearens albidus basi omni aftixus, irregulariter llexuosns, in superfieic libern carivis 5 longitudinalibus, externis marginalibus interdum dilatatis, in plano basali crista mediana humili.

Hab. 1 : No. 16, near Morro Light, Depth $292 \mathrm{fms}$.

Der farblose Wurm, welcher 7 thoracale und 82 abdominale Segmente besitzt, ist mit Einschluss der Kieme 25,5mm., ohne diese $16 \mathrm{~mm}$. lang, in seiner ganzen Länge mit Ausnahme der allerletzton Körperstrecke, gleichmässigr, etwas über $1 \mathrm{~mm}$. breit. Von der Körperlïnge entfallen 3,5mm. auf den Thorax, 12,5mm. auf das Abdomen.

Die zusammengelegte Kieme ist drehrund, desgleichen der' vordere 'Theil des Thorax, während derselbe weiterhin auf der Ventralfliche abgeplattet ist; das Abdomen ist in seiner vorderen Hälfte auf der Ventralfläche der Länge nach furchenartig vertieft, weiterhin fehlte diese Furche, die Bauchfläche ist hier platt, das Körperendstiick dagegen, welches zugespitzt ausläuft, ist fast spatelförmig abgeplattet und auf der Ventralfäche tief längsgefurcht. (Taf. 59, Fig. 4.)

Die deckellose Kieme besteht aus zwei ver]ingerten, um mehr als im Halbkreis eingerollten Basalblättern, von denen jedes 27 Kiemenstrahlen 
tritgt. und ans zwei isoliert dancben stehenden 'Tentakeln. Das einzelne liasalblatt ist an seinem dorsalen Ursprunge ganz niedrig, auf der Ventralflitche in cin langes schmales zugespitztes blatt ausgezogen, welches hier falst die halbe Läinge der gamzen lieme ausmacht. (Fig. 4, 5, 6.) - Die Kiemenstrahlen reichen, mit Ausnahme der beiden letzten am ventralen Ende der lieihe stehenden, gleichmissigr weit nach vorn; der vorletzte dagegen etwa mu halb so weit, und der letzte, von der Spitze des Kiemenblattes entspringende ist wiederum $u$ m die Iiilfte kiirzer als dieser. Die in zwei Reihen stehenden Kiemenfiiden sind J̃-6mal linger als der Schaft breit, und stehen dicht an einander; unmittelbar unter der Spitze des Strahles verkïrzen sie sich: diese selbst ist kaum nackt.

Die neben dem rentralen Ursprunge der Basalbliitter der Kiemen stehenden Antemen sind dïnne, schlanke, griflelfömige und starre Fäiden, welche die halbe Liinge der ventralen Verlingermug des Basalblattes kaum erreichen. (Fig. 5.)

Am Thorax ist das Buccalsegment linger als breit, fast so lang als die 3 nächsten thoracalen Segmente zusammen; seine Dorsalfläche ist der Länge nach schwach rimmenartig vertieft; gegen das nächste Segment erschien es auf der Dorstlliäche wie mit einem Querwulste abgesetzt. (Fig. 6.) Es trägt jederseits ein sehr kleines Bündel von einfachen eapillaren schwach gesäumten Borsten. Die Thoracalmembran ist auf die Flanken dieses Segmentes beschrïkt; hier bildet sie jelerseits einen grossen flïgelförmigen, dünnen Lappen, welcher abgebogen sich breiter erweist als der Körper selbst, so dass zusammengeschlagen die beiden Blïtter sich überlagern. (Fig. 6.) Ich habe bei sorgsamer Behandlung nicht ausfindig machen kömmen, dass diese fligrelförmigen Bliitter nach hinten sich auf die folgenden thoracalen Segmente fortsetzten. Vom greift jerles Blatt so weit vor', dass es den dorsalen 'Theil der Basalblätter der Kieme deckt. Mit einem gradlinigen Einschnitte setzt es sich jederseits ron dem umparen, ein Collare bildenden ventralen Hautlappen $a b$, der sehr weit und daher in Lïngsfalten mehr oder weniger zusammengeschoben ist, mit seinem grerad abgeschnittenen Vorderrande so weit als die beiden thoracalen Lappen vorragt. (Fig. 4, 5.)

Die folgenden thoracalen Segrmente sind dreimal breiter als lang; auf Bauch- und Riickenflïche treten Segmentfurchen nicht heraus, am Seitenumfunge reben die grossen diunhäutig und flossenartig erweiterten Polster der Hakenborsten die Segmentierung an. Die dorsalen Borstenbündel enthalten starke gelbe capillare Borsten, deren spitz auslaufende Endstrecke 


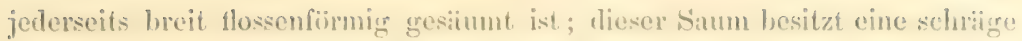
Streifung, sein liand ist ather nicht geziilmelt, wennschon bei einer Ansicht von oben die Streifung des Sanmes den Ausdruck einer Randziilnelung hervorbringen kam (Fig. S); die Borsten ragen etwa so weit vor, als dals Seurment lang ist. - Die langen Reihen der Ifakenborsten laufen dem fieien geschwungenen Rande der Flosse parallel; sie entsprechen in ihrer Ausdelnumg nicht gan\% der Flankenhöhe des Kïrpers und nehmen an den Segmenten von vorn mach hinten etwats ab; aul der. Ventralliache ist der Abstand der einander gegeniiber stehenden Querreihen fist gleich gross. Die in grosser Anzahl und dicht gedrïngt stehenden IJaken sind Platten, deren mit einer Reihe spitzer Ziilhne besetzte Kante linger als die Basis ist, da die Kuppe abgerundet dreieckig ausgezogen und die Basalecke in einen kum zweisehenklig ausgeschnittenen Stiel verlingert ist; die Stellung ist die normale. (Fig. T.)

An den vier vorletzten thoracalen Segmenten steht jederseits auf der Banchflïche unterhalb und ror der Hakenreihe ein kreisförmiger weisslicher Fleck von der Länge des Segmentes, vermuthlich ein Driisenpolster. (Fig. $4,5$.

Ain Ende des Thorax steht jederseits hinter dem letzten thoracalen Haken tragenden Flösschen ein nach hinten frei vorragendes diunnes Iautliippchen, in seiner Form und Stellung dem vormstehenden Flüssehen iihnlich. (Fig. $4,5$.$) Mir ist die Bedeutung dieses Läppchens nicht klar; möglicherweise$ stellt es den hinteren Theil einer thoracalen Membran dar, welche an den vorangehenden Segmenten durch Reduetion geschwunden ist; doch ist auch die Bildung mit welcher bei Pomotostegus stelludus der Hinterrand des letzten thoracalen Segmenten sich flossenartig erweitert, zum Vergleich heramzuziehen. Aus dieser isolierten Beobachtumg lässt sich dariiber Sicheres nicht entnehmen, aber mir ist anch keme Angabe in der Literatur bekannt, welche hier ergänzend und dentend verwerthet werden kömnte.

Dies Abdomen geht mit seiner rimnenartig vertieften Vorderstrecke so aus dem Thorax hervor, dass dessen Tentralfliche wie vorgewölbt erseheint (Fig. 4); an seiner ganzen Länge ist jederseits die Segmentierung durch die Wülste, auf denen die IIaken stehen, ausgedriickt, auf der hinteren Körperstrecke sind am dorsalen Umfange auch Segrmentgrenzen zu erkonnen. Die Segmente sind rorn etwa fïnfmal breiter als lang, in der hinteren Strecke verkürzen sie sich um das Doppelte, so dass vor dem zugespitzten spatelförmigen Endabschnitt etwa 10 Segmentlängen auf die Körperbreite grehen. 
An allen Sewmenten bilden die Inken, die von den thoracalen nur durch seringere (irïsse sich unterscheiden, in kleiner '/ahl eine kurze, unter der Lupe als kurzes Fleckehen erscheinende Querreihe; die ventralen Capillarborsten sind meist nur in der Einzahl jederseits im Segment vorhanden, sehr kurz und einfiteh, an den letzten Segmenten nicht verlingert.

Dem Aftersegment fellen cirrenartige Anhänge.

Die dickwandige weisse ganz aulliegende Kalkwöhre hat bei cylindrischem Lumen einen prismatischen Quer-chnitt; sie ist in der Lünge unregelmässig gekriummt, mit einzelnen queren Zuwachsstreifen, und in der ganzen Lünge anf der fieien Oberfliche mit fïnf lïngslaufenden Kielen versehen, welche alle ziemlich gleichmäissig geziihnelt sind ; der jederseits am tiefsten stehende Kiel kann die untere Kante bilden, aber auch noch zu einer unregelmässigen flachen Erweiterung auswezogen sein. Auffallender Weise besitzt auch die autliegende platte Fliiche in ihrer Mitte oder wenig davon abweichend eine niedrige liingslaufende Firste. (Fig. 9, 9a.) Das diirfte darauf hinweisen, dass ein Variationskreis dieser Art besteht, in welcher die Rühre sich von der Unterlige erhebt, frei aufgerichtet steht und ringsum Kiele besitzt.

Ich stelle die Art zur Gattung Protula, da sie deckellos ist, die Kieme eine geringe spiralige Aufrollung zeigt und Antennen vorhanden sind. Hält man als typischen Vertreter der Gattung Protulu intestinum fest, so ist diese allerdings durch den von Claparède bestätigten Mangel der Hakenborsten am Thorax in besonderer Weise ansgezeichnet, und von dieser Art zu tremen. Es dïirfte das bedeutungsvoller sein, als die geringe Ausbildung, welche die Thoracalmembran bei Prolula antemata besitzt. - Protula longiscta (Schm.) von Jamaica hat eine vollstiindige Thoracalmembran und verlingerte hintere abdominale Borsten, Prolulu appendiculata (Schm.) von dem gleichen Ort trägt zwischen den Kiemen und der Thoracalmembran fünf häutige Lappen (Antennen?). 


\section{l'RO'I'IS, n. ‥}

11 pwris, if nom. prinpr.

Norum genus Serpulidarm branchia sine operenlo, setis buccalibus lamina serrata ad basin apieis denticulati munitis, uncinis parce sed fortiter dentatis, setis thoracalibus carpillaribus limbatis, alxdouninalibus simplicibus.

$$
\begin{gathered}
\text { Protis simplex, 11. sp. } \\
\text { Tuf. 56, Fiy. 10-14. }
\end{gathered}
$$

Pallida, antice teres postice paullum attenuata subtusque depressa, segmentis 53. Branchia dimidiam corporis longitudinem fere attingens in lamina basali vix semicirenlari utrinque 10 radios crassiusculos aequales usque ad apiecm simplicem filis branchialibus longis munitos, opereulum nullum gerens. Thomx abdominis longitudine dimidia longior, segmentis 7 , collare antice rectum, utrinque pallium per totam longitudineu dimilio segmento latius gerens; seurmentum buccale longitudine fere proxima tria aequans, fisciculum setarum proximis majus autrorsum rersus gerens; setae luccales prae apicem longum acutum denticulatum lamina rotumlata nucronato-dentata serratae; segmenta sequentia quater fere latiora quam longiora, setas capillares longas flavidas utrinque sub apicem in limbo denticulatas, uneinos in acie sexdentatos series posteriora rersus latiores prae margiuem cutaneum tororum collocatas fingentes, maculasque ventmles albidas postice medio in segmento fere contiguas gerentia. Abdomen a thorace valde sejunctum in segmentis anticis paullum longioribus quam latioribus, posticis 10-12ies latioribus quan longioribus setas capillures simplices teunes, posticas valde elongatas, et uncinos thoracalibns similes sed dimidio fere minores, anticos perpaneos, posticos series in toris promiuulis latas componentes gerens,

Tubus calcarcus nitidus subrectus cylindratus, raris carinulis cinctus.

Hab. : No. 41 , depth 860 fms, Lat. $28^{\circ} 42^{\prime} \mathrm{X}$.; Long. $83^{\circ} 13^{\prime} \mathrm{W}$.

Der firblose Wurm ist im Ganzen $8,5 \mathrm{~mm}$. lang; daron entfallen auf die Kieme 3mm., während am Körper der Thomx 2 mm., das Abdonen 3,כ̆mm. lang ist; die Breite betrïgt durchschnittlich $1 \mathrm{~mm}$; dabei ist der nur am hinteren Körperende verjüngte Leib in der vorderen Strecke fast cylindrisch, wird aber im hinteren Theile des Abdomen platt und auf der Tentralfläche längsgefurcht. (Taf. 56, Fig. 10.)

Die Kieme besteht aus den beiden niederen, fast halbkreisförmigen Basalblättern, welche zusammen 20 fast gleichlange Kiemenstrahlen tragen. Der einzelne dicke durchscheinende Strahl trägt bis an die Endspitze hinauf in Doppelreihe die nur dicht vor der Endspitze kürzer rerdenden Kiemenfïden; diese entspringen am Strahl in greringen Intervallen von einander mit einer kleinen Auftreibungr und sind so lang, dass sie die Dicke des Strahles 7 -8mal uibertreffen. 
Der 'Thorax triant, der durch Segmentfurchen nicht ansgedrickten Gliedegune entsprechend, 7 l'arar von Bïndeln dorsaler Capillarborsten, von denen das crste in der borstenform von den tolgenden abweicht, unter denen auf flossenartigen Eiweiterungen Quereihen von Haken stehen. In den Seiten des 'Thorix verlitult in ganzer Lïnge iiber den dorsalen Borsten entspringend die dïnnhäutige gleichbreite 'Thoraculmembran, welehe angelegt von jeder seite her iiber die dorsale Mittellinie himwegegreift, mit dem frei nach vorn vorragenden Ilantlappen jelerseits am Seitenumfimge des Körpers etwa bis auf die IIöhe des unteren Randes der vorderen Hakenreihe reicht, und hier mit geradlinigem Einschnitie von dem madianen, quer stehenden IIantlappen des Kargens getremnt ist; dieser iibertriflt an llöhe etwas den Vorderrand der Thorncalmembran, ist iibrigens gleichmissig hoch und völlig ganzrandigr. (Fig. 10.)

Auf der Ventralliache steht jederseits unter je einer Hakenreihe ein bei auflillendem Licht weisslich erscheinender kreisförmigrer Fleck, der Länge eines Segmentes etwa gleichkommend; vom vordersten dieser Flecke erstreckt sich, undeutlich nur zu erkennen, ein gleichgefïbter schmaler Streif bis an die Basis des. Kragens. Diese Bildung beruht wahrseheinlich auf einer Entwicklung von IIautdriisen. (Fig. 10.)

Die Strecke des ersten buccalen Segmentes ist fast so lang als die der drei niehsten Segmente zusammen; diese sind etwa viermal breiter als lang. - Das ansehnliche, nach vorn gerichtete erste Borstenbündel enthält nur cine Form ron Borsten; diese, die grösser als die der folgenden Bündel sind, haben vor dem zugespitzt auslaufenden Endtheil eine fliigelartige Erweiterung, deren Rand mit einer grösseren Anzahl spitzer Zähnchen hechelartig' besetzt ist; aus dieser Erweiterung geht die auf der Kinte mit haarartigen Ziihnehen gesiimmte schlanke Endspitze, mit halsartiger Einziehung, aber geradlinig hervor. (Fig. 11.)

Die dorsalen Biindel der folgenden thoracalen Segmente sind nach hinten gerichtet und ragen so weit hervor, dass sie die Lïnge ihres Segmentes übertreffen. Die Borsten sind sämmtlich gelblich capillar, am Endtheil breit gesiumnt, und mit hatrartigen Zähnchen besetzt. (Fig. 12.) - Die Querreihen der Ilakenborsten, welche parallel zu und vor dem Rande einer flossenartigen II autausbreitung stehen, nehmen die Flanken des Körpers ein, dabei von vorn nach hinten an Ausdehnung wachsend, so dass die damit verschobenen Drisenflecke des letzten Segmentes nur um wenig mehr als ihre eigne Breite von cinauder getremnt bleiben. Die Form des einzelnen Hakens ist eine 
Patte, deren Schneide mit 6 die spitze nach rom wentenden siigezilhnen besetzt ist. (ligr. 13.)

Das Abdomen, welches wie mit einer kleinen Eimsehniirung aus dem 'Thorax hervorzugehen scheint, hat etwa $t 6$ segmente, zwischen denen jedoch Segrmentfurchen kaum zu erkemen sind. Diese Zahl ergielst sich nach einer 'Vithlumg der Borstenbiundel. Wie num dieselben am Abdomen entlang in sehr moleichen, nach hinten an Lïnge erheblich alnehmenden Abstanden stehen, erriebt es sich, dass das erste mud zweite der abdominalen Sermente wenig lïnger als breit sind; dam rïcken die Borsten näher an cinander, bis die Segmentstrecken des hinteren Körpertheiles 10 lis 12mal breiter als lang sind. Dass an der vorderen abdominalen Strecke borstenlose Segmente sich befinden, kann ich nach dieser Aufiassung mit der Berïcksichtigung allein der äusseren Körperverhïltnisse nicht annehmen; allerdings liegt eine solche Auflassung nahe, da die einzelnen Borsten nicht nur in relativ grossen Abständen stehen, sondern bei ihrer Klemheit auch nur schwer nachzureisen sind. Die ventral stehenden Capillarborsten bilden keine Bündel, da an den Segmenten jederseits doch nur eine, ansnahmsweise zwei stelıen; diese sind einfache feine Capillurborsten, welche an den letzten 22 Segmenten diejenigen der vorhergehenden un das Doppelte an Liinge ïbertreffen, und damit fast der Kürperbreite an Lünge grleichkommen. — Die einreihig dorsal stehenden Haken sind an den ersten der abdominalen Segmente nur in ganz geringer Zahl vorhanden und bilden daher eine Reihe, welche wenig breiter als lang ist; allmählich nehmen die Reihen nach hinten an Ausdehmung zu, bis sie iiber die grüssere Strecke der Kürperflanke sich ausdehnen; dam prominiert auch ihre Basis und num treten die wrulstigen Querreihen dentlich hervor. In der Form stimmen diese Haken mit den thoracalen ïberein, sind aber um mehr als die Itïlfte lileiner als diese.

Am Afterende habe ich kemerlei Cirrenbildung gresehen.

Der Trurm stak in einer isolierten Kalkröhre, welche seine Länge um ein Vielfaches ïbertraf; diese Röhre war cylindrisch und fast gerade, glänzend weiss und fast glatt, nur von einzelnen schwachen ringtörmigen Leisten, wohl Zuwachsstreifen, umgeben. (Fig. 14.)

Diese aus bedentender Tiefe stammende Art schliesst sich nahe an die Protula arctica, wie dieselbe aus noch grösserer 'Tiefe stammend ron Ammaner Hansen ${ }^{1}$ beschrieben ist. Die beiden Arten unterscheiden sich besonders

1 Armaner Hansen, Deu norske Nordshars-Expedition, IS7G-1878, VII. Zoolog. Annelida, p. 43, Tab. VII, Fig. 28-33. 
dureh die Kieme, nicht sowohl dadurch dass diese bei Prolulu arelica fast doppelt soviel strahlen als bei $I^{\prime}$. simplex besitzt, als vielmehr dass dieselbe

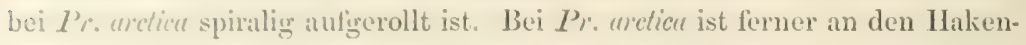
borsten der unterste Zahn an der Schneide doppelt so gross als die voranstehenden, wiihrend bei $P \%$ simplex der unterste dieser Zihhe von den folgenden nicht so abgesetzt ist. Bei reichlicherem Material wird zu entscheiden sein, wie weit diese Unterschiede stichhaltig sind. Jedenfalls gehört die Proluk ardica in die ron mir aufgestellte Gattung Protis, ob auch die von Levinsen ${ }^{1}$ als fragliche Synonyme zu Pr.arclica aufgeführten Protula borcalis (Surs) und Protula motensu (Möbius) hierher gehören bleibt zur Zeit unentschieden. Die Prolulu mediu (Stimps.) Mübius besitzt Hakenborsten mit zahlreichen kleinen Zïhnen und gehört danach jedenfalls in einen anderen Kreis.

Für die Verwandtschaftbeziehungen der Gattung Protis wird die Form der Bucealborsten zu berücksichtigen sein, welche sich bei der Gattung Filigrana (Berk.) Salmacina (Clprd.); aber auch bei Spirorbis finden. 


\section{BERICHTIGUYG.}

Auf $\mathrm{pg} .11$ ist folgender Fundort ausgefallen und vor Zeile 6 von oben linker Theihe einzuschiében.

Off Harama: Pontogenia sericoma, n. sp., So.

Diopratra l'ourtalesii, n. sp., 127.

Eunice tibiana (Pourt.), $127,175$.

Lumbriconereis robusta, 11. sp., 175 .

Stylarioides scutiger, n. sp., 100.

Eumenia slabra, n. s1)., 175 .

I'lacostegus incomptus, n. sp., 129.

Near Haranma: Eunice tibiana (Pourt.), 292.

IJ jalopomatus Laugerhansi, n. sp., 292. 



\section{VERZEICINISS}

\section{DER IM TEXT VORKOMMEXDEN FAMULI- GATTLYG- UND AR'TAMEN.}

Diejenigon Namen der Familien, Gattungen unil Arten, von welchen susfülrlicher gebandelt ist, sind im Druck ber-
vorgehoben, desglejchen die Zahlen der. Seiten, auf weichen dieses feschehen ist.

A.

Acocten (Gr.), 35, 53.

A coetes lupina (St.), $\bar{b} G$.

Pleei (Aud. \& M.-Edw.), 56.

Aglaopliamus (libg.), 128.

Aglaura fulgida (Sav.), 111.

Amage (Mlimgn.), 220.

Amage auricula (Mman.), 2.24.

tumida, n. sp., $8,11,15,16,201,208,220 \mathrm{f}$.

Ammocharidae, 1:?

Ampharete (Mlmgn.), 2:36.

Ampharete gracilis (Mlmgn.), 236. patagonica, 201.

Ampharetidae, 8, 12, 17. $200 \mathrm{f}$.

Amphicteis (Gr.), 204, 206, 205, 226, 231.

Amphicteis acutifrons (Gr.), 232.

grönlandica, 231, 2:32?.

Gunneri (Sars), 231.

invalida (Gr.), 232 .

nasuta, n. sp., $S, 11,16,232$ f.

Philippinarum (Gr.), 231.

procera, n. sp., $8,11,15,16,204,205,205$, 224,226 f., 236 .

Sunderalli (Mlmgn.), 231, 232 .

Vega (Wirén), 201.

Amphictenidae, 8, 12, 17, 194, 200.

Amphinome (Brug.), 26 f.

Amphinome carunculata (Pall.), 14.

macrotricha (Schm.), 30.

Pallasii (Qtrfg ), 5, 9, 10, 15, 26 f.

smaragdina (Schm.), 29.

Amphinomidae, 5, 12, $18 \mathrm{f}$.

Amphiro (Ǩ̉og.), 60, 67.

Amplitrite (Müll.), 240.

Amphitrite incana (Clprd.), 240.

Johnstoni (Mnimgn.), 240.

multisetosa (Gr.), 240.

Anaitis (Mlmgn.), 137-140, 142.
Anaitis cephalotes (Clprd.), 137, 139.

lineata (Clprd.), 137-139.

Wahlbergi (Mlmgn.), 137-139.

Andromache (Kug.), 110.

Anobothrus (I.evins.), 236.

Aphrodite (L.), 3i-39 $\mathbf{f}$.

Aphrodite aculeata, 37, 39. 41.

acuminata, n. sp., 5, $9,15,39$ f. 43.

alta (Kilig.), 16, :37, 42, 13 .

complauata (Pall.), 29.

obtecta, n. sp., 5, 10,11, 16, 38, 42 f.

Aphroditidae, 5, 12, 35 f.

Aphrogenia (Khog.), 38.

Arabella (Gr.), 6t, 10S, 112.

Arabella planiceps (Gr.), 113.

Aracoda (Schm. char. emend.), 11 f.

Aracoda debilis, n. sp., $7,11,15,16,112$ f. multidentata, n. sp., $7,11,15,16,68$, $112 \mathrm{f}$.

Arenicola (Lam.), 173.

Arenicola antillensis (Ltk.), S-10, 15, 173. Claparedii (Ler.), 173.

marina (d. Ch. Clprd.), 173.

Ariciidae, 1:.

Auchenoplax, n. gen., 202, 203, 207, 208.

Auchenoplax crinita, n. sp., 11, 15, 200, 201, 206,209 f., 224.

Axionice (Mlmgn.), 253.

P.

Branchiomma (Köll.), 254.

Branchiomma bioculatum, n. sp., 8, 11, 15, $260 \mathrm{f}$.

Branchiomma lobiferum, n. sp., 8, 10, 15, $254 \mathrm{f}$.

Köllikeri (Clprd.), 259, 263.

vesiculosum (Mont.), 259. 
Limanchiomma vi-ilans (chri.), 259.

Brauchiosyllis, 11. gen., $\mathbf{1 + 8}$.

Branchiosyllis oculata, n. sp., $5,10,15,148$ f

C.

('apicella (131r.), 175, :11

Caritellidae, \&, 1․, 171.

(eratonereis (libr.). 7. 117.

(eratonerejs mirabilis (Kin.), 11s, 120. tentaculata (liles), 118-1:0.

(linetopteridae, 1:2

Chlopia (sit), $18 \mathrm{f}$

Chlocia camlicla ( $\mathrm{kbg}$ ), 2t euglochis, n. sp., $5,9,10,15,18$ f. momlesta, 나 $\mathrm{f}$. viriclis (schm.), 23.

Chlornemilate, s. 1‥ 15s.

('irratulidae. 8, 12, 1.i.).

Cirratulus (Lam.). 155.

Cirratulus melanacanthus (Gro), 8, 10, 13, 15, $155 \mathrm{f}$.

('Tymene (Sar.), 15.2. 185.

Clymene cingulata, n. sp., s, 11, 15, 16, 185 f. cirrata, 21. sp., s, 9, 15, 16, $182 \mathrm{f}$

I).

Jasruranchus (Gr.), 171.

Dasybranchus eaducus (Gi:), 17t.

cirratus (Gr.), 174, 17.5.

lumbricoides (Gi.), 174

lunulatus, n. sp., s, 10, 15, $174 \mathrm{f}$.

mubrinus (ir.) $, 174,176$.

Dasyehone (M. S.). -66 ti.

Datschone argus (M. s.), 270 .

conspersa, n. sp., 9, 10, 15, 266 f.

Dalvelli (Küll.), 270 .

Diopatra (Aud. \& M.-Edw.), Qtrfgs., 17, 65, iit, 73.

Diopatra brevibrachiata (Ehl.), 72 .

Eschrichtii (Oerd.), 6. 9, 10, 13, 15, 73 f. 77 .

(Paradiopatra) fragosa, n. sp., 6, 9, 10, 13, 1.), $16,75 \mathrm{f}$.

(l'aradiopatra) glutinatrix, u. sp., 6, 10, 15. $76 \mathrm{f}$.

(1)uphis) hyperhorea (Alm. IIns.), 78.

(Heptaceras) phyllocirra (Schm.), 76.

Pourtalesii, n. sp., 6, 10, 11, 15, 16, 72, $74 \mathrm{f} ., 5 \mathrm{~T}$.

quadricuspis (Sars), 71 .

F.

Euarche, n, gen., 37, 53.

Euarche tubifez, n. sp., 6, 11, 15, 16, 54 f.

Emmenia (Oerd.), 169)

Eumenia crassa (Oerd.), 172.

glabra, n. sp.. 8, 15, 16. $169 \mathrm{f}$
Eumenia longisetosa (Thíel), 171.

Eunice (cur.), 6ti, 69, S:2 f., 95-100, 100 .

Eusice aequabilis (Gr.), 89.

antillensis, n. sp., $6,11,15,16,84 \mathrm{f}$

articulata, n. sp., $6,4,15,83$.

binominata (Qtrfgs.) $6,10,15,81,85 \mathrm{f}$.

brasiliensis (libg.), 88 .

cariboa (Gr., Oerd.), 95.

conglomerans, 11 . sp., $7,10,11,15,89$, $93 \mathrm{f}$.

filamentosa (Gr., Oerd.), 95.

floridana (Pourt.), 7, 9, 10, 13, 15, 88 f., [y:3, 94 .

fucata, 11. sp. $7,10,15,91 \mathrm{f}$.

Guildingi (Baird), 84,89 .

norvegica (I..), $65,8 \downarrow$.

punctata (Gr., Oerd.), 6, 11, 15, 81, 85.

quadrioculata (Gis), 100 .

rubra (Gr., Kr.), 6, 10, 15, 87 f., 93.

Saviguyi (Gr.), 83.

sicilicusis (Gr.), 91, 98, 99

tibjana (Pourt.), 7, 11, 15, 16, 90 f., 91.

violaceo-maculata, 13. sp., $6,10,15, \mathrm{~S} 6 \mathrm{f}$.

Eumicidae, 6, 12, 13, 64 f., 99, 115.

Eunicidae habidognathe, 10 s.

labidognathae nudac, 64,67 .

labidognathae tentaculatae, 64 .

prionognathae, 68 .

Bunoe (Mlmgn.), 50.

Eunoe Oerstedi, 50.

Eiphrosyne (Sitv.), 31 f.

Euphrosyne polybranchia (Schm.), 33.

triloba, 11. sp., $5,9,10,15,31 \mathbf{f}$.

Eupomatus (Hhil.), 285.

Eupomatus uncinatus (Ph.), 9-11, 14, 15, $285 \mathrm{f}$.

Eupompe (Kbg.), 53, 55.

Eurysyllis tuberculata (EhI.), 149.

Eirrytioe (K bg), 29.

Eury thoe complanata (Pall.), 5, 9, 10, 15, 29 f.

F.

Filigrana (Oken. char. emend.), 314, 328.

Fjligrama Dysteri (Hxl.), 317.

Huxleyi, n. sp., 9, 10, 15, 314 f.

implexa (Berk.), 320.

incrustans (Lgh.), :318.

Schleideni (O. Schm.), 320.

G.

Glycera (Sar. char. emend.), 121, 150.

Glycera capitata, 123.

oxycephala, n. sp., 7, $121 \mathrm{f}$.

papillosa (Gr., Kr.), 123.

Glyceridae, $7,12,121$.

Glyphanostomum (Levins.), 202, 201, 208.

Goviada (Aud. \& 11.-Edw.), 124 
(ioniada omerita (Aut. \& Mt.-Edw.), 7, 10, 11, 11, 1,i, 124.

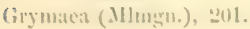

II.

Halla (Costa), 61, 6s, 106i-10s.

Ilalla parthenopeia (d. Cli.), 107 .

Heptaceras (Ehl.), bit, vit.

Hermeilidac, 12.

Hermionea (Gi:), 35, $36 \mathrm{f}$.

llermodice (libg.), $27 \mathrm{f}$.

Hermodice carumculata (Pall.), Kug., 5, 9-11, $1.5,27 \mathrm{f}$.

Hesione (sav), 14:3, 147.

Hesione margaritae (Hus.), I\$3-147. picta (F. Mull. ), 113, 145, 14i. praetexta, 13. sp., 8, 11, 15, 147 f. proctochona (Sclum.) , 113-117. vittigera, n. sp., S, 10, 15, 143 f.

Iesioniclae, 8, 12, 143, 150, 151.

Hyalinoecia (Mlmgn.), 73, 79.

Hyalinoecia rigida (Clprd.), so. varians (Baird), S?.

IIyalopomatus (Mrzi.), 304

Iýaloponıtus Claparedii (Marzl.), 17, 307. Langerhansi, n. sp., 9, 11, 16, 17, 304 Marenze!leri (Lgh.), 17, 307.

Iypsicomus (Gr.), $2 \pi 0$.

11 ypsicomus albicollis (Gr.), 277. circumspicieus, 11. sp., 9, 15, 271 f. fuscotaenia (Gr.), 277 . phaeotaenia (Schm.), 277. scoparia (Gr.), 27\%. simplex (Qtrfgs.), Gr., 277. stichophthalmos $\left(\mathrm{Gr}^{\circ}\right), 27 \%$.

I.

Iphioue (Sat.), 35, 36.

\section{L.}

Laetmatonice ( $\mathrm{Kbg}$.), 37, 38, 40, 44.

Laetmatonice armata. (Verr.), 41. filiformis (Kbg.), 44, 45 .

Kimbergi (Baird) 5, 9-11, 13, 15, 16, $44 \mathrm{f}$. producta (Gr.), 45. violascens (Gr.), 45.

I.aonome (Mlmgn.), 266 .

Leanira Ilystricis (Ehl.), 17.

I.eodice (Gr.), S3, S7, 89, 91, 93.

Lepraea (Mlmgn.), 201.

Lirione (Kug.), 21.

Lumbriconereidae, 110, 111.

Lumbriconereis (Blr.), 61, 66-69, 92, 102 f., $106-108,111$.

Lumbriconereis bidens, n. sp., 7, $9,10,11,15$, $103 \mathrm{f}$.
Lusubriennereis brasiliensis (Klig.), 10:3 floridana, n. sp., $7,10,15,103$.

Jaunitii (fir.), lus.

aceanicia (Klug.), 10:3. robusta, $11 . \mathrm{sp} ., 7, !), 15,104 \mathrm{f}$. ternis (Verr.), 10:3.

Lycoridate, 12, 114.

J veoris mutia (s:as.) 115.

Lysarete: (Kilys.), (j.5, ti7, 6is, 106, 107, 111.

Lysarete brasiliensis (KOg.), 7, 9, 13, 15, $107 \mathrm{f}$.

Lysidice (siav.), ti(j, 10!).

Lysidice americana (Verr.), 102. notata, n. sp., $7,10,11,15,100 \mathrm{f}$.

II.

Macloria (Gr.), 112 .

Maldane (Gr.), 8, 178.

Maldane cuculligera, n. sp., 8, 11, 16, 178 f. marsupialis (Gr.), 15?.

Maldamidiae, $8,12,17,178$

Marpliysa ((2tifgs.), 67, 95, 100 .

Marphysa Bellii (Aud. \& M.Edw.), 7, 11, 11$16,95 \mathrm{f}$.

Leidii (Qtrf. ), 97.

Parishii (Batri), 7, 10, 15, 97 .

sanguinea (Aont.), $7,10,11,11,15,97$.

Melimna (Mlmen.), 201-207, 211.

Melimna adriatica (Marzl.), 220. cristata (Sars), 214 f., $2: 32$ maculata (Wibst.), 220. palmata (Gr.), 2:0.

parumdentata, n. sp., $8,11,15,16,214 \mathbf{f}$.

N.

Nematonereis (Schm.), 66, 67 .

Nephthydidae, 12, 120.

Nephthys (Cur.), 125.

Nephthiss caeca (Fabr.), 133. ciliata, 133 .

imbricala (Gr., Oerd.), 131.

(Aglnophamus) inermis, n. sp., $7,9,15$ $125 \mathrm{f}$.

phyllocirra, n. sp., $7,9,10,15,131$ f. squamosa, 1. sp. $7,9,10,15,128 \mathrm{f}$.

Nereis (L.), 114

Nereis aegrptia (Sav.), 115.

(Nereilepas) angusta (Kibg.), 115.

articulata, n. sp.. $7,10,15,16,114$ f.

Costae (Gr.), 117 .

Elilersiana (Clprd.), 117.

excisa (Gr.) , 118, 124.

floridana (Ehl.), 14.

Kinberciana (Clprd.). 117.

(Ceratonereis) mirabilis (Kog.), $7,10,11$, 13. 15. $117 \mathrm{f}$.

pectinifera (Gr.), 117. 


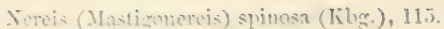

(Nicon) tahitana (Kily.). 115.

(ceratonevis) versipedata, n. sp., 7, 11, i. $116 \mathrm{f}$.

Nimillide, 12.

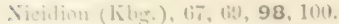

Nicidion brevis, n. sp, 7. 10, 15. 98 f.

ineerta (. Imu. Hus.), 110.

Nicomachella (Levins), l!1!.

Nicomachella picta. «. sp., 8, 11, 15, 16, 192 f. tentui (Thée), 192, 19:3.

Ninoe (libg.), 1t, 10, 10\%.

Nine brasiliensis ( klug.), 106. chilensis (libe. ), 106.

Kinbergi, 12. sp., 7, 11, 15, 10, 105 f. nigripes (Verr:), 10t. oculata (lír. ), 100.

Notomastus roseus (Lghns.), 175.

Notepyesos (Gr.), $2 \pm f$.

Notopygos crinita (Gr.), $\bar{j}, 4), 10,14,15,24$ f. maculata (Gr.), 235 . oruata (Gr.), 25.

O.

Oenone (Sat:), 13.5, 109.

Oenone diphyllidia (Schm.), $7,9,11,15,68$, $109 \mathrm{f}$.

Incicin (sar.). 110.

Olizomuathus (singl.), 11:?.

Unuplis (Auil. \& M.-Edw.), Qtrfgs., 17, 65, 67, 73, 78, 92.

Onuphis conchylema (Sars), 73 .

Eschrichtii (Oerd.), 7;

(P'monuphis) gracilis, n. sp., 6, 9, 10, 11, 1ti. 78 f. tubicola (Miiil.), 79.

Onheliidae. $8,12,15 \overline{4}$.

Ophryotrocha (Clprd. Meczn.), 66 Anmerk., 69.

P.

l'almrra (Sar.), 10, 15.

I'almyra obscura (Gi:), 31.

P'almyridae, 5, 12, 31 .

Panthalis melanonotus (Gr.), 53. nigromaculata (Gr.), 53.

Paracticus (Levins.), G7.

P'uradionatra (Jihl.), 67, 73, 76.

l'aramarphysa (lihl.), 67, 99.

Paramarphysa longula, $11 . \mathrm{sp} ., 7,15,16,99 \mathrm{f}$.

P'aronuphis (Ehl.), 67, 73.

P'ectinaria (Lam.), 1nt.

Pectinaria ('etta) pellucida, n. sp., $8,10,15$, 1ti, $194 \mathrm{f}$.

Petta (Mlingn.), S, 10, 191.

Petta pusilla (MImgn.), 194.

Phyllodoce (Sar.), 135.), 1:35, 139.

Phyllodoce badia ( Kugg. I, 137 .
Phyllodoce calloana (Gri, lirr.), 112.

catenula (Verr.), 110.

citrisa (Mllmgn.), 1:30.

corniculatin (C'lpucl.), 133.

frigilis (What.), 110.

gracilis (Verr:), 110.

groulausdica (Uerd.), 1:37.

Jamelliger: (Ehl.), 1:34.

liminosa, 138.

lineata (Clprà.), 1:99.

longipes (Kibg.), 110.

macrophthaliuos (Gr., Oerd.) 140.

mueviata (Muill.), 135, 137, 138.

Madeirensis (J.ghns.), 137.

mucosa (Oerd.), 137.

oculata, n. sp.. $8,11,15,135$ f., $141,112$.

(Auaitis) papillosa, n.sp., 8, 10, 15, $140 \mathrm{f}$.

liathkii (Qtrfg.), 112.

Phylloulocidae, 12, 135.

Placostegus (I'hil.), 300.

tricuspidatus (Sowbr.), 301, 303.

triclentatus (Arm. Hns ), 301, 303.

incomptus, $\boldsymbol{n}$. sp., $9,11,15,16,300 \mathrm{f}$.

Pleione tetracilra (M.-Edw.), 26.

P'olycirrus (Gr.), 200.

Polylepirda, 35.

Polynone simplices (Sav.), 35.

Polynoe (Sav), 35.

Polynoe Antillarum (Schm.), 52.

clarata (Gr., Oerd.), כ̄l.

fusco-marnorata (Gr.), 51.

granulata, n. sp., $6,10,50 \mathrm{f}$.

lactea, $\mathbf{n}$. sp., $6,10,15,16,52 \mathbf{f}$.

marginata (Gr., lix.), 51 .

patagonica (Ḱbg.), 51.

polytricha (Schm.), 5, 9, 15, 49 f.

taeniata, u. sp., $6,9,15,51$ f.

Polynoint (Gr.), 33i, 36, $88 \mathbf{f}$.

Polyodontes (Aud. \& M.-Ed\%.), 53.

Polyoriontes gulo, 55.

maxillosus, 55.

Pomatostegus (Schı.), 2!)6.

l'omatostegus brachysoma (Sclun.), 299.

macrosoma (Schm.), 299.

stellatus (Abldg.), 9, 10, 15, 2\$4, 296 f., 3323.

Pontogenia (Clprd, char. emend.), 37, 38, 46.

Pontogenia chrysocoma (Baird, Clprd.), 48. indica (Gr.), 48.

sericcma, n. sp., $5,15,46 \mathrm{f}$.

Potamis, n. gen., 278.

Potamis spathiferus, n.sp., 9, 10, 15, 16, 278 f.

Protis, n. gen., 17, 325.

Protis simplex, n. sp., 0, 10, 16, 17, 325 f.

P'rotula (Risso char. emend.), 321.

Protula autennata, n. sp., $9,10,15,16,321$ f. appendiculata (Schm.), 324.

arctica (Arm. IIns.), 17, 327.

borealis (Sars), 328 .

Iysteri (Hxl.), 3:0.

intestinum, 324 . 
R'rotula longikela (Selım.), 3:24. media (Stimps., Mob.), 325. protensa (11ub.), 32s:

lesectri ( (ir.). $5,10,31$.

l'teroseolex (1.tk.), 173.

\section{li.}

Rhamphobrachium, n. gen., $60,67,70$.

Rhamphobrachium Agassizii, n. sp., $(j, y-11$, $10,17,70 \mathrm{f}$. brevibrachiatum (Lh1.), 17, 72.

lihodine (Mlmgn, char, emend.), 189.

Rlodiue sima, ı. sp., 8, 11, 15, 16, 189 f. Loveni (Mllungu.), 159, 191.

liotifera, 69.

\section{$i$.}

Sabella (L.), 263.

Sabella acrophthalmos (Gr), 259.

Lynceus (Kr.), 270 .

manicata (Gr.), 266

melanostigma (Schm.) 9, 10, 15, $263 \mathrm{f}$. viola (Gr.), 266.

Sabellidae, 8, 12, 251.

Salnacina (II, R. Clprd.), 320, 325.

Scalibremma, 171.

Scalibregma abyssorum (Arm. Hus.), 172. longisetosum, 17:2. parrum (Arm. Hns.), 171.

Scalibreguidae, 8, 12, 18, 169.

Scione (Mlmgn.), 253.

Serpulidae, 9, 12, 284.

Sigalion (Kog.), 57.

Sigalion amboinense (Gri:), 60.

Antillarum (Gr.), 58

arenicola (Vers.), 58, 60 .

Buski (McInt.), 60.

Edwardsi (Kbg.), 58.

Mathildae (Aud. \& Mf.-Edw.), 60.

Pourtalesii, n. sp., 6, 9, 15, 57 f.

squamatum (d. Ch.), 60.

Sigalionina (Gr.), 35, 36, 57.

Siphonostomum (Otto), 155.

Siphonostomum cariboum (Gr.), 8, 10, 15, $158 \mathrm{f}$.

ciugulatum (Gr.), 164.

Sosane (Mllmgn.), 207.

Spionidae, 12.

Spirobranchus (Blr.), 256.

Spirobranchus giganteus (Pall.), 9, 14, 15, $286 \mathrm{f}$.

incrassatus $\left(\mathrm{Kr}_{\mathrm{r}}\right)$, Mrch., 14, 289, 293, $294 \mathrm{f}$.
Spirobranclus tricornis (Mrch. char. cmend. I, !1, 10, 11, 15, :191, $292 \mathrm{f}$

Spiromajulis Spallanzanii, 2258.

Sprirorbis (1)aul.), 32s.

statrocephalielae, tit, (is

Sthenelais (Jilug.), rol.

Sthenelais Linertoni (Verr.), 63. gracilis (Verr.), (j:3.

ineisa $(6 ; \mathrm{r}),.(\mathrm{ij})$

laevis (libe.), (j:3.

Inxuriosa ( (ir). , 63.

picta (Vierr.), (ij).

simplex, 12. sp., (j, 11, 15-17, $60 \mathrm{f}$.

Stylarioides (d. Cls.), Clpit. 1ij].

Stylarioides collarifer, 2. 8 p., $b-11,15,11$, $161 \mathrm{f}$.

parmatus (Gir.), 159, 168.

scutiger, 12. sp., $8,1.5,16,15 \%, 165$ f.

Syllidae, 8, 12, 142.

syllis brevicollis (Kh1.), 149.

Krohnii (1:hl.), 15:3.

zonata (ii.), 151.

l.

Telethusae, 19, 18, 17:3.

Terebella (L.), : 237 .

Terebella brumueo-comata, n. sp., \&, 10, 15 , $237 \mathrm{f}$.

cetrata, 1. sp., S, 10, 15, 20.5, 248 f.

frondosa (Gr., Oerd.), 211.

reticulata, u. sp., S, 10, 15, 245 f.

Terebella turgidula, 12 . sp., s, 10, 15, 241 f.

Terebellidae, 8, 12, 200, 201, 20.5, 207, 205, 21:, $2: 37$.

Tibiana (Ell.), 90.

Travisia (Johnst.), $15 \pi$.

Travisia carnea (Verr.)? 8, 11, 13, 15, 16. $157 \mathrm{f}$.

Forbesi (Johnst.), 157.

Trypanosyllis (Clprd. char. emend.), $151 \mathrm{f}$.

Trypanosyllis vittigera, $n$. sp., $S, 10,15,151 \mathrm{f}$. Zebra (Gr.), 151.

Typosyllis Krohnii (Ehl.), 15:3.

\section{V.}

Vermilia (Ph.), 308.

Vermilia annulata (Schm.), 9-11, 15, $308 \mathrm{f}$. clarigera (Ph.), 312, 313 .

infundibulum (Gm.), 31:, 31:

multicostata (I'h.), 313 .

multiraricosa (M.), : $: 13$.

rugosa (Lughns.), 312, 31 \%

spirorbis (Lnghns.), 313. 



\section{T A F E L N}

UND

TA F E E R K L $̈$ R U N E N. 


\section{TAFEL 1.}

Fig. 1. Chlocia euglochis n. sp.; erwachsenes Thier von der Rückenfläche gesehen; natiurliche Grösse.

Iir. :- Chlocia euglochis n. sp.; junges Thier vom Rücken gesehen. Vergr. 2.

T: - 3. Notopygos crinita Gr.; rom Rücken gesehen. Vergr, 1, 5.

F: 1. Amphinome Pallasii (Qtrfg.); erwachsenes mittelgrosses Thier, vom Rücken gesehen; das hintere Körperende und die rechte Flanke der hinteren Körperstrecke aufwärts gebogen; natürliche Grösse. 


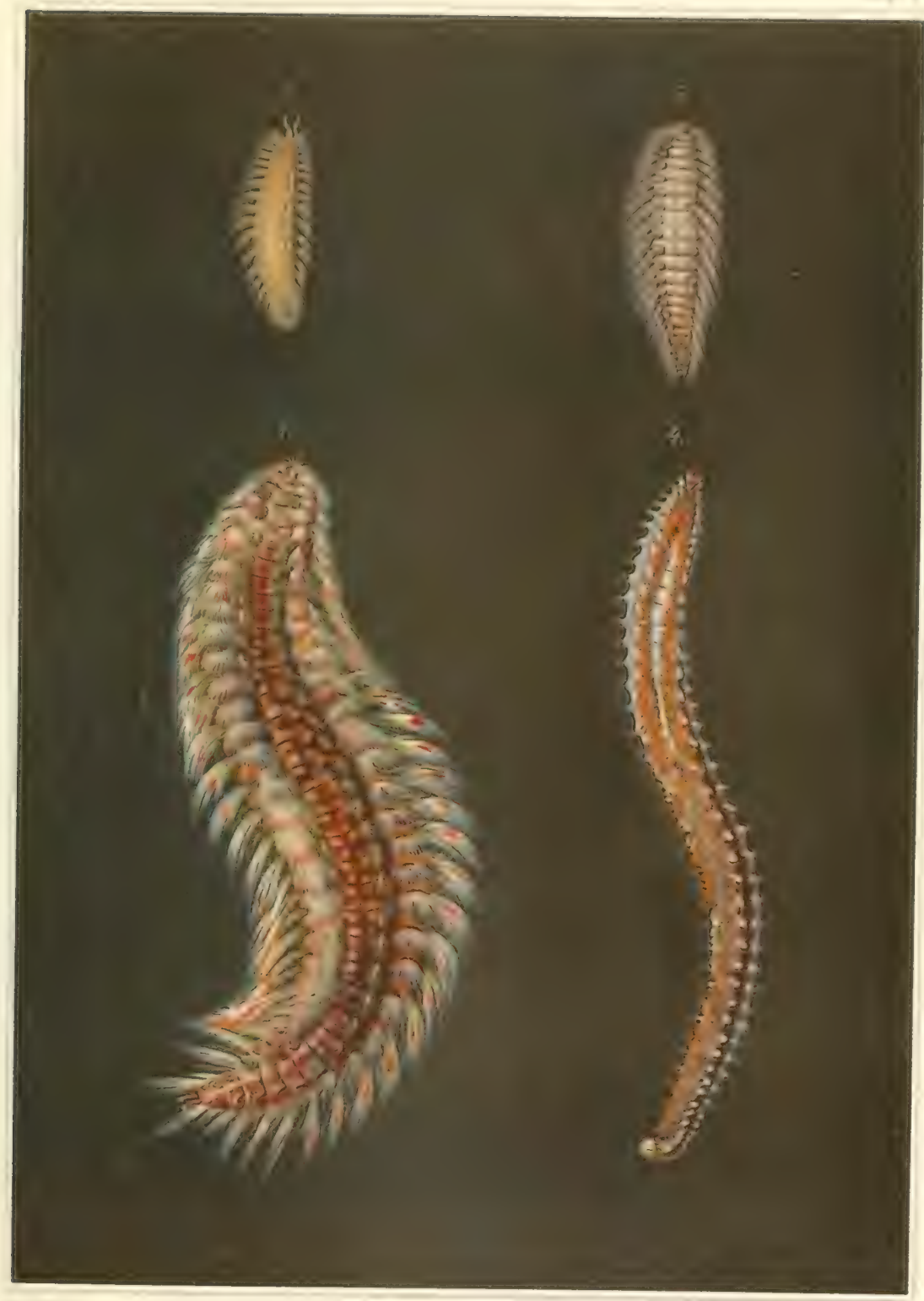





\section{TAFEL 2.}

1: - 1. Chlocia cuglochis n. sp.; errachsenes Thier; Vorderende etwas aufwärts gebogen und vom liücken gesehen. Vergr. $\check{.}$.

1:. 2. Dasselbe von der Bauchfliche gesehen. Vergr. 5.

$1 \%: 3$. Hinterende desselben Thieres, von der Rückenfläche. Vergr. 5.

Fi: 4 und 5. Borsten desselben. Vergr. 220.

1:i.. 6. Chlocia englochis n. sp.; junges Thier, Vorderende vom Rücken gesehen. Vergr. 20.

Ii . $_{7}$. Dasselbe von der Bauchfläche. Vergr. 20.

Iis. S. Borste des ventralen Büudels. Vergr, 250. 

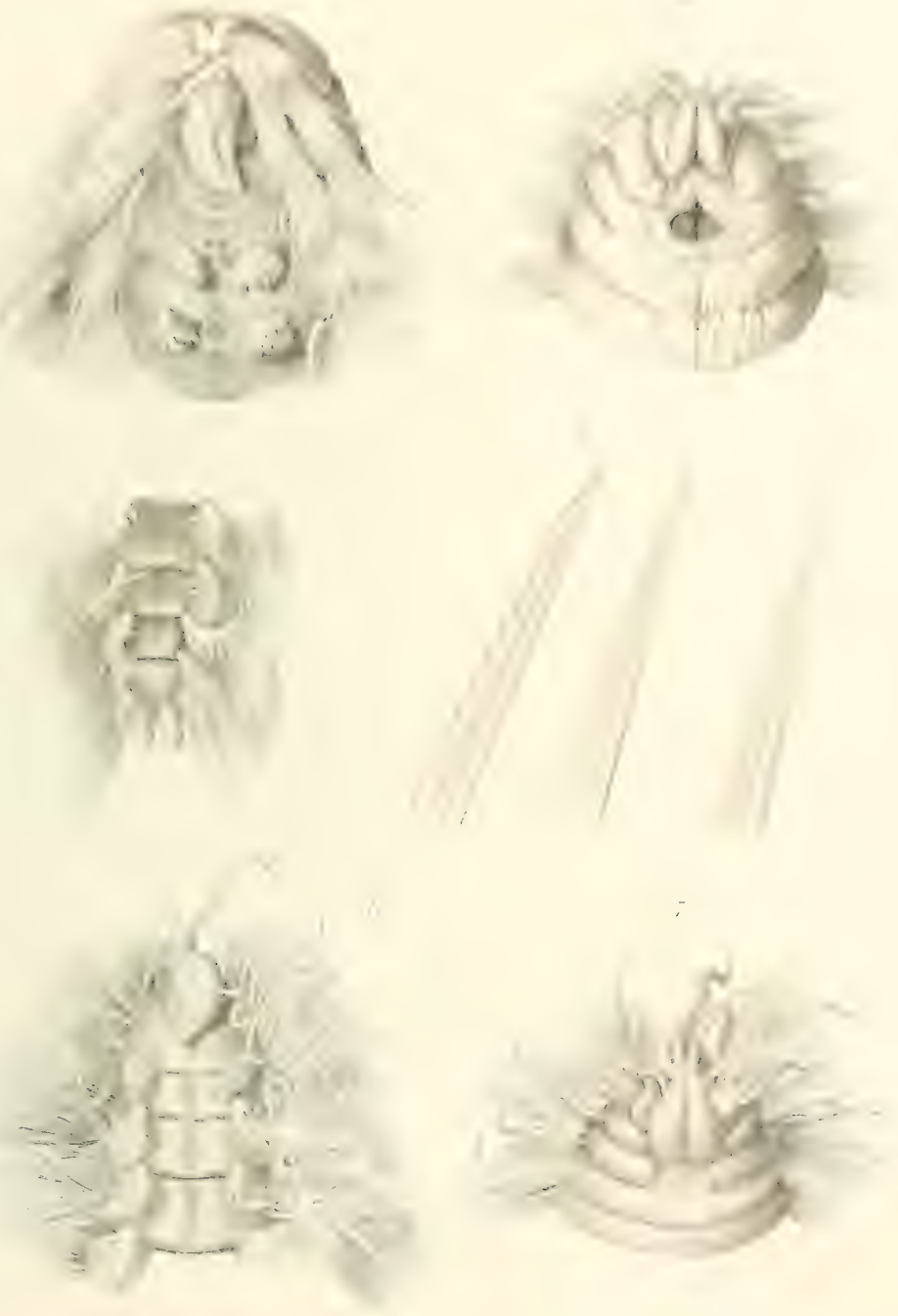


TAFEL 3.

Fi: 1. Chloeia englochis n. sp.; erwachsenes Thier, Kieme von der Rückenfläche gesehen. Tergr. 12.

Ii: : :. Dieselbe ron der ventralen Fläche. Vergr. 12.

Iif: :.: Kieme einer jungen Chloeia englochis. Vergr. 70.

Ii. 4. Kieme eines etwas älteren Thieres. Vergr. 70 .

Y. ז. .. Notopygos crinita Gr.; Vorderende vom Rücken gesehen, Vergr, 6.

Mif. (j. Hinterende desselben Thieres vom Rücken. Vergr. 6.

Fi: $;$. Ein Ruder dieses Wurmes, von oben gesehen. Vergr. 9. 

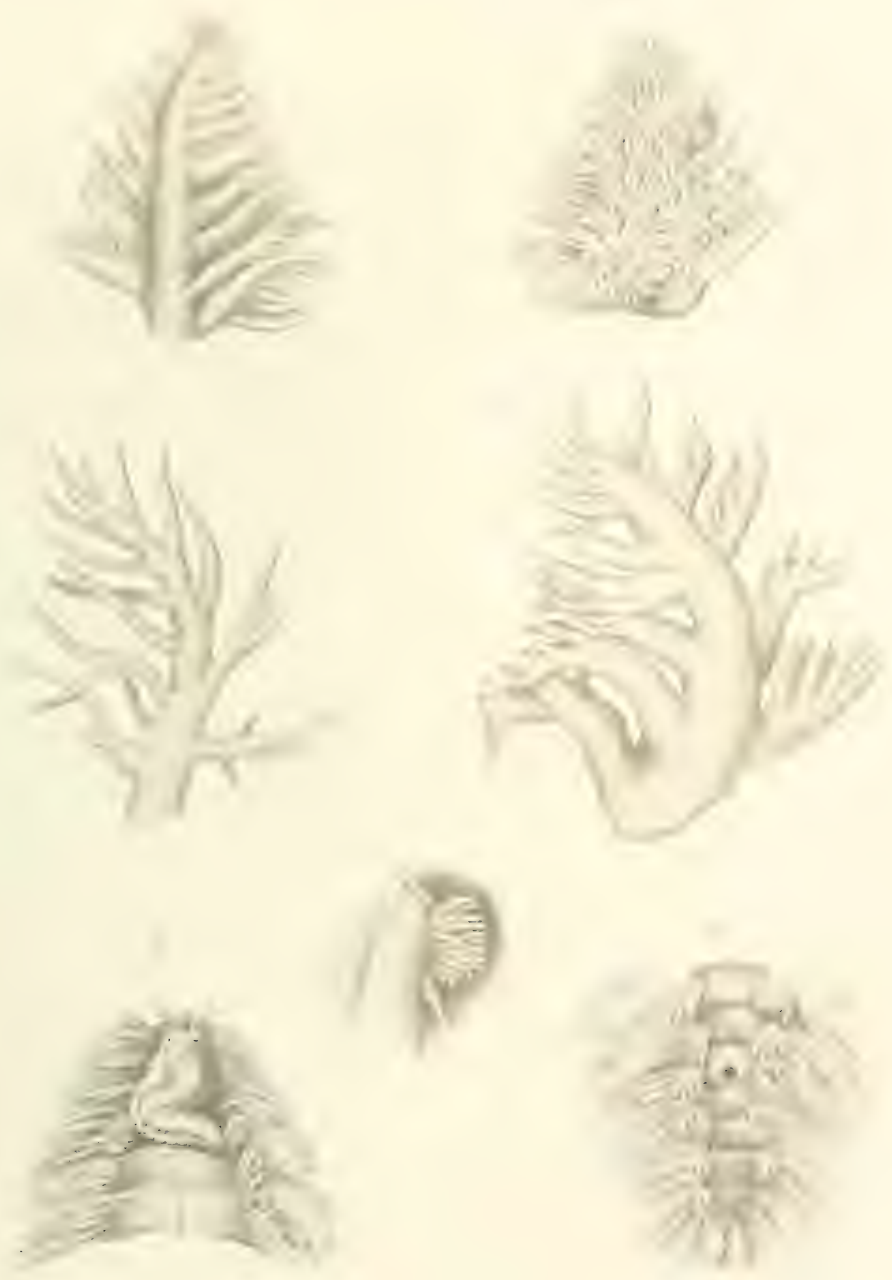



\section{'TAEEL 4.}

I: : 1. Euphrosyne triloba n. sp.; ganzes Thier von der Rückenfläche. Vergr. 4, 5 .

I:-2. 2. Dasselbe; Ansicht der Bauch

1'ig. 3. Vorderende des Wurmes von der Rückenflïehe. Vergr. 22.

1: $\therefore$ t. Dasselbe ; Ansicht der Bauchfäche. Vergr. 22.

I: $\therefore$. Eine aus dem seitlichen Körperumfang herausgeschnittene Strecke, mit den Cirren, Kiemen und 13orsten. Vergr. 30.

Fig. 6 und 7 . Die beiden Borstenformen, nach Durchtränkung mit Glycerin, dabei tritt die compacte Spitze gesondert rom übrigen Theile und stark glänzend hervor. Vergr. 250. 


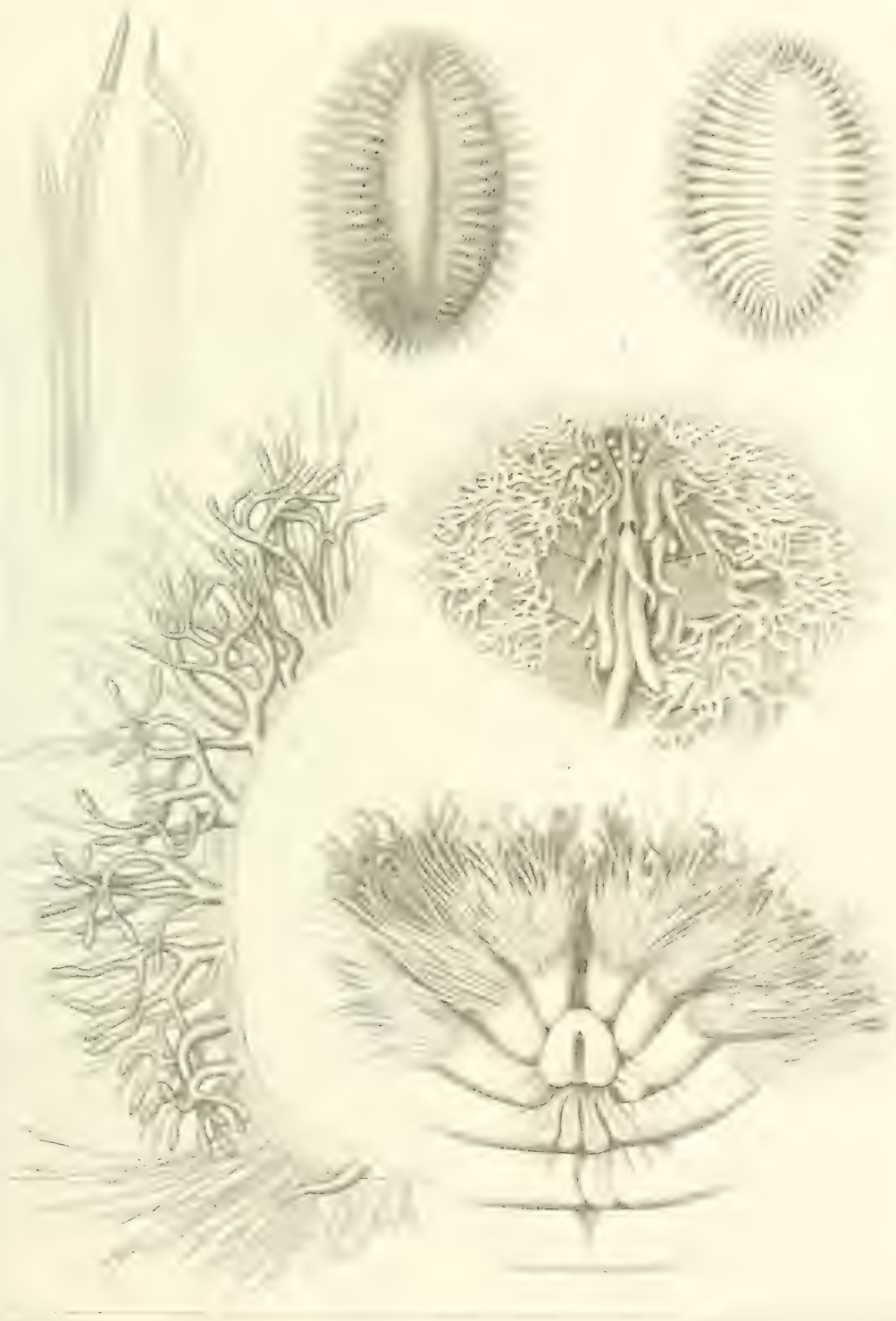





\section{.}




\section{TAFEL 5.}

I:L. 1. Aphrolite acuminatu n. sp.; Ansicht der Bauchfläche. Natüliche Grösse.

I: $:$ :. Dasselbe 'Thier von der Rückenfliche. Natiurliche Grösse.

Hig. ... Das Vorderende des Thieres von der Rückenfläche gesehen, nachdem der Rückenfilz durch einen Längsschnitt gespalten und mit den vorderep Elytren zur Seite geselilagen ist; damit sind der Kopflappen und die Subtentakel frei gelegt. Vergr. 14.

Iig. 4. Ein Iiuder, vom Körper abgetrennt. Vergr. 10.

Fiң. .j. Endstrecke einer gebärtelten Borste aus dem ventralen Ruderast. Vergr. 660. 

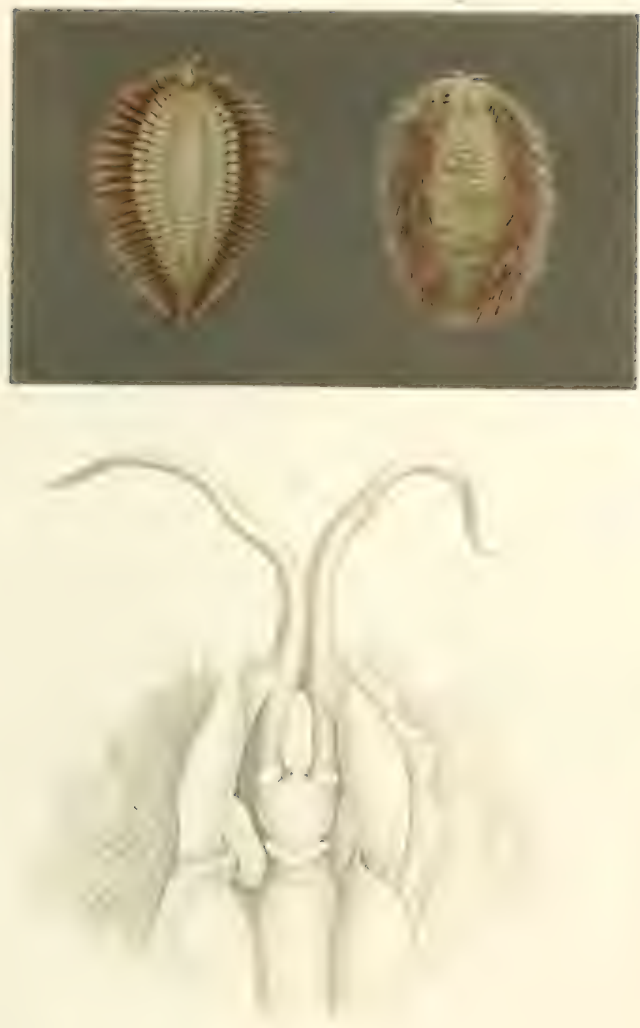

$\operatorname{sen} \mid$ 




\section{TAFEL 6 .}

Ii.. 1. Aphrodite obtecta $\mathrm{n}$. sp.; Rückenansicht des ganz vom schlammdurchsetzten Filz bedeckten Thieres. Tergr. 2,5 .

I:. 2. Dasselbe Thier von der Bauchflïche. Vergr. 2, 5 .

Yi.: : V. Torderende des Wurmes von der Rückenfläche gesehen, nachdem die Filzdecke gespalten und zur Seite geschlagen, die ersten Elytren etwas aufwärts gebogen sind. Vergr. 10.

F: . 4. Dasselbe von der Ventralfläche gesehen; die Spitzen der Subtentakel treten unter der Filzüberdacliung ror dem. Mundpolster frei heraus. Vergr. 10.

Y: _. ․ Ein Ruder, aus der Körperwand herausgeschnitten. Vergr, 12, 5.

$1: \ldots$ if. Endspitze einer Borste des ventralen Ruderastes. Vergr. 200.

Ii : . - $\therefore$. Einfache Borsten aus dem dorsalen Ruderaste. Vergr. 200. 


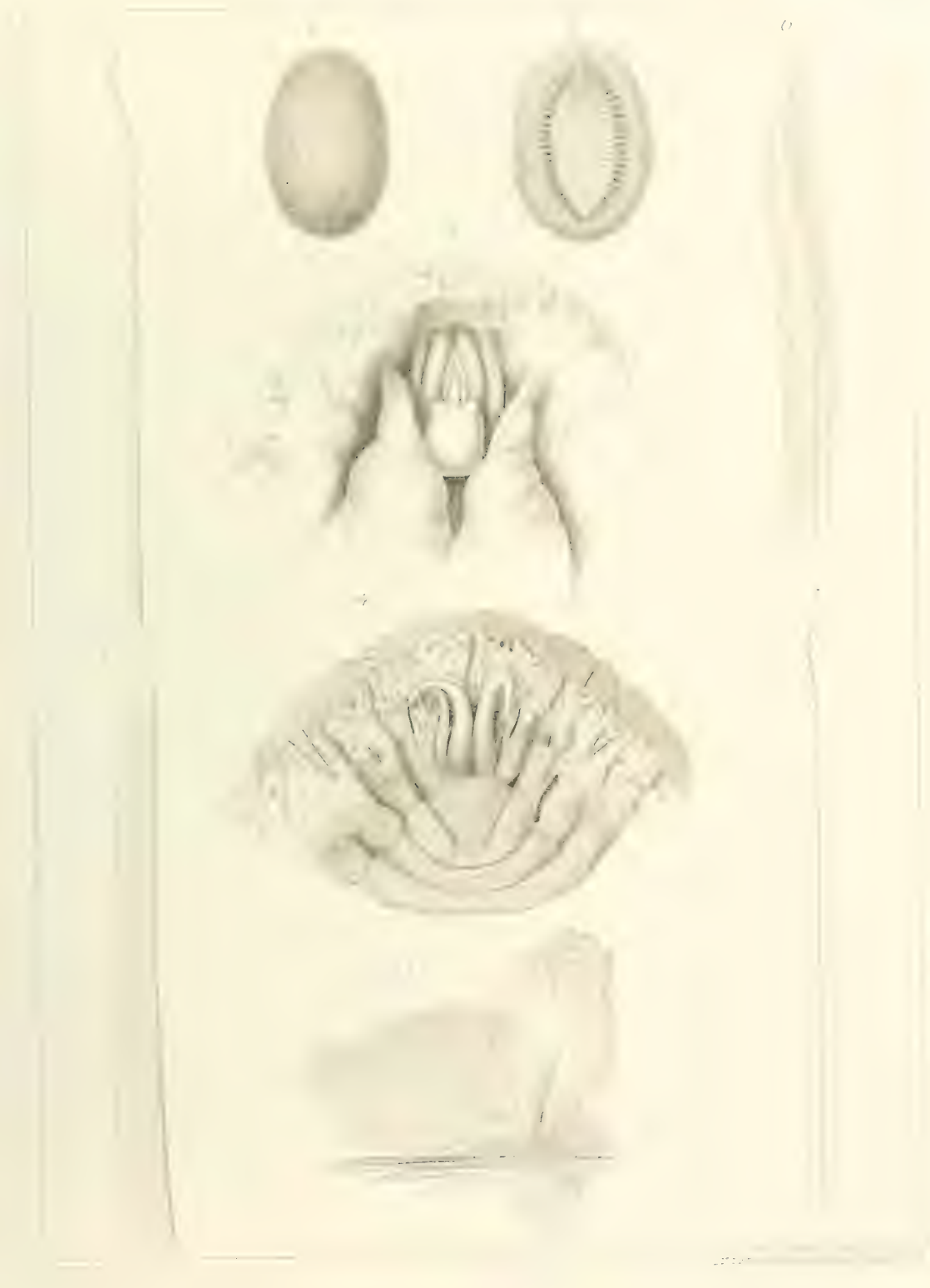






\section{TAFEL 7 .}

Ii.. 1. Pontogenia sericoma n. sp.; Riuckenansicht. Vergr. 2, 5 .

Y:_... Vorderende desselben Wurmes; das Thier liegt auf der Rüickenfliche, die linke Seite ist gehoben, das Kopfende aufwärts gebogen, so dass man das Mundpolster, den zwịschen den Subtentakeln stehenden Facialtuberkel, den Tentakel mit dem rerdiekten, von Y'apillen besetzten Basalstiick, und die Augen auf der Rückenflïche des Koptlappens sieht. Vergr. 10.

Ii_.: Derselbe Wurm von der Bauchfläche gesehen. Vergr. 6.

1.1. Horsten. Vergr. 45.

Ii_..., B

Yi_. 6. Laetmutonice Kinbergi (Baird); Ansicht der Rückenfläche. Vergr. 2. 

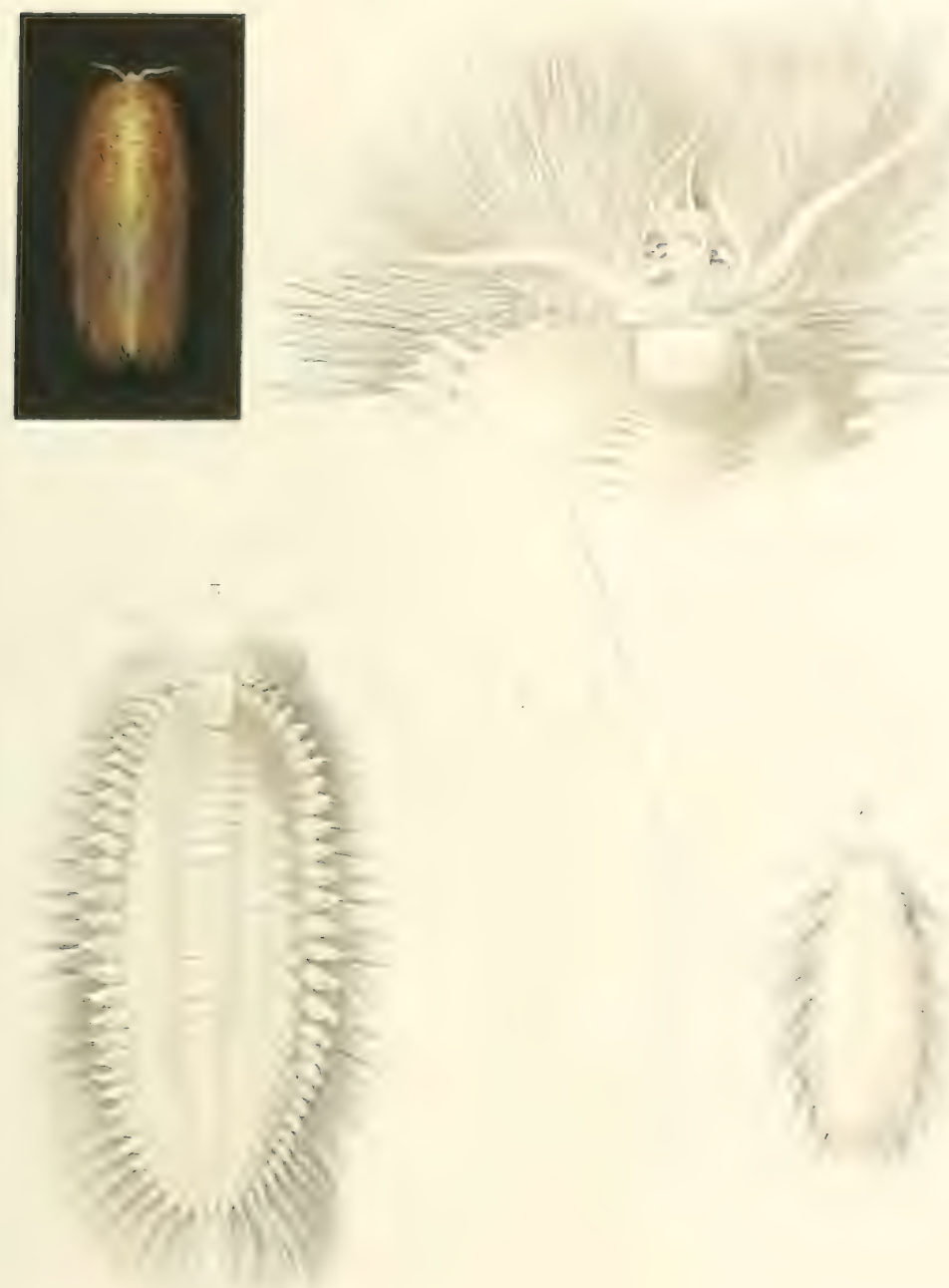




\section{TAFEL 8.}

Fig. 1. Laetmatonice Kinbergi (Baird); Kopflappen mit den Anhängen und erstes Ruderpaar in der Ansicht rom Rücken her. Vergr. 10.

Fig. 2. Ruder mit Rückencirrus. Vergr. 11.

Fig. 3. Ruder mit Elytron. Vergr. 11.

lig. 4. Zwei Borsten aus dem ventralen Ruderaste mit einem und zwei dornartigen Zihnen vor der Basis der gebiritelten Endspitze. Vergr. 45.

Fig. 5. Endspitze einer spiessigen Borste aus dem dorsalen Ruderast. Vergr. 45. 



TAFEL 9.

1:- 1. Polynoe lactea n. sp.; Torderende des Thieres rom Rücken gesehen; die Elytren sind aufwiirts und zur Seite gebogen, um den Kopflappen und dessen Anhänge frei zu legen. Vergr. 7 .

Fis.:2. Ruder mit Elytron. Vergr. 15.

Ii.. 3. Ruder mit Rückencirrus. Vergr. 15.

I: $:$ 1. Ein kleiner Abschnitt der dorsalen Elytrenfläche, um die Warzen auf derselben in der Ansicht von oben zu zeigen. Vergr. 180.

I. . .. Die grösseren Elytrenwarzen in Profilansicht. Vergr. 180.

1 $\therefore$ i. Randpapillen der Elytren. Vergr. 180.

F. . . Borsten des ventralen Ruderastes. Vergr. 150. 

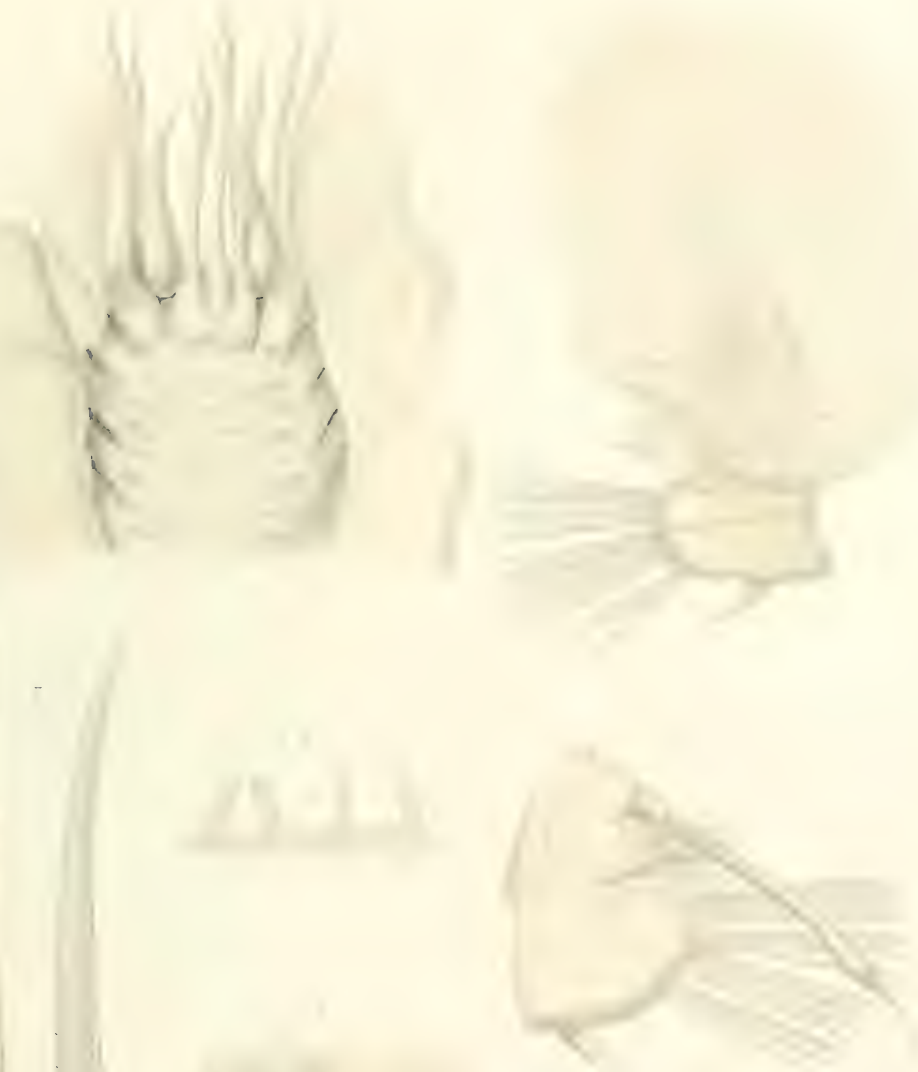


TAFEL 10.

Fig. 1. Polynoe tacniata n. sp.; Topflappen mit' 'Tentakeln und Subtentakeln, Ansicht von obeu. lergr. 41.

Fig. 2. liuder, dessen Elytron abgefallen ist. Vergr. 40.

Fig. 3. Abgelöstes Elytron ron der liückentliche. Vergr. 20.

Fig. 4 und ह̌. Elytrenwarzen. Vergr. 350.

Fig. 6. Borsten des unteren liuderastes. Vergr. 380.

Fig. $\tau$ und S. Borsten des oberen liuderastes. Vergr. 380.

Fig. 9. Polynoc polytricha (Schmarda)? Yorderende nach Ablösung der Elytren vom liücken gesehen. Vergr. 20.

[i.. 1". Ruder mit Rïickencirrus. Vergr. 25. 


TAFEL 11.

Fiz. 1. Polynoe polytricha (Schmarda)? Elytron. Vergr. 38.

Fin. 2. Polynoe granulata n. sp. ; ganzes Thier vom Rücken gesehen. Vergr. 2.

Y.... 3. Vorderes Kürperende desselben, vom Rücke» gesehen, die Elytren abgebogen. Vergr. 14.

Y.. 4. Ruder mit Rükencirrus. Vergr. 16.

Tri.. 5. Elytron. Vergr. 16.

Ii.. 6. Borste aus dem ventralen Ruderast. Vergr. 250.

I: $\therefore$. . Borste aus dem dorsalen Ruderast. Vergr. 250. 


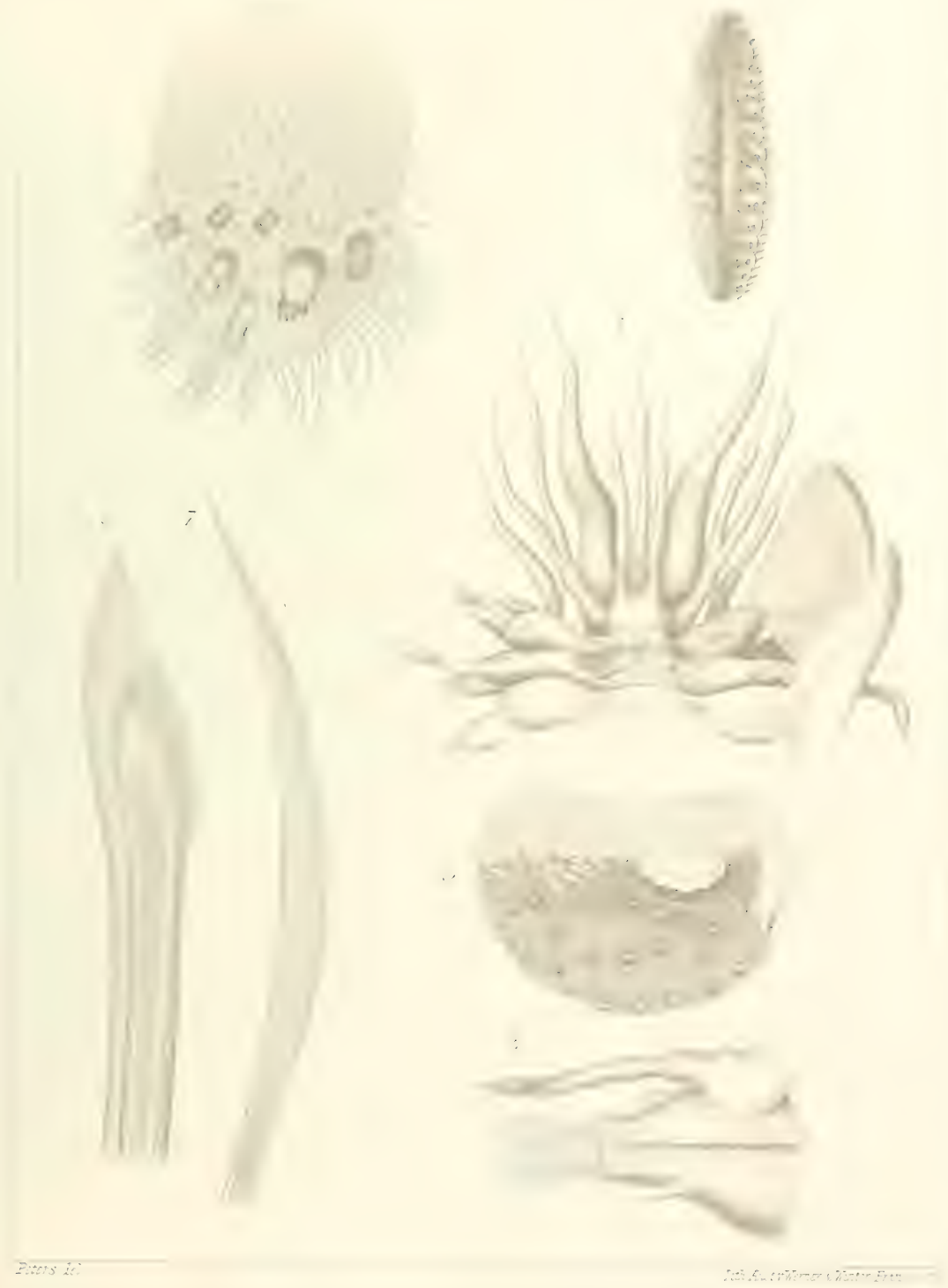




TAFEL, 12.

Fig. 1. Euarche tubifex n. sp.; Torderende des Wurmes mit ausgestrecktem Rüsscl. vu Rücken geselien. Vergr. S.

Fig. 2. Dasselbe; Ansicht der Bauchfläche. Vergr. 8.

Fig. 3. Eingang in den ausgestreckten und geölfneten Rüissel; der dorsale Unfang dirselben anf der Tafel abwïrts gewendet. Die Abbildung zeigt den Piljillenkranz und den Kieferapparat. Vergr. 10.

Fig. 4. Ruder ohne Rückencirrus. Vergr. 15.

Fig. J. Ruder mit Rüekencirrus. Vergr. 15.

Fig. 6 und 7. Borsten des unteren Ruderastes. Vergr. 410. 

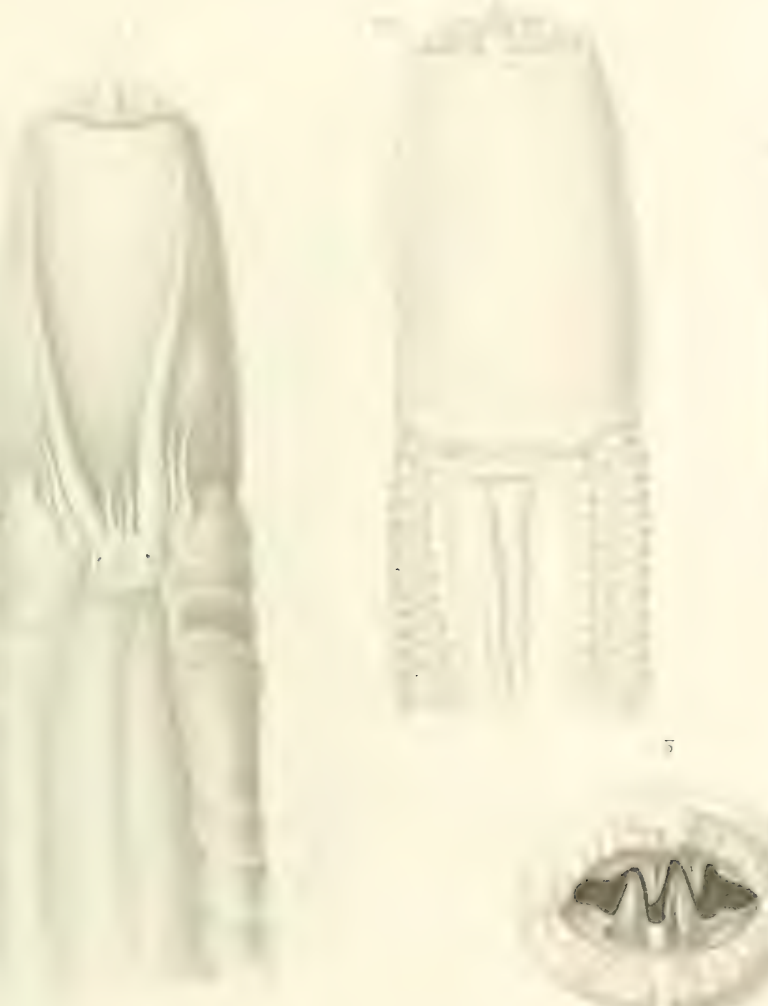


TAFEL 13.

Fig. 1. Tordere und hintere Endstrecke der Röhre von Euarche tubifex n. sp.; natürliche Grösse.

Fig. 2. Stheneltris simplex n. sp.; vorderes Körperende vom Rücken gesehen. Vergr. 15. Fig. 3. Dasselbe von der Ventralfäche. Vergr. 15. 

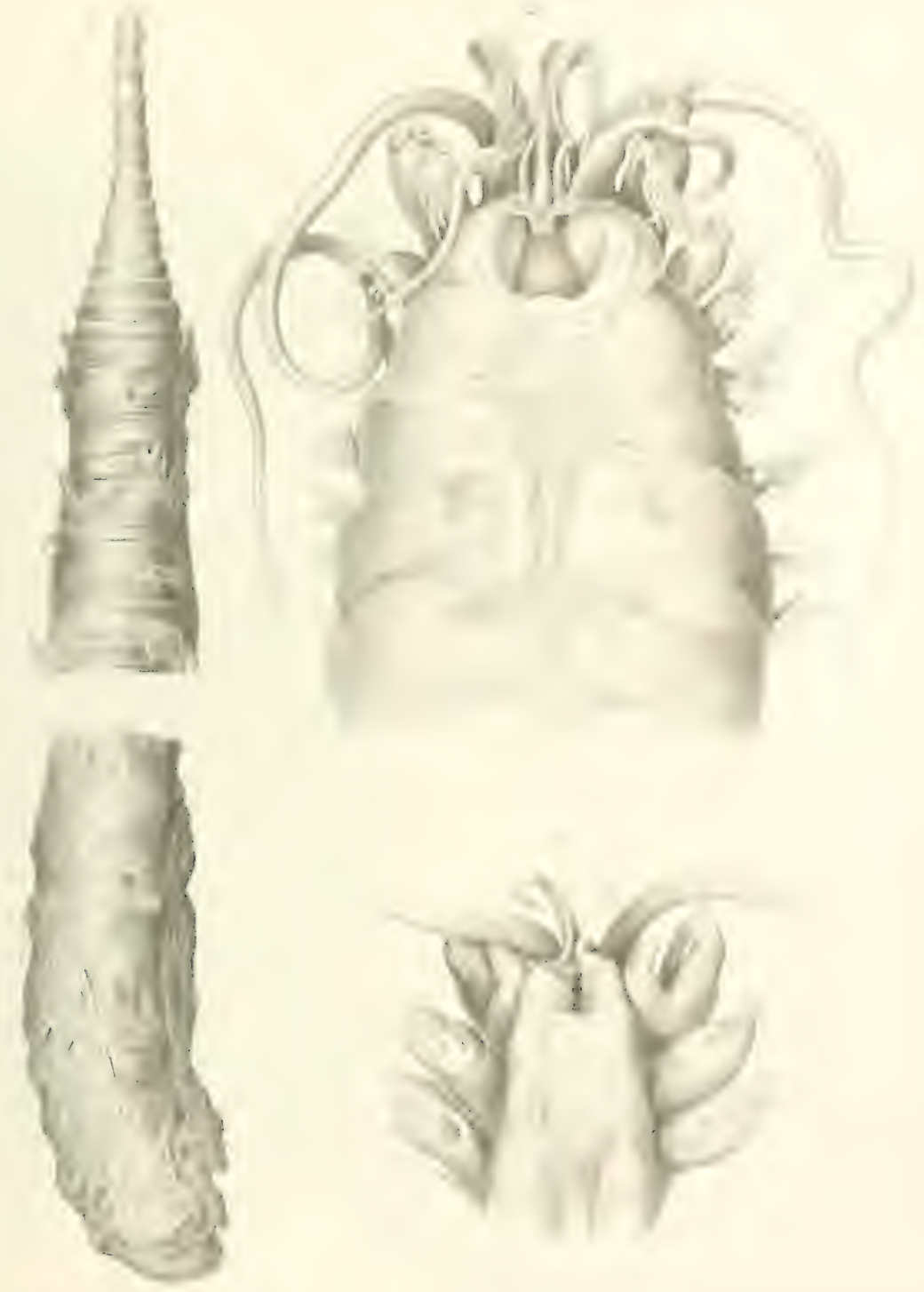
TAFEI, 14.

I: $\therefore$ 1. Sthenelais simplex; 10tes Ruder mit einem Theil der Körperwand abgeschnitten, von der hinteren Fläche gesehen; der Elytrophor, ohne Elytron, steht hoch über der liuderbasis. Vergr. etwa 30 .

I: $: 2$. Elftes Ruder desselben Thieres in gleicher Weise abgetrennt, von der vorderen Fläche geseheu; an Stelle des Elytrophors ein kristenartig comprimirter Höcker. Vergr. 30.

I:... ... Ein abgelüstes Elytron der vorderen Ruder. Vergr. 14.

I: . 4. Borsten aus dem dorsalen und ventralen Ruderaste. Vergr. 110.

I: $\therefore$. Endstrecke der Borsten des ventralen Ruderastes, von der Fläche und in schräger Profilstellung gesehen; die hohle Fläche ist feilenartig gekerbt. Vergr. 280.

Fir. 6. Eimblick in den geüffneten Rüsseleingang. Vergr. 8. 


$$
\mid \begin{array}{ll}
x+4 \\
\text { a }
\end{array}
$$



TAFEL 15.

Fig. 1. Sigalion Pourtalesiin. sp.; das vordere Körperende des Wurmes, dessen Elytren seitwürts abgebogen sind, vom Rücken gesehen. Vergr. 10, 5.

Fig. 2. Dasselbe ron der Teutrallaiche gesehen. Vergr. 10, 5 .

Fig. 3. Dicke Borste aus dem oberen Theile des Bündels des unteren Ruderastes (vergl. Taf. 16, lig. 6-10). Vergr. 400.

Fig. 4. Borste aus dem oberen Theile des Bündels des unteren Ruderastes derjenigen Segmente, welche Elytren tragen. Vergr. 500. 

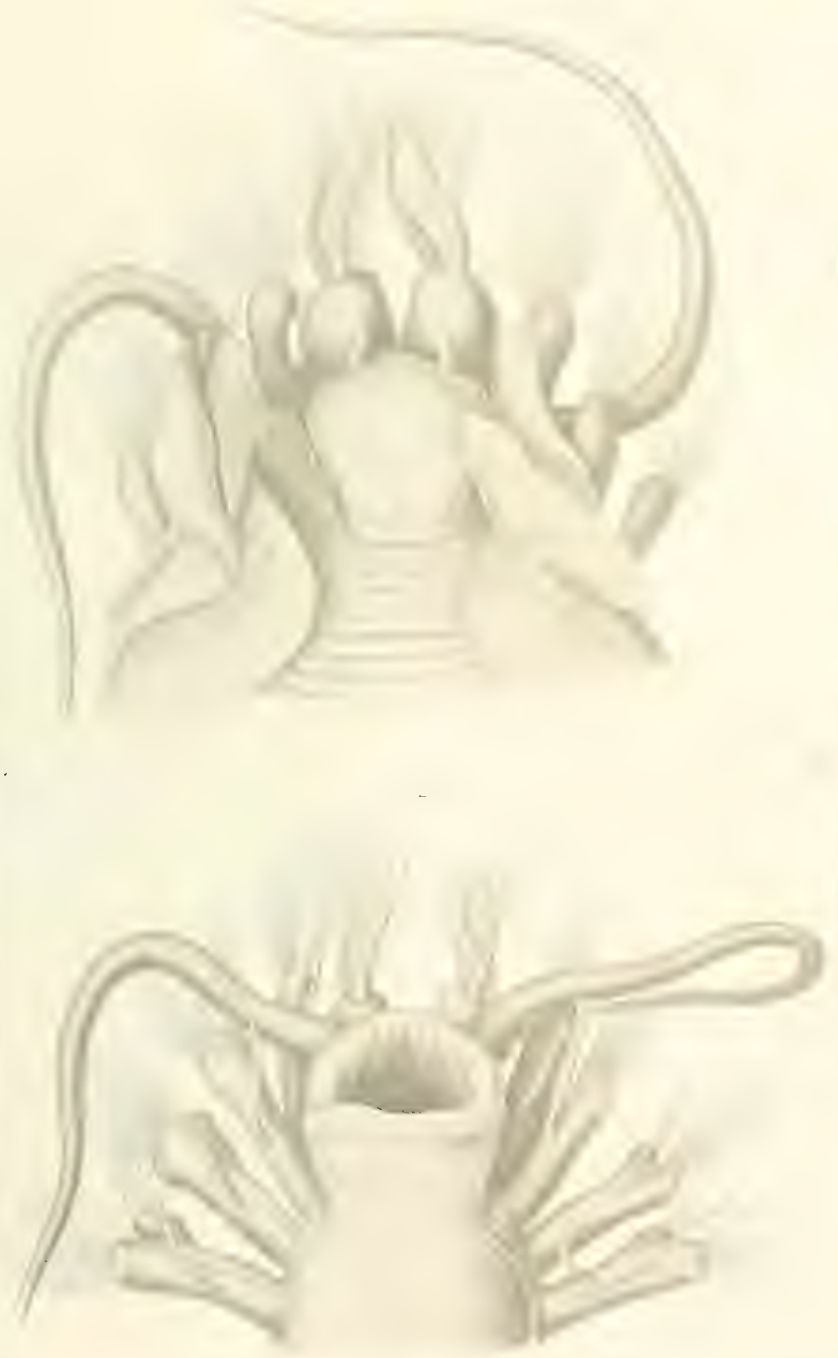




\section{TAFEL 16.}

Fig. 1. Sigalion Pourtalesii n. sp. ; ein Ruder ohne Elytron mit einem Theil der Körperwand abgeschnitten, und von der vorderen Fliiche her betrachtet; der an der Stelle des Elytrophors stehende Höcker trïgt die Kieme, an deren Basis eine kleine fadenförmige l'apille (rudimentärer liückencirrus) sitzt. Vergr. $\tau, 5$.

T: : 2. Das gleiche Ruder in der Ansicht von hinten. Vergr. $7,5$.

1\%: 3. Ein Elytron mit dem Elytrophor abgelöst und von der Flïche gesehen; dicht unter dem Elytron steht die hakenförmige Kieme. Vergr. 31.

lis. 4. Capillare Borsten aus dem Bündel des oberen $\Lambda$ stes. Vergr. 85.

Iif. 5. Die feine zweihakige Ludspitze einer solchen Borste. Vergr. 85.

Fir. 6 und 7 . Ungleiche Formen der Borsten des unteren Ruderastes. Vergr. 85.

H.r. S. Endglied einer Borste wie in Fig. 6 mit zangenartige Spitze. Vergr. 400.

I"is. 9. Spitze und Basis des Endgliedes einer schlank ausgezogenen Borste dieser Categorie. Vergr. 400.

Fig. 10. Eine Strecke des mit sägezähnigen queren Blättchen besetzten Schaftes einer Borste dieser Art. Vergr. 400. 



TAFEL 17.

Fig. 1. Rhamphobrachizm Agassizii n. sp.; Vorderende von der Rückenflïche gesehen. Vergr. 14.

Fig 2. Dasselbe in Seitenansicht. Vergr. 14.

Fig. 3. Dasselbe von der Bauchfä̀che gesehen. Vergr. 14.

Fig. 4. Oberkiefer ron der dorsalen Fläche. Vergr. 26.

Fig. 5. Unterkiefer in gleicher Lagerung. Vergr. 26. 

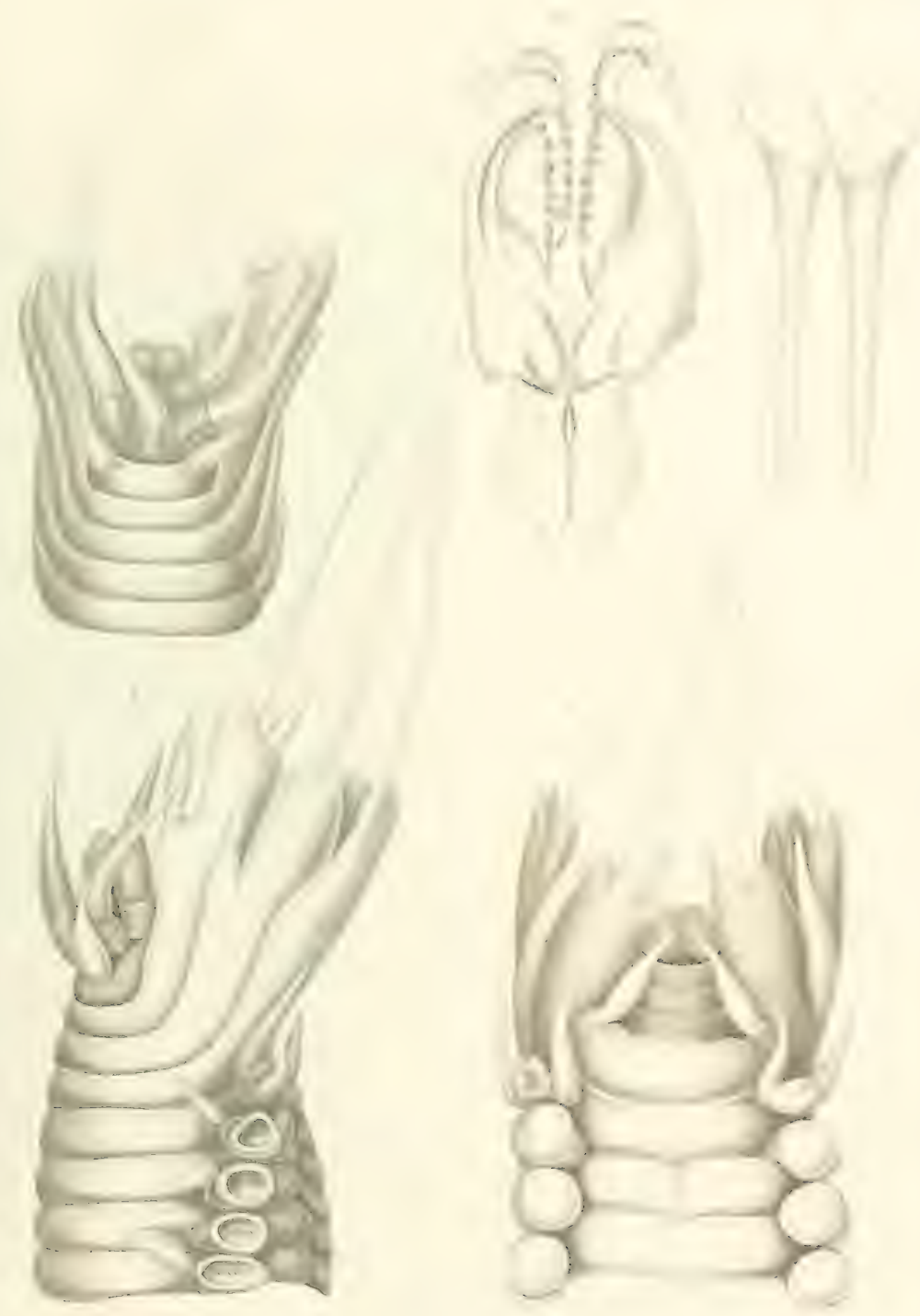


TAFEL 18.

lig. 1. Thamphobrachinm Agassizii n. sp.; capillare Borste der hinteren Ruder. Vergr. (6)0.

Fig. :- Hakenfürmige Eudspitze der sehr langen Borsten der drei vorderen Tinder. Vergi. 600 .

Yig. 3. Eine Strecke des vierkantigen Schaftes dieser Borsten, um den Besatz desselben mil Hürehen zu zeigen. Vergr. 600.

Fig. 4. Acicula tler hinteren liuder. Vergr. 4\$0.

Fig. 5. Meisselförmige Borste. Vergr. 480.

Fig. 6. Acicula ter rorderen liuder. Vergr. 160.

Fig. 7. Capillarborste aus einem der vorderen Iinder. Vergr. 320.

Fig. S. Dreizelntes liuler; hintere Fliiche. Vergr. 25.

Fig. 9. Zwei und zwanzigstes liuder mit einem Theil der Körperwand. Vergr. 25.

Fig. 10. Diopatra glutinatrix n. sp.; Iöhre. Vergr. 3.

Fig. 11. Vorderes Kürperende des Thieres, vom Riücken gesehen. Vergr. 17.

Fic. 12. Erstes Iiuder, dessen grüssere Lippe umgebogen ist. Vergr. 20.

Fic. 13. Spitze der Stütznadel aus diesem Ruder. Vergr. 233.

Fig. 14. Dreissigtes Ruder der linken Kö̈perhälfte; über der Ruderbasis schimmern Drïsenschliuche durch die Körperwand. Vergr. 33.

Fig. 1.. Die Thurzel des Rückencirrus und der hinter derselben stehende Höcker (rudimentïre Kieme?) von lemselben Iiuder. Vergr. 70.

Fir. 15. Fünfzelntes Ruder der linken Körperhälfte. Vergr. 46. 

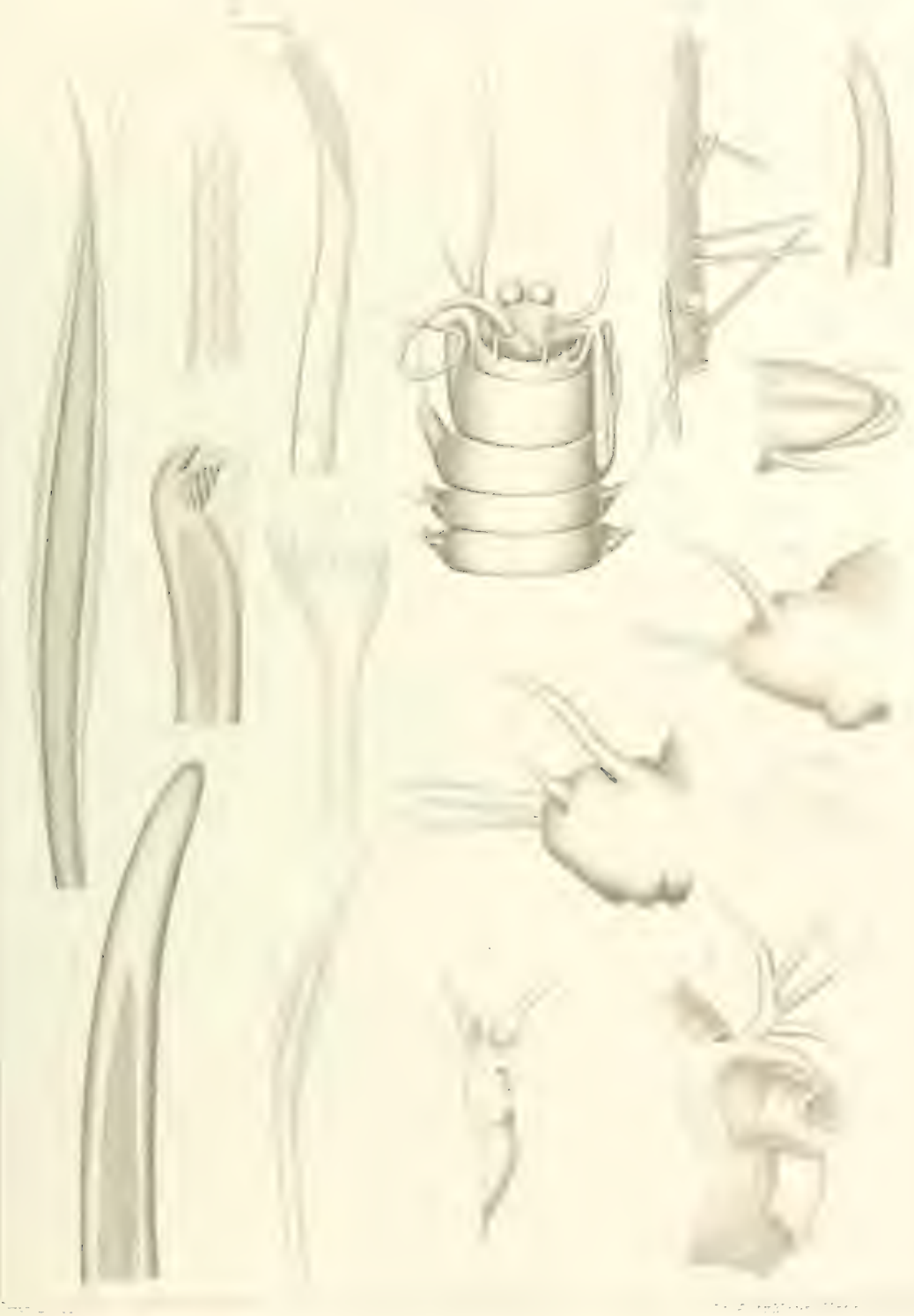


TAFEL 19.

I: $:$ 1. Stützudelartige Borste aus dem Ruder der Diapatra glutinatrix. Vergr. 250.

$1:$ 2. Endstück einer Jeisselborste, eben daher. Vergr. 750.

1. 3. Endstrecke einer gesiiumten Capillarborste eben daher. Vergr. 200.

I: 5 4. Oberkiefer ron Diopatra glutinatrix. Vergr. 40.

I: 5. 5unterkiefer derselben; die hinteren Strecken derselben nicht gezeichnet. Vergr. 40.

I: $:$ 6. Fordere Kürperstrecke der Diopat’a Pourtalesii n. sp. Vergr. 18.

I:. \% Erstes

I: \&. Viertes

I: $\therefore$. Yeuntes

Ruder dieses Wurmes. Vergr, 40.

I. . 10. Zwanzigstes 

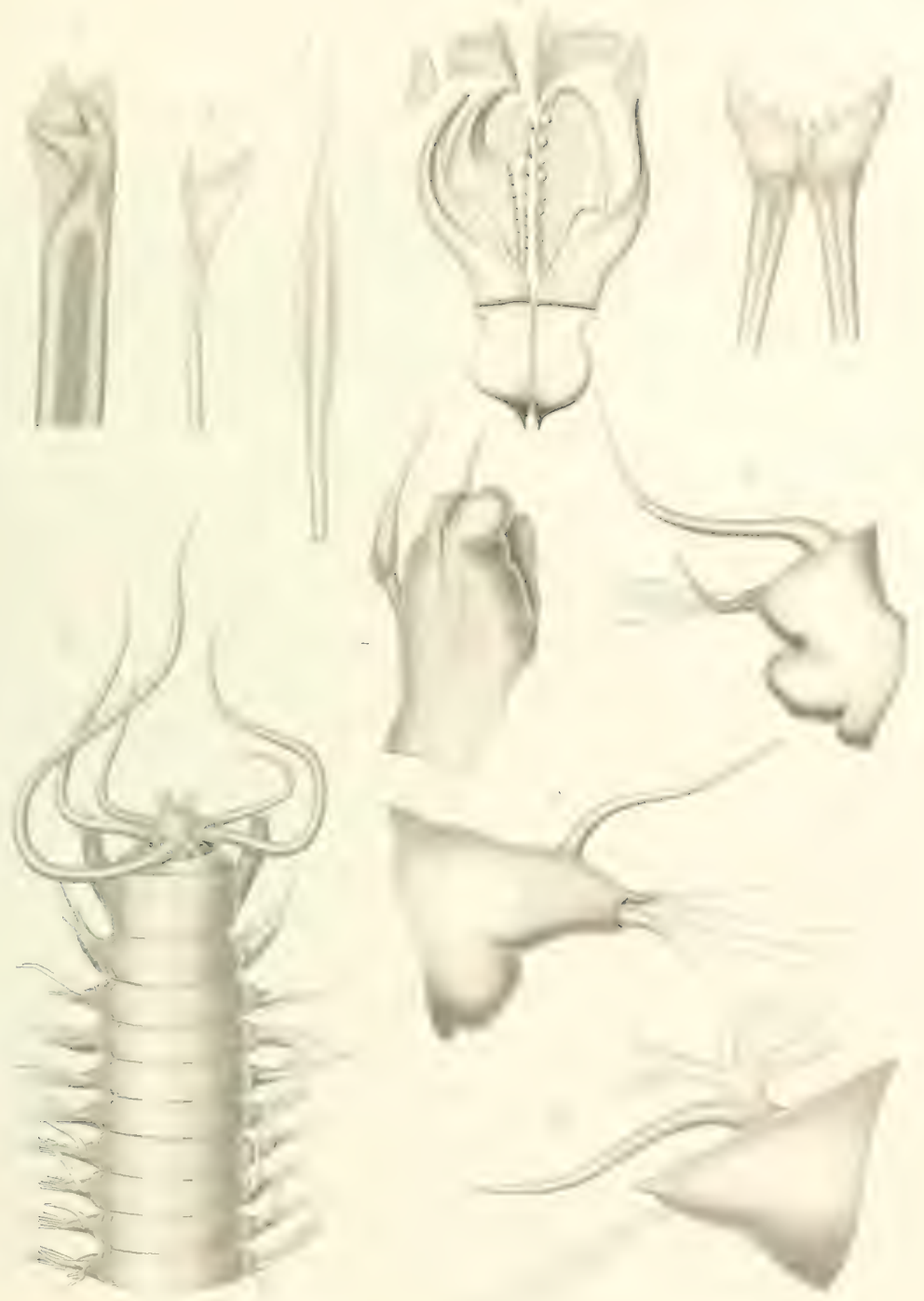




\section{TATEL 20.}

$\left.\begin{array}{lll}\text { I1: } 1 . & \text { Oberkicfer } \\ \text { I1.: }: . & \text { Unterkiefer }\end{array}\right\}$ von Diopatra Pourtalesii. Vergr. 35.

11: : Endstrecke der Stiitznadel aus dem ersten Ruder. Vergr, 135.

11.: 4. Capillarborste der hinteren Ruder in Seitenlage. Vergr. 120.

Ii: $\therefore$ Meisselborste. Vergr. 600 .

I. i. b. I'latte, pergamentartige Röhre von Diopatra Pourtalesii mit vereinzelt aufgekitteten Fremukörpern. Nat. Gr.

I. ․ . Diopatra fragosa n. sp.; Vorderstrecke rom Rücken gesehen. Vergr. 18.

I: \& \&. Dieselbe von der Banchflüche gesehen, etwas schrïg gelagert. Vergr. 18.

I: $:$ Erstes Ruder; Ansicht der hinteren Flïhe. Vergr. 103.

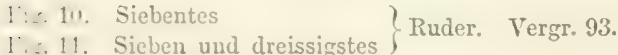

II: 1:. IIeisselborste. Vergr. 500.

Fi: 1:3. Endstrecke der im ersten Ruder stehenden Borsten. Vergr. 615.

Fin. 14. Gesäumte Borste der hinteren Ruder. Vergr. 500. 


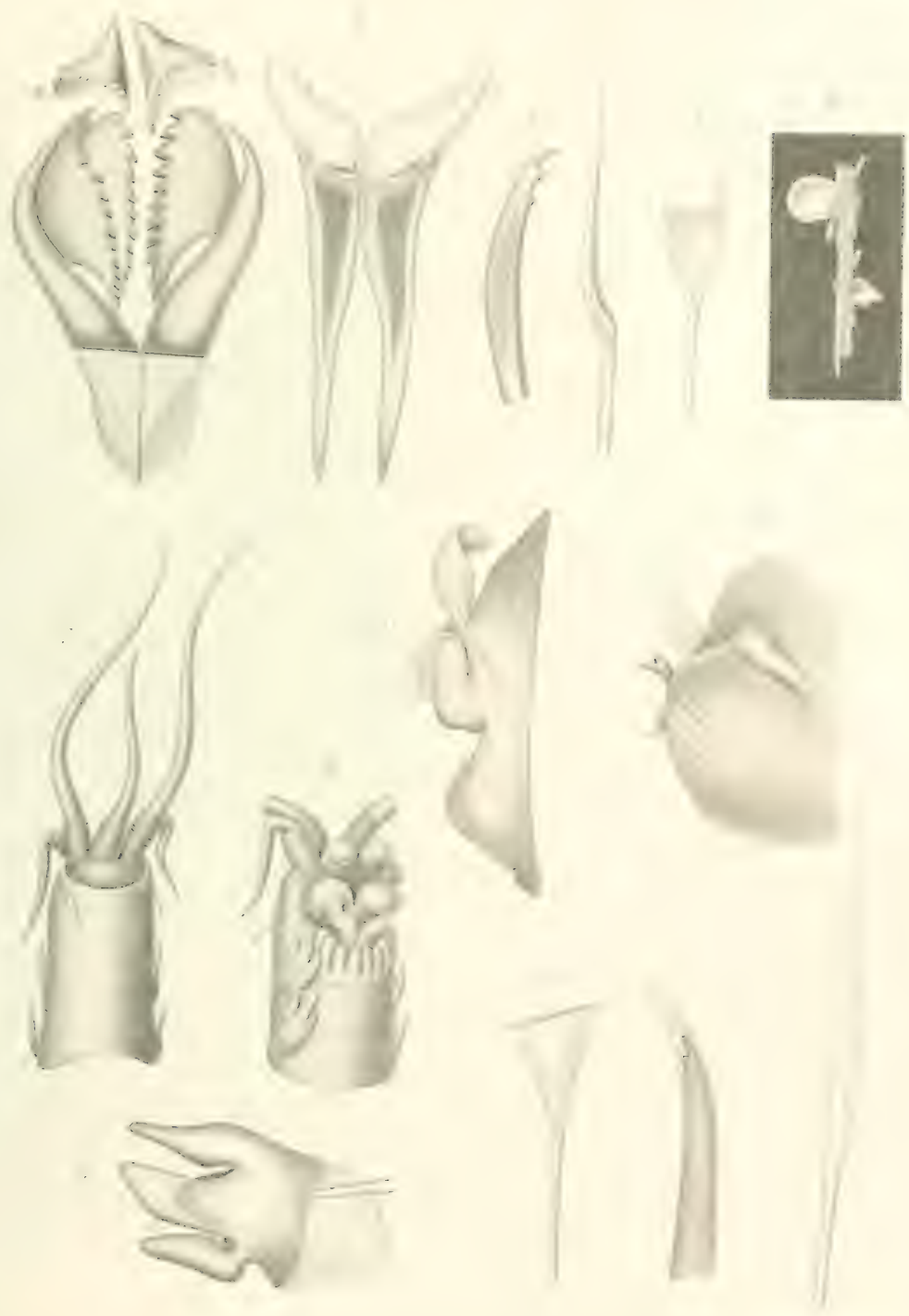



. 
TANEL 21.

1. : 1 Oberkiefer der Dioputu fingosa. Vergr. 50.

1. . - Unterkiefer ron der Tentralfiche, unr eine Hailfte gezeiehnet. Vergr. 50.

i. . .. Dic Vorderkante desselben von der Rückenflüche. Vergr. 50.

1. . 1. Iï̈re der Diopatru fragosa incrustirt mit quer gestellten scherbenförmigen Bruchstücken. Vergr. 2.

1. . 5. Onuphis (Puronup)his) gracilis n. sp.; Vorderstrecke des in glasartig durchscheinender lï̈hre steckenden Thieres, von der Ventralfiache. Vergr. 30.

I. : i. Torlerstrecke cines anderen Exemplares, von liüken gesehen; die mittleren Fuhler zurickgebpgen, ıı die Augenflecke zu zeigen. Vergr. 60.

I. - . Stutzmadelfümige Borste aus den linteren Rudern. Vergr. 500.

I. . S. Zusummengesetzte Borste aus dem 1ten und 2ten Ruder. Vergr. 670.

1: $\therefore$ 9. Einfache Capillarborste a.s don hinteren Rudern, in geringer Zahl über den folgenden. Vergr, 350.

1: $\therefore$ 111. Gesäumte Borste. Vergr, 350。

I:_. 11. Meisselförmige Borste. Wexgr, 350.

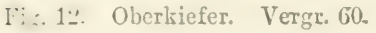

Ií. 1i. Die eine Hälfte des Gnterlefers. Vergr. 60. 

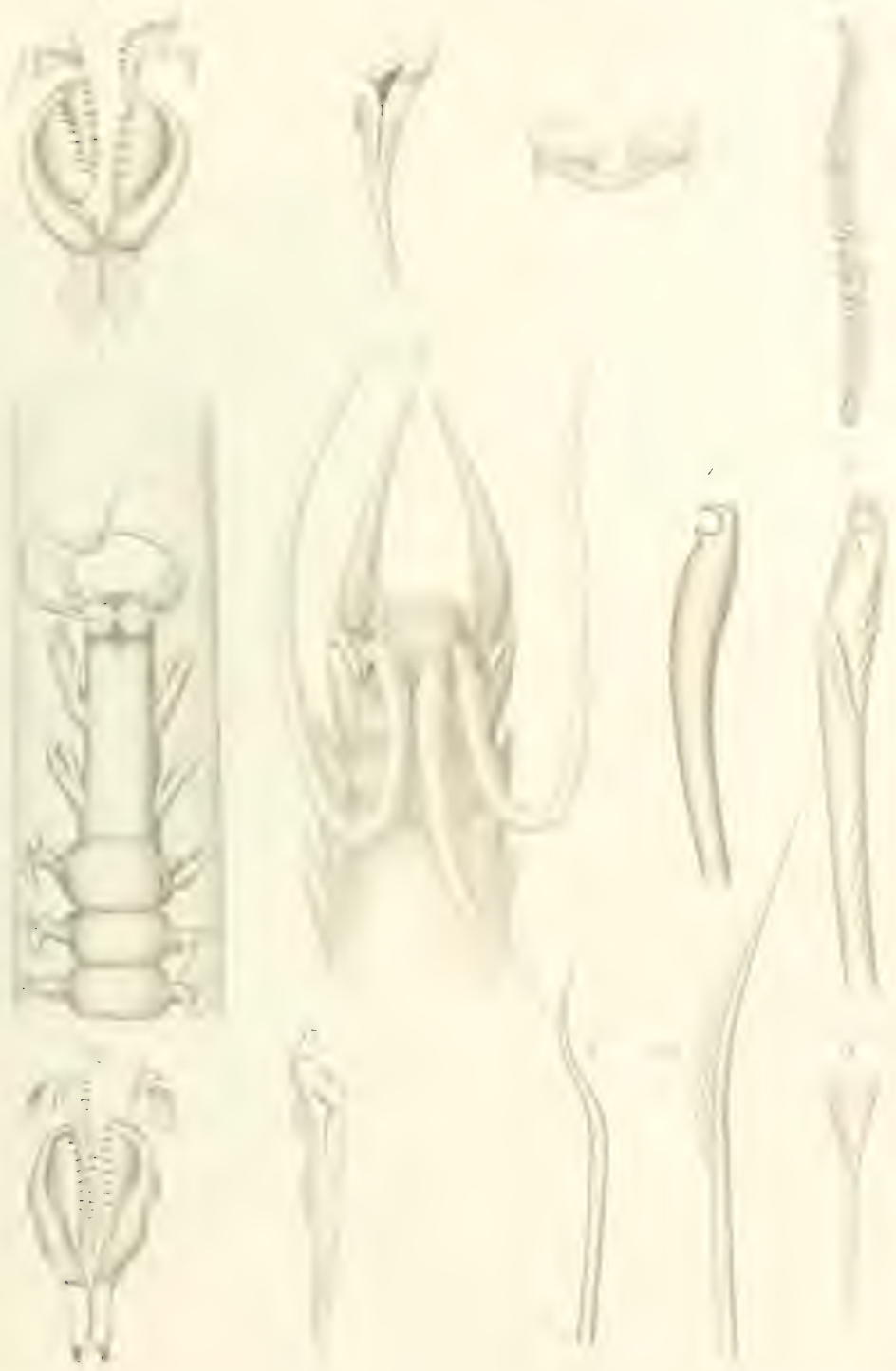

TAFEL 22 .

Fis. 1. Eine gersundene mit seitlichen Oeffnungen rersehene Röhre der Eunice floridana (l'ourt.); die an ler linken absteigenden Strecke anheftende Masse ist eine spongie. Natürliche Grösse.

I:_. :- Vordere Körperstrecke der Éunice foridana. Vergr. 3.

1: : : Ne Teun und dreissigstes liuder, dessen Kiemenfäden zum Theil gegabelt sind. Vergr. 16.

Fi: 4. Ruder mit der gewöhnlichen Kiemenbildung, Vergr. 16.

Fis. i. Oberkiefer. Tergr. 9

Yir. c. Unterkiefer. Vergr, 9.

1: . . . Endstück der zusammengesetzten Borsten. Vergr. 460. 


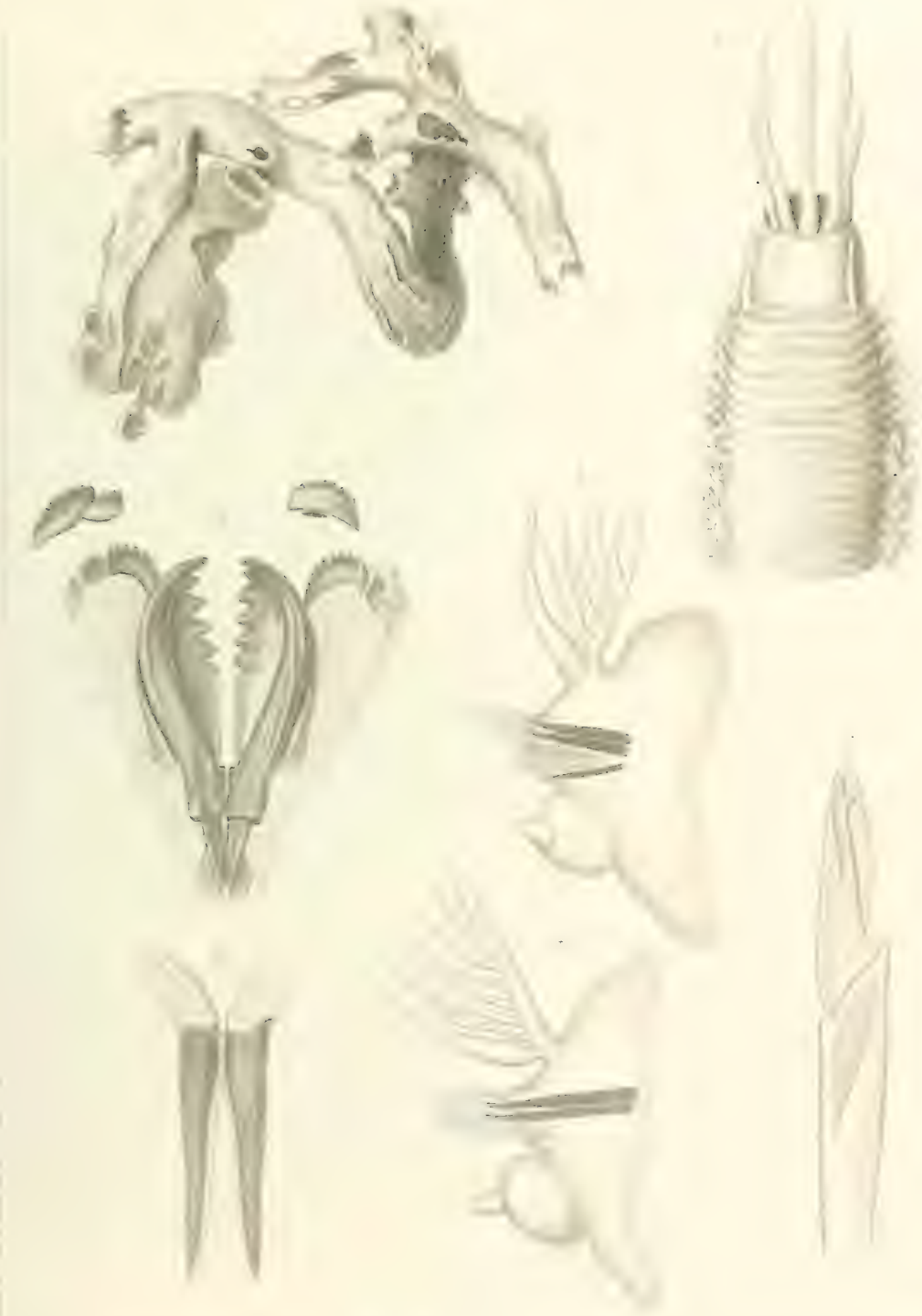




'TAFEL 23.

1. . 1. Vordere und mittlere Tï̈perstrecke von Ëunice conglomerans. Vergr. 1, 5 .

!. . 2. liühre des Wurmes mit der nach abwärts gerichteten vorderen Oeffnung und den geschlossenen Seitenzmeigen. $\frac{2}{3}$ der natürliche Grösse.

1: : 3. Das Vorderende eines Wurmes aus einem in den Bau einer Röhre einbezogenen Schneckenhaus hervorragend. Natürliche Grösse.

F... Achtes

1:i. 5. Siebzigstes

l:m. 6. Zweihundert und zwanzigstes

Ruder. Vergr. 16.

I: $\therefore$. 7 . Zweihundert fünf und vierzigstes

I'if... Oberkiefer ! Vergr. 8 .

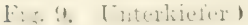



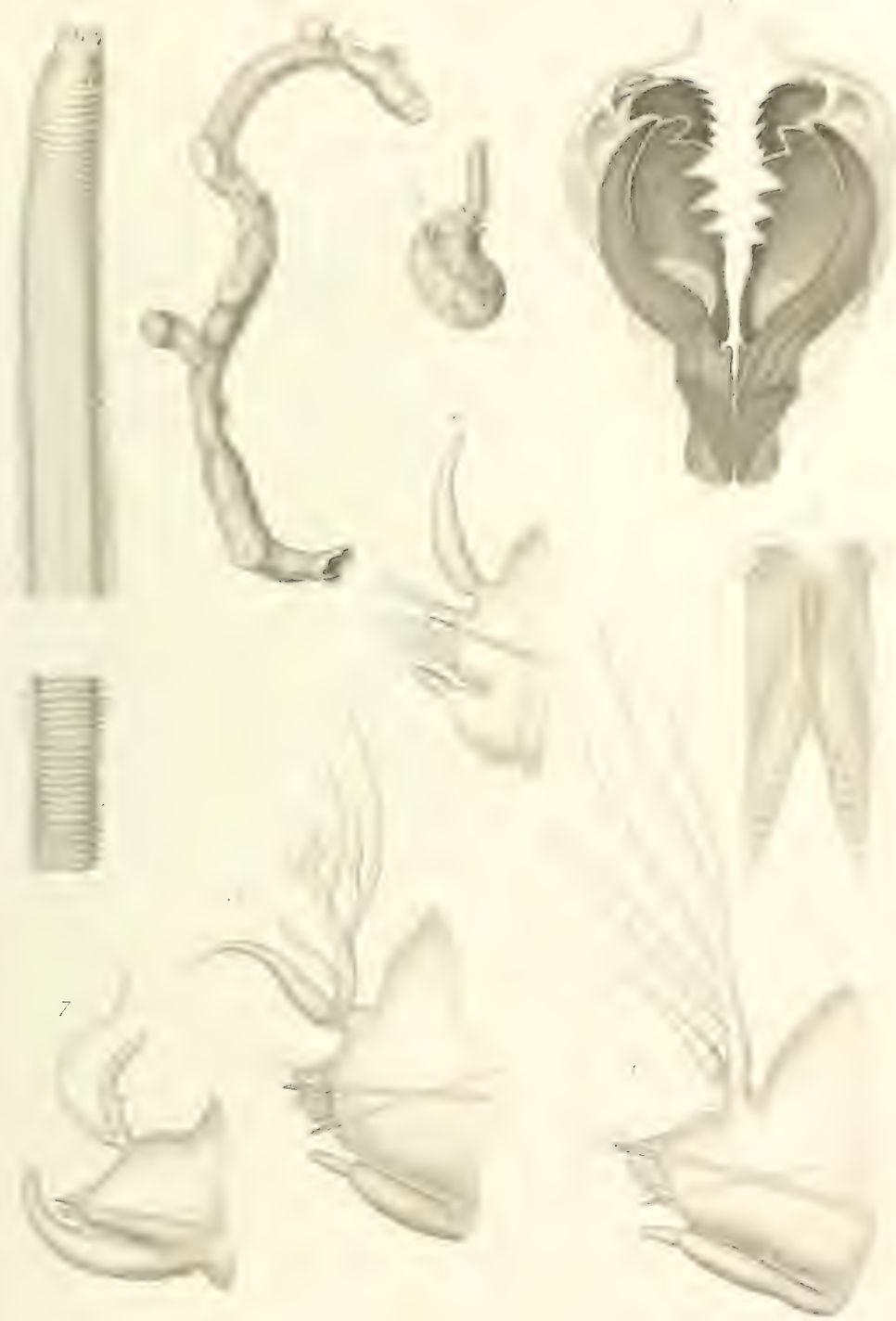

TAFEL 24.

$1 . \therefore$ 1. Heisselborste von Einice conglomerans n. sp. Vergr. 380.

$1 \quad \therefore \quad$ :. Capillarborste der vorderen Ruder. Vergr, 380.

I ... : .. Zusammengesetzte Borste der hinteren Ruder. Vergr. 380.

1 1. 1. Zusammengesetzte Borste der vorderen Ruder. Vergr. 380.

I: . i. Eunice antillensis n. sp.; vordere Körperstrecke. Vergr. 5.

1: $\therefore$ i. Siebzehntes Iiuder derselben. Vergr. 37 .

I. $\therefore$;. Zusammengesetzte Borste aus demselben. Vergr. 520.

l: : .. Eunice articulata n. sp.; vordere Kürperstrecke. Vergr. 8.

I: $\therefore$ !) Neuntes Ruder derselben. Vergr. 20.

I: ¿. 10. Zusammengesetzte Borste. Vergr. 430.

I::. 11. Eunice violaceo-maculata n. sp. Vergr. nicht ganz 3 .

Ii : 1:. Aittlere Körpersegmente desselben Thieres, die rechto Körperhälfte etwas gehoben. Vergr. nicht ganz 3. 


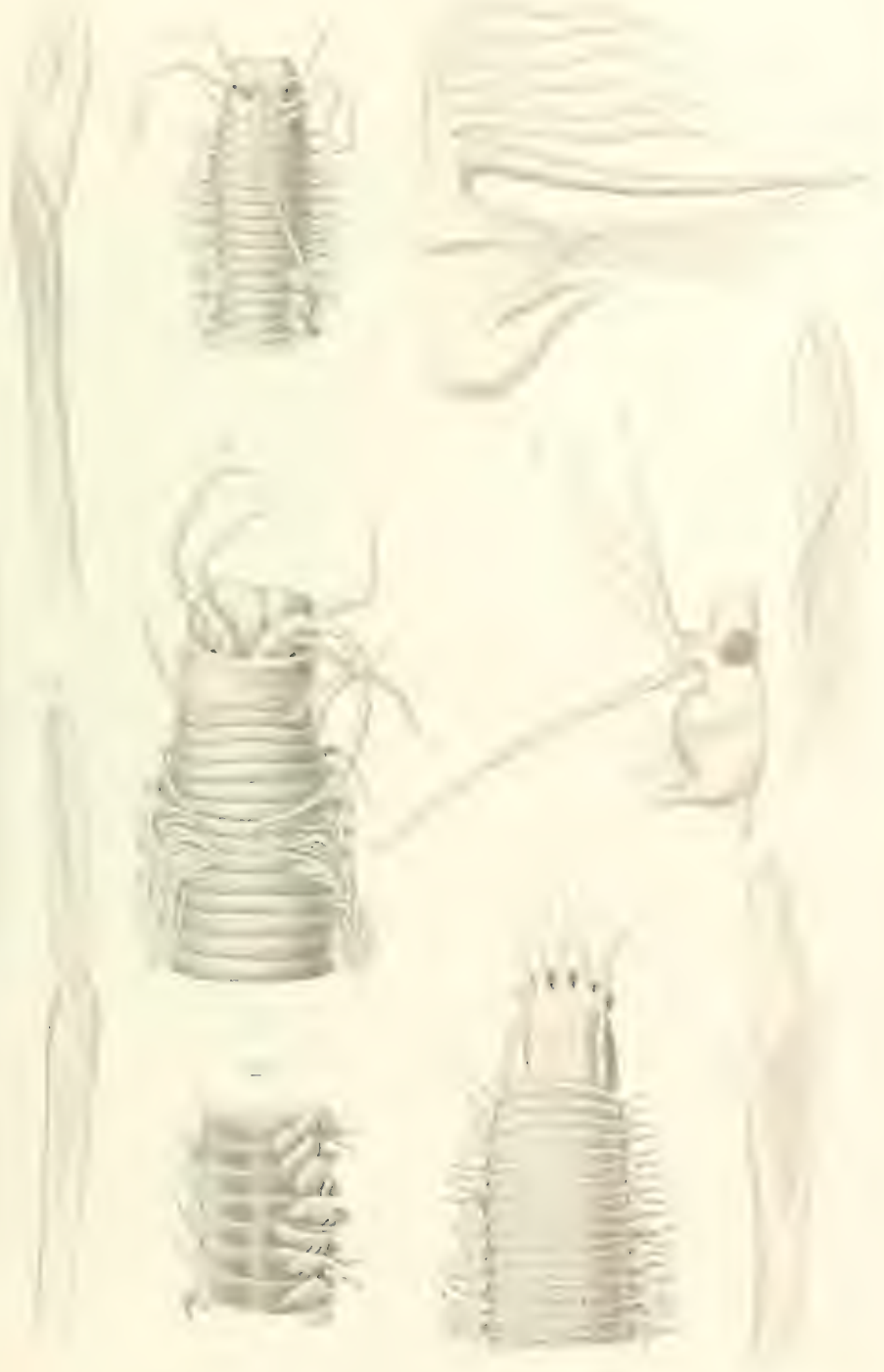
For 

TAFEL 25.

I. : 1. Aehtzelntes liuler von Emice violaceo-maculata n. sp. Tergr. 12.

11. $\because$. deht und fünfzigstes Ruder derselben. Vergr. 12.

1. $\therefore$ Uberkiefer derselben. Vergr. 9.

1.. I. Unterkicfer derselben; ventrale Fläche. Vergr. 9.

II. $\therefore$ Unterkicfer; dorsale Fliiche. Vurgr. 9.

!. . i. Stiitznalel aus dem 1Sten Ruder. Vergr. 192.

I... . Zusammengesetzte Borste, aus demselben. Vergr. 192.

i. . S. Eunice fucata n. sp.; vordere Körperstrecke. Vergr. 4.

I': $:$ 9. Mittlere Fürpersegmente derselben, mit den ringförmigen Wülsten der Rückenthiiche. Vergr. 4.

I. : i". Einhundert drei und siebzigstes Iiuder. Vergr, 20.

11.. 11. Dreizehntes Iiuler. Vergr. 20.

$1: \therefore$ 12. Kieme mit geringer secundiirer Falenbildung. Vergr. 20.

1:… Kieme mit reicher Verzmeigung. Vergr. 20.

1. . 11. Meisselborste aus den hinteren Rudern. Vergr. 500.

I". $:$ 1. St Stitznadelituliche Borste aus dem unteren Bündel der hinteren Ruder. Vergr. 200.

IV : 11. Desgleichen mit gerader Spitze. Vergr. 200.

$1 ' \therefore$ 1. Zusammengesetzte Borste aus dem unteren Bündel der vorderen Ruder. Vergr. 500.

I. : 1Y. Meisselborste der vorderen Ruder. Vergr. 500.

1: : 19. Stuitznadel der vorderen Ruder. Vergr. 200.

Fi: 20. Capillarborste derselben. Vergr. 500 . 


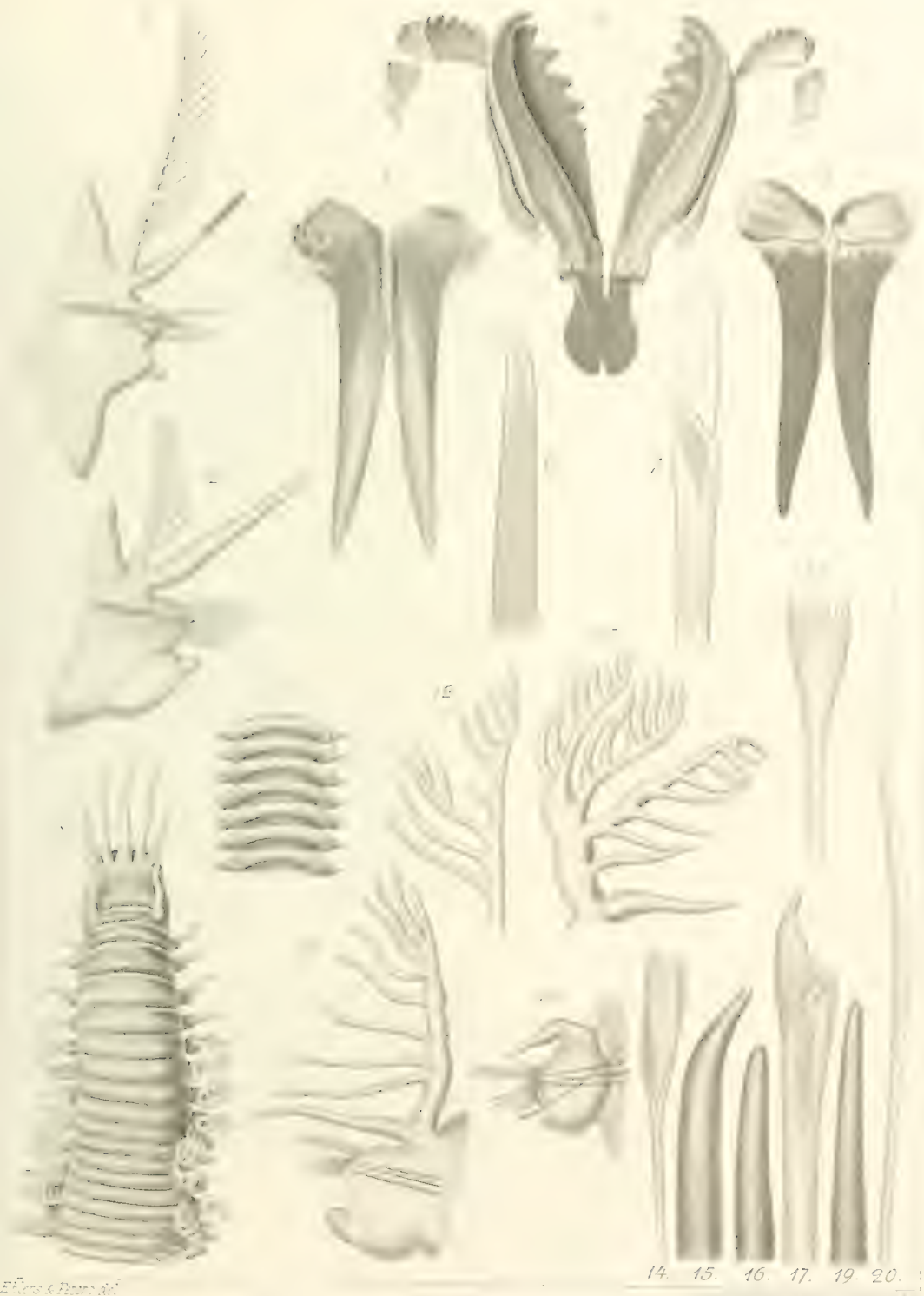





.


TAFEL 26.

1\%: 1. Eunice mbra Gr. Vergr. 2.

I :- :. Vorderstrecke derselben. Vergr. 14.

I": $\therefore$ : : Fünftes

1i.. 4. Vier und zwanzigstes Ruder. Vergr. 25.

Fi_. D. Drei und sechszigstes

F: C. Capillarborste des oberen Bündels. Vergr. 420 .

$7 \because \therefore$. Zusammengesetzte Borste des unteren Bündels. Vergr. 420.

I: _. \. Meisselborste aus dem oberen Bündel. Vergr. 420.

I'if. A. Acicula aus den hinteren Rudern. Vergr. 420.

Iis. 10. Oberkiefer. Vergr. 19.

I... 11. Unterkicfer. Vergr. 19. 

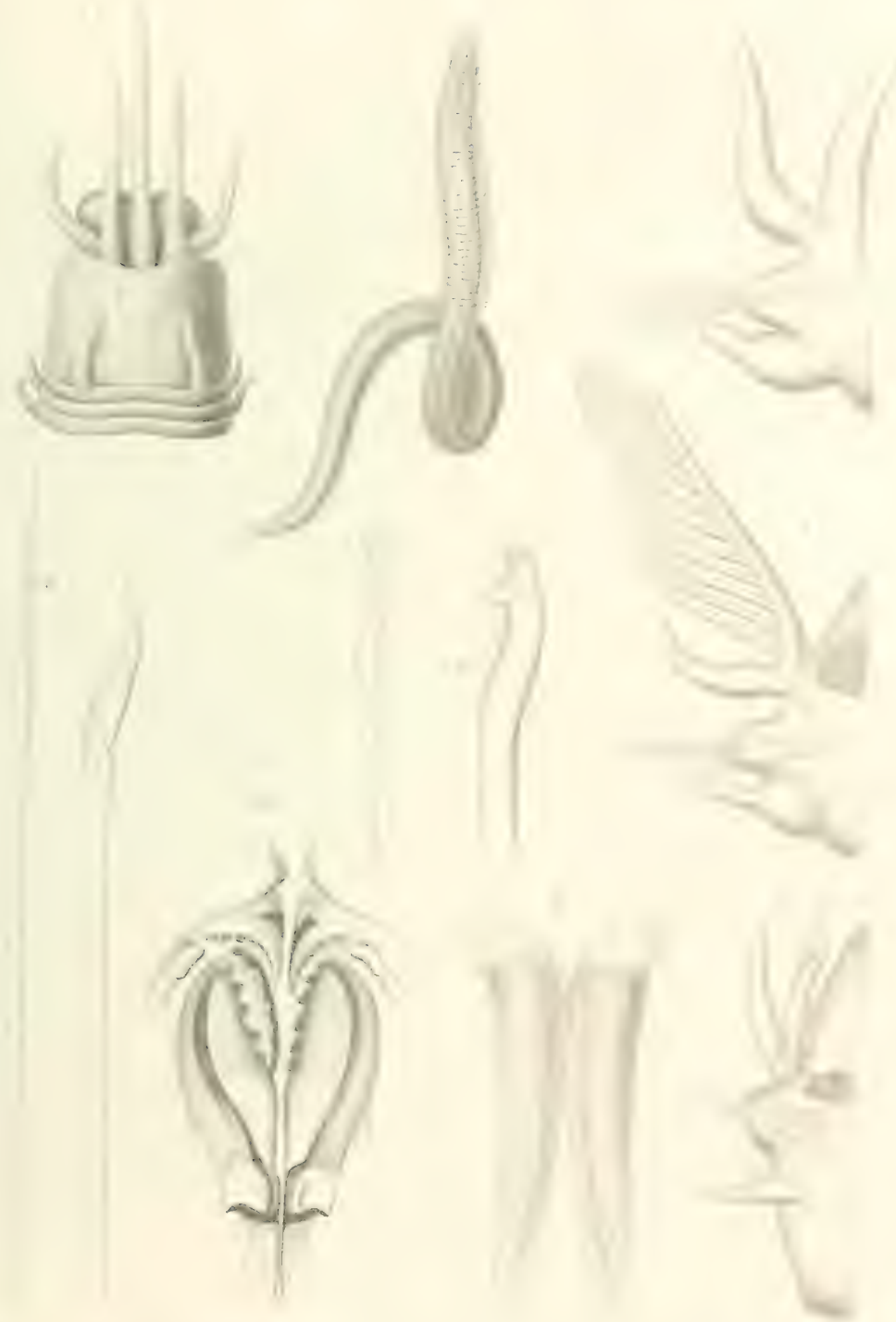


TAFEL 27.

$\because \therefore$ 1. Eunice tibinna (Pourt.). Tordere Kürperstrecke. Vergr. 7.

!. : ‥ liöhre des Wurmes, welcher aus einer der scitlichen Oeffnungen hervorragt. Natiirliche Grösse.

1. . : : Eine Strecke der Röhre, um die Zipfel der Seitenöffnungen zu zeigen.

I. : 4. Eine andere Rülıre mit einer kaum gerrundenen Strecke. Natürliche Grösse.

$1 .$. i. Zwölftes

1. $\therefore$ i. Zwei und dreissigstes

I. $\therefore$. Einhundert nem und dreissigstes

I. : \&. Zusammengesetzte Borste des unteren Bündel. Vergr. 450.

IY: $\because$ Meisselborsten. Vergr. 450 .

I!: 1.. Stütznadeln aus den hinteren Rudern. Vergr. 450.

I: : 11. Capillarborsten aus den hinteren Rudern. Vergr. 450.

T!: 1:. Oberkiefer. Vergr. 26.

Fi: 1?. Unterkiefer. Vergr. 26 . 


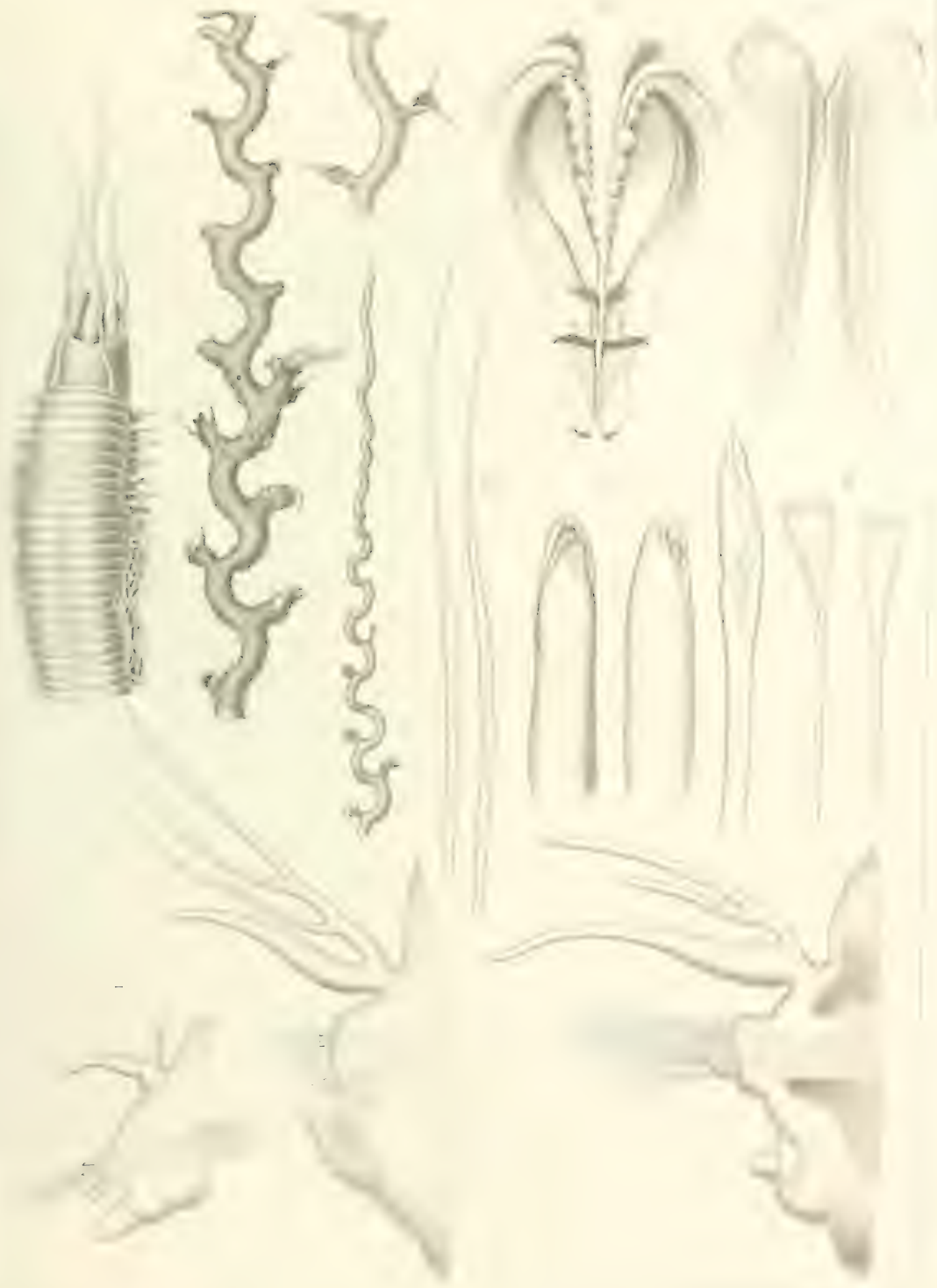






\section{TAFEL, 28.}

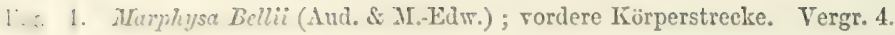

$1 \%$ : Vorderes

I: : : Kiementragendes Ruder. Vergr. 45.

I:s. Hinteres

I $\therefore$. Z Zusammengesetzte Borste. Vergr. 480 .

li: i. Capillarborste. Vergr. 480.

I $:$ i. Oberkiefer. Vergr. 28.

lis. Unterkiefer. Vergr. 28.

lis. !. Vicilion breris n. sp. Tergr. 2, 5.

I: $;$ 111. Torderstrecke des Wurmes mit schrïg nach aufwïrts gewendeter Ventralflïche. Vergr. 5 .

I: 11 . Kopflappen und vordere Segmente; Rückenfläche. Vergr. 6.

Y: $1:$.: Vorderes Ruder. Vergr. 110.

Vis. 1:3, Hinteres Ruder, Vergr. 110.

Fir. 11. Zusammengesetzte Borste. Vergr. 950. 


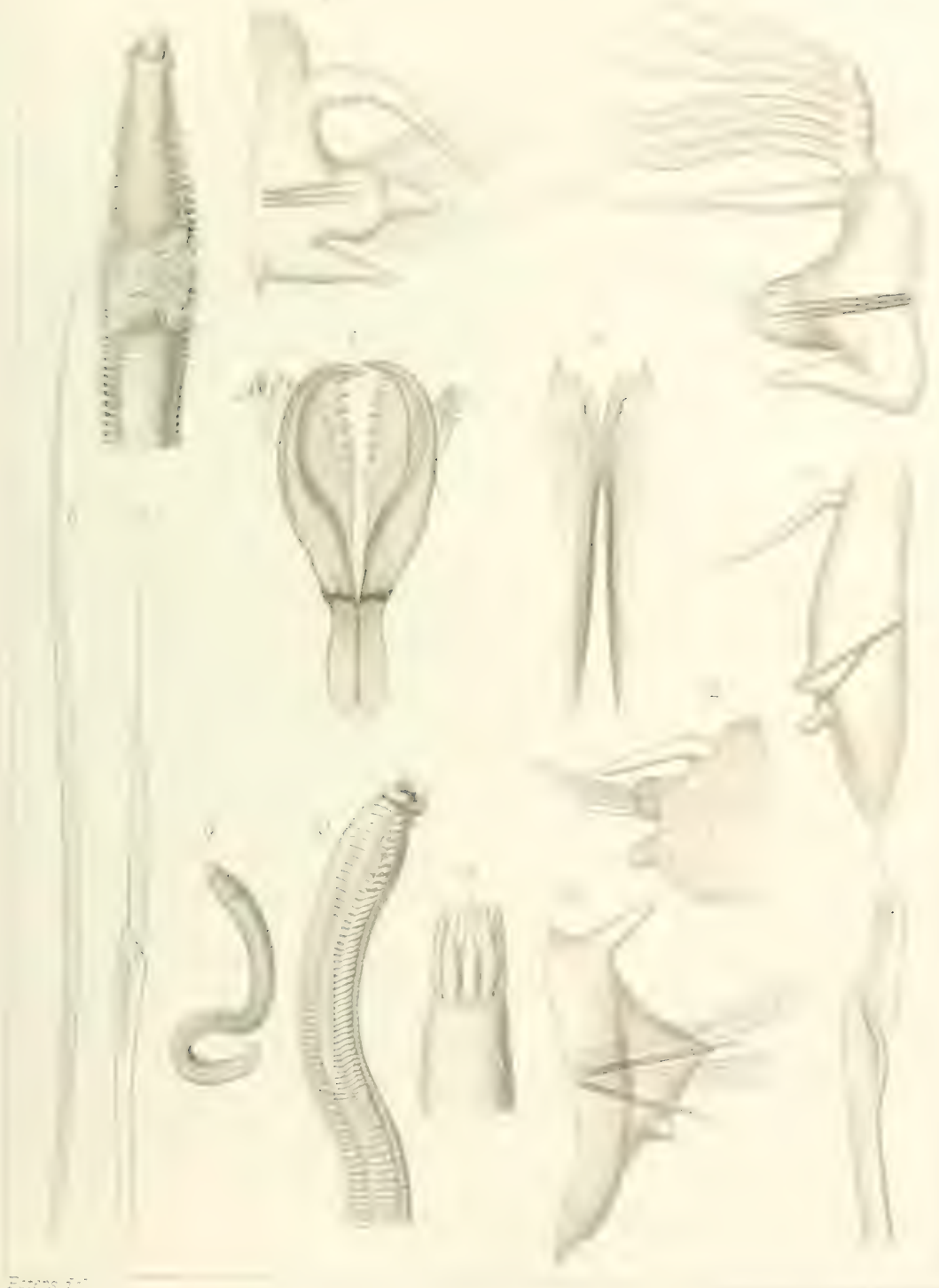



TAFEL 29.

: : 1. Nicillion breris n. sp. Oberkiefer; das zur linken Seite vereinzelt liegende Stück ist die dorsale l'latte am Eingange des Kiefersackes. Vergr. 47.

"' : 2. Unterkiefer, in Terbindung mit der chitinösen, den Kiefersack auskleidenden Membran. Tergr. 17.

I: : A. Paramarphy/sa longula n, sp. Vergr. 17.

1. : 1. Kopflappen und vordere Segmente des Wurmes; etwas schriig gelegt. Vergr. S0.

$\left.\begin{array}{l}\text { I: } \therefore \text { V. Vorderes } \\ \text { 1. } \therefore \text { i. Ilinteres }\end{array}\right\}$ Ruder. Vergr. 140 .

I: $\therefore$ ¡. Zusammengesetzte Borste aus den vorderen Rudern. Vergr. 935.

I. . s. Zusammengesetzte Borste aus den hinteren Rudern. Vergr. 816.

I: : !. Meisselborste aus dem oberen Bündel. Vergr. 720.

I'. 11). Oberkiefer. Vergr, 51 .

Ti.. 11. Unterkiefer; dorsale Fläche. Vergr. 51.

I $i:$ 1:. Vorderstück desselben; ventrale Fläche. Vergr. 51. 


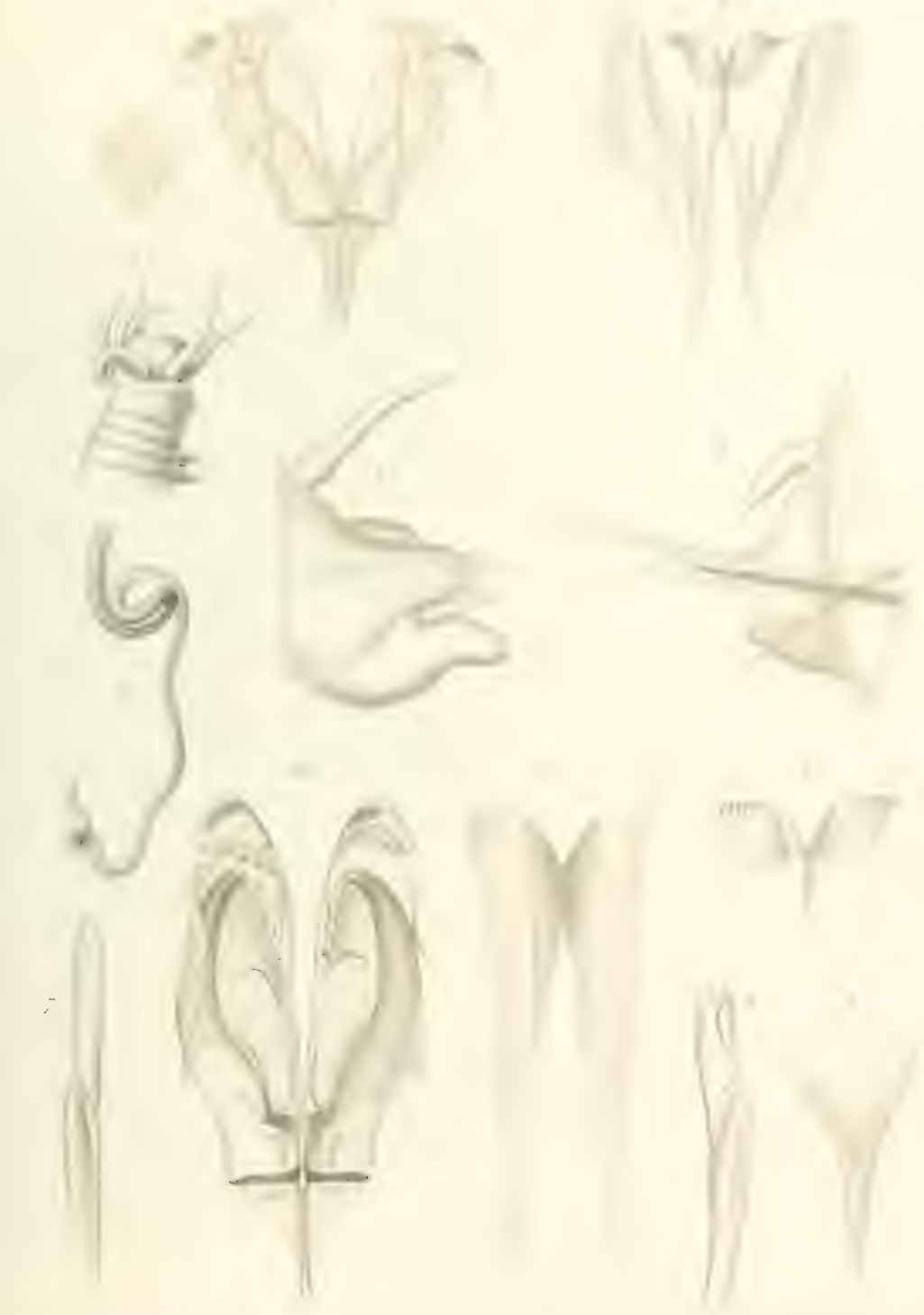




TAFEL 30.

1. I. Lysidice notutu n. sp. ; Profilstcllung; Kopflappen und Füller zum Theil eingezo:men. Tergr. 26.

4. .. Tordere Kürperstrecke eines anderen Exemplares, vom Rücken gesehen. Vergr. 15.

1. Limler ans der hinteren Kürperstrecke. Vergr. 120.

1. S. Silitze der Stützmadel des unteren Borstenbündels. Vergr. 660.

1.1. $\therefore$ Zusammengesetzte Borste des unteren Buindels. Vergr. 660 .

1. . Stutznadel des oberen Buindels. Tergr. 660.

$\because i \therefore$. Capillarborste des oberen Bündels. Vergr. 660 .

. $\checkmark$ Oberkiefer; die einzelnen Süge- und Reibplatten von einander verschoben, die linkseitige parige sügeplatte liegt isoliert und zeigt den langen Rand, mit wclchem sie nach hinten ausläuft. Vergr. 120.

1. . Unterkiefer : dorsale Niäche, nur die eine Hülfte ist ausgezeichnet. Vergr.120.

.1. Im Liviconereis foridana n. sp.; vordere Körperstrecke von der Bauchfliiche. Vergr. 15.

I.. . 11. Mittlere Körpersegmente. Vergr. 15.

. 12. Oborkiefer. Vergr. 30.

. I.:. Unterkiefer. Vergr. 30.

¿.1. Zusammengesetzte Borste der vorderen Ruder. Vergr. 280.

: . 1.). Einfache Hakenborste, welche in den hinteren Rudern die Stelle der in Fig. 14 gezeichneten einnimmt. Vergr. $2 S 0$. 


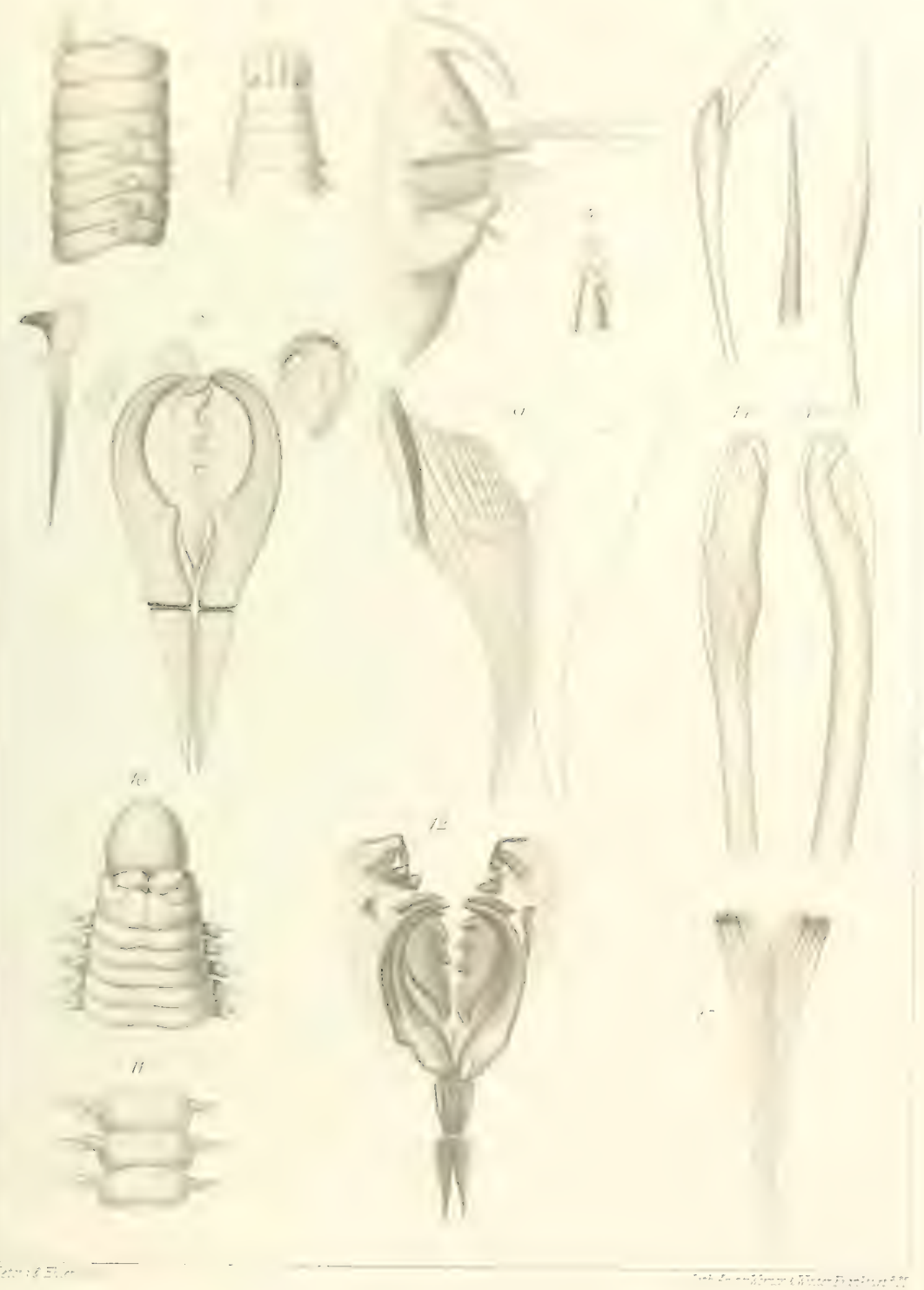




TAFEL, 31.

Fip. 1. Lumb̈riconcreis robusta n. sp.; vordero Kürperstrecke und mittlere Kürpersegmente; lïickentlitiche. Vergr. 1, כ.

Fie. ‥ Oberkiefer; rechte II:ilfte. Vergr. 17.

Fig. 3. Unterkiefer; Ventrallikiche. Vergr. 17.

Fig. 4. liuder der vorleren Kü̈perstrecke. Vergr. 35.

Fig. 5. Capillarborste. Vergr. 250.

Iiz. 6. Gesiumte Itakenborste der hinteren Iiuder. Vergr. 500.

Hig. T. Lumbriconereis bidens n. sp.; Profilstellung; die Kü̈kenfliche der vorderen Segmente ist stark aufgetrieben, der Kopflappen abgeplattet. Vergr. 7.

Fig. S. Tordere Kürperstrecke eines anderen Exemplares, vom Rücken. Vergr. 11.

Fig. 9. Dasselbe von der Bauchfläche. Tergr. 11.

Vig. 10. Iuter der vorderen Iï̈rperstrecke. Vergr. 40.

Fì. 11. liuder der hinteren Kürperstrecke. Vergr. 40.

Fig. 12. Capillarborste der vorderen Ruder. Vergr. 400.

Fig. 1:3. Zusammengesetzte Borste der vorderen Ruder; auf die Schneide des Endgliedes gesehen. Tergr. $6 \pi 0$.

Fig. 11. Hakenborste der hinteren Ruder. Vergr. 670:

Niq. 15. Oberkiefer; die Zangen und die nur zweizinkigen Zähne aufwärts mit den Schneiden gewendet. Vergr. 16.

Fig. 16. Unterkicfer; Ventralfl̈iche. Vergr. 16.

Hig. 17. Derselbe; Dorsalfläche. Vergr. 16. 


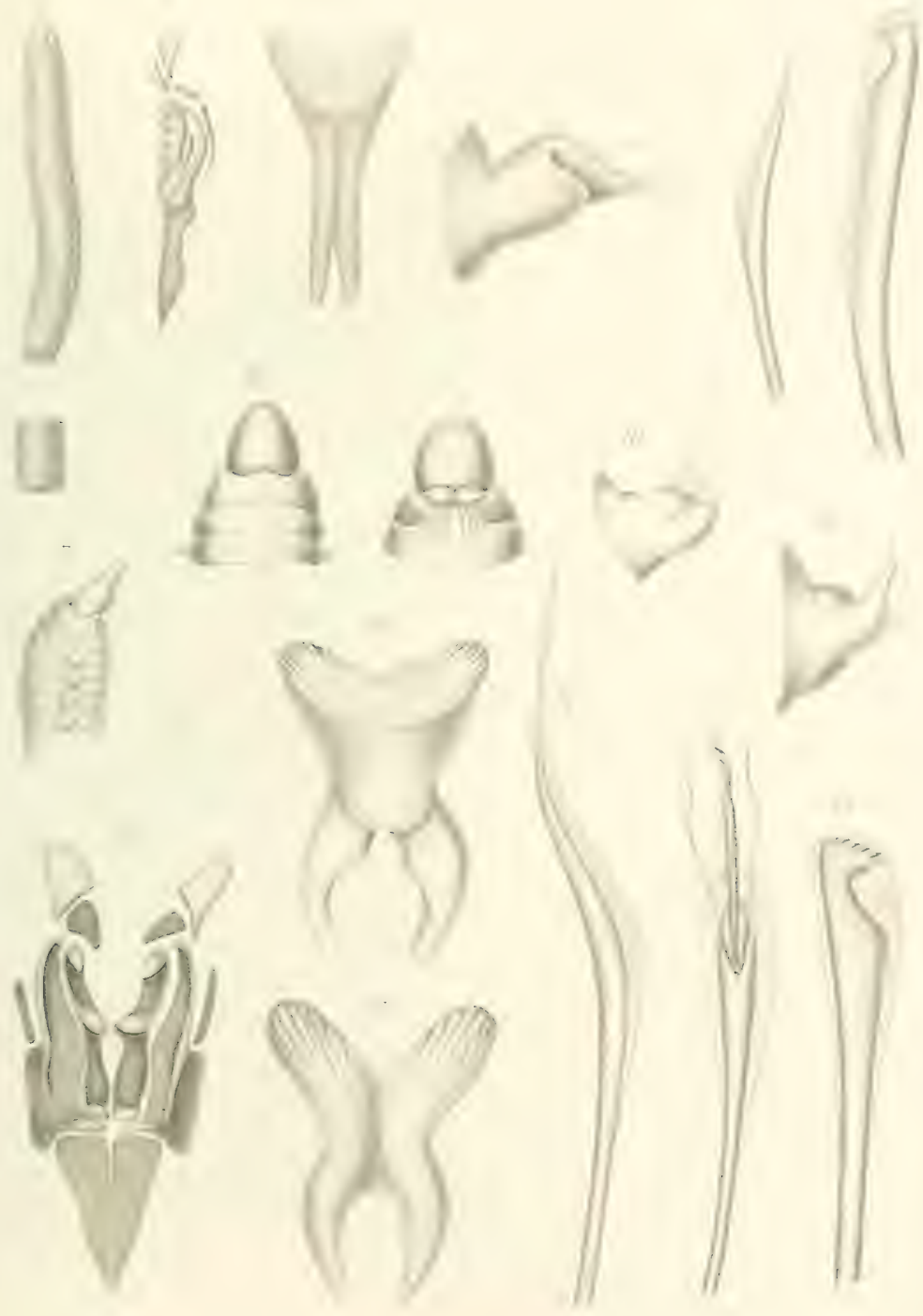




TAFEL 32.

1. . 1. Ninoe Kinlergi n. sp.; Vordere Kürperstrecke, lie linke Seite etwas gehoben. Vergr. 15.

$1 \ldots 2$. Fiopflappen und crste Segmente mit durchscheinenden Nackenwülsten Dorsalthiiche. Vergr. 25 .

I. $\therefore$. Ventralfäiche der vorderen Sermente und des Kopflappens. Vergr. 25.

1. ․ 1. Zranzigstes Iiuder; Vorderfliche. Vergr. 120.

I $\therefore$. Fünfzigstes liuder; hintere Flïche. Vergr. 120.

1\% : 1. Stumpe Borsten mit zweizälnuiger Spitze. Vergr. 460.

1. : $:$. Dieselbe ron der Selneide. Vergr. 460.

I: $\therefore$. Oberkiefer. Vergr. 85 .

I: $:$ Unterkiefer. Vergr. S5. 

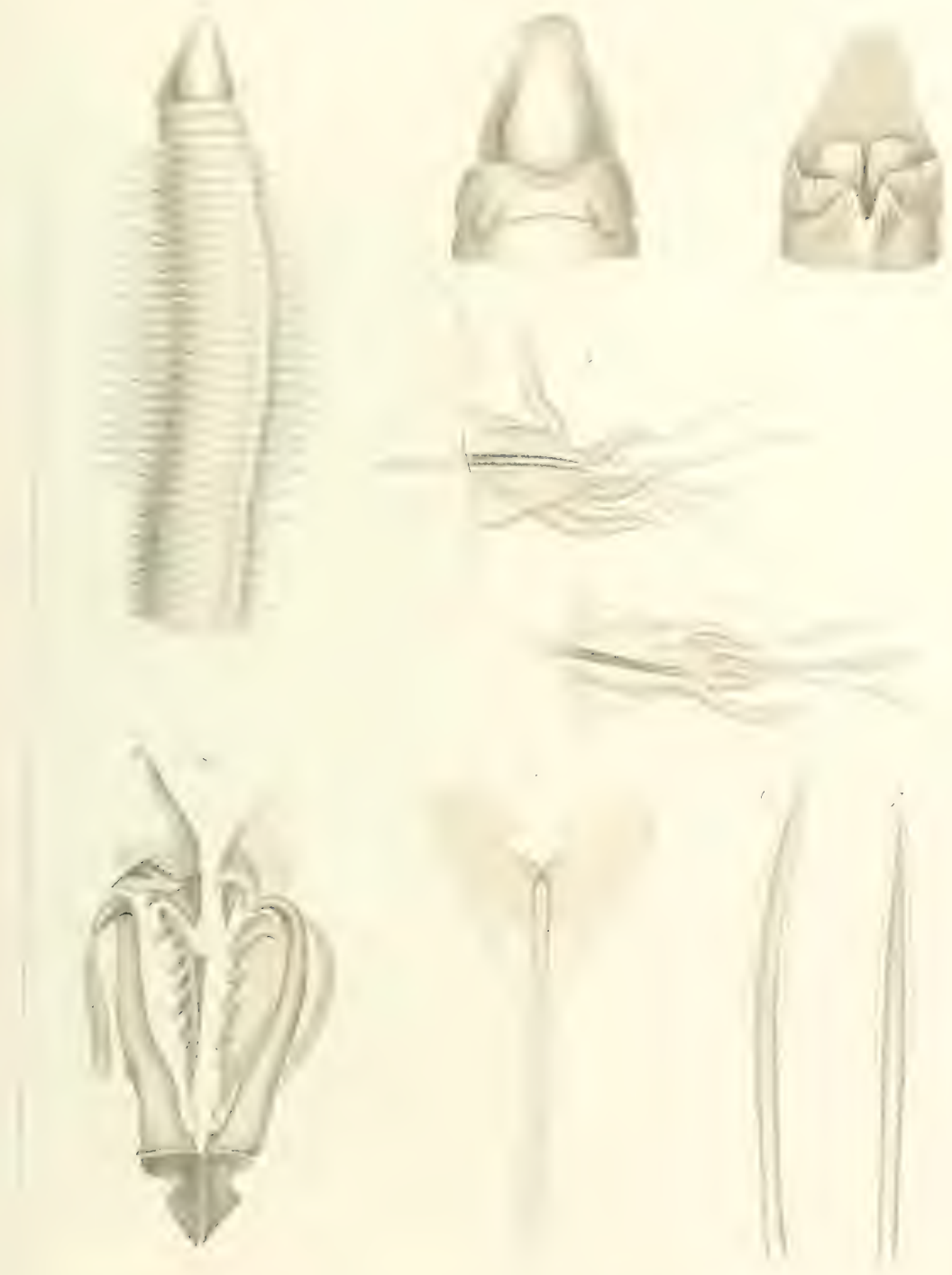

Exters EiT: 


TAFEL 33.

Fig. 1. Iysarcte brasiliensis (Kinberg); vordere Körperstrecke. Vergr. 3.

Fig. 2. Ventralfiiche des Kopfendes. Vergr. 3.

Fig. 3. Mittlere Körpersegmente; Dorsalfäche. Vergr. 3.

Fig. 4. "Sechs und zwanzigstes Ruder. Vergr. 10.

Fig. 5. Zweihundert zwei und fünfzigstes Ruder. Vergr. 10.

Fig. 6. Oberkiefer. Vergr. 15.

Fig. 7. Unterkiefer; Ventralfäche. Vergr. 15.

Fig. 8. Unterkiefer; Dorsalfläche. Vergr. 15. 


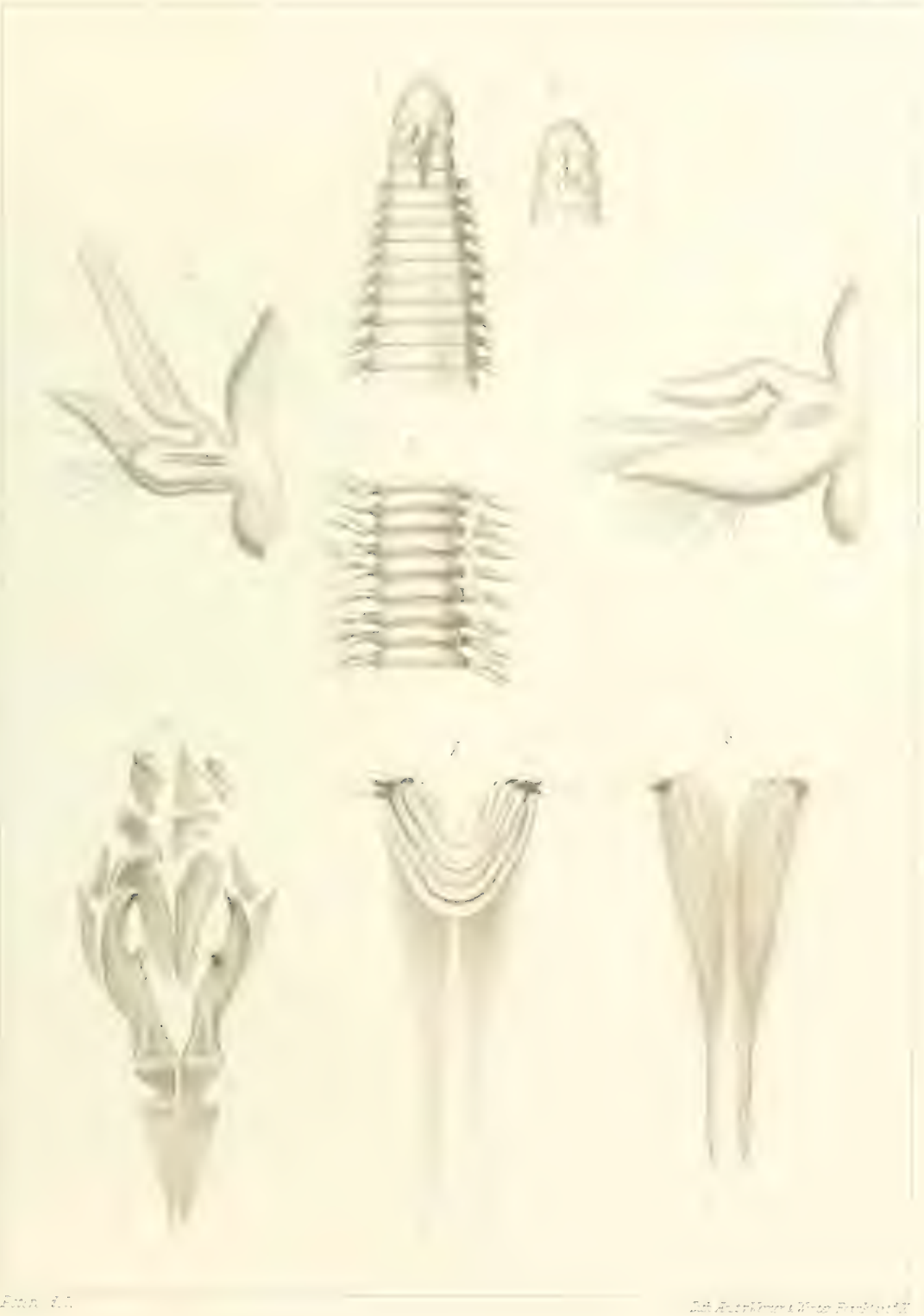



TAEEL 34 .

Fig. 1. Oenone diphyllidia (Schmarda). Vergr. 1, 6.

Iig. 2. Tordere Iürperstrecke, Rückenflïche. Tergr. 5.

lịg. 3. Kopfende mit theilweise ausgestülptem Rüssel, Vergr. 5.

Iig. 1. Ein hundert sechs und sechszigstes Ruder. Vergr. 35.

Fig. 5. Spitze einer Borste des unteren Bündels. Vergr. 390.

Iï. 6. Oberkiefer. Vergr. 32.

Fig. 7. Unterkiefer. Vergr. 32. In Fig. 6 und 7 ist die glänzend schwarze Färbung der lieferstücke nicht wiedergegeben.

Fig. S. Aracoda multidentata ; vordere Körperstrecke, Rückenfläche. Vergr. 10.

Fig. 9. Tioptlappen und erste Segmente; Ventralflïche. Vergr. 10.

Fig. 10. Ruder. Vergr. 30. 

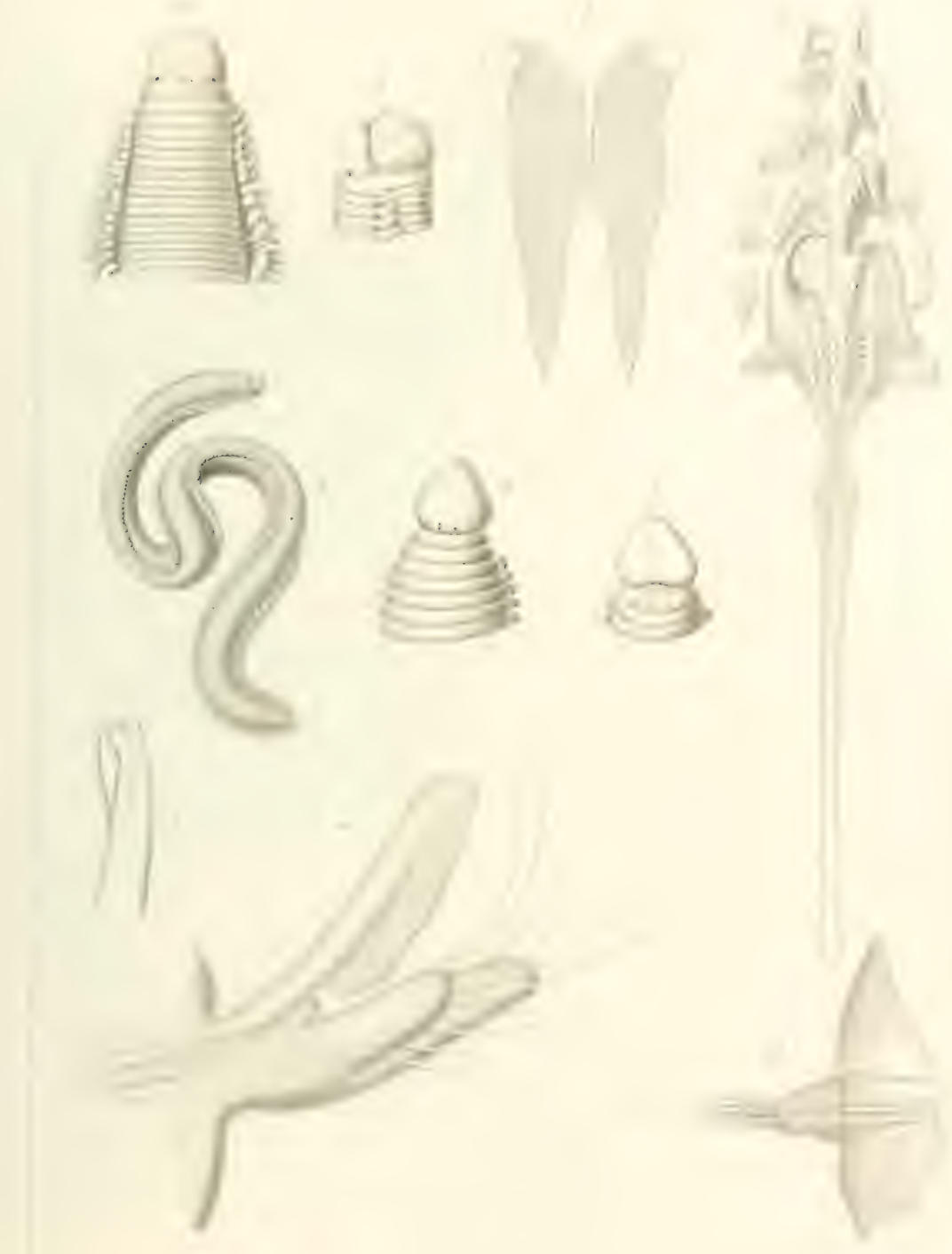

TAFEL 35.

Fig. 1. Arceoda multidentata n. sp.; Oberkiefer. Vergr. 100.

Iig. .. Unterkiefer desselben Wurmes. Vergr. 100.

Fig. 3. Capillarborsten. Vergr. 700.

Fig. 5. Aracodu debilis 11. sp.; Kopfende in Profilstellung; die Rüsselröhre etras ausgestreckt. Vergr. 14, 5.

Fig. 6. Ein Ruder des Wurmes mit den Borsten. Vergr. 110.

Fig. 7 . Oberkiefer des Wurmes; unter dem vorderen Theile der stabförmigen Träger die plattenartige Verdickung in der Chitinauskleidung des Kiefersackes. Vergr. 72.

Fig. 8. Unterkiefer des Wurmes. Vergr. 72. 

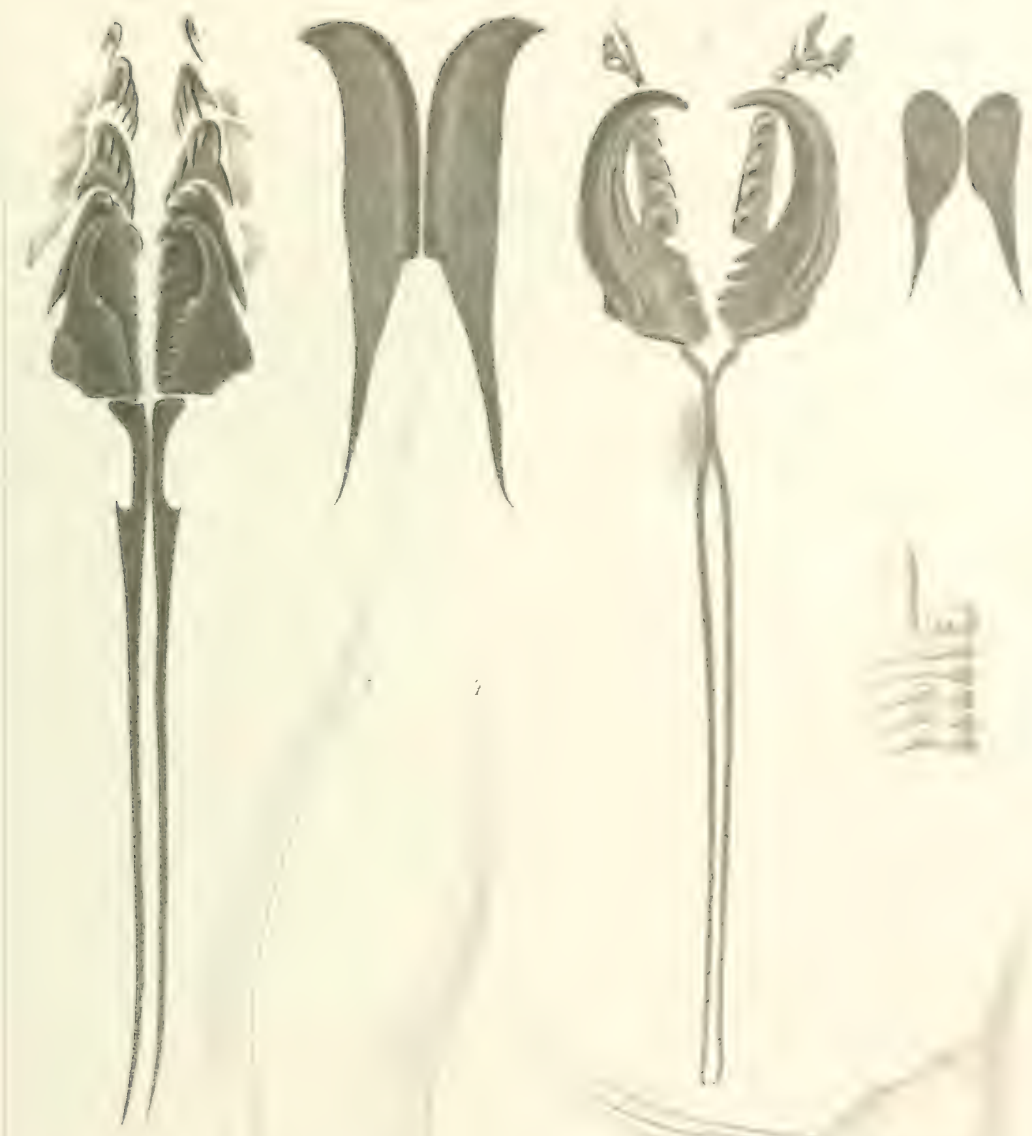

. 
TAFEL 36.

Fig. 1. Aereis articulata n. sp.; vordere Körperstrecke; jederseits fehlt ein Fühlercirrus. Vergr. 45 .

Fig. :2. Ruler. Vergr. 94.

Fig. 3. Sichelborste. Vergr. 710.

Fiø. 4. Gritenborste. Vergr. 710.

Fig. 5. Nercis versipedata n. sp.; vordere Körperstrecke mit vorgestülptem Rüssel. Vergr. 16.

Fig. 6. Rüssel von der Ventralflïche. Vergr. 16.

Fig. 7. Zwölftes

Fig. 8. Sechs und dreissigstes $\}$ Ruder. Vergr. 56.

Fig. 9. Sichelborste. Vergr. 780 .

Fig. 10. Grätenborste. Vergr. 780 . 


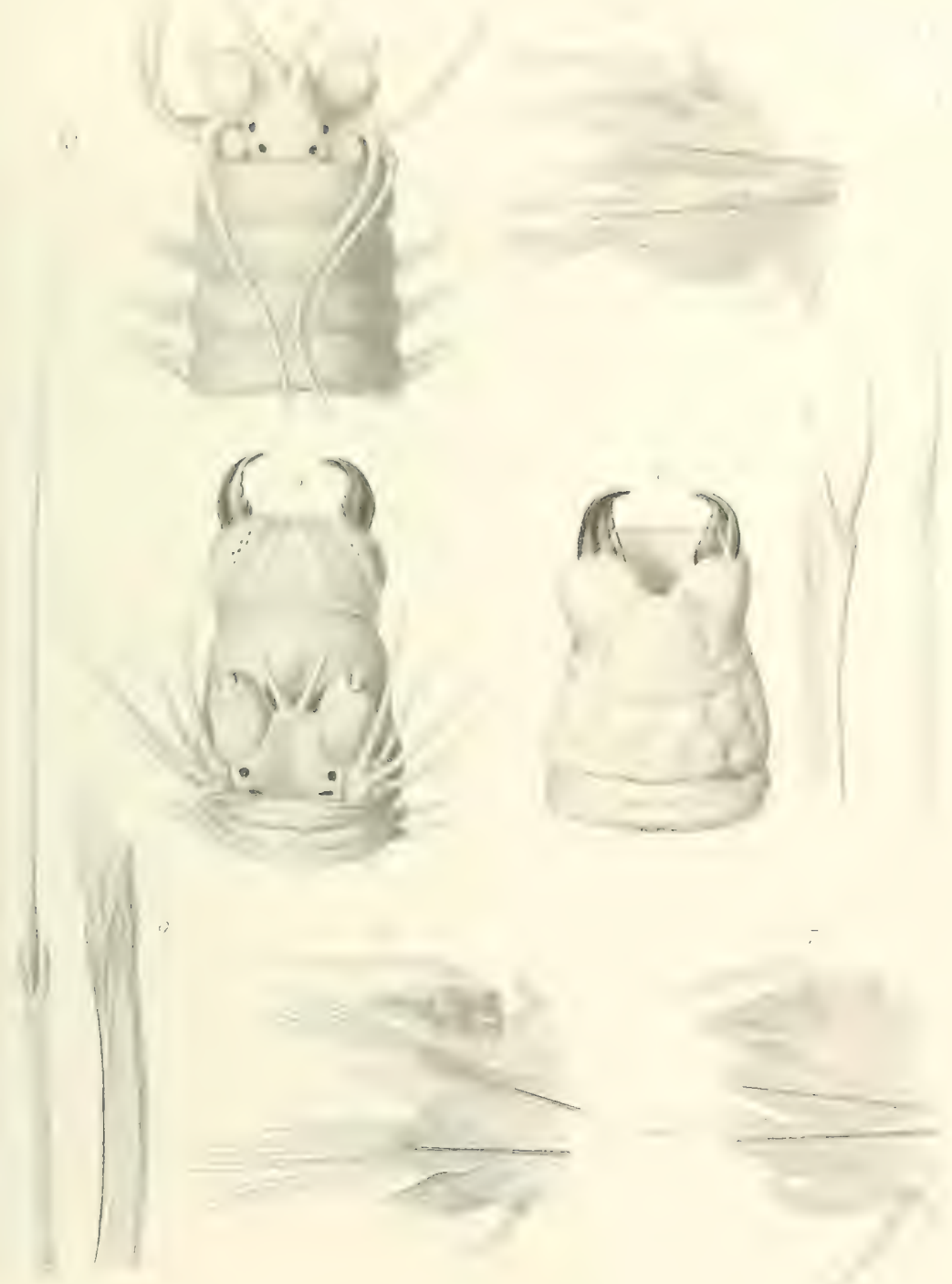






\section{TAFEL 37.}

I’. 1. Tereis miralilis (Kinberg); vordere Körperstrecke. Vergr. 18.

1.: ‥ Vier und rierzigstes Iiuder. Vergr. 30.

1... : Sichelborste. Tergr. 640.

I: : 1. Griitenborste. Vergr. 610.

I: $\therefore$. Tüssel, ventrale Fliiche. Vergr. 12.

I. $\therefore$ Iiüssel, dorsale Flïche. Vergr. 12.

1: : .. Tephthys squamosa n. sp.; vordere Kürperstrecke. Vergr. 16.

I: : $\therefore$ Iiuder, vordere Fliiche. Vergr, 40.

I: $:$ :! Einfache Borste. Vergr. 410.

Fis. 11. Feilkerbige Borste von der gerippten Fläche und im Profil. Vergr. 410. 


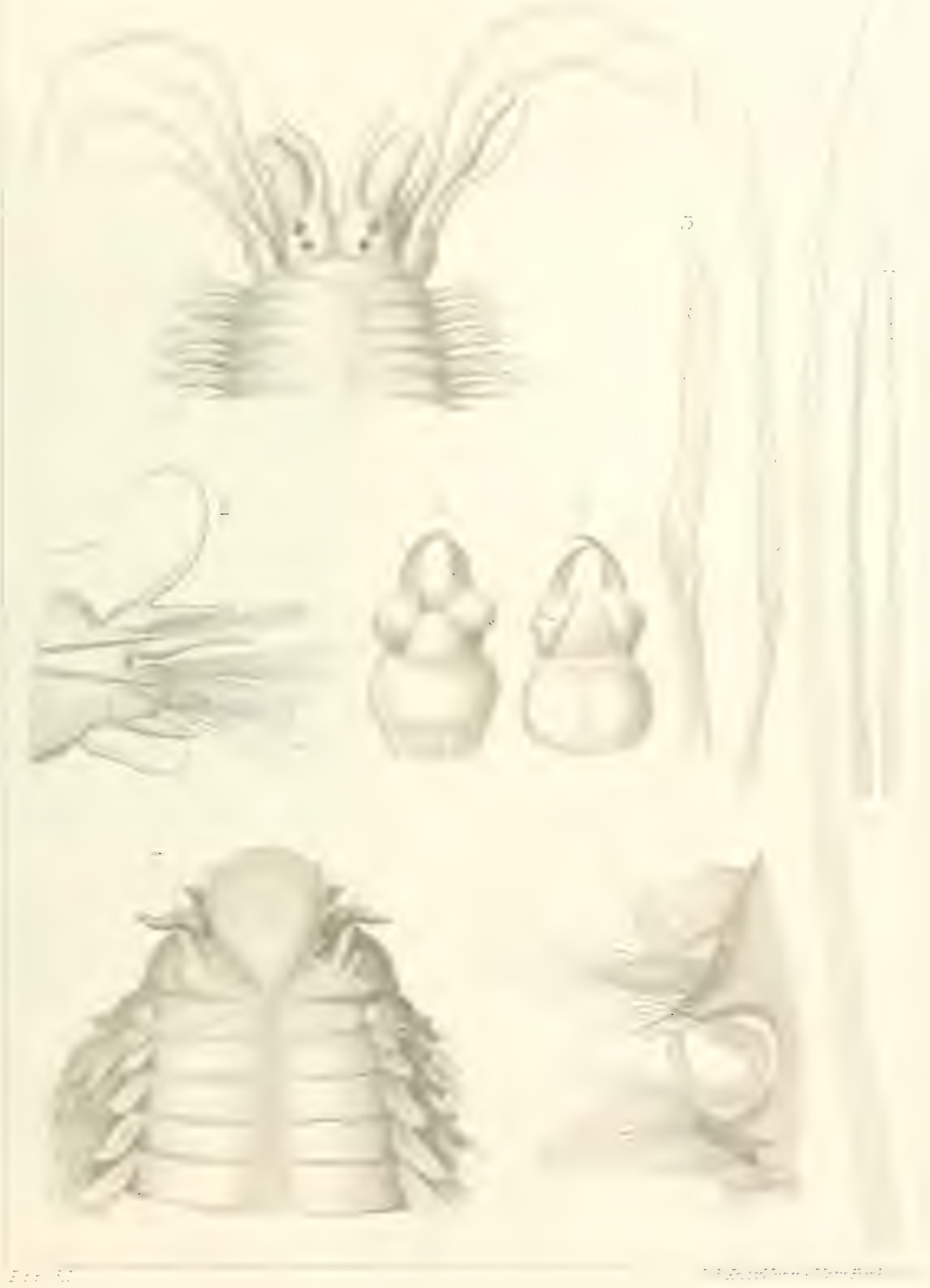



TAFEL 38.

Fig. 1. Wiphthys inemis n. sp.; Tordertheil des Körpers mit ausgestrecktem Rüssel. Vergr. 26 .

Fig. 2. Hinteres Tï̈perende. Vergr. 26.

Fig. 3. Fünf und neunzigstes $\{$ Ruder. Vergr. 45.

Fig. 5. Einfache Borste. Vergr. 5 S0.

Fig. 6. Leierförmige Borste. Vergr. 5s0.

Fig. 7. Tephthys phyllocirra n. sp.; rordere Körperstrecke; Rückenfläche. Vergr. 25.

Wig. S. Dieselbe; Ventralfliiche. Vergr. 25.

Iig. 9. Ruder, hintere Flïche. Vergr. 50.

Fig. 10. Gekerbte Borste des oberen Ruderastes. Vergr. 250.

Fig. 11. Einfache Capillarborste; der feine Härchenbesatz ist bei dieser Vergrösserung nicht zu erkennen. Vergr. 250. 


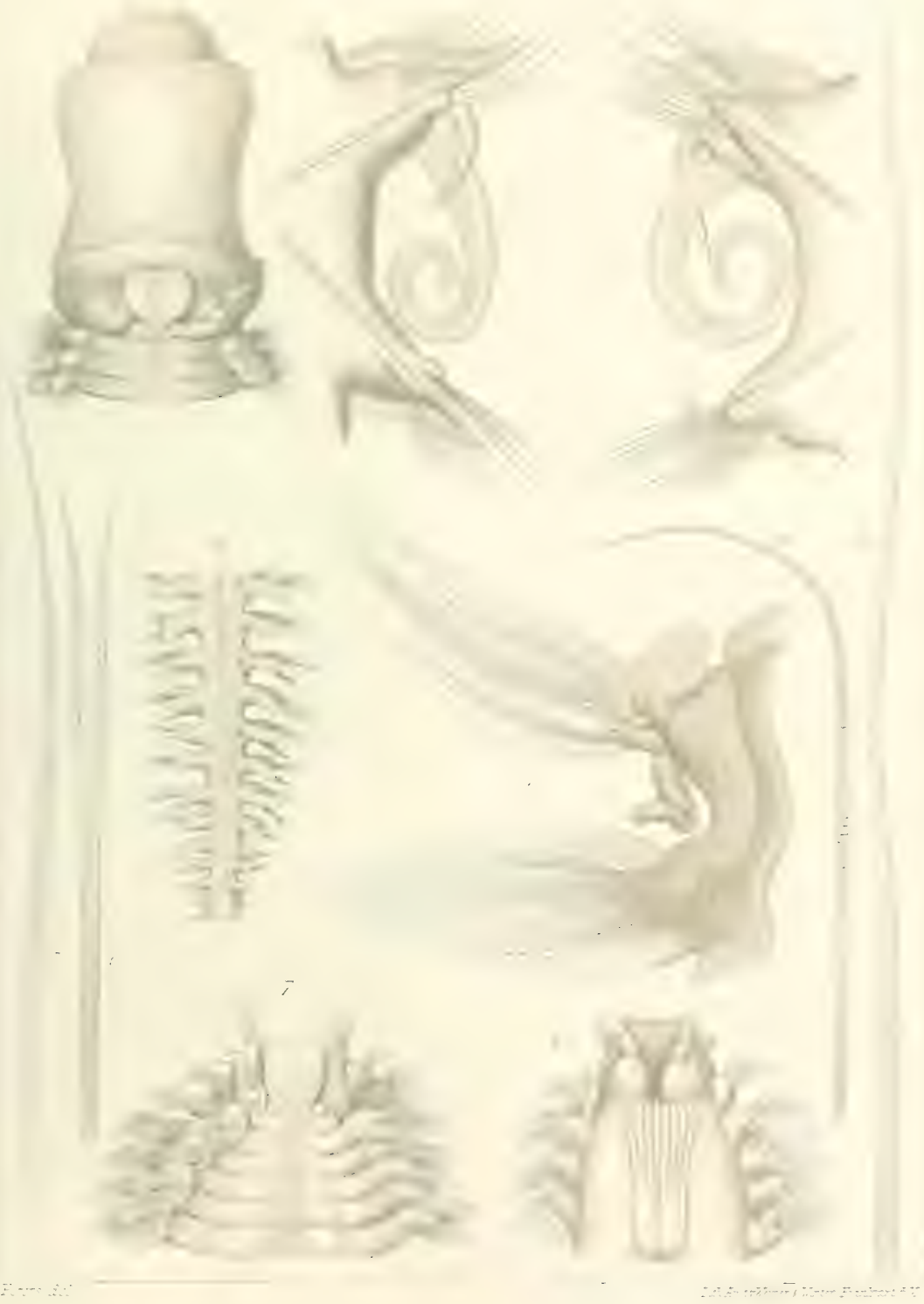



'TAFEL 39.

Iig. 1. Branchiosyllis oculata n. gen. 1. sp.; vordere Körperstrecke, Rückenflüche. Vergr. 20.

Fig.:- Dieselbe; Ventralflïche. Vergr. 20.

Fig. :). Die vordere Körperstrecke, an welcher die ventrale Körperwandung mit einem seitlichen Liingsschnitt durchschnitten, und nach links umgeschlagen ist; damit ist die rentrale Flïche der vorderen Strecke des Darmrohres freigelegt. Vergr. 20.

I: _. 4. Rückenfliche der rorderen Strecke des Darmrohres. Vergr. 20.

I: . . ป. Ruder mit dem Seitentheile des Kö̈rperumfanges; vordere Fläche. Vergr. 60.

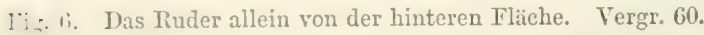

$I \because$. . 7. Borsten, bei zweien ist das Endglied ausgebrochen. Vergr. 540. 

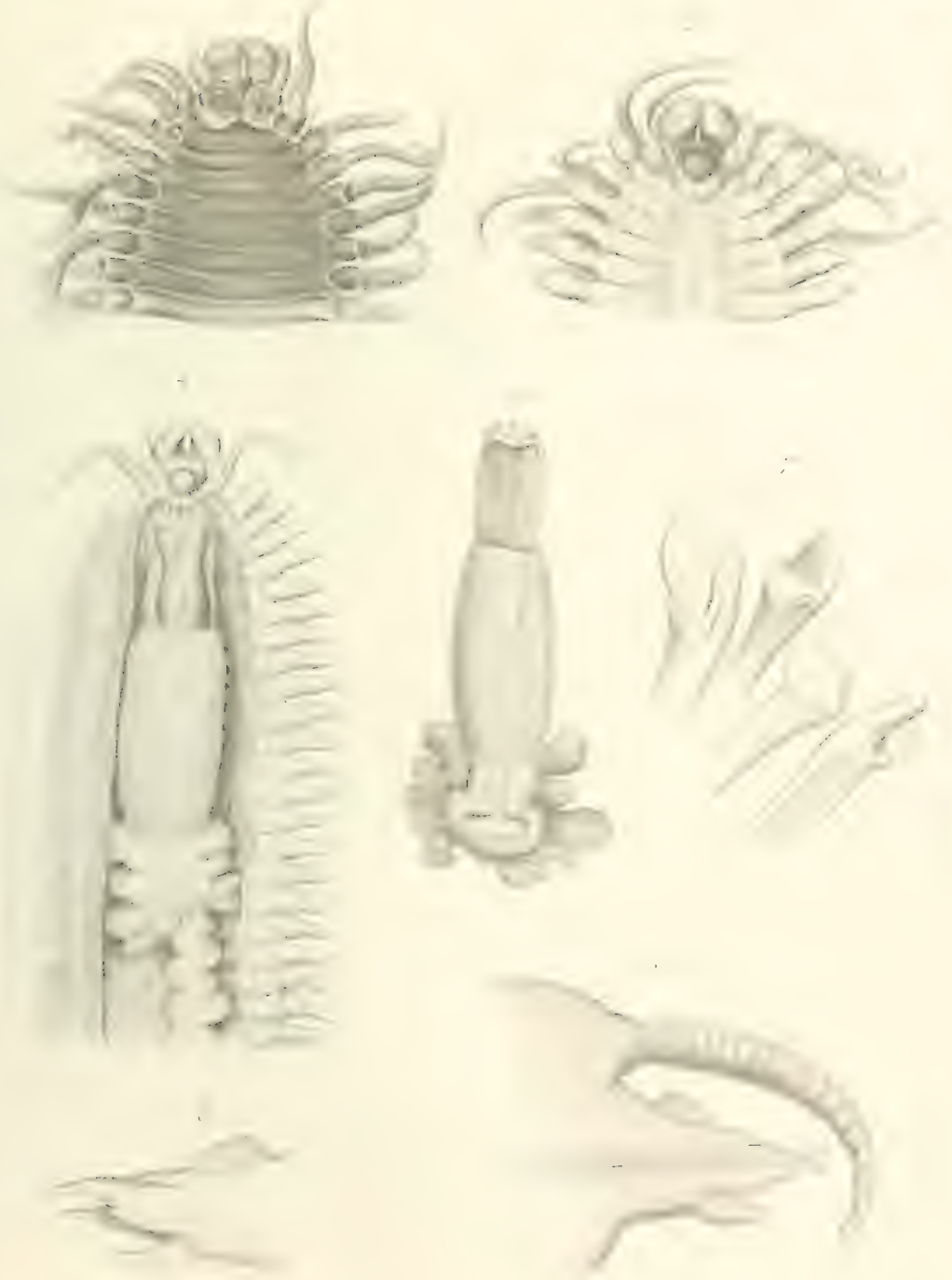


TAFEL 40.

1:- 1. Trypanosyllis vittigera n. sp.; vordere Körperstrecke. Vergr. 12.

I:_.: :- Iinder. Vergr. 20.

I:...... Borste. Vergr. 400.

I: . I. I'hyllodoce oculata n. sp.; vordere Körperstrecke. Vergr. 18.

I: $\therefore$. Iiuder, Vergr. SO.

I: .. 1i. Borste in der Seitenlage und Gelenkende einer Borste von der Ruickenfläche. Vergr. 400.

Iソ.. -. Phyllodoce papillosa n. sp.; vordere Körperstrecke, Rückenflïche. Vergr. 11.

$1 \because \ldots$ Iiuder. Vergr. 45 .

Ii : 9. Borste mit Eudglied rom Rücken, und Gelenlsstück von der Seite. Vergr. 360. 


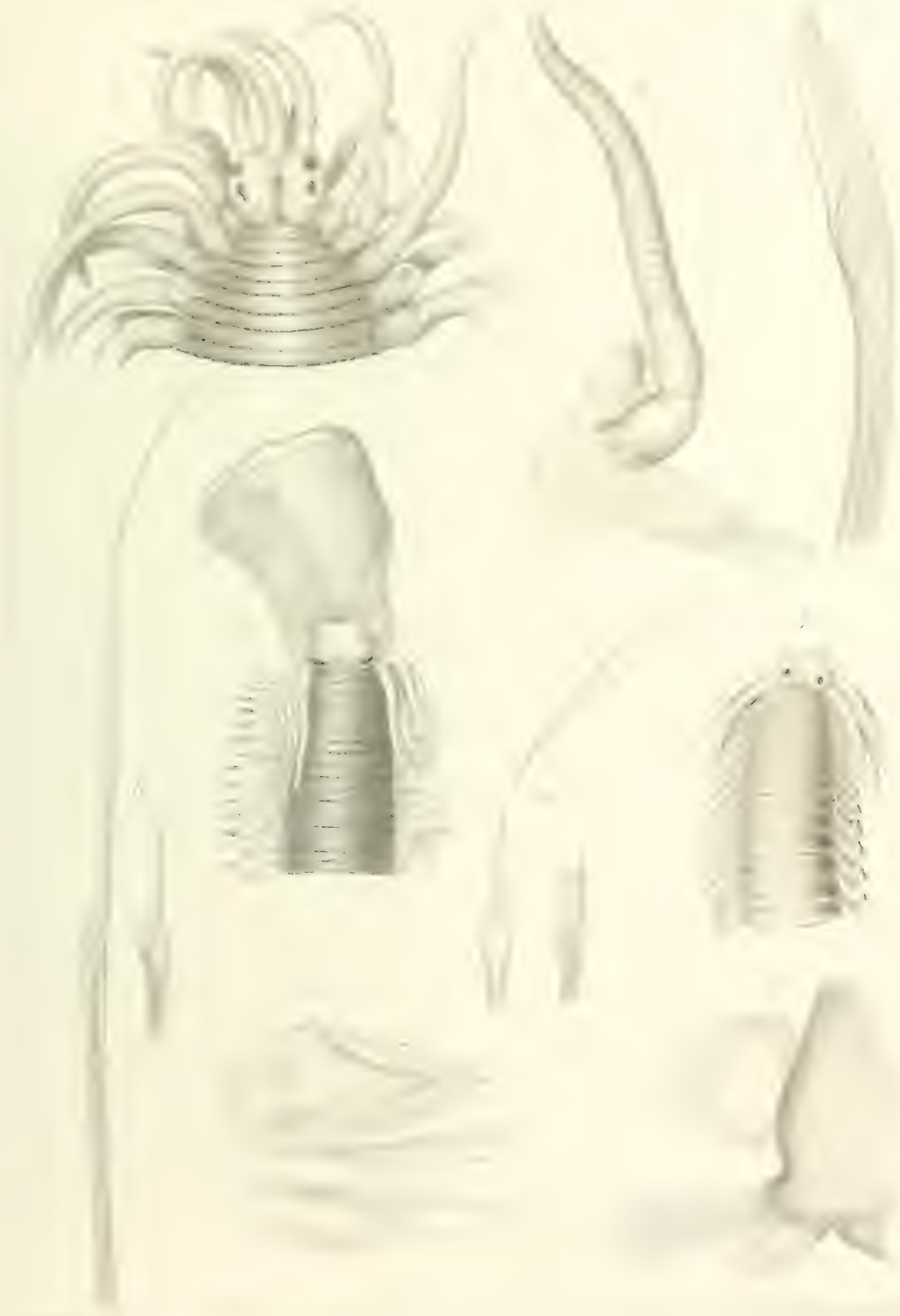



TAFEL 41.

Fig. 1. Tesione viltuta n. sp.; ganzes Thier mit etras forgestrecktem Rüssel rom Iiuicken. Vergr. 2.

Fig. 2. Torderende desselben Thieres. Vergr. 5.

Fig. 3. Ruder. Vergr. 15 .

Fig. 4. Borste. Vergr. 585 .

Fig. 5. IIesione praetexta n. sp.; liuder. Vergr, 15.

Fig. 6. Borste. Vergr. 480.

Fig. 7. Glycera oxycephlala n. sp. ; mit ausgestrecktem Rüssel in Seitenlage. Tergr. 16.

Fig. S. Torderende des Kiopflappens. Vergr. 120.

Fig. 9. Ruder. Vergx. 26.

Fig. 10. Borsten. Vergr. 400.

Fig. 11. Papillen der Rüsselröhre. Vergr. 270. 

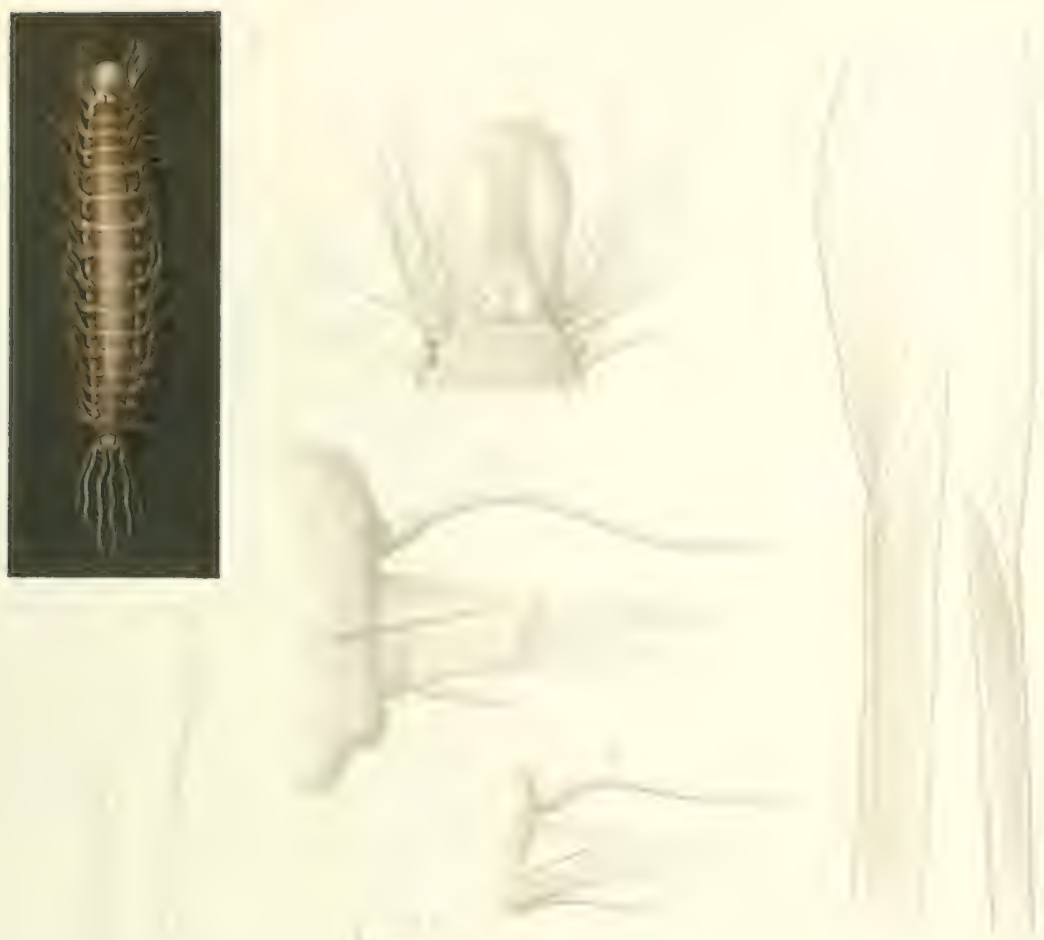




\section{'TAFEL 42.}

Tis. 1. Stylarioilles scutiger n. sp.; ganzes Thier in Seitenlage. Vergr. 3.

1: ..... Vordere Kürperstrecke des Wurmes von der Ventralflïche. Vergr. 10.

1:. 3. Dieselbe ron der Dorsalfliche, der linke lkand ettras gehoben. Vergr. 10.

Fig. 4. Dorsale Borsten. Vergr. 200.

F. . V. Ventrale Borsten der hinteren Körpersegmente. Vergr. 200.

Iig. 1. Siphonostomum cariboum Gr. ; in Seitenlage. Vergr. 5.

I: $;.$. Vorderes Körperende eines anderen Exemplares, bei welchem der Kopflappen mit Kiemenfäden und einem Tentakel ausgestreckt ist. Vergr. 15.

Fis. \&. Dasselbe von einem anderen Wurme, bei dem aur die Tentakel ausgestreckt sind; Profilstellung. Vergr. 20.

Fi. 9. Die fast rierkantige hintere Körperstrecke eines Wurmes, um die fast segmentale Vertheilung der fadenförmigen Papillen am dorsalen Borstenbündel, und die knopfartigen l'apillen neben den ventralen Borsten zu zeigen. Vergr. 30. 


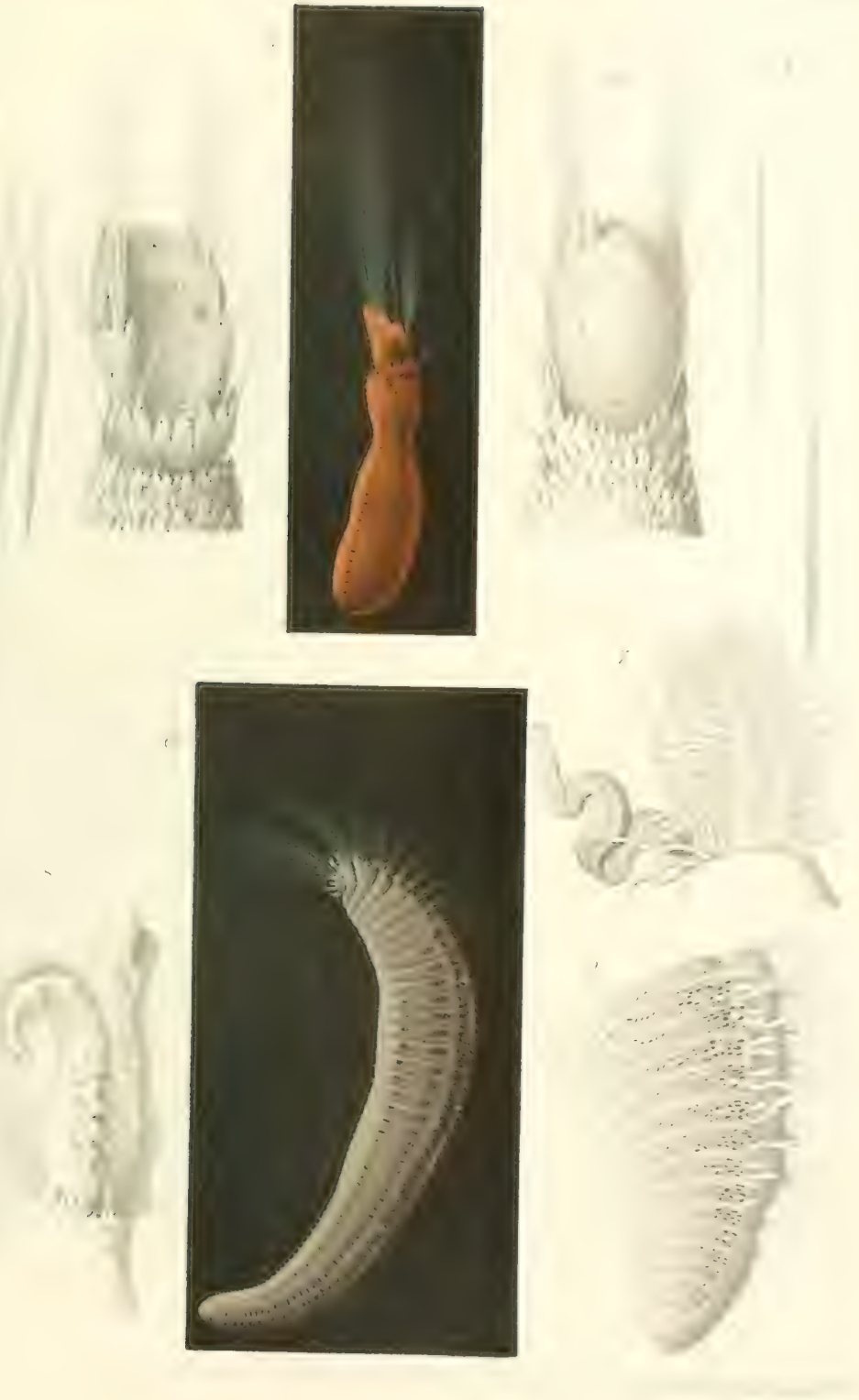



TAFEL 43.

I: . 1. Siphonostomum curiboum; rentrale Borstenreihe, daneben zwei der grösseren Papillen mit heller Eudhiiche, und unregelmässig vertheilt kleinere Papillen. Vergr. 203.

Tí:2. Stylarioides collurifer n. sp.; ganzes Thier von der Bauchfliche, Vergr, 7.

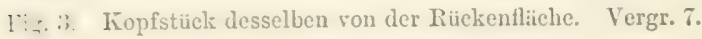

Fi. 1. Borste des dorsalen Buindels. Vergr. 166.

I: . 5. Borsten der ventralen Bundel; diejenige mit schwach hakenförmigem Endgliede im $\tilde{j}-7$ ten Segmente; die einfache daneben in den hinteren Segmenten. Vergr. 300.

li. f. Ein anderes Exemplar des Stylaroides collarifer, mit starker Schlamminerustirung und segimentaler Gliederung; von der Rückenfläche gesehen. Vergr. 7.

I i 6. Ein anderes Exemplar, weniger inerustirt; in P'rofilstellung. Vergr. 7. 

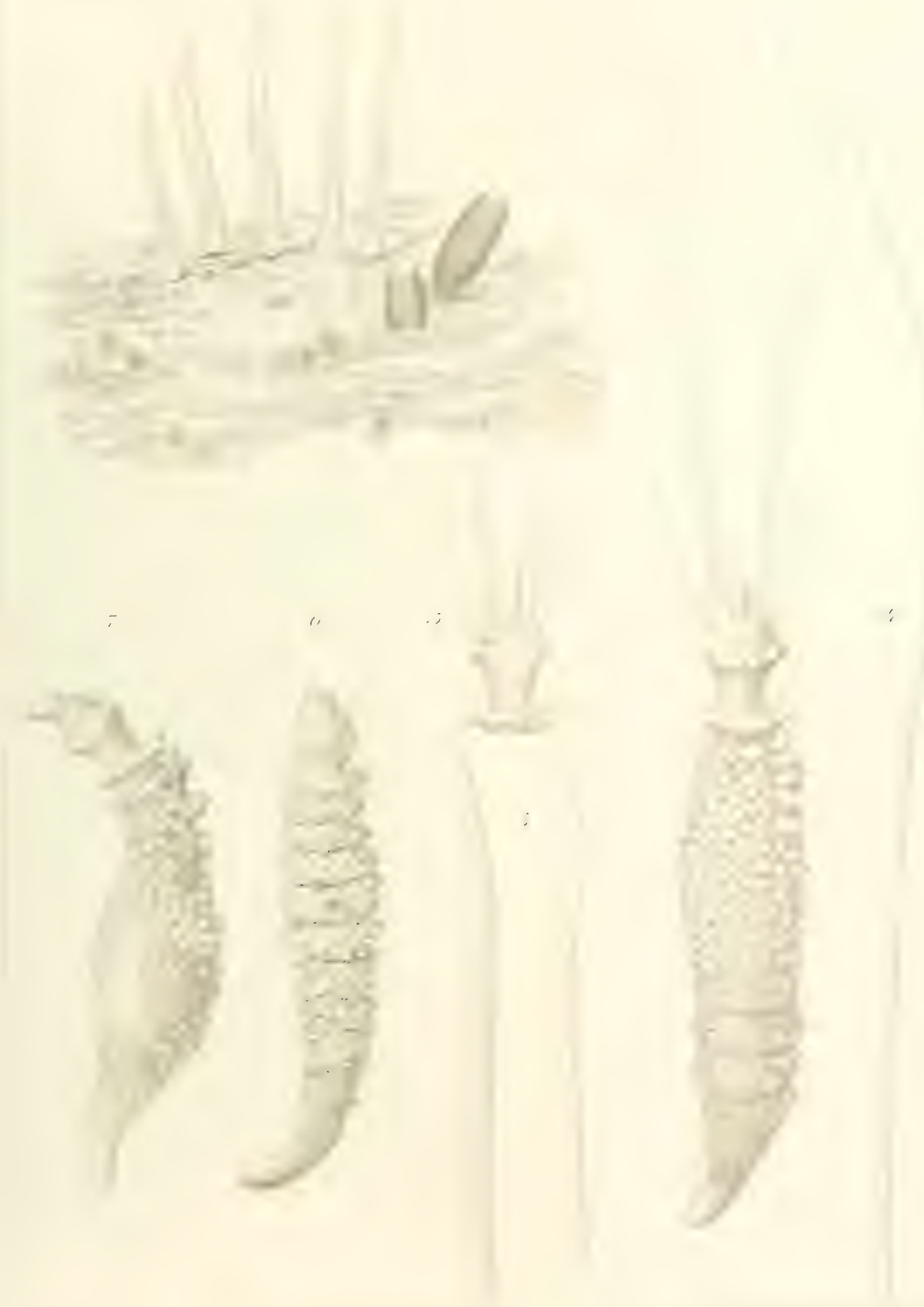

T.AFEL 4.

1. . 1. Pectinaria (Petta Mllmgr.) pellucida n. sp.; Thier vom Rücken gesehen. Vergr. 4.

I. . ... Das liopfstück des Wurmes von der Ventralfläche. Vergr. 10.

I: : : $:$ Dasselbe in Profilstellung. Vergr. 10.

I: $\therefore$ 4. Dasselbe rom liücken gesehen. Vergr. 10.

Fi. i. Das Hinterende des Wurmes. Vergr. 10.

Iir. (i. Dorsale Borsten. Vergr. 180.

Ii: - Haken in Seitenlage. Vergr. 900 .

Fi. s. Dieselben in Kantenstellung, Fig. $8^{\mathrm{a}}$ in Schrïgprofil. Vergr. 900.

I: : !. Rühre des Wurmes. Vergr, 1, 5 .

Iï. 11". Auchenoplax crinita n. sp.; Wurm vom Rücken gesehen. Vergr. 4.

I: _. 11. Vordere Iï̈rperstrecke desselben von der Ventralflüche. Vergr. 20.

T"... 1:. Dieselbe von der Dorsalfläche. Vergr. 20.

Ii.: 1:;. Dieselbe in Profilstellung. Vergr. 20.

Ii . 14. Hintere Segmente von der Rückenfläche. Vergr. 20.

Fig. 1J. Gesäumte Capillarborste aus den vorderen Segmenten. Vergr. 800.

Fis. 16. Haken in Profilstellung und von der Schneide gesehen. Vergr. 880. 


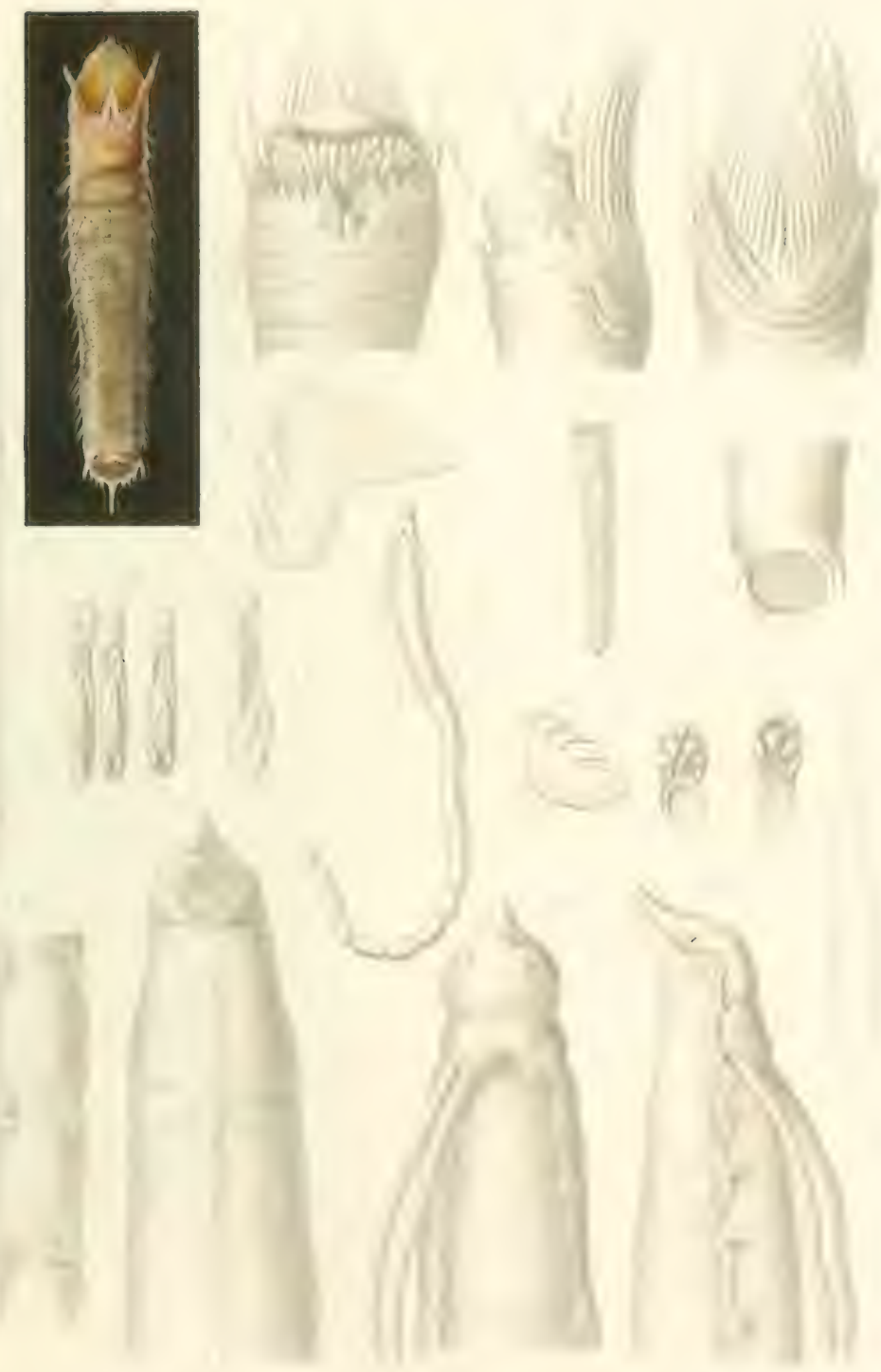




TAFEL 45.

r: . 1. Eumenic glubra $\mathrm{n}$, sp. ; ganzer Wurm in l'rofilstellung. Vergr. 1, 5.

1: :-2. Vordere Kürperstrecke von der Bauchfliche, das etwas gekrümmte Kopfende von rom gesehen. Vergr. 9.

I: . 3. Hintere Kürperstrecke, deren aus 6 Segmenten bestehendes Endstück anlangartig verduinnt ist, und die auf einem gefurchten Felde stehende Afteröfnung trïgt. Vergr, 9.

Yi . 4. Eine Capillar- und drei Gabelborsten. Vergr. 615.

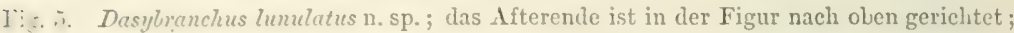
die vorlere Körperstrecke liegt derartig in Profilstellung; dass die Borstenbündel und die zwisehen diesen gelegene seichte Furche gesehen werden; die in der hinteren Kürperstrecke gezeichneten hellen Flecke stellen den durchschimmernden Darminhalt vor. Vergr. 5.

Fig. 1. Vordere Körperstrecke von rom gesehen und etwas nach links gewerdet; man sielnt von vorn auf den zum Theil in das Buccalsegment eingezogenen Kropflappen. Vergr. 20.

Ii _. . . Kopflappen im P'rofil, zum Theil eingezogen, mit dem Pigmentfleck. Vergr. 20.

I: . S. Ansicht der Bauchfliiche der hinteren Segmente, auf welchen dic Polster in der tiefen Medianfurche zusanmenstossen; am oberen Rande der Polster sind Kiemen ungleicher Bildung zum Theil ausgestreckt. Vergr. 25.

Fi s. ?. Gesäunte Capillarborste der vorderen und Hakenborste der hinteren Segmente. Vergr. 900. 

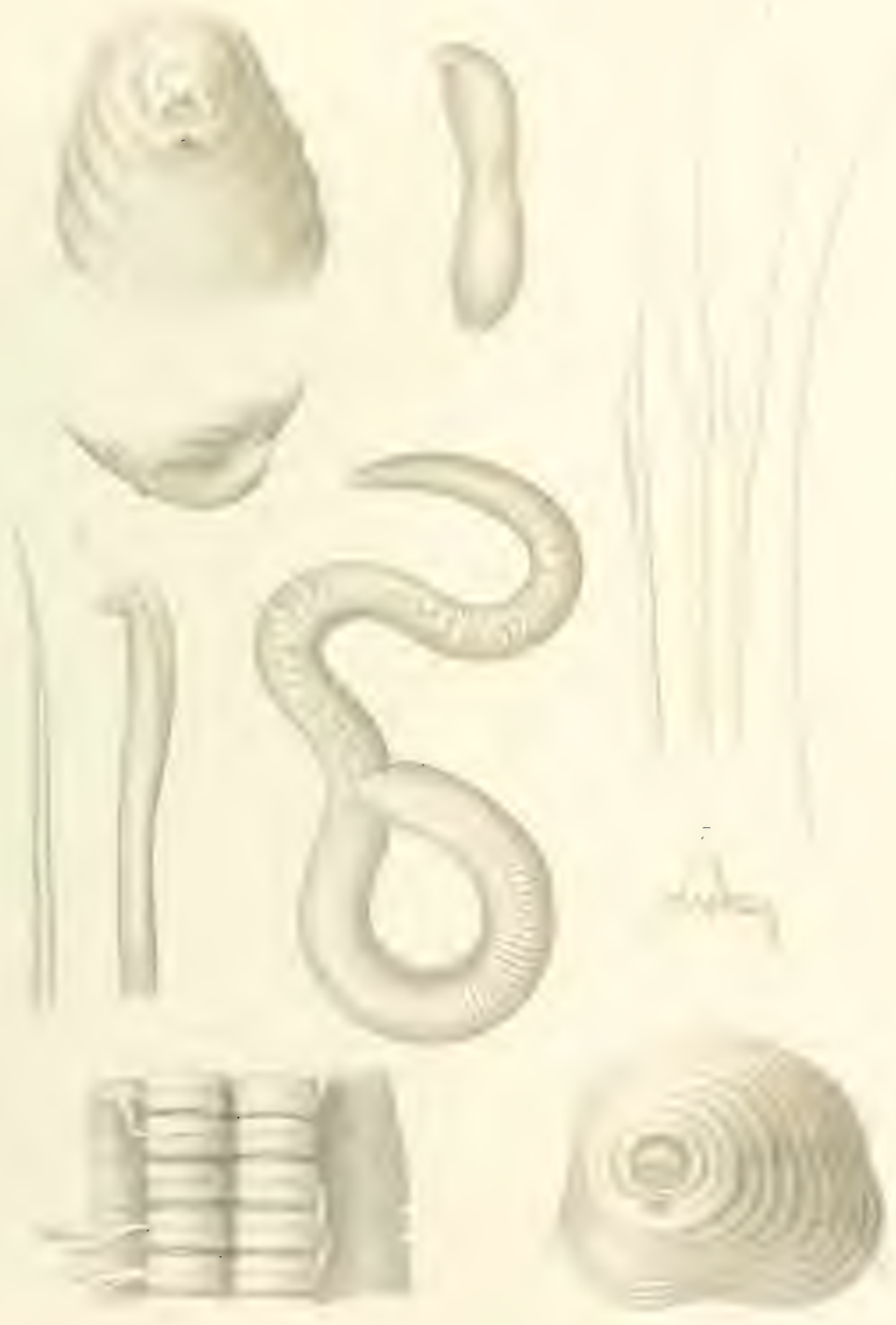

TAFEL, 46.

I: : 1. Truluane cuculligera n. sp.; rordere Rï̈rperstrecke in Profilstellung. Vergr. 8.

I: .. :. Dieselbe von der Ventralfliclse. Vergr. 8.

I: $\therefore$. Roplappen ron rorn auf die Scheitelfliche gesehen. Vergr. 12.

I:- I. Bucealsegment von der Tentralfliche und etwas nach rückwärts geneigt gesehen, um die Ifundüffunng unter dem Stimrande zu zeigen. Vergr. 12.

$\because \therefore$ i. Hinteres Körperende mit After in l'rofilstellung. Vergr. 12.

I . 1. Dasselbe ron einem anderen Exemplar mit etwas anderer Gestaltung der Analplatte. Vergr. 12.

Fı. ․ Capillarborste. Vergr. 250. Fig. $7^{a}$. Endstrecke derselben bei starker Vergrösserung; die Zühnelung zeigend. Vergr. 1300.

I $:$ S. Hakenborste. Vergr. 720.

I:̊. 9. Scheitelansichten derselben. Vergr. 720 .

IY.. 11. Clymene cirrata n. sp. ; vordere Körperstrecke im Profil. Vergr. 6.

Ií. 11. ITintere Kürperstrecke derselben; Rückenflïche. Vergr. 6.

Fi :. 12. Kopflappen von der Scheitelfäche. Vergr. 12.

Iig. 13. Hakenborste. Vergr. 600. 


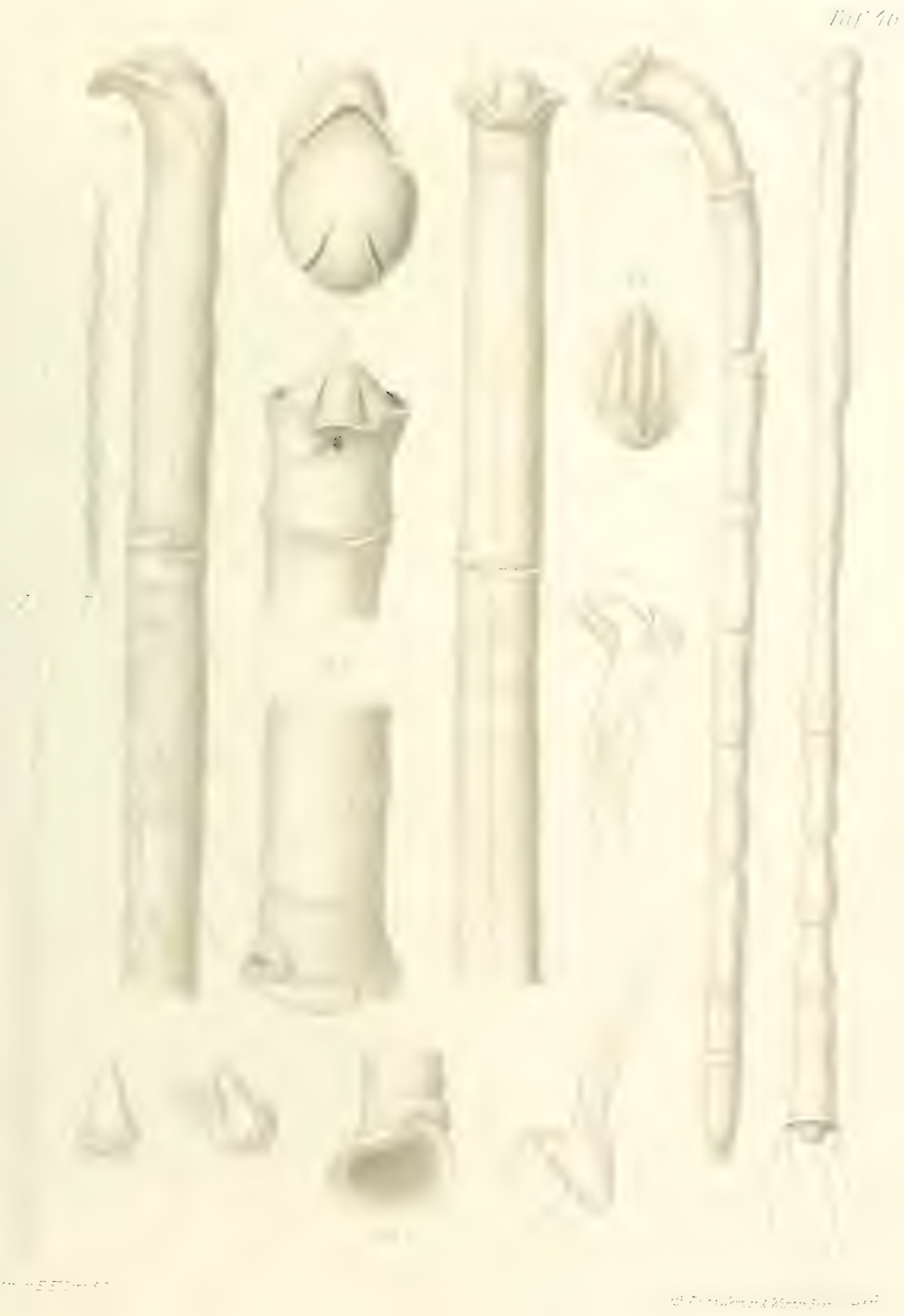



TAFEL 4T.

I: 1. Ficomachella picta n. sp.; Profilstellung. Vergr. 7 .

I. :.. Clymene cingulata n. sp.; P'rofilstellung. Vergr. $8, \tilde{5}$.

I‥ : . Kopfende desselben Wurmes, stiirker vergrüssert. Vergr. 18.

$1: \therefore$ 4. Capillarborste. Vergr. 420.

I: $\therefore$ Hakenborste. Vergr. 520 .

1:- i. lihodine sima n. sp.; l'rofilstellung. Vergr. 6, 5.

1.. - - Capillarborste. Tergr. 480.

I: $\therefore \quad \therefore \quad$ Zrei Hakenborsten der parabolischen Reihe; Seitenansicht. Vergr. 480.

1: . 4. Hakenborsten der parabolischen Reihe, vom Scheitel gesehen. Vergr. 480.

I: r. 11. Hakenborsten der einfachen Reihe. Vergr. 480. 


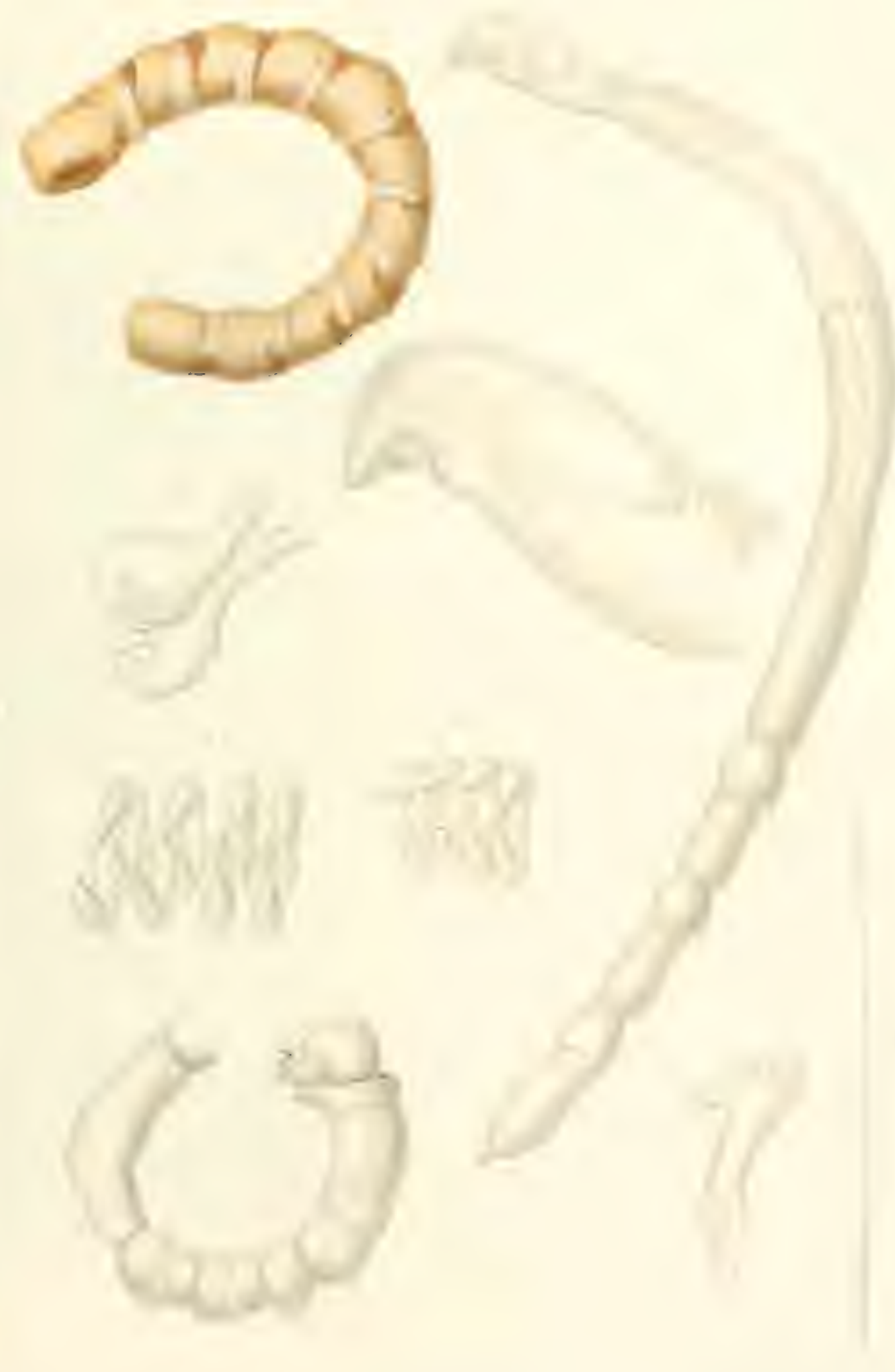



- 
TALEI 48 .

1: : 1. Amplicteis procera n. sp.; ganzes Tlier ron der Riuckenfliche. Tergr. 2.

I :. : $\therefore$. Torderende desselben 'Thieres, in gleicher Lage. Vergr. 12.

I': : :. Vorderende eines anderen Exemplares von der Bauchfläche. Vergr. 12.

Ii: \&. Vorderende desselben in Profilstellung. Vergr. 12.

$11 \therefore \quad \therefore$ Segmente desselben Wurmes aus der linteren Kürperstrecke. Vergr. 12.

II: i. Afterende desselben in Seitenlage. Vergr. 12.

I': . Capillarborsten. Vergr. 2700.

$1: \therefore$. Haken der vorderen Segmente in Seitenlage und von der Schneide. Verg. 700.

Is: 9. IIaken der hinteren Segmente ron der Selneide. Vergr. 700.

II: 11". Amage tumiela n. sp.; in Seitenlage. Vergr. 3.

I: $: 11$. Torderes Körperende in Seitenlage. Vergr. 9.

Ii. 12. Hintere Kïrperstrecke des Thieres in Seitenlage. Vergr. 9.

liz: 1:3. Das Vorderende des Wurmes ron der Bauchfliche. Vergr. 9.

If: 11 . Kopfende eines anderen Exemplares mit zurückgebogenen Kiemen, vom Rücken geselien. Vergr. 9.

Fi:. 15. Dasselbe in Seitenlage. Vergr. 9,

Ii $:$ 16. Flüsschen der vorderen Segmente der hinteren Kürperstrecke mit cirrusïhnlichen Hëckern. Vergr. 25.

I $\therefore$ 17. Hinteres Körperende. Vergr. 25.

I!z. 15. Haken aus den vorderen Segmenten in Seitenlage. Vergr. 925.

Tig. 19. Haken aus den hinteren Segmenten in Seitenlage und nicht völliger Kantenstellung. Vergr. 925 . 

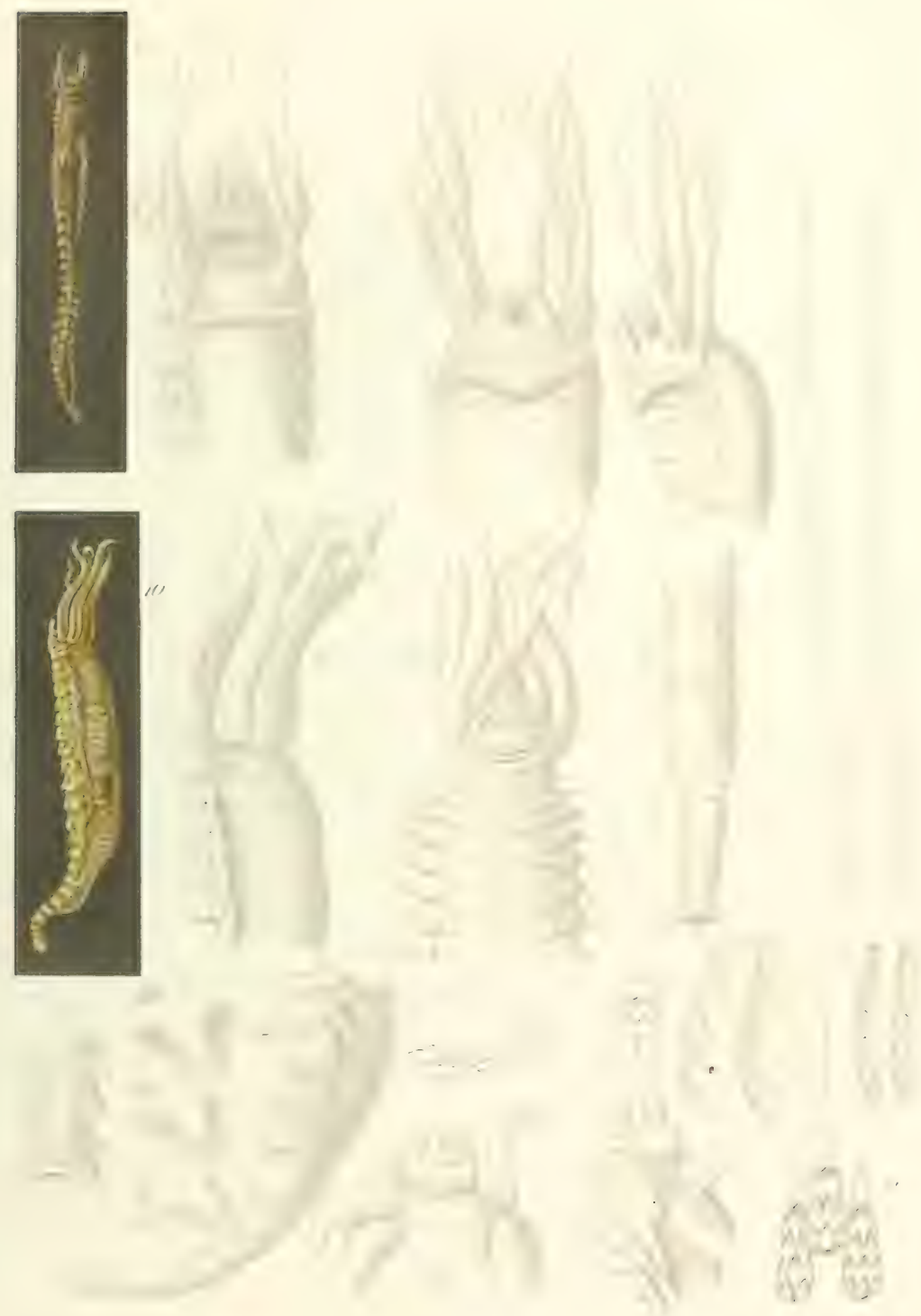


TAFEL 49.

I:.. 1. Ampharete nasute n. sp.; vordere Förperstrecke im Profil. Vergr. 26.

I: ... Dasselbe ron einem anderen Exemplar mit abgefallenen Kiemen; Rückenfläche. Yergr. 26.

I: . . Das Exemplar der Fig. 1 ron der Bauchfliche. Tergr. 26.

I: $\quad$ 1. Ganzes Thier ron ler Ventralftizche. Vergr. 4.

I. $\therefore \quad \therefore \quad$ IIaken der rorderen Segmente; Profil. Tergr. 92う.

I:. f. Haken der hinteren Segmente, Profil und Kantenstellung. Tergr. 925.

Ii: i. Melinna cristata (Sars). Vordere Körperstrecke von der Bauchfläche. Vergr. 7.

I: $\therefore$ \& Dieselbe ron der Rückenflïche. Vergr. 7 .

Ii : 9. Segmente der hinteren Körperstrecke, im Profil. Tergr. 7.

IY. . 11.. IInteres Kürperende, im Profil. Vergr. 7. 


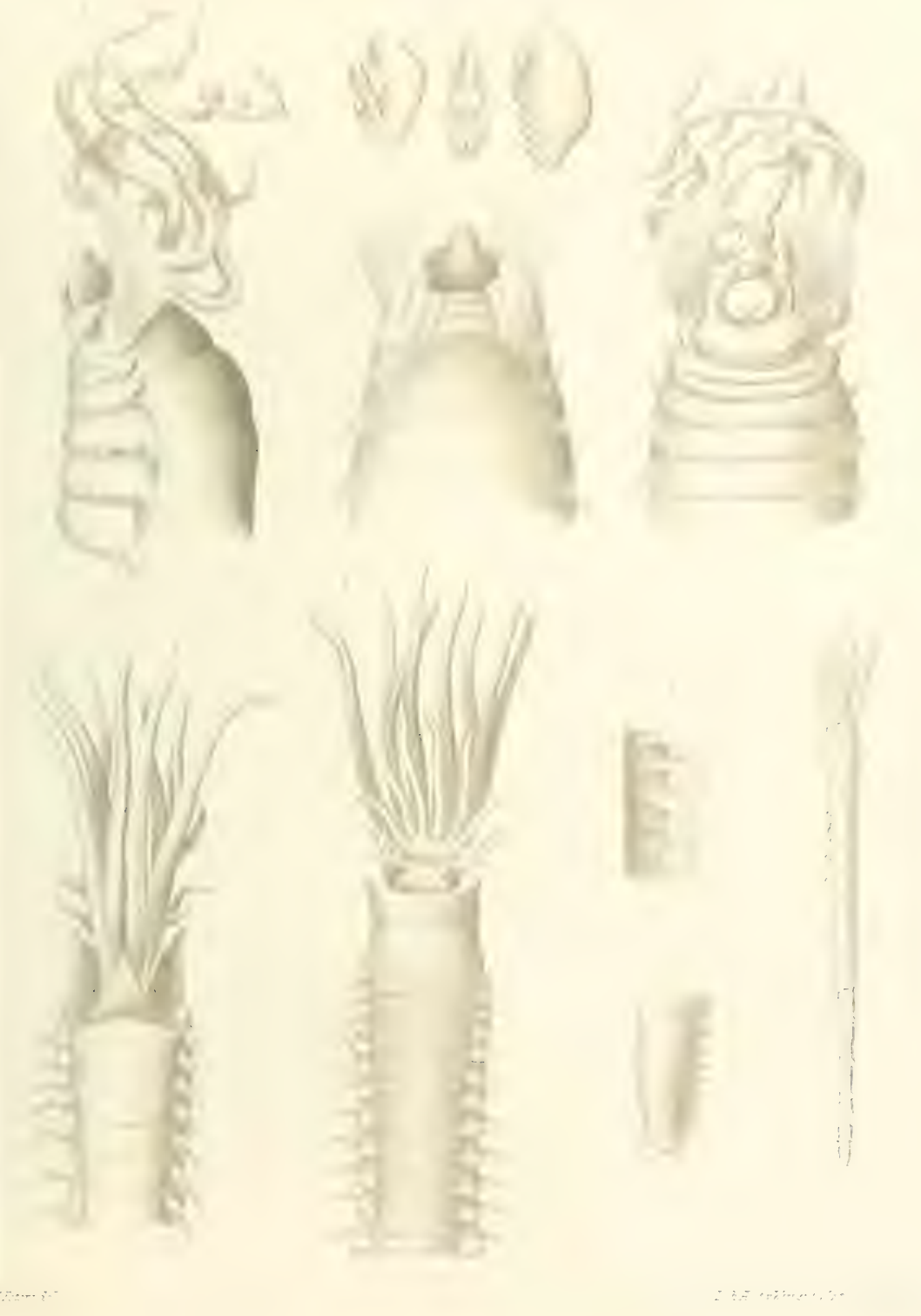



TAFEI, 50.

I: $\therefore$ 1. Ifelinna parumdentata n. sp.; ganzes Thier von der Bauchfliche. Vergr. 10.

I'i \&. 2. Vordere Kürperstrecke ron der Bauchflïche. Vergr. 17.

Y: . 3. Vordere Kürperstrecke eines anderen Exemplares vom Rücken. Vergr. 20.

$1:$ 1. Dasselbe in Schriigstellung. Vergx. 20.

$Y_{2} \therefore$. $\therefore$ IIinterende in P'rofilstellung. Vergr. 20.

1: ¿. 6. Capillarborste. Tergr. 450.

$\mathrm{Fi}$. . . Haken von den ersten Flösschen; in Profil- Schrig- und Kantenstellung. Vergr. 7 so.

1. _.. S. Seitenwand des Kürpers mit verlängertem Flösschen. Vergr. 150. Fig. 8 . Haken desselben. Vergr. 680 .

I: : !. Letztes Flüsschen mit Stütznadeln. Vergr. 150. Fig. $9^{3}$. Haken aus demselben, in Kantenstellung. Vergr. 780. 

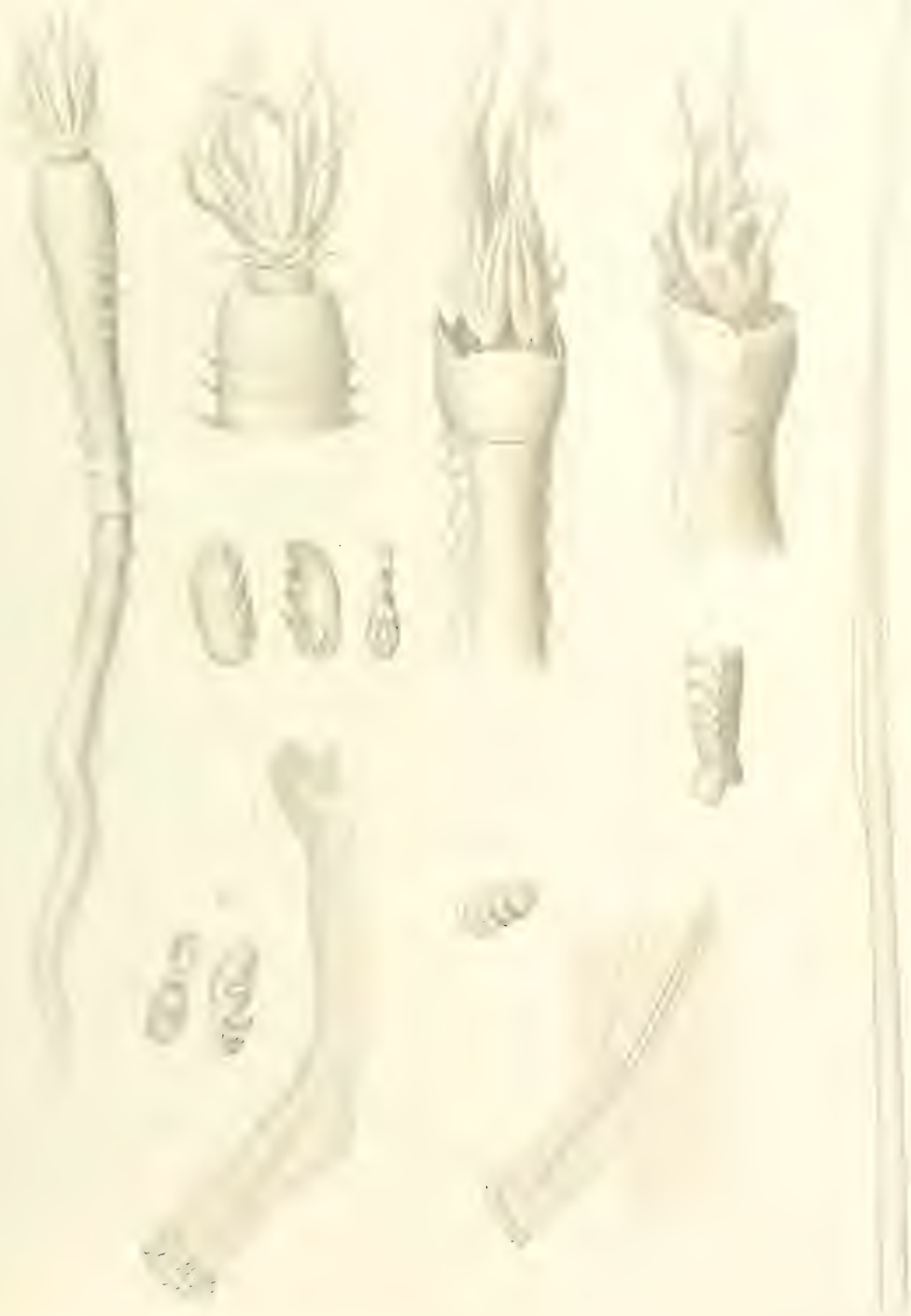




\section{TAFEL 51.}

Iis. 1. Terebella brunneo-comata n. sp.; rordere Körperstrecke im Profil. Vergr. 7.

1:s. 2. Dasselbe ron der Bauchfliche. Vergr. 7.

lị. 3. Hinteres Körperende im Profil. Vergr. 7.

1:_. 4. Capillarborsten. Fig. 4. Etwas andere Form. Vergr. 450.

Mir. $5^{\mathrm{a}}$. Haken in Profil. Fig. $\tilde{5}^{\mathrm{b}}$. Haken in Kantenstellung in der Doppelreihe. Vergr. 685. 


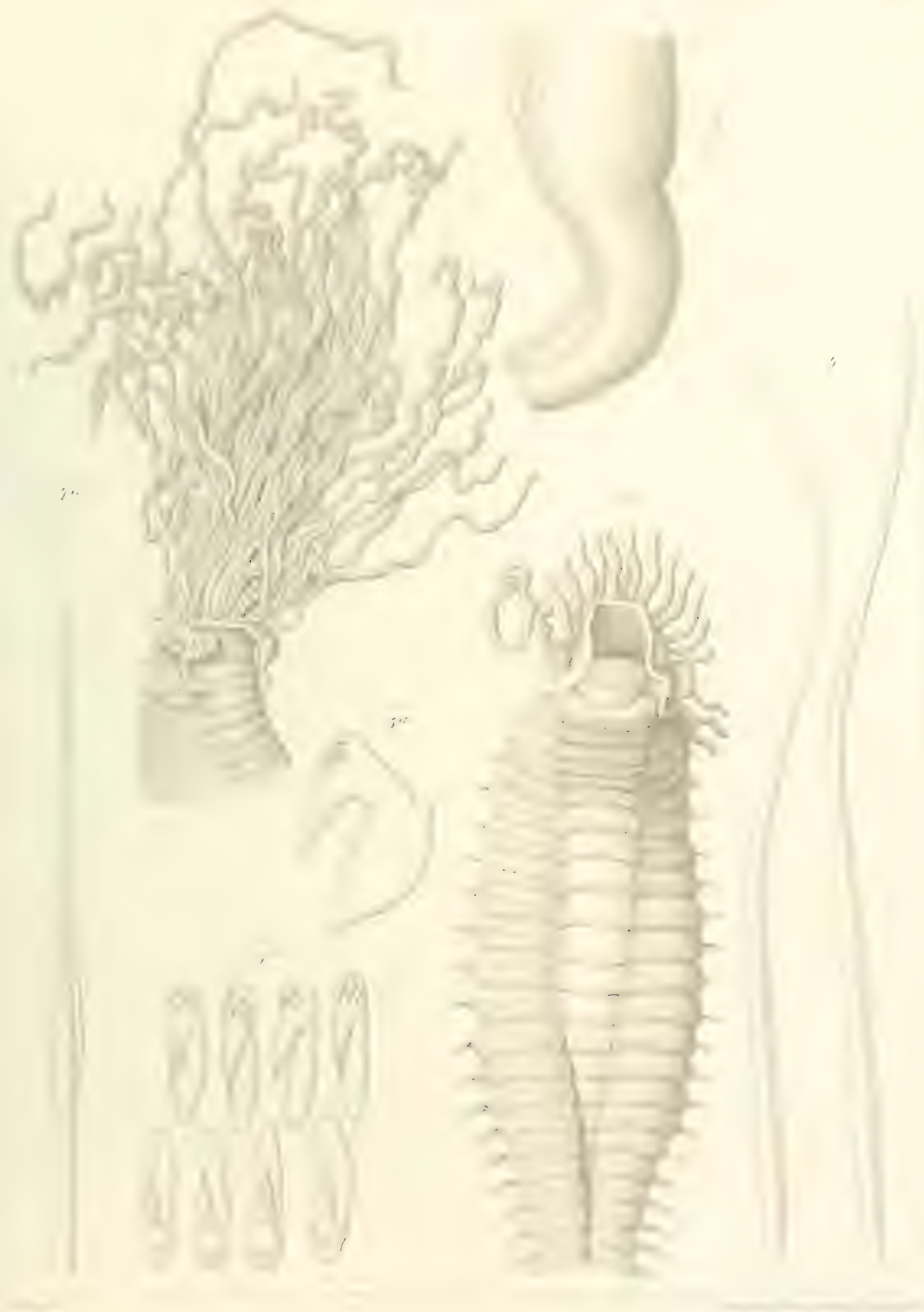






\section{THELL}

Hig. 1. Terebellat turguhutu n. sp.; ganzes Thier schräg von der Bauchfliche; die Borstenhïeker sind nicht alle sichtbar. Vergr. 4.

lig. 2. Vorlerente desselben Thieres, Rückenfliche, Kiemen zum Theil abgefallen. Vergr. 4.

Fig. 3. Darselbe im l'rofil, linke Seite vorliegend. Vergr. 4.

Fit. 4. Haken der verschriinkten Doppelreihe in Schrïgstellung. Vergr. 545.

Fig. 5. Terelella reticulata n. sp.; vordere Körperstrecke; Ventralfläche mit etwas gehobener rechter Kante. Vergr. 18.

Fig. 6. Dieselle in P'rofilstellung; rechte Seite vorliegend. Vergr. 13.

Fis. 7. Hintere liürperstrecke in Profil. Vergr. 13.

Fig. Sa. Inken im P'rofil. Fig. $\$^{b}$. Vom Scheitel gesehen. Vergr. 1110.

Fig. 9. Terebella cctrata n. sp.; rordere Körperstrecke; Rückenfliche, die linke Kieme ist abgebrochen. Tergr. 10.

Fis. 10. Dieselbe im Profil; linke Seite vorliegend. Vergr. 10.

Fis. 11. Hintere Segmente; Ventralfliche. Vergr. 10.

Fic. 12. lieme ausgebreitet. Vergr. 20.

Fig. 13. Capillarborste. Vergr. 330.

Fig. 14: Haken im Profil. Fig. 14". Von der Schneide. Vergx. 810. 


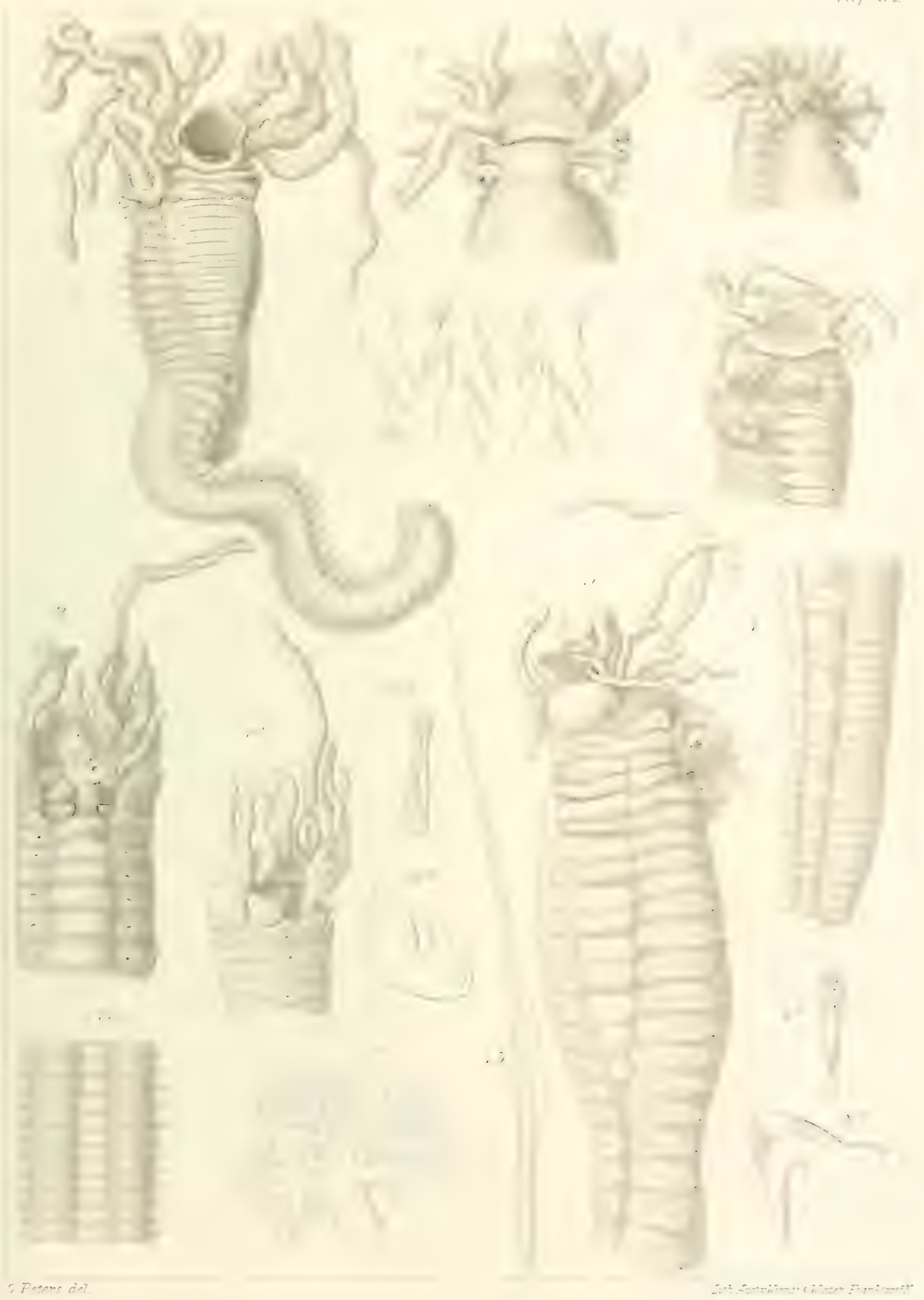




TAFEL 53.

Fig. 1. Brancliomma bioculatum n. sp.; rordere Körperstrecke, Bauchfläche; die Kiemen etwas ausgebreitet. Verg. 3,3 .

Fig. 2. Riickenfliiche der vorleren Segmente, und Kiemenbasis. Vergr. 3, 3.

Fie. 3. Rühre, natürl. Grösse.

Fig. 4. Terminalauge ron der äusseren Fliche. Vergr. 66.

Hig. 5. Dasselbe ron der inneren Fliache. Vergr. 66.

Fig. 6. Ansicht der Buccalzipfel von der Tentralfliche; die Kragenlappen sind zurückgeschlagen, die Kiemen aus einander gebogen. Vergr. 8.

Fig. 7. Gleitborste aus der Doppelreihe der thoracalen Segmente. Vergr. 390.

Fig. S. Eine Strecke ron der thoracalen Doppelreihe der Haken; die Haken von der Spitze gesehen. Vergr. 330.

Fig. 9. Hakenborste in Seitenansicht. Vergr. 206.

Fig. 10. Branchiomma lobiferum n. sp.; ron der Ventralfläche. Tergr. 3.

Fig. 11. Rückenfliche der rorderen Segmente und Kiemenbasis. Vergr. 3.

Fig. 12. Endstrecke eines Kiemenstrahles. Vergr. 3.

Fig. 13. Dieselbe; das Terminalauge im optischen Längschnitt nach Glycerindurchtränkung. Vergr. 60.

Tig. 14. Ansicht der Carunkel und der Buccalzipfel zwischen den auseinandergebogenen Kiemen ron rorn her; die dreieckigen Iappen am oberen Umfange der Zeichnung gehören dem Kragen an. Vergr. 5.

Fig. 15. Haken. Vergr. 313. 


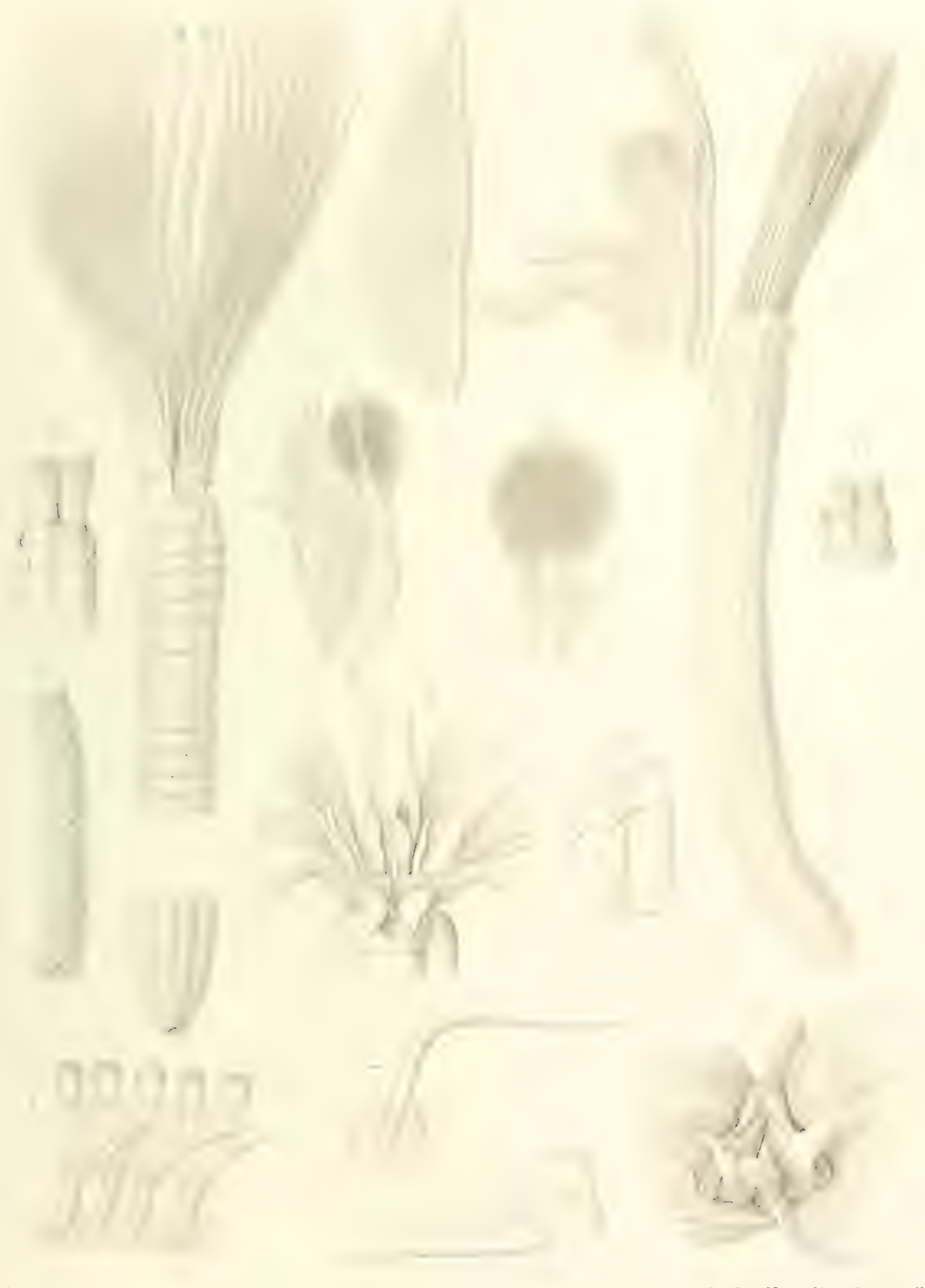






\section{TAFEL 5.4.}

Fig. 1. Dasychone conspersa n. sp.; Ventralfliiche. Vergr. 5.

Fig. 2. Vordere Kürperstrecke mit der Kiemenbasis im Profil, um den niedrigen Kragen, die thoracale Region und die Vertheilung der Pigmentflecke zu zeigen. Vergr. 8.

Fig. 3. Ein Kiemenstrahl im 1'rofil. Vergr. 25.

Fig. 4. Die beiden 13uccalzipfel. Vergr. 25.

Fig. 5. Capillarborste. Vergr.685.

Fig. 6. IIaken im Seitenlage. Vergr. 583.

Fig. T. Potamis spathiferus n. gen. n. sp.; ganzes Thier, dorsale Fläche. Vergr. 3, 5 .

Fig. 8. Tordere Strecke desselben, die Bauchfliiche etwas aufwärts gedreht; die Kiemenstralılen gelockert, um die ventrale zipfelförmige Verlïgerung der Kiemenbasis zu zeigen. Vergr. 10.

Fig. 9. Vorlere Körperstrecke in Seitenlage mit den thoracalen, und ersten abdominalen Segmenten, Basis der zusammengelegten Kieme. Vergr. 10.

Fig. 10. Tordere Kürperstrecke mit Kiemenbasis, Dorsalf̈̈̈che. Vergr. 10.

Fig. 11. Dieselbe; die Kiemen auseinandergebogen, um die Buccalmembran zu zeigen. Vergr. 10. 


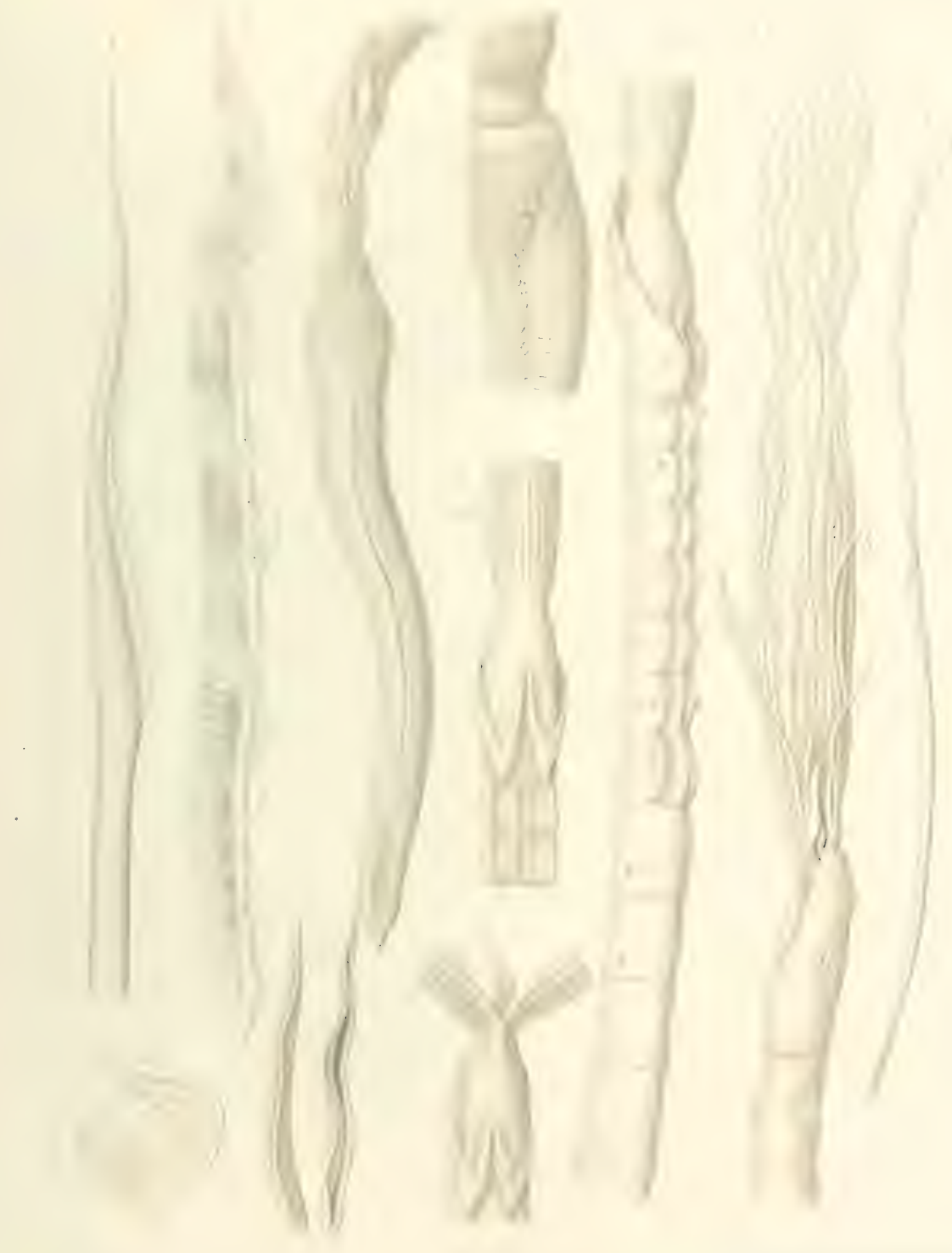




TAFEL 55.

I: . 1. Yotamis spathiferus; Borsten des iten thoracalen Polsters. Vergr. 200.

1\%: 1. Eines dieser Borstenpaare in Seitenlage. Vergr, 200.

II: :. Doppelreihe der ungleichförmigen Capillarborsten vom 2 ten thoracalen Segment. Vergr. 200.

Ii.: .3. Capillarborsten des 3ten abdominalen Segmentes. Vergr. 410.

Hi.. 4. Hakenreihe desselben Segmentes. Vergr. 315.

II. . . II/psicomus circumspiciens n. sp.; ganzes Thier in Seitenlage. Vergr. 3.

I: $\therefore$ (i. Vordere Segmentreihe des Wurmes aus der braunen hornartigen Röhre herrorragend, in Seitenlage. Vergr. 13.

I!s. - R Rückenfliche der vorderen Segmente. Vergr. 13.

I': $\therefore$ Vordere Segmente nach links, die Rückenflüche etwas aufwärts gewendet. Vergr. 13.

I: : !. Dasselbe; nach rechts, die Bauchfläche aufwirts gewendet. Vergr. 13.

I: $\therefore$ 11. Die augentragende Streeke eines Kiemenstrahles im Profil. Vergr. 140.

Y: 1 $^{1 \cdots}$. Die Endstrecke desselben. Vergr. 140.

I: 11 . Kiemenstrahl von der äusseren Fläche, vordere Strecke der beiden Augenreihen. Vergr. 140.

F: - 1:. Hintere Strecke derselben. Vergr. 140 .

Ii.. 1.. Drei Augen im Profil; die in der Epithelialschicht eingebetteten mit gewölbter Flïche über das Niveau derselben herrorragenden lichtbrechenden Körper ragen mit dem zugespitzteu Theile in die Pigmentschicht hinein; die unregelmüssig netzförmig erscheinende Substanz ist von den Knorpelzellen der Achse gebildet. Vergr. 470. 


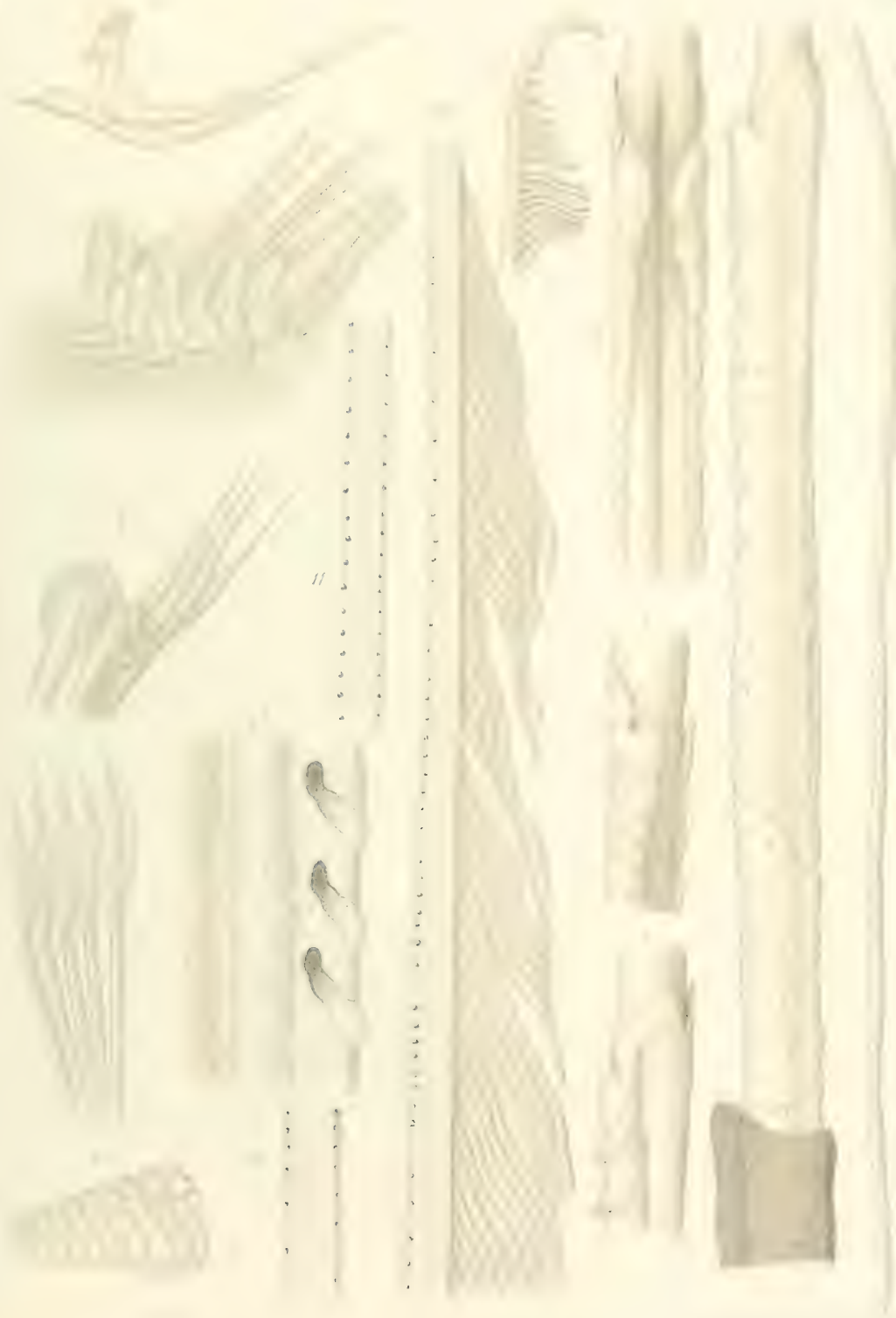



. 
TAFEL 56.

1. .. 1. Iypsicomus circumspiciens n. sp.; Borsten des Sten thoracalen Polsters. Vergr. 250.

l: 2. 2. Aus der Hakenreihe eines abdominalen Segmentes. Vergr. 310.

I:. 3. Dazu gehörende Capillarborsten. Vergr. 310.

I: $\therefore$ 4. Filigrana Inxicyi n. sp.; ganzes Thier in Seitenlage, Conturzeichnung nach einem mit Glycerin durchtränkten Exemplare. Vergr. 60.

$I: g$. ‥ Terminalorgan eines Kiemenstrahles, nach Durchtränkung mit Glycerin. Vergr. 270 .

T: . i. Borste des Buccalsegmentes. Vergr. 780.

I:.. - Beide Formen der Capillarborsten aus den thoracalen Segmenten. Vergx. 1000.

F : S. Capillarborste aus einem abdominalen Segment. Vergr. 1000.

Iis. 3. Haken in Seitenlage. Vergr. 1500.

1:- 111. Protis simplex n. gen. et sp.; in Seitenlage. Vergr. 11.

$1:$. 11. Borste vom Buccalsegment. Vergr. 316 .

I: 12. Capillarborste rom thoracalen Segment. Vergr. 316.

F. . 1:. Haken. Vergr. 480.

Fin. 14. Röhre. Vergr. 2. 


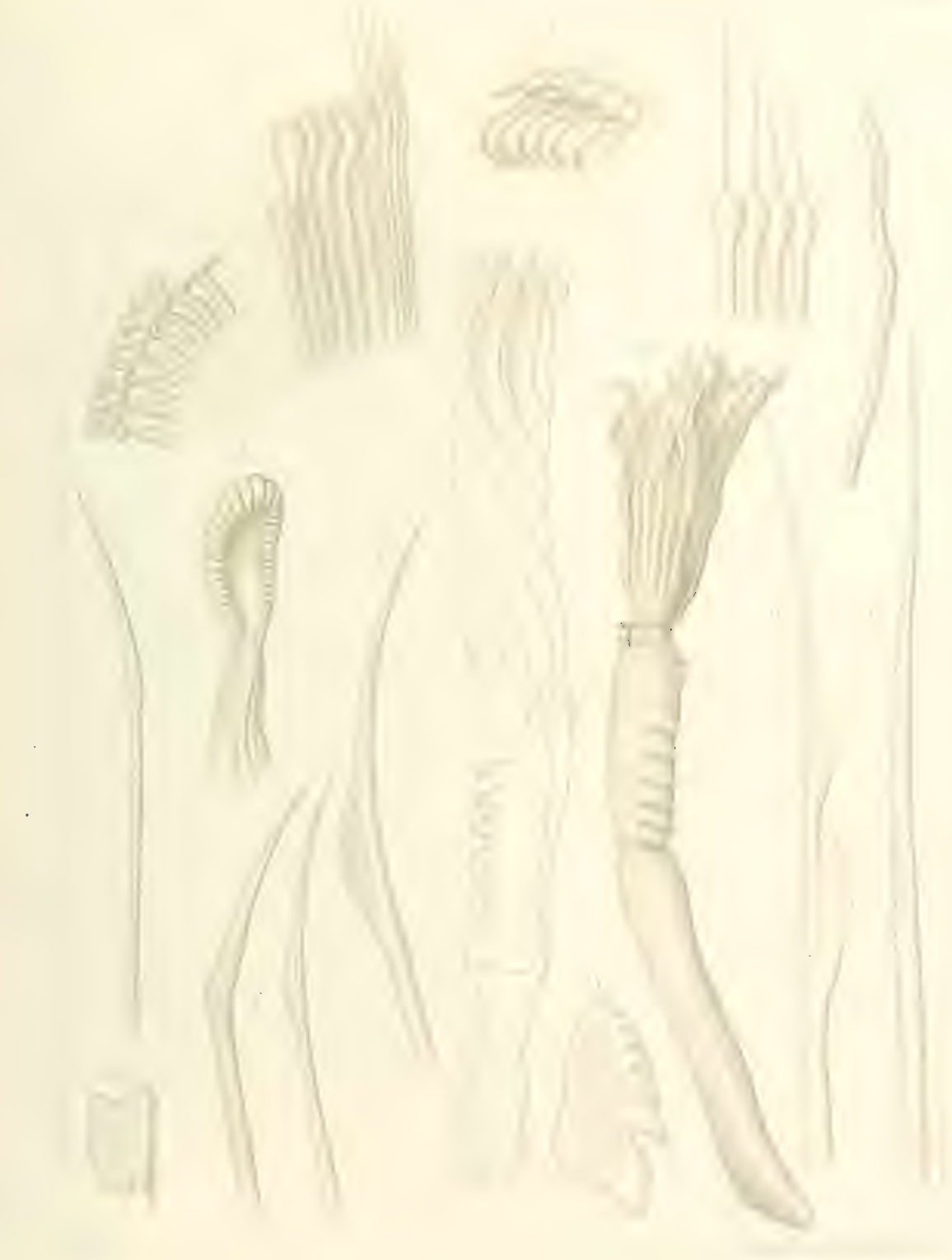





$$
\text { - }
$$


TAFEL 57.

Fiz. 1. Spirobranchus giganteus (1'all.); ganzes Thier in Seitenlage, Bauchfläche etwas nufwirts gewendet. Vergr. 2.

Fig. 2. Vordere Kürperstrecke desselben; Bauchfliche. Vergr. 2.

Fig. 3. Abgelüste Deckelscheibe von der freien Fläche. Vergr. 2.

Fir. 4. Deckelstiel ohne die kalkige Deckelscheibe. Vergr. 2.

Fie. i. Endstrecke der Buccalborste. Vergr. 395.

Fig. 6. Capillarborste rom Abdomen, Vergr. 39г̃.

Fig. 7 . Haken in Seitenlage. Vergr. 460.

Fig. S. Y. Thus trimmis (Mörch); ganzes Thier in Seitenlage, Bauchfliche aufwärts gemendet. Vergr.:-2.

Fig. 9. Vordere Körperstrecke; Rückenfläche; der zwischen den Kiemen stehende Deckel. stiel und die Deckelscheibe von hinten gesehen. Vergr. 2.

Fị. 10. Vordere Körperstrecke; Bauchfläche. Vergr. 2.

Fig. 11. Buccalborste. Vergr. 416.

Fig. 12. Capillarborste rom Thorax. Vergr, 416.

Fiz. 13. Capillarborsten rom Abdomen mit und ohne ausgezogene Spitze. Vergr. 416.

Fig. 14, $14^{a}, 14^{\mathrm{b}}$. Haken aus ein und derselben Reihe; $14^{\mathrm{a}}$ und $14^{\mathrm{b}}$ vom Ende der Reihe, Vergr. 460.

Fig. 15. Deckelscheibe von der freien Fläche. Vergr. 2.

Fig. 16. Deckelscheibe von Spirabranchus incrassatus. Vergr. 2. 


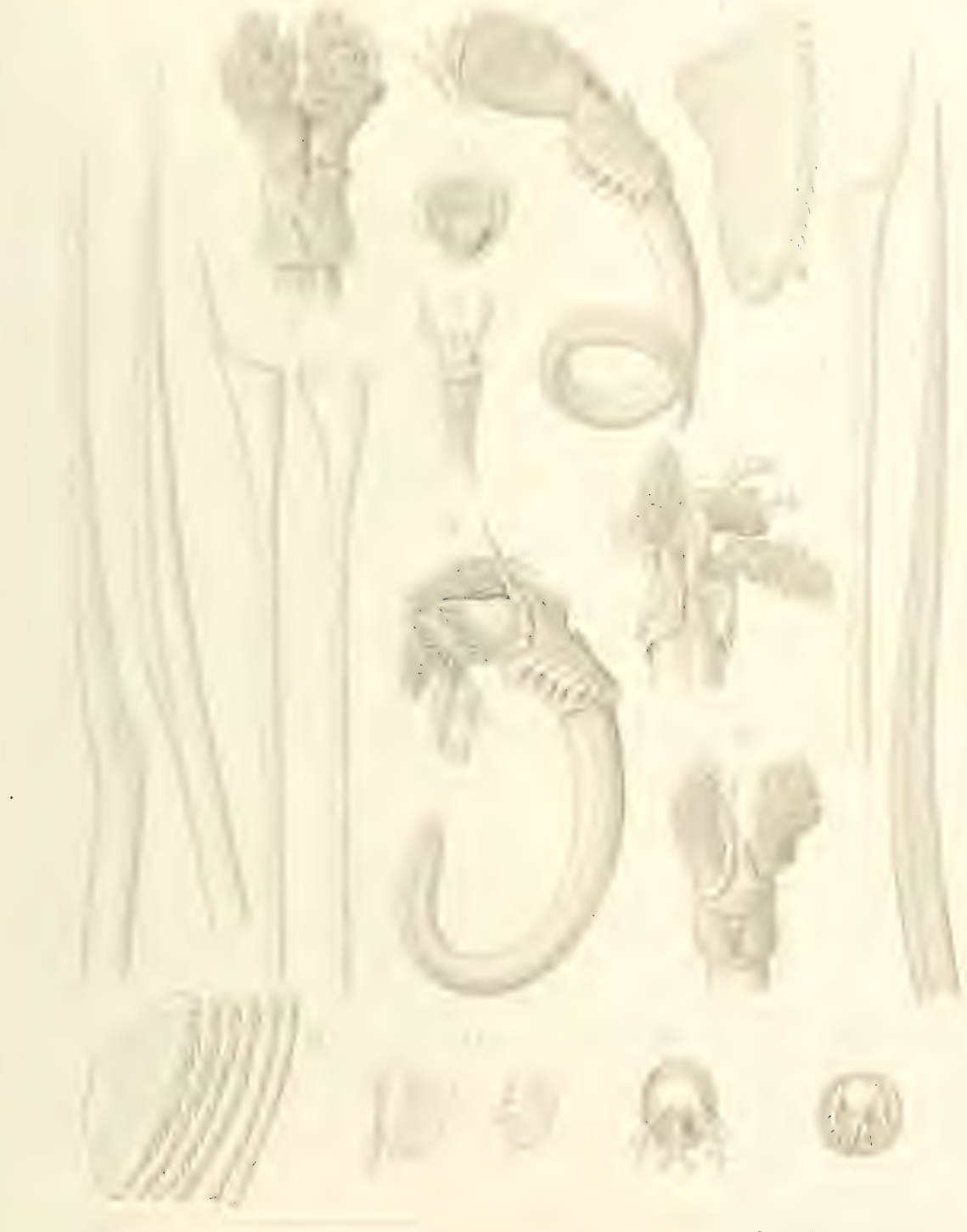




TAFEL 5 S.

Fig. 1. Spirobranchus incrassatus (Mörch) Buccalborste in Seitenlage. Vergr. 660.

Fig. "-. Buccalborste ron der Selneide, um die Stelle zu zeigen, wo die Biegung beginnt. Vergr. 660.

Fig. 3. Capillarborste rom Thorax. Vergr. 445.

Fig. t. Capillarborste rom Abdomen in Seitenlage; $4^{a}$ von der Schneide. Vergr. 435.

Fig. 5. Haken in Seitenlage. Vergr. 640.

Fig. 6. Eupomatus uncinatus (1'hil.). Vergr. 3.

Fig. 7. Deckelscheibe auf dem Stiele. Vergr. 30.

Fig. S. Dieselbe von der freien Fläche. Vergr, 30.

Fig. 9. Buecalborste. Vergr. 470.

Fig. 10. Capillarborste vom Abdomen. Fig. 10. In Profilstellung. Tergr. 750.

Fig. 11. Haken. Tergr. 750.

Hig. 12. Tormilia annulata (Schmarda); ganzes Thier; Rückenfliche; Kiemen ausgebreitet und Deckelstiel freigelegt. Vergr. 8.

Fig. 13. Freie Fliiche des aus dem Kiemenbündel herrorragenden Deckels. Vergr. 8.

Fig. 14. Deckel eines anderen Exemplares. Vergr. 8.

Fig. 15. Isolirter Haken in Seitenlage. Vergr. 1630.

Fig. 16. Haken im Verband der Reihe; $16^{\text {a }}$ aus der Mitte; $16^{\text {b }}$ rom Ende derselben. Vergr. 1630. 


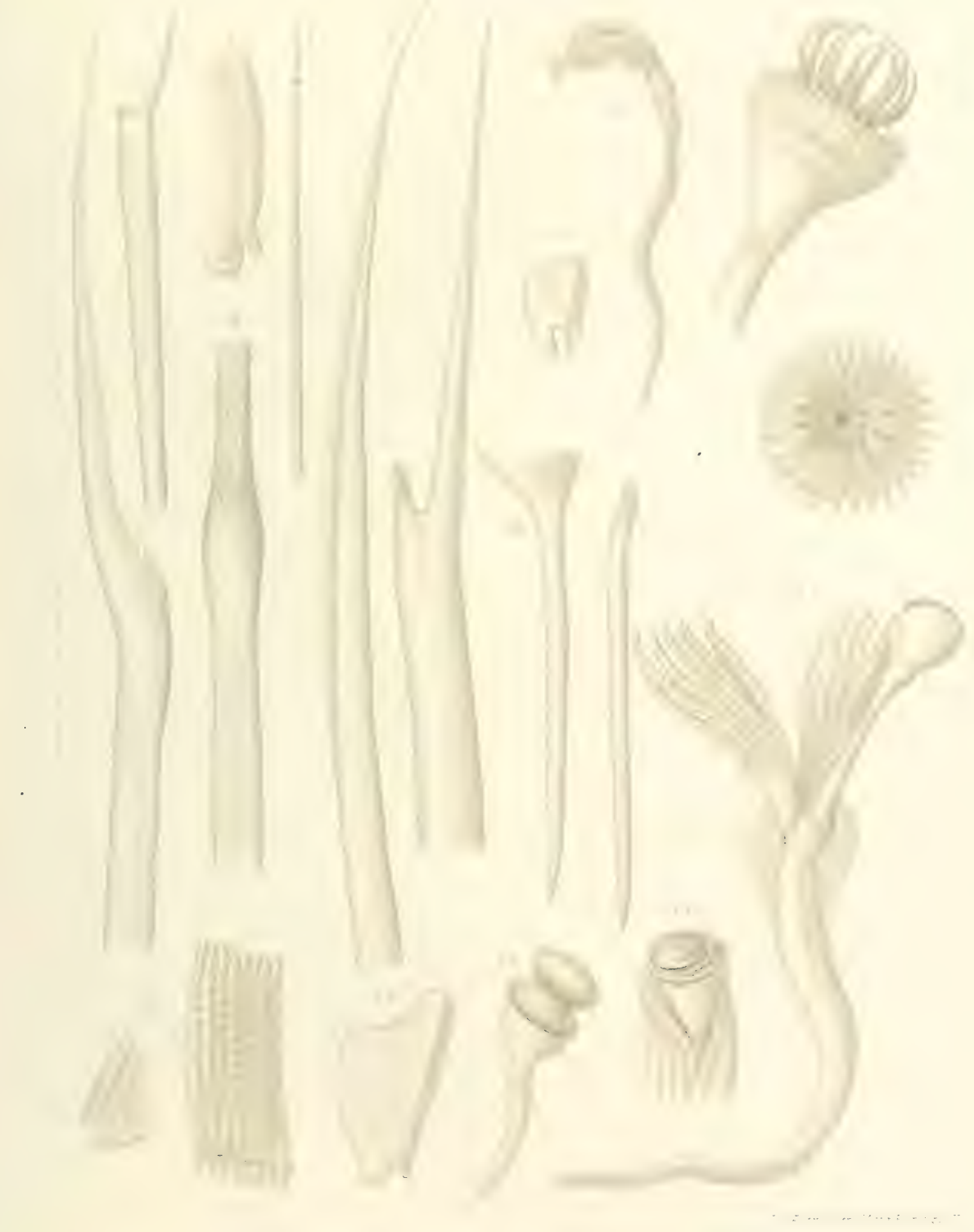





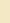


TAFEL 59 .

I: 1. Vemilia annelata (Schmarda); Capillarborste rom Thorax; der Uebergang des Schaftes in die Endstrecke ist in diesem Falle scharf ausgeprägt. Vergr. 500.

Yis.:.. Zweite Form der thoracalen Capillarborsten. Vergr. 500.

Jis.: i. Vorderende der kalkigen Röhre. Vergr. 4, 5.

1:. 4. Protula antennata n. sp.; Vorder- und Hinterende in Seitenlage, Kieme zusammengelegt. Tergr. 11.

Fig. 5. Vorderende; Bauchfliche schräg aufwärts gewendet; Kiemen von einander gebogen. Vergr. 11.

Iił. 1. Dasselbe vom Rücken; die Thoracalmembran jederseits entfaltet. Vergr. 11.

Fig. :. IJaken. Vergr. 812.

IFi... Capillarborste vom Thorax. Vergr. 720.

Fi_. 9. Röhre von der freien Fliiche; 9 Querschnitt der Röhre. Vergr. 3, 25. 

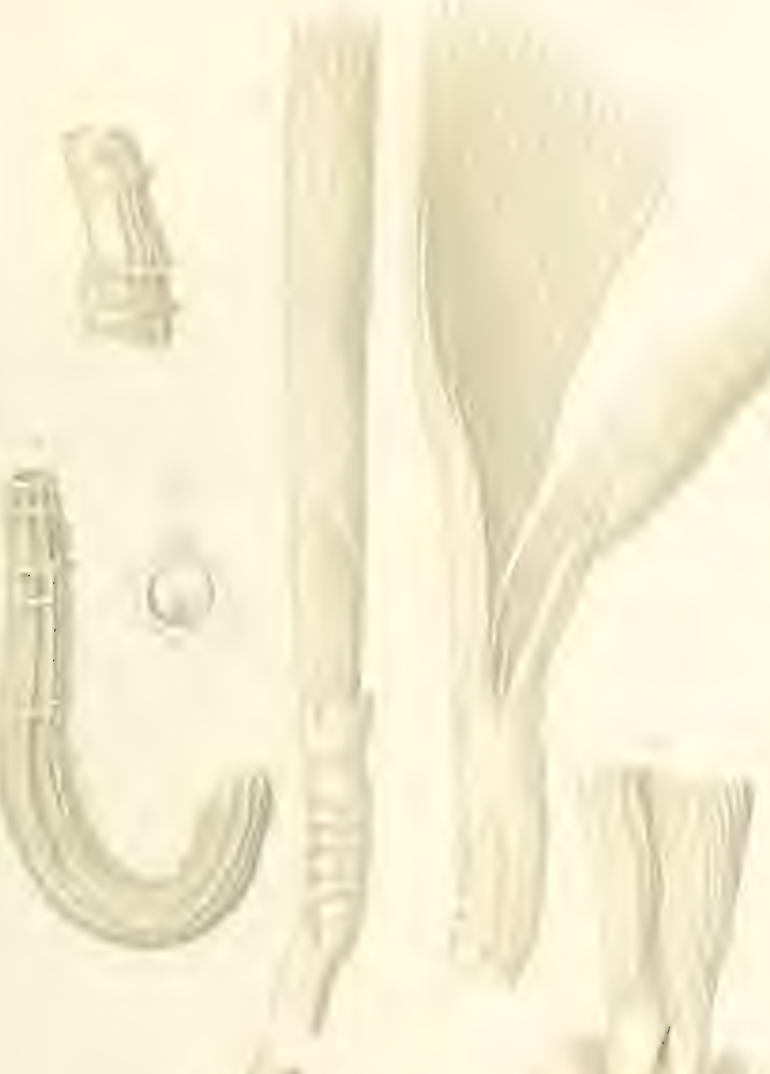



$$
\text { . }
$$


TAFEI, 60.

1.. 1. Plucostegus incomptus; ganzes Thier in Conturzeichnung nach einem mit Glycerin durchtrïnkten Exemplare; Bauchfliche nicht voll aufwärts gewendet. Vergr. 1s.

I::. 2. Vorderes Kürperende ron der Rïckenflïche; Thoracalmembran und Kragen ausgebreitet; kiemen kurz abgebrochen. Vergr. 18.

I: $\therefore$. Augen(?) auf der Bauchfläche des Buccalsegmentes. Vergr. 90.

$1 \%$ 4. Capillarborste vom Thorax. Vergr. 750.

lis. $\therefore$ Capillarborsten vom Abdomen. Vergr. 560.

IFi. (i. Haken in Reihenstellung von der Schneide. Vergr. 600.

1: . . Dieselben einzeln, in Seitenlage und von der Schneide. Vergr. 1200.

1: $\therefore$ \&. Glasartige Rühre von der freien Fläche. Vergr. 6.

$\Gamma:-9 . \quad$ Torderende der Röhre in Seitenansicht. Vergr. 6.

I's. 11. Hyalopomatus Langerhansi n. sp. ; Vorderende im Profil. Vergr. 17.

II: $\therefore$ 11. Hinterende im P'rofil. Vergr. 17.

Fir. 12. Buccalborste. Vergr. 974.

Fir. 1:3. Capillarborste vom Thorax. Vergr. 974.

Fis. 11. Haken in Seitenansicht. Vergr. 974.

Iï. 1j. Röhre. Vergr. 2. 


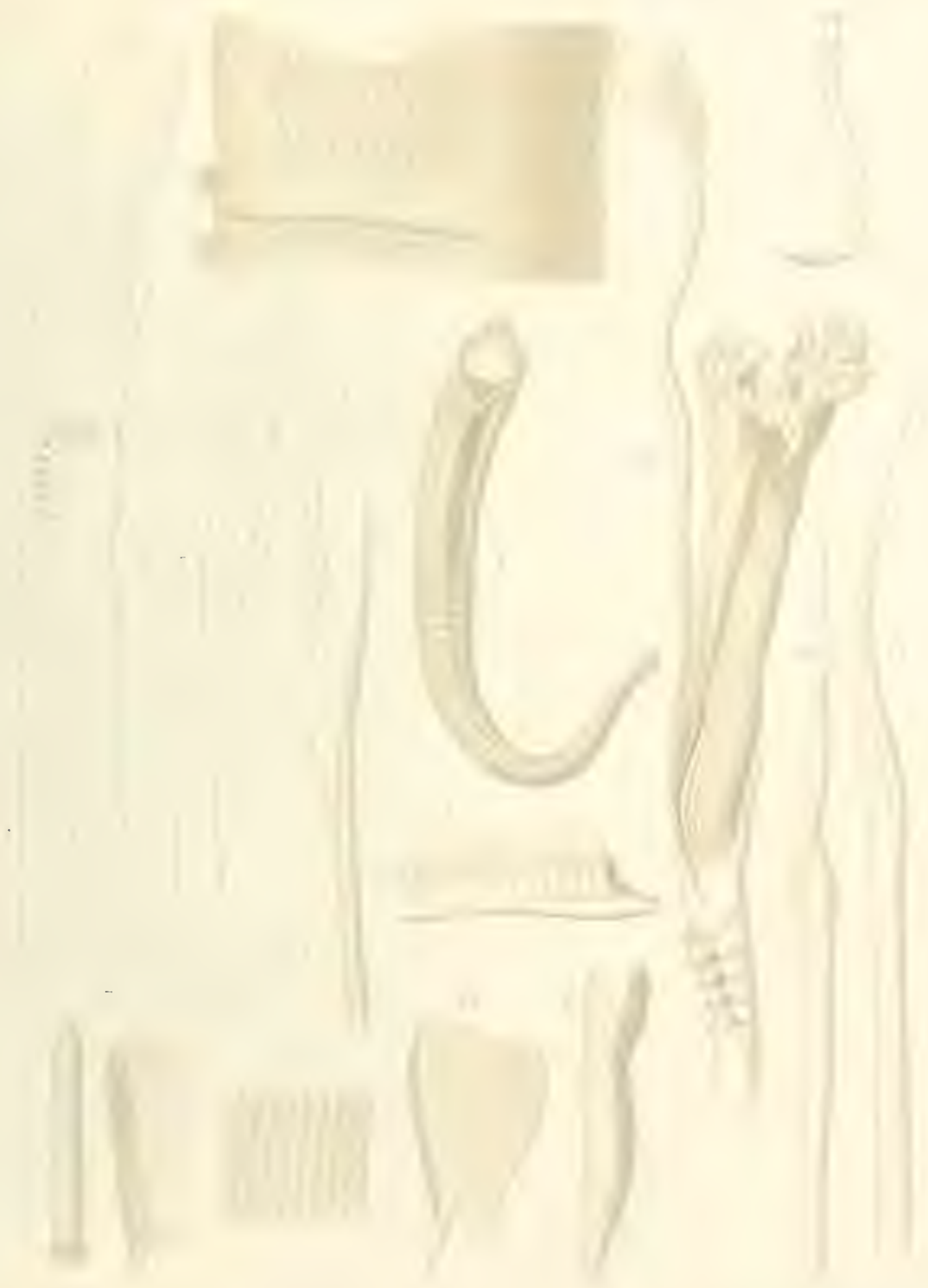






QL

1

H35

V.15

Biological

\& Medical

Serials
Harvard University. Museum of Comparative Zoology Memoirs

PLEASE DO NOT REMOVE

CARDS OR SLIPS FROM THIS POCKET

UNIVERSITY OF TORONTO LIBRARY

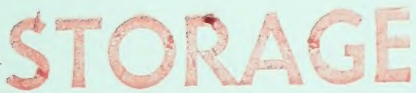

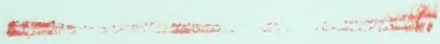




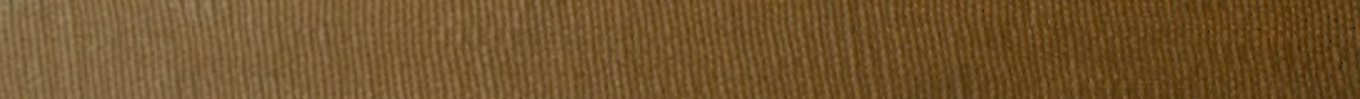
(5)

$5(1.20$. H.

E(S)

$$
\text { (5) }
$$

$(x+2)$ 